\title{
PROPUESTA METODOLÓGICA PARA LA CARACTERIZACIÓN DEL COMPORTAMIENTO ENERGÉTICO PASIVO DEL PARQUE EDIFICATORIO RESIDENCIAL EXISTENTE CONSIDERANDO SU CONTEXTO URBANO
}

\section{Tesis Doctoral}

Autora: Marta Braulio Gonzalo Directoras: Ma José Ruá Aguilar Ma Dolores Bovea Edo 



\section{Propuesta metodológica para la caracterización del comportamiento energético pasivo del parque edificatorio residencial existente considerando su contexto urbano}

TESIS DOCTORAL

Autora: Marta Braulio Gonzalo

Directoras: Ma José Ruá Aguilar

Ma Dolores Bovea Edo 

Quiero dar mi más sincero agradecimiento a mis directoras de tesis, $M \underline{a}$ José y Loles, por guiarme durante esta investigación, por vuestros valiosos consejos y por vuestra disponibilidad y dedicación.

Sois para mí un referente y un ejemplo a seguir.

Muchas gracias por todo.

A Pablo Juan, a quien también dedico una especial mención. Sense la teua col/laboració i aportacions, aquest treball no hauria estat posible. Gràcies per la teua implicació.

A Fernando, por creer en mí y apoyarme siempre en aquello por lo que lucho. Por tu paciencia, por levantarme el ánimo incontables veces y por sacarme siempre una sonrisa.

A mis padres, por vuestro apoyo incondicional y cariño, por enseñarme a superarme cada día desde niña y, porque gracias a vosotros, hoy soy quien soy.

A mis compañeros de Departamento y del Área de

Construcciones Arquitectónicas, por vuestro asesoramiento cuando os lo he solicitado. A Dani, por tu ayuda con los bloqueos informáticos y tus ánimos para comenzar este trabajo y seguir adelante.

$Y$ a todos aquellos que, de algún modo u otro, me habéis dedicado gestos de ánimo durante el desarrollo de esta tesis. 

El sector de la edificación ha experimentado un gran crecimiento en las últimas décadas, dejando un extenso parque residencial de edificios que ha contribuido a desarrollar y dar forma a la ciudad. La legislación en materia de eficiencia energética empezó a desarrollarse en la década de 1970, coincidiendo con el fin de la etapa de mayor crecimiento del sector. Como consecuencia, gran parte del actual parque de viviendas se encuentra alejado de los estándares promovidos por dicha legislación, provocando que su uso sea responsable de un alto porcentaje del consumo global de energía. Ante esta situación, la evolución de legislación se ha orientado en estos últimos años hacia la intervención en la ciudad consolidada e impulsa, desde la iniciativa de las administraciones públicas, la rehabilitación edificatoria y la regeneración urbana con el objetivo de promover un desarrollo urbano más sostenible.

Con ello, surge la necesidad de desarrollar instrumentos que proporcionen ayuda durante la toma de decisiones a administraciones locales y a otros agentes involucrados en los procesos de regeneración urbana. Así, esta tesis propone una metodología para caracterizar el comportamiento energético pasivo del parque edificatorio residencial existente considerando su contexto urbano, de forma que permita realizar un diagnóstico energético de áreas urbanas consolidadas e identificar aquellas con mayor vulnerabilidad energética.

La revisión del estado del arte en relación con las herramientas de evaluación de la sostenibilidad urbana y las metodologías de evaluación energética desarrolladas hasta la fecha, ha permitido identificar por un lado, un conjunto de indicadores para evaluar el comportamiento energético pasivo del parque edificatorio residencial (demanda energética de refrigeración $\left(D_{r}\right)$ y de calefacción $\left(D E_{c}\right)$ y horas de disconfort térmico en verano $\left(H D_{v}\right)$ e invierno $\left(H D_{i}\right)$ ) y, por otro, un conjunto de covariables que influyen en dicho comportamiento, tanto a nivel de edificio (factor de forma (S/V) y año de construcción (A)) como a nivel urbano (manzana urbana (MU), proporción de calle $(\mathrm{H} / \mathrm{W})$ y orientación (O)). Ello permite integrar la perspectiva urbana en la propuesta metodológica, confiriéndole a la misma un enfoque holístico que no se centra únicamente en el edificio como elemento individual y aislado.

La metodología se compone de cuatro etapas. En la Etapa I se establece el procedimiento para caracterizar la taxonomía urbana en cuatro escalas: la ciudad, el barrio, la manzana urbana residencial y el edificio. El análisis del Plan General de Ordenación Urbana (PGOU), la cartografía y la información catastral de la ciudad donde se implemente la metodología, será necesario para clasificar los elementos urbanos en las cuatro escalas anteriores. El uso de Sistemas de Información Geográfica (SIG) permite crear una base de datos georreferenciada para tratar dicha información, que se utilizará también en etapas posteriores. Como resultado de esta etapa se obtiene la definición de las covariables y un conjunto de edificios representativos del área urbana.

En la Etapa II de la metodología se realiza la evaluación energética de los edificios representativos previamente identificados. Mediante la combinación de las covariables se obtiene un conjunto de hipótesis de cálculo que serán objeto de simulación dinámica. Como resultado, se obtienen los valores de los indicadores energéticos para cada una de las hipótesis planteadas, que constituirán los datos de entrada en la siguiente etapa.

La Etapa III tiene como objeto la modelización estadística de los resultados de la evaluación energética mediante la metodología Integrated Nested Laplace Approximation (INLA), basada en la estadística Bayesiana. El tratamiento estadístico de los datos permite obtener un conjunto de cuatro ecuaciones matemáticas para predecir los indicadores energéticos de un área urbana, teniendo en 
cuenta el efecto de todas las covariables. Además, ello permite identificar la significancia de las mismas y su efecto sobre los indicadores energéticos.

En la Etapa IV, el diagnóstico energético es extrapolado desde la escala de edificio a la escala urbana, siguiendo un enfoque bottom-up, de manera que los cuatro indicadores pueden ser determinados para cada edificio que compone un área urbana objeto de estudio. A través del entorno SIG, los resultados son representados en mapas urbanos energéticos, los cuales proporcionan la interfaz gráfica a la metodología.

Por último, la propuesta metodológica se implementa en la ciudad de Castellón de la Plana, seleccionada como caso de estudio. Los resultados muestran el diagnóstico energético de todo un barrio que, representados en mapas urbanos energéticos, permiten identificar con facilidad aquellas zonas urbanas que tienen asociado un peor comportamiento y que requieren con mayor urgencia intervenciones de rehabilitación. El análisis en profundidad de la influencia de las covariables sobre los indicadores que evalúan el comportamiento energético pasivo del parque edificatorio residencial, permite sugerir ciertas estrategias que podrían ser implementadas a nivel de barrio existente y también a nivel de nuevos desarrollos urbanos, con el fin de conseguir ahorros energéticos y mejorar el confort térmico de sus habitantes. 
El sector de l'edificació ha experimentat un gran creixement en les últimes dècades, deixant un extens parc residencial d'edificis que ha contribuït a desenvolupar i donar forma a la ciutat. La legislació en matèria d'eficiència energètica va començar a desenvolupar-se en la dècada de 1970, coincidint amb la fi de l'etapa de major creixement del sector. Com a conseqüència, gran part de l'actual parc d'habitatges es troba allunyat dels estàndards promoguts per aquesta legislació, provocant que el seu ús siga responsable d'un alt percentatge del consum global d'energia. Davant d'aquesta situació, l'evolució de legislació s'ha orientat en aquests últims anys cap a la intervenció en la ciutat consolidada i impulsa, des de la iniciativa de les administracions públiques, la rehabilitació edificatòria i la regeneració urbana amb l'objectiu de promoure un desenvolupament urbà més sostenible .

Arran d'això, sorgeix la necessitat de desenvolupar instruments que proporcionen ajuda durant la presa de decisions a administracions locals $\mathrm{i}$ altres agents involucrats en els processos de regeneració urbana. Així, aquesta tesi proposa una metodologia per a caracteritzar el comportament energètic passiu del parc edificatori residencial existent considerant el seu context urbà, de manera que permeta realitzar un diagnòstic energètic d'àrees urbanes consolidades i identificar aquelles amb major vulnerabilitat energètica.

La revisió de l'estat de l'art relativa a les ferramentes d'avaluació de la sostenibilitat urbana i les metodologies d'avaluació energètica desenvolupades fins a la data, ha permès identificar, d'una banda, un conjunt d'indicadors per tal d'avaluar el comportament energètic passiu del parc edificatori residencial (demanda energètica de refrigeració $\left(D E_{r}\right)$ i de calefacció $\left(D E_{c}\right)$ i hores de disconfort tèrmic en estiu $\left(H D_{v}\right)$ i en hivern $\left(H D_{i}\right) i$, d'altra, un conjunt de covariables que influeixen en aquest comportament, tant a escala d'edifici (factor de forma (S/V) i any de construcció (A)) com a escala urbana (mansana urbana (MU), proporció de carrer $(\mathrm{H} / \mathrm{W})$ i orientació $(\mathrm{O})$ ). Això permet integrar la perspectiva urbana en la proposta metodològica, conferint a la mateixa un enfocament holístic que no se centra únicament en l'edifici com a element individual i aïllat.

La metodologia es compon de quatre etapes. En l'Etapa I s'estableix el procediment per caracteritzar la taxonomia urbana en quatre escales: la ciutat, el barri, la mansana urbana residencial i l'edifici. L'anàlisi del Pla General d'Ordenació Urbana (PGOU), la cartografia i la informació cadastral de la ciutat on s'implemente la metodologia, serà necessari per classificar els elements urbans en les quatre escales anteriors. L'ús de Sistemes d'Informació Geogràfica (SIG) permet crear una base de dades georreferenciada per tractar aquesta informació, la qual serà utilitzada també en etapes posteriors. Com a resultat d'aquesta etapa s'obté la definició de les covariables i un conjunt d'edificis representatius de l'àrea urbana.

En I'Etapa II de la metodologia es realitza l'avaluació energètica dels edificis representatius prèviament identificats. En combinar les covariables s'obté un conjunt d'hipòtesis de càlcul que seran objecte de simulació dinàmica. Com a resultat, s'obtenen els valors dels indicadors energètics per a cadascuna de les hipòtesis plantejades, que constituiran les dades d'entrada a la següent etapa.

L'Etapa III té com a objecte la modelització estadística dels resultats de l'avaluació energètica mitjançant la metodologia Integrated Nested Laplace Approximation (INLA), basada en l'estadística Bayesiana. El tractament estadístic de les dades facilita obtenir un conjunt de quatre equacions matemàtiques per predir els indicadors energètics d'una àrea urbana, tenint en compte l'efecte de 
totes les covariables. A més, això permet identificar la significança d'aquestes i el seu efecte sobre els indicadors energètics.

En l'Etapa IV, el diagnòstic energètic és extrapolat des de l'escala d'edifici a l'escala urbana, seguint un enfocament bottom-up, de manera que els quatre indicadors poden ser determinats per a cada edifici que compon una àrea urbana objecte d'estudi. A través de l'entorn SIG, els resultats són representats en mapes urbans energètics, els quals proporcionen la interfície gràfica a la metodologia.

Finalment, la proposta metodològica s'implementa a la ciutat de Castelló de la Plana, seleccionada com a cas d'estudi. Els resultats mostren el diagnòstic energètic de tot un barri que, representats en mapes urbans energètics, permeten identificar amb facilitat aquelles zones urbanes que tenen associat un pitjor comportament $\mathrm{i}$ que requereixen amb major urgència intervencions de rehabilitació. L'anàlisi en profunditat de la influència de les covariables sobre els indicadors que avaluen el comportament energètic passiu del parc edificatori residencial, permet suggerir certes estratègies que podrien ser implementades a nivell de barri existent $i$ també a nivell de nous desenvolupaments urbans, per tal d' aconseguir estalvis energètics i millorar el confort tèrmic dels seus habitants. 
The building sector has rapidly grown in recent decades, and has left a large residential building stock that has influenced city development. Legislation on energy efficiency began in the 1970s, and coincided with the end of the period of densest growth in the sector. Consequently, much existing housing stock is now far from the standards promoted by this legislation, which means that the building sector is responsible for a high percentage of overall energy consumption. To face this situation, legislation in recent years has focused on intervention in consolidated cities and, in line with government initiatives, promotes building renovation and urban regeneration to achieve more sustainable urban development.

Consequently, the need to develop tools that support decision making for local authorities and other actors involved in urban regeneration processes has emerged. This PhD proposes a methodology for characterising the passive energy performance of the existing residential building stock by considering its urban context to make an energy diagnosis of consolidated urban areas and to identify those with the greatest energy vulnerability.

The review of the state of the art on the urban sustainability assessment tools and energy assessment methodologies developed to date has allowed two main aspects to be identified. On the one hand, a set of indicators to assess the passive energy performance of the residential building stock (energy demand for cooling $\left(D E_{r}\right)$ and heating $\left(D E_{c}\right)$ and thermal discomfort hours in summer $\left(H D_{v}\right)$ and winter $\left.\left(H D_{i}\right)\right)$. On the other hand, a set of covariates that influences these indicators, on both the building scale (form factor $(S / V)$ and year of construction $(A)$ ) and the urban scale (urban block (MU), proportion of street (H/W) and orientation (O)). This allows the urban perspective to be included in the methodology, and provides a holistic approach that focuses on the building as an individual and isolated element.

The methodology comprises four stages. Stage I establishes the procedure to characterise urban taxonomy on four scales: city, neighbourhood, residential block and building. The analysis of the land-use plan, cartography and cadastral information of the city where the methodology is implemented is necessary to classify urban elements on the four scales above. Use of Geographic Information Systems (GIS) enables a geo-referenced database to be created to process such information, which will be used in later stages. As a result of this stage, the definition of covariates and a set of representative buildings of the urban area are obtained.

In Stage II of the methodology, an energy assessment of the previously identified representative buildings is made. By combining covariates, a set of calculation hypotheses is obtained, which would be subjected to dynamic simulation. As a result, the values of the energy indicators for each hypothesis are obtained, which constitute the input data in the next methodology stage.

Stage III involves the statistical modelling of the energy assessment results, following the Integrated Nested Laplace Approximation (INLA) methodology based on Bayesian statistics. Statistical data processing allows a set of four mathematical equations to be obtained, to be used to predict the energy indicators of an urban area by considering the effect of all the covariates. This also allows the identification of the significance of covariates and their effect on energy indicators.

In Stage IV, the energy diagnosis is extrapolated from the building scale to the urban scale by a bottom-up approach so that the four indicators can be determined for each building that comprises an urban area under study. Through the GIS environment, the results can be represented on urban energy maps, which provide a graphical interface to the methodology. 
Finally, the methodology was implemented in the city of Castellon de la Plana (east Spain), selected as a case study. The results showed the energy diagnosis of an entire neighbourhood represented on urban energy maps, which allowed us to easily identify those urban areas with a related deficient energy performance and which required urgent renovation interventions. The in-depth analysis of the influence of covariates on energy indicators enabled a set of strategies to be suggested, which could be implemented to existing neighbourhoods and to new urban developments to not only achieve energy savings, but to also improve its inhabitants' thermal comfort. 
A: Año de construcción

ACS: Agua Caliente Sanitaria

ASHRAE: American Society of Heating, Refrigerating, and Air-Conditioning Engineers

BCN: Sistema Municipal d'Indicadors de Sostenibilitat de la Diputació de Barcelona

BIL: Indicadores de Sostenibilidad de Bilbao

BREEAM: Building Research Establishment Environmental Assessment Method

BRIDGE: SustainaBle uRban planning Decision support accounting for Urban mEtabolism

CASBEE UD: Comprehensive Assessment System for Building Environmental Efficiency for Urban Development

CEN: Comité Europeo de Normalización

CGYM: Indicadores y Condicionantes para Ciudades Grandes y Medianas

DB HE: Documento Básico de Ahorro de Energía

$\mathrm{CO}_{2}$ : emisiones de dióxido de carbono

COP: Conference of the Parts

COP: Coefficient Of Performance

CPO: Conditional Predictive Ordinate

CTE: Código Técnico de la Edificación

D: Profundidad

$\mathrm{DE}_{\mathrm{c}}$ : Demanda Energética de calefacción ( $\left.\mathrm{kWh} / \mathrm{m}^{2} \mathrm{año}\right)$

$D E_{r}$ : Demanda Energética de refrigeración $\left(\mathrm{kWh} / \mathrm{m}^{2} \mathrm{año}\right)$

DGC: Dirección General del Catastro

DIC: Deviance Information Criterion

E: Este

ECC: EarthCraft Communities

EPBD: Energy Performance of Buildings Directive

FIS: Forecasting Information Systems

GEI: Gases de Efecto Invernadero

GLM: Generalized Linear Models

H: Altura

H/W: Proporción de calle (ratio altura-anchura) 
HESU: Herramientas de Evaluación de la Sostenibilidad Urbana

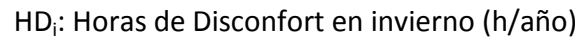

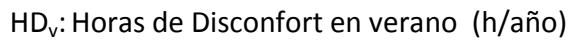

HQE2R: Haute Qualité Environnementale et Economique Réhabilitation

HVAC: heating, ventilation, and air conditioning (calefacción, ventilación y aire acondicionado)

INLA: Integrated Nested Laplace Approximation

IVACE: Instituto Valenciano de Competitividad Empresarial

KITCASP: Key Indicators for Territorial Cohesion and Spatial Planning

L3R: Ley de rehabilitación, regeneración y renovación urbanas

LB: Libro Blanco de la Sostenibilidad en el Planeamiento Urbanístico Español

LEED ND: Leadership in Energy and Environment Design for Neighborhood Development

MCMC: Markov Chain Monte Carlo

MEE: Medidas de Eficiencia Energética

MV: Normas Técnicas del Sector de la Edificación

MU: Manzana Urbana

$\mathrm{N}$ : Norte

NBE: Norma Básica de la Edificación

NRE: Norma Reglamentària d'Edificació

NTE: Normas Tecnológicas de la Edificación

OECD: Organisation for Economic Co-operation and Development

O: Oeste

O: Orientación solar

PAU: Programas de Actuación Urbanística

PERI: Planes Especiales de Reforma Interior

PF: Plurifamiliar

PGOU: Plan General de Ordenación Urbana

PP: Planes Parciales

R: Resistencia térmica

RITE: Reglamento de Instalaciones Térmicas en los Edificios

RMSE: Root Mean Square Error

RUI: Regeneración Urbana Integrada

S: Sur

S: Superficie 
SCR: Sustainable Community Rating

SEV: Plan Especial de Indicadores de Sostenibilidad Ambiental de la Actividad Urbanística de Sevilla SIG: Sistemas de Información Geográfica

SMIS: Sistema Municipal de Indicadores de Sostenibilidad

SPEDE: Stochastic Partial Differential Equation

$\mathrm{S} / \mathrm{V}$ : Factor de forma del edificio $\left[\mathrm{m}^{-1}\right]$

U: Transmitancia térmica

UE: Unión Europea

UF: Unifamiliar

UN: United Nations

V: Volumen

W: Anchura

$\theta$ : Temperatura 



\section{INTRODUCCIÓN}

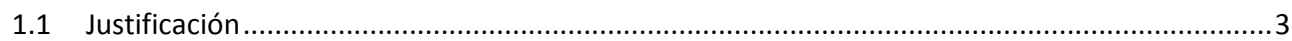

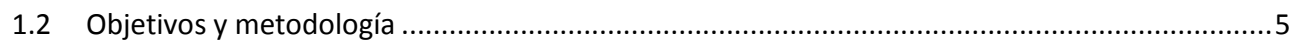

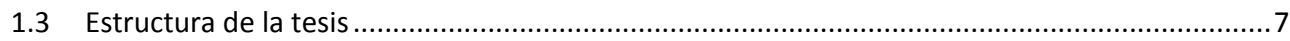

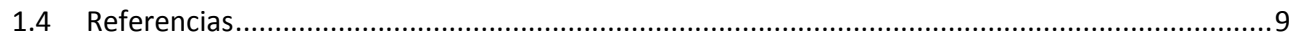

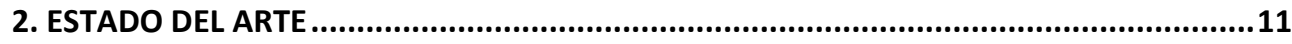

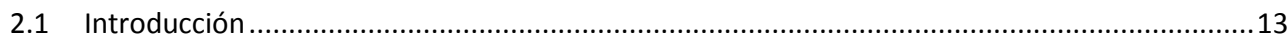

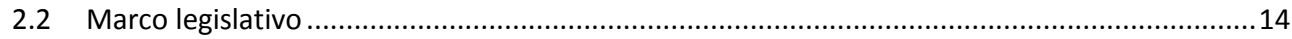

2.2.1 Marco legislativo en el contexto europeo ........................................................................15

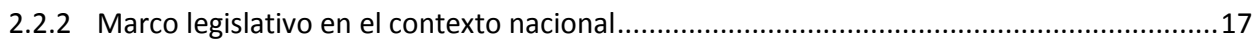

2.3 Revisión de herramientas de evaluación de la sostenibilidad urbana (HESU) ...........................20

2.4 Revisión de metodologías de evaluación energética del parque edificatorio ..............................28

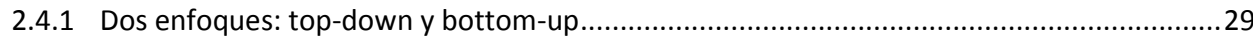

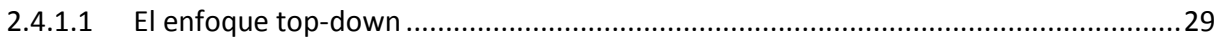

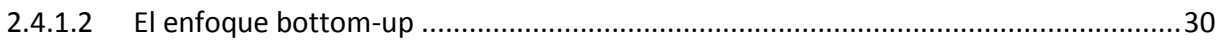

2.4.1.3 Comparativa entre el enfoque top-down y bottom-up ............................................. 31

2.4.2 Metodologías existentes de evaluación energética del parque edificatorio .......................33

2.4.2.1 Revisión de metodologías a nivel internacional .........................................................33

2.4.2.2 Revisión de metodologías a nivel nacional ............................................................... 41

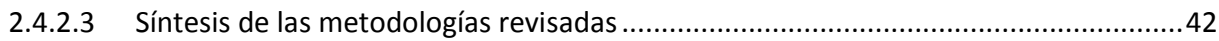

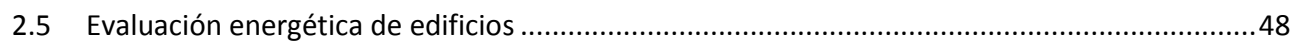

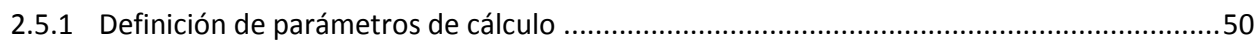

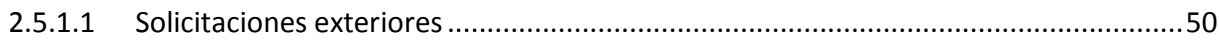

2.5.1.2 Solicitaciones interiores y condiciones operacionales ..............................................50

2.5.1.3 Definición morfológica y constructiva del edificio ...................................................52

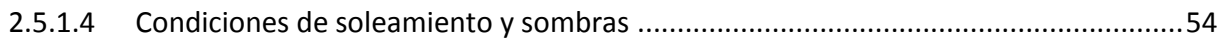

2.5.1.5 Sistemas de calefacción, ventilación y aire acondicionado (HVAC) y agua caliente

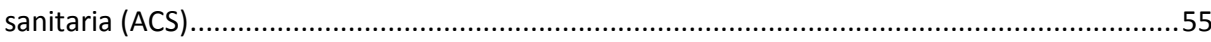

2.5.2 Herramientas informáticas de simulación energética …...................................................56

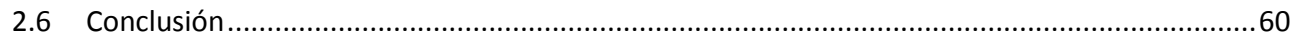


3. SELECCIÓN DE VARIABLES PARA LA EVALUACIÓN ENERGÉTICA PASIVA......................71

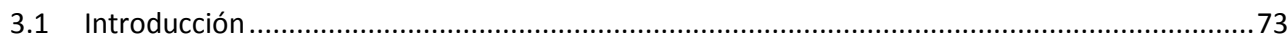

3.2 Análisis de indicadores de sostenibilidad urbana propuestos por las HESU ............................74

3.2.1 Propuesta de estructura común de clasificación de indicadores .......................................75

3.2.2 Análisis comparativo de indicadores contenidos en las HESU .........................................92

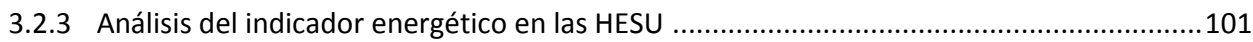

3.3 Análisis de aspectos considerados en las metodologías de evaluación energética .................109

3.4 Definición de variables respuesta y covariables.....................................................................111

3.4.1 Definición de variables respuesta (indicadores energéticos) ...........................................112

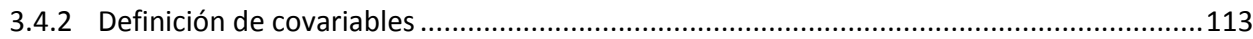

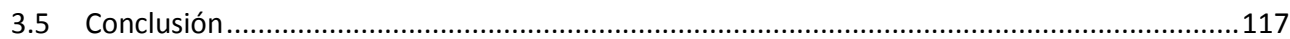

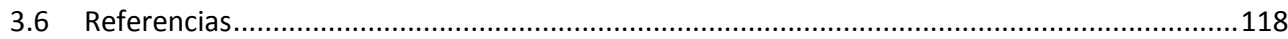

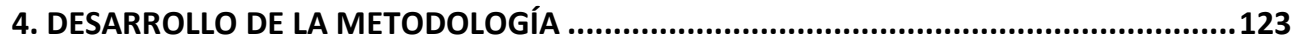

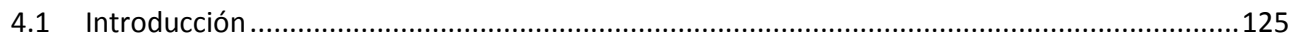

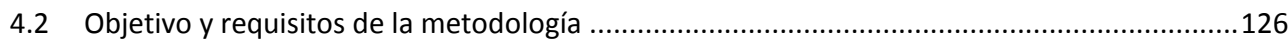

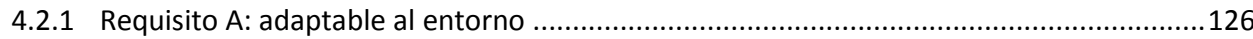

4.2.2 Requisito B: evaluación energética pasiva mediante los indicadores energéticos DE y HD

4.2.3 Requisito C: consideración del edificio y de la morfología urbana mediante covariables

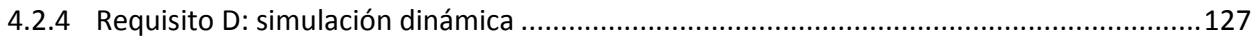

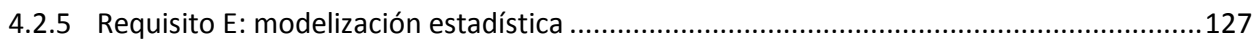

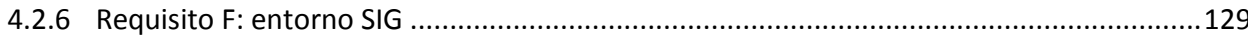

4.3 Justificación de la necesidad de una nueva metodología .......................................................130

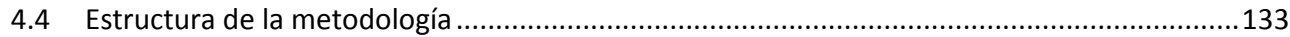

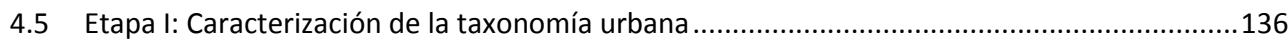

4.5.1 I.1 Escala de ciudad: identificación de patrones urbanos .................................................137

4.5.2 I.2 Escala de barrio: identificación de tipos de barrios …..............................................137

4.5.3 I.3 Escala de manzana urbana: identificación de patrones de manzana............................138

4.5.4 I.4 Escala de edificio: identificación de tipologías edificatorias .....................................139

4.5.5 I.5 Configuración de la taxonomía urbana representativa ...............................................141

4.5.6 I.6 Selección de los edificios representativos.......................................................................141 
4.5.7 Creación de una base de datos en entorno SIG

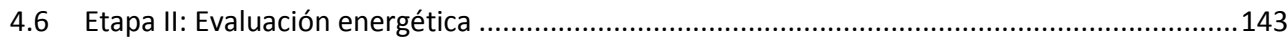

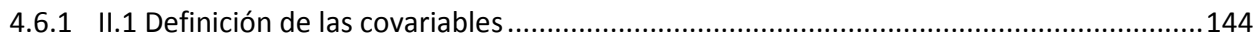

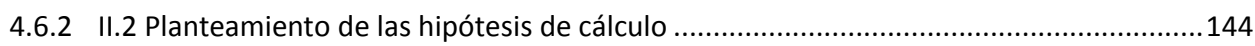

4.6.3 II.3 Definición de los parámetros de cálculo para la obtención de las variables respuesta .....

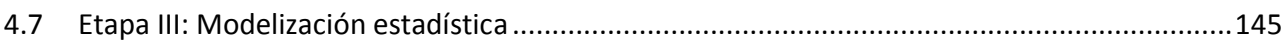

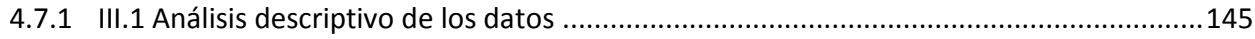

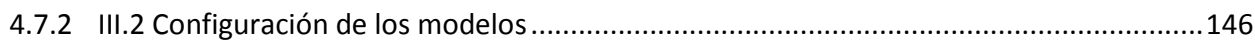

4.7.3 III.3 Selección de modelos con mejor ajuste .............................................................147

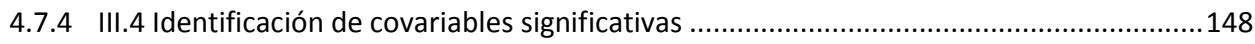

4.8 Etapa IV: Extrapolación del diagnóstico energético a escala urbana ......................................149

4.8.1 IV.1 Cálculo de los indicadores energéticos en cada edificio ...........................................150

4.8.2 IV.2 Desarrollo de una escala de valoración para los indicadores energéticos ..................150

4.8.3 IV.3 Desarrollo de mapas urbanos energéticos .............................................................151

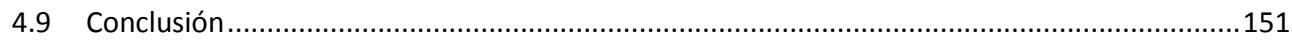

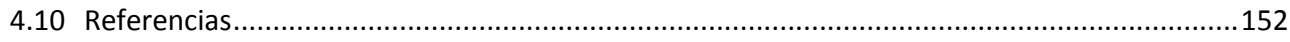

5. IMPLEMENTACIÓN DE LA METODOLOGÍA EN UN CASO DE APLICACIÓN.....................157

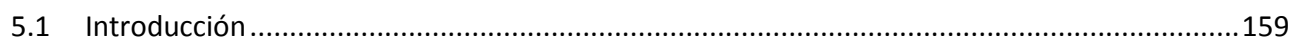

5.2 Descripción del desarrollo urbanístico de Castellón de la Plana ..............................................160

5.2.1 La villa medieval amurallada de los siglos XIII y XIV ........................................................160

5.2.2 El surgimiento de los arrabales hasta el siglo XVIII .......................................................161

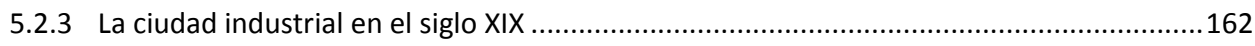

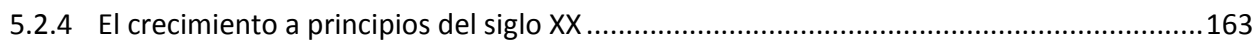

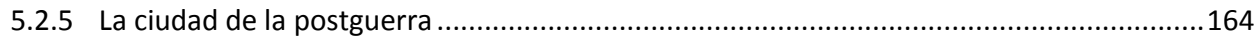

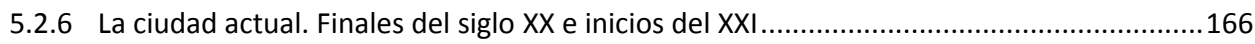

5.3 Etapa I: Caracterización de la taxonomía urbana ................................................................167

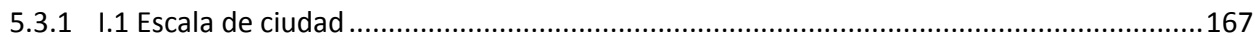

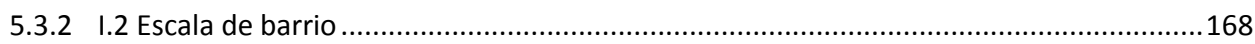

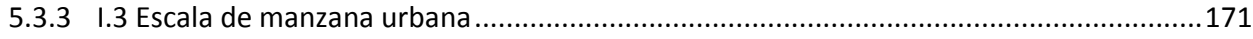

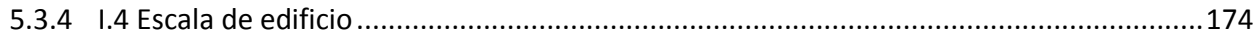

5.3.4.1 Identificación de la clase de edificio ...................................................................... 174

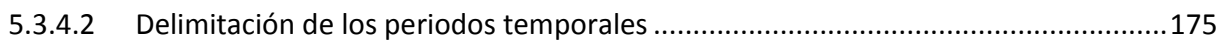


5.3.4.3 Obtención de la matriz de tipologías edificatorias ...................................................181

5.3.5 I.5 Configuración de la taxonomía urbana representativa ................................................ 185

5.3.6 I.6 Selección de los edificios representativos................................................................187

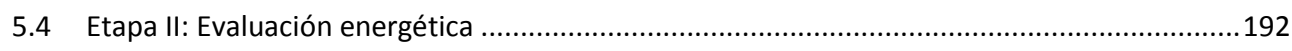

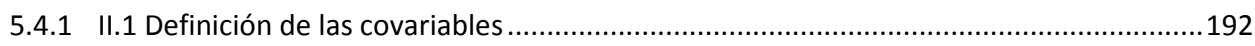

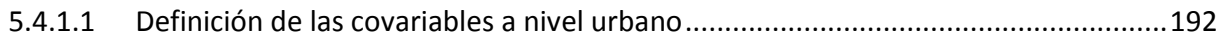

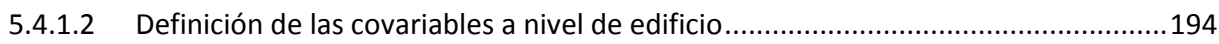

5.4.1.3 Resumen de covariables para evaluar el comportamiento energético del barrio....202

5.4.2 II.2 Planteamiento de las hipótesis de cálculo ..............................................................202

5.4.3 II.3 Definición de los parámetros de cálculo para la obtención de las variables respuesta ...... .204

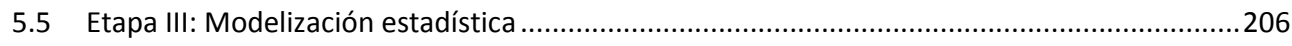

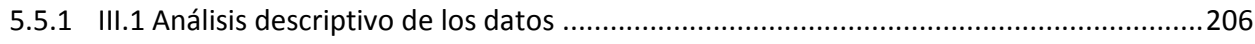

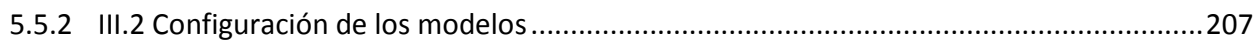

5.5 .3 III.3 Selección de modelos con mejor ajuste ..............................................................210

5.5.4 III.4 Identificación de covariables significativas .............................................................213

5.6 Etapa IV: Extrapolación del diagnóstico energético a escala urbana .......................................214

5.6.1 IV.1 Cálculo de los indicadores energéticos en cada edificio ..........................................215

5.6.2 IV.2 Desarrollo de una escala de valoración para los indicadores energéticos ...................216

5.6.3 IV.3 Desarrollo de mapas urbanos energéticos ...........................................................217

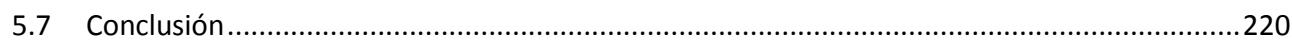

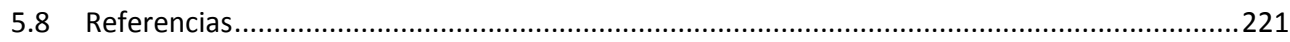

6. ANÁLISIS DE LA INFLUENCIA DE LAS COVARIABLES EN EL COMPORTAMIENTO

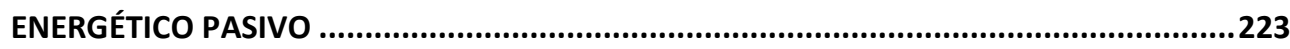

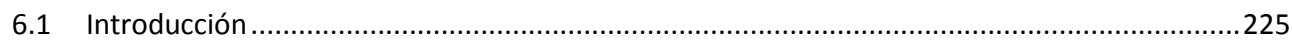

6.2 Análisis de la influencia de las covariables sobre los indicadores energéticos .......................226

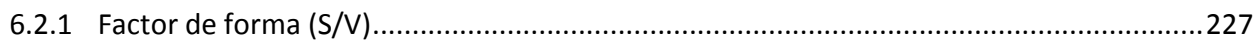

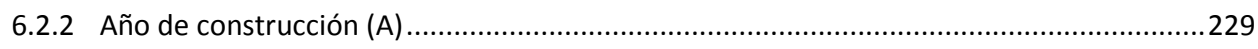

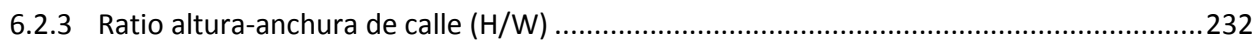

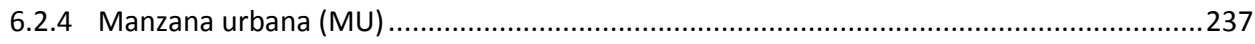

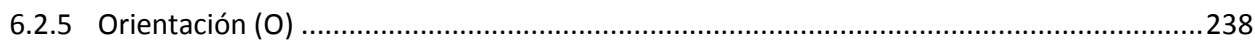

6.3 Propuesta de nueva configuración urbana y su evaluación energética ..................................242

6.4 Relación de estrategias pasivas para mejorar el comportamiento energético del parque

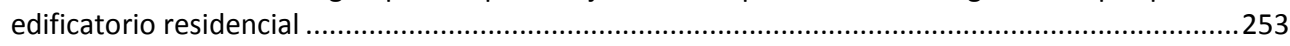




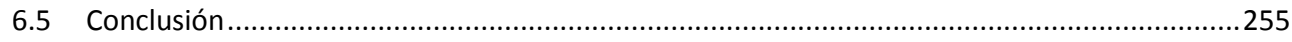

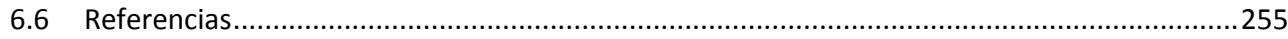

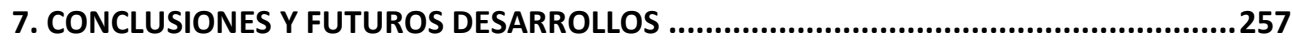

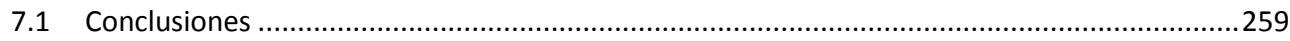

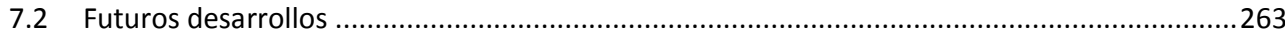

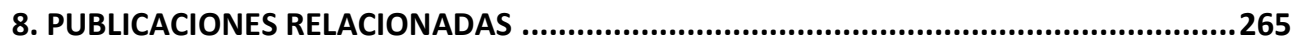

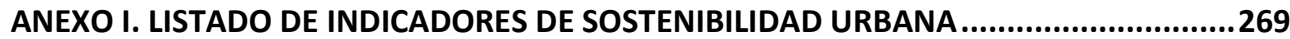

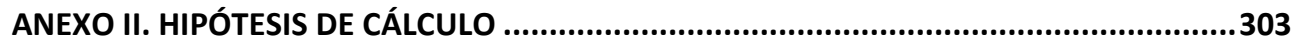

ANEXO III. ANÁLISIS DETALLADO DE LA DEMANDA DE REFRIGERACIÓN .......................311 



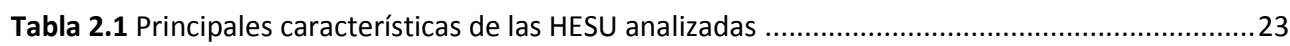

Tabla 2.2 Estructura de indicadores de las HESU analizadas.........................................................2

Tabla 2.3 Fortalezas y debilidades de los enfoques top-down y bottom-up ......................................32

Tabla 2.4 Revisión de metodologías para la evaluación energética del parque edificado ...................43

Tabla 2.5 Clo según el nivel de vestimenta ISO 7730 ....................................................................51

Tabla 2.6 Características generales de los programas de simulación dinámica ..................................57

Tabla 2.7 Comparación de las capacidades de los programas de simulación dinámica .......................58

Tabla 3.1 Estructura en dos niveles de categorías y subcategorías..................................................76

Tabla 3.2 Análisis del nivel de relación entre las 14 categorías propuestas ........................................79

Tabla 3.3 Clasificación de indicadores en la categoría "sitio y suelo" ................................................ 81

Tabla 3.4 Clasificación de indicadores en la categoría "morfología urbana" .....................................82

Tabla 3.5 Clasificación de indicadores en la categoría "movilidad y transporte" ................................83

Tabla 3.6 Clasificación de indicadores en la categoría "naturaleza y biodiversidad" ..........................84

Tabla 3.7 Clasificación de indicadores en la categoría "edificación y vivienda" ...................................85

Tabla 3.8 Clasificación de indicadores en la categoría "energía" ........................................................86

Tabla 3.9 Clasificación de indicadores en la categoría "agua" ..........................................................87

Tabla 3.10 Clasificación de indicadores en la categoría "materiales" ..................................................87

Tabla 3.11 Clasificación de indicadores en la categoría "residuos" ..................................................8

Tabla 3.12 Clasificación de indicadores en la categoría "contaminación" ........................................8 88

Tabla 3.13 Clasificación de indicadores en la categoría "aspecto social" ............................................89

Tabla 3.14 Clasificación de indicadores en la categoría "aspecto económico" ..................................90

Tabla 3.15 Clasificación de indicadores en la categoría "gestión e institución" ...................................91

Tabla 3.16 Clasificación de indicadores en la categoría "innovación" ...............................................91

Tabla 3.17 Comparación de la distribución del porcentaje de pesos en las herramientas LEED ND,

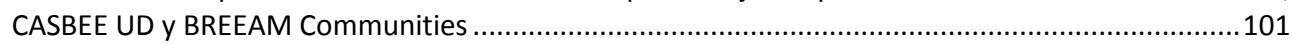

Tabla 3.18 Clasificación de las subcategorías del aspecto "energía" ...............................................102

Tabla 3.19 Indicadores relacionados con el aspecto "energía" que tienen en cuenta el comportamiento pasivo en la edificación y el urbanismo ..............................................................103

Tabla 3.20 Aspectos relevantes para evaluar el comportamiento pasivo derivados de los indicadores

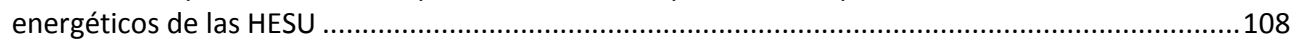

Tabla 3.21 Aspectos considerados en los modelos bottom-up analizados ....................................110

Tabla 4.1 Alcance de los modelos bottom-up analizados ...........................................................131 
Tabla 4.2 Paquete de valores de transmitancias térmicas (U) para cada periodo temporal constructivo 140

Tabla 4.3 Ejemplo de información de entrada (tabla de atributos) para la creación de la base de datos SIG proporcionada por la DGC.

Tabla 4.4 Codificación de tipologías edificatorias según Dirección General del Catastro español....143

Tabla 4.5 Primera batería de modelos considerando las covariables $\mathrm{H} / \mathrm{W}, \mathrm{A}, \mathrm{O}$ y $\mathrm{S} / \mathrm{V}$ por separado, comparando las $\mathrm{MU}$

Tabla 4.6 Segunda batería de modelos considerando las covariables H/W, A, O y S/V de forma conjunta, comparando las MU

Tabla 4.7 Tercera batería de modelos considerando todas las covariables (H/W, A, O, S/V y MU) por separado

Tabla 4.8 Cuarta batería de modelos considerando todas las covariables (H/W, A, O, S/V y MU) de forma conjunta 147

Tabla 4.9 Formato de la tabla de atributos de SIG. 150

Tabla 4.10 Escala de valoración para los indicadores $D E_{r}, y D E_{c}$ 151

Tabla 4.11 Escala de valoración para los indicadores $D E_{r}, y E_{c}$ 151

Tabla 5.1 Síntesis de Planes Urbanísticos de Castellón de la Plana 167

Tabla 5.2 Delimitación de barrios en Castellón de la Plana según zonas residenciales del PGOU ....169

Tabla 5.3 Tipologías y características de las manzanas urbanas identificadas en la ciudad 172

Tabla 5.4 Obtención de clases de edificio 174

Tabla 5.5 Identificación de clases de edificios. 175

Tabla 5.6 Evolución temporal de los sistemas constructivos en edificios residenciales 179

Tabla 5.7 Matriz de tipologías edificatorias en la ciudad 184

Tabla 5.8 Análisis de la superficie construida por tipología edificatoria en el barrio para selección de los edificios muestra representativos. .188

Tabla 5.9 Número de edificios, superficie construida $\left(\mathrm{m}^{2}\right)$ y \% de superficie construida por clase de edificio y por tipología de manzana 191

Tabla 5.10 Características de las manzanas urbanas residenciales 193

Tabla 5.11 Características dimensionales de los edificios muestra $\mathrm{PF}_{\mathrm{M}(>4)}, \mathrm{PF}_{\mathrm{M}(\leq 4)}$ y $\mathrm{UF}_{\mathrm{M}(\leq 4)}$..... 194

Tabla 5.12 Transmitancias térmicas de las soluciones constructivas contempladas en los cinco periodos temporales .199

Tabla 5.13 Transmitancias térmicas de los puentes térmicos en los cinco periodos temporales .....202

Tabla 5.14 Definición de covariables..... 202

Tabla 5.15 Parámetros de cálculo considerados en DesignBuilder 205

Tabla 5.16 Descripción de las variables respuesta $D E_{r}, D E_{c}, H D_{v}$ y $H D_{1}$ 206

Tabla 5.17 DIC para la primera batería de 32 modelos considerando las covariables $\mathrm{H} / \mathrm{W}, \mathrm{A}, \mathrm{O}$ y S/V por separado, comparando $\mathrm{MU}_{1}$ y $\mathrm{MU}_{2}$ 208 
Tabla 5.18 DIC para la segunda batería de 8 modelos considerando las covariables $\mathrm{H} / \mathrm{W}, \mathrm{A}, \mathrm{O}$ y S/V

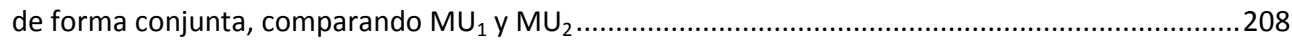

Tabla 5.19 DIC para la tercera bacteria de 24 modelos considerando todas las covariables (H/W, A, $\mathrm{O}, \mathrm{S} / \mathrm{V}$ y $\mathrm{MU}$ ) por separado 208

Tabla 5.20 DIC para la cuarta bacteria de 4 modelos considerando todas las covariables $(H / W, A, O$, $\mathrm{S} / \mathrm{V}$ y $\mathrm{MU}$ ) de forma conjunta..... 209

Tabla 5.21 CPO para la primera batería de 32 modelos considerando las covariables H/W, A, O y S/V por separado, comparando $\mathrm{MU}_{1}$ y $\mathrm{MU}_{2}$ .209

Tabla 5.22 CPO para la segunda batería de 8 modelos modelos considerando las covariables H/W, A, $\mathrm{O}$ y $\mathrm{S} / \mathrm{V}$ de forma conjunta, comparando $\mathrm{MU}_{1}$ y $\mathrm{MU}_{2}$ 209

Tabla 5.23 CPO para la tercera batería de 24 modelos considerando todas las covariables (H/W, A, O, $\mathrm{S} / \mathrm{V}$ y $\mathrm{MU}$ ) por separado .209

Tabla 5.24 CPO para la cuarta batería de 4 modelos considerando todas las covariables (H/W, A, O, $\mathrm{S} / \mathrm{V}$ y MU) de forma conjunta. 209

Tabla 5.25 Correlación y RMSE para la primera batería de 32 modelos ..........................................210

Tabla 5.26 Correlación y RMSE para la segunda batería de 8 modelos............................................210

Tabla 5.27 Correlación y RMSE para la tercera batería de 20 modelos..............................................211

Tabla 5.28 Correlación y RMSE para la cuarta batería de 4 modelos .................................................211

Tabla 5.29 Efectos fijos: $\beta_{i}$ (media [percentil 2,5; percentil 97,5]). Primer conjunto de 32 modelos 213

Tabla 5.30 Efectos fijos: $\beta_{i}$ (media [percentil 2,5; percentil 97,5]). Segundo conjunto de 8 modelos .213

Tabla 5.31 Efectos fijos: $\beta_{i}$ (media [percentil 2,5; percentil 97,5]). Tercer conjunto de 20 modelos

Tabla 5.32 Efectos fijos: $\beta_{i}$ (media [percentil 2,5; percentil 97,5]). Cuarto conjunto de 4 modelos 213

Tabla 5.33 Cálculo de los cuatro indicadores energéticos para cada edificio .215

Tabla 5.34 Escala de valoración para el indicador energético DE basado en la clasificación propuesta por la legislación española para edificios existentes $\left(\mathrm{kWh} / \mathrm{m}^{2}\right.$ año) 216

Tabla 5.35 Escala de valoración para el indicador energético HD (horas/año) .................................216

Tabla 6.1 Comparativa de DE y HD de una misma vivienda orientada a N, E, S y O... 241

Tabla 6.2 Estudio de dos diseños de manzana urbana 244

Tabla 6.3 Análisis del soleamiento en las fachadas S, E y O de la manzana en el solsticio de invierno (n)

Tabla 6.4 Características dimensionales del edificio tomado como referencia .247

Tabla 6.5 Determinación de indicadores para las diferentes orientaciones de la manzana 249

Tabla 6.6 Cálculo de los indicadores energéticos en la planificación urbana propuesta .252 
Tabla 6.7 Comparativa entre configuración existente y propuesta para una superficie de referencia de $17,6 \mathrm{Ha}$

Tabla 6.8 Estrategias pasivas para mejorar el comportamiento energético del parque edificatorio residencial 254

Tabla 8.1 Publicaciones relacionadas con la tesis .267

Tabla Al.1 Lista de indicadores en la herramienta LEED ND 271

Tabla Al.2 Lista de indicadores en la herramienta BREEAM Communities 273

Tabla Al.3 . Lista de indicadores en la herramienta CASBEE UD 275

Tabla Al.4 Lista de indicadores en la herramienta ECOCITY 278

Tabla AI.5 Lista de indicadores en la herramienta Le modele INDI-RU 2005 288

Tabla Al.6 Lista de indicadores en la herramienta BIRDGE 291

Tabla Al.7 Lista de indicadores en la herramienta KITCASP 292

Tabla Al.8 Lista de indicadores en la herramienta LB 293

Tabla AI.9 Lista de indicadores en la herramienta SMIS 296

Tabla Al.10 Lista de indicadores en la herramienta CGYM 298

Tabla Al.11 . Lista de indicadores en la herramienta SEV 300

Tabla Al.12 . Lista de indicadores en la herramienta BCN 301

Tabla AI.13 . Lista de indicadores en la herramienta BIL 302

Tabla All.1 Lista de indicadores en la herramienta LEED ND 305

Tabla All.1. Cálculo de la inercia térmica de la fachada considerada en el periodo temporal 1 (anterior a 1940) 316

Tabla Alll.2 Comparativa de demandas energéticas entre H82 y edificio aislado 319 


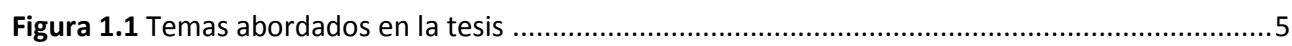

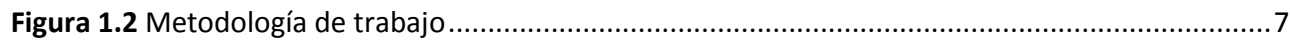

Figura 1.3 Estructura de la tesis y relación entre capítulos, objetivos y resultados esperables ............8

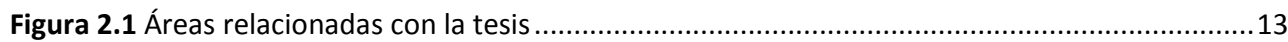

Figura 2.2 Evolución de las directivas europeas relacionadas con la eficiencia energética ................17

Figura 2.3 Evolución de viviendas construidas a lo largo del siglo XX e inicios del XXI y relación con la legislación española (elaboración propia a partir de datos del Instituto Nacional de Estadística ........19

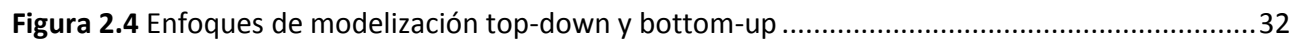

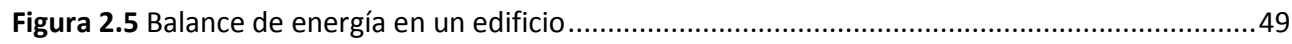

Figura 2.6 Cerramientos de la envolvente térmica del edificio ........................................................53

Figura 2.7 Reflexión solar de las superficies del edificio sobre el mismo u otro edificio.......................54

Figura 2.8 Reflectancia solar en el edificio producida por obstrucciones. Reflexión difusa de la radiación directa sobre la superficie de un voladizo (a), reflexión difusa de la radiación solar del cielo en un voladizo (b), reflexión directa especular desde la superficie de la fachada de un edificio

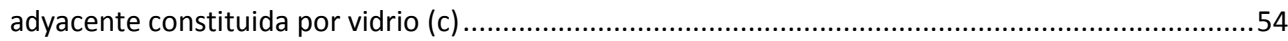

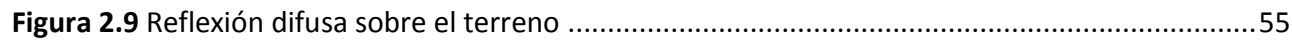

Figura 2.10 Posición de los dispositivos de protección solar con respecto al hueco.............................55

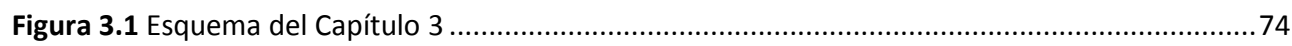

Figura 3.2 Metodología aplicada para proponer una estructura de indicadores ...............................74

Figura 3.3 Número de indicadores que cada HESU analizada confiere a las 14 categorías propuestas

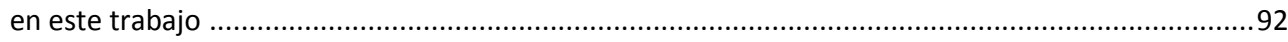

Figura 3.4 Número de indicadores de las $13 \mathrm{HESU}$ analizadas contenidos en las 14 la categorías .....93

Figura 3.5 Distribución estadística del número de indicadores en las 14 categorías propuestas ........97

Figura 3.6 Distribución del porcentaje de pesos en las 14 categorías propuestas por las herramientas

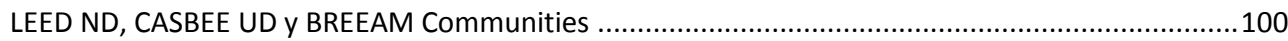

Figura 3.7 Covariables y variables respuesta seleccionadas..........................................................112

Figura 3.8 Covariables consideradas para analizar el comportamiento energético de los edificios a escala urbana (O: orientación; H/W: proporción de calle; A: año de construcción; S/V: factor de forma; MU: configuración urbana)

Figura 3.9 Manzanas en trazado radial (izquierda) y manzanas en trazado ortogonal (derecha) (Fuente: elaboración propia a partir de Google Maps) 114

Figura 3.10 Obstrucción solar provocada por el ratio $\mathrm{H} / \mathrm{W}$ de una calle en una latitud de $40^{\circ} \mathrm{N} \ldots . . .115$

Figura 3.11 Definición de la orientación solar de la fachada principal en CTE (izquierda) y en el marco de la tesis (derecha) 116 
Figura 4.1 Estructura del Capítulo 4

Figura 4.2 Requisitos de la metodología

Figura 4.3 Etapas de la metodología propuesta

Figura 4.4 Procedimiento para la caracterización de la taxonomía urbana 136

Figura 4.5 Ejemplos de ciudades con trazados urbanos característicos de la ciudad española 137

Figura 4.6 Metodología para la caracterización de la tipología edificatoria. 140

Figura 4.7 Procedimiento de asociación de tipologías edificatorias a tipologías de manzana urbana 141

Figura 4.8 Información necesaria para cada parcela catastral 142

Figura 4.9 Procedimiento a seguir para el planteamiento de las hipótesis objeto de simulación energética..... 144

Figura 4.10 Enfoque metodológico para la modelización estadística 145

Figura 4.11 Procedimiento de agregación 149

Figura 5.1 Ubicación de Castellón de la Plana 159

Figura 5.2 Castellón de la Plana en los siglos XIII y XIV según Vicente Traver Tomás. 160

Figura 5.3 Castellón de la Plana en el siglo XVI según Gimeno Michavila. Arrabal de Roser y San Francisco al sur y el de les Forques al norte 161

Figura 5.4 Murallas Carlistas en Castellón de la Plana en la segunda mitad del siglo XIX 162

Figura 5.5 Forma circular de Castellón de la Plana en la década de los 50 165

Figura 5.6 Desarrollo urbano de Castellón de la Plana 166

Figura 5.7 Identificación de patrones urbanos en la ciudad. 168

Figura 5.8 Identificación de barrios y superposición a la evolución urbana de la ciudad. 171

Figura 5.9 Períodos temporales de construcción propuestos 181

Figura 5.10 Obtención de las 30 tipologías edificatorias en la ciudad 181

Figura 5.11 Procedimiento a seguir para la obtención de las clases de edificios en un SIG 182

Figura $\mathbf{5 . 1 2}$ Visualización de las clases de edificios en el entorno SIG 183

Figura 5.13 Visualización de los años de construcción de los edificios en el entorno SIG 183

Figura 5.14 Ejemplo de la tabla de atributos en gvSIG 184

Figura 5.15 Evolución en la construcción de edificios en Castellón de la Plana 185

Figura 5.16 Taxonomía urbana de la ciudad de Castellón de la Plana. 186

Figura 5.17 Ubicación del barrio Parque del Oeste en el contexto de la ciudad 187

Figura 5.18 Edificios muestra representativos y superficie construida 189

Figura 5.19 Visualización en entorno SIG de las clases de edificios y tipologías de manzanas contenidas en el barrio.... 190 
Figura 5.20 Configuración de las manzanas $\mathrm{MU}_{1}$ y $\mathrm{MU}_{2}$ en el barrio.

Figura 5.21 Orientación de las fachadas de los edificios en el barrio

Figura 5.22 Planta baja (inferior) y planta tipo (superior) del edificio $P F_{M(>4)}$ 195

Figura 5.23 Planta baja (inferior) y planta tipo (superior) del edificio $\mathrm{PF}_{\mathrm{M}(\leq 4)}$ 196

Figura 5.24 Planta baja, primera, segunda y bajo cubierta (de abajo a arriba) del edificio UF $\mathrm{M}_{\mathrm{M}(\leq 4) \ldots 197}$

Figura 5.25 Configuración de las 240 hipótesis para determinar las cuatro variables respuesta......202

Figura 5.26 Ejemplo de configuración de la H81, H82, H83 y H84 en DesignBuilder ..... 203

Figura 5.27 Ejemplo de configuración de la H229, H230, H231 y H232 en DesignBuilder 204

Figura 5.28 Histograma (izquierda) y diagrama de cajas y bigotes (derecha) de las variables respuesta 207

Figura 5.29 Histograma (arriba) y diagrama de cajas y bigotes (abajo) de las variables respuesta para $\mathrm{MU}_{1}$ (izquierda) y $\mathrm{MU}_{2}$ (derecha) .

Figura 5.30 Coeficiente de correlación ente los valores observados y los predichos de los modelos seleccionados..... .212

Figura 5.31 Mapa energético urbano para el indicador $\mathrm{DE}_{\mathrm{r}}$ 217

Figura 5.32 Mapa energético urbano para el indicador $D_{c}$ .218

Figura 5.33 Mapa energético urbano para el indicador $\mathrm{HD}_{\mathrm{v}}$ 219

Figura 5.34 Mapa energético urbano para el indicador $\mathrm{HD}_{\mathrm{i}}$ 219

Figura 6.1 Estructura del Capítulo 6 226

Figura 6.2 Resultados de las variables respuesta $\left(D E_{r}, D E_{c}, H D_{v}, H D_{i}\right)$ en los tres factores de forma (S/V), para la $\mathrm{MU}_{1}$ y $\mathrm{MU}_{2}$

Figura 6.3 Resultados de las variables respuesta $\left(D E_{r}, D E_{c}, H D_{v}, H D_{i}\right)$ en los cinco periodos temporales, para la $\mathrm{MU}_{1}$ y $\mathrm{MU}_{2}$

Figura 6.4 Evolución temporal de la transmitancia térmica ( $\mathrm{kWh} / \mathrm{m} 2 \mathrm{año}$ ) de los elementos de envolvente térmica. 230

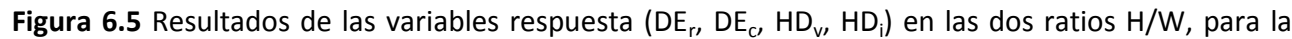
$\mathrm{MU}_{1}$ y $\mathrm{MU}_{2}$. 233

Figura 6.6 Datos sobre radiación solar propia del sitio y resultados de ganancias internas y solares en las $\mathrm{H} 82$ y $\mathrm{H} 102$ 234

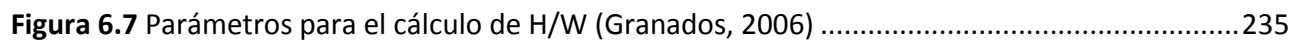

Figura 6.8 Carta solar estereográfica para la latitud 39,98o (Matusiak, 2016) .............................236

Figura 6.9 Resultados de las variables respuesta $\left(\mathrm{DE}_{\mathrm{r}}, \mathrm{DE}_{\mathrm{c}}, \mathrm{HD}_{\mathrm{v}}, \mathrm{HD}_{\mathrm{i}}\right)$ en $\mathrm{MU}_{1}$ y $\mathrm{MU}_{2} \ldots \ldots \ldots \ldots \ldots \ldots . . . \ldots 237$

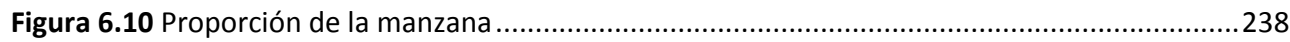

Figura 6.11 Resultados de las variables respuesta $\left(D E_{r}, D E_{c}, H D_{v}, H D_{i}\right)$ en las cuatro orientaciones, para la $\mathrm{MU}_{1}$ y $\mathrm{MU}_{2}$ 239

Figura 6.12 Vivienda tipo $B$ de la planta 6 en el edificio $P F_{M(>4)}$ 240 
Figura 6.13 Procedimiento para definir la configuración urbana

Figura 6.14 Configuración geométrica de la nueva manzana.

Figura 6.15 Gráfico de relación entre la demanda energética y la orientación. Orientación óptima 250

Figura 6.16 Soleamiento en la orientación de manzana óptima (solsticio invierno). 251

Figura 6.17 Configuración urbana existente (izquierda) y propuesta (derecha) 251

Figura 6.18 Configuración de las edificaciones en la manzana urbana propuesta 252

Figura AllI.1 Resultados de confort térmico para la H82 314

Figura All. 2 Resultados del balance térmico en la H82 315

Figura All..3 Resultados horarios de confort en el día de máxima $\theta_{\mathrm{bs}}$ para la H82 317

Figura All..4 Resultados de demandas energéticas mensuales para la H82 318

Figura Alll.5 Resultados de demandas energéticas mensuales para la H82, suponiendo el edificio aislado 318 


\section{INTRODUCCIÓN}

Propuesta metodológica para la caracterización del comportamiento energético pasivo del parque edificatorio residencial existente

considerando su contexto urbano. 



\subsection{JUSTIFICACIÓN}

Según el informe World Urbanization Prospects (United Nations, 2014), en la actualidad el 54\% de la población mundial vive en áreas urbanas y, en la Unión Europea (UE), este porcentaje asciende al $73 \%$, donde además se espera que alcance el $80 \%$ en el año 2050 . Frente a este escenario, la comunidad científica pone sus miras en las áreas urbanas, pues estas son grandes consumidoras de recursos y, por tanto, responsables de una parte vital del impacto global causado al medioambiente. Sin embargo, por este mismo motivo, las áreas urbanas también ofrecen un amplio campo sobre el que actuar para establecer políticas encaminadas a fomentar su sostenibilidad.

El término Desarrollo Sostenible emerge en 1987 a partir del informe Brundtland (1987) y comienza a abordarse así el concepto de sostenibilidad. A partir de entonces se han realizado numerosos esfuerzos por medir el nivel de sostenibilidad de diferentes sistemas a través del uso de indicadores. En el ámbito de la edificación, dichos esfuerzos se dirigieron, en un principio, a desarrollar herramientas de evaluación focalizadas en los edificios a nivel individual, pero dos décadas más tarde, algunas de dichas herramientas ya han evolucionado para dar respuesta a las exigencias que supone afrontar la sostenibilidad desde una perspectiva más amplia y global, la urbana. Las dimensiones clásicas de la sostenibilidad, la ambiental, la social y la económica, constituyen sus tres pilares fundamentales y también están presentes cuando hablamos de sostenibilidad urbana. Sin alguno de ellos sería inviable diseñar entornos urbanos que generen un bajo impacto sobre el medio ambiente, que den respuesta a las necesidades de su población y que desarrollen los mecanismos económicos adecuados para construirlos de manera asequible.

En el sector de la edificación, la dimensión ambiental presenta una estrecha relación con el aspecto energético y el entorno construido, ya que los edificios son responsables del $40 \%$ del consumo total de energía en la UE (Comisión Europea, 2010). Es por ello que la reducción del consumo energético en el sector de la edificación constituye un importante reto para minimizar la dependencia energética, del $72,9 \%$ en el caso español (Eurostat, 2014), y las emisiones de gases de efecto invernadero (GEI).

Dentro de este sector, los edificios de uso residencial son clave tanto en el contexto actual nacional como en el europeo debido a la importancia que adquiere su demanda energética, la cual, en términos de consumo total y de consumo eléctrico asciende respectivamente a un $17 \%$ y $25 \%$ a nivel nacional, y a un $25 \%$ y $29 \%$ a nivel de la UE (IDAE, 2011). Si bien es cierto que este sector en términos comparativos respecto a otros sectores presenta actualmente menor consumo, en términos relativos es uno de los sectores, junto al de servicios, que en los últimos años ha experimentado un mayor crecimiento. Asimismo, son diversos los factores que hacen prever una tendencia futura al alza, entre ellos, el incremento del número de hogares, los hábitos de consumo de sus ocupantes o el aumento en el equipamiento, propiciado por un mayor poder adquisitivo y una mejora en el nivel de vida.

Por otro lado, como consecuencia del aumento en el precio de la energía, los hogares de la UE gastaron de media un $6,4 \%$ de sus ingresos para hacer frente a las facturas energéticas, pero también como consecuencia de la crisis financiera en la que esta se ve inmersa, el $11 \%$ de los hogares no fueron capaces de mantener unas condiciones adecuadas de confort térmico (European Commission, 2014), cayendo así en riesgo de pobreza energética. Ello constituye una creciente preocupación que merece especial atención y hace necesario el estudio de mecanismos que mejoren la eficiencia energética del parque edificado. Por estos motivos, el sector de la edificación 
residencial ocupa una posición preferente en las políticas y estrategias energéticas y medioambientales, tanto presentes como futuras.

A pesar de la introducción de nuevos requerimientos sobre eficiencia energética en la legislación en materia de edificación, los edificios de nueva planta solo consumen la mitad que aquellos que fueron construidos en la década de los 80 (European Commission, 2014). El bajo rendimiento de sus instalaciones térmicas, la inexistencia de aislamiento térmico en la envolvente o la todavía abundante presencia de vidrios simples en las ventanas, son solo algunos ejemplos de los motivos que llevan a esta situación. Por ello, se prevé que sean introducidos progresivamente en la legislación nuevos estándares en los próximos años. En los futuros edificios que están por construir, por tanto, se implementarán nuevas limitaciones que aseguren la reducción de su consumo energético, pero no hay que olvidar que es en los edificios existentes donde reside el mayor potencial de ahorro, pues el volumen edificado que no atiende a ningún criterio de eficiencia energética (del $58 \%$ en el caso español), es superior al volumen a construir. Por ello, actualmente la legislación también fija su mirada en la intervención en la ciudad consolidada y su parque edificatorio residencial existente.

Estos hechos constatan la obsolescencia de la ciudad y de su parque de vivienda, abriendo paso a la necesidad de intervenir sobre el tejido residencial ya consolidado. En 2010, la Declaración de Toledo (Presidencia Española, 2010) ve la luz precisamente con el objetivo de afrontar los retos urbanos actuales y garantizar la consecución de un desarrollo urbano más inteligente, sostenible y socialmente inclusivo, otorgando importancia a la Regeneración Urbana Integrada (RUI) como instrumento estratégico para alcanzar dicho objetivo (Presidencia Española, 2010). Tres años más tarde, entra en vigor en España la Ley 8/2013 (L3R), que trata de potenciar la rehabilitación edificatoria y la regeneración y renovación urbanas, eliminando trabas actualmente existentes y creando mecanismos específicos que la hagan viable y posible. Es de destacar que esta concede la iniciativa de las acciones a los propietarios y, muy especialmente, a las administraciones públicas, quienes deberán adoptar medidas que aseguren la realización de obras de conservación, actuaciones de rehabilitación edificatoria y el desarrollo de instrumentos para combatir, entre otros aspectos, la vulnerabilidad de barrios y las situaciones de pobreza energética (Gobierno de España, 2013). Además, establece como una de las actuaciones prioritarias aquellas dirigidas a fomentar un uso racional de la energía. Así, la administración cobra un papel relevante que será clave para asegurar la conservación y constante renovación de la ciudad, lo que hace cobrar fuerza a la dimensión institucional como aspecto a integrar en los pilares de la sostenibilidad.

Ante este panorama, no cabe duda que es necesario el desarrollo de instrumentos y estrategias que permitan hacer frente a estos objetivos. No obstante, la adopción de estrategias debe ser conducida con objetividad y transparencia y, para ello, resulta necesario evaluar previamente el escenario actual. Por ello, las herramientas de diagnóstico adquieren relevancia en este sentido y constituyen el primer paso para el desarrollo de acciones encaminadas a la mejora de la ciudad consolidada, desde la perspectiva de la sostenibilidad.

Esta tesis propone una metodología que puede ser utilizada como herramienta de diagnóstico para la identificación de barrios energéticamente vulnerables y para proporcionar asistencia en los procesos de toma de decisión durante las intervenciones de rehabilitación urbana, en las que se ven involucradas las administraciones locales y otros agentes del sector, como arquitectos, arquitectos técnicos, ingenieros y urbanistas.

Con todo ello, la tesis aborda tres aspectos fundamentales recogidos en la Figura 1.1, que son, el parque edificatorio residencial existente, su eficiencia energética y cómo esta puede contribuir a alcanzar la sostenibilidad urbana. En este contexto, se va a profundizar en las siguientes temáticas:

- Legislación relativa a eficiencia energética en los edificios 
- Herramientas de evaluación de la sostenibilidad urbana

- Metodologías de evaluación de la eficiencia energética del parque edificatorio

- Evaluación energética de edificios

Estas cuatro temáticas serán estudiadas en el Capítulo 2.

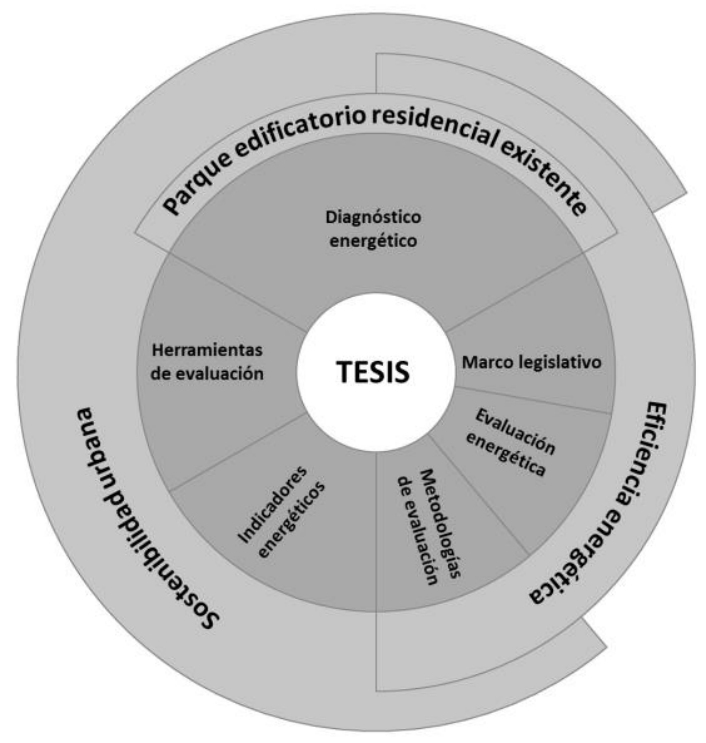

Figura 1.1 Temas abordados en la tesis

\subsection{OBjetivos y Metodología}

El objetivo principal de esta tesis es desarrollar una metodología para caracterizar el comportamiento energético pasivo del parque edificatorio residencial existente considerando su contexto urbano, que permita realizar un diagnóstico energético de áreas urbanas consolidadas.

Para alcanzar este objetivo principal, se plantean seis objetivos específicos:

- Objetivo 1: Conocer el estado del arte sobre cada una de las temáticas que se abordan en la tesis.

- Objetivo 2: Identificar un conjunto de variables que permitan evaluar el comportamiento energético pasivo del parque edificatorio residencial existente.

- Objetivo 3: Proponer un procedimiento para caracterizar el parque residencial de edificios de un entorno urbano consolidado e identificar la taxonomía urbana representativa.

- Objetivo 4: Desarrollar un modelo de predicción, basado en los métodos experimental y estadístico, que permita estimar, a escala urbana, el comportamiento energético pasivo de los edificios, a través de los indicadores y covariables previamente identificados. 
- Objetivo 5: Proponer un procedimiento que permita representar los resultados de implementar la metodología en mapas urbanos energéticos.

- Objetivo 6: Implementar la metodología propuesta en un caso de aplicación.

Para alcanzar dichos objetivos, es necesario llevar a cabo las siguientes tareas que se mencionan a continuación:

Objetivo 1: Conocer el estado del arte sobre cada una de las temáticas que se abordan en la tesis.

- 1.1: Revisión de las herramientas y sistemas de indicadores de evaluación de la sostenibilidad urbana presentes en la literatura.

- 1.2: Revisión de las metodologías de evaluación energética de edificios presentes en la literatura.

- 1.3: Estudio de la legislación que ampara el panorama actual sobre eficiencia energética en edificios.

- 1.4: Revisión de los fundamentos de la simulación energética de edificios y las herramientas existentes en el mercado.

Objetivo 2: Identificar un conjunto de variables que permitan evaluar el comportamiento energético pasivo del parque edificatorio residencial existente.

- 2.1: Identificación de un conjunto de indicadores energéticos de evaluación del comportamiento energético pasivo del parque edificatorio residencial existente.

- 2.2: Identificación de un conjunto de covariables, urbanas y edificatorias, susceptibles de influir en el comportamiento pasivo del parque edificatorio residencial existente.

Objetivo 3: Proponer un procedimiento para caracterizar el parque residencial de edificios de un entorno urbano consolidado e identificar la taxonomía urbana representativa.

- 3.1: Desarrollo de un procedimiento para identificar la taxonomía urbana representativa.

- 3.2: Desarrollo de un procedimiento para obtener una base de datos de información urbana georreferenciada.

Objetivo 4: Desarrollar un modelo de predicción, basado en los métodos experimental y estadístico, que permita estimar, a escala urbana, el comportamiento energético pasivo de los edificios, a través de los indicadores y covariables previamente identificados.

- 4.1: Desarrollo de un procedimiento para la evaluación energética pasiva, mediante la simulación de unas hipótesis de cálculo que representen a la taxonomía urbana de una determinada área urbana objeto de estudio. 
- 4.2: Desarrollar un conjunto de ecuaciones matemáticas de predicción, obtenidas mediante el análisis estadístico de los resultados experimentales, para estimar los indicadores energéticos de un área urbana objeto de estudio.

Objetivo 5: Proponer un procedimiento que permita representar los resultados de implementar la metodología en mapas urbanos energéticos.

- 5.1: Propuesta de un procedimiento para generar mapas urbanos energéticos.

Objetivo 6: Implementar la metodología propuesta en un caso de aplicación.

- 6.1: Definición de la taxonomía urbana de la ciudad objeto de estudio.

- 6.2: Obtención del diagnóstico energético del barrio objeto de estudio y representación gráfica de los resultados en mapas urbanos energéticos, los cuales permiten priorizar las futuras intervenciones de rehabilitación en aquellas áreas con necesidades preferentes.

- 6.3: Propuesta de recomendaciones a implementar en nuevos tejidos urbanos y existentes, a partir del análisis de los resultados obtenidos del caso de aplicación.

\subsection{Estructura de LA TESIS}

La tesis consta de siete capítulos. El primero de ellos, correspondiente al presente Capítulo 1, contextualiza el trabajo, presenta los objetivos del mismo y expone la metodología aplicada para llevarlo a cabo. Los Capítulos 2, 3, 4, 5 y 6 constituyen el grueso del trabajo y cada uno de ellos tiene el cometido de desarrollar uno o varios de los objetivos específicos que se establecen en el apartado 1.2. Finalmente, el Capítulo 7 recoge las conclusiones de la tesis y los futuros desarrollos.

Los diferentes capítulos de la tesis desarrollan cronológicamente el procedimiento de trabajo seguido, el cual se muestra en la Figura 1.2 y se describe a continuación.

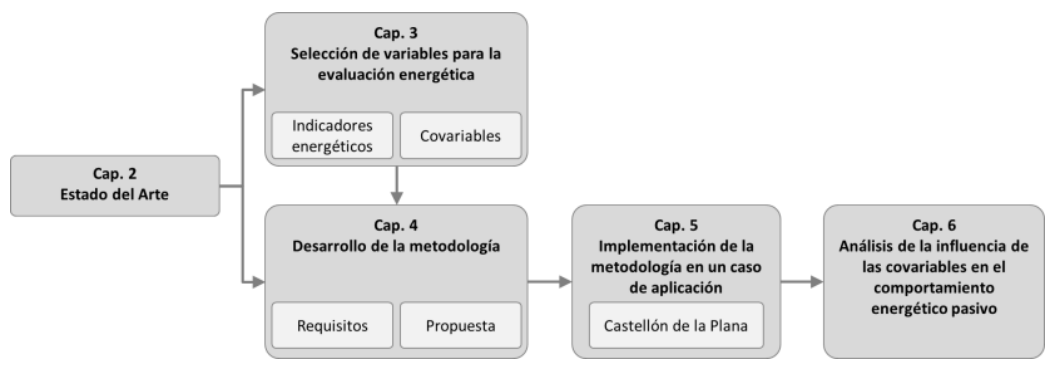

Figura 1.2 Metodología de trabajo 
- Capítulo 2. Revisión del estado del arte relativo a las herramientas de evaluación de la sostenibilidad urbana, las metodologías de evaluación energética, la legislación relativa a la eficiencia energética en los edificios y los fundamentos sobre evaluación energética de edificios, con la finalidad de conocer los trabajos y la literatura desarrollados hasta la fecha.

- Capítulo 3. Identificación de variables que permitan evaluar con objetividad y transparencia el comportamiento energético pasivo del parque edificatorio residencial existente, teniendo en cuenta tanto condicionantes del edificio como urbanos, que puedan tener una influencia sobre dicho comportamiento. Para ello, se profundiza en la revisión de aspectos e indicadores considerados por las herramientas de evaluación de la sostenibilidad y las metodologías de evaluación energética, lo que tiene como resultado la definición de un conjunto de indicadores energéticos y un conjunto de covariables, que ambos serán integrados en la metodología.

- Capítulo 4. Desarrollo de la metodología para la caracterización del comportamiento energético pasivo del parque edificatorio residencial existente. En primer lugar, se establecen los requisitos que debe reunir la metodología y, a continuación, se desarrollan las diferentes etapas que la constituyen.

- Capítulo 5. Implementación de la metodología en un caso de estudio. Se selecciona el municipio de Castellón de la Plana para aplicar las diferentes etapas de la metodología, que tiene como resultado el diagnóstico energético de uno de sus barrios.

- Capítulo 6. Análisis de la influencia de las covariables en el comportamiento energético pasivo. Los resultados de la evaluación energética del parque edificatorio residencial del barrio objeto de estudio en el Capítulo 5, son analizados críticamente con el objetivo de proponer un conjunto de estrategias a tener en cuenta a la hora de rehabilitar el tejido urbano del barrio y en el supuesto de planificar nuevos desarrollos urbanos. En este capítulo, además, se propone una nueva configuración urbana teniendo en cuenta dichas estrategias, de manera que es posible validar el ahorro energético que supondría planificar nuevos desarrollos urbanísticos con la nueva configuración urbana.

De forma sintética, la Figura 1.3 relaciona cada uno de estos capítulos con el objetivo u objetivos que aborda y las tareas necesarias para su consecución.

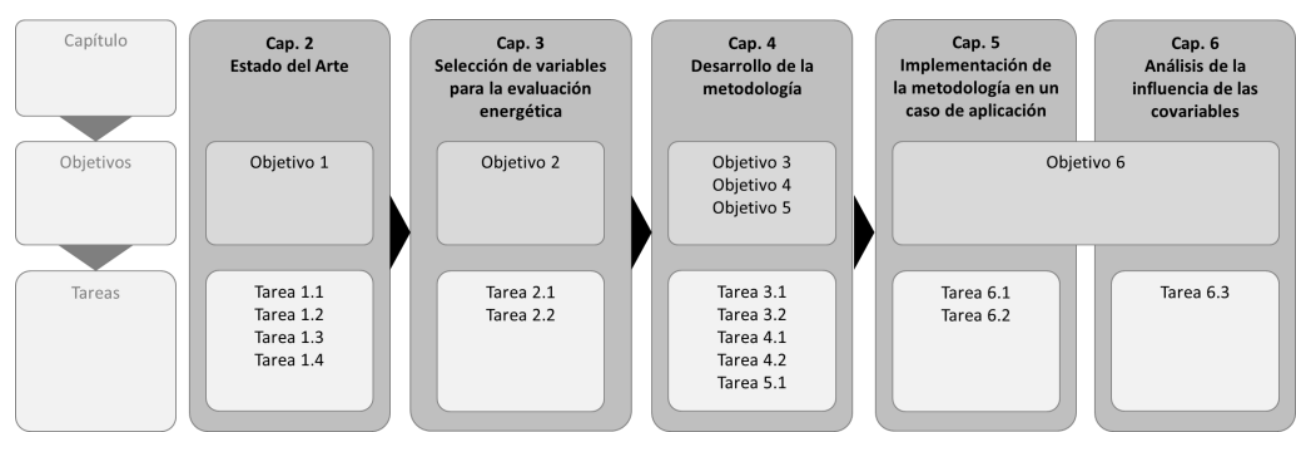

Figura 1.3 Estructura de la tesis y relación entre capítulos, objetivos y resultados esperables 


\subsection{Referencias}

Brundtland, G.H., 1987. Report of the World Commission on Environment and Development: Our Common Future. Oslo.

Comisión Europea, 2010. Directiva 2010/31/UE del parlamento Europeo y del Consejo de 19 de mayo de 2010 relativa a la eficiencia energética de los edificios. Comunidad Europea.

European Commission, 2014. Communication from the Commission to the European Parliament and the Council. Energy Efficiency and its contribution to energy security and the 2030 Framework for climate and energy policy. Brussels.

Eurostat, 2014. Energy dependence [WWW Document]. URL http://ec.europa.eu/eurostat/tgm/table.do?tab=table\&init=1\&language=en\&pcode=tsdcc310 \&plugin=1 (accedido 2.21.16).

Gobierno de España, 2013. Ley 8/2013, de 26 de junio, de rehabilitación, regeneración y renovación urbanas. España.

IDAE, 2011. PROYECTO SECH-SPAHOUSEC. Análisis del consumo energético del sector residencial en España. Informe final. Ministerio de Industria, Energía y Turismo.

Presidencia Española, 2010. Declaración de Toledo, Reunión informal de Ministros. España.

United Nations, 2014. World Urbanization Prospects: the 2014 Revision. New York. 



\section{ESTADO DEL ARTE}

Propuesta metodológica para la caracterización del comportamiento energético pasivo del parque edificatorio residencial existente

considerando su contexto urbano. 



\subsection{INTRODUCCIÓN}

Como se desprende del Capítulo 1, el parque edificatorio residencial existente juega un papel estratégico en el camino hacia la sostenibilidad. El enfoque urbano que esta adquiere, hace que aspectos de muy diversa índole deban ser integrados, lo que genera un problema complejo de desmenuzar y de poner en práctica para alcanzar unos niveles adecuados de sostenibilidad. En particular, lidiar con el aspecto energético supone un importante reto para cumplir con los objetivos de reducción de emisiones de GEI y de consumo energético, y luchar así contra el cambio climático y la dependencia energética de los países, respectivamente.

El presente capítulo aborda una revisión del estado del arte de cada una de las cuatro temáticas relacionadas con la tesis, expuestas en el capítulo anterior: marco legislativo relativo a la eficiencia energética de los edificios, herramientas de evaluación de la sostenibilidad urbana, metodologías de evaluación energética del parque edificatorio y evaluación energética de edificios.

En primer lugar, se analiza el marco legislativo relativo a la eficiencia energética en los edificios con el objeto de conocer las normativas que, impuestas desde la Unión Europea, condicionan los requerimientos del parque edificatorio y su desarrollo.

En segundo lugar, se realiza una revisión de las principales herramientas de evaluación de la sostenibilidad urbana que existen en la literatura. Con ello, se analiza el diferente enfoque de cada una de ellas y cómo estructuran los indicadores de evaluación, lo que servirán como uno de los puntos de partida del Capítulo 3 para seleccionar los indicadores a integrar en la propuesta metodológica.

A continuación, se revisan las metodologías de evaluación energética del parque edificatorio, tanto a nivel internacional como nacional, y se comparan los dos enfoques principales que estas adoptan, bottom-up y top-down (Moffatt, 2001). Se analiza un amplio número de trabajos existentes en la literatura para comparar las características generales que cada uno de los modelos incorpora. Esta revisión también sirve como punto de partida del Capítulo 3, donde se lleva a cabo un análisis en profundidad de los aspectos evaluados por cada una de las metodologías.

Por último, en relación con la evaluación energética de edificios, se analizan, por un lado, los fundamentos y parámetros de cálculo que deben ser considerados y, por otro, las principales herramientas de simulación energética disponibles en el mercado, cuyo análisis aporta una comparativa entre todas ellas para asistir en la selección de aquellas más adecuadas según el enfoque que adquiera la evaluación energética.

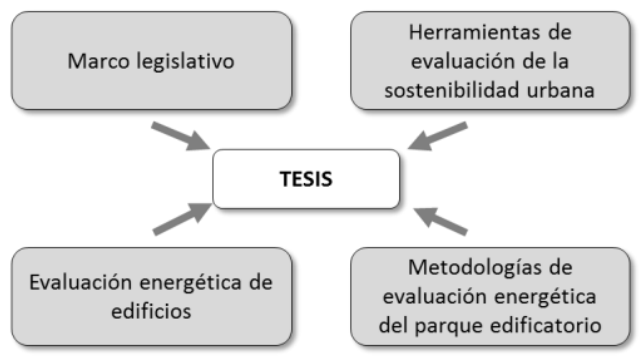

Figura 2.1 Áreas relacionadas con la tesis 


\subsection{Marco legislativo}

Como consecuencia de la creciente preocupación frente al cambio climático, desde el año 1995 se vienen celebrando las llamadas Conferencias de las Partes (COP, acrónimo de Conference of the Parts) dando lugar a los tratados internacionales que buscan el acuerdo entre los diversos países. Es especialmente destacable la COP del año 1997, en la que se gestó el Protocolo de Kioto, el cual supuso por primera vez un compromiso por parte de los países industrializados de reducir sus emisiones de GEI en los sectores energético, industrial, agrícola, de cambio de uso de la tierra, silvicultura y desechos. El principal objetivo era conseguir un recorte conjunto de los GEI en un $5 \%$ con respecto a los niveles de 1990, en el periodo de 2008-2012. Durante la celebración del mismo, se admitió que no era posible alcanzar niveles similares a los que existían anteriormente a la revolución industrial, momento en que las emisiones a la atmósfera comenzaron a superar lo que la misma podía procesar, pero al menos, se estableció el compromiso de mantener el calentamiento global por debajo de $2^{\circ} \mathrm{C}$, compromiso que no ha podido ser satisfecho por las partes a día de hoy.

El protocolo de Kioto no entró en vigor hasta el año 2004 con la ratificación por parte de Rusia, con la que se superaba el porcentaje de países necesarios, pero, finalmente no todos los países lo ratificaron. Países altamente contaminantes como Estados Unidos o China, no se adhirieron al protocolo. Así, el mismo solo fue el precusor de multitud de sucesivas COP que no llegaron a acuerdos firmes. La última COP celebrada en París en diciembre de 2015 , supone el primer acuerdo en el que tanto las naciones desarrolladas como los países en vías de desarrollo se comprometen a gestionar la transición hacia una economía baja en carbono. Para ello, se establece el objetivo de lograr que el aumento de las temperaturas se mantenga bastante por debajo de los $2^{\circ} \mathrm{C}$ y compromete a los firmantes a realizar esfuerzos para limitar el aumento de las temperaturas a $1,5^{\circ} \mathrm{C}$ en comparación con la era preindustrial. El texto aprobado deberá ahora ser ratificado por 55 países que representen al menos $55 \%$ de las emisiones globales de gases de efecto invernadero.

Dentro del contexto europeo, se apunta al sector de la edificación como uno de los grandes consumidores de energía. Concretamente, el $40 \%$ del consumo total de energía en la Unión Europea corresponde a los edificios (Comisión Europea, 2010). Teniendo en cuenta que el sector se encuentra en fase de expansión, se prevé que el consumo de energía siga en aumento en los próximos años. Por ello, la reducción del consumo de energía y el uso de energía procedente de fuentes renovables en el sector de la edificación constituyen una parte importante de las medidas necesarias para reducir la dependencia energética y las emisiones. Las medidas adoptadas para reducir el consumo de energía permitirán, junto con un mayor uso de la energía procedente de fuentes renovables, que la Unión Europea cumpla sus compromisos de mantener el aumento de la temperatura global por debajo de $1,5^{\circ} \mathrm{C}$ y su compromiso de reducir, para 2020 , las emisiones totales de gases de efecto invernadero en un $20 \%$ como mínimo con respecto a los niveles de 1990 y en un $30 \%$ en el caso de lograrse un acuerdo internacional.

La reducción del consumo de energía y un mayor uso de la energía procedente de fuentes renovables desempeñan asimismo un papel importante a la hora de fomentar la seguridad del abastecimiento energético y el desarrollo tecnológico y de ofrecer oportunidades de empleo y desarrollo regional, especialmente en zonas rurales.

En este apartado, se analiza el marco legislativo en relación a la eficiencia energética de edificios, en los contextos europeo y nacional. 


\subsubsection{MARCO LEgISLATIVO EN EL CONTEXTO EUROPEO}

Las Directivas Europeas que han contribuido al objetivo de la eficiencia energética de los edificios tienen como precursora a la Directiva 93/76/CEE, de 13 de septiembre de 1993, relativa a la limitación de las emisiones de dióxido de carbono $\left(\mathrm{CO}_{2}\right)$ mediante la mejora de la eficacia energética (Comisión Europea, 1993). Dicha directiva apuntó al sector de la edificación como uno de los grandes responsables en lo relativo al consumo energético y emisiones de $\mathrm{CO}_{2}$ en Europa y propuso la certificación energética como herramienta necesaria para conseguir su reducción, recomendando a los estados miembros su puesta en vigor antes de 1995. Sin embargo, su falta de concreción, así como la gran inercia en el sector de la edificación en algunos países, provocó implantaciones muy desiguales entre los estados. Países como Dinamarca y Alemania fueron los primeros en establecer nuevas demandas energéticas restrictivas y métodos para la certificación energética de edificios. Sin embargo, países como Francia, Italia y España han tardado considerablemente más, concretamente en el caso español no se estableció hasta el año 2007.

Posteriormente se promulgaron las directivas conocidas con el acrónimo EPBD (Energy Performance of Buildings Directive), que recogen ya los objetivos del protocolo de Kioto. La primera fue la Directiva 2002/91/CE, que trataba específicamente el comportamiento energético de los edificios (Comisión Europea, 2002). Dicha directiva supuso un avance efectivo y concreto de las líneas de acción que ya fueron indicadas en la Directiva 93/76/CEE para el sector de la edificación. Con ella, entre otras cosas, se pretendía reducir las grandes diferencias entre los estados miembros e instar a establecer una metodología de cálculo de la eficiencia energética integrada de los edificios, que llevase al sector de la edificación a niveles de comportamiento energético superiores a los entonces actuales, que debía comprender los siguientes aspectos:

- Aislamiento térmico

- Instalaciones de calefacción y aire acondicionado

- Utilización de fuentes de energía renovables

- Tener en cuenta el diseño del edificio

La EPDB 2002 incide especialmente en los edificios de nueva construcción, dejando a los edificios existentes relegados a un segundo plano, ya que únicamente obliga a actuar en aquellos grandes edificios con una superficie mayor a $1.000 \mathrm{~m}^{2}$, que sean objeto de reformas importantes. Así, la directiva define como reformas importantes los casos en que los costes totales de la renovación referentes al cerramiento exterior del edificio o a instalaciones energéticas tales como calefacción, suministro de agua caliente, aire condicionado, ventilación e iluminación, sean superiores al $25 \%$ del valor del edificio, excluyendo el valor del terreno en el que está construido, o cuando se renueva más del $25 \%$ del cerramiento exterior del edificio. Indica además que, no obstante, la mejora de la eficiencia energética global de un edificio existente no significa necesariamente una renovación total del edificio, sino que puede limitarse a aquellas partes que sean más importantes para la eficiencia energética del edificio y tengan una rentabilidad adecuada. Por tanto, sólo en casos muy concretos existía la obligatoriedad de actuar en ellos, lo que no promovía la renovación del parque existente edificatorio.

Por otro lado, establece la obligatoriedad de inspeccionar periódicamente las calderas y sistemas de aire acondicionado de edificios y evaluar el estado de la instalación de calefacción con calderas de más de 15 años.

Posteriormente, y ante la evidencia de que no se iban a alcanzar los compromisos de Kioto, surge la Directiva EPDB 2010/31/UE de 19 de mayo (Comisión Europea, 2010), cuyo texto refundido aumenta las exigencias en cuanto a eficiencia energética y modifica y añade algunos aspectos a la 
anterior directiva. Entre otras novedades, establece que la metodología de cálculo de la eficiencia energética debe tener en cuenta, además de los aspectos de la EPDB 2002, los siguientes:

- Elementos pasivos de calefacción y refrigeración

- Sombreado

- Calidad del aire interior

- Iluminación natural

Ello denota que el diseño del edificio y el uso de estrategias pasivas comienzan a cobrar importancia para afrontar el reto de reducir la demanda energética y las emisiones de $\mathrm{CO}_{2}$ en los edificios.

En cuanto a los edificios existentes, se mantiene la obligatoriedad de cumplir la normativa en los edificios que sean objeto de reformas importantes, pero se introducen ciertas modificaciones. La principal es que se elimina el límite de superficie, por lo que se establece que en todos los edificios existentes en los que se renueven elementos, dichos elementos deben adaptarse a los requisitos mínimos de eficiencia energética, priorizando aquellos que tengan más relevancia para la eficiencia energética del edificio, con criterios de coste-efectividad. La directiva deja a potestad de los estados miembros la tarea de definir el concepto de reforma importante, bien en términos del valor del edificio (como el valor actuarial o el valor actual basado en el coste de la reconstrucción, excluyendo el valor del terreno), o bien en términos de porcentaje de renovación de envolvente.

Entre otras cosas, respecto a la eficiencia energética de los edificios, se incorpora la necesidad de recomendar medidas de mejora energética teniendo en cuenta su viabilidad económica, para conocer el periodo de retorno de la inversión.

También establece la obligatoriedad de certificar energéticamente aquellos inmuebles que vayan a ser alquilados o vendidos y que sean públicas las calificaciones alcanzadas para el nuevo comprador o arrendatario, añadiendo así un criterio más de elección para el usuario. También deberá ser visible la etiqueta energética en edificios en los que una autoridad pública ocupe una superficie útil total superior a $250 \mathrm{~m}^{2}$.

La Directiva de 2010 también insta a la redacción de Planes Nacionales destinados a aumentar el número de edificios de consumo de energía casi nulo, proporcionando una definición poco concreta sobre los mismos: "los edificios de consumo de energía casi nulo son edificios con un nivel de eficiencia energética muy alto, cuyos requerimientos bajos de energía quedan mayoritariamente cubiertos por energía procedente de fuentes renovables, incluida energía procedente de fuentes renovables producida in situ o en el entorno". La directiva otorga la responsabilidad de concretar dicha definición a los estados miembros, lo que genera ciertas desigualdades en la interpretación del concepto de edificio de consumo de energía casi nulo y en la temporalidad, no estando todavía definida en el caso de España. Algunos de ellos relacionan el concepto con las emisiones de $\mathrm{CO}_{2}$, mientras que otros, prefieren asociarlo al consumo de energía o la autosuficiencia energética. Junto a esta definición, establece la fecha límite de construcción de edificios de consumo de energía casi nulo en el 31 de diciembre de 2020 para los edificios nuevos y en el 31 de diciembre de 2018 para edificios nuevos que sean propiedad de autoridades públicas.

Por otro lado, y más recientemente, surge la Directiva 2012/27/UE del Parlamento Europeo y del Consejo, de 25 de octubre de 2012 (Comisión Europea, 2012), relativa a la eficiencia energética, por la que se modifican las Directivas 2009/125/CE (Comisión Europea, 2009) y 2010/30/UE en lo referente a etiquetado de productos relacionados con la energía, y por la que se derogan las Directivas 2004/8/CE (Comisión Europea, 2004) y 2006/32/CE sobre eficiencia del uso final de la energía y los servicios energéticos (Comisión Europea, 2006). Con ella se pretende establecer un marco común de medidas para el fomento de la eficiencia energética dentro de la Unión Europea y 
alcanzar los objetivos de la Estrategia Europa 20/20/20 (20\% (30\%) reducción emisiones efecto invernadero, aumento del $20 \%$ energías renovables, aumento del $20 \%$ eficiencia energética). Esta nueva directiva afecta a normas destinadas a eliminar barreras en el mercado de la energía y a superar deficiencias que obstaculizan la eficiencia en el abastecimiento y el consumo de energía y dispone también el establecimiento de objetivos nacionales orientativos de eficiencia energética para el año 2020. Esta complementa a la EPDB 2010 relativa a la eficiencia energética de edificios, en lo referente a la función ejemplarizante de los edificios de los organismos públicos.

La Figura 2.2 resume la evolución de las directivas europeas en material de eficiencia energética.

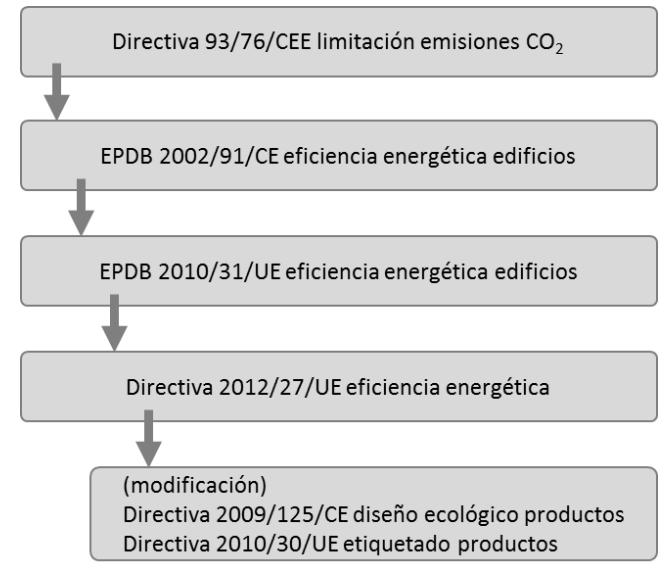

Figura 2.2 Evolución de las directivas europeas relacionadas con la eficiencia energética

\subsubsection{MARCO LegisLativo En El CONTEXTO NACIONAL}

En España, hasta el año 1979 no se publica ninguna normativa en lo referente a ahorro de energía en los edificios. Con la Norma Básica de la Edificación sobre Condiciones Térmicas en los edificios (NBE-CT-79, 1979), se introduce la necesidad de reducir las pérdidas térmicas a través de los cerramientos, evitar el riesgo de formación de condensaciones en los mismos y mejorar su confort térmico interior. La norma establece unos límites de transmisión global de calor a través del conjunto del cerramiento, definidos por el denominado coeficiente $\mathrm{K}_{\mathrm{G}}$, según la zona climática y el factor de forma del edificio. Ello supone, según zonas climáticas, la incorporación de aislamiento térmico en algunos de los cerramientos de la envolvente, así como la inclusión de vidrios dobles, para conseguir reducir dicho coeficiente.

Con la entrada en vigor de la EPDB 2002, esta se transpone a la normativa española, parcialmente, por medio del RD 314/06 de 17 de marzo, por el que se aprueba el Código Técnico de la Edificación (CTE, 2006). El CTE consta de varios documentos que derogan las antiguas Normas Básicas de la Edificación (NBE). A efectos energéticos, corresponde al Documento Básico de Ahorro de Energía (DB HE) establecer los nuevos estándares de confort térmico y adecuarlos a la realidad de una España muy alejada de lo que era en la década de los 70. Sin embargo, la implementación del CTE DB HE llega, en cierta manera, algo tarde, pues el fuerte crecimiento del sector de la construcción, que dejó un extenso legado de nuevos edificios, tuvo su auge precisamente en los años previos a la aprobación de dicha normativa, lo que deja a una gran parte del parque edificatorio lejos de los estándares actuales de eficiencia energética. 
El documento DB HE1 tiene como objetivo limitar la demanda energética de los edificios. En este se definen aspectos clave para aumentar la eficiencia energética, como es la mejora de la envolvente térmica y sus limitaciones de transmitancia térmica, según zonas climáticas. Este documento establece para cada uno de los tipos de cerramientos una limitación de transmitancia térmica (U) y de condensaciones, y establece dos procedimientos para la verificación de su cumplimiento, la opción simplificada (cumplimentación de fichas) y la opción general (mediante la herramienta LIDER). El endurecimiento de los requisitos con respecto a la NBE CT-79 hace aumentar los espesores de aislamiento térmico en los elementos de la envolvente y mejorar también las prestaciones de las carpinterías.

El documento DB HE2 hace referencia a las instalaciones térmicas de los edificios y remite al Reglamento de Instalaciones Térmicas en los Edificios (RITE) (Ministerio de la Presidencia, 2007a), a través del cual también se transpone parcialmente la EPDB 2002. El DB HE3 se centra en las instalaciones de iluminación y los DB HE4 y HE5 aseguran una cierta presencia de energías renovables para el funcionamiento del edificio.

Además, para dar respuesta a la incorporación de una metodología para la certificación energética de edificios, como establece la EPDB 2002, se desarrolló el RD 47/2007, de 19 de enero, por el que se aprobó el Procedimiento básico para la certificación de eficiencia energética de edificios de nueva construcción (Ministerio de la Presidencia, 2007b) y que entró en vigor el 30 de abril de 2007. Asimismo, en 2007 se aprobó una revisión del RITE, que establecía las condiciones que debían cumplir las instalaciones destinadas a atender la demanda de bienestar térmico e higiene, a través de las instalaciones de calefacción, climatización y agua caliente sanitaria, para conseguir un uso racional de la energía.

Cuando los procedimientos normativos comienzan a ver la luz en el territorio español, tiene lugar la aprobación de la EPDB 2010, que obliga de nuevo a adaptar las exigencias. Así pues, no fue hasta el año 2013 cuando se aprueba la modificación del DB HE (CTE, 2013). El nuevo CTE introduce como novedad un nuevo Documento Básico, el DB HEO, que tiene como objetivo limitar el consumo de energía. Para ello, establece unos límites de consumo energético en los edificios, según su uso y zona climática en la que se ubican. EI DB HE1 también sufre importantes modificaciones, especialmente en cuanto al procedimiento de verificación, que ya establece la opción general como único procedimiento, la cual implica el manejo de la Herramienta Unificada LIDER-CALENER (Universidad de Sevilla, 2013), basada en la simulación dinámica. Los requisitos se endurecen significativamente y la nueva normativa ya no centra el cumplimiento únicamente en la limitación de la transmitancia térmica de los elementos de la envolvente, sino que señala como aspecto clave el propio diseño del edificio para reducir la demanda energética. Además, el nuevo DB HE1 incluye a los edificios existentes y obliga a que estos cumplan unas exigencias mínimas cuando se renueve algún elemento de su envolvente térmica o vayan a ser objeto de reformas importantes, término ya definido anteriormente.

En lo relativo a la certificación energética, se aprueba un nuevo procedimiento mediante el RD 235/2013 (Ministerio de la Presidencia, 2013), que engloba también a los edificios existentes. Además, establece la obligatoriedad de exhibir la etiqueta energética en edificios para la venta y el alquiler, y poner a disposición del ciudadano un registro oficial de certificados energéticos, que deja a potestad de las Comunidades Autónomas. En la Comunidad Valenciana, el Decreto 112/2009 del Consell, regula las actuaciones en materia de eficiencia energética de edificios (GVA, 2009) y designa al Instituto Valenciano de Competitividad Empresarial (IVACE) como órgano competente para el seguimiento de la certificación de eficiencia energética de edificios y encargado de coordinar y mantener el registro.

En lo que respecta al parque edificado, la construcción de viviendas en España sigue una tendencia ascendente, como se muestra en la Figura 2.3, alcanzando su mayor auge en las décadas de los años 
1960 y 1970, con 3,6 y 5 millones de viviendas construidas, respectivamente. Sin embargo, la legislación anteriormente mencionada comienza a tener su efecto a lo largo de la década de 1980, de manera que, el $54,10 \%$ del parque de viviendas españolas existente en la actualidad carece de los estándares necesarios, dejando a gran parte del parque de edificios residenciales obsoleto. Ello pone de manifiesto la necesidad que existe en intervenir sobre el mismo y desarrollar los mecanismos adecuados para llevar a cabo, no solo su conservación, sino también su rehabilitación energética.

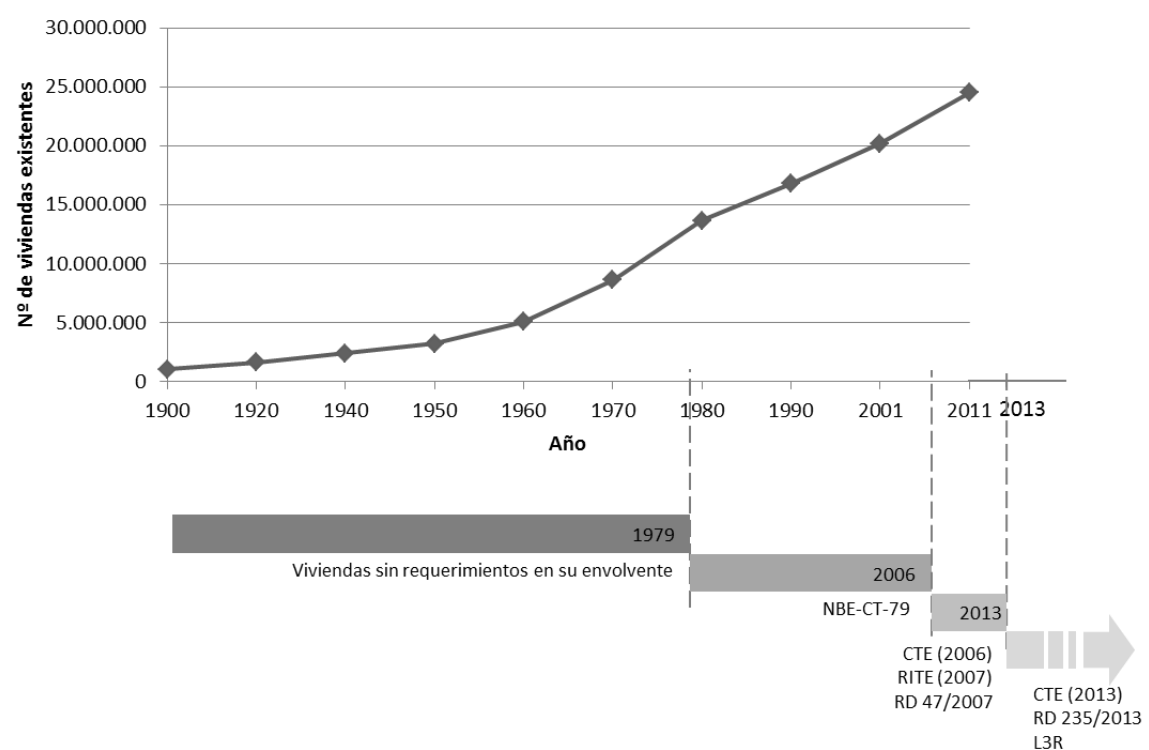

Figura 2.3 Evolución de viviendas construidas a lo largo del siglo XX e inicios del XXI y relación con la legislación española (elaboración propia a partir de datos del Instituto Nacional de Estadística (INE, 2011)

Junto con las novedades introducidas en la legislación en relación a los edificios existentes, se aprueba en el año 2013, la Ley 8/2013 de 26 de junio, de rehabilitación, regeneración y renovación urbanas (L3R) (Gobierno de España, 2013), con un enfoque claramente urbano y centrado en la ciudad consolidada, que tiene como principales objetivos:

- Potenciar la rehabilitación edificatoria y la regeneración y renovación urbanas, eliminando trabas actualmente existentes y creando mecanismos específicos que la hagan viable y posible.

- Ofrecer un marco normativo idóneo para permitir la reconversión y reactivación del sector de la construcción, encontrando nuevos ámbitos de actuación, en concreto, en la rehabilitación edificatoria y en la regeneración y renovación urbanas.

- Fomentar la calidad, la sostenibilidad y la competitividad, tanto en la edificación, como en el suelo, acercando nuestro marco normativo al marco europeo, sobre todo en relación con los objetivos de eficiencia, ahorro energético y lucha contra la pobreza energética.

Así, con esta nueva ley, basada en un enfoque más amplio, el urbano, se pretende corregir el desequilibrio estructural que existía en el ordenamiento urbanístico y jurídico en nuestro país, en lo referente a la planificación urbanística de nuevos desarrollos y a la intervención sobre los tejidos existentes (Rubio del Val, 2015), y así se expresa en una de las razones que motivan la ley: "la 
tradición urbanística española [...], se ha volcado fundamentalmente en la producción de nueva ciudad, descompensando el necesario equilibrio entre dichas actuaciones y aquellas que, orientadas hacia los tejidos urbanos exitentes, permiten intervenir de manera inteligente en las ciudades, tratando de generar bienestar económico y social y garantizando la calidad de vida a sus habitantes".

No obstante, la ley L3R, además de centrar sus esfuerzos en corregir este desequilibrio, pretende crear un nuevo marco normativo que facilite la gestión y contribuya a lograr la financiación de las actuaciones, coordinadas a través de las comunidades de propietarios u otras figuras de gestión, mientras no exista un desarrollo legal que canalice los obstáculos legales que persisten e impiden la puesta en práctica de las actuaciones de rehabilitación, regeneración y renovación.

Cabe indicar, como apunta Rubio del Val (2015), que se debe discernir entre las operaciones de mero mantenimiento y conservación del edificio y las actuaciones de rehabilitación, persiguiendo estas últimas la actualización del edificio a los estándares de aislamiento térmico, instalaciones básicas y accesibilidad, que permanece todavía hoy en el ámbito de la actuación voluntaria por parte de las comunidades de propietarios. Destaca también que la ley L3R facilita notablemente las cosas a quien quiera promover actuaciones de rehabilitación, eliminando algunos obstáculos existentes en la legislación (Ley de Propiedad Horizontal, CTE, etc.), siempre que se haga en ámbitos delimitados y aprobados por las administraciones competentes, y siempre, de la mano de estas, que como se menciona en el Capítulo 1, adquieren un papel muy relevante que será clave para la regeneración de la ciudad consolidada.

\subsection{ReVISIÓN DE hERRAMIENTAS DE EVALUACIÓN DE LA SOSTENIBILIDAD URBANA (HESU)}

Desde la aparición del término Desarrollo Sostenible (Brundtland, 1987), se han realizado numerosos esfuerzos para medir el nivel de sostenibilidad de sistemas urbanos a través de indicadores (OECD, 2014). Desde mediados de los años 1990, las autoridades locales han afrontado diversos retos dentro del contexto de políticas encaminadas a alcanzar la sostenibilidad urbana, principalmente en Europa y Norte América (Bulkeley, 2010). Los primeros indicadores sobre desarrollo sostenible emergieron de una recomendación establecida por la Agenda 21 (United Nations, 1995), dirigida a identificar y desarrollar indicadores que pudieran proporcionar una base sólida durante los procesos de decisión a todos los niveles (regional, nacional e internacional). A su vez, la recomendación establecía que los indicadores propuestos debían quedar recogidos en una base de datos ampliamente accesible y actualizada regularmente (UN Sustainable Development, 1998).

La lista de los indicadores de sostenibilidad incluía un total de 134 indicadores, de los cuales, los países involucrados en la Agenda 21 fueron invitados a hacer una selección para adaptar dichos indicadores a su contexto propio. Sin embargo, tras haber implementado los indicadores en 22 países y tras los procesos de participación que se llevaron a cabo para intercambiar experiencias y buenas prácticas, se concluyó que no todos los indicadores citados en la lista eran relevantes en el contexto globalizado de los países, ya que no estaban expresamente enfocados a las características específicas de cada contexto. Por otro lado, debido a la excesiva extensión de la lista, a los elevados tiempos requeridos para su implementación y al bajo nivel de fluidez durante las consultas, la mayoría de los países priorizaron para su implementación criterios como la asequibilidad, la accesibilidad a datos e información, la utilidad y la relevancia en las políticas abordadas. 
La necesidad de desarrollar indicadores de sostenibilidad adaptados al contexto específico de cada región es obvia y, en consecuencia, numerosas herramientas para evaluar la sostenibilidad en barrios y ciudades han sido ya desarrolladas (Castanheira y Bragança, 2014).

Tras el surgimiento del Building Research Establishment Environmental Assessment Method (BREEAM) en Reino Unido en el año 1990, dirigido a evaluar ambientalmente los edificios, han surgido muchas otras herramientas en el ámbito internacional con el mismo objetivo (Haapio y Viitaniemi, 2008; Huedo y López-Mesa, 2013). Actualmente, sin embargo, los esfuerzos van más allá y la comunidad científica muestra un creciente interés por evaluar no sólo el edificio como un elemento aislado sino por considerar aspectos más complejos que lo interrelacionan con su entorno construido. Así pues, surgen las herramientas cuyo objetivo es evaluar la sostenibilidad a una escala mayor que la del edificio, aproximándose a la escala de ciudad. Estas son, las herramientas de evaluación de la sostenibilidad urbana (HESU).

A nivel internacional, cabe destacar como herramientas de elevado nivel de reconocimiento: Leadership in Energy and Environment Design for Neighborhood Development (LEED ND) en 2009 (US GBC, 2009), Building Research Establishment Environmental Assessment Method (BREEAM Communities) en 2007 (BRE Global, 2011), Comprehensive Assessment System for Building Environmental Efficiency for Urban Development (CASBEE UD) en 2006 (IBEC, 2007), Haute Qualité Environnementale et Economique Réhabilitation (HQE2R) en 2001 (Blum, 2007), Ecocity en 2002 (Gaffron et al., 2005), Sustainable Community Rating (SCR) en 2007 (SCR, 2014), EarthCraft Communities (ECC) en 2003 (EarthCraft, 2014), SustainaBle uRban planning Decision support accounting for Urban mEtabolism (BRIDGE) en 2013 (Chrysoulakis et al., 2013) y Key Indicators for Territorial Cohesion and Spatial Planning (KITCASP) (Daly et al., 2013).

En el contexto español, existe la herramienta VERDE, que fue desarrollada para evaluar únicamente el edificio (Macías y García Navarro, 2010). A nivel urbano, Mercader-Moyano et al. (2015) desarrollaron un sistema de indicadores de sostenibilidad específicamente enfocado a la rehabilitación de la tipología de barriadas típicas de la España de las décadas de los 60 y 70 . Sin embargo, no se han desarrollado hasta la fecha herramientas con un enfoque méramente urbano. No obstante, existen publicaciones que establecen directrices a seguir para la implementación de criterios sostenibles en ciudades españolas, como por ejemplo: el Libro Blanco de la Sostenibilidad en el Planeamiento Urbanístico Español (LB) (Ministerio de Vivienda del Gobierno de España, 2010), Sistema Municipal de Indicadores de Sostenibilidad (SMIS) (Grupo de trabajo de Indicadores de Sostenibilidad de la Red de Redes de Desarrollo Local Sostenible, 2010), Sistema de Indicadores y Condicionantes para Ciudades Grandes y Medianas (CGYM) (Ministerio de Medio Ambiente y Medio Rural y Marino, 2010). Además, algunos sistemas de indicadores han sido específicamente desarrollados para ciudades concretas, como es el caso del Plan Especial de Indicadores de Sostenibilidad Ambiental de la Actividad Urbanística de Sevilla (SEV) (Agencia de Ecología Urbana de Barcelona, 2007), Sistema Municipal d'Indicadors de Sostenibilitat de la Diputació de Barcelona (BCN) (Diputación de Barcelona, 2009) e Indicadores de Sostenibilidad de Bilbao (BIL) (Ayuntamiento de Bilbao, 2008).

Hasta la fecha, aunque se han llevado a cabo análisis cualitativos de las herramientas y sistemas de indicadores (Bourdic et al., 2012; Gil y Duarte, 2013; Haapio, 2012; Nguyen y Altan, 2011), el primer análisis cuantitativo fue el realizado por Luederitz et al. (2013), quienes clasificaron los indicadores presentes en la literatura en 17 categorías y cuantificaron el número de artículos en cada una de ellas. No obstante, en su estudio, no todos los criterios de la sostenibilidad son abordados por estas 17 categorías y los indicadores incluidos en ellas no fueron analizados en gran profundidad. Sharifi y Murayama (2013) realizaron un análisis comparativo de 7 herramientas (LEED ND, BREEAM Communities, CASBEE UD, HQE2R, Ecocity, SCR y ECC) a través del cual destacaron las fortalezas y debilidades de cada una de ellas, propusieron recomendaciones de mejora y sugirieron un conjunto de temas y criterios para agrupar a los indicadores contenidos en ellas, lo que permitió identificar el 
grado de énfasis puesto en cada uno de los aspectos. La mayoría de autores coinciden en que las tres herramientas de referencia (LEED ND, BREEAM Communities y CASBEE UD) carecen de robustez dado el uso indistinto de criterios cualitativos y cuantitativos, los cuales se encuentran mezclados en una misma escala de evaluación, a pesar de que esta es cuantitativa. De sus conclusiones, se identifica la necesidad de establecer sistemas de indicadores capaces de evaluar objetivamente y con transparencia los diferentes aspectos de las dimensiones de la sostenibilidad, haciendo uso de indicadores que sean cuantificables y que puedan ser comparados por medio de una escala de valoración.

Se analiza pues, a continuación, el conjunto de 13 sistemas de indicadores y herramientas de referencia, citados anteriormente. La selección se basa en el criterio territorial (escala internacional, nacional y regional) y temporal (herramientas recientemente desarrolladas, desde 2005 hasta el presente). Estas son: tres herramientas a escala internacional aplicables universalmente (BREEAM Communities, LEED ND y CASBEE UD), dos herramientas desarrolladas ad hoc en el ámbito Europeo (ECOCITY y Le Modele INDI-RU 2005), ambas integradas en el marco de proyectos europeos; otros dos recientes proyectos europeos (BRIDGE y KITCASP) y, por último, seis sistemas de indicadores desarrollados en España que pueden ser aplicados en todo el ámbito nacional (LB, SMIS, CGYM), solo en regiones (BCN y BIL) o incluso, únicamente a escala de ciudad (SEV).

La Tabla 2.1 presenta las características principales de cada herramienta: desarrollador, año de publicación, país de origen y potencial de aplicación a otras regiones o países, alcance, necesidad de evaluación por terceras partes y sistema de puntuación o evaluación, en su caso. 


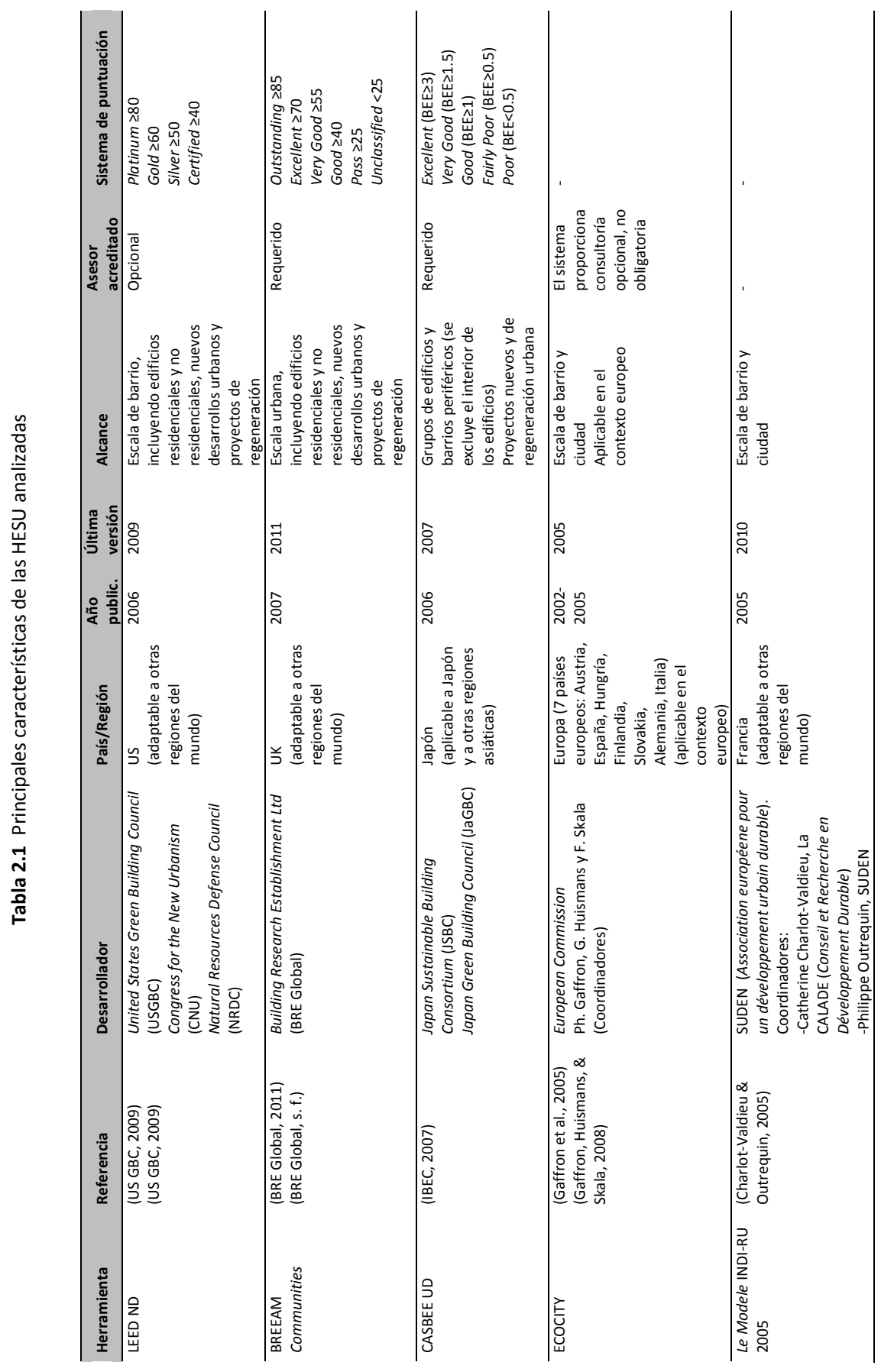




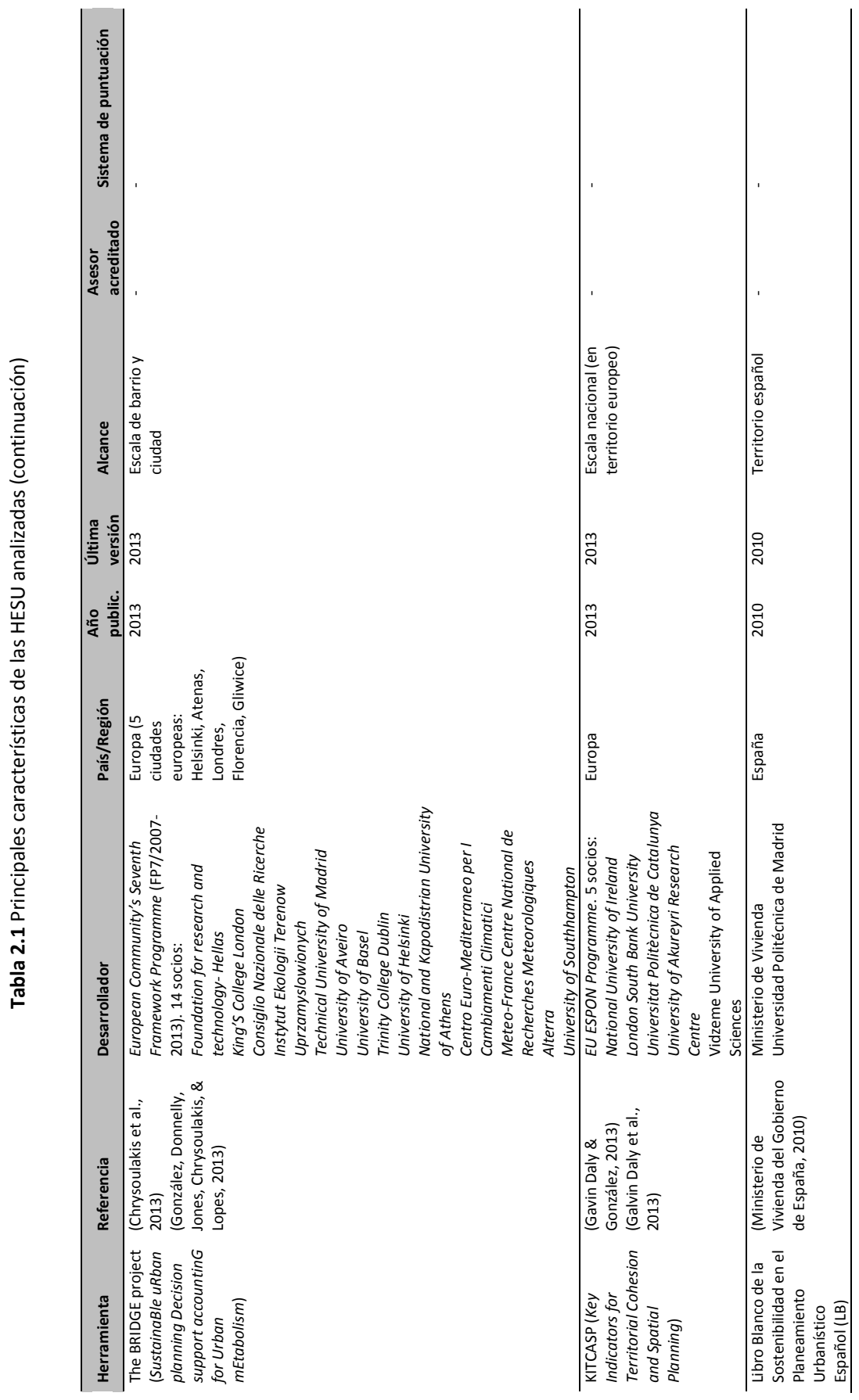




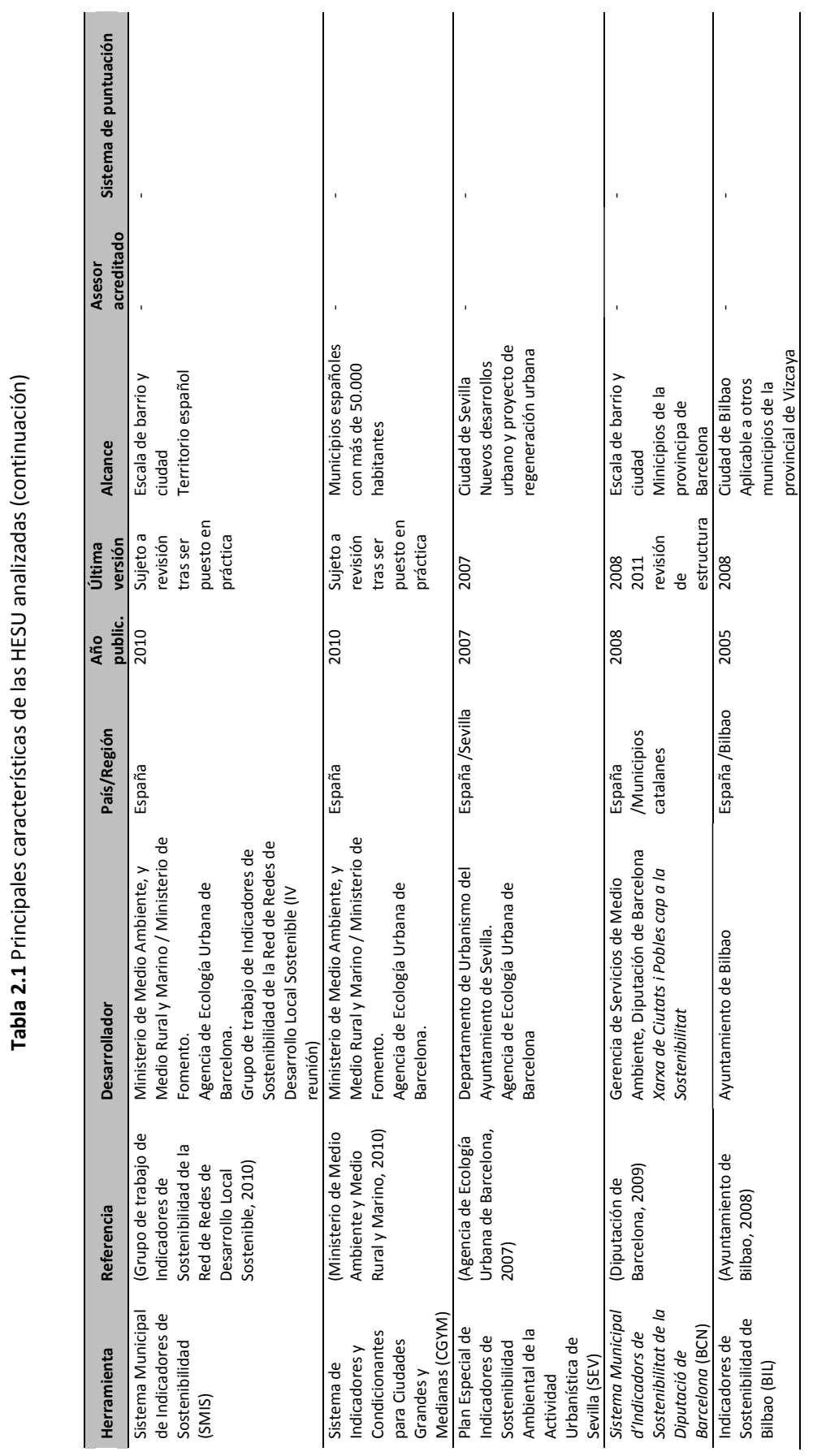


Como se muestra en la Tabla 2.1, las herramientas presentan ciertas fortalezas y debilidades. Las tres herramientas con mayor reconocimiento internacional, LEED ND, BREEAM Communities y CASBEE UD, son aplicables dentro del territorio en el que se han desarrollado, Estados Unidos, Reino Unido y Japón, respectivamente. Sin embargo, las tres pueden adecuarse a otras regiones del mundo, siempre y cuando ciertos aspectos sean adaptados previamente al contexto específico de dichas regiones. Ello supone, por un lado, una ventaja, ya que su enfoque globalizado hace que se consideren aspectos generales reconocibles en todas las regiones del mundo. Pero, por otro lado, ello supone a su vez un inconveniente, y es que muchos de los indicadores incluidos suelen ser tan generales, que muchas veces es difícil que sean evaluados de forma justa en otras regiones en las que se aplique la herramienta. Además, quedan patentes en muchos de los indicadores propuestos, aspectos característicos del país de origen de las herramientas que en otros contextos son inexistentes, por lo que carece de sentido su implementación.

En cuanto al alcance de las herramientas, este se centra principalmente en barrios o áreas urbanas delimitadas, que en muchos casos alcanza también el ámbito de ciudad. Solo KITCASP, LB y SMIS abarcan el ámbito de todo un territorio nacional.

Con un mayor grado de profundidad, la Tabla 2.2 muestra cómo las herramientas están estructuradas e indica la naturaleza de los indicadores incluidos, según los siguientes aspectos:

- Estructura de indicadores: se refiere al modo en cómo los indicadores están organizados y clasificados. La nomenclatura varía de unas herramientas a otras, siendo: categorías, temas, objetivos, medidas, criterios, estrategias, etc., hasta el nivel último que es el de indicador.

- Tipo de sistema de indicadores: dependiendo de sus características inherentes, los indicadores pueden ser cualitativos o cuantitativos. Algunas herramientas mezclan ambos tipos de indicadores para establecer estrategias de sostenibilidad. Sin embargo, aquí el término cualitativo o cuantitativo se refiere al método general de valoración de la herramienta. Cuando esta establece una escala de valoración con pesos concretos asignados a cada indicador, se denomina cuantitativo, mientras que cuando no lo establece (aún pudiendo contener indicadores de tipo cuantitativo), se denomina cualitativo.

- Número de indicadores: indica el número de indicadores contenidos en cada herramienta. La lista exhaustiva de indicadores que contiene cada una de las herramientas analizadas se presenta en el Anexo I.

- Método de ponderación: se refiere al método utilizado de valoración o cuantificación del peso de cada indicador en relación al global de la herramienta. 
Tabla 2.2 Estructura de indicadores de las HESU analizadas

\begin{tabular}{|c|c|c|c|c|c|}
\hline Herramienta & Estructura & $\begin{array}{l}\text { Tipo de } \\
\text { sistema de } \\
\text { indicadores }\end{array}$ & № ind. & Pre-requisitos $^{c}$ & $\begin{array}{l}\text { Método de } \\
\text { ponderación }\end{array}$ \\
\hline LEED ND & $\begin{array}{l}5 \text { categorías } \\
44 \text { indicadores }\end{array}$ & Cuantitativo & 56 & $\begin{array}{l}\text { Incluye } 12 \text { pre-requisitos en las } \\
\text { categorías (excepto Innovacion), } \\
\text { para obtener la certificación. } \\
\text { ( } 21 \% \text { obligatorios) }\end{array}$ & $\begin{array}{l}\text { No existe diferencia en } \\
\text { el sistema de } \\
\text { puntuación, según la } \\
\text { región }\end{array}$ \\
\hline $\begin{array}{l}\text { BREEAM } \\
\text { Comm. }\end{array}$ & $\begin{array}{l}9 \text { categorías } \\
63 \text { indicadores }\end{array}$ & Cuantitativo & $\begin{array}{l}62+1 \\
\text { (innovat } \\
\text { ion) }\end{array}$ & $\begin{array}{l}\text { Incluye } 15 \text { pre-requisitos en } \\
\text { algunas categorías (obtener al } \\
\text { menos } 1 \text { punto), para obtener la } \\
\text { certificación. } \\
\text { ( } 24 \% \text { de los indicadores son } \\
\text { obligatorios, y el } 8 \% \text { de la } \\
\text { puntuación es obligatoria) }\end{array}$ & $\begin{array}{l}\text { Diferente sistema de } \\
\text { puntuación según la } \\
\text { región de UK donde se } \\
\text { implementa la } \\
\text { herramienta (London, } \\
\text { South East, South } \\
\text { West, North East, } \\
\text { North West, East Mids, } \\
\text { West Mids, East } \\
\text { England) }\end{array}$ \\
\hline CASBEE UD & $\begin{array}{l}6 \text { categorías (en dos } \\
\text { secciones: } Q^{a} \text { and } L^{b} \text { ), } \\
31 \text { subcategorías } \\
82 \text { indicadores }\end{array}$ & Cuantitativo & 82 & $\begin{array}{l}\text { No existen pre-requisitos. } \\
\text { ( } 0 \% \text { obligatorios) }\end{array}$ & $\begin{array}{l}\text { Diferente sistema de } \\
\text { puntuación según la } \\
\text { localización donde se } \\
\text { implementa la } \\
\text { herramienta (centro } \\
\text { de la ciudad o general) }\end{array}$ \\
\hline ECOCITY & $\begin{array}{l}5 \text { áreas } \\
18 \text { temas } \\
39 \text { objetivos } \\
186 \text { medidas }\end{array}$ & Cualitativo & 189 & $\begin{array}{l}\text { No existen pre-requisitos. } \\
\text { ( } 0 \% \text { obligatorios) }\end{array}$ & - \\
\hline $\begin{array}{l}\text { Le } \quad \text { Modele } \\
\text { INDI-RU } 2005\end{array}$ & $\begin{array}{l}5 \text { objetivos } \\
21 \text { sub- objetivos } \\
73 \text { indicadores }\end{array}$ & Cualitativo & 73 & $\begin{array}{l}\text { No existen pre-requisitos. } \\
\text { (0\% obligatorios) }\end{array}$ & - \\
\hline BRIDGE & $\begin{array}{l}3 \text { dimensiones } \\
12 \text { objetivos } \\
28 \text { indicadores }\end{array}$ & Cualitativo & 28 & $\begin{array}{l}\text { No existen pre-requisitos. } \\
\text { ( } 0 \% \text { obligatorios) }\end{array}$ & - \\
\hline KITCASP & $\begin{array}{l}4 \text { temas } \\
20 \text { indicadores }\end{array}$ & Cualitativo & 20 & $\begin{array}{l}\text { No existen pre-requisitos. } \\
\text { (0\% obligatorios) }\end{array}$ & - \\
\hline LB & $\begin{array}{l}7 \text { criterios } \\
19 \text { estrategias } \\
93 \text { indicadores }\end{array}$ & Cualitativo & 93 & $\begin{array}{l}\text { No existen pre-requisitos. } \\
\text { ( } 0 \% \text { obligatorios) }\end{array}$ & - \\
\hline SMIS & $\begin{array}{l}6 \text { áreas } \\
13 \text { sub-áreas } \\
39 \text { indicadores }\end{array}$ & Cualitativo & 39 & $\begin{array}{l}\text { No existen pre-requisitos. } \\
\text { (0\% obligatorios) }\end{array}$ & - \\
\hline CGYM & $\begin{array}{l}7 \text { áreas } \\
18 \text { sub- áreas } \\
52 \text { indicadores }\end{array}$ & Cualitativo & 52 & $\begin{array}{l}\text { No existen pre-requisitos. } \\
\text { (0\% obligatorios) }\end{array}$ & - \\
\hline SEV & $\begin{array}{l}7 \text { áreas } \\
44 \text { indicadores }\end{array}$ & Cualitativo & 44 & $\begin{array}{l}\text { No existen pre-requisitos. } \\
\text { (0\% obligatorios) }\end{array}$ & - \\
\hline $\mathrm{BCN}$ & $\begin{array}{l}4 \text { categorías } \\
13 \text { indicadores }\end{array}$ & Cualitativo & 13 & $\begin{array}{l}\text { No existen pre-requisitos. } \\
\text { ( } 0 \% \text { obligatorios) }\end{array}$ & - \\
\hline BIL & $\begin{array}{l}12 \text { categorías } \\
34 \text { indicadores }\end{array}$ & Cualitativo & 34 & $\begin{array}{l}\text { No existen pre-requisitos. } \\
\text { ( } 0 \% \text { obligatorios) }\end{array}$ & - \\
\hline
\end{tabular}

${ }^{a} \mathrm{Q}$ : calidad ambiental en el desarrollo urbano (environmental quality in urban development)

${ }^{\mathrm{b}} \mathrm{L}$ : carga ambiental en el desarrollo urbano (environmental load in urban development)

'Pre-requisitos son las exigencies obligatorias que han de ser implementadas para obtener un nivel de certificación en la herramienta o sistema. 
De las herramientas analizadas, solamente tres de ellas utilizan un método de ponderación cuantitativo (LEED ND, BREEAM Communities y CASBEE UD). Por lo tanto, un método objetivo de cuantificación del nivel de cumplimiento de cada uno de los indicadores que proponen. Dos de las citadas herramientas (LEED ND y BREEAM Communitites) establecen, además, un conjunto de prerequisitos que son necesarios cumplir poder alcanzar un nivel mínimo de sostenibilidad en la escala de ponderación que proponen.

Como se observa en la Tabla 2.2, la totalidad de las herramientas se estructuran en temáticas organizadas en categorías, subcategorías, estrategias, áreas o sub-áreas, las cuales intentan abordar diversos aspectos de la sostenibilidad urbana, hasta llegar al nivel más concreto, que son los propios indicadores.

Aquellas herramientas basadas en un método cualitativo no establecen un sistema para cuantificar el cumplimiento de las exigencias, sino que proponen una serie de estrategias o recomendaciones que deberían ser adoptadas para alcanzar la sostenibilidad. Por ello, los métodos cualitativos tienen, en la mayoría de los casos, el inconveniente de confiar en la subjetividad del agente que implementa la herramienta. No por ello, se consideran menos importantes, pues proponen estrategias muy pertinentes. En estos casos, la integración de un método de valoración contribuiría a implementar con objetividad y transparencia los indicadores.

Así pues, los indicadores contenidos en cada una de las herramientas merecen ser analizados en profundidad, ya que aquellos que hacen referencia al aspecto energético contribuirán a identificar los aspectos más relevantes que deben ser tenidos en cuenta a la hora de proponer la metodología en el presente trabajo. Con el objetivo de llevar a cabo un análisis exhaustivo de los indicadores contenidos en las herramientas y poder compararlas entre ellas, se presenta en el Anexo I el listado completo de indicadores.

\subsection{Revisión de metodologías de evaluación energética del parque EDIFICATORIO}

Las exigencias y objetivos establecidos por la Unión Europea sobre cambio climático en materia de reducción de emisiones de GEl y de mejora de la eficiencia energética (European Commission, 2008), son cada vez más restrictivos y su cumplimiento exige ser verificado desde un enfoque global que aborde la totalidad de regiones o incluso países. Por ello, en el sector edificatorio, las miras deben ir más allá de la escala edificio y acometer la complejidad de la escala urbana. Conocer el uso de energía asociado al parque residencial de edificios, especialmente el derivado de su fase de uso, resulta un factor clave para poder establecer políticas energéticas adecuadas e implementar medidas dirigidas a reducir el consumo de energía y, por tanto, las emisiones de GEI.

En los últimos años, se ha identificado un creciente interés por evaluar el uso de energía asociado al parque residencial de edificios (Uihlein y Eder, 2010). Hasta la fecha, se han desarrollado ya herramientas que evalúan el comportamiento energético de los edificios (Swan y Ugursal, 2009) e incluso, en algunos casos, desde una perspectiva más amplia, la urbana (Shimoda et al., 2004). Sin embargo, como consecuencia de la complejidad del parque edificatorio y de la heterogeneidad que presentan sus características físicas y técnicas, no resulta sencillo abordar la evaluación atendiendo a todas las particularidades del entorno. Por ello, se hace necesario el uso de modelos complejos que reflejen la realidad de las ciudades y que permitan estimar el comportamiento energético del parque edificado, teniendo en cuenta los diversos parámetros que pueden influir en el mismo. Estos modelos serán fundamentales para dar soporte a la formulación de conclusiones a una escala 
urbana y servir como herramienta de ayuda en la toma de decisiones y en el planteamiento de políticas energéticas en el ámbito de la edificación.

Así pues, para dar respuesta a la gestión del uso de la energía en el entorno construido de una manera más sostenible y alcanzar los objetivos europeos establecidos para el año 2020, el comportamiento de las áreas urbanas debe ser estudiado como un conjunto (Jones et al., 2007). Como ya apuntaba Moffatt (2001), analizar el comportamiento ambiental de los componentes de los edificios es el mejor método disponible para alcanzar dicho objetivo, ya que los flujos de energía y de recursos son función de las relaciones dinámicas que ocurren entre la envolvente del edificio, su equipamiento, sus sistemas integrados y su funcionamiento. Utilizando modelos dinámicos a pequeña escala (la de edificio) y después agregando los resultados para trasladarlos a una escala mayor, es posible analizar y dar respuesta al uso de energía y al comportamiento ambiental o energético de un conjunto edificatorio con gran precisión.

Swan y Ugursal (2009) revisaron las técnicas de modelado utilizadas para predecir el consumo de energía e identificaron dos enfoques principales cuyas características son bien diferentes: el enfoque de abajo hacia arriba (bottom-up) y el enfoque de arriba hacia abajo (top-down). Ambas técnicas, así como sus fortalezas y debilidades, se describen en el siguiente apartado.

\subsubsection{DOS ENFOQUES: TOP-DOWN Y BOTTOM-UP}

\subsubsection{El enfoque top-down}

El enfoque top-down trata al sector residencial de edificios como un sumidero de energía, de manera que no es capaz de discernir los usos finales a los que esta energía se destina (calefacción, refrigeración, ACS, iluminación, etc.). Este método utiliza datos históricos disponibles a largo plazo y predice el uso de energía asociado al parque de edificios como una función de variables de gran escala.

Dentro de este enfoque se distinguen dos técnicas: la econométrica y la tecnológica. La primera está basada en indicadores macroeconómicos como son el producto interior bruto (PIB), tasas de empleo, índices de precios e ingresos o precio de la energía, mientras que la segunda atribuye el uso de energía a características más generales del parque de edificios como son las tendencias de las instalaciones, datos climáticos o tasas de construcción y demolición. No obstante, existen modelos que adoptan características de ambos métodos.

La principal ventaja de los modelos top-down es que pueden operar con datos globales acumulados que generalmente están amplia y fácilmente disponibles y que dependen de los valores energéticos del sector residencial, lo que le aporta cierta inercia al modelo. Como el sector residencial rara vez se somete a cambios energéticos importantes, es posible generar un modelo ponderado que proporcione una buena capacidad de predicción para las pequeñas desviaciones con respecto a la situación actual. Por ejemplo, si el sector residencial incrementa el número de unidades en un $2 \%$, mediante un modelo top-down se puede predecir un incremento total en el consumo energético de un $1,5 \%$, ya que las nuevas viviendas construidas consumirán menos energía al ser más eficientes de acuerdo con los nuevos parámetros establecidos en la legislación (Swan y Ugursal, 2009).

Sin embargo, la confianza únicamente en datos macroeconómicos e históricos representa precisamente el hándicap de este enfoque, ya que no tiene en cuenta los posibles cambios tecnológicos que pueden sucederse a lo largo del paso del tiempo y, por lo tanto, lo hace inservible para identificar las áreas específicas con potencial de mejora. 
Como desventaja, también cabe destacar que los modelos top-down suelen conllevar una categorización incorrecta del parque de edificios, debido a la falta de detalle de los datos en los que apoyan.

\subsubsection{El enfoque bottom-up}

El enfoque bottom-up estima el uso de energía en un conjunto representativo de edificios para extrapolar los resultados de la escala de edificio a la escala regional o incluso nacional. Este enfoque abarca todos los modelos que utilizan datos de entrada de un nivel jerárquico inferior al nivel superior del sector en su conjunto. Los modelos bottom-up pueden explicar el consumo de energía de los usos finales individuales, viviendas individuales o grupos de viviendas para luego extrapolar las conclusiones extraídas y representar una región o nación, basándose en el peso representativo de la muestra modelada. Puesto que utiliza una información mucho más detallada de las características del edificio (constructivas y de equipamiento), desde este enfoque se permite modelar diferentes casuísticas inherentes del edificio y su entorno, como son su geometría, instalaciones térmicas o patrones de sombras del entorno.

Dentro de este enfoque se diferencian dos técnicas: las técnicas estadísticas y las técnicas de ingeniería (también conocidas como métodos físicos o empíricos):

- Las técnicas bottom-up estadísticas se utilizan para determinar la contribución de demanda energética de los usos finales, incluyendo aspectos de comportamiento obtenidos de simples facturas energéticas y encuestas. Este método, por tanto, confía en información histórica y utiliza el análisis de regresión para atribuir el consumo energético a usos finales individuales. Establecida la relación entre los usos finales y el consumo energético de un determinado número de viviendas representativo, con el modelo se puede estimar el consumo o uso global de la energía de un parque completo de edificios.

- Las técnicas bottom-up de ingeniería se utilizan para calcular el consumo de energía de los usos finales basándose en descripciones detalladas de una muestra representativa de edificios. Los métodos de ingeniería tienen en cuenta expresamente el consumo de energía de los usos finales a base de la especificación de potencias, uso de equipos y sistemas energéticos y/o la transferencia de calor y las relaciones termodinámicas. Este método permite además determinar el impacto de la implementación de nuevas tecnologías, así como identificar las áreas susceptibles de ser mejoradas.

Entre los datos de entrada comunes a ambas técnicas bottom-up se incluyen características como las propiedades de la vivienda (geometría, envolvente térmica, equipos y aparatos, etc.), las características del clima, las temperaturas interiores, los horarios de ocupación y las horas de uso de los equipos y aparatos. Este alto nivel de detalle representa un punto fuerte del modelo y le aporta la capacidad de modelar diferentes opciones tecnológicas y de generar diferentes escenarios. A su vez, esta ventaja se puede considerar en determinadas ocasiones como un inconveniente, por la gran cantidad de datos que son necesarios para proceder al cálculo y a la simulación del comportamiento energético de un edificio.

Una vez se ha determinado el consumo energético, el modelo permite calcular el consumo total sin necesidad de confiar en datos históricos. Otra capacidad del modelo es que permite abordar explícitamente el comportamiento de los ocupantes y otros aportes de energía alternativa, como son las ganancias solares pasivas. A pesar de que históricamente estos aportes de energía han sido descuidados durante el análisis energético, ahora son un punto de diseño importante en el que se hace hincapié para el estudio de tecnologías de energía alternativa (Swan y Ugursal, 2009).

Los métodos estadísticos atribuyen todo el consumo de energía global a los usos finales y, al hacerlo, incorporan el comportamiento de los ocupantes con respecto al uso y a la configuración del 
equipamiento de las viviendas. Sin embargo, si no se contabilizan todas las fuentes de energía (como pueden ser las ganancias solares pasivas), la fiabilidad de las estimaciones sobre el consumo de energía global puede verse perjudicada.

En contraposición, el método de ingeniería basado en principios físicos, posee la capacidad de integrar estos niveles de consumo de energía adicional, incluyendo las energías alternativas. Sin embargo, el comportamiento de los ocupantes resulta difícil de integrar, ya que se ha demostrado que el comportamiento varía ampliamente y de forma impredecible. Como punto débil, Kavgic et al. (2010) identifican la falta de transparencia y cuantificación de las incertidumbres inherentes y la falta de datos públicos disponibles en lo que respecta a consumos de energía reales, los cuales pueden ayudar a identificar las tendencias tecnológicas y sociales del parque existente de edificios.

Así pues, los modelos bottom-up proporcionan una base esencial para el desarrollo de Sistemas Urbanos de Gestión Medioambiental (Urban EMS-Urban Environmental Management Systems), los cuales funcionan de forma similar que los estándares ISO, pero sustituyendo una entidad (como es una empresa o industria) por una entidad geográfica, como puede ser una ciudad o región. Además, el modelo bottom-up permite su integración con los Sistemas de Información Geográfica (SIG), proporcionando una interfaz visual, aspecto que se abordará en capítulos posteriores.

La agregación del parque edificatorio (Stock Aggregation) (Moffatt, 2001) constituye el proceso para evaluar el comportamiento energético de un edificio utilizando la evaluación ambiental de los componentes de todo un parque de edificios (stock). Como se basa en datos detallados de una muestra representativa de edificios para posteriormente extrapolar los resultados a una escala urbana, el proceso de agregación del parque edificatorio está basado en el enfoque bottom-up. Los métodos que siguen este proceso pueden contribuir a la toma de decisiones de dos formas. Por un lado, pueden asistir durante el diseño de un edificio acerca de cómo las diferentes variables que intervienen en el proceso pueden afectar al comportamiento energético, y por otro, pueden proporcionar apoyo durante la elaboración de políticas y durante el diseño del planeamiento urbano a diferentes escalas (local, regional o nacional), generando una base de datos con aspectos energéticos, ambientales, de recursos y también relacionados con el coste.

\subsubsection{Comparativa entre el enfoque top-down y bottom-up}

A modo de síntesis, la Figura 2.4 esquematiza gráficamente el funcionamiento de los modelos topdown y bottom-up y sus perspectivas descendente y ascendente, respectivamente. 


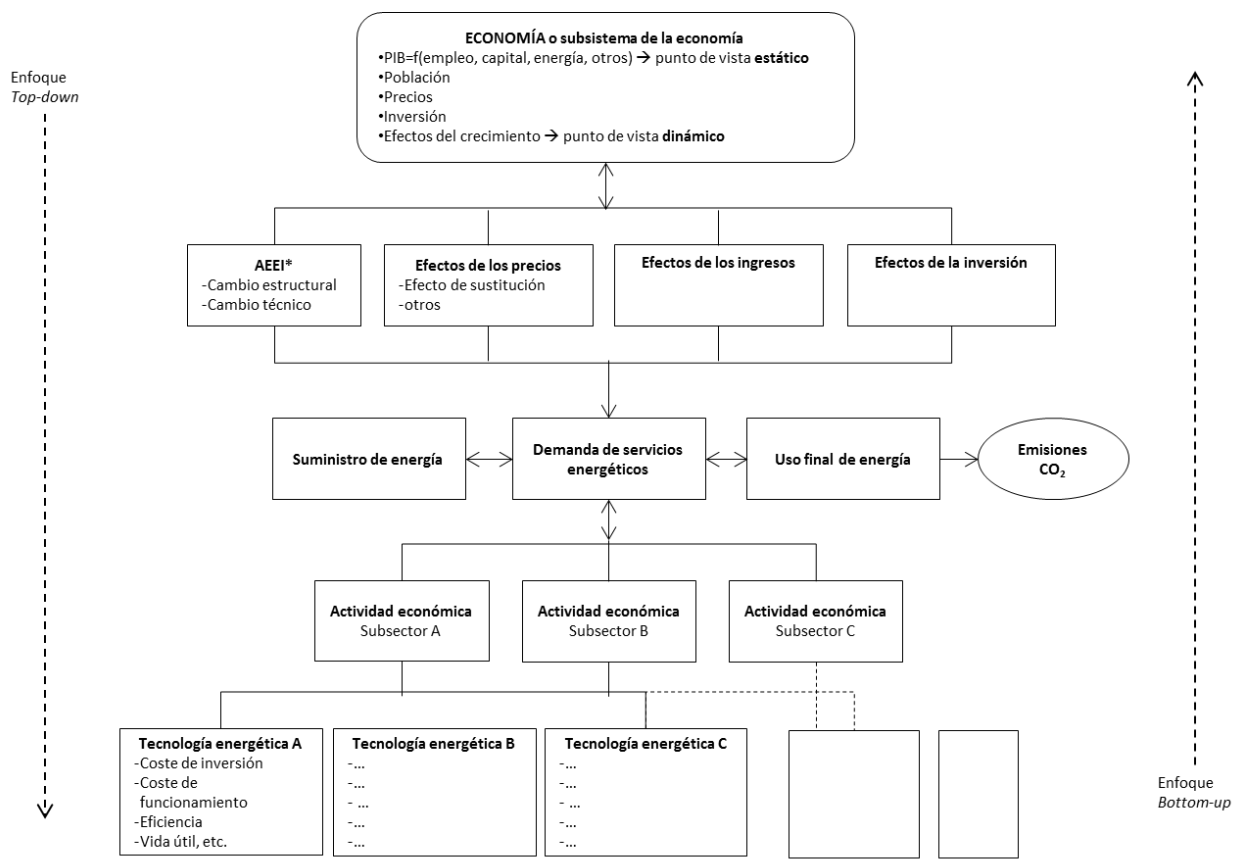

*AEEI (Autonomous Energy Efficiency Index; Índice de autonomía en eficiencia energética)

Figura 2.4 Enfoques de modelización top-down y bottom-up (adaptado de Kavgic et al. (2010))

Aunque ambos enfoques son válidos y aplicables para llevar a cabo la evaluación energética de un conjunto de edificios, las fortalezas y debilidades de cada uno de ellos descritas anteriormente se resumen en la Tabla 2.3, con el fin de servir de guía rápida a la hora de decantarse por uno de ellos.

Tabla 2.3 Fortalezas y debilidades de los enfoques top-down y bottom-up (adaptado de Swan y Ugursal (2009))

\begin{tabular}{|c|c|c|c|}
\hline & \multirow[t]{2}{*}{ Top-down } & \multicolumn{2}{|l|}{ Bottom-up } \\
\hline & & Estadístico & De ingeniería \\
\hline Fortalezas & $\begin{array}{l}\text { - Predicción a largo plazo en } \\
\text { ausencia de discontinuidades } \\
\text { - Incorporación de efectos } \\
\text { macroeconómicos y } \\
\text { socioeconómicos } \\
\text { - Información de partida } \\
\text { relativamente simple con } \\
\text { disponibilidad } \\
\text { - Engloba tendencias }\end{array}$ & $\begin{array}{l}\text { - Incorpora el comportamiento de } \\
\text { los ocupantes } \\
\text { - Incorporación de efectos } \\
\text { macroeconómicos y } \\
\text { socioeconómicos } \\
\text { - Determina usos finales } \\
\text { energéticos típicos } \\
\text { - Utiliza datos de facturas y de } \\
\text { encuestas }\end{array}$ & $\begin{array}{l}\text { - Permite modelar nuevas } \\
\text { tecnologías y determinar su } \\
\text { impacto } \\
\text { - Estimación energética "desde } \\
\text { cero" } \\
\text { - Determinación de cada uso final } \\
\text { de energía por tipo, ratio, etc. } \\
\text { - Determinación de los usos } \\
\text { finales basado en la simulación }\end{array}$ \\
\hline Debilidades & $\begin{array}{l}\text { - Confía en históricos de consumo } \\
\text { - No explicita los usos finales } \\
\text { - Análisis basto } \\
\text { - No apto para formular políticas } \\
\text { energéticas }\end{array}$ & $\begin{array}{l}\text { - Confía en históricos de consumo } \\
\text { - Multicolinearidad de variables } \\
\text { - Requiere de exhaustividad de la } \\
\text { muestra para explotar la } \\
\text { variedad }\end{array}$ & $\begin{array}{l}\text { - Asunción de comportamiento } \\
\text { de ocupantes incierto } \\
\text { - Información de entrada muy } \\
\text { detallada } \\
\text { - Intensividad computacional y } \\
\text { tiempo requerido } \\
\text { - No considera factores } \\
\text { económicos }\end{array}$ \\
\hline
\end{tabular}




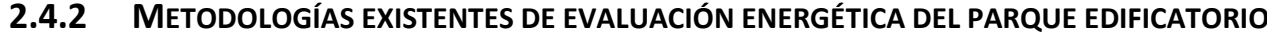

En las últimas décadas, diversos autores han desarrollado métodos enfocados a evaluar energéticamente el parque edificado, tanto desde la perspectiva bottom-up como desde la topdown. A continuación, se presenta una revisión de las mismas, clasificadas por su aplicación a nivel internacional y nacional.

\subsubsection{Revisión de metodologías a nivel internacional}

Los primeros esfuerzos dirigidos a evaluar el comportamiento energético del parque edificatorio se remontan a 1998 en Canadá (Farahbakhsh et al., 1998), lo que denota una tardía toma de conciencia en relación al impacto ambiental que tiene el comportamiento energético de los edificios. Sin embargo, durante un periodo de tiempo relativamente corto referido hasta la actualidad, se observan ya diversas metodologías surgidas en muchos países de los continentes de América, Europa y Oceanía.

Como se observará a continuación, cabe destacar que la mayoría de metodologías proponen, en una fase previa a la evaluación energética, una clasificación del parque edificatorio que permita caracterizar y estandarizar las tipologías edificatorias con el fin de simplificar el proceso de evaluación energética.

A continuación se describe, para cada país, las iniciativas surgidas relativas a la evaluación del comportamiento energético del parque edificatorio, que se clasifican en función de su año, enfoque, región, escala, sector, metodología seguida y otros aspectos, según se muestra en la Tabla 2.4.

\section{Canadá}

En Canadá destaca la metodología CREEM (The Canadian Residential Energy End-use Model) empleada por Farahbakhsh et al. (1998), que diferencia cuatro franjas temporales (pre 1941, 1941$1966,1967-1978$, post-1978) y cinco tipologías edificatorias: unifamiliar aislado, unifamiliar pareado, edificios de menos de cinco plantas, edificios de más de cinco plantas y casas móviles, todos ellos incluidos dentro del sector residencial. Con el modelo, se pretende investigar el impacto de varias estrategias para la reducción de las emisiones de $\mathrm{CO}_{2}$ en base a dos diferentes escenarios según dos normativas del país. La limitación del modelo reside en que no están recogidas todas las tipologías que representan el parque de edificios existente en Canadá y en que los edificios antiguos construidos previamente a las normativas tampoco son contemplados.

\section{Estados Unidos}

En Estados Unidos, Huang y Berkeley (2000) proponen un modelo para analizar las cargas térmicas de calefacción refrigeración asociadas a los elementos de la envolvente térmica (ventanas, cubiertas, fachadas, instalaciones de acondicionamiento, etc.). En él se analizan edificios construidos en diferentes periodos temporales y se tiene en cuenta tanto el sector residencial como el comercial. En el sector residencial se discierne entre las viviendas unifamiliares y diferentes tamaños de edificios en función del número de viviendas. A posteriori, para realizar la evaluación energética, se tiene en cuenta el tipo de suministro de energía y se evalúa el potencial de medidas de conservación energética. Sin embargo, el modelo no proporciona una información clara sobre en qué parte del parque edificatorio dichas medidas son más efectivas o beneficiosas.

Estiri (2014) selecciona un conjunto de variables (ingresos, tamaño de vivienda, estado civil de los ocupantes, número de adultos, tipología de edificio, número de espacios y tamaño) y analiza su influencia en el consumo energético de los edificios residenciales a través de un modelo estadístico. 


\section{Brasil}

Con un enfoque puramente urbano, Martins et al. (2014) analizan los condicionantes del urbanismo para identificar las oportunidades de diseño de las tipologías edificatorias. La metodología se desarrolla para el ámbito de Brasil y expone un caso de estudio en la ciudad de Maceió. El estudio analiza un doble reto: el potencial para aprovechar la energía solar como fuente de energía renovable para producción de electricidad y la demanda energética debida a las ganancias solares indeseadas en los edificios. Los programas utilizados para realizar el estudio son RADIANCE y modeFRONTIER, aunque estos se combinan con Matlab y un análisis estadístico para extraer resultados. Además, la metodología utiliza tecnología SIG para representar los resultados a escala urbana.

\section{Australia}

En Australia, Ren et al. (2012) desarrollan un modelo bottom-up físico para estimar el consumo anual del parque de viviendas a nivel de local (según el Census Collection District-CCD) con una resolución de cada hora, para posteriormente extrapolarlo a nivel nacional. Realizando simulaciones considerando las características constructivas y los materiales, el equipamiento, las zonas climáticas y los patrones de ocupación, se consigue obtener el consumo total de energía, incluyendo diferentes usos: calefacción y refrigeración, agua caliente sanitaria, iluminación y otros aparatos de uso doméstico. Los resultados se centran en el consumo de electricidad, ya que con respecto al gas natural y otros combustibles no se dispone de datos. Se diferencian cuatro tipologías edificatorias (vivienda unifamiliar aislada, vivienda unifamiliar pareada, edificio de viviendas de hasta 2 plantas, edificio de viviendas de más de 2 plantas), para las que se adopta una superficie media construida, según las estadísticas del país. Se tienen además en cuenta diferentes perfiles de ocupación en las viviendas, que permiten hacer estimaciones del consumo energético en diferentes periodos del día.

\section{Finlandia}

En el caso de Finlandia, el modelo propuesto por Snäkin (2000) fue uno de los pioneros y fue desarrollado como herramienta de ayuda a la toma de decisiones para las autoridades locales, en relación a aspectos energéticos, ambientales y también del coste de la energía. Los usos considerados abarcan desde el residencial, comercial, educativo, oficinas, etc., hasta el industrial. En cuanto al uso residencial, los edificios son diferenciados en viviendas aisladas, viviendas pareadas y edificios de viviendas. Se tiene también en cuenta el año de construcción del edificio con la diferenciación de siete periodos temporales (pre-1920, 1921-1939, 1940-1959, 1960-1969, 19701979, 1980-1989, post-1990). Además, por las características climáticas del país, en la metodología se incluyen aspectos no considerados en otros modelos, como son el tipo de calefacción utilizada y el tipo de suministro de energía.

\section{Reino unido}

En el Reino Unido existen siete modelos para evaluar el parque residencial de viviendas existente y predecir su comportamiento en escenarios futuros; todos ellos basados en un enfoque bottom-up físico, a través de la simulación con programa informático y métodos empíricos. El primero de ellos, BREHOMES (a physically-based model of the energy use of the housing stock), surgió a principios de los años 90 y fue desarrollado por Shorrock y Dunster (1997), que incorpora 1000 categorías de viviendas para definir el parque existente y diferentes patrones de uso de la calefacción. El modelo plantea dos escenarios, denominados de referencia y eficiente, aportando el coste de las medidas de conservación energética. 
En 2003, Johnston et al. (2005) plantean otro modelo para predecir el comportamiento energético de los edificios del Reino Unido en 2050 en base al año 1996, y para ello propone tres escenarios: situación actual de referencia (business as usual), escenario asumiendo las exigencias normativas (demand side) y escenario integrado considerando además el suministro energético (integrated). La metodología divide el parque de edificios en dos franjas temporales (pre 1996 y post 1996) coincidiendo con la normativa de edificación. El primero de ellos, escenario business as usual, representa el caso base o de referencia en el que se considera que no se darán cambios sustanciales en las tendencias futuras de las políticas de eficiencia energética y que existe abundancia en los recursos energéticos, aspectos que conllevan un aumento en el consumo de energía, la reducción de los precios y, además, limitación en las posibilidades de inversión en medidas de eficiencia energética. En el segundo de los escenarios, demand side, se toma conciencia sobre los efectos evidentes del cambio climático, por lo que se encaminan esfuerzos hacia objetivos más estrictos en la reducción de emisiones de carbono a través de soluciones técnicas para aumentar la eficiencia energética. Sin embargo, no se consideran cambios en las formas de suministro de energía más allá de las identificadas en el escenario business as usual. El tercer y último de los escenarios, integrated, aglutina tanto cambios en la forma de suministro de energía como en mejoras sustanciales de eficiencia energética. Este describe un futuro dramático en cuanto al impacto negativo sobre el cambio climático, por lo que tiene en cuenta importantes reducciones en las emisiones de gases de efecto invernadero para acometer los objetivos a largo plazo para el año 2050. Ello además conduce a la generalización de las energías renovables y a la utilización de nuevas tecnologías avanzadas.

Boardman (2007) propone el modelo UKDCM (UK Domestic Carbon Model) a través del $40 \%$ house escenario, que define una estrategia en Reino Unido para conseguir reducir el $60 \%$ de las emisiones en el sector residencial antes de 2050). En este modelo se utiliza una clasificación muy desagregada a nivel nacional, basada en el año de construcción, la tipología edificatoria, la tipología constructiva, el número de plantas y la superficie construida.

En el mismo año, Natarajan y Levermore (2007) plantea el modelo DECarb (future climate data and current housing stock data for the UK ) con un total de 8064 combinaciones entre distintas variables: seis periodos de construcción y otras variables como la tipología edificatoria, características constructivas y de aislamiento térmico, etc.

En el modelo CDEM (Community Domestic Energy Model) planteado por Firth et al. (2010) se proponen 47 arquetipos según el año de construcción y la morfología y tipología edificatoria.

Todos ellos están basados en un enfoque bottom-up físico y emplean la herramienta BREDEM (BRE, 2005) para modelar los edificios, que requiere los siguientes datos de entrada: elementos $y$ características de la envolvente térmica, sistema de calefacción, temperaturas interiores y exteriores, patrones de uso de la calefacción, número de ocupantes y ganancias solares.

Posteriormente en el año 2011, Cheng y Steemers (2011) analizan las debilidades de los modelos anteriores destacando la falta de transparencia y cuantificación de las incertidumbres en los datos de entrada en los modelos para obtener predicciones fiables, y cuestiona su aplicabilidad en las políticas energéticas para la toma de decisiones. Como mayor deficiencia en los modelos, nombran la generalización en los patrones de ocupación y el comportamiento de los ocupantes de las viviendas, que pueden llegar a tener una influencia decisiva en la determinación de los consumos y emisiones de $\mathrm{CO}_{2}$. Así pues, proponen el modelo DECM (Domestic Energy and Carbon Model) en el que se establece una relación entre los patrones de comportamiento de los ocupantes y su estatus socio-económico, definiendo cuatro patrones de comportamiento de los ocupantes (en días laborables y fines de semana). Además, este trabajo aporta un análisis de sensibilidad para estudiar cómo varían los resultados del modelo al variar los datos de entrada, lo que permite examinar la importancia relativa de los diferentes parámetros tenidos en cuenta en el modelo. 
Por último, en Reino Unido, Jones et al. (2007) critican la carencia de modelos que abarquen la escala urbana y proponen un modelo para estimar el comportamiento energético del entorno construido, llamado EEP (Energy and Environment Prediction). Este incorpora el uso de energía en los edificios, pero también el flujo de transporte y la salud pública.

\section{Bélgica}

En Bélgica, el modelo propuesto por Hens et al. (2001) para el sector residencial clasifica al parque existente de viviendas por año de construcción (pre-1945, 1946-1979, 1971-1980, 1981-1990), por tipología edificatoria (viviendas en hilera, viviendas pareadas y edificios de viviendas), por superficie construida (hasta $64 \mathrm{~m}^{2}$, de 65 hasta $104 \mathrm{~m}^{2}$ y más de $105 \mathrm{~m}^{2}$ ), por el tipo de energía primaria (electricidad, butano, gas, petróleo, otros) y por la presencia o no de calefacción central. La propuesta únicamente tiene en cuenta las instalaciones de calefacción central y el suministro energético, dejando de lado las posibles instalaciones de refrigeración, iluminación y el equipamiento en las viviendas, como ocurre en la mayoría de los modelos propuestos. Cabe destacar que este modelo otorga toda la importancia a las instalaciones del edificio, no haciendo hincapié en las características constructivas de la envolvente. Con el modelo se demuestra que las políticas focalizadas en los nuevos edificios y la rehabilitación de los existentes no están siendo suficientes para alcanzar los objetivos de reducción de emisiones y por ello, se requieren mayores esfuerzos.

\section{Grecia}

En Grecia se ha publicado numerosa bibliografía que recoge distintos sistemas de caracterización de los edificios existentes. Entre los sistemas implementados, destaca el elaborado por Theodoridou et al. (2011a) que clasifica el parque edificado griego, dividiendo el país en cuatro zonas climáticas de acuerdo con la normativa estatal y agrupando los edificios en función de su año de construcción (1919-1945, 1946-1980, 1981-1990, 1991-2010, octubre 2010 hasta la actualidad), su uso y tipología, el número de plantas y los materiales constructivos. Además, se tienen en cuenta aspectos socioeconómicos e históricos, que ejercen una influencia relevante en las características constructivas de los edificios. Teniendo en cuenta lo anterior, se extraen cinco clases de edificios para ser evaluados a través de simulaciones con la herramienta EnergyPlus con información de entrada basada en las especificaciones de la normativa nacional sobre eficiencia energética de edificios y que, posteriormente, constituyen una base de datos que sirve para analizar el comportamiento energético de los edificios griegos a escala nacional.

Aspectos intrínsecos de los edificios y la relación de dependencia con el consumo energético son estudiados por Theodoridou et al. (2011b) a través de un análisis estadístico llevado a cabo con la herramienta SPSS. Las conclusiones que se extraen son que el consumo energético de los edificios residenciales aumenta a medida que el año de construcción decrece (mayor antigüedad de los edificios) y que este también se incrementa a mayor número de ocupantes o superficie construida. Por otro lado, se concluye que los acristalamientos simples en huecos perjudican el consumo energético, así como aquellos elementos de la envolvente térmica que no poseen aislamiento térmico. Además, en el trabajo se tratan aspectos sociales, demostrando que a mayores ingresos en la unidad familiar se produce un mayor consumo energético en la vivienda. Los datos son extraídos mediante encuestas enviadas electrónicamente a los usuarios de las viviendas y entrevistas realizadas puerta a puerta, para conocer aspectos como son la tipología edificatoria y estructural, el sistema de calefacción, refrigeración y agua caliente sanitaria, si se han efectuado obras de reforma en las viviendas, etc. Todos estos datos posteriormente son procesados para extraer las conclusiones comentadas. 
En sucesivos estudios de los mismos autores, dicha categorización del parque existente sirve como punto de partida para crear un SIG mediante la herramienta ArcGIS, centrándose en tres tipologías principales de edificios (aislado, medianero en una de sus caras y medianero en hilera). La herramienta SIG permite tratar aspectos como el potencial para la instalación de sistemas de energías renovables, calcular el potencial para la instalación de sistemas solares en las cubiertas según la superficie disponible, la posibilidad de implementar cubiertas vegetales y otros aspectos como la orientación o las sombras. Además, se hace especial hincapié en el factor de forma del edificio, que se identifica por los autores como el mejor indicador para correlacionar la estructura y forma de un edificio con su perfil de comportamiento energético Theodoridou et al. (2012). Para validar la metodología propuesta, ésta se aplica a un caso de estudio a escala de ciudad, en dos municipios griegos: Thessaloniki (17.949 edificios) y Kalamaria (5.987 edificios).

Desde el enfoque top-down, Balaras et al. (2007) proponen una clasificación más genérica, dividiendo el parque edificatorio griego en tres franjas temporales (anterior a 1980, 1981-2001, 2002-2010) y diferenciando entre dos tipologías edificatorias: vivienda individual y edificio de viviendas, en cada una de las cuatro zonas climáticas presentes en el país. Esta clasificación que da como resultado un total de 24 categorías de edificios en base a los anteriores tres criterios: año, tipología y zona climática. En este trabajo se presenta un paquete de medidas de ahorro energético (ECM, energy conservation measures) según un orden de prioridad, así como el establecimiento del potencial de ahorro de energía y el coste económico de las mismas.

También basado en la clasificación anterior, se encuentra el trabajo desarrollado por Dascalaki et al. (2011) que emplea la clasificación en las mismas 24 tipologías de edificios para estimar el consumo de energía térmica y las emisiones de $\mathrm{CO}_{2}$ asociadas a los edificios a escala nacional. Con ello se demuestra que las tipologías edificatorias suponen un modelo sólido para predecir el consumo energético del parque residencial de edificios de un país.

\section{Italia}

En Italia se ha desarrollado numerosa bibliografía basada en diversas metodologías. Una de las más significativas es la propuesta elaborada por Dall'O' et al. (2012), que se basa en un enfoque bottomup estadístico y empírico (de ingeniería) en un entorno SIG. La metodología parte de la recabación de documentación (planos, información catastral, plano de situación, datos del edificio, etc.) para su posterior inserción en una plataforma SIG. A partir de datos del censo estadístico de edificios, se toman como muestra ciertos edificios representativos que serán posteriormente evaluados energéticamente para determinar su calificación. Mediante el tratamiento de los datos en SIG, se obtiene finalmente una base de datos que permite a las autoridades locales estimar el nivel de calificación energética de los edificios de todo un municipio, en base a unas variables previamente definidas. Los autores apuntan que, demasiada información introducida en el SIG puede sobrecargar la base de datos y complicar enormemente el estudio y la inspección de los edificios que se tomarán como muestra. Por ello, recomiendan establecer un número limitado de variables para caracterizar los edificios individualmente, variables que se introducirán a posteriori en la base de datos SIG, y que son las siguientes: zona climática, aspectos geométricos (factor de forma del edificio (S/V), superficie transparente/superficie opaca), características constructivas de la envolvente térmica (transmitancia térmica de huecos y opacos), tipo de regulación en planta (centralizada, local, etc.), uso (residencial, comercial, etc.). La base de datos se compone de determinados valores a partir de los cuales se calcularán las variables anteriores (superficie, altura del edificio, número de plantas, volumen, superficie de huecos, etc.). Con dicha información, la metodología permite estimar la calificación energética de los edificios de un municipio, y por tanto su consumo de energía asociada y emisiones de $\mathrm{CO}_{2}$. 
Otra de las aportaciones interesantes de este trabajo es la introducción de un indicador para estimar el nivel de eficiencia energética de los edificios (calificación energética) a través de rectas de regresión basadas en la correlación entre el consumo de energía y el factor de forma del edificio $(\mathrm{S} / \mathrm{V})$, durante los diferentes periodos de construcción. Así pues, se demuestra que los edificios con menores $\mathrm{S} / \mathrm{V}$ se comportan mejor y que la eficiencia energética de los edificios ha tendido a aumentar con el paso de los años.

Otros autores, como Caputo et al. (2013), realizan un planteamiento similar, llevando a cabo la caracterización de los edificios y el tratamiento de los datos en SIG. Definen cuatro arquetipos (según su tamaño, número de plantas, factor de forma) e identifican siete periodos de construcción (pre-1919, 191-1945, 1946-1960, 1961-1971, 1972-1981, 1982-1991, post-1991), que sirven tanto para edificios residenciales como comerciales. Aplicando esta metodología en la ciudad de Milán, consiguen estimar el consumo de energía final para calefacción, para iluminación y equipamiento, para agua caliente sanitaria y para instalaciones de cocina. Sin embargo, dejan de lado la estimación del consumo asociado a la refrigeración, que en determinados periodos estivales puede llegar a aumentar notablemente el consumo energético de las viviendas. Se destaca en este trabajo, la importante labor que ejercen herramientas accesibles como son Google Earth, Street View y las bases estadísticas del censo de los municipios proporcionadas por las oficinas del catastro.

También empleando la plataforma SIG, Ascione et al. (2013) desarrollan una metodología analítica para caracterizar el comportamiento energético de edificios nuevos y existentes para verano e invierno, aplicada a escala urbana. La clasificación de los edificios se realiza teniendo en cuenta el año de construcción, el número de plantas, el número de viviendas que compone el edificio, la existencia o no de edificios continuos, la orientación, la habitabilidad y las sombras. A diferencia de otros trabajos, los autores otorgan importancia a los puentes térmicos y para tenerlos en cuenta aplican un porcentaje de aumento de la transmitancia térmica en los elementos de la envolvente, en función de las características constructivas. También tienen en cuenta para la evaluación energética la irradiancia solar sobre las superficies verticales de los edificios. Para modelar el comportamiento energético de los edificios, estos autores realizan simulaciones dinámicas empleando DesignBuilder como interfaz del programa EnergyPlus y determinan la calificación energética de los edificios con el programa nacionalmente reconocido. Con los datos introducidos en SIG, confeccionan mapas urbanos energéticos (urban energy maps) para evaluar el parque de edificios a escala urbana, aportando un caso de aplicación en un barrio de la ciudad de Benevento.

Por otro lado, la tradición en la conservación del patrimonio histórico en Italia, no puede obviar su adaptación a los requerimientos energéticos de las nuevas directivas. En su trabajo, Fabbri et al. (2012) centra sus esfuerzos en evaluar los edificios históricos con el objetivo de determinar el grado de tolerancia en la actuación de los mismos, para mejorar su comportamiento energético. Así pues, en su propuesta los autores engloban los edificios de todo tipo de usos (residenciales, oficinas, sanitario, educativo, etc.) construidos en tres franjas temporales (preindustriales 1945, 1946-1991, 1991-2001) según criterios históricos y normativos. A través del tratamiento de la información catastral disponible en SIG y el desarrollo de un indicador energético de zona (consumo de energía/número de unidades urbanas), se consigue cuantificar y evaluar el comportamiento energético de toda la ciudad o bien de una zona determinada.

Mauro et al. (2015) proponen un modelo, llamado SLABE (Simulation-based Large-scale uncertainty/sensitivity Analysis of Building Energy performance), para estimar medidas costoefectivas para rehabilitar los edificios, centrándose en una tipología muy concreta: los edificios con una geometría rectangular. Para realizar las simulaciones se emplean los programas EnergyPlus y Matlab, a partir de los cuales se determina la demanda energética, horas de disconfort, costes y efectividad de la implementación de medidas de eficiencia energética. Planteada la metodología, ésta se aplica a los edificios de oficinas del sur de Italia. 


\section{Portugal}

Entre las aportaciones desarrolladas en Portugal, destaca el trabajo realizado por Gouveia et al. (2012), donde se identifican los parámetros más influyentes en la demanda energética de los edificios residenciales a través de un análisis de sensibilidad, para predecir el escenario en el año 2050. Se emplea el modelo TIMES (The Integrated MARKAL-EFOM System) para evaluar las opciones tecnológicas y la variación de parámetros para cada uso final de energía, en seis usos diferenciados: calefacción y refrigeración de espacios, agua caliente sanitaria, equipamiento en cocina, refrigeración y aparatos de limpieza (lavadoras, secadoras y lavavajillas), iluminación y otros. El objetivo final es poder determinar en qué usos finales y en qué parámetros en particular, deben centrarse las políticas energéticas para alcanzar los objetivos de reducción de consumo. El parque de edificios portugués se estructura en cuatro tipologías edificatorias, distribuidas en dos zonas climáticas: vivienda unifamiliar y edificio de viviendas en el sur del país, y vivienda unifamiliar y edificio de viviendas en el norte. Además, se diferencian tres periodos temporales (pre 1900, 19902005 y post 2005) y se identifican las características constructivas de la envolvente térmica (aislamiento, porcentaje de acristalamiento y factor solar).

\section{Francia}

Desde un enfoque top-down, Salat (2009) cuantifica las cargas energéticas y las emisiones de $\mathrm{CO}_{2}$ del parque de edificios de Paris en base a la morfología urbana, tipologías edificatorias, sistemas energéticos y comportamiento de los usuarios. En su estudio, la selección de variables es interesante y todas son susceptibles de afectar al comportamiento energético de los edificios. Sin embargo, la opacidad de la metodología hace difícil identificar la procedencia de los datos y no permite identificar cómo afectan dichas variables de una manera objetiva.

Florio y Teissier (2015) realizan una estimación de los certificados de eficiencia energética de un parque de viviendas, caracterizado a través de variables cualitativas que definen la tipología de las viviendas. Los autores proponen la metodología como una herramienta para evaluar la pobreza energética. La clasificación de las viviendas se lleva a cabo en el marco del proyecto europeo EIE TABULA (2009-2013) (Loga et al., 2012), desarrollado por trece países en el marco de Intelligent Energy Europe (European Project Partners, 2012). El objetivo del trabajo es asignar una calificación energética de la $\mathrm{A}$ a la $\mathrm{G}$ a cada tipología, en base a su energía primaria asociada a la calefacción, al agua caliente sanitaria y a la ventilación.

\section{Suiza}

Fonseca y Schlueter (2015) presentan un modelo integrado para la caracterización espacio-temporal de los patrones de consumo energético de los edificios residenciales, industriales y administrativos, a escala de barrio y de ciudad, utilizando un entorno SIG. Los datos de entrada en el modelo se componen de diversas bases de datos: climática, urbana en SIG, de arquetipos de edificios y de mediciones basadas en datos disponibles. A través de un modelo estadístico, los autores relacionan los consumos anuales de energía con edificios mediante unas ecuaciones matemáticas. A continuación, a través de un modelo analítico, determinan hora a hora las necesidades de electricidad, agua caliente sanitaria y climatización. Con ello, determinan de una forma muy detallada las cargas necesarias para satisfacer las necesidades energéticas en los edificios. Una vez analizados los arquetipos de forma individual, los resultados se agregan a una escala mayor a través de la estadística, lo que apoyado en la herramienta SIG, permite representar los resultados a escala urbana. El estudio permite analizar el potencial de la rehabilitación de edificios mediante la suposición de varios casos. Finalmente el método es validado mediante el programa EnergyPlus. 


\section{Suecia}

En Suecia, destaca el modelo propuesto por Mata et al. (2013), denominado ECCABS (Energy, Carbon and Cost Assessment for Building Stocks), mediante el cual se modela el uso de la energía, las emisiones de $\mathrm{CO}_{2}$ y los costes de la implementación de 12 medidas de eficiencia energética para la rehabilitación de edificios. El enfoque bottom-up permite estimar dichos parámetros para la totalidad del parque residencial de edificios sueco y evaluar los efectos de las medidas de ahorro de energía. Los autores concluyen que la implementación de las medidas puede llegar a reducir el $55 \%$ de la energía y el $63 \%$ de las emisiones de $\mathrm{CO}_{2}$. Las herramientas utilizadas para desarrollar el modelo son Matlab y Simulink.

\section{Alemania}

McKenna et al. (2013) analizan el potencial de desarrollo del parque residencial alemán y la capacidad para acometer los objetivos de política energética, estudiando escenarios temporales entre 2010 y 2050 . El método empleado se basa en un enfoque bottom-up y utiliza proyecciones de futuro de la demanda energética por superficie y ratios de construcción/demolición dinámicos en el tiempo. Por un lado, propone un modelo para caracterizar los edificios residenciales basado en el año de construcción (pre 1918, 1919-1948, 1949-1957, 1958-1968, 1969-1978, 1979-1983, 19841990, 1991-1995, 1996-2000, 2001-2010) y la tipología constructiva (viviendas unifamiliares aisladas, viviendas unifamiliares pareadas, pequeños edificios de viviendas, grandes edificios de viviendas, edificios de gran altura). Con ello, propone una expresión para estimar el tamaño, en términos de superficie, del parque de edificios en el futuro, teniendo en cuenta las ratios de construcción y demolición. Por otro lado, propone un modelo para estimar la demanda energética del parque en los escenarios futuros planteados hasta el año 2050, tanto para edificios nuevos como existentes. Para ello, plantea tres niveles de rehabilitación de los edificios, de acuerdo con la normativa nacional vigente. Para ilustrar la variabilidad de los datos de entrada en el modelo, se efectúa un análisis de sensibilidad en el que se demuestran los efectos de variación de los parámetros. Finalmente, los autores concluyen que el modelo llega a obtener resultados muy similares a otros modelos propuestos en Alemania, pero más austeros, debido a la consideración de mayor número de parámetros y su variación en el tiempo (en base a procedimientos dinámicos, no estacionarios).

\section{Eslovenia}

Košir et al. (2014) analizan siete configuraciones urbanas con diferentes tipologías de edificios para estudiar el potencial solar del urbanismo, especialmente para la rehabilitación de los mismos. Los cálculos se realizan con el programa SHADING y los resultados revelan que las configuraciones urbanas existentes no son tan problemáticas como las tipologías y la orientación de los edificios, que presentan un reto mayor.

\section{Nivel europeo}

Más ambicioso es el estudio propuesto por Uihlein y Eder (2010), que analizan el potencial de las políticas de la Unión Europea para mejorar la eficiencia de los edificios residenciales con respecto a la demanda energética, las emisiones de GEI y los costes asociados, a escala europea. Los autores pretenden demostrar cómo la renovación de elementos menores del edificio con baja eficiencia (cubiertas y ventanas) puede ser muy significativa, en contraste a las recientes directrices de la Unión Europea centradas principalmente en los edificios de nueva planta y en aquellos existentes sujetos a grandes reformas integrales. En este estudio, el parque de edificios residencial de 27 países de la Unión Europea queda dividido en seis clases de edificios: tres tipologías edificatorias (viviendas 
unifamiliares, edificios de viviendas, edificios de viviendas de gran altura) diferenciadas cada una de ellas entre edificios existentes y nuevos. Con los datos de las superficies construidas se analiza el comportamiento del parque edificado construido entre 1900 y 2006 para predecir posteriormente el impacto ambiental y económico hasta el año 2060. Para ello, se diferencian tres grandes zonas climáticas en Europa (norte, centro y sur) y cuatro niveles de eficiencia energética en función del grado de rehabilitación prevista para los edificios.

\subsubsection{Revisión de metodologías a nivel nacional}

A nivel nacional, la bibliografía no es muy extensa en lo que se refiere a la evaluación del parque existente de edificios. Además, la variabilidad entre las diferentes zonas de España es muy amplia, debido al gran abanico de zonas climáticas que encontramos y a razones que atienden a aspectos socio-económicos e históricos. La forma de construir entre el norte y el sur del país presenta diferencias notables y por ello, es difícil establecer una metodología que se adapte y que reúna todas las características del parque edificado para representarlo de forma fidedigna.

Probablemente, por este motivo, la bibliografía existente se centra en el estudio de una región determinada del país, más concretamente de una Comunidad Autónoma, lo que permite acotar a un menor rango las zonas climáticas y realizar una clasificación de los edificios más ajustada a cada realidad.

\section{País Vasco}

En el País Vasco, Terés-Zubiaga et al. (2013) proponen una metodología para la ciudad de Bilbao con el objetivo de medir el comportamiento energético de las viviendas sociales a través de la selección, estudio y monitorización de diez viviendas representativas del municipio. Según los autores, los resultados podrían ser extrapolables no sólo al municipio de Bilbao sino al resto de la región del País Vasco. Los autores señalan que la vivienda social es uno de los sectores con mayor riesgo de pobreza energética y de ahí la importancia de actuar en su rehabilitación, especialmente en aquellas viviendas construidas anteriormente al año 1980, previamente a la legislación en materia de condiciones térmicas, Norma Básica de la Edificación de Condiciones Térmicas en los Edificios (NBECT-79, 1979). Para efectuar la caracterización de los edificios, previamente realizan un análisis histórico de los acontecimientos más importantes y de la normativa, con lo que extraen cinco periodos temporales (1900-1939, 1939-1957, 1957-1980, 1980-2006, post-2006). Para cada uno de estos periodos se seleccionan dos edificios representativos y se describen sus características: edad y número de los ocupantes, periodo de ocupación, transmitancias térmicas de los elementos de envolvente térmica, superficie y suministro de energía.

La originalidad del estudio radica en la monitorización de las viviendas estudiadas para determinar los consumos reales, a través de ciertos parámetros: humedad y temperatura interior, facturas energéticas y mediciones reales de consumos (en cinco períodos estacionales clave), estudios termográficos y cuestionarios realizados a los ocupantes.

El estudio pone especial atención a la influencia del comportamiento de los ocupantes en el consumo energético de las viviendas, que se evalúa a través de cuestionarios para conocer los hábitos de los usuarios.

\section{Cataluña}

De forma similar ocurre en Cataluña, donde Garrido-Soriano et al. (2012) proponen una caracterización del parque existente basada en trece tipologías de edificios, en las cuatro zonas climáticas presentes en la región, la tipología edificatoria y las características constructivas de la 
envolvente térmica. A su vez se proponen cuatro franjas temporales: pre-1940, 1940-1980, 19801990 (post NBE CT-79), 1990-2001 (post NRE-AT-87, legislación regional en Cataluña). Como citan los autores, el 60\% de las viviendas en Cataluña fueron construidas en el periodo 1940-1980, previamente a la entrada en vigor de la NBE-CT-79. Una vez realizada la caracterización del parque edificatorio en Cataluña, se realiza una estimación de la demanda energética, del consumo energético y de las emisiones de $\mathrm{CO}_{2}$ hasta el año 2005 (justo antes de la entrada en vigor del CTE), para posteriormente predecir el escenario en el año 2015. Para ello, se hace una estimación del número de edificios en cada una de las categorías para el año 2015 y se determinan mediante simulación con las herramientas LIDER y CALENER VyP el consumo energético y las emisiones de $\mathrm{CO}_{2}$ (en los supuestos de rehabilitar el $2 \%$ del parque y el $100 \%$ ). Además, se calcula el impacto económico que supondría la rehabilitación de los edificios para alcanzar dichas reducciones.

\section{Comunidad Valenciana}

En el contexto de la Comunidad Valenciana, el Instituto Valenciano de la Edificación participa en el marco del proyecto europeo EIE TABULA (2009-2013) (Loga et al., 2012), integrando a España como país asociado. Este proyecto propone un marco armonizado común para comparar los parques de edificios residenciales de los diferentes países europeos que se integran como socios, en relación a su eficiencia energética. Cada tipología nacional de edificios se clasifica según su tamaño, antigüedad, zona climática e instalaciones, de manera que se obtiene para cada país un conjunto de edificios que representan todo el parque de edificios existente, con un ejemplo de cada tipología. Cada uno de los socios participantes en el proyecto ha realizado dicha clasificación, aportando un folleto de tipologías de edificios. La herramienta Web TABULA (EIE TABULA Intelligent Energy, 2012) proporciona un cálculo online de los edificios ejemplo de todos los países participantes, mostrando sus características energéticas y los posibles ahorros que se pueden lograr mediante la aplicación de medidas de rehabilitación energética (medidas estándar y medidas avanzadas), aportando datos sobre demanda, consumo, energía primaria, emisiones de $\mathrm{CO}_{2}$ y costes.

En su informe de resultados, el Instituto Valenciano de la Edificación propone una clasificación en las siguientes tipologías de edificios: vivienda unifamiliar aislada, vivienda adosada entre medianeras, edificios plurifamiliares entre medianeras, bloque de apartamentos aislado. Por otro lado, se consideran tres zonas climáticas y seis periodos temporales (pre-1900; 1901-1936; 1937-1955; 19561979; 1980-2006), con lo que surge una matriz con 72 tipologías edificatorias que caracteriza el parque residencial del Estado Español (Instituto Valenciano de la Edificación, 2014).

Como continuidad a este proyecto, se está desarrollando actualmente una línea de investigación para monitorizar los edificios y conocer el consumo energético real de los mismos, a través del proyecto europeo EPISCOPE (Diefenbach et al., 2014).

\subsubsection{Síntesis de las metodologías revisadas}

Las principales características de los modelos revisados se sintetizan en la Tabla 2.4. 


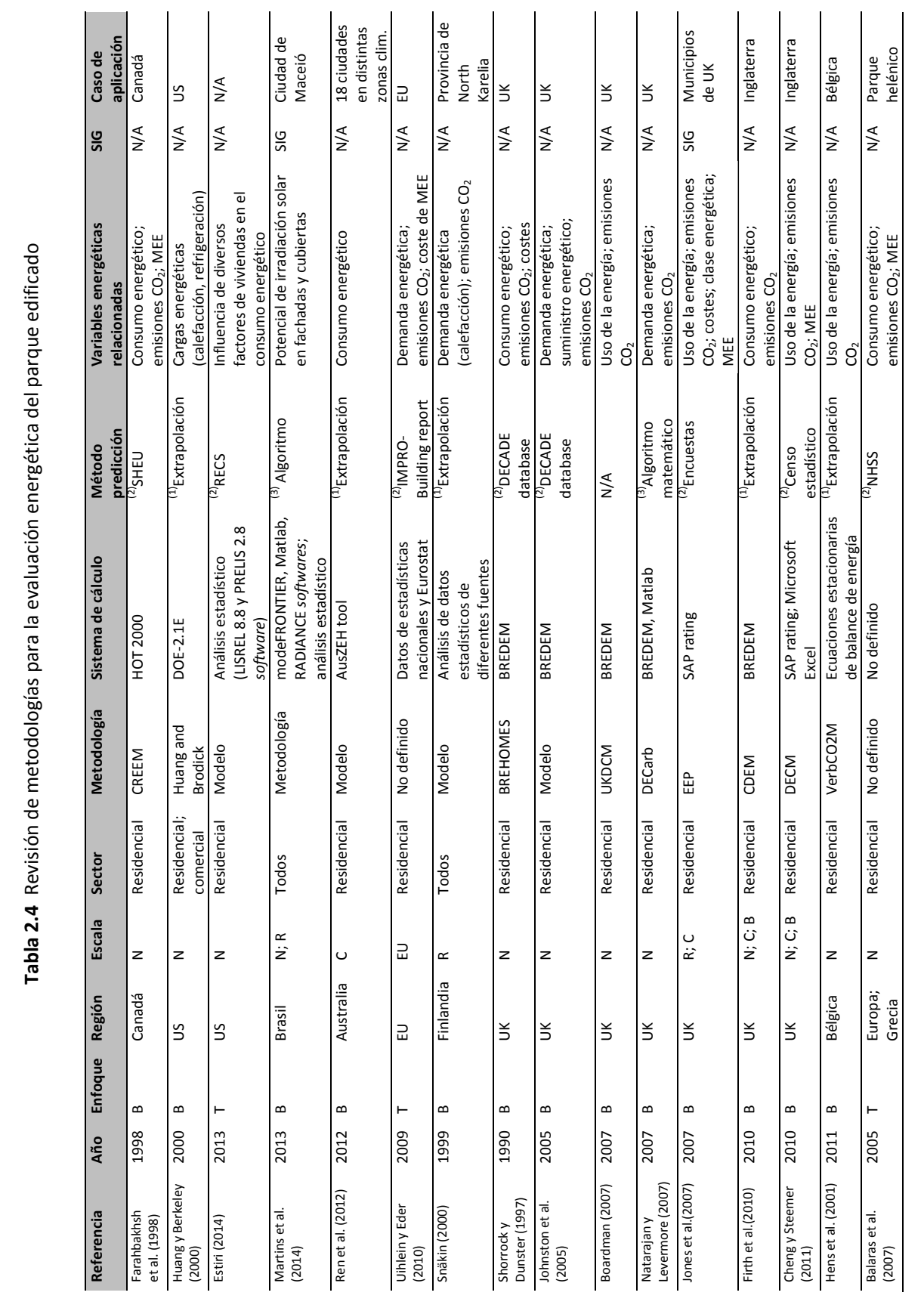




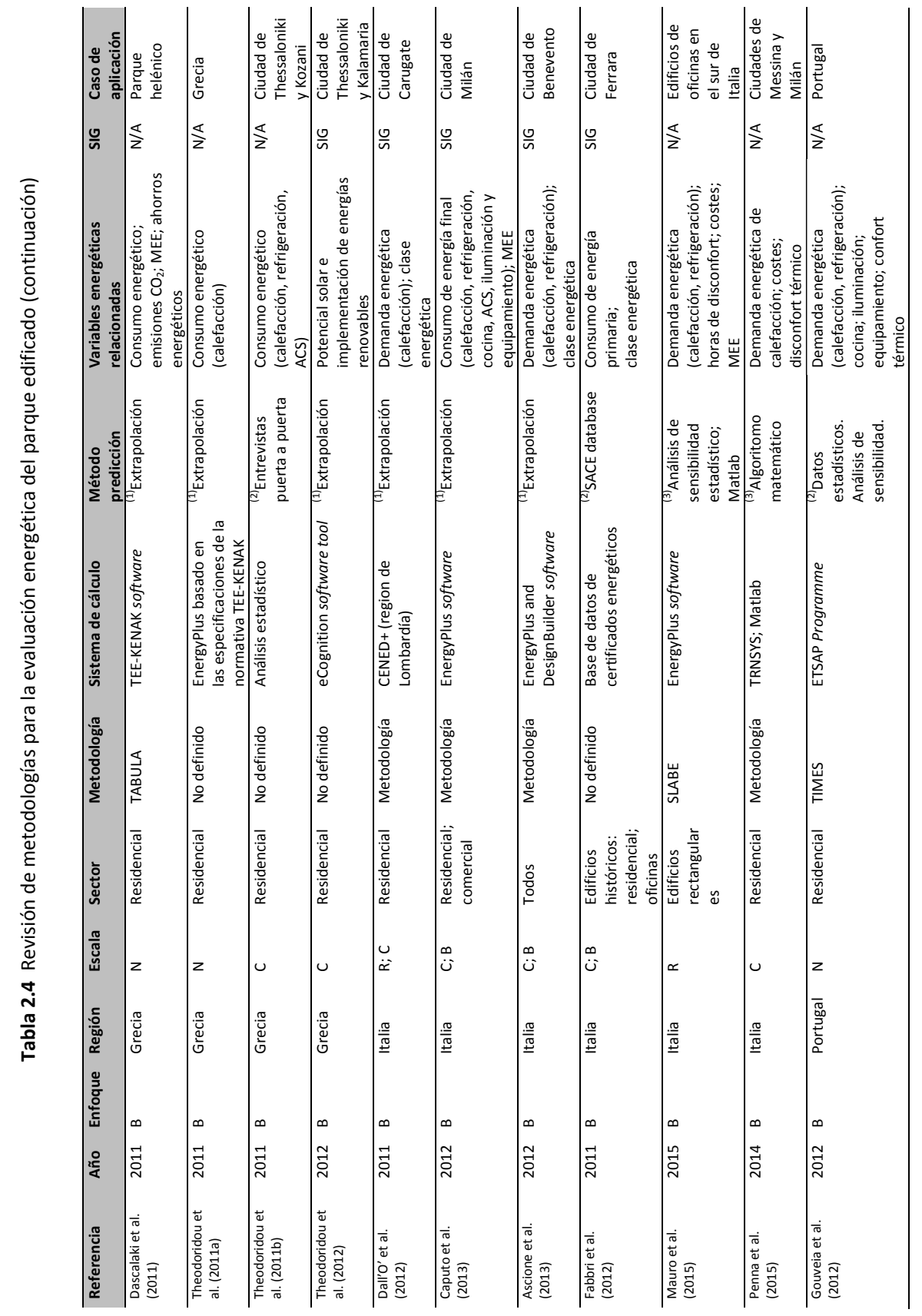




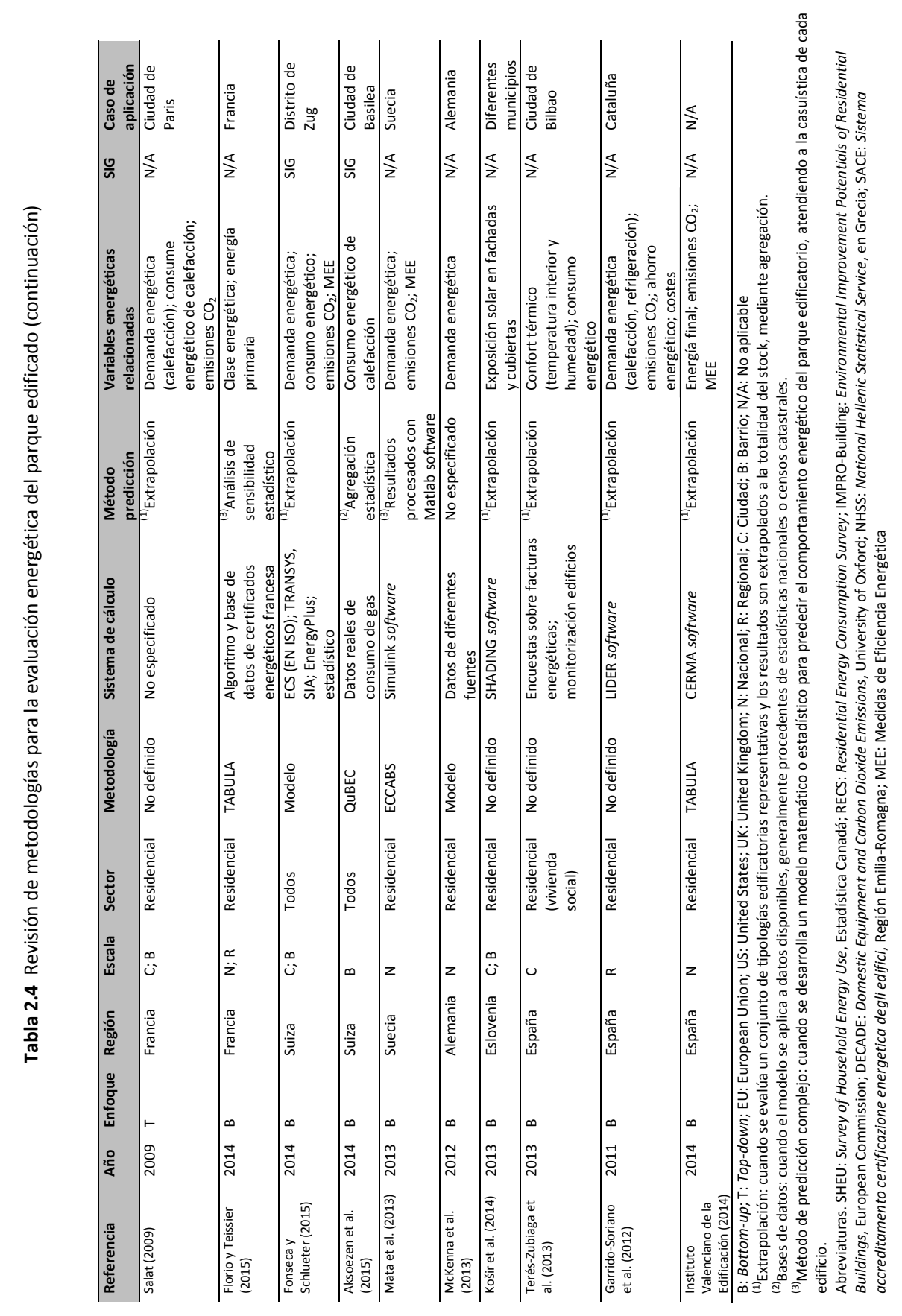


Se observa que muchos de los estudios analizados se basan en un enfoque bottom-up, a excepción de Balaras et al. (2007) en Grecia, Estiri (2014) en US, Salat (2009) en Francia, Uihlein y Eder (2010) en Europa, que están desarrollados en el marco del enfoque top-down. Además, la mayoría de los estudios se centran en el sector residencial, con algunas excepciones como el desarrollado por Martins (2014) en Brasil, Ascione et al. (2013), Caputo et al. (2013) y Fabbri et al. (2012) en Italia, Fonseca y Schlueter (2015) en Suiza, Huang y Berkeley (2000) en US y Snäkin (2000) en Finlandia, que extienden su alcance a otros sectores como el comercial, el de oficinas, el público o el religioso. Sin embargo, hay estudios que únicamente están centrados en casos muy concretos, como es el trabajo realizado por Fabbri et al. (2012), que estudia los edificios históricos dentro de los sectores residencial y de oficinas. Muchos de los trabajos revisados desarrollan modelos concretos (Boardman, 2007; Cheng y Steemers, 2011; Dascalaki et al., 2011; Farahbakhsh et al., 1998; Gouveia et al., 2012; Hens et al., 2001; Huang y Berkeley, 2000; Johnston et al., 2005; Jones et al., 2007; Mata et al., 2013; Natarajan y Levermore, 2007; Shorrock y Dunster, 1997; Snäkin, 2000), mientras que otros simplemente definen una metodología (Ascione et al., 2013; Caputo et al., 2013; Dall'O' et al., 2012; Martins et al., 2014; Terés-Zubiaga et al., 2013) o presentan un caso de estudio (Balaras et al., 2007; Fabbri et al., 2012; Garrido-Soriano et al., 2012; Košir et al., 2014; Salat, 2009; Theodoridou et al., 2011b).

En cuanto a los sistemas de cálculo empleados, se puede decir que estos proceden de una naturaleza muy diferente. Aquellos modelos desarrollados específicamente para el Reino Unido están principalmente basados o bien en BREDEM (BREHOMES (Shorrock y Dunster, 1997), Johnston et al. model (Johnston et al., 2005), UKDCM (Boardman, 2007), DECarb (Natarajan y Levermore, 2007)), o bien en SAP rating (EEP (Jones et al., 2007) y DECM (Cheng y Steemers, 2011)), ambos creados por el Building Research Establishment (BRE, 2005). De la misma manera, a menudo los autores adoptan estándares nacionales basados en la legislación y utilizan herramientas desarrolladas específicamente para cada país como sistema de cálculo, como es el caso de HOT 2000 en Canadá (Farahbakhsh et al., 1998), DOE-2.1E en Estados Unidos (US) (Huang y Berkeley, 2000), TEE-KENAK en Grecia (Dascalaki et al., 2011), CENED+ en la región Lombardi de Italia (Dall'O' et al., 2012), LIDER en España (Garrido-Soriano et al., 2012), CERMA también en España (Instituto Valenciano de la Edificación, 2014) o ETSAP en Portugal (Gouveia et al., 2012). Sin embargo, otros autores se decantan por programas de cálculo reconocidos internacionalmente como EnergyPlus en el caso de (Ascione et al., 2013; Caputo et al., 2013; Fonseca y Schlueter, 2015; Mauro et al., 2015), Matlab (Martins et al., 2014; Mata et al., 2013; Mauro et al., 2015) o RADIANCE (Martins et al., 2014).

Con respecto al método de predicción empleado, este puede estar basado en tres enfoques:

- Extrapolación: cuando se evalúa un conjunto de tipologías edificatorias representativas y los resultados son extrapolados a la totalidad del parque edificado, mediante agregación.

- Bases de datos: cuando el modelo se aplica a datos disponibles, generalmente procedentes de estadísticas nacionales o censos catastrales.

- Método de predicción complejo: cuando se desarrolla un modelo matemático o estadístico para predecir el comportamiento energético del parque edificatorio, atendiendo a la casuística de cada edificio.

Aquellos estudios, generalmente los no basados en métodos de ingeniería, confían en datos disponibles en bases de datos oficiales (Aksoezen et al., 2015; Cheng y Steemers, 2011; Farahbakhsh et al., 1998; Gouveia et al., 2012; Johnston et al., 2005; Shorrock y Dunster, 1997; Uihlein y Eder, 2010), o utilizan entrevistas y encuestas a usuarios para obtener información sobre facturas energéticas y patrones de comportamiento (Jones et al., 2007; Terés-Zubiaga et al., 2013; Theodoridou et al., 2011b). Entre los que utlilizan modelos complejos de predicción destacan los 
desarrollados por Natarajan y Levermore (2007) y Penna et al. (2015), que desarrollan algoritmos matemáticos, Florio y Teissier (Florio y Teissier, 2015) y Mauro et al. (Mauro et al., 2015), que realizan análisis estadísticos de sensibilidad, y Mata et al. (2010), que procesa los resultados del análisis experimental con Matlab para desarrollar el modelo de predicción. El objeto de los modelos de predicción en algunos modelos es predecir diferentes escenarios (Estiri, 2014; Martins et al., 2014; Snäkin, 2000; Theodoridou et al., 2011b).

Por lo que concierne a las variables energéticas evaluadas, muchos de los estudios exploran el uso de la energía en sus diferentes modalidades (energía final consumida para calefacción, refrigeración, agua caliente sanitaria (ACS), iluminación y equipamiento). No obstante, la demanda energética es ampliamiente estudiada por muchos de ellos (Ascione et al., 2013; Dall'O' et al., 2012; Fonseca y Schlueter, 2015; Garrido-Soriano et al., 2012; Gouveia et al., 2012; Huang y Berkeley, 2000; Johnston et al., 2005; Mata et al., 2013; Mauro et al., 2015; McKenna et al., 2013; Natarajan y Levermore, 2007; Salat, 2009; Snäkin, 2000). Mientras tanto, otros autores estudian las emisiones de carbono (Balaras et al., 2007; Boardman, 2007; Cheng y Steemers, 2011; Dascalaki et al., 2011; Farahbakhsh et al., 1998; Fonseca y Schlueter, 2015; Garrido-Soriano et al., 2012; Hens et al., 2001; Johnston et al., 2005; Jones et al., 2007; Mata et al., 2013; Natarajan y Levermore, 2007; Salat, 2009; Shorrock y Dunster, 1997; Snäkin, 2000), los costes (Garrido-Soriano et al., 2012; Jones et al., 2007; Mata et al., 2013; Mauro et al., 2015; Shorrock y Dunster, 1997), la calificación energética (Ascione et al., 2013; Dall'O' et al., 2012; Fabbri et al., 2012; Florio y Teissier, 2015; Jones et al., 2007) y medidas de eficiencia energética (MEE) (Balaras et al., 2007; Caputo et al., 2013; Cheng y Steemers, 2011; Dascalaki et al., 2011; Jones et al., 2007; Mata et al., 2013; Mauro et al., 2015). Aunque el confort térmico en el ambiente interior representa un aspecto fundamental para analizar el comportamiento pasivo de los edificios, sólo dos de los estudios lo tienen en cuenta. Terés-Zubiaga et al. (2013) analizó el confort térmico a través de la monitorización de diez viviendas para determinar la temperatura y la humedad, y Mauro et al. (2015) utilizaron simulación dinámica para determinar las horas de discomfort a las que estaban expuestos los usuarios. Por otro lado, otros autores (Košir et al., 2014; Martins et al., 2014) se centran en evaluar el potencial solar para diferentes propósitos, como por ejemplo, determinar la superficie disponible de cubierta en los edificios para instalar paneles fotovoltaicos, o maximizar las ganancias solares a través de las fachadas de los edificios para reducer la demanda energética de calefacción.

Con respecto a el uso de SIG, seis de los trabajos confían en esta tecnología para llevar a cabo los estudios (Ascione et al., 2013; Caputo et al., 2013; Dall'O' et al., 2012; Fabbri et al., 2012; Farahbakhsh et al., 1998; Fonseca y Schlueter, 2015; Jones et al., 2007; Martins et al., 2014), de los cuales sólo Jones et al. (2007) desarrolla específicamente un modelo que utiliza SIG para procesar información de edificios individuales para posteriormente agregar los resultados a un nivel geográfico intermedio.

Por lo tanto, se puede concluir de esta revisión que, una metodología adecuada de evaluación energética del parque edificado debe dar respuesta a la heterogeneidad de las características físicas de los edificios y del entorno edificado, las cuales pueden variar considerablemente incluso dentro de un mismo país y, además, debe ser versátil para poder adaptarse ampliamente al contexto específico de la región en la que ésta se implementa. Muchos de los estudios analizados tienen en cuenta un amplio rango de aspectos centrados en las especificidades de la región en la que se desarrollan, como es el caso de aquellos que utilizan metodologías ad hoc y programas basados en la legislación territorial. Sin embargo, no todos ellos pueden aplicarse directamente a cualquier región ni combinan diferentes tecnologías para mejorar la eficacia de sus métodos. De hecho, Kavgic et al. (2010) ya revisaron exhaustivamente diferentes técnicas para modelar el consumo energético en el sector residencial con un enfoque bottom-up. Pero después de realizar un crítico análisis, destacaron la necesidad creciente de continuar desarrollando metodologías más sofisticadas que incorporen aspectos multidisciplinares. 


\subsection{EVAlUaCión ENERGÉtica de EDIFICIOS}

Una vez revisadas las metodologías existentes para analizar energéticamente el parque edificatorio existente, se observa que todas ellas se basan en el estudio del uso de la energía de los edificios que lo componen, a partir de simulaciones energéticas mayoritariamente. Por tanto, la evaluación energética de los edificios representa otro elemento clave, que va a ser analizado en este apartado desde diferentes perspectivas:

- Relación entre demanda energética y consumo energético

- Parámetros de cálculo que deben ser considerados en la evaluación energética

- Herramientas informáticas de simulación energética

La simulación energética de edificios trata de estimar el comportamiento térmico de las diferentes zonas que conforman el edificio y las prestaciones que están dando las instalaciones y equipos en las condiciones de trabajo puntuales en cada instante de tiempo, con el fin de integrarlas durante el periodo de tiempo simulado.

El objetivo de la simulación térmica o energética de edificios puede ser diverso. Se pueden analizar los consumos de energía y las emisiones de $\mathrm{CO}_{2}$ asociadas, analizar el comportamiento de los equipos o sistemas de climatización y ventilación, observar la evolución de la temperatura y la humedad relativa de las diferentes zonas del edificio, o analizar las condiciones de confort térmico interiores, entre otros.

La simulación debe realizarse en todo un periodo anual, subdividido en franjas de tiempo menores, que generalmente son horarias. Ello premite descender a un nivel pormenorizado de análisis que proporcione una información bastante precisa sobre el comportamiento de un edificio.

En la simulación pueden incluirse las instalaciones que originen un consumo de energía, como son la calefacción, la refrigeración, el ACS y la iluminación. En este caso, la simulación proporcinará información sobre el consumo energético del edificio y sus emisiones de $\mathrm{CO}_{2}$ asociadas. Sin embargo, las instalaciones pueden no incluirse, en cuyo caso la simulación proporcionará información sobre el comportamiento pasivo del edificio, es decir, sobre su funcionamiento energético en condiciones libres teniendo en cuenta únicamente el diseño del edificio (sus características dimensionales y morfológicas) y sus características constructivas. En este caso, el consumo energético no podrá ser determinado, ni tampoco sus emisiones de $\mathrm{CO}_{2}$, pero sí podrá ser estimada la demanda energética de dicho edificio, definida como la energía útil necesaria que tendrían que proporcionar los sistemas técnicos para mantener en el interior del edificio unas condiciones óptimas de confort en función del uso del edificio y del clima en el que se ubique (CTE, 2013). La demanda energética, de la misma manera que el consumo, se puede dividir en demanda energética de calefacción, de refrigeración, de ACS y de iluminación.

En relación a estos dos conceptos, consumo energético y demanda energética, cabe indicar ciertas puntualizaciones. Por un lado, el consumo energético asociado a un edificio no siempre da una medida de las necesidades energéticas reales, pues en él influyen otros factores que son enormemente variables, como son la ocupación y la condición socio-económica de sus ocupantes. Así pues, una vivienda puede tener una alta demanda energética debido a sus deficientes prestaciones $y$, sin embargo, tener asociado un consumo energético casi nulo. Esta situación puede darse en el caso de usuarios con un nivel de renta bajo que se encuentren en riesgo de pobreza energética y que no puedan hacer frente al coste económico que supondría poner en funcionamiento las instalaciones térmicas. En esta situación, la vivienda no consumirá energía y no emitirá $\mathrm{CO}_{2}$ en relación a dicha instalación, pero sus ocupantes se mostrartán disconformes con las condiciones interiores. $\mathrm{O}$, una vivienda desocupada o utilizada solamente en periodo vacacional, 
puede no tener consumo durante ciertos meses del año. En tal caso, el edificio podría tener un consumo energético muy bajo, lo que no sería aplicable a la demanda energética, la que, en contraposición, podría ser muy alta, porque depende del diseño del propio edificio y de la calidad de su envolvente térmica, como se menciona anteriormente. Por estas razones, no se deben obviar otros aspectos que influyen en el consumo, como es el humano a través del uso que los ocupantes hacen del edificio, o el socio-económico.

Por otro lado, la brecha energética (energy gap) entre el consumo de energía estimado por las herramientas de cálculo y el real, es considerable, siendo un $46 \%$ más en viviendas unifamiliares y un $43 \%$ más en edificios plurifamiliares (Balaras et al., 2016), debido a la imposibilidad de definir de manera precisa los factores humanos que influyen en el consumo del edificio.

Por último, en el caso de edificios existentes, a la hora de estimar el comportamiento energético en un parque urbano consolidado, la gran heterogeneidad en la tipología de instalaciones técnicas hace muy complejo estandarizarlas. La sustitución de las instalaciones a voluntad y necesidad del usuario es muy variable a lo largo del tiempo, lo que causa una gran heterogeneidad de equipos, incluso, dentro de un mismo edificio. Por ejemplo, un usuario de una vivienda de un edificio construido en 1980 puede mantener el termo eléctrico instalado de origen, mientras que otro usuario puede haber sustituido dicho equipo por una instalación de caldera mixta de condensación para calefacción y ACS abastecida por gas natural, la que resultaría mucho más eficiente y tendría un consumo energético asociado más bajo. Ello hace muy complejo predecir con exactitud qué tipo de instalaciones existen en el parque edificado y, por tanto, también estandarizarlas para su simulación.

La Figura 2.5 muestra la relación entre los factores que influyen en la demanda energética de un edificio y en su consumo.

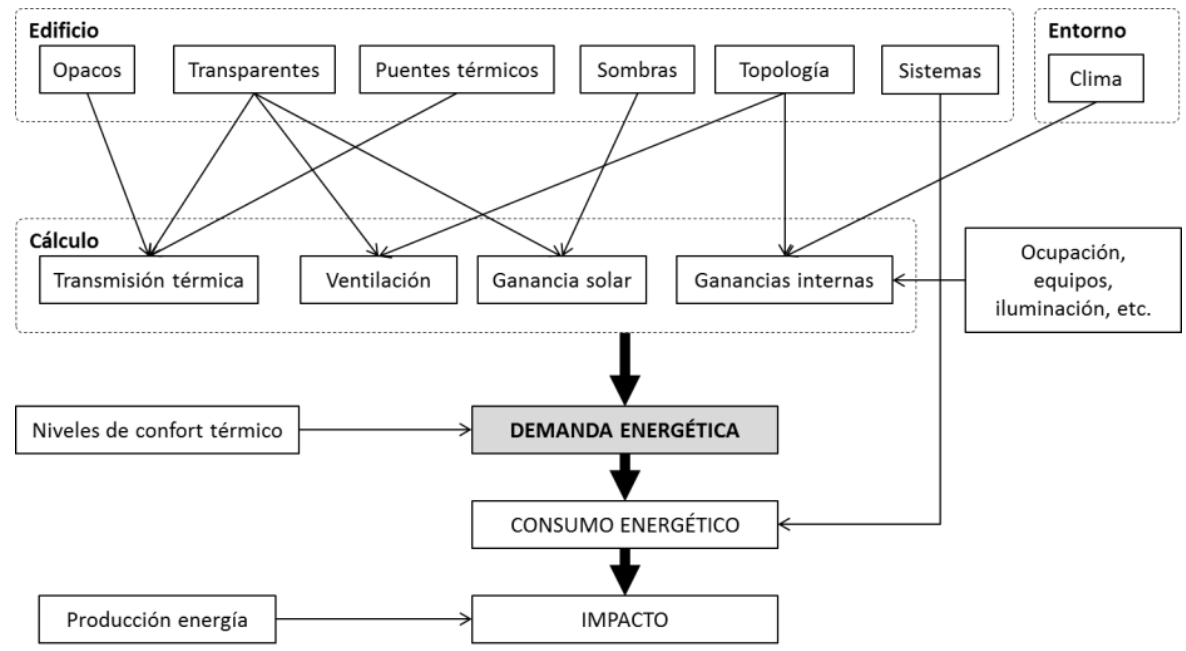

Figura 2.5 Balance de energía en un edificio (adaptado de Solé-Bonet (2003))

La relación que existe entre demanda energética y consumo energético viene dada por la expresión:

$$
\text { Consumo }=\int_{\text {anual }} \frac{\text { Demanda }_{\text {calefacción }}}{\bar{\eta}_{\text {sistema calefacción }}}+\int_{\text {anual }} \frac{\text { Demanda }}{\bar{\eta}_{\text {sistema refrigeración }}}+\int_{\text {anual eración }} \frac{\text { Demanda }_{A C S}}{\bar{\eta}_{\text {sistema ACS }}}+\int_{\text {anual }} \frac{\text { Demanda }_{\text {ilu } \min \text { ación }}}{\bar{\eta}_{\text {sistema ilu min ación }}}
$$

donde $\bar{\eta}_{\text {sistemas }}$ es el rendimiento de los sistemas o instalaciones del edificio. 
Tanto la demanda como el consumo se expresan en términos de $\mathrm{kWh} / \mathrm{m}^{2}$ año.

Así pues, mientras que la demanda energética de un edificio indica la cantidad de energía necesaria para mantener las condiciones de confort en su interior, el consumo energético expresa la cantidad de energía consumida por los equipos y, por ende, el impacto económico y ambiental asociado a estos.

En los próximos apartados, 2.5 .1 y 2.5.2, se definen los parámetros de cálculo que deben ser tenidos en cuenta para llevar a cabo una simulación energética y se revisa el estado del arte en cuanto a programas de simulación energética de edificios, respectivamente.

\subsubsection{DEFINICIÓN DE PARÁMETROS DE CÁLCULO}

En los procesos de evaluación energética de edificios deben asumirse ciertos parámetros que resultan fundamentales para analizar su comportamiento. Estos son: las solicitaciones exteriores definidas por el clima de la región, las solicitaciones interiores y condiciones operacionales, las características morfológicas y constructivas del edificio, las condiciones de soleamiento y sombras y los sistemas técnicos. Variaciones en dichos parámetros provocarán diferencias notables, por lo que estos deben ajustarse con valores lo más próximos posible a la realidad, de forma que estén adecuadamente adaptados al contexto urbano y del edificio. Los siguientes apartados definen cuáles son y cómo se definen los parámetros de cálculo para la simulación energética.

\subsubsection{Solicitaciones exteriores}

Se consideran solicitaciones exteriores las acciones del clima sobre el edificio con efecto sobre su comportamiento térmico y, por tanto, sobre su demanda energética. Las condiciones climáticas describen las condiciones del lugar en el que el edificio está ubicado. Existen plantillas con las condiciones climáticas definidas para un gran abanico de ciudades a nivel mundial disponibles en la página web del programa EnergyPlus (U.S. Department of Energy, 2013), que pueden ser tomadas como climas de referencia. El CTE, a efectos de cálculo, establece para el territorio español un conjunto de zonas climáticas para las que se define un clima de referencia, con las solicitaciones exteriores en términos de temperatura y radiación solar. Estos valores se encuentran tabulados y recogidos en los climas de referencia para cada zona climática, proporcionados por la Dirección General de Arquitectura, Vivienda y Suelo, del Ministerio de Fomento.

\subsubsection{Solicitaciones interiores y condiciones operacionales}

Se consideran solicitaciones interiores las cargas térmicas generadas en el interior del edificio debidas a los aportes de energía de los ocupantes, equipos e iluminación. Las condiciones operacionales se definen por las temperaturas de consigna y las cargas internas debidas a la ocupación, a la iluminación y a los equipos.

A continuación, se enumeran y describen dichos parámetros:

- Densidad de ocupación (personas $/ \mathrm{m}^{2}$ ): establece el número de personas por unidad de superficie que ocupan cada zona definida en el edificio. Generalmente, este valor depende del uso al que se destina cada espacio, residencial o terciario.

- Patrones de comportamiento de los ocupantes. La ocupación está controlada por unos horarios en los que se prevé dicha ocupación en el edificio. Se puede diferenciar entre días laborables, fines de semana e incluso días festivos, que pueden ser programados tanto en lo que a horario se refiere, como a intensidad de ocupación. 
- Tasa metabólica (W/persona). La tasa metabólica indica el nivel de actividad de las personas que habitan el espacio interior del edificio y determina la cantidad de ganancia de calor por persona en cada zona del mismo. El calor es generado en el cuerpo humano por oxidación en una ratio denominada tasa metabólica, como consecuencia de la actividad humana. Este calor es disipado por la superficie corporal y la respiración a través de los procesos de radiación, convección y evaporación. El factor metabólico se establece en 1 para hombres, 0,85 para mujeres y 0,75 para niños. La proporción relativa de calor sensible y latente generado por una persona es una función compleja entre la tasa metabólica y las condiciones ambientales.

- Nivel de vestimenta. La vestimenta reduce la pérdida de calor corporal y es clasificada según el valor de aislamiento térmico que proporciona. La unidad generalmente usada para medir el aislamiento de la vestimenta es el $\mathrm{Clo}\left(1 \mathrm{Clo}=0,155 \mathrm{~m}^{2 \circ} \mathrm{C} / \mathrm{W}\right)$. Los Clo pueden ser calculados por adición del Clo asociado a cada prenda de vestir, los cuales, según la norma ISO 7730 (AEN/CTN 81, 2006), son los que se presentan en la Tabla 2.5 .

Tabla 2.5 Clo según el nivel de vestimenta ISO 7730 (AEN/CTN 81, 2006)

\begin{tabular}{|l|l|}
\hline Prenda de vestir & Valor de Clo \\
\hline Desnudez & 0,0 \\
\hline Calzoncillos, bragas & 0,06 \\
\hline Camiseta & 0,09 \\
\hline Bragas y sujetador & 0,05 \\
\hline $\begin{array}{l}\text { Ropa interior larga } \\
\text { Superior } \\
\text { Inferior }\end{array}$ & 0,35 \\
\hline Camisa & 0,35 \\
\hline Ligera, manga corta & \\
Gruesa, manga larga & 0,14 \\
Añadir 5\% por corbata o cuello alto & 0,29 \\
\hline Falda & $+5 \%$ \\
\hline Pantalones & $0,22-0,70$ \\
\hline Jersey & $0,26-0,32$ \\
\hline Calcetines & $0,20-0,37$ \\
\hline Traje o vestido de verano ligero & $0,04-0,10$ \\
\hline Ropa de trabajo & 0,30 \\
\hline Combinación de ropa de invierno típica & 0,80 \\
\hline Traje & 1,0 \\
\hline
\end{tabular}

- Temperaturas de consigna $\left({ }^{\circ} \mathrm{C}\right.$ ). Indica la temperatura ideal (por ejemplo, la fijada en el termostato de los espacios, individualmente o en el edificio completo) a partir de la cual la operación de los sistemas térmicos es necesaria. Se establece una temperatura de consigna para refrigeración, en periodo de verano, y una temperatura de consigna para calefacción, en periodo de invierno. Si se tiene en consideración la ventilación natural del edificio para refrigerarlo de forma natural, también es posible establecer una temperatura de consigna de ventilación natural para indicar el límite a partir del cual deben operar o no los sistemas de refrigeración durante el periodo estival.

- Ganancias internas $\left(\mathrm{W} / \mathrm{m}^{2}\right)$. Además de las cargas generadas por la propia ocupación, el equipamiento también es responsable del aumento de las cargas internas en el interior de los espacios del edificio, que harán aumentar la demanda de refrigeración en verano y reducirán la de calefacción en invierno. Se establece un valor en vatios por unidad de superficie. 
- Tasa de infiltración de aire (renovación/hora). La ventilación natural viene definida por la tasa de renovaciones hora en cada espacio o a nivel de edificio. El caudal de aire en $\mathrm{m}^{3} / \mathrm{s}$ a una presión normal se transforma a renovaciones/hora $(r / h)$ según la siguiente expresión:

$$
r / h=\frac{m^{3} / s}{V_{\text {zona }}\left(m^{3}\right)} \cdot 3600
$$

donde,

m metros

$s$ segundos

h hora

$\checkmark$ volumen

La ventilación también se define por la cantidad aire exterior mínimo que entra al edificio por persona, mediante litros/segundo por persona ( $/ \mathrm{s}$ persona) o por unidad de superficie $\left(\mathrm{I} / \mathrm{s} \cdot \mathrm{m}^{2}\right)$.

\subsubsection{Definición morfológica y constructiva del edificio}

En relación a la configuración física del edificio, existen dos factores clave que influyen en su demanda energética y que será necesario controlar para reducirla. El primero de ellos es el propio diseño del edificio, es decir, las características dimensionales que definen su morfología. El segundo, es la calidad constructiva de su envolvente térmica.

Según el Código Técnico de la Edificación (CTE, 2013), la envolvente térmica de un edificio está compuesta por todos los cerramientos que delimitan los espacios habitables con el aire exterior, el terreno u otro edificio, y por todas las particiones interiores que delimitan los espacios habitables con espacios no habitables en contacto con el ambiente exterior. En definitiva, la envolvente térmica se considera como la piel del edificio y debe cumplir con la función de limitar la transferencia de calor entre el ambiente interior y el exterior, ayudando a mantener estables las condiciones interiores óptimas de confort. Será, pues, la responsable principal de limitar la demanda energética del edificio. Los elementos del edificio que la componen, tal y como se indica en la Figura 2.6, según su posición y adyacencia, son los siguientes: muro exterior, muro enterrado, muro interior, cubierta plana, cubierta inclinada, suelo sobre el terreno, suelo enterrado, suelo exterior, suelo interior, puerta, abertura. 


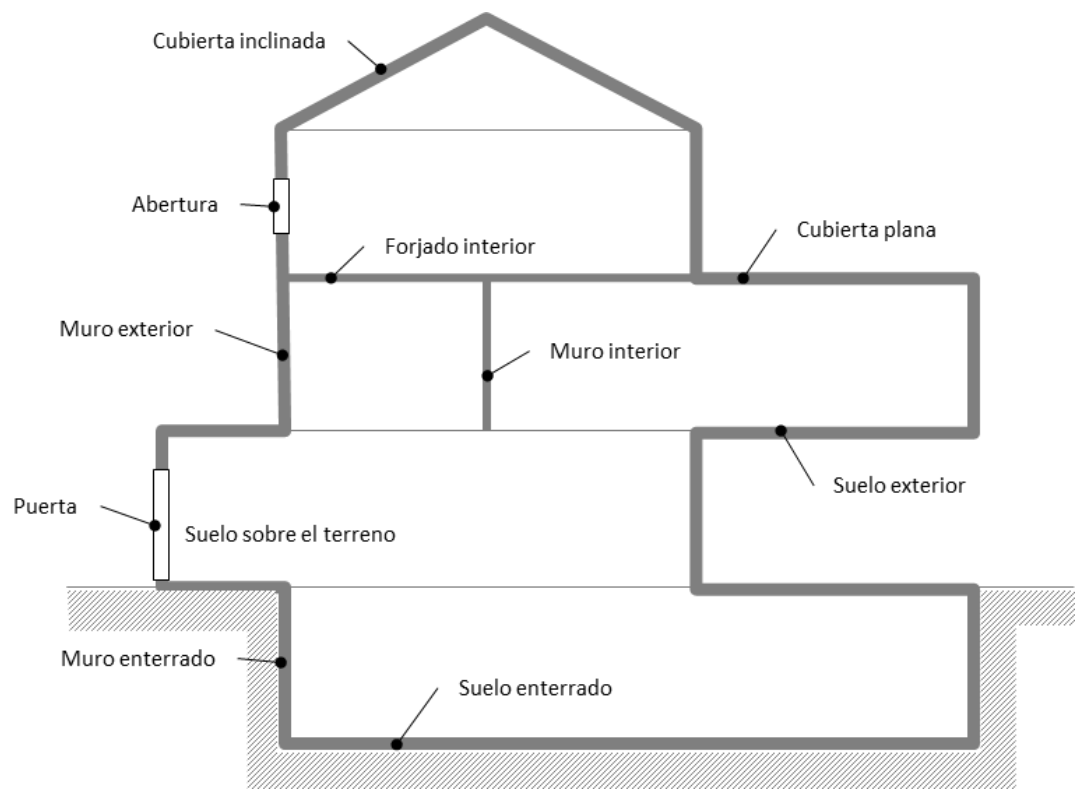

Figura 2.6 Cerramientos de la envolvente térmica del edificio

Cada elemento de la envolvente, y por tanto cada solución constructiva, lleva asociada una determinada transmitancia térmica $(U)$ que se define como el flujo de calor, en régimen estacionario, para un área y diferencia de temperatura unitarias de los medios situados a cada lado del elemento que se considera $(C T E, 2013)$, y se expresa en $\left(W / m^{2} K\right)$ según la expresión:

$$
U=\frac{1}{\sum R_{i}}\left[W / m^{2} K\right]
$$

La transmitancia térmica es inversamente proporcional a la resistencia térmica ( $R, m^{2} K / W$ ), la cual se calcula mediante el sumatorio de las resistencias térmicas parciales de las capas que conforman un cerramiento. La resistencia térmica de un elemento se determina por la expresión:

$$
R=\frac{e}{\lambda}\left[m^{2} K / W\right]
$$

donde,

$$
\begin{array}{ll}
e & \text { espesor del elemento }[\mathrm{m}] \\
\lambda & \text { conductividad térmica del elemento }[\mathrm{W} / \mathrm{mK}]
\end{array}
$$

Para cada uno de estos cerramientos que componen el edificio, se debe definir una solución constructiva mediante la introducción de las diversas capas que lo conforman, lo que dará como resultado la transmitancia térmica del elemento $\left(\mathrm{U}, \mathrm{W} / \mathrm{m}^{2} \mathrm{~K}\right)$. 
Además, se deben definir las aberturas mediante indicación del tipo de marco, el factor de marco y el tipo de acristalamiento, lo que dará también como resultado una $U$ relativa a elementos transparentes.

Al igual que para los cerramientos opacos y transparentes, se deben definir las características de los puentes térmicos, por lo que se deberá especificar la transmitancia térmica lineal $(\mathrm{W} / \mathrm{mK})$ en los encuentros de: cubierta-muro, muro-suelo terreno, muro-muro, muro-suelo, dintel, alféizar y jambas.

\subsubsection{Condiciones de soleamiento y sombras}

La radiación directa de onda corta, tanto si incide en el exterior de un cerramiento como si lo hace en el interior tras atravesar un acristalamiento, supone un aporte de energía no uniforme espacialmente sobre las superficies.

En general, las condiciones de insolación y sombreamiento pueden ser debidas a diversas causas: por sombras propias del edificio, por sombras de elementos accesorios del edificio, por sombras externas y por sombras geográficas generadas por el entorno topográfico.

- Sombras por el propio edificio. El propio edificio puede reflejar la radiación en alguna superficie del mismo, dependiendo de su morfología. Si las superficies son opacas provocan radiación solar difusa, mientras que si son de vidrio provocan radiación especular. Ver Figura 2.7.

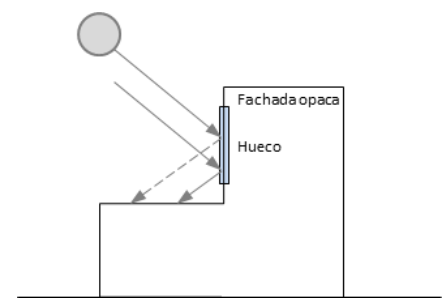

Figura 2.7 Reflexión solar de las superficies del edificio sobre el mismo u otro edificio (DesignBuilder UK, 2015a)

- Sombras por elementos accesorios del edificio y sombras externas (voladizos, edificios circundantes) que generan radiación difusa y reflectancia, derivada de las propiedades de los materiales que componen los muros y los huecos. Ver Figura 2.8.

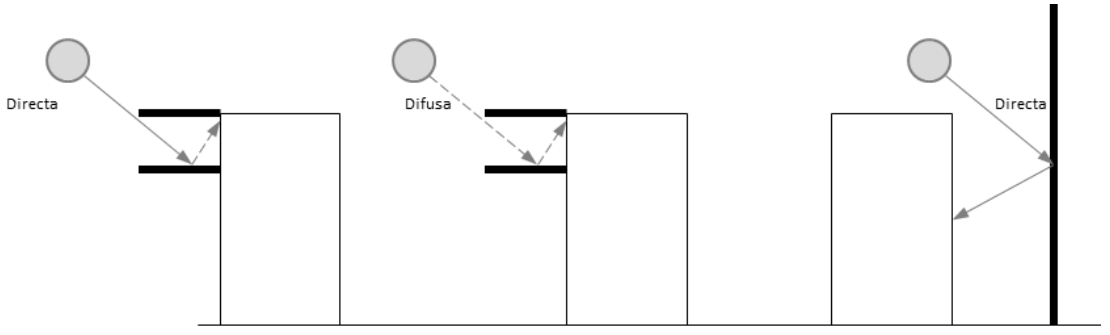

(a)

(b)

(c)

Figura 2.8 Reflectancia solar en el edificio producida por obstrucciones. Reflexión difusa de la radiación directa sobre la superficie de un voladizo (a), reflexión difusa de la radiación solar del cielo en un voladizo (b), reflexión directa especular desde la superficie de la fachada de un edificio adyacente constituida por vidrio (c)

(DesignBuilder UK, 2015a) 
- Superficie del terreno. El sombreado del terreno causado por los edificios afecta a la reflexión directa. La radiación difusa en edificios procedente de la incidencia de radiación directa sobre el terreno, sólo ocurre en zonas iluminadas o soleadas (A y C), pero no en zonas sombreadas (B). Ver Figura 2.9.

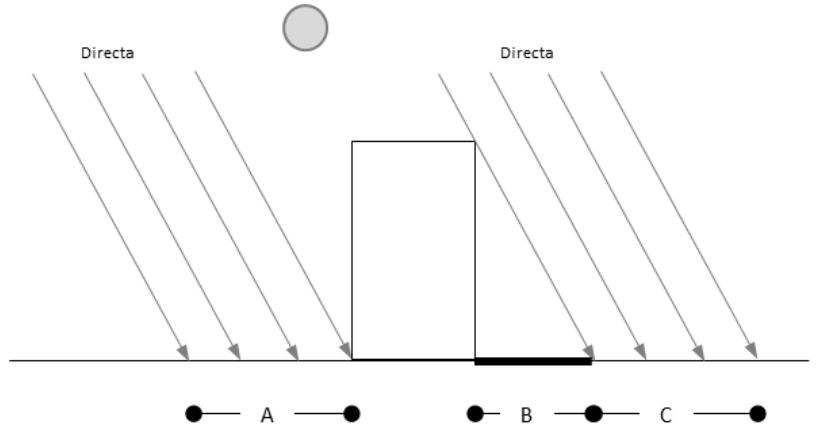

Figura 2.9 Reflexión difusa sobre el terreno (DesignBuilder UK, 2015a)

Así pues, las protecciones solares del edificio juegan un papel muy importante, por lo que los elementos de sombreamiento en puertas y ventanas transparentes presentes en el edificio deben ser incluidos en el cálculo, ya que reducen las ganancias solares y aumentan la resistencia a la conducción del calor debido al efecto de éstos. Los dispositivos de protección solar pueden constituirse por lamas, persianas o vidrios con prestaciones especiales (inteligentes, electrocrómicos, con control solar, etc.). Se debe especificar también la posición de los dispositivos (interior, exterior, incorporada entre el propio vidrio), ver Figura 2.10.
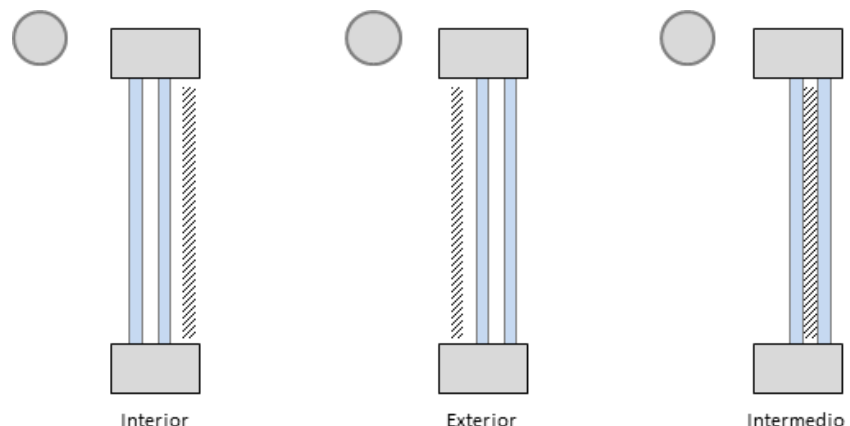

Figura 2.10 Posición de los dispositivos de protección solar con respecto al hueco (DesignBuilder UK, 2015a)

\subsubsection{Sistemas de calefacción, ventilación y aire acondicionado (HVAC) y agua caliente sanitaria (ACS)}

Los sistemas técnicos que se incorporan al edificio para satisfacer la demanda energética pueden ser los siguientes: sistema de ACS, sistema de refrigeración, sistema de calefacción, sistema de iluminación, sistema de ventilación y sistema de control de la humedad. Las propiedades de cada uno de estos sistemas deberán ser definidas para poder ser simuladas. 
Ahora bien, como se ha comentado anteriormente, los sistemas pueden ser necesarios o no. En la situación ideal de que la demanda energética de calefacción y/o refrigeración en un edificio fuera nula, no sería necesario incorporar o poner en funcionamiento los equipos, lo que no generaría ningún consumo.

Algunos programas de cálculo permiten considerar la ventilación natural del edificio, a través de sus condiciones de operación (periodo anual y horario de apertura de ventanas, así como caudal estimado de entrada de aire) y temperatura de consigna, lo que puede resultar interesante al poder contribuir esta a reducir la demanda energética de refrigeración.

\subsubsection{HERRAMIENTAS INFORMÁTICAS DE SIMULACIÓN ENERGÉTICA}

La demanda energética es muy variable con el tiempo, y depende de las condiciones ambientales o zona climática, del tipo de edificio y sus características térmicas, y del uso y control que se establezca en el mismo (ATECYR, 2008). Además, se debe tener en cuenta el concepto de inercia térmica, el cual representa la velocidad con la que cualquier variación de las condiciones ambientales produce un efecto sobre las condiciones térmicas interiores del edificio y, por tanto, sobre su demanda. Esta inercia nunca es despreciable, lo que conlleva el uso de procedimientos no estacionarios para acercarnos a establecer con rigor la demanda energética del edificio, especialmente en el caso de la refrigeración, cuando las condiciones ambientales oscilan sobre la temperatura de consigna.

Los equipos varían sus prestaciones (rendimiento, potencia útil, COP (coefficient of performance), etc.) con las condiciones ambientales y con la proporción de carga que compensan en un cierto instante sobre sus prestaciones nominales. Por lo tanto, un procedimiento estacionario basado en rendimientos estacionales solo produce una aproximación al valor del consumo real en términos totales, y a las condiciones pico y cargas máximas de calefacción y refrigeración (Beattie y Ward, 1999), pero no permite conocer qué ocurre en los diferentes momentos del tiempo.

Por estos motivos, una simulación energética que aspire a proporcionar información precisa debe basarse en procedimientos dinámicos, los cuales sí son capaces de estimar con precisión la transferencia de energía en un edificio y explicar su funcionamiento en los diversos instantes temporales a lo largo de todo un año.

Existen diversos programas y herramientas de cálculo para la simulación energética de edificios. Algunas de ellas, generalmente las desarrolladas para la verificación de las normativas a nivel estatal de forma simplificada, están basadas en procedimientos estacionarios, como por ejemplo, en España, el CERMA (ATECYR y Universidad Politécnica de Valencia, 2011), CE3X (CENER y EFINOVATIC, 2012) o CE3 (CENER y EFINOVATIC, 2012).

A continuación, se revisan las herramientas informáticas de simulación energética dinámica más extendidas a nivel mundial, que se describen de forma general en la Tabla 2.6. 
Tabla 2.6 Características generales de los programas de simulación dinámica

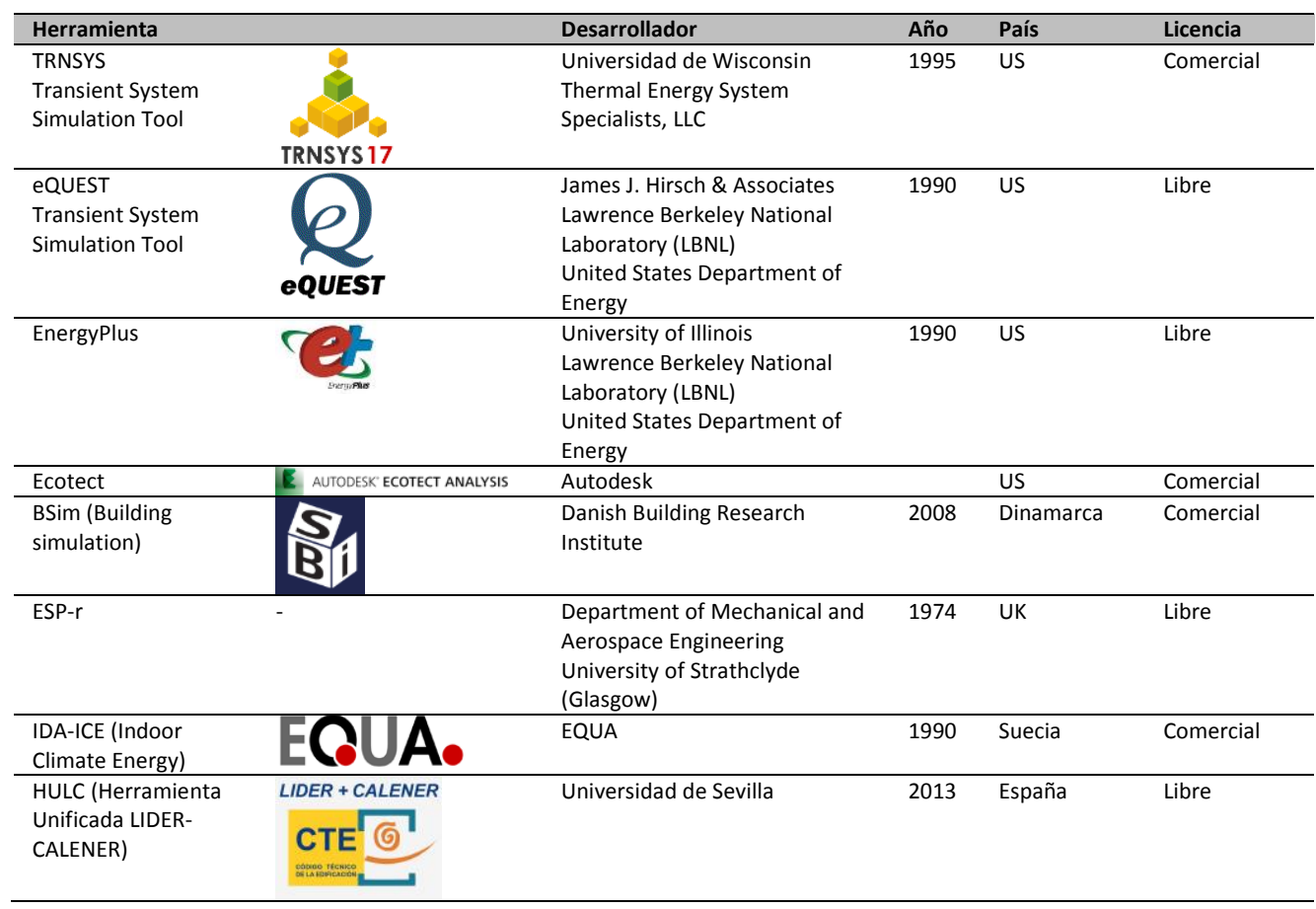

En Estados Unidos, durante la década de 1970 surgió DOE-2 (U.S. Department of Energy, 1970) como iniciativa de la administración americana. En la misma época, se desarrolla también en Estados Unidos la herramienta BLAST (Building Loads Analysis and Systems Thermodynamics) (U.S. Department of Defense, 1970). Años más tarde, las mejores características de cada uno de ellos se combinan para dar lugar a un nuevo programa llamado EnergyPlus (U.S. Department of Energy, 2013), el cual ofrece un potente motor de cálculo de simulación (Crawley et al., 2001). Sin embargo, el mayor hándicap que este presenta es que no ofrece una interfaz gráfica que permita visualizar el modelo del edificio generado, lo que dificulta también el proceso de introducción de datos.

Otros programas como el TRNSYS (Transient Simulation of Systems), desarrollado inicialmente por la Universidad de Wisconsin-Madison (Thermal Energy System Specialists, 1995), tienen un ámbito de existencia generalmente universitario, aunque recientemente se han creado aplicaciones para generar los modelos geométricos en 3D a simular con mayor facilidad que le otorgan un carácter más comercial.

En Europa, por el contrario, no existe en estos momentos una organización que centralice y aúne el esfuerzo para el desarrollo de este tipo de programas, como ocurre en Estados Unidos. Por ello, son los propios estados miembros los que desarrollan, por iniciativa propia, herramientas de simulación (ATECYR, 2008). En Dinamarca, existe BSim (Danish Building Research Institute, 2008), desarrollado por el Instituto Danés para la investigación en edificios, en Inglaterra, ESP-r (University of Glasgow, 1974), de la Universidad de Strathclyde de Glasgow, de código abierto, y en Suecia, el IDA-ICE (EQUA, 1990), un programa comercial con un motor de simulación común y módulos con diversas aplicaciones. Existen también empresas que producen programas comerciales para la introducción de la geometría del modelo de una forma más sencilla e intuitiva, como por ejemplo IISiBat (CSTB, 
2016), en Francia, que utiliza como motor de cálculo el TRNSYS, o DesignBuilder (DesignBuilder UK, 2015b) en Inglaterra, que ayuda a generar un fichero (en formato .idf) que es interpretado por EnergyPlus. En España existe el programa CALENER VyP, recientemente integrado en Herramienta Unificada LIDER-CALENER (Universidad de Sevilla, 2013), la cual emplea el motor de cálculo DOE-2 y ha sido especialmente desarrollada para justificar el cumplimiento de la normativa de ahorro de energía del CTE (DB HEO y HE1) y la certificación energética de edificios.

La Tabla 2.6 muestra las características generales de ocho de los programas más extendidos. En la Tabla 2.7 se analizan y comparan, detalladamente, las capacidades de cada uno de ellos.

Tabla 2.7 Comparación de las capacidades de los programas de simulación dinámica (ATECYR, 2008)

\begin{tabular}{|c|c|c|c|c|c|c|c|c|}
\hline Capacidades relativas a... & 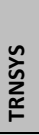 & 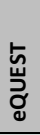 & 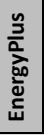 & 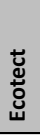 & 点 & 产 & $\begin{array}{l}\text { U⿱宀 } \\
\text { 它 }\end{array}$ & $\stackrel{\cup}{?}$ \\
\hline \multicolumn{9}{|l|}{ Geometría } \\
\hline Importación de la geometría desde programas CAD & $\bullet$ & & & $\bullet$ & $\bullet$ & & $\bullet$ & $\bullet$ \\
\hline Número de zonas/superficies/equipos/sistemas ilimitados & $\bullet$ & $\bullet$ & $\bullet$ & $\bullet$ & $\bullet$ & $\cdot$ & $\bullet$ & \\
\hline \multicolumn{9}{|l|}{ Cargas térmicas } \\
\hline Balance de energía & $\bullet$ & $\bullet$ & $\bullet$ & $\bullet$ & $\bullet$ & $\bullet$ & $\bullet$ & $\bullet$ \\
\hline Tiene en cuenta la absorción de vapor por los materiales & $\bullet$ & & $\bullet$ & & & $\bullet$ & & $\bullet$ \\
\hline Tiene en cuenta la masa térmica & $\bullet$ & $\bullet$ & $\bullet$ & $\bullet$ & $\bullet$ & $\bullet$ & $\bullet$ & $\bullet$ \\
\hline Confort humano & $\bullet$ & & $\bullet$ & $\bullet$ & $\bullet$ & $\bullet$ & $\bullet$ & \\
\hline Cálculos automáticos para dimensionar los equipos (día de diseño) & $\bullet$ & $\bullet$ & $\bullet$ & $\bullet$ & $\bullet$ & & $\bullet$ & \\
\hline \multicolumn{9}{|l|}{ Análisis solar } \\
\hline Radiación solar directa y reflexiones a través de ventanas & & $\bullet$ & $\bullet$ & $\bullet$ & $\bullet$ & & $\bullet$ & $\bullet$ \\
\hline Radiación solar difusa (diferenciación si proviene del cielo o reflejada del suelo) & & $\bullet$ & $\bullet$ & & & & $\bullet$ & \\
\hline Radiación solar reflejada del entorno (edificios próximos u otros elementos) & $\bullet$ & $\bullet$ & $\bullet$ & & & & $\bullet$ & \\
\hline Transmitancia variable de los elementos que sombrean & & & $\bullet$ & $\bullet$ & & & & \\
\hline Asistente para optimizar sombras & & & & $\bullet$ & & & & \\
\hline Programación del horario de los elementos de sombra por el usuario & $\bullet$ & $\bullet$ & $\bullet$ & $\bullet$ & $\bullet$ & & $\bullet$ & \\
\hline \multicolumn{9}{|l|}{ Opciones de acristalamientos } \\
\hline Posibilita la inclusión de persianas en los acristalamientos & $\bullet$ & $\bullet$ & $\bullet$ & $\bullet$ & $\bullet$ & $\bullet$ & $\bullet$ & $\bullet$ \\
\hline Posibilita la inclusión de persianas dentro de los acristalamientos múltiples & $\bullet$ & $\bullet$ & $\bullet$ & $\bullet$ & & $\bullet$ & $\bullet$ & \\
\hline Posibilita la inclusión de vidrios electrocromáticos/termocromáticos & & $\bullet$ & $\bullet$ & $\bullet$ & & $\bullet$ & $\bullet$ & \\
\hline Posibilita la inclusión de vidrios con gases especiales & & & $\bullet$ & $\bullet$ & & $\bullet$ & & \\
\hline Incluye una base de datos de vidrios & $\bullet$ & $\bullet$ & $\bullet$ & $\bullet$ & & & $\bullet$ & $\bullet$ \\
\hline \multicolumn{9}{|l|}{ Cálculos de la envolvente térmica } \\
\hline BLAST & & & $\bullet$ & & & & & \\
\hline DOE-2 & & $\bullet$ & $\bullet$ & & & & & $\bullet$ \\
\hline ASHRAE & & & $\bullet$ & & & & & \\
\hline Definido por el usuario & $\bullet$ & & $\bullet$ & & & $\bullet$ & $\bullet$ & \\
\hline Otros & & & & & $\bullet$ & $\bullet$ & $\bullet$ & \\
\hline \multicolumn{9}{|l|}{ Control de la luz natural } \\
\hline Iluminación interior por ventanas y lucernarios & & $\bullet$ & $\bullet$ & $\bullet$ & $\bullet$ & $\bullet$ & $\bullet$ & \\
\hline Reflexión de la luz natural en el interior & & $\bullet$ & $\bullet$ & & & $\bullet$ & & \\
\hline \multicolumn{9}{|l|}{ Conducción a través de superficies } \\
\hline $1 \mathrm{D}$ & $\bullet$ & $\bullet$ & $\bullet$ & $\bullet$ & $\bullet$ & $\bullet$ & $\bullet$ & $\bullet$ \\
\hline $2 \mathrm{D}$ y/o 3D & & & $\bullet$ & & & $\bullet$ & & \\
\hline \multicolumn{9}{|l|}{ Conducción al terreno } \\
\hline $1 \mathrm{D}$ & $\bullet$ & $\bullet$ & $\bullet$ & $\bullet$ & $\bullet$ & $\bullet$ & $\bullet$ & $\bullet$ \\
\hline $2 \mathrm{D}$ y/o 3D & & & $\bullet$ & & & & & \\
\hline \multicolumn{9}{|l|}{ Ventilación e infiltración } \\
\hline Tiene en cuenta las infiltraciones por zonas & $\bullet$ & $\bullet$ & $\bullet$ & $\bullet$ & $\bullet$ & $\bullet$ & $\bullet$ & $\bullet$ \\
\hline Tiene en cuenta la ventilación natural & & & $\bullet$ & & $\bullet$ & & $\bullet$ & \\
\hline Tiene en cuenta la ventilación híbrida (natural y mecánica) & & & & & $\bullet$ & & $\bullet$ & \\
\hline Apertura de ventanas controlable para ventilación & & & $\bullet$ & & & $\bullet$ & & \\
\hline Ventilación nocturna para refrigeración & $\bullet$ & $\bullet$ & $\bullet$ & & & $\bullet$ & $\bullet$ & \\
\hline
\end{tabular}


Tabla 2.7 Comparación de las capacidades de los programas de simulación dinámica (continuación)

\begin{tabular}{|c|c|c|c|c|c|c|c|c|}
\hline Capacidades relativas a... & $\begin{array}{l}\underset{n}{\pi} \\
\underset{\sim}{\sim} \\
\vdash\end{array}$ & 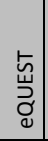 & 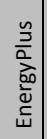 & 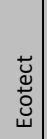 & $\underset{\bar{\Sigma}}{\varepsilon}$ & c̀̀ & $\begin{array}{l}u \\
\frac{u}{\dot{u}} \\
\varrho\end{array}$ & 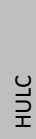 \\
\hline \multicolumn{9}{|l|}{ Sistemas de energías renovable o bioclimáticos } \\
\hline Muros trombe & $\bullet$ & $\bullet$ & $\bullet$ & $\bullet$ & $\bullet$ & $\bullet$ & $\bullet$ & $\bullet$ \\
\hline Captadores solares & $\bullet$ & & $\bullet$ & $\bullet$ & & $\bullet$ & & $\bullet$ \\
\hline Sistemas solares definidos por el usuario & $\bullet$ & & & & & & & \\
\hline Paneles fotovoltaicos & & $\bullet$ & $\bullet$ & $\bullet$ & $\bullet$ & $\bullet$ & & \\
\hline Energía eólica & $\bullet$ & & & & & $\bullet$ & & \\
\hline \multicolumn{9}{|l|}{ Sistemas HVAC } \\
\hline Dimensionado automático de equipos & & $\bullet$ & $\bullet$ & & $\bullet$ & & $\bullet$ & \\
\hline Unidades terminales de aire forzado (fancoil, ventilador, calentador, etc.) & & - & - & & $\bullet$ & $\bullet$ & $\bullet$ & - \\
\hline Equipos unitarios (expansión directa, calderas, bomba de calor aire-aire/aire-agua) & $\bullet$ & $\bullet$ & $\bullet$ & & • & & & $\bullet$ \\
\hline Control de humidificación/deshumidificación & $\bullet$ & $\bullet$ & $\bullet$ & & $\bullet$ & $\bullet$ & $\bullet$ & \\
\hline Intercambiadores de calor & $\bullet$ & $\bullet$ & & & & $\bullet$ & $\bullet$ & \\
\hline Equipos de producción de frío & $\bullet$ & $\bullet$ & $\bullet$ & $\bullet$ & $\bullet$ & $\bullet$ & $\bullet$ & $\bullet$ \\
\hline Equipos de condensación/evaporación & $\bullet$ & $\bullet$ & $\bullet$ & & & $\bullet$ & $\bullet$ & $\bullet$ \\
\hline Equipos de producción de calor & $\bullet$ & $\bullet$ & $\bullet$ & & & $\bullet$ & $\bullet$ & $\bullet$ \\
\hline Recuperadores de calor aire-aire & $\bullet$ & $\bullet$ & $\bullet$ & & $\bullet$ & $\bullet$ & $\bullet$ & \\
\hline Agua caliente sanitaria (ACS) & $\bullet$ & $\bullet$ & $\bullet$ & & & $\bullet$ & $\bullet$ & $\bullet$ \\
\hline Incluye termostatos y estrategias de control & $\bullet$ & $\bullet$ & $\bullet$ & & $\bullet$ & $\bullet$ & $\bullet$ & \\
\hline \multicolumn{9}{|l|}{ Emisiones medioambientales } \\
\hline Gases efecto invernadero $\left(\mathrm{CO}_{2}, \mathrm{CO}, \mathrm{CH}_{4}, \mathrm{NO}_{\mathrm{x}}\right)$ & & $\bullet$ & $\bullet$ & & & $\bullet$ & & $\bullet$ \\
\hline Contaminantes $\left(\mathrm{Pb}, \mathrm{PM}, \mathrm{SO}_{2}\right)$ & & & $\bullet$ & & & & & \\
\hline Precusores de ozono $\left(\mathrm{NH}_{3}, \mathrm{CH}_{4}, \mathrm{NMVOC}\right)$ & & & $\bullet$ & & & & & \\
\hline \multirow{2}{*}{\multicolumn{9}{|c|}{$\begin{array}{l}\text { Contaminantes peligrosos }(\mathrm{Pb}, \mathrm{Hg}) \\
\text { Datos meteorológicos }\end{array}$}} \\
\hline & & & & & & & & \\
\hline Los datos están integrados en el programa & & $\bullet$ & $\bullet$ & $\bullet$ & $\bullet$ & $\bullet$ & $\bullet$ & $\bullet$ \\
\hline \multicolumn{9}{|l|}{ Análisis económico } \\
\hline Coste de la energía y tarifas & - & - & - & & - & - & $\bullet$ & \\
\hline Coste de ciclo de vida & $\bullet$ & $\bullet$ & $\bullet$ & & & & & \\
\hline \multicolumn{9}{|l|}{ Resultados e informes } \\
\hline Cargas térmicas: horaria, semanal, mensual, anual & $\bullet$ & $\bullet$ & $\bullet$ & & $\bullet$ & $\bullet$ & $\bullet$ & \\
\hline Uso final de la energía & $\bullet$ & $\bullet$ & $\bullet$ & $\bullet$ & $\bullet$ & $\bullet$ & $\bullet$ & $\bullet$ \\
\hline Demanda pico (carga térmica) & $\bullet$ & $\bullet$ & $\bullet$ & $\bullet$ & $\bullet$ & $\bullet$ & $\bullet$ & $\bullet$ \\
\hline Demanda pico por horas/días/semanas & $\bullet$ & $\bullet$ & $\bullet$ & & & & & \\
\hline Consumo por tipo de energía & $\bullet$ & $\bullet$ & $\bullet$ & $\bullet$ & & & $\bullet$ & \\
\hline \multicolumn{9}{|l|}{ Interfaz gráfica intuitiva } \\
\hline Permite la visualización del modelo durante la introducción de datos & & $\bullet$ & & $\bullet$ & $\bullet$ & $\bullet$ & $\bullet$ & $\bullet$ \\
\hline
\end{tabular}

Como se desprende de la Tabla 2.7, la herramienta TRNSYS es bastante polivalente, pues permite la definición de sistemas de acondicionamiento complejos, energías renovables e incluso modelar sistemas constructivos no convencionales (como cerramientos bioclimáticos), así como es capaz de proporcionar resultados de una forma muy detallada (horaria, por uso final de la energía, por tipo de energía, etc.). Sin embargo, la introducción de datos es tediosa y la interfaz del programa no resulta demasiado intuitiva. El análisis solar tampoco es un punto fuerte de la herramienta.

eQUEST ofrece un proceso intuitivo y rápido para la introducción de datos y es capaz de generar informes detallados de resultados. También permite la introducción de una gran variedad de sistemas y equipos de acondicionamiento, pero no proporciona datos sobre emisiones medioambientales. Tampoco realiza un análisis solar exhaustivo ni proporciona información sobre el confort térmico de los ocupantes. 
El programa EnergyPlus puede decirse que es el más competo de todos, pues incorpora prácticamente la totalidad de las capacidades analizadas. El abanico de posibilidades que ofrece es tan amplio, que puede modelarse casi cualquier tipo de instalación o sistema constructivo de un edificio. Su gran inconveniente, como se apunta anteriormente, es que no posee una interfaz gráfica intuitiva, por lo que su manejo es tedioso. No obstante, se han desarrollado algunas interfaces que facilitan la modelización de la geometría y la introducción de datos del edificio para posteriormente simular a través del motor de cálculo de EnergyPlus. Es el caso de DesignBuilder, como programa comercial, y Open Studio (2016), como programa libre.

Ecotect se presenta como una herramienta muy adecuada para el análisis del soleamiento, pues fue concebida específicamente para ello, pero se muestra más limitada a la hora de realizar cálculos térmicos que incluyan, por ejemplo, los sistemas de acondicionamiento activo y las energías renovables. La herramienta no es capaz de proporcionar datos sobre emisiones medioambientales, o resultados de cargas térmicas detallados, es decir, de forma horaria.

BSim, Esp-r e IDA-ICE tienen capacidades bastante similares. Las tres herramientas permiten la introducción de la geometría a través de programas CAD y tienen una interfaz visual que facilita la entrada de datos. Tienen en cuenta un alto grado de detalle de información para el cálculo de las cargas térmicas y proporcionan datos sobre confort térmico. El análisis solar es algo limitado, concretamente Esp-r no lo considera. Las tres herramientas ofrecen la posibilidad de incluir la ventilación en la dinámica del edificio, aunque solo Esp-r permite controlar la programación de dicha ventilación por el usuario. Las tres poseen un gran abanico de posibilidades a la hora de introducir sistemas y, de nuevo, Esp-r es la que ofrece mayores posibilidades a la hora de introducir energías renovables. En cuanto a los datos de emisiones medioambientales, Esp-r permite la obtención de información sobre gases de efecto invernadero. Cualquiera de las tres herramientas proporciona información detallada de resultados, alcanzando el nivel horario.

La HULC, a pesar de ser una herramienta de simulación dinámica, los cálculos que ofrece son bastante limitados. Incorpora prácticamente todos los aspectos principales analizados en la Tabla 2.7 pero sin gran nivel de detalle, y su rigidez no permite introducir soluciones constructivas o sistemas de acondicionamiento, más allá de los meramente incluidos en la base de datos del programa. Los resultados proporcionados por la herramienta dan muestra de las cargas totales pico, pero los resultados no se muestran de forma horaria. Por otro lado, el desarrollo de la herramienta específicamente para el contexto español, hace que no pueda ser utilizada en otras regiones. Por ejemplo, los datos climáticos que incorpora son los propios de las zonas climáticas del territorio español y no permite definir nuevos datos metereológicos por el usuario.

Tras analizar dichas herramientas, se identifica como requerimiento destacado a incluir por una herramienta de simulación, el poseer una interfaz intuitiva que facilite tanto la modelización de la geometría del edificio como la introducción de la información sobre sistemas constructivos e instalaciones. También es de notable importancia la posibilidad de incorporar datos climáticos de cualquier región y de proporcionar los resultados de forma detallada, que ofrezcan al usuario la posibilidad de llevar a cabo un análisis energético exhaustivo del edificio estudiado. La selección de un programa para la simulación energética deberá dar respuesta a las necesidades de cada caso y ser capaz de proporcionar los resultados que se pretendan obtener con la simulación energética.

\subsection{CONCLUSIÓN}

En este capítulo se realiza una revisión del estado del arte de las principales temáticas que se abordan en la tesis: el marco legislativo que rodea a la eficiencia energética de los edificios, las 
herramientas de evaluación de la sostenibilidad urbana, las metodologías de evaluación energética del parque edificatorio y, por último, los aspectos que deben ser considerados durante la evaluación energética de edificios y las herramientas de cálculo disponibles.

En relación al marco legislativo relativo a la eficiencia energética de edificios, se han revisado las directivas a nivel europeo y la legislación que las concreta a nivel nacional dentro del territorio español. En este sentido, el crecimiento acelerado del sector de la construcción en los últimos años y la escasa celeridad en la transposición de las directivas, han provocado que gran parte del parque edificatorio español no esté sujeto a los últimos estándares energéticos, lo que deja, por otro lado, un parque con un amplio potencial de mejora para alcanzar los objetivos establecidos en los últimos acuerdos internacionales sobre cambio climático.

En relación a los indicadores de evaluación de la sostenibilidad urbana, se han revisado las principales herramientas de referencia existentes, tanto a nivel internacional como nacional, y que proporcionan un conjunto de indicadores para evaluar las diferentes dimensiones de la sostenibilidad. Como principal conclusión de esta revisión, se extrae que una herramienta debe ser adaptable a las características del entorno en el cual se aplica, amparando tanto los aspectos físicos, económicos, como sociales. Así, una herramienta demasiado globalizada no proporcionará un diagnóstico adecuado del área urbana analizada, si no es capaz de tener en cuenta las particularidades de su entorno. Sin embargo, puesto que el objetivo de la tesis está relacionado con el aspecto energético pasivo del parque edificatorio, es necesario profundizar más en el análisis de los indicadores que permiten cuantificar este aspecto.

En relación a las metodologías de evaluación energética del parque edificatorio, se extrae una conclusión muy similar a la anterior, lo que la reafirma. Una metodología adecuada de evaluación energética debe ser planteada de forma general y ser capaz de adaptarse a las especificidades de la región donde vaya a ser implementada. Las metodologías revisadas de la literatura están desarrolladas específicamente para una región determinada, por lo que no pueden replicarse con facilidad en otras áreas urbanas. Por tanto, el carácter genérico es un aspecto importante a tener en cuenta cuando se plantea una metodología de evaluación energética. Por ello, resulta necesario llevar a cabo un estudio de los aspectos considerados en cada una de las metodologías, de una forma pormenorizada, para contribuir a la selección de las variables para la realización de este trabajo.

Los métodos de evaluación energética pueden tener en cuenta diversas variables para proporcionar información sobre el comportamiento de un parque edificado. El consumo energético, la demanda energética, las cargas térmicas, las emisiones de $\mathrm{CO}_{2}$, los costes, los resultados de implementar medidas de eficiencia energética o el confort térmico, entre otros. La elección de unos aspectos $u$ otros dependerá del objetivo que se pretenda alcanzar con la evaluación. El sistema de cálculo por el que se opta también es diverso; en muchos casos se toman como referencia programas o legislación nacionales, mientras que en otros, se opta por programas reconocidos por la comunidad internacional. También cabe destacar que integrar el uso de SIG puede ser muy útil, especialmente en estos casos en los que la evaluación tiene un enfoque urbano. Por otro lado, la mayoría de métodos revisados se basan en un enfoque bottom-up, y el motivo reside en que, aunque este conlleva un mayor tiempo y esfuerzo de definición, permite modelar con precisión las características del parque edificado, determinar el desglose de usos finales de la energía e incorporar el comportamiento de los ocupantes de los edificios y de efectos macroeconómicos y socioeconómicos. Tras analizar una muestra representativa de edificios, las conclusiones de dicha muestra pueden ser extrapoladas a la totalidad del parque edificatorio, otorgando un enfoque urbano a la metodología.

Por último, en relación a la simulación energética de edificios, se han analizado las dos posibles vertientes, simulación en régimen estacionario o simulación dinámica, concluyendo que esta última 
permite obtener resultados más precisos y con un mayor nivel de detalle. También se describen los parámetros de cálculo que deben ser tenidos en cuenta a la hora de llevar a cabo una simulación dinámica de un edificio y se analizan las herramientas existentes en el mercado, aportando una comparativa de las capacidades que ofrece cada una de ellas, lo que permite seleccionar la herramienta adecuada según el objetivo final que se persiga con la evaluación energética.

En resumen, las conclusiones del capítulo son las que se relacionan a continuación. Estas servirán como apoyo para establecer los requisitos de la metodología de evaluación energética a proponer en esta tesis.

- Las herramientas de evaluación de la sostenibilidad urbana deben ser adaptables al contexto físico, económico, social, etc. donde se apliquen.

- Para realizar la evaluación energética de un parque edificatorio, el enfoque adecuado es el bottom-up, el cual parte del análisis pormenorizado de una selección de edificios representativos para extrapolar, posteriormente, los resultados a escala urbana.

- Una metodología o modelo de evaluación energética debe contener variables que permitan cuantificar determinados aspectos del comportamiento energético del parque edificado.

- El método de cálculo más apropiado para llevar a cabo un análisis energético es la simulación dinámica.

- Una metodología o modelo de evaluación energética debe tener un sistema de agregación para extrapolar los resultados de la escala edificio a la escala de ciudad, o viceversa.

- El entorno SIG resulta una herramienta útil para tratar información urbana.

\subsection{RefERENCIAS}

AEN/CTN 81, 2006. UNE-EN ISO 7730:2006. Ergonomía del ambiente térmico. Determinación analítica e interpretación del bienestar térmico mediante el cálculo de los índices PMV y PPD y los criterios de bienestar térmico local. España.

Agencia de Ecología Urbana de Barcelona, 2007. Plan Especial de Indicadores de Sostenibilidad Ambiental de la Actividad Urbanística de Sevilla. Sevilla.

Aksoezen, M., Daniel, M., Hassler, U., Kohler, N., 2015. Building age as an indicator for energy consumption. Energy Build. 87, 74-86. doi:10.1016/j.enbuild.2014.10.074

Ascione, F., De Masi, R.F., de Rossi, F., Fistola, R., Sasso, M., Vanoli, G.P., 2013. Analysis and diagnosis of the energy performance of buildings and districts: Methodology, validation and development of Urban Energy Maps. Cities 35, 270-283. doi:10.1016/j.cities.2013.04.012

ATECYR, 2008. Guía técnica. Procedimientos y aspectos de la simulación de instalaciones térmicas en edificios. Instituto para la Diversificación y Ahorro de la Energía (IDAE), Madrid.

ATECYR, Universidad Politécnica de Valencia, 2011. CERMA Programa informático simplificado según el método abreviado para la calificación de eficiencia energética de edificios residenciales.

Ayuntamiento de Bilbao, 2008. Indicadores de sostenibilidad de Bilbao 2008. 
Balaras, C.A., Dascalaki, E.G., Droutsa, K.G., Kontoyiannidis, S., 2016. Empirical assessment of calculated and actual heating energy use in Hellenic residential buildings. Appl. Energy 164, 115-132. doi:10.1016/j.apenergy.2015.11.027

Balaras, C.A., Gaglia, A.G., Georgopoulou, E., Mirasgedis, S., Sarafidis, Y., Lalas, D.P., 2007. European residential buildings and empirical assessment of the Hellenic building stock, energy consumption, emissions and potential energy savings. Build. Environ. 42, 1298-1314. doi:http://dx.doi.org/10.1016/j.buildenv.2005.11.001

Beattie, K.H., Ward, I.C., 1999. The advantages of building simulation for building design engineers, en: Nakahara, N., Yoshida, H., Udagawa, M., Hensen, J. (Eds.), Sixth Internation IBPSA Conference. Organazing Committee of Building Simulation '99, Kyoto, pp. 1079-1084.

Blum, A., 2007. HQE2R-research and demonstration for assessing sustainable neighborhood development, en: Deakin, M., Mitchell, G., Nijkamp, P., Vreeker, R. (Eds.), Sustainable urban development volume 2: the environmental assessment methods. New York, pp. 412-428.

Boardman, B., 2007. Examining the carbon agenda via the $40 \%$ House scenario. Build. Res. Inf. 35, 363-378. doi:10.1080/09613210701238276

Bourdic, L., Salat, S., Nowacki, C., 2012. Assessing cities: a new system of cross-scale spatial indicators. Build. Res. Inf. 40, 592-605. doi:10.1080/09613218.2012.703488

BRE, 2005. The Government's Standard Assessment Procedure for Energy Rating of Dwellings.

BRE Global, 2016. BREEAM web page [WWW Document]. URL http://www.breeam.org/page.jsp?id=346 (accedido 5.15.15).

BRE Global, 2011. SD5065 technical guidance manual: version 1. BREEAM for Communities assessor manual: development planning application stage.

Brundtland, G.H., 1987. Report of the World Commission on Environment and Development: Our Common Future. Oslo.

Bulkeley, H., 2010. Cities and the Governing of Climate Change. Annu. Rev. Environ. Resour. 35, 229253. doi:10.1146/annurev-environ-072809-101747

Caputo, P., Costa, G., Ferrari, S., 2013. A supporting method for defining energy strategies in the building sector at urban scale. Spec. Sect. Long Run Transitions to Sustain. Econ. Struct. Eur. Union Beyond 55, 261-270. doi:http://dx.doi.org/10.1016/j.enpol.2012.12.006

Castanheira, G., Bragança, L., 2014. The evolution of the sustainability assessment tool SBToolPT: from buildings to the built environment. ScientificWorldJournal. 2014, (2356-6140), 62 (4), p. 1. doi:10.1155/2014/491791

CENER, EFINOVATIC, 2012. CE3X Programa informático para la calificación de eficiencia energética de edificios residenciales y terciarios.

Charlot-Valdieu, C., Outrequin, P., 2005. Des indicateurs de developpement Durable pour l'evaluation des Projets de renouvellement urbain: Le modele INDI - RU 2005.

Cheng, V., Steemers, K., 2011. Modelling domestic energy consumption at district scale: A tool to support national and local energy policies. Environ. Model. Softw. 26, 1186-1198. doi:10.1016/j.envsoft.2011.04.005

Chrysoulakis, N., Lopes, M., San José, R., Grimmond, C.S.B., Jones, M.B., Magliulo, V., Klostermann, J.E.M., Synnefa, A., Mitraka, Z., Castro, E. a., González, A., Vogt, R., Vesala, T., Spano, D., Pigeon, G., Freer-Smith, P., Staszewski, T., Hodges, N., Mills, G., Cartalis, C., 2013. Sustainable 
urban metabolism as a link between bio-physical sciences and urban planning: The BRIDGE project. Landsc. Urban Plan. 112, 100-117. doi:10.1016/j.landurbplan.2012.12.005

Comisión Europea, 2012. Directiva 2012/27/UE relativa a la eficiencia energética, por la que se modifican las Directivas 2009/125/CE y 2010/30/CE, y por la que se derogan las Directivas 2004/8/CE y 2006/32/CE. Comunidad Europea.

Comisión Europea, 2010. Directiva 2010/31/UE del parlamento Europeo y del Consejo de 19 de mayo de 2010 relativa a la eficiencia energética de los edificios. Comunidad Europea.

Comisión Europea, 2009. Directiva 2009/125/CE del Parlamento Europeo y del Consejo de 21 de octubre de 2009 por la que se instaura un marco para el establecimiento de requisitos de diseño ecológico aplicables a los productos relacionados con la energía. Comunidad Europea.

Comisión Europea, 2006. Directiva 2006/32/CE del parlamento y del Consejo de 5 de abril de 2006 sobre la eficiencia del uso final de la energía y los servicios energéticos y por la que sederoga la Directiva 93/76/CEE del Consejo. Comunidad Europea.

Comisión Europea, 2004. Directiva 2004/8/CE del parlamento y del Consejo de 11 de febrero de 2004 relativa al fomento de la cogeneración sobre la base de la demanda de calor útil en el mercado interior de la energía y por la que se modifica la Directiva 92/42/CEE. Comunidad Europea.

Comisión Europea, 2002. Directiva 2002/91/CE del parlamento Europeo y del Consejo de 16 de diciembre de 2002 relativa a la eficiencia energética de los edificios. Comunidad Europea.

Comisión Europea, 1993. Directiva 93/76/CEE del Consejo, de 13 de septiembre de 1993, relativa a la limitación de las emisiones de dióxido de carbono mediante la mejora de la eficacia energética (SAVE). Comunidad Europea.

Crawley, D.B., Lawrie, L.K., Winkelmann, F.C., Buhl, W.F., Huang, Y.J., Pedersen, C.O., Strand, R.K., Liesen, R.J., Fisher, D.E., Witte, M.J., Glazer, J., 2001. EnergyPlus: Creating a new-generation building energy simulation program. Energy Build. 33, 319-331. doi:10.1016/S03787788(00)00114-6

CSTB, 2016. IISiBat Centre Scientifique et Technique du Bâtiment.

CTE, 2013. Orden FOM/1635/2013, de 10 de septiembre, por la que se actualiza el Documento Básico DB-HE Ahorro de Energía del Código Técnico de la Edificación, aprobado por Real Decreto 314/2006, de 17 de marzo. España.

CTE, 2006. Real Decreto 314/2006, de 17 de marzo, por el que se aprueba el Código Técnico de la Edificación. España.

Dall'O', G., Galante, A., Torri, M., 2012. A methodology for the energy performance classification of residential building stock on an urban scale. Energy Build. 48, 211-219. doi:10.1016/j.enbuild.2012.01.034

Daly, G., González, A., 2013. Key indicators for territorial cohesion and spatial planning: The reform of EU cohesion policy and the new role of spatial indicators. Borderl. J. Spat. Plan. Irel. 77-89.

Daly, G., González, A., Gleeson, J., McCarthy, E., Adams, N., Pinch, P., Burns, M.C., Johannesson, H., Sigurbjarnarson, V., Valtenbergs, V., Līvina, A., 2013. KITCASP Key Indicators for Territorial Cohesion and Spatial Planning.

Danish Building Research Institute, 2008. BSim Building Simulation programme. 
Dascalaki, E.G., Droutsa, K.G., Balaras, C.A., Kontoyiannidis, S., 2011. Building typologies as a tool for assessing the energy performance of residential buildings - A case study for the Hellenic building stock. Energy Build. 43, 3400-3409. doi:http://dx.doi.org/10.1016/j.enbuild.2011.09.002

DesignBuilder UK, 2015a. DesignBuilder help [WWW Document]. URL http://www.designbuilder.co.uk/helpv3.4/ (accedido 12.12.15).

DesignBuilder UK, 2015b. DesignBuilder software.

Diefenbach, N., Loga, T., Stein, B., 2014. EPISCOPE. Energy Performance Indicators for Building Stocks 23 .

Diputación de Barcelona, 2009. Memoria de sostenibilidad. Los municipios: avanzando hacia escenarios más sostenibles. Barcelona.

EarthCraft, 2014. Homepage of EarthCraft [WWW Document]. URL http://earthcraft.org/communities

EIE TABULA Intelligent Energy, 2012. EIE TABULA Web Tool [WWW Document]. URL http://www.episcope.eu/building-typology/ (accedido 3.3.15).

EQUA, 1990. IDA-ICE Indoor Climate and Energy software.

Estiri, H., 2014. Building and household X-factors and energy consumption at the residential sector. Energy Econ. 43, 178-184. doi:10.1016/j.eneco.2014.02.013

European Commission, 2008. Communication from the Commission. Energy efficiency: delivering the $20 \%$ target. Brussels.

European Project Partners, 2012. Project EIE TABULA-Intelligent Energy Europe [WWW Document]. URL http://www.episcope.eu/building-typology/ (accedido 6.18.15).

Fabbri, K., Zuppiroli, M., Ambrogio, K., 2012. Heritage buildings and energy performance: Mapping with GIS tools. Energy Build. 48, 137-145. doi:10.1016/j.enbuild.2012.01.018

Farahbakhsh, H., Ugursal, V.I., Fung, A.S., 1998. A residential end-use energy consumption model for Canada. Int. J. Energy Res. 22, 1133-1143. doi:10.1002/(SICI)1099114X(19981025)22:13<1133::AID-ER434>3.0.CO;2-E

Firth, S.K., Lomas, K.J., Wright, a. J., 2010. Targeting household energy-efficiency measures using sensitivity analysis. Build. Res. Inf. 38, 25-41. doi:10.1080/09613210903236706

Florio, P., Teissier, O., 2015. Estimation of the Energy Performance Certificate of a housing stock characterised via qualitative variables through a typology-based approach model: A fuel poverty evaluation tool. Energy Build. 89, 39-48. doi:10.1016/j.enbuild.2014.12.024

Fonseca, J.A., Schlueter, A., 2015. Integrated model for characterization of spatiotemporal building energy consumption patterns in neighborhoods and city districts. Appl. Energy 142, 247-265. doi:10.1016/j.apenergy.2014.12.068

Gaffron, P., Huismans, G., Skala, F., 2008. Ecocity book II: how to make it happen. Vienna.

Gaffron, P., Huismans, G., Skala, F., 2005. Ecocity book I: a beter place to live. Vienna.

Garrido-Soriano, N., Rosas-Casals, M., Ivancic, A., Álvarez-del Castillo, M.D., 2012. Potential energy savings and economic impact of residential buildings under national and regional efficiency scenarios. A Catalan case study. Energy Build. 49, 119-125. doi:http://dx.doi.org/10.1016/j.enbuild.2012.01.030 
Gil, J., Duarte, J.P., 2013. Tools for evaluating the sustainability of urban design: a review. Proc. ICE Urban Des. Plan. 166, 311-325. doi:10.1680/udap.11.00048

Gobierno de España, 2013. Ley 8/2013, de 26 de junio, de rehabilitación, regeneración y renovación urbanas. España.

González, A., Donnelly, A., Jones, M., Chrysoulakis, N., Lopes, M., 2013. A decision-support system for sustainable urban metabolism in Europe. Environ. Impact Assess. Rev. 38, 109-119. doi:10.1016/j.eiar.2012.06.007

Gouveia, J.P., Fortes, P., Seixas, J., 2012. Projections of energy services demand for residential buildings: Insights from a bottom-up methodology. Energy 47, 430-442. doi:10.1016/j.energy.2012.09.042

Grupo de trabajo de Indicadores de Sostenibilidad de la Red de Redes de Desarrollo Local Sostenible, 2010. Sistema municipal de indicadores de sostenibilidad.

GVA, 2009. Decreto 112/2009, de 31 de julio, del Consell, por el que regula las actuaciones en materia de certificación de eficiencia energética de edificios. Valencia.

Haapio, A., 2012. Towards sustainable urban communities. Environ. Impact Assess. Rev. 32, 165-169. doi:10.1016/j.eiar.2011.08.002

Haapio, A., Viitaniemi, P., 2008. A critical review of building environmental assessment tools. Environ. Impact Assess. Rev. 28, 469-482. doi:10.1016/j.eiar.2008.01.002

Hens, H., Verbeeck, G., Verdonck, B., 2001. Impact of energy efficiency measures on the CO2 emissions in the residential sector, a large scale analysis. Energy Build. 33, 275-281.

Huang, Y.J., Berkeley, L., 2000. A Bottom-Up Engineering Estimate of the Aggregate Heating and Cooling Loads of the Entire US Building Stock Prototypical Residential Buildings, en: Proceedings of the 2000 ACEEE summer study on energy efficiency in buildings. Pacific Grove, pp. 135-148.

Huedo, P., López-Mesa, B., 2013. Revisión de herramientas de asistencia en la selección de soluciones constructivas sostenibles de edificación. Inf. la Construcción 65, 77-88. doi:10.3989/ic.11.048

IBEC, 2007. CASBEE UD Comprehensive Assessment System for Built Environment Efficiency for Urban Development. Technical manual 2007 edition.

INE, 2011. Censos de Población y Viviendas 2011. Viviendas [WWW Document]. URL http://www.ine.es/ (accedido 2.22.16).

Instituto Valenciano de la Edificación, 2014. TABULA. Catálogo de tipología edificatoria residencial en España. Valencia.

Johnston, D., Lowe, R., Bell, M., 2005. An exploration of the technical feasibility of achieving CO2 emission reductions in excess of $60 \%$ within the UK housing stock by the year 2050. Energy Policy 33, 1643-1659. doi:10.1016/j.enpol.2004.02.003

Jones, P., Patterson, J., Lannon, S., 2007. Modelling the built environment at an urban scale-Energy and health impacts in relation to housing. Landsc. Urban Plan. 83, 39-49. doi:10.1016/j.landurbplan.2007.05.015

Kavgic, M., Mavrogianni, a., Mumovic, D., Summerfield, a., Stevanovic, Z., Djurovic-Petrovic, M., 2010. A review of bottom-up building stock models for energy consumption in the residential sector. Build. Environ. 45, 1683-1697. doi:10.1016/j.buildenv.2010.01.021 
Košir, M., Capeluto, I.G., Krainer, A., Kristl, Ž., 2014. Solar potential in existing urban layouts-Critical overview of the existing building stock in Slovenian context. Energy Policy 69, 443-456. doi:10.1016/j.enpol.2014.01.045

Loga, T., Diefenbach, N., Stein, B., Balaras, C.A., Villatoro, O., Wittchen, K.B., 2012. Typology Approach for Building Stock Energy Assessment . Main Results of the TABULA project. Darmstadt.

Luederitz, C., Lang, D.J., Von Wehrden, H., 2013. A systematic review of guiding principles for sustainable urban neighborhood development. Landsc. Urban Plan. 118, 40-52. doi:10.1016/j.landurbplan.2013.06.002

Macías, M., García Navarro, J., 2010. Metodología y herramienta VERDE para la evaluación de la sostenibilidad en edificios. Inf. la Construcción 62, 87-100. doi:10.3989/ic.08.056

Martins, T.A.L., Adolphe, L., Bastos, L.E.G., 2014. From solar constraints to urban design opportunities: Optimization of built form typologies in a Brazilian tropical city. Energy Build. 76, 43-56. doi:10.1016/j.enbuild.2014.02.056

Mata, É., Kalagasidis, A.S., Johnsson, F., 2013. A modelling strategy for energy, carbon, and cost assessments of building stocks. Energy Build. 56, 100-108. doi:10.1016/j.enbuild.2012.09.037

Mata, É., Sasic Kalagasidis, A., Johnsson, F., 2010. Modeling future energy use scenarios for building stocks - assessing methodology, en: Thermal Performance of the Exterior Envelopes of Whole Buildings XI International Conference. Florida, USA.

Mauro, G.M., Hamdy, M., Vanoli, G.P., Bianco, N., Hensen, J.L.M., 2015. A new methodology for investigating the cost-optimality of energy retrofitting a building category. Energy Build. 107, 456-478. doi:10.1016/j.enbuild.2015.08.044

Mercader-Moyano, P., Garrido-Piñero, J., Ramírez-de-Arellano, A., 2015. Environmental Impact Indicator System in Residential Neighbourhood Renovation, en: Mercader-Moyano, P. (Ed.), The Sustainable Renovation of Buildings and Neighbourhoods. doi:10.2174/97816810806421150101

McKenna, R., Merkel, E., Fehrenbach, D., Mehne, S., Fichtner, W., 2013. Energy efficiency in the German residential sector: A bottom-up building-stock-model-based analysis in the context of energy-political targets. Build. Environ. 62, 77-88. doi:10.1016/j.buildenv.2013.01.002

Ministerio de la Presidencia, 2013. Real Decreto 235/2013, de 5 de abril, por el que se aprueba el procedimiento básico para la certificación de la eficiencia energética de los edificios. España.

Ministerio de la Presidencia, 2007a. Real Decreto 1027/2007, de 20 de julio, por el que se aprueba el Reglamento de Instalaciones Térmicas en los Edificios RITE. España.

Ministerio de la Presidencia, 2007b. Real Decreto 47/2007, de 19 de enero, por el que se aprueba el Procedimiento básico para la certificación de eficiencia energética de edificios de nueva construcción. España.

Ministerio de Medio Ambiente y Medio Rural y Marino, 2010. Sistema de indicadores y condicionantes para ciudades grandes y medianas.

Ministerio de Vivienda del Gobierno de España, 2010. Libro Blanco de la Sostenibilidad en el Planeamiento Urbanístico Español. Madrid.

Moffatt, S., 2001. Methods for the evaluation of the environmental performance of building stock. Editorial review by Illari Aho, Findland. 
Natarajan, S., Levermore, G.J., 2007. Predicting future UK housing stock and carbon emissions. Energy Policy 35, 5719-5727. doi:10.1016/j.enpol.2007.05.034

NBE-CT-79, 1979. Real Decreto. Norma Básica de la Edificación sobre condiciones térmicas en los edificios. España.

Nguyen, B.K., Altan, H., 2011. Comparative Review of Five Sustainable Rating Systems. Procedia Eng. 21, 376-386. doi:10.1016/j.proeng.2011.11.2029

OECD, 2014. Organisation for Economic Co-operation and Development webpage [WWW Document]. URL http://www.oecd.org (accedido 10.15.14).

Open Studio, 2016. Open Studio software.

Penna, P., Prada, A., Cappelletti, F., Gasparella, A., 2015. Multi-objectives optimization of Energy Saving Measures in existing buildings. 49th AICARR Int. Conf. - Hist. Exist. Build. Des. retrofit 95, 57-69. doi:10.1016/j.enbuild.2014.11.003

Ren, Z., Paevere, P., McNamara, C., 2012. A local-community-level, physically-based model of enduse energy consumption by Australian housing stock. Energy Policy 49, 586-596.

Rubio del Val, 2015. Potencial del nuevo marco normativo para el impulso de la rehabilitación y la regeneración urbana en los ámbitos autonómico y local. Inf. la Construcción 67(EXTRA-1, 5669. doi:http://dx.doi.org/10.3989/ic.14.072

Salat, S., 2009. Energy loads, CO2 emissions and building stocks: morphologies, Typologies, Energy Systems and Behaviour. Build. Res. Inf. 37, 598-609. doi:10.1080/09613210903162126

SCR, 2014. Homepage of sustainable community rating. [WWW Document]. URL http://www.places.vic.gov.au/?c=VPage\&cid=1192185989323\&pagename=Sustainability\%2FL ayout

Sharifi, A., Murayama, A., 2013. A critical review of seven selected neighborhood sustainability assessment tools. Environ. Impact Assess. Rev. 38, 73-87. doi:http://dx.doi.org/10.1016/j.eiar.2012.06.006

Shimoda, Y., Fujii, T., Morikawa, T., Mizuno, M., 2004. Residential end-use energy simulation at city scale. Build. Environ. 39, 959-967. doi:10.1016/j.buildenv.2004.01.020

Shorrock, L., Dunster, J., 1997. The physically-based model BREHOMES and its use in deriving scenarios for the energy use and carbon dioxide emissions of the UK housing stock. Energy Policy 25, 1027-1037. doi:10.1016/S0301-4215(97)00130-4

Snäkin, J.-P.A., 2000. An engineering model for heating energy and emission assessment The case of North Karelia, Finland. Appl. Energy 67, 353-381.

Solé-Bonet, J., 2003. Aislamiento térmico en la edificación. Tarragona.

Swan, L.G., Ugursal, V.I., 2009. Modeling of end-use energy consumption in the residential sector: A review of modeling techniques. Renew. Sustain. Energy Rev. 13, 1819-1835. doi:10.1016/j.rser.2008.09.033

Terés-Zubiaga, J., Martín, K., Erkoreka, a., Sala, J.M., 2013. Field assessment of thermal behaviour of social housing apartments in Bilbao, Northern Spain. Energy Build. 67, 118-135. doi:10.1016/j.enbuild.2013.07.061

Theodoridou, I., Karteris, M., Mallinis, G., Papadopoulos, A.M., Hegger, M., 2012. Assessment of retrofitting measures and solar systems' potential in urban areas using Geographical 
Information Systems: Application to a Mediterranean city. Renew. Sustain. Energy Rev. 16, 6239-6261. doi:http://dx.doi.org/10.1016/j.rser.2012.03.075

Theodoridou, I., Papadopoulos, A.M., Hegger, M., 2011a. A typological classification of the Greek residential building stock. Energy Build. 43, 2779-2787. doi:http://dx.doi.org/10.1016/j.enbuild.2011.06.036

Theodoridou, I., Papadopoulos, A.M., Hegger, M., 2011b. Statistical analysis of the Greek residential building stock. Energy Build. 43, 2422-2428. doi:10.1016/j.enbuild.2011.05.034

Thermal Energy System Specialists, 1995. TRNSYS Transient System Simulation Tool.

U.S. Department of Defense, 1970. BLAST software.

U.S. Department of Energy, 2013. Energy Plus software.

U.S. Department of Energy, 1970. DOE-2 software.

Uihlein, A., Eder, P., 2010. Policy options towards an energy efficient residential building stock in the EU-27. Energy Build. 42, 791-798. doi:10.1016/j.enbuild.2009.11.016

UN Sustainable Development, 1998. Indicators of sustainable development: Guidelines and methodologies.

United Nations, 1995. Agenda 21 [WWW Document]. URL http://web.archive.org/web/20090420073232/http://www.un.org/esa/sustdev/documents/a genda21/spanish/agenda21sptoc.htm (accedido 9.5.14).

Universidad de Sevilla, 2013. HULC Herramienta Unificada LIDER-CALENER.

University of Glasgow, 1974. Esp-r software.

US GBC, 2009. LEED ND Leadership in Energy and Environmental Design for neighborhood development. 



\section{SELECCIÓN DE VARIABLES PARA LA EVALUACIÓN ENERGÉTICA PASIVA}





\subsection{INTRODUCCIÓN}

De las conclusiones presentadas en el Capítulo 2, se extrae la necesidad de definir unos indicadores para evaluar la sostenibilidad urbana que permitan llevar a cabo una valoración objetiva y transparente de los diferentes aspectos que la integran. En particular, este trabajo pretende abordar, dentro de la perspectiva ambiental, el aspecto energético, por lo que en el presente capítulo se lleva a cabo una selección de variables que serán empleadas para desarrollar la metodología propuesta en esta tesis.

Como se ha apuntado anteriormente, esta tesis propone una metodología de evaluación energética pasiva del parque edificatorio residencial existente para la que se tienen en cuenta los condicionantes de los edificios y también del entorno urbano en el que se encuentran. Por tanto, aporta un enfoque holístico, no centrándose únicamente en el edificio como elemento individual y aislado.

Tomando como punto de partida el análisis descriptivo de las HESU y de las metodologías de evaluación energética presentado en el Capítulo 2, en este capítulo se plantea identificar aquellos indicadores que permitan caracterizar el comportamiento energético pasivo del parque residencial existente de edificios y las variables que influyen en el mismo. Para ello, en primer lugar se lleva a cabo un análisis exhaustivo de los indicadores de sostenibilidad que, desde una perspectiva más amplia, permitirá identificar las variables que evalúan energéticamente al parque edificado. $Y$, en segundo lugar, se realiza un análisis en profundidad de las metodologías de evaluación energética, para identificar los aspectos considerados en ellas que afectan al comportamiento energético.

Con ello, se identificarán, por un lado, unos indicadores, considerados como variables dependientes o respuesta, que aportan información cuantificable y comparable sobre el comportamiento energético del parque edificatorio; $y$, por otro, unos factores, tanto a escala de edificio como a escala urbana, llamados variables independientes o covariables, que tengan una influencia significativa sobre dicho comportamiento.

Este conjunto de variables y covariables será integrado para desarrollar la metodología que se propone en el marco de esta tesis. Así pues, las variables respuesta constituirán los resultados del modelo, mientras que las covariables, de las cuales dependen las variables respuesta, constituirán la información de entrada.

La Figura 3.1 muestra la estructura de este capítulo y la información de partida para el desarrollo de cada una de las secciones que lo componen. El punto de partida son las conclusiones extraídas en el Capítulo 2. 


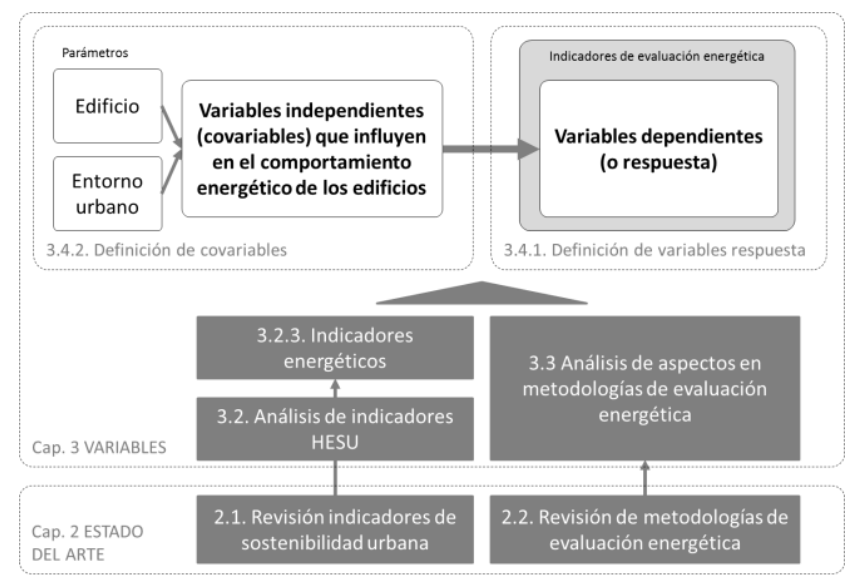

Figura 3.1 Esquema del Capítulo 3

\subsection{ANÁLISIS DE INDICADORES DE SOSTENIBILIDAD URBANA PROPUESTOS POR LAS HESU}

Este apartado pretende analizar cómo las HESU existentes en la literatura abordan el concepto de sostenibilidad urbana en sus tres dimensiones (ambiental, social y económica) y tiene como objetivo último identificar cómo es tratado el aspecto energético, como parte constituyente de la dimensión ambiental, lo que llevará a identificar unos indicadores energéticos para evaluar el comportamiento pasivo del parque edificatorio residencial existente. Para este cometido, se propone un marco común que permita la comparación entre todos los indicadores propuestos por las HESU. Así, los indicadores propuestos por cada HESU se integran y aglutinan según los diferentes aspectos que componen la sostenibilidad urbana.

La Figura 3.2 muestra el procedimiento empleado para proponer el marco común de comparación.

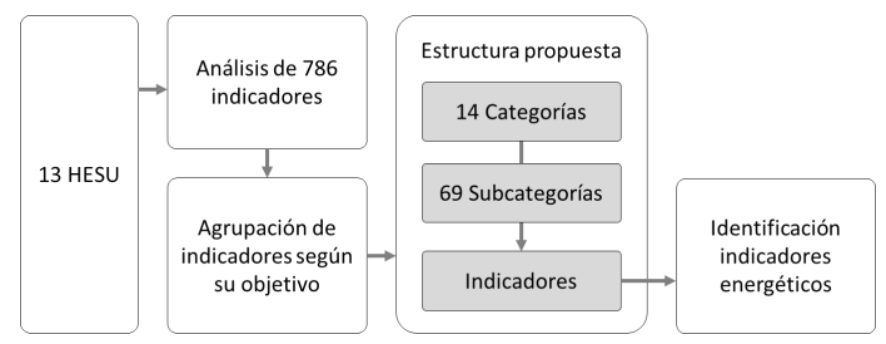

Figura 3.2 Metodología aplicada para proponer una estructura de indicadores 


\subsubsection{PROPUESTA DE ESTRUCTURA COMÚN DE CLASIFICACIÓN DE INDICADORES}

Previamente a comparar los indicadores utilizados en cada herramienta, es necesario definir una estructura común homogénea, pues cada herramienta utiliza un sistema de clasificación y organización de indicadores diferente, también con distinta nomenclatura, que dificulta su comparación.

Algunos autores realizaron anteriormente un trabajo similar. Por ejemplo, Sharifi y Murayama (2013) propusieron las siguientes categorías: "recursos y medioambiente", "transporte", "social", económico", "emplazamiento y selección de sitio", "patrones y diseño", "innovación", subdividiendo cada categoría en criterios. Luederitz et al. (2013) establecieron en su trabajo 11 categorías relacionadas con los principios de la sostenibilidad: "funcionalidad", "contexto", "estructura", "efectos externos", "integridad del sistema socio-ecológico", "subsistencia y oportunidad", "equidad intra-generacional", "equidad inter-generacional", eficiencia y mantenimiento de recursos", "civismo socio-ecológico y gobernanza democrática" y "precaución y adaptación". También Bourdic et al. (2012) propusieron un conjunto de indicadores que distribuyeron en una lista compuesta por 9 categorías específicamente desarrolladas para el contexto: "uso del suelo", "movilidad", "agua", "biodiversidad", "equidad", "economía", "residuos", "cultura y bienestar", "energía y bioclimatismo".

Sin embargo, estas clasificaciones no permiten indagar con claridad en el aspecto energético, con el fin de identificar las variables que influyen en el comportamiento energético pasivo del parque edificatorio residencial. Tampoco se especifica en ninguno de estos trabajos el objetivo específico que persigue cada una de las categorías, es decir, la finalidad que se pretende alcanzar con su implementación en un entorno urbano. Así pues, con el fin de homogeneizar y poder posteriormente agrupar el total de 786 indicadores contenidos en las HESU, cuyo listado se recoge en el Anexo I Listado de indicadores de sostenibilidad urbana ${ }^{1}$, se ha propuesto una nueva estructura en dos niveles de 14 categorías y 69 subcategorías, para las cuales se especifica el objetivo u objetivos perseguidos. Así pues, la nueva estructura lleva asociado al menos un objetivo a cada categoría, lo que permite, a posteriori, clasificar los indicadores contenidos en las HESU no sólo dentro de la temática abordada, sino también atendiendo a su objetivo.

La Tabla 3.1 presenta la estructura propuesta en la que posteriormente se agrupan los indicadores para ser comparados. Las 14 categorías definidas en esta clasificación son el resultado de un profundo análisis y abordan todos los aspectos tratados por los indicadores. Cada una de las categorías está, a su vez, dividida en subcategorías, y cada una de ellas persigue, al menos, un objetivo.

\footnotetext{
${ }^{1}$ En el Anexo I Listado de indicadores de sostenibilidad urbana se recoge la relación exhaustiva de indicadores contenidos en cada una de las 13 HESU analizadas.
} 
Tabla 3.1 Estructura en dos niveles de categorías y subcategorías

\begin{tabular}{|c|c|c|}
\hline Categoría & Subcategoría & Objetivo \\
\hline \multirow[t]{5}{*}{ Sitio y suelo } & Condiciones climáticas y del lugar & $\begin{array}{l}\text { Aprovechar las condiciones óptimas (topografía, vientos } \\
\text { predominantes, soleamiento) }\end{array}$ \\
\hline & Ocupación de suelo & Fomentar el uso eficiente del suelo \\
\hline & $\begin{array}{l}\text { Reutilización y conservación del suelo } \\
\text { y el patrimonio }\end{array}$ & Fomentar la reutilización de suelo existente y edificios abandonados \\
\hline & Compacidad & Ciudad compacta versus ciudad dispersa (Rueda, 2007) \\
\hline & & $\begin{array}{l}\text { Promover edificios plurifamiliares entre medianeras frente a viviendas } \\
\text { unifamiliares aisladas (Ghosh y Vale, 2009) }\end{array}$ \\
\hline \multirow{6}{*}{$\begin{array}{l}\text { Morfología } \\
\text { urbana }\end{array}$} & Diseño y calidad del espacio público & Asegurar el diseño adecuado de la ciudad \\
\hline & Usos mixtos & Estimular los edificios de usos mixtos (residencial, comercial, etc.) \\
\hline & Equipamiento & $\begin{array}{l}\text { Proveer al barrio de centros educativos, centros sanitarios, actividades } \\
\text { comerciales, etc. }\end{array}$ \\
\hline & $\begin{array}{l}\text { Diseño universal y barreras } \\
\text { arquitectónicas }\end{array}$ & $\begin{array}{l}\text { Asegurar que los elementos urbanos son utilizables por todos, incluso } \\
\text { por personas con diversidad funcional }\end{array}$ \\
\hline & Espacio para aparcamiento & Reducir los espacios de aparcamiento para vehículo privado \\
\hline & Seguridad, salubridad e higiene & Eliminar riesgos y asegurar la seguridad pública \\
\hline \multirow[t]{4}{*}{$\begin{array}{l}\text { Movilidad y } \\
\text { transporte }\end{array}$} & $\begin{array}{l}\text { Reducción de distancias y del uso del } \\
\text { vehículo privado }\end{array}$ & $\begin{array}{l}\text { Fomentar la ciudad compacta, reducir tiempos de desplazamiento } \\
\text { (Zhao et al., 2014) y mejorar las rutas a pie }\end{array}$ \\
\hline & $\begin{array}{l}\text { Transporte público y otras } \\
\text { alternativas sostenibles }\end{array}$ & $\begin{array}{l}\text { Fomentar el uso del transporte público y la bicicleta y mejorar las } \\
\text { conexiones }\end{array}$ \\
\hline & Eficiencia en el transporte público & $\begin{array}{l}\text { Uso eficiente de la energía y promover formas urbanas compactas } \\
\text { (Byrd y Ho, 2012) }\end{array}$ \\
\hline & Gestión del transporte & $\begin{array}{l}\text { Mejorar los sistemas logísticos y proporcionar información al } \\
\text { ciudadano sobre movilidad }\end{array}$ \\
\hline \multirow{5}{*}{$\begin{array}{l}\text { Naturaleza y } \\
\text { biodiversidad }\end{array}$} & Zonas verdes & Proveer el barrio de zonas verdes y corredores de vegetación \\
\hline & Huertos urbanos & $\begin{array}{l}\text { Integrar la agricultura ecológica para el autoconsumo y venta sin } \\
\text { intermediarios. }\end{array}$ \\
\hline & Recursos naturales & Prevenir la destrucción de los hábitats naturales de flora y fauna \\
\hline & Biodiversidad de especies & Conservar la biodiversidad \\
\hline & $\begin{array}{l}\text { Elementos arquitectónicos con } \\
\text { vegetación }\end{array}$ & Incluir la vegetación en cubiertas y fachadas de edificios \\
\hline \multirow[t]{7}{*}{$\begin{array}{l}\text { Edificación y } \\
\text { vivienda }\end{array}$} & $\begin{array}{l}\text { Cumplimiento de estándares y } \\
\text { legislación }\end{array}$ & Promocionar el uso de sellos de certificación ambiental en edificios \\
\hline & $\begin{array}{l}\text { Rehabilitación de edificios y } \\
\text { adaptación de uso }\end{array}$ & $\begin{array}{l}\text { Promover la rehabilitación energética de edificios existentes y la } \\
\text { adaptación de uso }\end{array}$ \\
\hline & Eficiencia en los recursos del edificio & Controlar el uso adecuado de los recursos en las viviendas \\
\hline & Demanda energética en el edificio & $\begin{array}{l}\text { Diseñar edificios con alta eficiencia energética para reducir su } \\
\text { demanda energética (Okeil, 2010) }\end{array}$ \\
\hline & Diseño bioclimático del edificio & $\begin{array}{l}\text { Acondicionar los edificios con sistemas naturales aprovechando las } \\
\text { condiciones microclimáticas favorables (soleamiento, ventilación } \\
\text { natural e iluminación) }\end{array}$ \\
\hline & Diversidad de viviendas & $\begin{array}{l}\text { Asegurar la diversidad de viviendas según el estatus de sus ocupantes y } \\
\text { el tamaño familiar }\end{array}$ \\
\hline & Mantenimiento de edificios & Reducir la necesidad de mantenimiento de edificios \\
\hline
\end{tabular}


Tabla 3.1 Estructura en dos niveles de categorías y subcategorías (continuación)

\begin{tabular}{|c|c|c|}
\hline Categoría & Subcategoría & Objetivo \\
\hline \multirow[t]{7}{*}{ Energía } & Soleamiento y sombras & $\begin{array}{l}\text { Mitigar las obstrucciones solares en invierno y proporcionar protección } \\
\text { y vegetación en verano. }\end{array}$ \\
\hline & Diseño bioclimático urbano & $\begin{array}{l}\text { Acondicionar los espacios urbanos con sistemas naturales } \\
\text { aprovechando las condiciones microclimáticas favorables } \\
\text { (soleamiento, ventilación natural e iluminación) }\end{array}$ \\
\hline & Isla de calor & Mitigar el efecto isla de calor en las ciudades \\
\hline & $\begin{array}{l}\text { Eficiencia energética de las } \\
\text { instalaciones y monitorización }\end{array}$ & $\begin{array}{l}\text { Mejorar la eficiencia energética (calefacción y refrigeración a nivel de } \\
\text { distrito, plantas de cogeneración, etc.) }\end{array}$ \\
\hline & Energías renovables & $\begin{array}{l}\text { Implementar energías renovables para promover la autosuficiencia } \\
\text { energética }\end{array}$ \\
\hline & Suministro de energía & $\begin{array}{l}\text { Asegurar el suministro de energía e incentivar la producción local de } \\
\text { energía para limitar la dependencia energética exterior }\end{array}$ \\
\hline & Consumo energético & Cuantificar el consumo energético \\
\hline \multirow[t]{5}{*}{ Agua } & Consumo de agua & $\begin{array}{l}\text { Reducir el consume de agua a través de dispositivos de ahorro en los } \\
\text { aparatos sanitarios }\end{array}$ \\
\hline & & Evitar pérdidas en las redes de distribución \\
\hline & & Mejorar la autosuficiencia de agua \\
\hline & Gestión del agua de lluvia y residual & $\begin{array}{l}\text { Reutilización de agua de lluvia para riego, hacer la colada, lavar el } \\
\text { coche e inodoros }\end{array}$ \\
\hline & Calidad del agua & $\begin{array}{l}\text { Evitar la contaminación del agua y la infiltración de aguas } \\
\text { contaminadas }\end{array}$ \\
\hline \multirow[t]{4}{*}{ Materiales } & Materiales de bajo impacto & $\begin{array}{l}\text { Utilizar materiales con bajo impacto ambiental durante su ciclo de vida } \\
\text { (manufacturación, implementación y demolición) } \\
\text { Utilizar materiales con alta durabilidad y que sean inventariables }\end{array}$ \\
\hline & Productos con distintivo ambiental & $\begin{array}{l}\text { Utilizar materiales con distintivo de calidad ambiental que proporcione } \\
\text { información fiable }\end{array}$ \\
\hline & Materiales reutilizados y reciclados & $\begin{array}{l}\text { Minimizar el uso de materiales y promocionar el uso de materiales } \\
\text { reutilizados y reciclados }\end{array}$ \\
\hline & Materiales locales & $\begin{array}{l}\text { Incentivar el uso de materiales locales para reducir el impacto } \\
\text { producido por el transporte }\end{array}$ \\
\hline \multirow[t]{2}{*}{ Residuos } & Minimización de residuos & Minimizar la producción de residuos \\
\hline & Tratamiento de residuos & Tratar los residuos \\
\hline \multirow[t]{6}{*}{ Contaminación } & Contaminación del suelo & Prevenir la contaminación del suelo \\
\hline & Contaminación del aire & Prevenir la contaminación del aire y asegurar su calidad \\
\hline & Contaminación del agua & Prevenir la contaminación del agua y asegurar su calidad \\
\hline & Contaminación acústica & Prevenir la contaminación acústica \\
\hline & Contaminación lumínica & Prevenir la contaminación luminosa \\
\hline & Contaminación de recursos y otros & Prevenir la contaminación de recursos \\
\hline \multirow[t]{7}{*}{ Aspecto social } & Cohesión social y barrios mixtos & $\begin{array}{l}\text { Fomentar la población mixta de diferentes edades, origen y poder } \\
\text { adquisitivo, para evitar el riesgo de pobreza y exclusión social }\end{array}$ \\
\hline & Participación ciudadana & $\begin{array}{l}\text { Considerar las autoridades locales los puntos de vista de los } \\
\text { ciudadanos durante los procesos de toma de decisión }\end{array}$ \\
\hline & & Incrementar el nivel de satisfacción de la población \\
\hline & Asociaciones cívicas & Promover la asociación y visibilidad de los ciudadanos \\
\hline & Vivienda asequible & $\begin{array}{l}\text { Posibilitar la vivienda asequible para los ciudadanos en todos los } \\
\text { barrios de la ciudad a través de vivienda de protección oficial }\end{array}$ \\
\hline & Pobreza energética & Luchar contra la pobreza energética \\
\hline & Educación & Reducir el absentismo y la delincuencia en las escuelas \\
\hline
\end{tabular}


Tabla 3.1 Estructura en dos niveles de categorías y subcategorías (continuación)

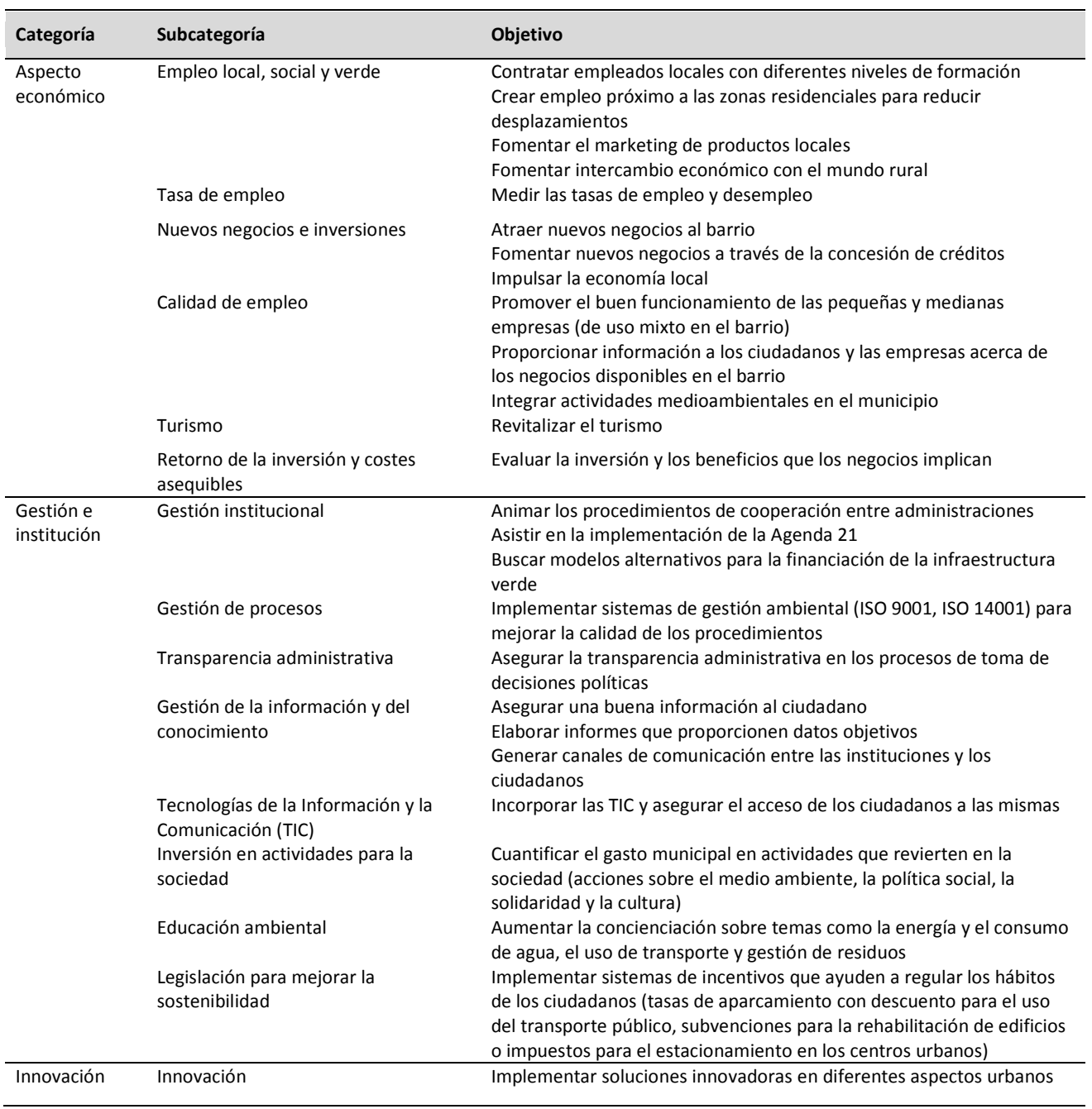

Desglosar las categorías no es tarea fácil, pues algunas guardan íntima relación entre ellas, y en algunos casos, persiguen objetivos similares. En la Tabla 3.2 se presenta el nivel de relación entre las 14 categorías, indicando si se trata de una relación fuerte, media o si, por el contrario, no guarda relación alguna. 
Tabla 3.2 Análisis del nivel de relación entre las 14 categorías propuestas

\begin{tabular}{|c|c|c|c|c|c|c|c|c|c|c|c|c|c|c|}
\hline Categoría & SS & MU & MT & NB & EV & E & A & M & $\mathbf{R}$ & C & AS & $\mathrm{AE}$ & GI & I \\
\hline \multicolumn{15}{|l|}{ Sitio y suelo (SS) } \\
\hline Morfología urbana (MU) & $\bullet \bullet$ & & & & & & & & & & & & & \\
\hline Movilidad y transporte (MT) & $\bullet \bullet$ & $\bullet \bullet$ & & & & & & & & & & & & \\
\hline Naturaleza y biodiversidad (NB) & $\bullet \bullet$ & $\bullet$ & - & & & & & & & & & & & \\
\hline Edificación y vivienda (EV) & $\bullet \bullet$ & $\bullet \bullet$ & - & $\bullet$ & & & & & & & & & & \\
\hline Energía (E) & $\bullet \bullet$ & $\bullet \bullet$ & $\bullet \bullet$ & $\bullet$ & $\bullet \bullet$ & & & & & & & & & \\
\hline Agua (A) & $\bullet$ & - & - & $\bullet$ & $\bullet \bullet$ & $\bullet$ & & & & & & & & \\
\hline Materiales (M) & $\bullet$ & - & $\bullet$ & $\bullet$ & $\bullet \bullet$ & $\bullet$ & - & & & & & & & \\
\hline Residuos (R) & $\bullet$ & - & - & & $\bullet \bullet$ & - & - & $\bullet$ & & & & & & \\
\hline Contaminación (C) & $\bullet$ & - & $\bullet$ & $\bullet$ & $\bullet \bullet$ & $\bullet$ & $\bullet \bullet$ & $\bullet$ & $\bullet$ & & & & & \\
\hline Aspecto social (AS) & - & $\bullet$ & - & - & $\bullet$ & - & - & - & - & - & & & & \\
\hline Aspecto económico (AE) & - & $\bullet$ & - & - & - & - & - & - & - & - & $\bullet$ & & & \\
\hline Gestión e institución (GI) & - & $\bullet$ & $\bullet$ & - & - & $\bullet$ & $\bullet$ & - & $\bullet$ & $\bullet$ & $\bullet \bullet$ & $\bullet \bullet$ & & \\
\hline Innovación (I) & - & - & - & - & - & - & - & - & - & - & - & - & - & \\
\hline
\end{tabular}

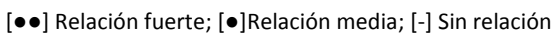

Como se extrae de la Tabla 3.2, resultado del análisis de las tablas que listan los indicadores de las HESU (Anexo I), los aspectos que guardan una relación más íntima son "sitio y suelo" y "morfología urbana" debido a que el propio diseño de la ciudad da forma a muchos aspectos físicos, ambientales y socio-económicos. Por ejemplo, ambos determinan aspectos tan importantes como son la localización, el clima, el diseño urbano, la compacidad y la mixicidad de usos, entre otros.

La "movilidad y transporte" está también fuertemente relacionada con "la morfología urbana", pues la estructura de la ciudad determina las distancias que la población debe recorrer para realizar sus actividades cotidianas, como ir a trabajar, al colegio o hacer la compra; factor que a su vez condiciona la accesibilidad (Gaffron et al., 2008). Los resultados del estudio realizado por Zhao et al. (2014) revelan la estrecha relación existente entre la compacidad de una ciudad y el tiempo que sus habitantes deben emplear en su movilidad diaria. Así, estos autores indican que altos ratios de urbanización sin un adecuado planeamiento urbano contribuyen a generar una compacidad pobre que, consecuentemente, desemboca en grandes tiempos de desplazamiento. La relación entre ambos aspectos es tan íntima que la herramienta SEV propone una única categoría que aúna los aspectos de morfología y transporte ("espacio público y movilidad").

En relación con la categoría de "energía", la estructura urbana determina la tipología de edificios que pueden construirse en una determinada área, marcada por el planeamiento urbano de la ciudad. Como destaca Okeil (2010), las tipologías edificatorias y la morfología urbana son aspectos muy significativos en el comportamiento energético de los edificios, en el uso de la electricidad (Wilson, 2013) y las emisiones de gases de efecto invernadero. Makido et al. (2012) demostraron en su estudio que los edificios compactos y altos muestran un mejor comportamiento energético a escala urbana que las viviendas unifamiliares aisladas. 
En cuanto a la categoría "morfología urbana", esta está también relacionada con factores socioeconómicos, pues una alta compacidad urbana aproxima distancias entre los ciudadanos y promueve las relaciones entre ellos, lo que fomenta también la creación de asociaciones cívicas donde reunirse y fomentar la participación ciudadana. El uso mixto de los usos residencial y comercial en el mismo barrio, también atrae nuevos negocios en la zona, ayudando a promover la economía local.

Por lo que respecta a la categoría de "gestión e institución", cabe decir que representa un factor clave para asegurar el funcionamiento eficaz de la sociedad. Una buena gestión y una transparencia administrativa real son necesarias para asegurar la objetividad en los procesos de diagnosis, toma de decisiones, promover nuevos planeamientos urbanos, a su vez que integrar la Agenda 21.

Finalmente, la "innovación" contribuye a evaluar la implementación de nuevas soluciones en los diferentes aspectos de la sostenibilidad urbana. Sin embargo, cabe apuntar que no se identifican relaciones específicas entre ella y otras categorías.

Establecido el marco común de comparación, los 786 indicadores, listados en el Anexo I, son agrupados según las categorías y subcategorías propuestas. A continuación, se muestra dicha agrupación en las tablas siguientes (Tabla 3.3 - Tabla 3.16). 


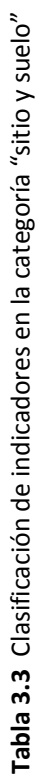

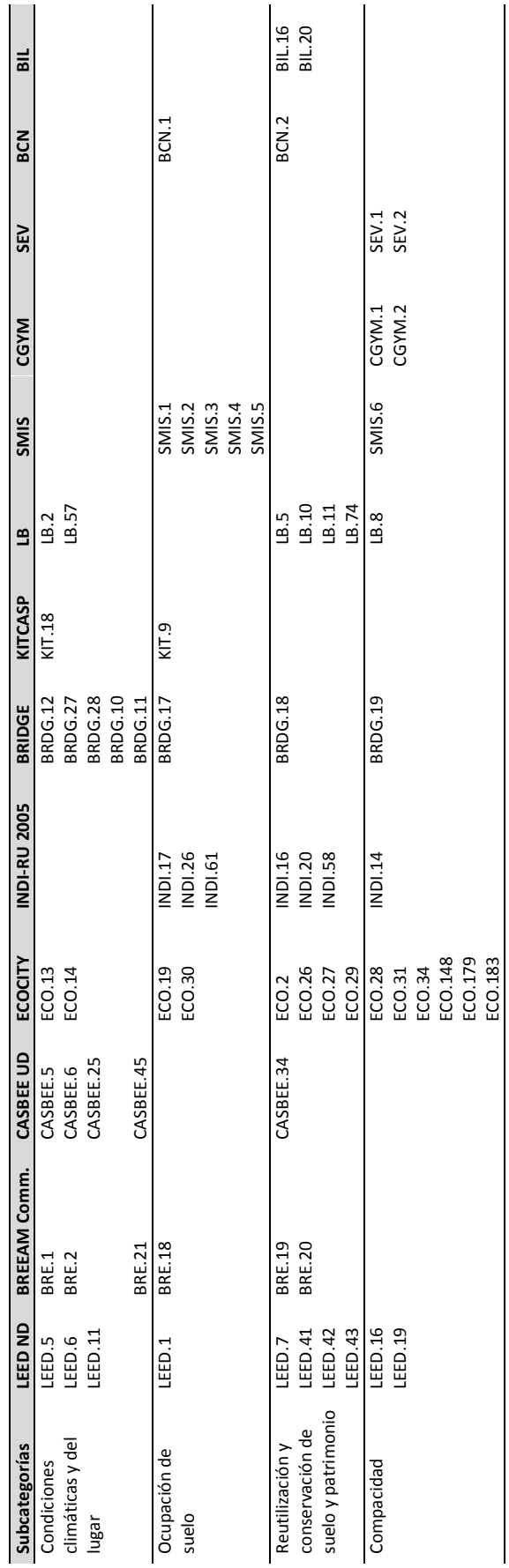




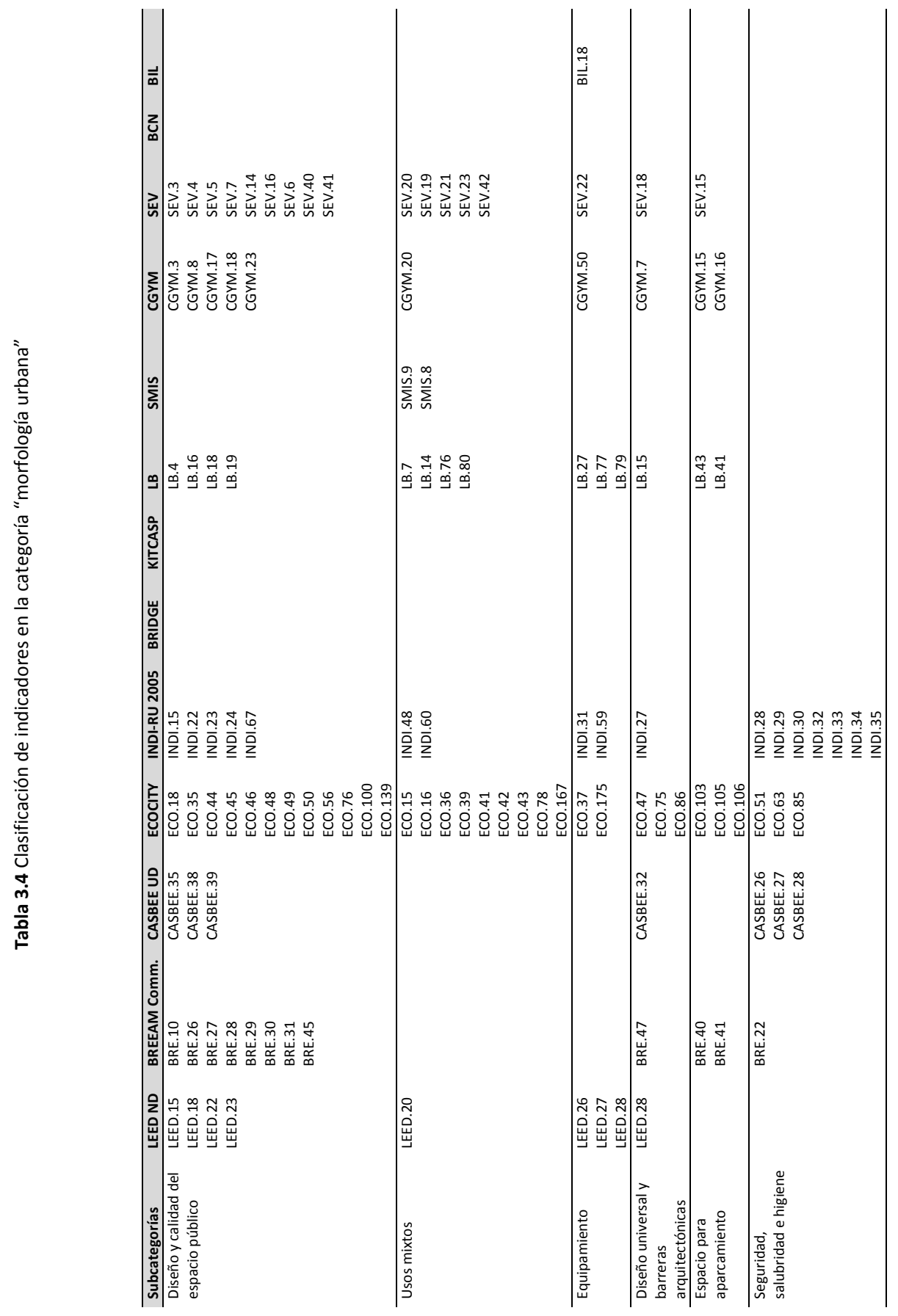




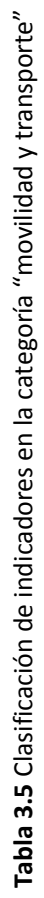

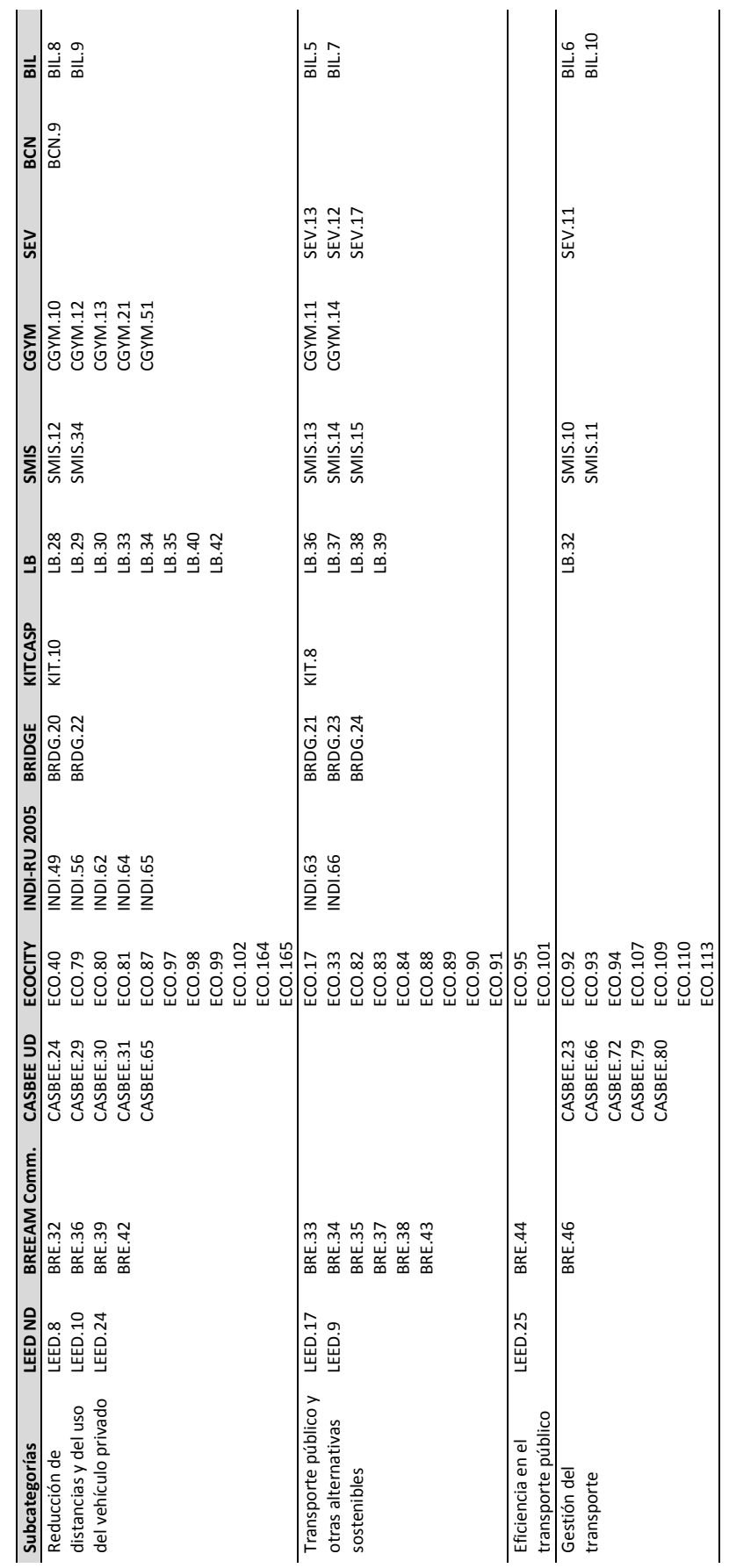




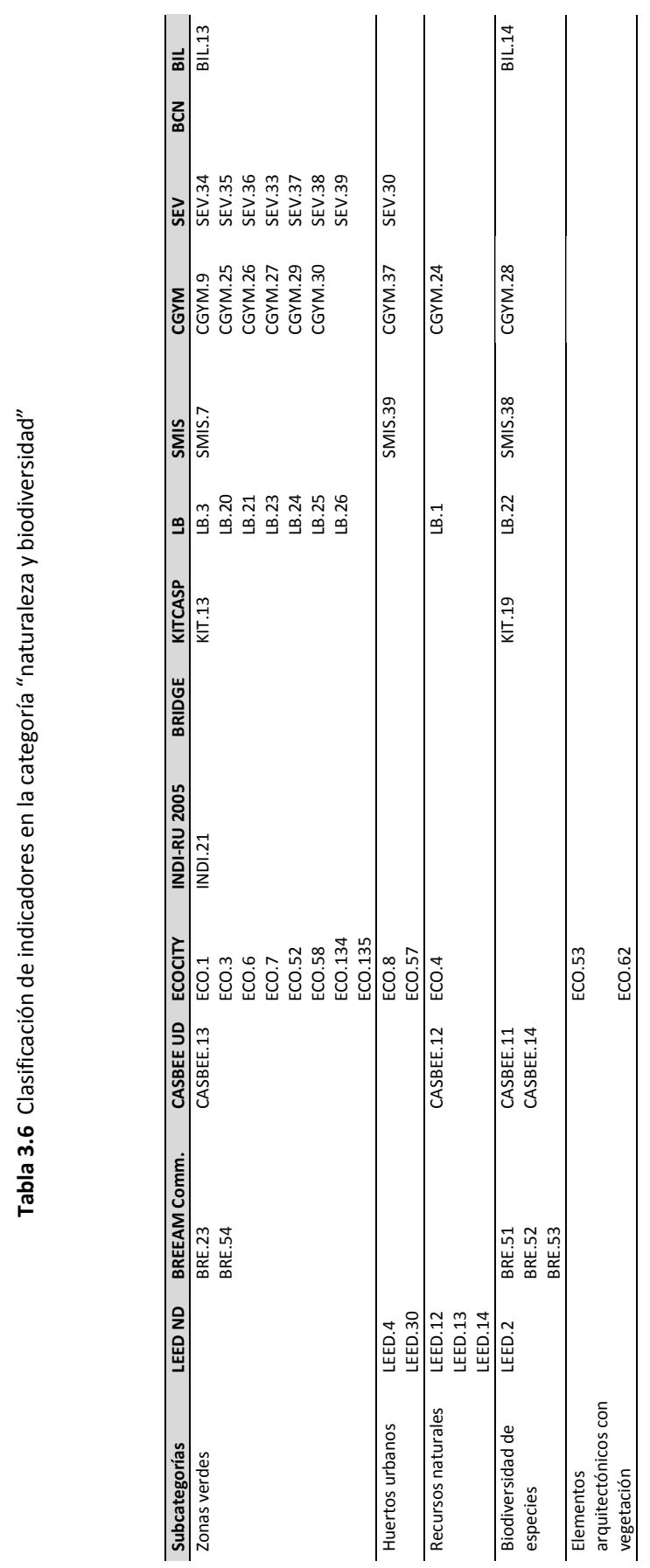




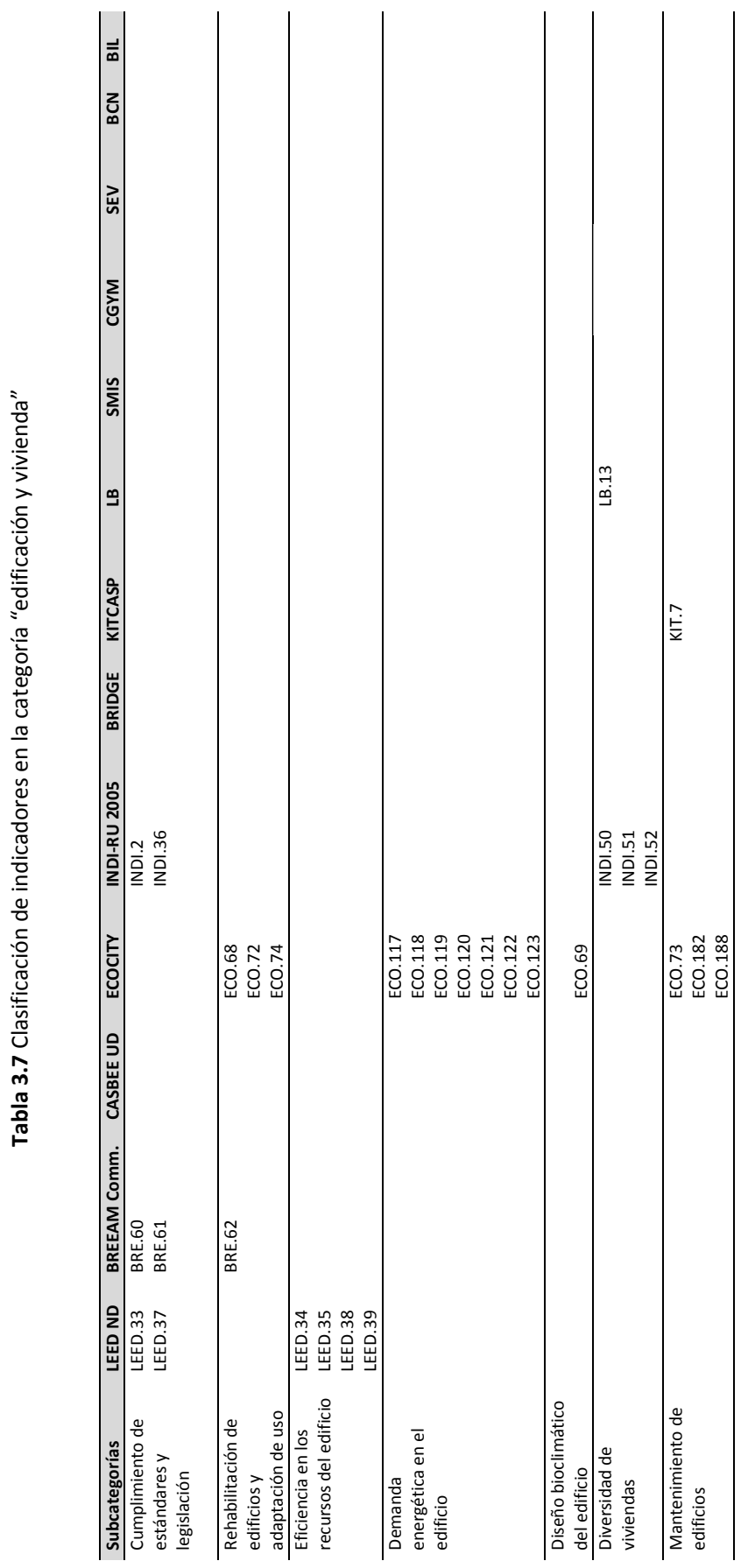




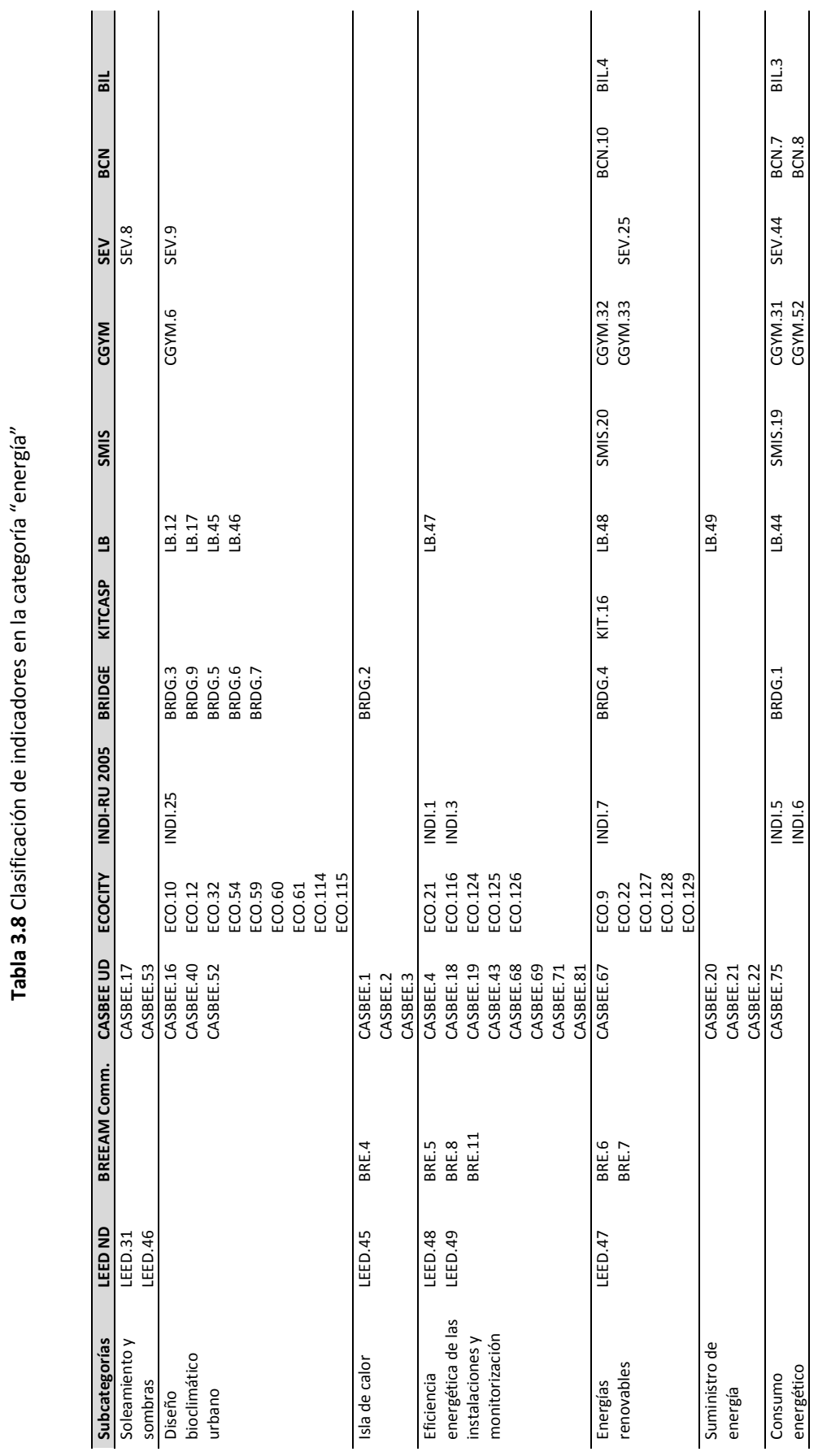



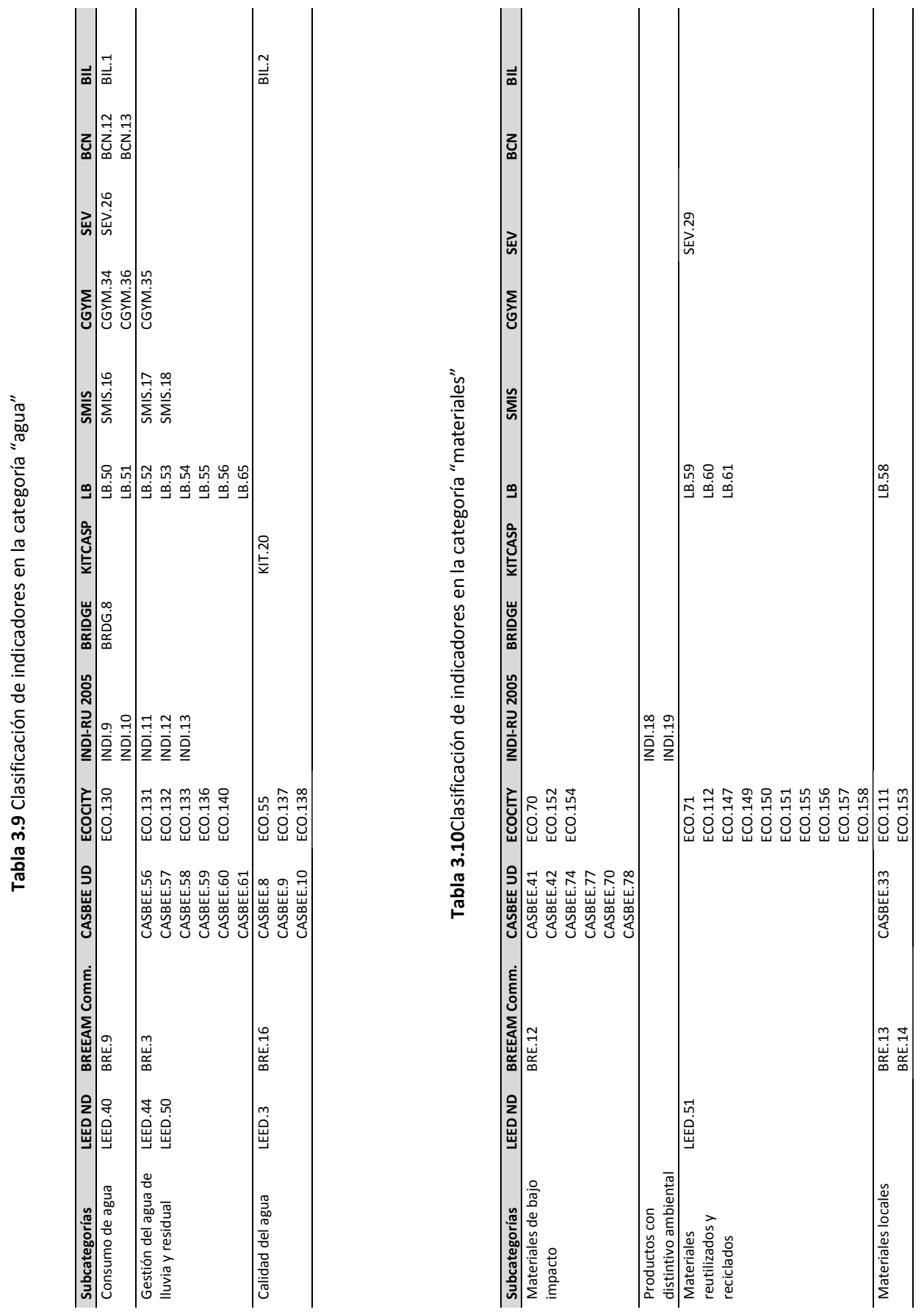

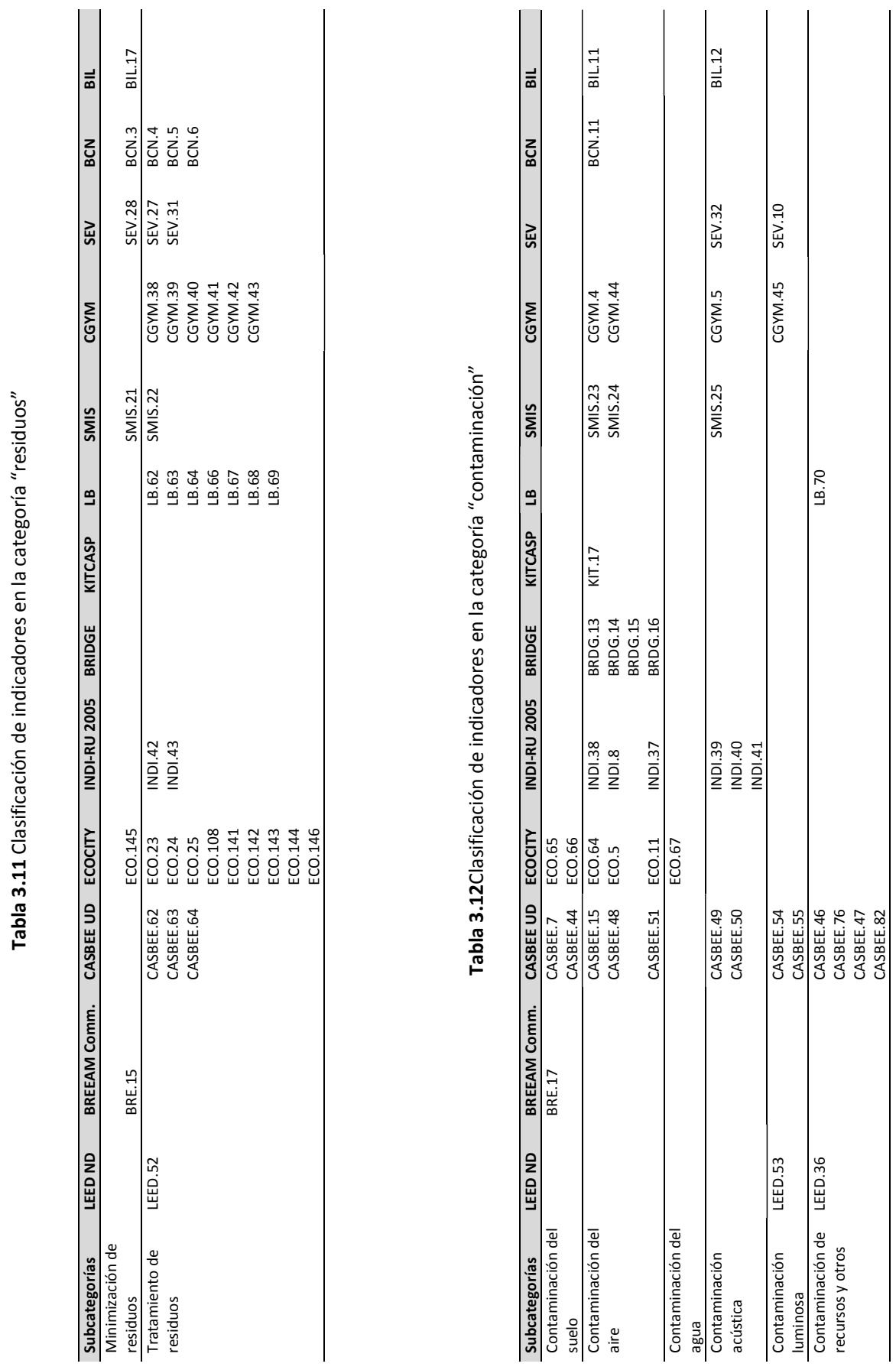


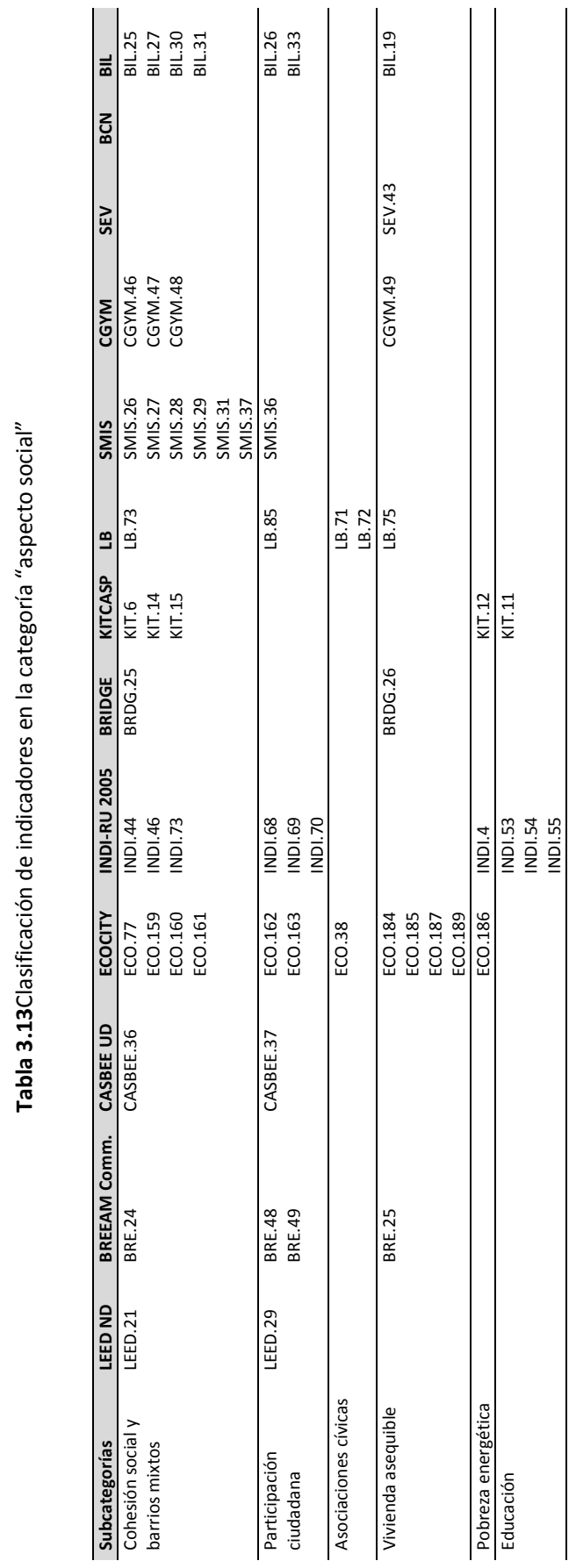




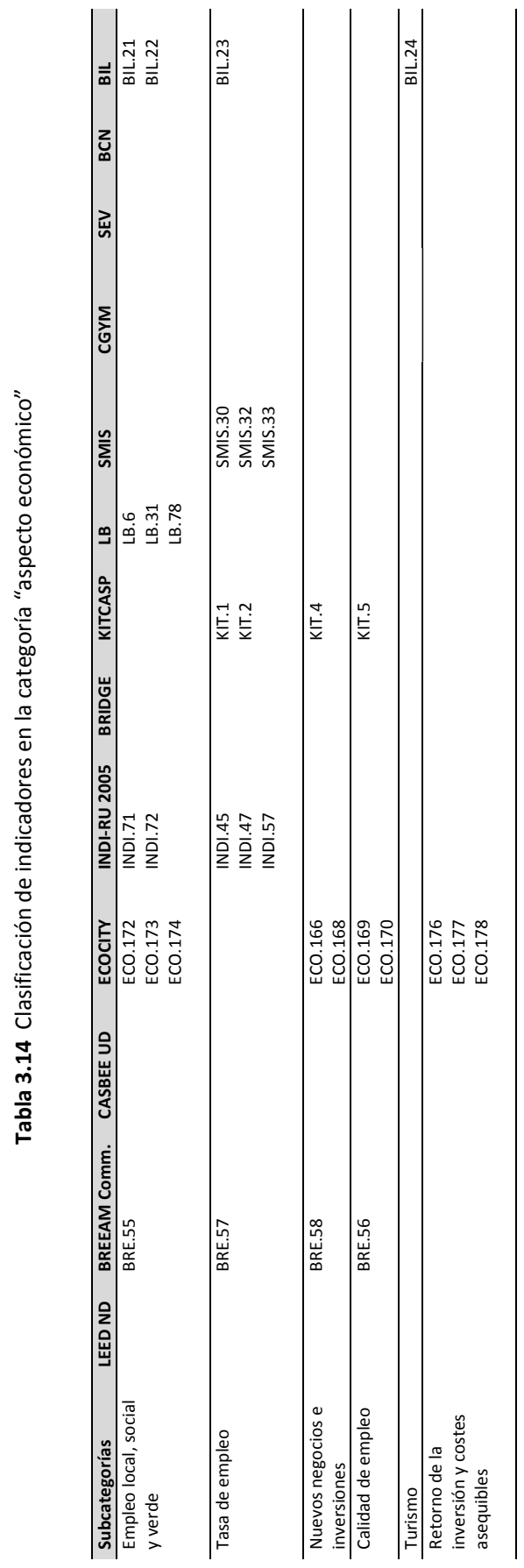



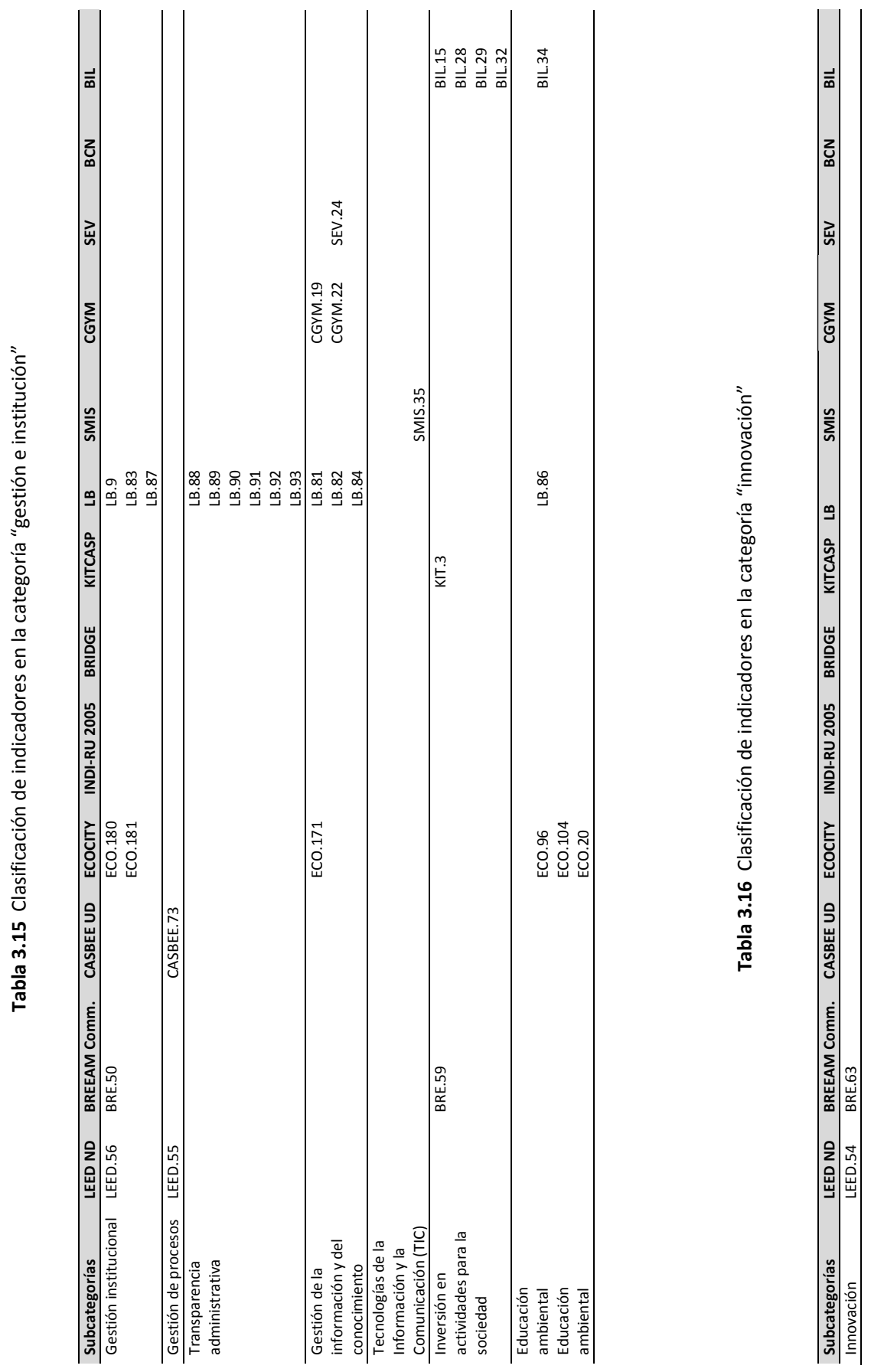


\subsubsection{ANÁLISIS COMPARATIVO DE INDICADORES CONTENIDOS EN LAS HESU}

En esta sección se analizan los indicadores propuestos por las 13 HESU por categoría y subcategoría. Para poder determinar qué aspectos son en los que las herramientas hacen mayor y menor hincapié, se ha determinado el número de indicadores dedicados a cada subcategoría. Los resultados se muestran en la Figura 3.3. Mientras esta representa el número de indicadores que las 13 herramientas incluyen en las 14 categorías propuestas, la Figura 3.4 ahonda en las 69 subcategorías, mostrando de forma pormenorizada, el número de indicadores contenidos en cada una de ellas.

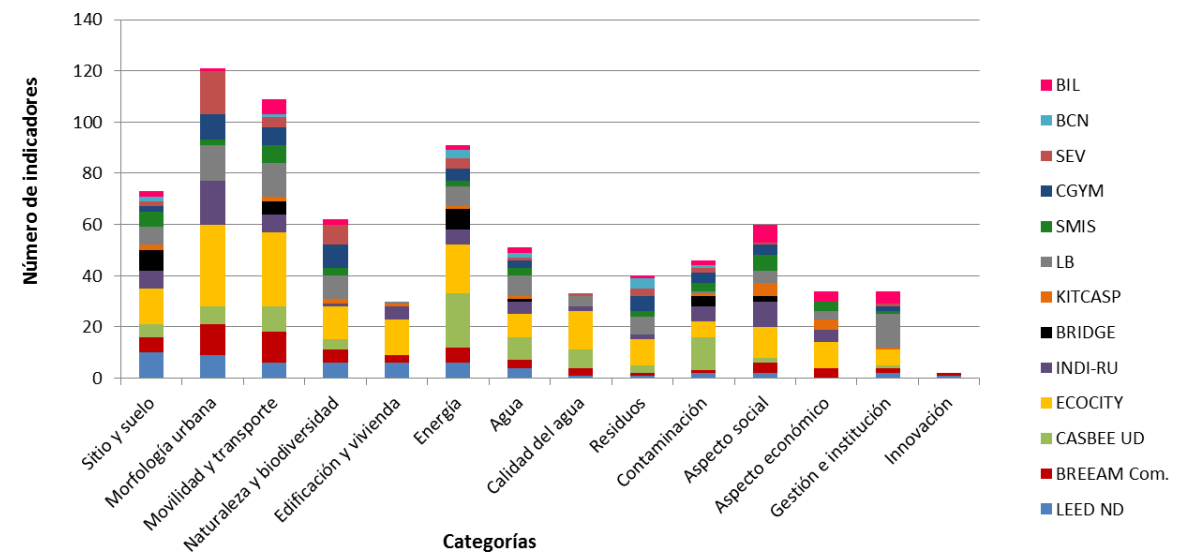

Figura 3.3 Número de indicadores que cada HESU analizada confiere a las 14 categorías propuestas en este trabajo 


\section{Sitio y suelo}

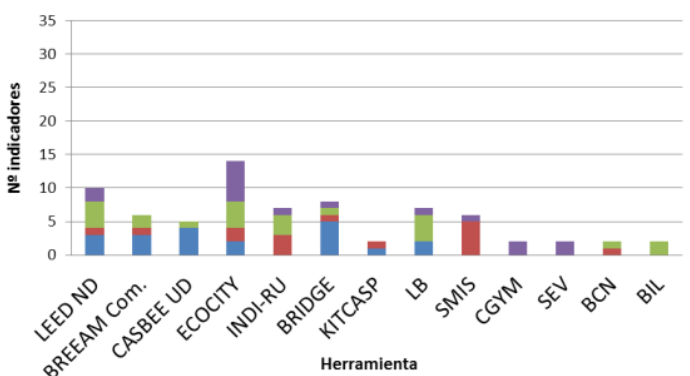

Subcategorías

- Compacidad

- Reutilización y

conservación del suelo y

el patrimonio

- Ocupación de suelo

Morfología urbana

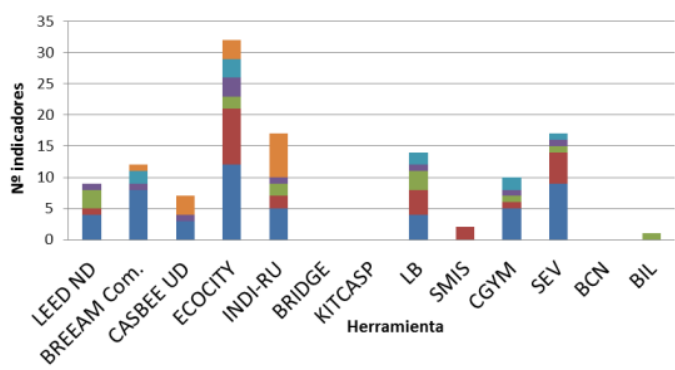

Subcategorías

= Seguridad, salubridad $\mathrm{e}$ higiene

= Espacio para aparcamiento

E Diseño universal y barreras

arquitectónicas

Equipamiento

nsos mixtos

- Diseño y calidad del espacio público

\section{Movilidad y transporte}

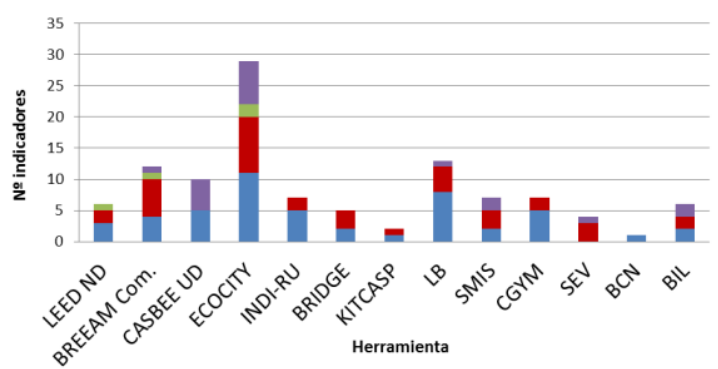

Subcategorias

- Gestión del transporte

Eficiencia en el transporte público

- Transporte público y otras alternativas sostenibles Reducción de distancias y del uso del vehículo privado

Naturaleza y biodiversidad

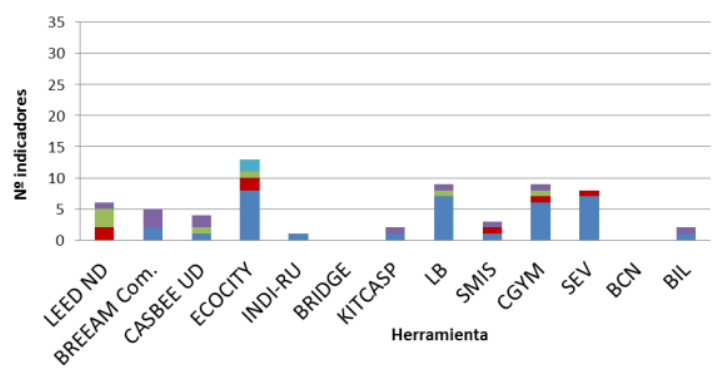

Subcategorías

Elementos arquitectónicos con vegetación n Biodiversidad de especies

necursos naturales

- Huertos urbanos

Figura 3.4 Número de indicadores de las 13 HESU analizadas contenidos en las 14 la categorías 

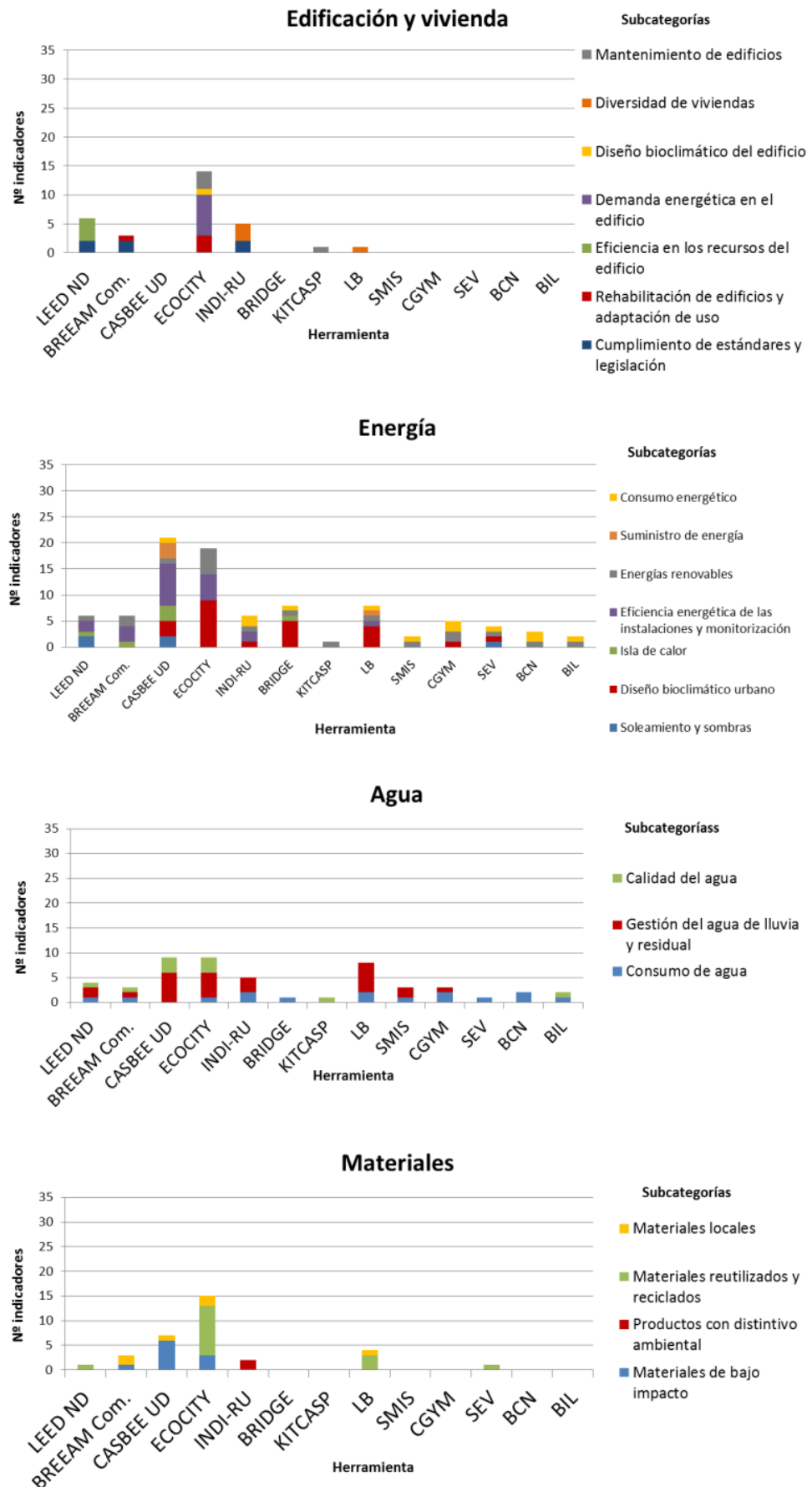

Subcategorías

m Materiales locales

= Materiales reutilizados y reciclados

- Productos con distintivo ambiental

- Materiales de bajo impacto

Figura 3.4 Número de indicadores de las 13 HESU analizadas contenidos en las 14 la categorías (continuación) 


\title{
Residuos
}

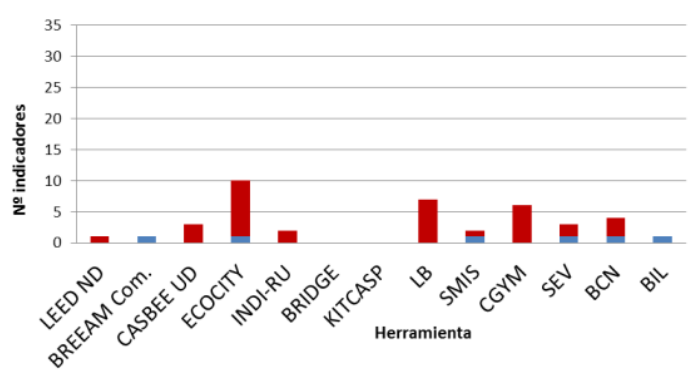

Subcategorías

- Tratamiento de residuos

Minimización de residuos

\section{Contaminación}

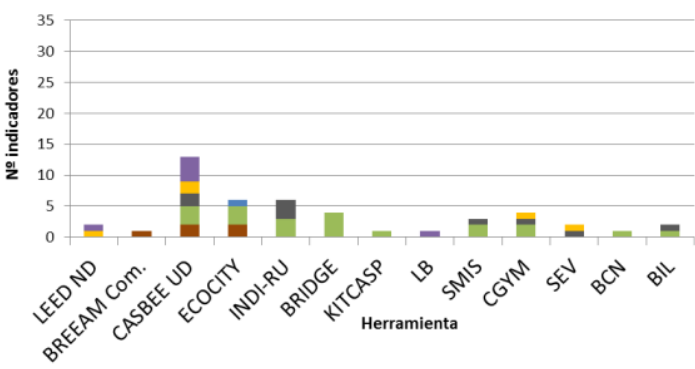

\section{Subcategorías}

- Contaminación de recursos y otros

in Contaminación

lumínica

- Contaminación acústica

- Contaminación del agua

\section{Aspecto económico}

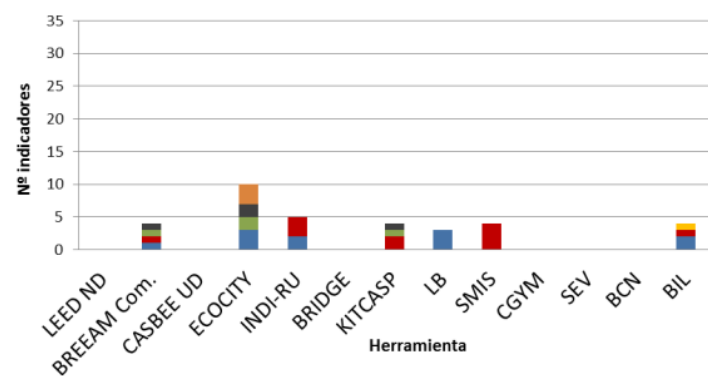

\author{
Subcategorías \\ netorno de la inversión \\ $y$ costes asequibles \\ nurismo \\ - Calidad de empleo \\ = Nuevos negocios e \\ inversiones \\ - Tasa de empleo \\ - Empleo local, social y \\ verde
}

\section{Aspecto social}

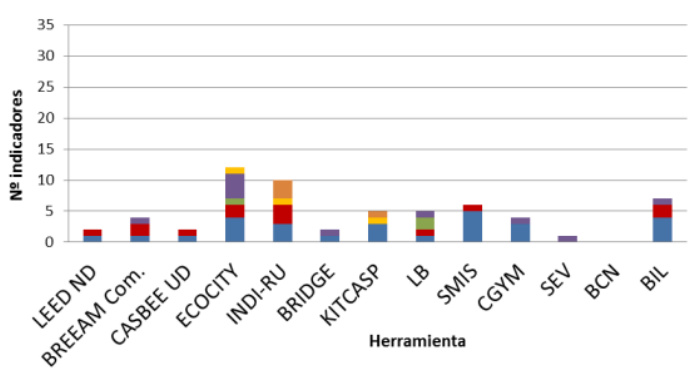

Figura 3.4 Número de indicadores de las 13 HESU analizadas contenidos en las 14 la categorías (continuación) 

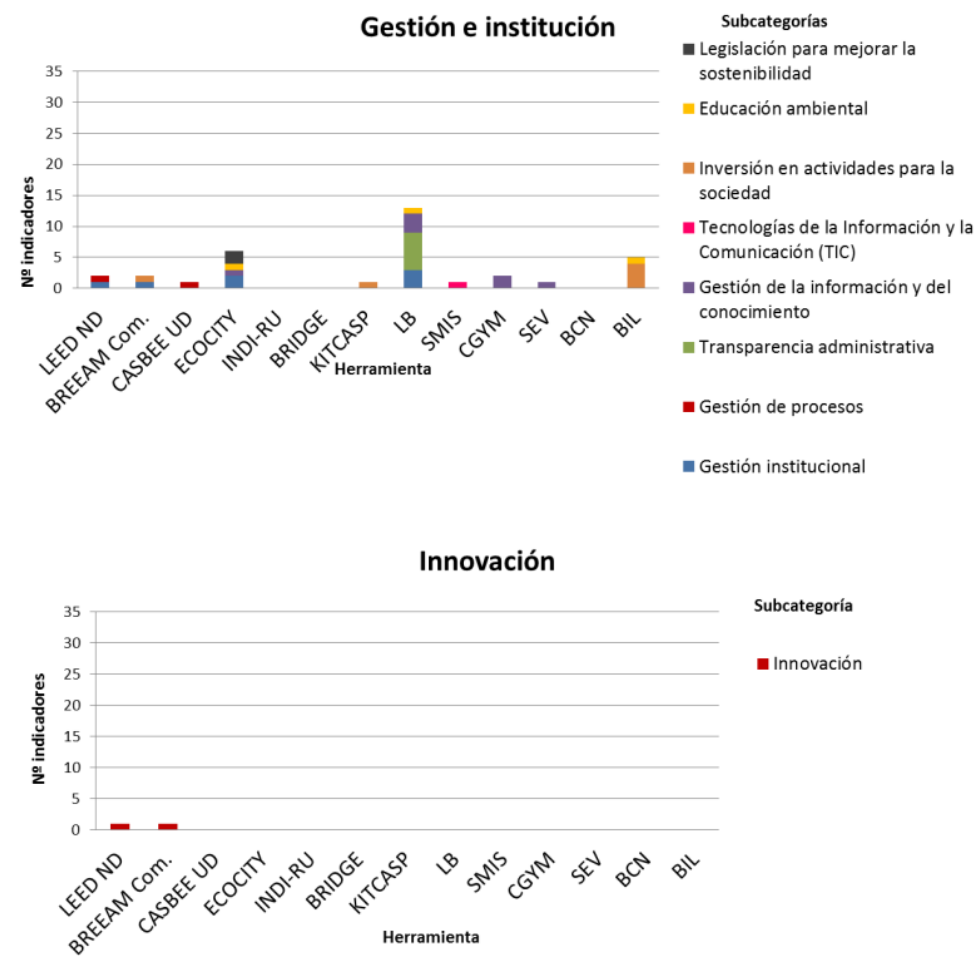

Figura 3.4 Número de indicadores de las 13 HESU analizadas contenidos en las 14 la categorías (continuación)

La Figura 3.5 muestra la distribución estadística de los datos en un diagrama de cajas y bigotes. El diagrama de cajas y bigotes permite identificar las categorías más y menos enfatizadas por el conjunto de las herramientas.

Los resultados evidencian el balance desequilibrado entre los pilares de la sostenibilidad: ambiental, social y económico. A los tres pilares clásicos de la sostenibilidad se incorpora, tal y como ya apuntaron Sharifi y Murayama (2013), el aspecto institucional, considerado como el cuarto pilar de la sostenibilidad. Sin embargo, como se refleja en la Figura 3.5, junto al aspecto económico todavía es uno de los aspectos menos tratados por las herramientas. 


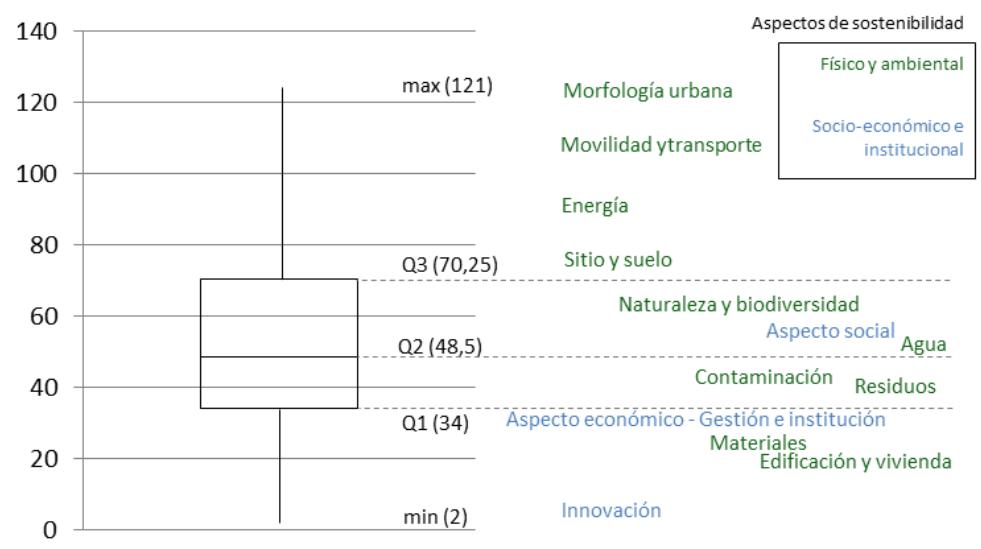

Figura 3.5 Distribución estadística del número de indicadores en las 14 categorías propuestas

Como se observa en el diagrama de cajas y bigotes de la Figura 3.5, las categorías de "morfología urbana", "movilidad y transporte", "energía", y "sitio y suelo" son las más destacadas por las HESU, pues el número de indicadores contenidos en cada una de ellas (121, 109, 91 y 73, respectivamente) está por encima del tercer cuartil $(70,25)$. Por ello, se puede decir que las herramientas generalmente otorgan más importancia a estas cuatro categorías que a las demás. En concreto, la categoría más tratada en general por el conjunto de herramientas es "morfología urbana", que como se extrae de la Tabla 3.2. Esta es, además, la que guarda más relación con otras.

Aquellas categorías en las que el número de indicadores está alrededor de la mediana (o segundo cuartil, 48,5) son: "naturaleza y biodiversidad", "aspecto social", "agua", "contaminación" y "residuos". El número de indicadores de estas cinco categorías varía entre 40 y 62, rango ubicado en el centro de la distribución.

Las categorías que se encuentran por debajo del primer cuartil (34) representan los aspectos menos enfatizados por las herramientas, siendo estos: "aspecto económico", "gestión e institución", "materiales", "edificación y vivienda" e "innovación". Estas categorías llevan asociadas muy pocos indicadores; por ejemplo, en el caso de "innovación", únicamente dos.

Los gráficos presentados en la Figura 3.4 proporcionan un análisis en profundidad de las subcategorías, ya que indican el número de indicadores que cada una de las herramientas confiere a las 69 subcategorías propuestas. Como se observa, la herramienta ECOCITY aborda tres de las categorías más destacadas ("morfología urbana", "movilidad y transporte" y "energía"). Sin embargo, CASBEE UD es la herramienta que confiere más indicadores al aspecto "energía". También merece la pena destacar que, SEV e INDI-RU, consideran la "morfología urbana" esencial para alcanzar la sostenibilidad, mientras que BCN, BRIDGE and KITCASP no conceden ningún indicador a este aspecto.

La subcategoría más abordada dentro de la categoría de "morfología urbana" es "diseño y calidad del espacio urbano", pues 8 de las 13 herramientas la tratan en profundidad. La "mixticidad de usos" también destaca dentro de esta categoría. Por lo que respecta a la categoría "movilidad y transporte", todas las herramientas a excepción de SEV, hacen grandes esfuerzos por integrar la subcategoría de "reducir distancias y el uso del vehículo privado" con el objetivo de acortar 
distancias para los habitantes y mitigar el impacto ambiental negativo derivado del uso del transporte privado.

Diferencias menos marcadas se encuentran en la categoría de "sitio y suelo", donde cada herramienta le confiere al menos 2 indicadores. Es importante apuntar que se aprecia una asociación clara entre este aspecto y la "morfología urbana". La "compacidad" es el aspecto más destacado en "sitio y suelo" porque está presente en 8 de las herramientas (precisamente en aquellas europeas y españolas), pues junto con la "mixticidad de usos" representa una característica esencial de la ciudad mediterránea (Rueda, 2007).

La categoría "naturaleza y biodiversidad" es fuertemente considerada en las herramientas ECOCITY, LB, CGYM y SEV, y la subcategoría más tratada es la generación de "elementos arquitectónicos con vegetación" en los barrios y ciudades. La conservación de la "biodiversidad de especies" también es destacada por muchas herramientas, como en BREEAM Communities o en CASBEE UD.

A pesar de que el "aspecto social" es considerado por la mayoría de las herramientas analizadas, con la excepción de $\mathrm{BCN}$, es importante destacar que generalmente está pobremente tratado, especialmente si se tiene en cuenta que es uno de los pilares fundamentales de la sostenibilidad. En esta categoría, la "cohesión social y barrios mixtos" es el punto más tratado, pues las 13 herramientas lo abordan. "Vivienda asequible" también destaca dentro del aspecto social y es considerado en 7 de las herramientas. Sin embargo, la "pobreza energética" es un tema muy poco abordado que, dada la situación actual de escasos recursos para afrontar los costes de la energía por las familias (Bouzarovski et al., 2011), requiere una mayor discusión por parte de las herramientas. Únicamente es considerado de forma muy superficial en ECOCITY, INDI-RU y KITCASP.

"Agua" y "contaminación" son tenidas en cuenta en las 13 herramientas, pero con límites. En cuanto a "agua", la subcategorías más notable es "gestión de aguas pluviales y residuales", mientras que 6 subcategorías son distinguidas en "contaminación", incluyendo la contaminación de "suelo", "agua", la "lumínica", de "recursos", del "aire" y la "acústica", donde las dos últimas son las más destacadas. En particular, BRIDGE es la herramienta que más destaca la subcategoría de "aire" debido a que integra los componentes del metabolismo urbano en la evaluación de impacto durante las intervenciones en el planeamiento urbano (González et al., 2013).

La categoría "residuos" también es abordada por todas las herramientas, especialmente la subcategoría de "tratamiento de residuos", que está cobrando cada vez más importancia, también debido a la legislación que la impulsa (Parlamento Europeo, 2008).

Otro aspecto olvidado, al igual que el aspecto social e institucional, es el "aspecto económico". LEED ND, CASBEE UD, BRIDGE, CGYM, SEV y BCN no lo contemplan, mientras que ECOCITY es la herramienta que lo aborda con más énfasis. La subcategoría más tratada es "empleo local, social y verde", la cual promueve la comercialización de productos locales y el empleo relacionado con temas ambientales y sociales. Se puede concluir, pues, que el "aspecto económico" debería ser mucho más abordado, por constituir un pilar real de la sostenibilidad urbana.

La categoría de "materiales" se enfoca hacia el uso de materiales de bajo impacto ambiental y que son producidos en el ámbito local, y hacia la promoción de la reutilización y reciclaje de productos. Los materiales con sellos de certificación ambiental de producto (subcategoría "productos con distintivo ambiental") también son premiados en esta categoría. Siete de las herramientas consideran las subcategorías de "productos con distintivo ambiental" y "materiales reutilizados y reciclados" como las más relevantes.

"Gestión e institución", como se ha comentado, viene siendo un tema pobremente abordado ya que, a pesar de que 10 de las herramientas lo consideran, se le dedica un número muy bajo de indicadores. Como se apuntaba anteriormente, este es un tema importante al que se le debería de 
conferir más relevancia, pues es un aspecto clave para establecer canales de comunicación y posibilitar la transparencia administrativa. La herramienta LB, siendo la que muestra más preocupación por este aspecto, asigna un rol más prominente a la "transparencia administrativa" mientras que BIL considera la "inversión en actividades para la sociedad" más importante. Esta categoría establece un desafío para las instituciones en cuanto a dirigir esfuerzos para el correcto funcionamiento de las ciudades.

Finalmente, "edificación y vivienda" es también un tema escasamente tratado, posiblemente porque existen ya herramientas específicas para la evaluación de la sostenibilidad de edificios a nivel individual.

Como se refleja en la Tabla 2.2 del Capítulo 2, sólo tres herramientas (LEED ND, BREEAM Communities y CASBEE UD) emplean un método de ponderación cuantitativo integrado en una escala de valoración por categorías y subcategorías. En consecuencia, el realizar una comparación objetiva que analice el peso conferido a cada una de las categorías solo es posible en el marco de estas tres herramientas. En el resto, los indicadores propuestos son meramente orientativos de manera que establecen directrices o recomendaciones que no son cuantificables ni integrables en una escala común de valoración. El análisis del peso conferido por estas tres herramientas a las 14 categorías se muestra en la Figura 3.6. 
LEED ND

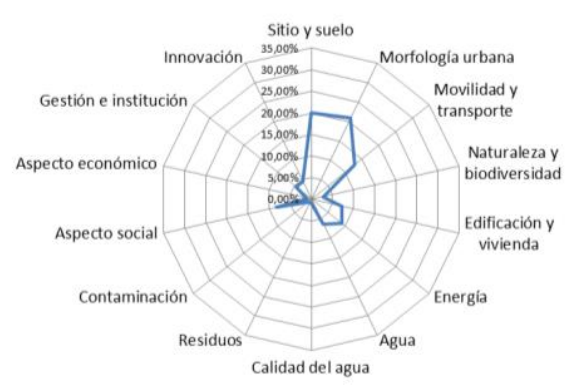

BREEAM Communities

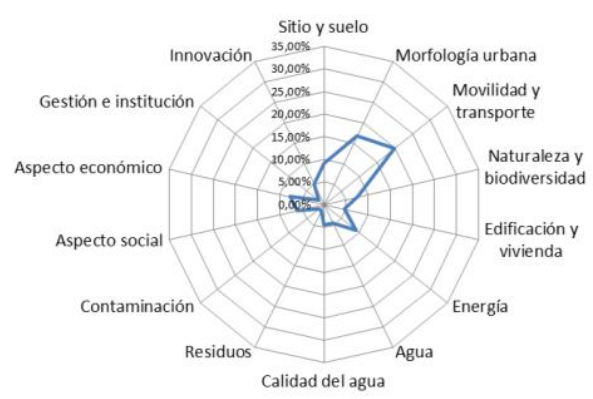

CASBEE UD

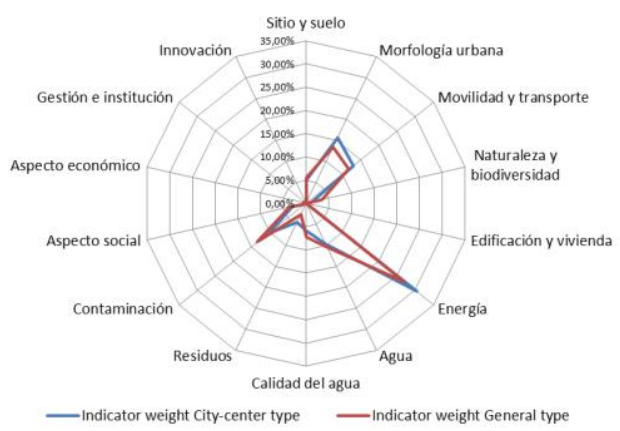

Figura 3.6 Distribución del porcentaje de pesos en las 14 categorías propuestas por las herramientas LEED ND, CASBEE UD y BREEAM Communities

Claramente, se observa que las tres herramientas ponen más énfasis en los aspectos ambientales y físicos ("sitio y suelo", "morfología urbana", "movilidad y transporte", "naturaleza y biodiversidad", "edificación y vivienda", "energía", "agua", "materiales", "residuos" y "contaminación" y dejan los aspectos socio-económicos e institucionales ("aspecto social", "aspecto económico", "gestión e institución" e "innovación") más de lado. La Tabla 3.17 presenta dichos porcentajes de distribución de pesos en términos numéricos, de donde se extrae que LEED ND y BREEAM Communities ofrecen alrededor del $80 \%$ del peso al primer grupo y sólo el $20 \%$ al segundo. La diferencia en CASBEE UD es incluso mayor, siendo el $95 \%$ y el $5 \%$, respectivamente. 
Tabla 3.17 Comparación de la distribución del porcentaje de pesos en las herramientas LEED ND, CASBEE UD y BREEAM Communities

\begin{tabular}{|c|c|c|c|c|c|c|c|}
\hline \multirow[t]{2}{*}{ Aspecto } & \multirow[t]{2}{*}{ Categoría } & \multicolumn{2}{|l|}{ LEED ND } & \multicolumn{2}{|c|}{ BREEAM Communities } & \multicolumn{2}{|l|}{ CASBEE UD } \\
\hline & & $\%$ & $\begin{array}{r}\text { Total } \\
\%\end{array}$ & $\%$ & Total \% & $\%$ & Total \% \\
\hline \multirow{10}{*}{$\begin{array}{l}\text { Aspectos físicos y } \\
\text { ambientales }\end{array}$} & Sitio y suelo & 20,00 & 81,82 & 9,18 & 79,59 & 5,50 & 94,90 \\
\hline & Morfología urbana & 20,91 & & 16,84 & & 13,50 & \\
\hline & Movilidad y transporte & 12,73 & & 19,90 & & 11,75 & \\
\hline & Naturaleza y biodiversidad & 2,73 & & 7,65 & & 3,50 & \\
\hline & Naturaleza y biodiversidad & 7,27 & & 4,59 & & 0,00 & \\
\hline & Energía & 9,09 & & 9,18 & & 26,93 & \\
\hline & Agua & 6,36 & & 4,59 & & 10,50 & \\
\hline & Materiales & 0,91 & & 4,59 & & 7,23 & \\
\hline & Residuos & 0,91 & & 1,53 & & 2,63 & \\
\hline & Contaminación & 0,91 & & 1,53 & & 13,37 & \\
\hline \multirow{4}{*}{$\begin{array}{l}\text { Aspectos socio- } \\
\text { económicos e } \\
\text { institucionales }\end{array}$} & Aspecto social & 8,18 & 18,18 & 6,12 & 20,41 & 4,15 & 5,10 \\
\hline & Aspecto económico & 0,91 & & 7,65 & & 0,00 & \\
\hline & Gestión e institución & 4,55 & & 1,53 & & 0,95 & \\
\hline & Innovación & 4,55 & & 5,10 & & 0,00 & \\
\hline
\end{tabular}

\subsubsection{ANÁLISIS DEL INDICADOR ENERGÉTICO EN LAS HESU}

En cuanto al aspecto que este trabajo aborda, "energía", se puede decir que las herramientas analizadas lo tratan de una manera amplia, posicionándolo en el tercer lugar de los aspectos mayormente abordados. LEED ND y BREEAM Communities le otorgan alrededor del $9 \%$ de los indicadores, mientras que CASBEE UD casi un $27 \%$. Ello denota la importancia que la energía tiene en el global de la sostenibilidad urbana. Llegados a este punto, la finalidad de realizar la revisión de indicadores radica en la necesidad de llevar a cabo una identificación de los indicadores energéticos existentes en la literatura para evaluar su adecuación en el presente estudio.

Puesto que este trabajo aborda la eficiencia energética desde la perspectiva pasiva, se analizan únicamente las subcategorías que incluyen indicadores o medidas pasivas encaminadas a mejorar el comportamiento energético en el entorno construido. La Tabla 3.18 diferencia las subcategorías del aspecto "energía" en aquellas que tratan aspectos pasivos y activos y, a su vez, indica a qué escala se hace referencia, si a la urbana o a la de edificio. 
Tabla 3.18 Clasificación de las subcategorías del aspecto "energía"

\begin{tabular}{lll}
\hline & Escala urbana & Escala de edificio \\
\hline Aspectos de diseño pasivo & $\begin{array}{l}\text { Soleamiento y sombras } \\
\text { Diseño bioclimático urbano } \\
\text { Isla de calor }\end{array}$ & $\begin{array}{l}\text { Demanda energética del edificio } \\
\text { Diseño bioclimático del edificio }\end{array}$ \\
\hline Aspectos de diseño activo & $\begin{array}{l}\text { Eficiencia energética en instalaciones y } \\
\text { monitorización }\end{array}$ & Eficiencia de los recursos en el edificio \\
& $\begin{array}{l}\text { Energía renovable } \\
\text { Suministro de energía } \\
\text { Consumo de energía }\end{array}$ & \\
\hline Otros & & $\begin{array}{l}\text { Cumplimiento de estándares y } \\
\text { normativa }\end{array}$ \\
& & Rehabilitación de edificios y adaptación \\
& de uso \\
& Diversidad de viviendas \\
& Mantenimiento de edificios \\
\hline
\end{tabular}

Se seleccionan pues cinco subcategorías: "soleamiento y sombras", "diseño bioclimático urbano", "isla de calor", "demanda energética del edificio" y "diseño bioclimático del edificio". En la Tabla 3.19 se analizan en profundidad los indicadores que contienen estas cinco subcategorías, definiendo: la herramienta de la cual proceden, el tipo (cualitativo o cuantitativo) y los aspectos con los que están interrelacionados. Para aquellos indicadores cuantitativos, se indica una descripción del método de medición propuesto por la herramienta correspondiente. Los aspectos que se consideran relevantes en el contexto de esta tesis se señalan en la última columna de la Tabla 3.19. A partir de estos, se inicia el proceso de selección de variables y covariables para evaluar el comportamiento energético del parque residencial edificatorio. 


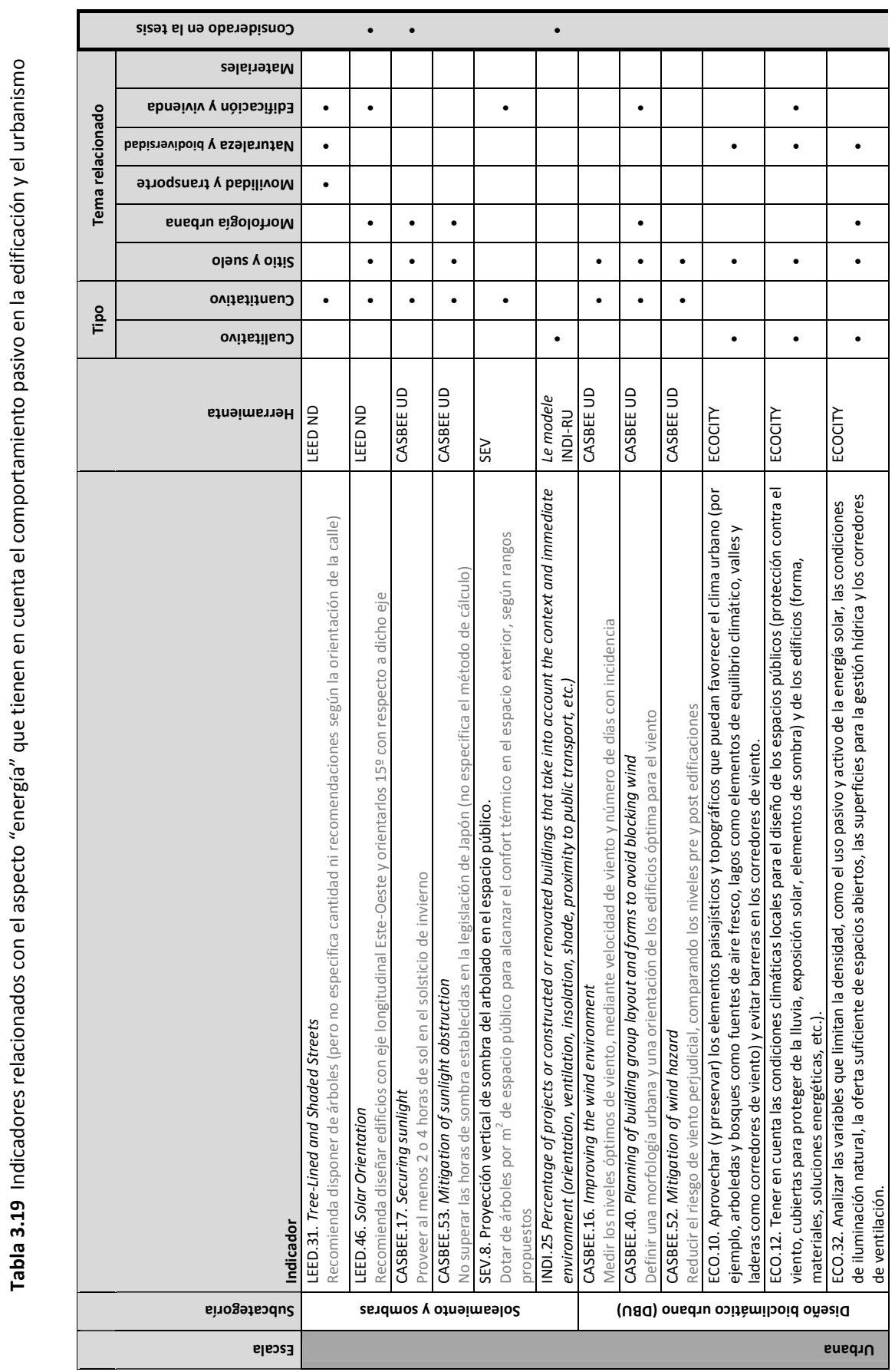




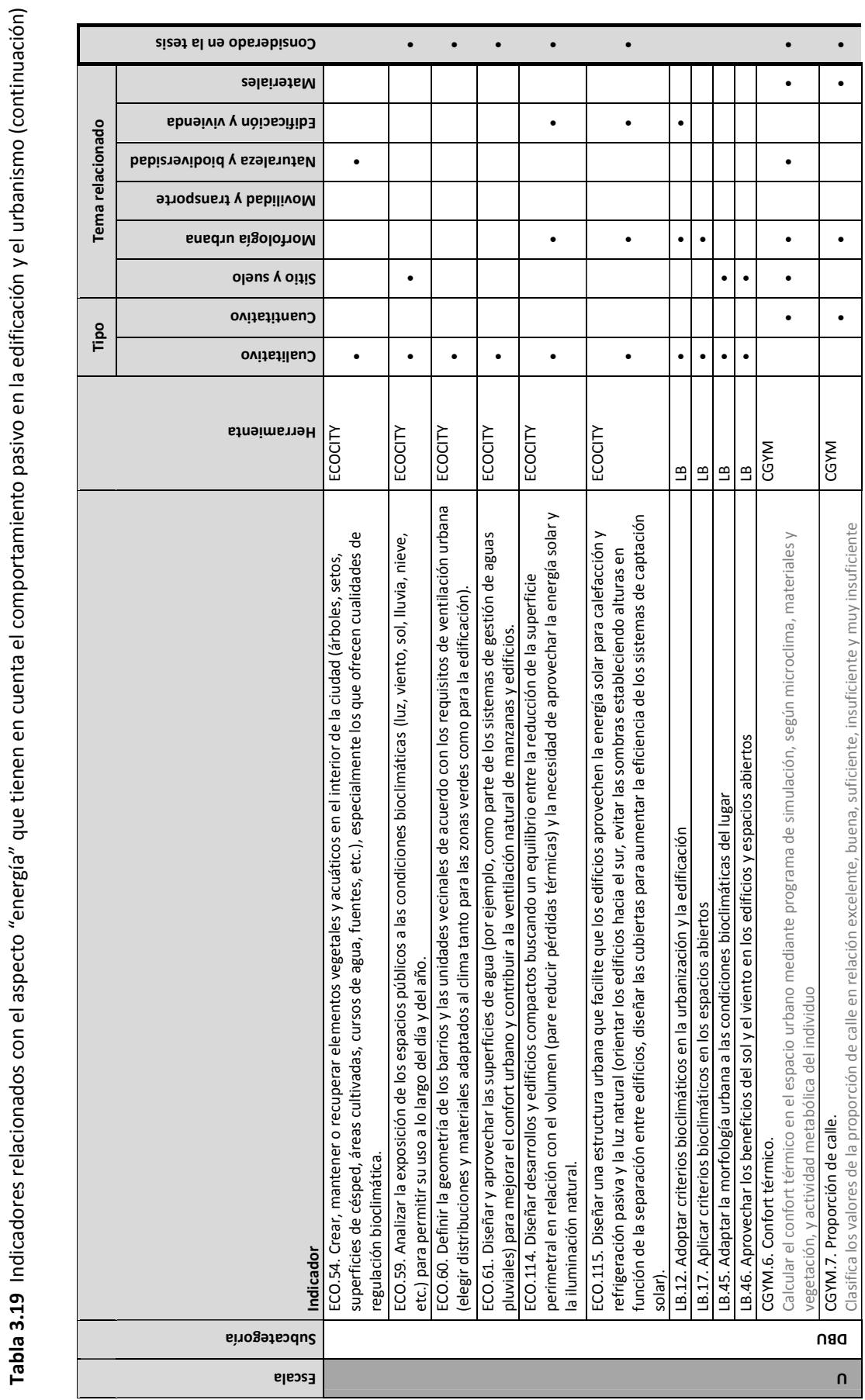




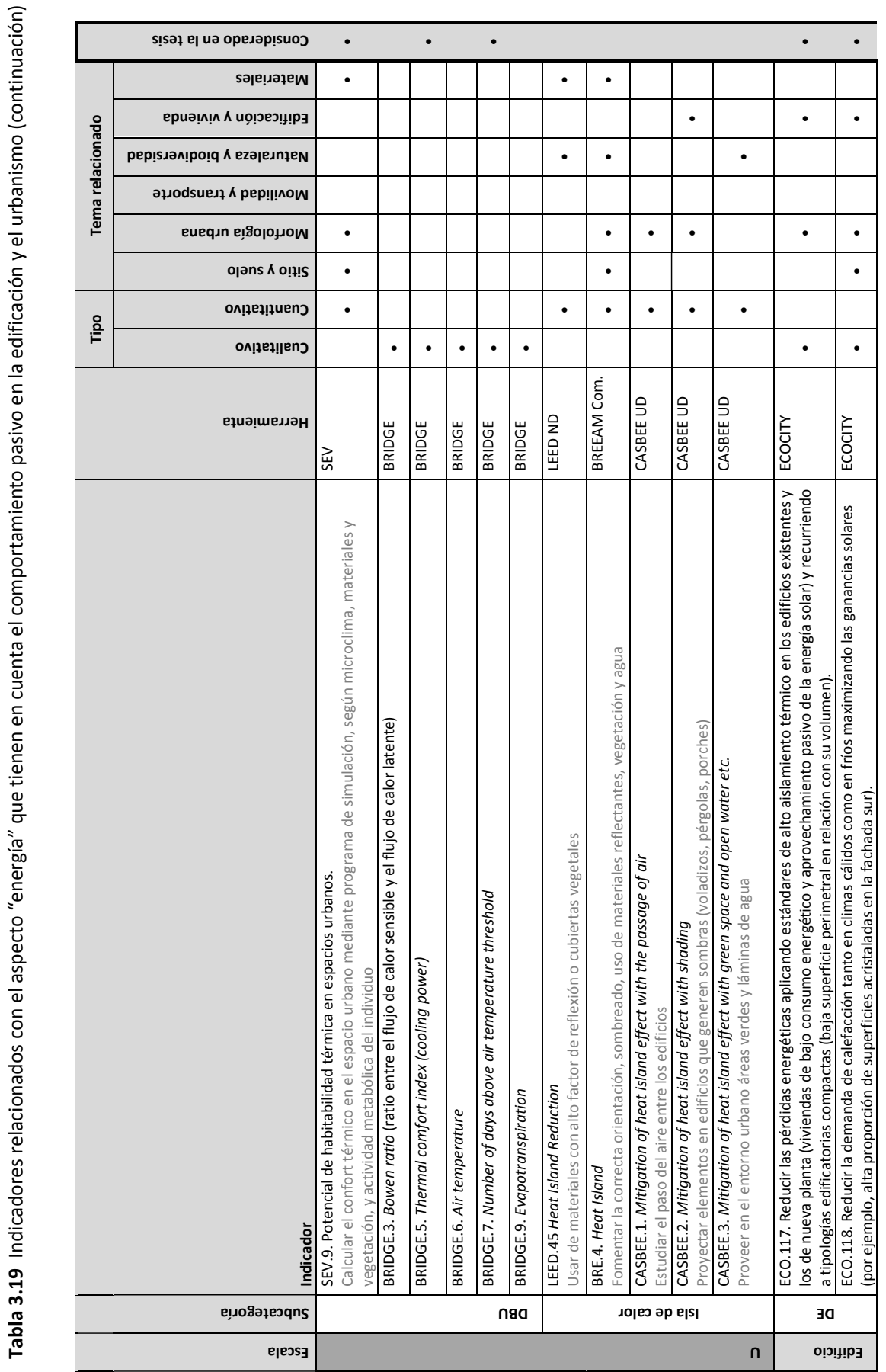




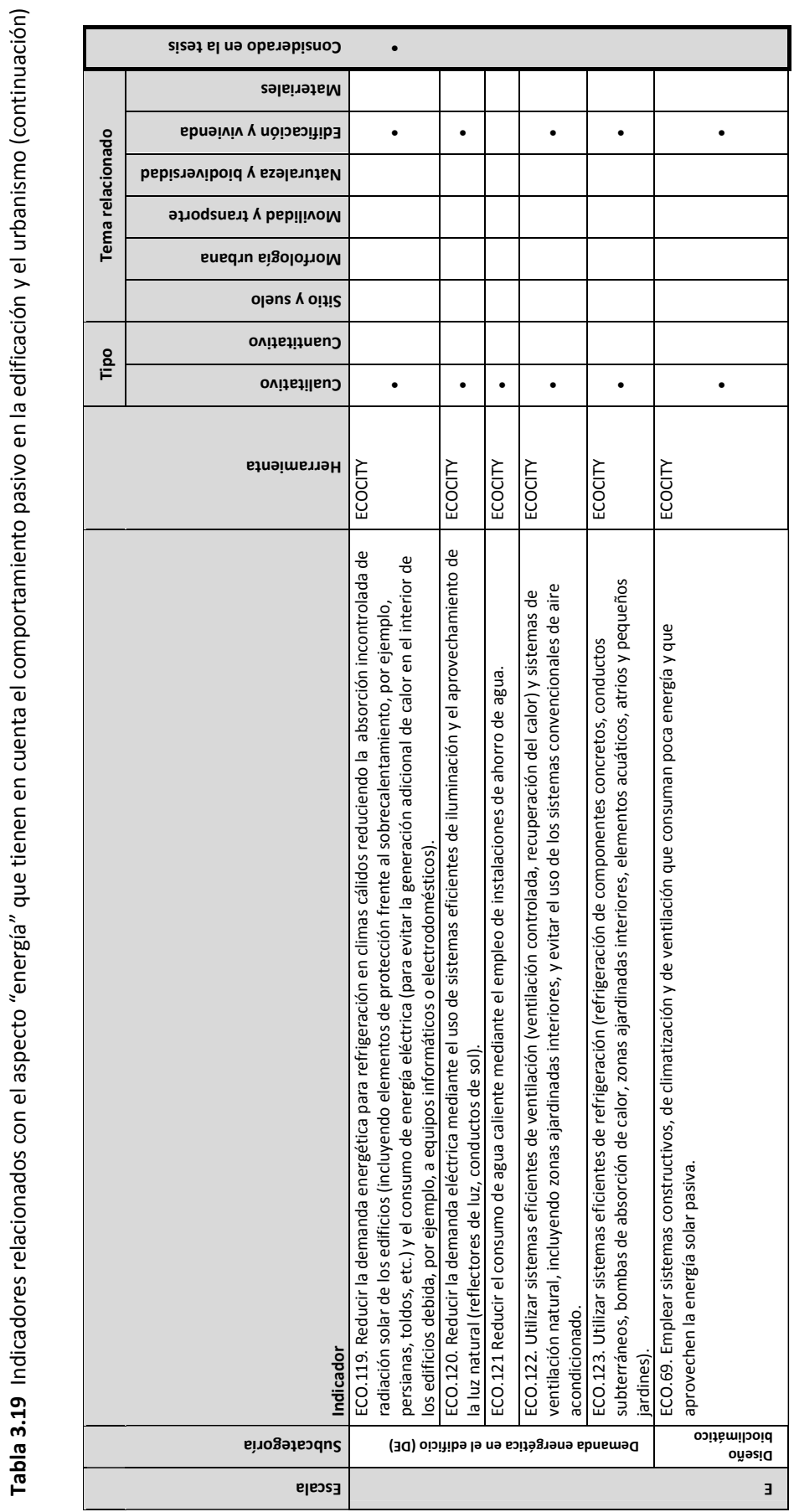


En la Tabla 3.19 se observa que predominan los indicadores cualitativos frente a los cuantitativos, de manera que las directrices que proporcionan muchas de las herramientas carecen de un método claro de evaluación. Por ejemplo, las herramientas ECOCITY y LB proponen indicadores muy interesantes, como son la adopción de criterios bioclimáticos, la adaptación de la morfología urbana a las condiciones del lugar o el estudio de la demanda energética. Sin embargo, estos no establecen criterios específicos que deban ser tenidos en cuenta para evaluar estos indicadores ni proponen recomendaciones concretas que faciliten el ponerlos en práctica y que permitan, pues, una valoración objetiva de su grado de implementación. De ahí radica la necesidad de proponer unos indicadores que, de una manera transparente, tengan en cuenta aquellos parámetros del diseño de los edificios y del entorno urbano que pueden afectar directamente a su comportamiento energético.

Por el contrario, las herramientas LEED ND, BREEAM Communities y CASBEE UD sí proponen indicadores cuantitativos, así como un método para su medición. Las herramientas SEV y CGYM, a pesar que ser cualitativas, proponen ciertos indicadores cuantitativos que sí ofrecen pautas concretas para ser valorados.

A la hora de realizar la selección de los aspectos relevantes en el contexto de esta tesis, cabe indicar que se tienen en cuenta aquellos indicadores que hacen referencia a factores pasivos propios del edificio y del espacio urbano, siempre y cuando estos últimos tengan una influencia directa sobre el edificio. Es decir, indicadores que abordan aspectos únicamente del urbanismo y no tienen una interferencia directa sobre el edificio, no son considerados en el marco de este trabajo. Es el caso de aquellos indicadores que hacen referencia a aspectos bioclimáticos relacionados con la vegetación, las condiciones de viento o el diseño edificatorio propio del entorno urbano más próximo, que por ser específicos del contexto más inmediato al edificio, requieren de un estudio pormenorizado, no admitiendo generalizaciones. Es por ejemplo el caso de LEED.31, SEV.8, LB.17 o aquellos relacionados con el efecto isla de calor.

También por ello, se mantienen al margen los indicadores que hacen referencia a las instalaciones térmicas y demás equipamiento activo del edificio. Además, aquellos relacionados con las condiciones de viento y ventilación, quedan fuera del alcance, por tratarse de aspectos complejos que requieren por sí solos una investigación independiente en profundo detalle.

Así pues, atendiendo a estos criterios, los indicadores seleccionados son los que se relacionan en la Tabla 3.20, de la cual se extraen los aspectos que serán integrados en el desarrollo de la metodología de evaluación energética. La influencia de dichos aspectos, pues, se concluye como relevante en el comportamiento energético del parque edificatorio, quedando así justificada su selección. 
Tabla 3.20 Aspectos relevantes para evaluar el comportamiento pasivo derivados de los indicadores energéticos de las HESU

\begin{tabular}{|c|c|c|c|}
\hline Indicador & Aspecto derivado & Nivel & Tipo de variable \\
\hline ECO.115 & Morfología urbana [1] & \multirow[t]{5}{*}{ Urbano } & \multirow{7}{*}{$\begin{array}{l}\text { (Co)variables influyentes } \\
\text { en el comportamiento } \\
\text { energético }\end{array}$} \\
\hline CGYM.7 & Proporción de la calle [2] & & \\
\hline LEED.46 & \multirow{3}{*}{$\begin{array}{l}\text { Orientación solar de los edificios según su } \\
\text { contexto urbano [3] }\end{array}$} & & \\
\hline CASBEE.17 & & & \\
\hline INDI.25 & & & \\
\hline ECO.114 & Grado de compacidad de los edificios [4] & \multirow[t]{2}{*}{ Edificio } & \\
\hline ECO.117 & $\begin{array}{l}\text { Transmitancia de la envolvente del edificio para } \\
\text { reducir la demanda energética [5] }\end{array}$ & & \\
\hline ECO.118 & \multirow{2}{*}{$\begin{array}{l}\text { Reducir la demanda energética de calefacción y } \\
\text { de refrigeración [6] }\end{array}$} & \multirow[t]{9}{*}{ Urbano-edificio } & \multirow{9}{*}{$\begin{array}{l}\text { Variables energéticas } \\
\text { para la evaluación del } \\
\text { comportamiento } \\
\text { energético pasivo }\end{array}$} \\
\hline ECO.119 & & & \\
\hline CGYM.6 & \multirow[t]{7}{*}{ Confort térmico en el entorno urbano [7] } & & \\
\hline SEV.9 & & & \\
\hline ECO.59 & & & \\
\hline ECO.60 & & & \\
\hline ECO.61 & & & \\
\hline BRIDGE.5 & & & \\
\hline BRIDGE.7 & & & \\
\hline
\end{tabular}

Así pues, se seleccionan como covariables las siguientes:

- La morfología urbana [1]

- La proporción de calle [2]

- La orientación solar de los edificios [3]

- $\quad$ La compacidad [4]

- La transmitancia térmica de la envolvente [5]

Como variables respuesta o indicadores para evaluar el comportamiento energético pasivo se seleccionan:

- La demanda energética [6]

- El confort térmico [7]

Se observa de la Tabla 3.19 y la Tabla 3.20 que los indicadores que abordan el edificio y el urbanismo están muchas veces íntimamente relacionados. Por ejemplo, en cuanto al aspecto de soleamiento y sombras que afectan a un edificio individual, las herramientas ensalzan el importante papel de los edificios que lo rodean, lo que reafirma una vez más que el urbanismo no puede ser obviado para analizar el comportamiento energético del parque edificatorio, aun a nivel individual de edificio. Así pues, la proporción de calle, junto con la morfología urbana, constituye un elemento de destacada importancia. En relación al edificio, la compacidad vendrá determinada por la propia morfología urbana, de manera que estas también están relacionadas. La transmitancia de la envolvente térmica es el único elemento que no viene condicionado por las otras cuatro covariables, pues únicamente depende de las soluciones constructivas que conforman los cerramientos del edificio. 
La demanda energética es seleccionada como indicador para evaluar el comportamiento energético del parque edificatorio, pues esta da una medida de las necesidades energéticas reales necesarias para alcanzar las condiciones de confort térmico, teniendo en cuenta aspectos inherentes a la configuración arquitectónica y constructiva del edificio, como son la morfología, la calidad de la envolvente o las condiciones de soleamiento, propios del diseño pasivo.

Por último, cabe indicar que, aunque destacan como especialmente interesantes los indicadores relativos al estudio del confort térmico (CGYM.6, SEV.9, ECO.59, ECO.60, ECO.61, BRIDGE.5 y BRIDGE.7), estos únicamente se tratan a nivel del espacio público urbano, y no del edificio, promocionando criterios como son la disposición de vegetación y láminas de agua que regulen el metabolismo urbano y mitiguen el disconfort térmico de los peatones. Se identifica así que no se aborda en las HESU el confort térmico propio del edificio, debido en parte, al enfoque urbano de las herramientas. Sin embargo, se considera este un factor importante para evaluar el comportamiento pasivo del parque edificado $y$, por tanto, un factor a tener en cuenta para el desarrollo de la metodología, pero abordado desde la influencia que tiene el diseño del entorno urbano en el confort térmico interior del edificio.

En este apartado, el análisis de los aspectos relacionados con la evaluación pasiva considerados por las HESU ha permitido seleccionar las variables respuesta y covariables, como elementos integrantes en el desarrollo de la metodología. Así, de la Tabla 3.20 se desprenden siete aspectos clave, dos de ellos como indicadores o variables respuesta de evaluación del comportamiento energético y los cinco restantes, como aspectos susceptibles de influir en dicho comportamiento energético del parque edificatorio, o covariables.

Seleccionadas las variables que integrarán la metodología, se abre paso a su definición. Para ello, el siguiente apartado se dedica al análisis de los aspectos considerados en las metodologías de evaluación energética analizadas en el apartado 2.4 del Capítulo 2, lo que contribuirá a definir las variables.

\subsection{ANÁlISIS DE ASPECTOS CONSIDERAdOS EN LAS MEtOdologías de EVALUACIÓN ENERGÉTICA}

Una vez las variables respuesta y las covariables han sido seleccionadas, en este apartado se analiza cómo las metodologías de evaluación energética abordan estas variables, lo que contribuirá a su definición. Partiendo de la revisión de las metodologías de evaluación energética del parque edificatorio, analizadas en el apartado 2.4 del Capítulo 2, se lleva a cabo un análisis exhaustivo de las mismas para identificar qué aspectos se consideran en cada una de ellas. Para ello, se seleccionan aquellos trabajos basados en un enfoque bottom-up que han desarrollado específicamente un modelo o metodología de evaluación energética.

La Tabla 3.21 presenta las variables que cada uno de ellos considera y las clasifica, respetando la misma estructura que en la Tabla 3.20, en: covariables influyentes en el comportamiento energético y variables energéticas que se evalúan. 


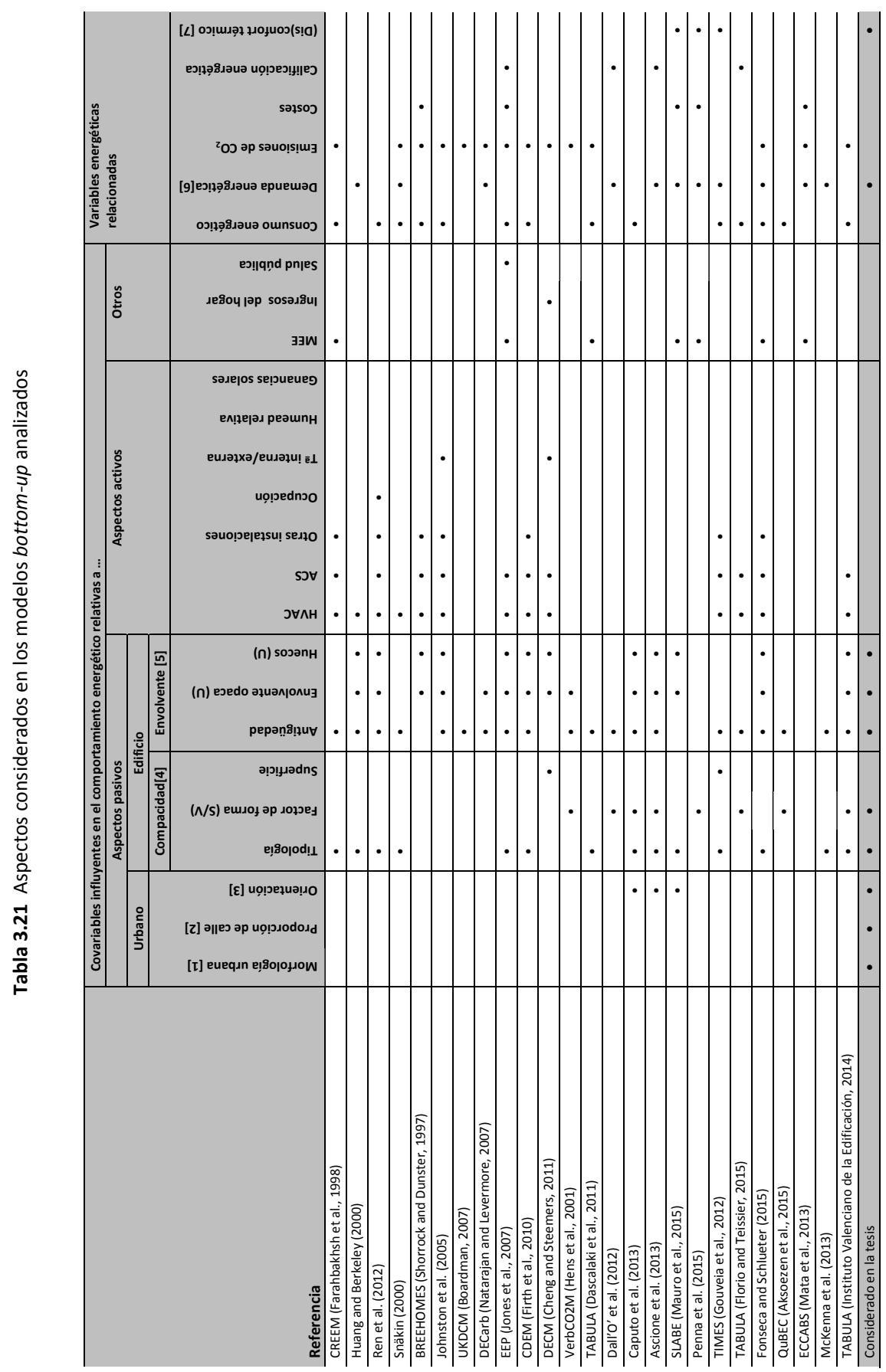


Cabe destacar que los aspectos relacionados con el entorno urbano (morfología urbana, proporción de calle y orientación), son prácticamente obviados en los estudios revisados. Sin embargo, como ya se ha apuntado anteriormente, estos cobran importancia en este trabajo, el cual integra la perspectiva urbana. Teniendo en cuenta lo expuesto en el apartado anterior 3.2.3, tanto la morfología urbana, la proporción de calle, como la orientación, son tomados como covariables susceptibles de influir en el comportamiento energético del parque edificado.

A nivel de edificio, se puede deducir de la observación de la Tabla 3.21 que, para definir el grado de compacidad, la mayoría de modelos consideran el factor de forma (S/V) y la tipología edificatoria. Por otro lado, para definir la transmitancia de la envolvente térmica, gran parte de los modelos tienen en cuenta la antigüedad del edificio, la cual lleva implícita información sobre la composición de sus cerramientos y, por tanto, de su transmitancia térmica (U). En el marco de este trabajo, tanto el factor de forma (S/V) como la antigüedad del edificio, serán tomadas como covariables.

En relación a los aspectos activos, las instalaciones térmicas (HVAC, ACS y otro equipamiento), a pesar de ser consideradas por casi la mitad de los modelos, no serán tenidas en cuenta en esta investigación, ya que la metodología a desarrollar se enfoca desde el punto de vista de comportamiento energético pasivo del parque edificado.

En cuanto a las variables energéticas analizadas, se identifica que predomina el estudio del consumo energético y las emisiones de $\mathrm{CO}_{2}$ asociadas. Sin embargo, para poder determinarlas deberían ser tenidas en cuenta las instalaciones del edificio, que como se ha indicado anteriormente, no dan muestra del comportamiento pasivo de los edificios. Lo mismo ocurre con la calificación energética. Esta es abordada en cuatro de los modelos, proporcionando una escala de valoración del consumo energético, pero sería necesario incluir las instalaciones para poder determinarla. Así, la demanda energética es considerada por la mitad de los modelos, como indicador para evaluar el comportamiento energético del parque edificado.

Por último, el confort térmico es analizado únicamente en dos de los modelos (Mauro et al., 2015; Penna et al., 2015) a través del indicador de tiempo en el que el edificio permanece en condiciones de disconfort. Sin embargo, como se apuntó en el apartado anterior, este resulta un aspecto muy interesante a ser evaluado, y más aún cuando se pretende evaluar el comportamiento energético de los edificios desde el punto de vista pasivo. Por ello, este es seleccionado como indicador variable energético en el contexto de este trabajo.

\subsection{Definición DE VARIABLES RESPUESTA y COVARIABLES}

Como conclusión de los apartados anteriores, quedan seleccionadas las siete variables que integrarán la metodología a proponer, la cual se aborda en el Capítulo 4. La Figura 3.7 muestra la selección de las variables respuesta y de las covariables. En los próximos apartados, 3.4.1 y 3.4.2, se definen las variables respuesta y las covariables, respectivamente, atendiendo a la revisión de la literatura realizada anteriormente. 


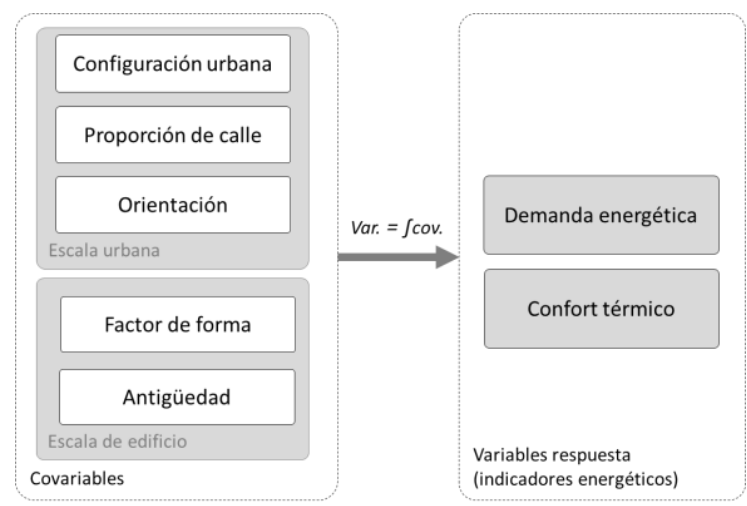

Figura 3.7 Covariables y variables respuesta seleccionadas

\subsubsection{DEFINICIÓN DE VARIABLES RESPUESTA (INDICADORES ENERGÉTICOS)}

El presente apartado define las dos variables respuesta seleccionadas, cada una de las cuales se desglosa en otras dos, distinguiendo entre el periodo de verano e invierno. Así pues, se definen cuatro indicadores cuyos valores constituirán los resultados de implementar la metodología en un área urbana consolidada.

- Demanda energética de refrigeración $\left(D_{r}\right)$ y demanda energética de calefacción $\left(D_{c}\right)$. Ambas variables miden la cantidad de energía que las instalaciones térmicas del edificio deben proporcionar para asegurar las condiciones interiores de confort, de acuerdo al uso del edificio y a la zona climática (CTE, 2013), para calefacción y refrigeración, respectivamente. Se expresa en $\mathrm{kWh} / \mathrm{m}^{2}$ año.

- Horas de disconfort en verano $\left(H D_{v}\right)$ y horas de disconfort de invierno $\left(H D_{i}\right)$. Estas son equivalentes a las horas no satisfechas de confort de acuerdo a ASHRAE y miden el tiempo en que el ratio de humedad y temperatura operativa no se corresponde con ASHRAE 552004 en verano e invierno, teniendo en cuenta el nivel de vestimenta (DesignBuilder UK, 2015); para verano e invierno, respectivamente. Se expresan en horas/año.

Tanto la demanda energética como el confort térmico constituyen dos indicadores que aportan una medida del comportamiento pasivo de los edificios. Los edificios pasivos combinan un confort térmico interior elevado con un consumo energético muy bajo. Las premisas para alcanzar estos dos objetivos son el uso de un alto grado de aislamiento térmico en la envolvente, un control riguroso de los puentes térmicos, un control de las infiltraciones de aire no deseadas, el uso de carpinterías de calidad y el aprovechamiento óptimo del soleamiento, de forma tal que mediante la ventilación mecánica a través de un recuperador de calor se consiga el aporte necesario para su climatización, tanto en invierno como en verano, sin recurrir a ningún otro sistema (Crespo et al., 2011). Por tanto, para el estudio del comportamiento pasivo de un edificio, se analizará su funcionamiento teniendo en cuenta estos factores de diseño y prescindiendo del efecto de los sistemas térmicos. Un edificio con baja demanda energética llevará asociado un bajo consumo energético para lograr las condiciones óptimas de confort, por lo que la premisa principal es limitar al máximo la demanda 
energética de los edificios, como ya exige el Código Técnico de la Edificación en su Documento Básico de Ahorro de Energía, DB HE1 Limitación de la demanda energética (CTE, 2013).

\subsubsection{DEFINICIÓN DE COVARIABLES}

A continuación, se describen las cinco covariables seleccionadas, las cuales se representan en la Figura 3.8.

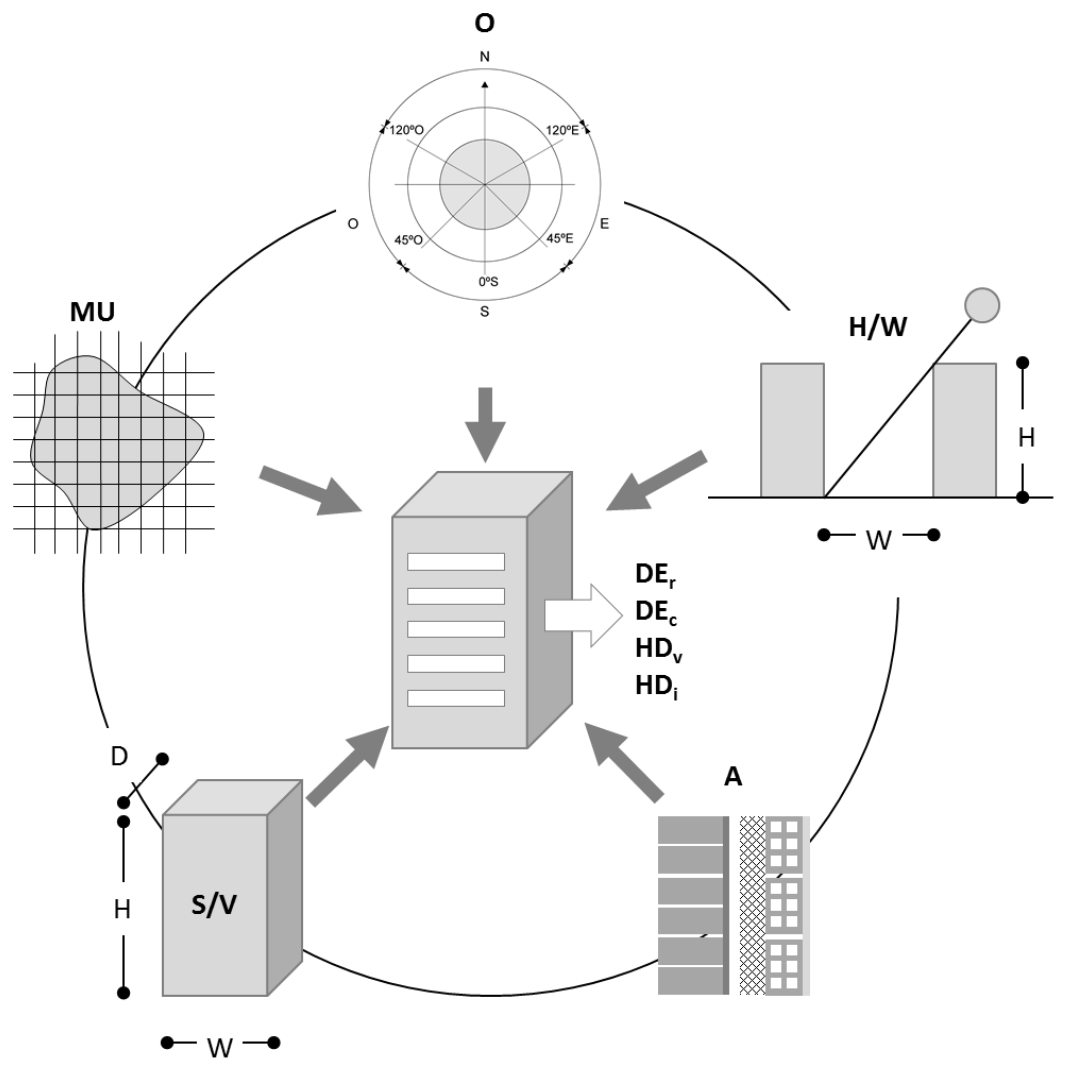

Figura 3.8 Covariables consideradas para analizar el comportamiento energético de los edificios a escala urbana

(O: orientación; H/W: proporción de calle; A: año de construcción; S/V: factor de forma; MU: configuración urbana)

\section{- Morfología urbana o patrón de manzana urbana (MU)}

La morfología urbana se refiere a la geometría del tazado urbano que define las manzanas donde los edificios están emplazados. Futcher y Mills (2013) apuntaron que el papel que juega la configuración urbana en el comportamiento energético de los edificios es habitualmente ignorado, cuando este puede influir enormemente en sus necesidades energéticas relativas a calefacción y refrigeración 
(Capeluto, 2003; Košir et al., 2014). Su impacto en los diferentes aspectos como por ejemplo, cargas energéticas, consumo energético, emisiones de $\mathrm{CO}_{2}$ y accesibilidad solar, ha sido destacado por numerosos autores. Por ejemplo, Salat (2009) indicó algunos aspectos que pueden variar considerablemente dependiendo de la morfología urbana (factor de forma de los edificios, densidad, porosidad, iluminación y ventilación natural y comportamiento de la envolvente térmica) y destacó que todos ellos afectan notablemente al comportamiento energético de los edificios. Así pues, el trazado urbano dibuja los patrones típicos de manzana urbana en una ciudad, las cuales representan la unidad urbana más pequeña que incluye no sólo el edificio aislado sino un conjunto de edificios que se comportan energéticamente como un conjunto.

Según el tipo de trazado del viario público (irregular, linear, radial u ortogonal), se conforman diferentes tipologías de manzanas. Dada la gran casuística existente, la morfología de la manzana deberá ser estudiada de forma pormenorizada para cada ciudad. La Figura 3.9 muestra un ejemplo de tipologías de manzana, originadas por un trazado de las calles que atiende a una retícula ortogonal propia de un ensanche urbano (derecha), y un ejemplo de tipologías de manzana irregular, originada por un trazado radial que da lugar a una estructura anárquica del viario, propia de un núcleo histórico (izquierda).
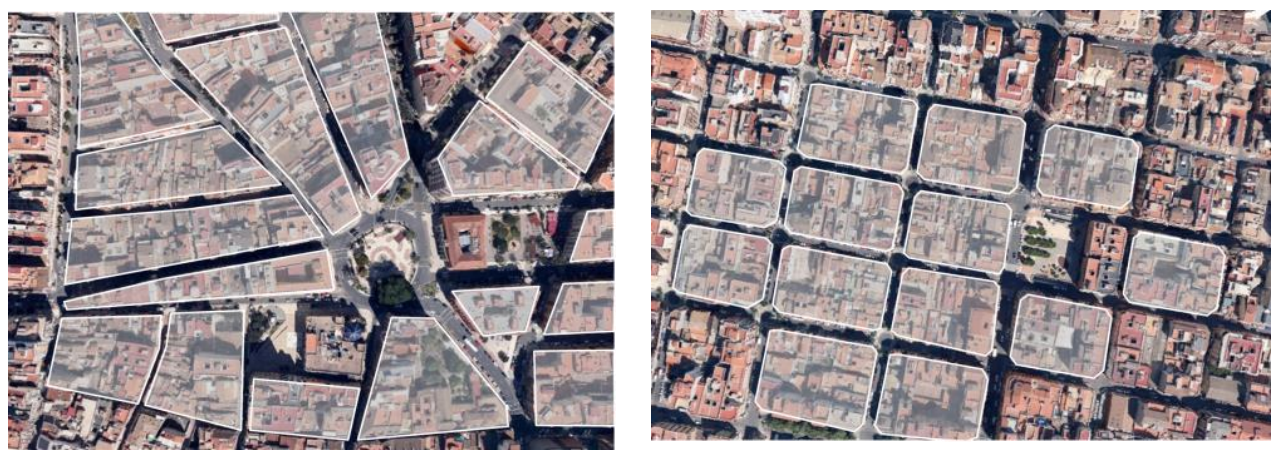

Figura 3.9 Manzanas en trazado radial (izquierda) y manzanas en trazado ortogonal (derecha)

(Fuente: elaboración propia a partir de Google Maps)

Será necesario un estudio en profundidad del planeamiento urbanístico de la ciudad para identificar los patrones de manzana urbana, que definirán su configuración.

\section{- Proporción o ratio altura-anchura de calle (H/W)}

Se define como la proporción que existe entre la distancia entre dos fachadas (W) y la altura de los edificios de los que forman parte $(\mathrm{H})$. Esta covariable $\mathrm{H} / \mathrm{W}$ incide en el confort térmico y lumínico de la calle y de los edificios, así como también en la percepción de equilibrio que se da entre el volumen edificado y el porcentaje de cielo que se visualiza desde el espacio público. Proporciona además información sobre la presión que ejerce la compacidad de un tejido urbano en la sección de calle.

La proporción H/W es responsable de la accesibilidad solar en los edificios. Altos ratios de H/W implican calles estrechas y por tanto menores oportunidades de soleamiento en los edificios de su entorno. De hecho, Okeil (2010) destacó la necesidad de definir indicadores solares para proveer a los urbanistas de herramientas para la toma de decisiones sobre el buen aprovechamiento del sol en las ciudades. Anteriormente, Oke (1988) señaló a la geometría urbana como un factor clave para el estudio de la accesibilidad solar y definió el porcentaje de superficie de iluminación en un muro 
orientado a sur para un rango de ratios $\mathrm{H} / \mathrm{W}$ en diferentes latitudes. En la misma línea, Futcher y Mills (2013) examinaron en su estudio la influencia de la forma de la calle en el comportamiento energético de los edificios del entorno, utilizando el ratio H/W. Con el mismo fin, Martins et al. (2014) propusieron en su modelo la distancia entre edificios en calles con eje norte-sur y este-oeste como un condicionante para analizar el potencial solar en la fachada de los edificios. Yezioro et al. (2006) examinaron el asoleo en las fachadas orientadas hacia los patios interiores de manzana en doce tipologías de manzana urbana con diferentes proporciones (longitud, anchura y altura).

En las propias HESU analizadas, el indicador CGYM.7 Proporción de calle, propone una clasificación de los tramos de calle en función del grado de apertura de vista en el cielo, desglosándolos en:

$$
\begin{array}{ll}
- & \mathrm{H} / \mathrm{W}<0,5 \text { : excelente } \\
\text { - } & 0,5<\mathrm{H} / \mathrm{W}<1 \text { : buena } \\
\text { - } & 1<\mathrm{H} / \mathrm{W}<2 \text { : suficiente } \\
\text { - } & 2<\mathrm{H} / \mathrm{W}<3,5 \text { : insuficiente } \\
\text { - } & \mathrm{H} / \mathrm{W}>3,5 \text { : muy insuficiente }
\end{array}
$$

La latitud tiene un papel importante en la proporción $\mathrm{H} / \mathrm{W}$, pues determina el ángulo de elevación solar. La elevación solar en el periodo estival es alta (por ejemplo, alcanza un valor de $73,45^{\circ}$ en el solsticio de verano en latitudes medias de $40^{\circ} \mathrm{N}$ ), por lo que los rayos solares no encontrarán en esta época del año dificultad en llegar a la superficie vertical de las fachadas e incluso a la superficie horizontal del viario público. Sin embargo, en el periodo invernal la elevación solar es muy baja $\left(26,55^{\circ}\right.$ en el solsticio de invierno para latitud $\left.40^{\circ} \mathrm{N}\right)$, lo que provocará que los propios edificios situados enfrente del edificio objeto de estudio obstaculicen los rayos solares en la mayoría de los casos. La Figura 3.10 muestra gráficamente ambas situaciones. Una relación alta H/W supondrá calles estrechas con alta obstrucción solar, mientras que una baja relación H/W aumentará las posibilidades de ganancia solar en los edificios que recaen a dichas calles.

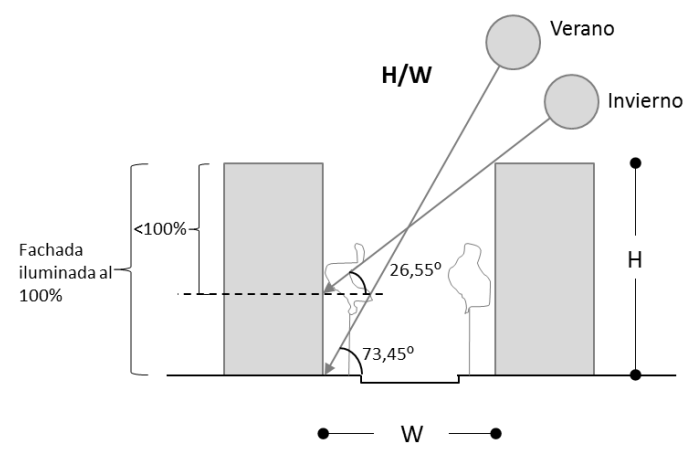

Figura 3.10 Obstrucción solar provocada por el ratio $\mathrm{H} / \mathrm{W}$ de una calle en una latitud de $40^{\circ} \mathrm{N}$

\section{- Orientación solar de la fachada principal (0)}

La orientación de una fachada se caracteriza mediante el ángulo $\alpha$, que es el formado por el norte geográfico y la normal exterior de la fachada, medido en sentido horario (CTE, 2013). Según el Código Técnico de la Edificación se distinguen ocho orientaciones, que han sido simplificadas en cuatro en el contexto del presente trabajo. La Figura 3.11 muestra cómo se ha realizado dicha 
simplificación y los sectores angulares resultantes contenidos en cada una de las cuatro orientaciones planteadas: norte, sur, este y oeste.
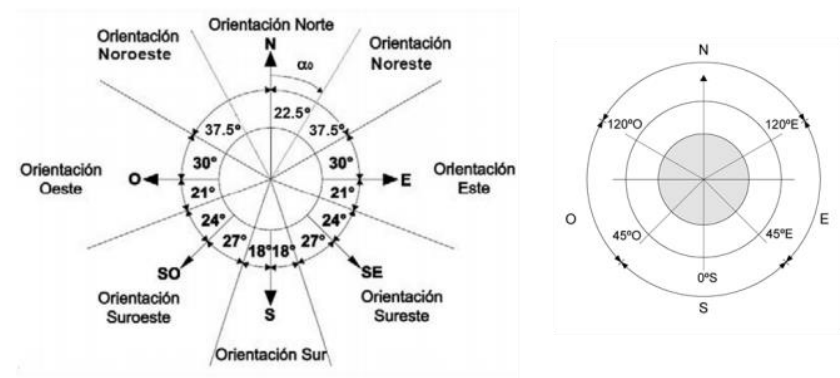

\begin{tabular}{|l|l|}
\hline Norte & $300^{\circ}>\alpha \leq 60^{\circ}$ \\
\hline Este & $60^{\circ}>\alpha \leq 135^{\circ}$ \\
\hline Sur & $135^{\circ}>\alpha \leq 225^{\circ}$ \\
\hline Oeste & $225^{\circ}>\alpha \leq 300^{\circ}$ \\
\hline
\end{tabular}

Figura 3.11 Definición de la orientación solar de la fachada principal en CTE (izquierda) y en el marco de la tesis (derecha)

\section{- $\quad$ Factor de forma del edificio (S/V)}

La tipología de edificio define su morfología. En la revisión anterior de aspectos se ha identificado que los autores caracterizan al edificio de dos formas diferentes: por su tipología edificatoria y por su factor de forma. De hecho, el factor de forma permite representar de una forma numérica la tipología del edificio. Este viene definido por la relación entre la superficie total externa de la envolvente del edificio (S) y su volumen interior $(\mathrm{V})$ :

$$
S / V\left[m^{-1}\right]=\sum \frac{S}{V}\left[m^{2} / m^{3}\right] \text { (Granadeiro et al., 2013) }
$$

donde,

$S$ superficie total externa de la envolvente del edificio $\left[\mathrm{m}^{2}\right]$

$V \quad$ volumen interno $\left[\mathrm{m}^{3}\right]$

En el presente trabajo, se ha tomado como referencia el factor de forma para identificar la tipología del edificio, de manera que esta pueda ser representada por un coeficiente numérico. El coeficiente $S / V$ cuantifica la superficie de envolvente expuesta al ambiente exterior $y$, por tanto, da una medida del intercambio de calor entre el edificio y el exterior que, como apunta Aksoezen et al. (2015), está íntimamente relacionado con el trazado urbano y la densidad edificatoria.

Desde el punto de vista energético, las tipologías se comportan de diferente forma. Por ejemplo, un edificio plurifamiliar entre medianeras y una vivienda unifamiliar aislada presentan, previsiblemente, distintos factores de forma, siendo mayor el de la vivienda aislada, pues la superficie de envolvente que está expuesta al ambiente exterior en relación a su volumen, es mucho mayor. Considerando que la temperatura exterior es generalmente el mayor condicionante para la demanda energética del edificio, el factor de forma es directamente proporcional a ésta, como apuntaba Enshen (2005) en su trabajo. Así, para un mismo volumen de edificio, un menor factor de forma significa mayor compacidad y por tanto, menor intercambio de calor entre el ambiente interior y el exterior, lo que está relacionado con una mayor eficiencia energética. Factores de forma altos implican una baja compacidad, por lo que edificios poco compactos tenderán a demandar más energía para alcanzar las condiciones de confort. 


\section{- Año de construcción (A)}

La última de las covariables corresponde a la transmitancia térmica de los cerramientos que constituyen la envolvente térmica de un edificio. La importancia de seleccionar el año de construcción del edificio como covariable reside en su fuerte interdependencia con la demanda energética, como Aksoezen et al. (2015) demostraron en su trabajo. En este sentido, como se extrae de la revisión de la Tabla 3.21 y del apartado 2.3.2 del Capítulo 2, la época de construcción de un edificio condiciona enormemente las soluciones constructivas empleadas para la ejecución de su envolvente térmica, y así lo reflejan muchos de los trabajos revisados, cuyos autores utilizan el año de construcción para definir las características de la envolvente. En la mayoría de trabajos, la línea temporal queda delimitada en diversos periodos temporales que responden a hitos históricos y legislativos, así como a situaciones económicas relevantes ocurridas en la historia.

Las diferentes soluciones constructivas de la envolvente de los edificios darán lugar a una transmitancia térmica que condicionará la transferencia de calor entre el interior del edificio y el ambiente exterior. Por ello, el año de construcción quedará definido en periodos temporales a los que se les asignará un conjunto de transmitancias térmicas para cada una de las soluciones constructivas de los cerramientos de la envolvente, típicas de cada uno de esos periodos.

\subsection{CONCLUSIÓN}

En este capítulo se ha abordado, desde la perspectiva del aspecto energético que integra la sostenibilidad urbana, la selección de las variables que serán consideradas para desarrollar la metodología de evaluación energética en el Capítulo 4. El objetivo de profundizar en las HESU es identificar qué aspectos tienen una influencia directa sobre el comportamiento energético pasivo del parque edificatorio, poniendo las miras más allá del edificio como ente aislado, y atendiendo así a la morfología urbana, que determina enormemente su comportamiento, como se desprende de la literatura revisada.

Analizadas las metodologías existentes en la literatura sobre evaluación energética del parque edificatorio, se identifica que los aspectos relacionados con el entorno urbano son prácticamente obviados por estas, las cuales ponen más énfasis en aquellos aspectos que tienen que ver con la eficiencia de las instalaciones técnicas para evaluar, principalmente, el consumo energético y las emisiones de $\mathrm{CO}_{2}$. Por ello, es necesario definir una metodología que asuma un enfoque diferente basado en los parámetros de diseño, tanto del edificio como del entorno urbano, que condicionan el comportamiento energético de los edificios que constituyen un entorno construido ya consolidado. Este aspecto le otorga a la metodología un carácter centrado en la evaluación pasiva, basada en los condicionantes del propio diseño del entramado urbano, reconocidos como estrategia fundamental para reducir la demanda energética en los edificios, previamente a hacer uso de los sistemas activos, que servirán más bien como elementos correctores.

Así pues, se identifican cuatro indicadores de evaluación energética del comportamiento pasivo, siendo estos: la demanda energética de calefacción $\left(D E_{c}\right)$ y de refrigeración $\left(D E_{r}\right)$ y las horas del disconfort en invierno $\left(H D_{i}\right)$ y en verano $\left(H D_{v}\right)$. Por otro lado, se identifican cinco covariables, tres de ellas relacionadas con el entorno urbano, morfología urbana (MU), proporción de calle (H/W) y orientación (O), y dos de ellas relacionadas con el edificio, factor de forma (S/V) y año de construcción $(A)$. 
Cabe indicar con respecto a la covariable A, la cual integra las características constructivas de la envolvente térmica de los edificios asociadas a periodos temporales de construcción, que el año de construcción se toma a partir de la información catastral que figura en la Dirección General del Catastro. Esta información no siempre se encuentra actualizada, ya que algunos edificios pueden haber experimentado reformas que no se encuentren controladas urbanísticamente. Por ello, este aspecto podría generar cierta incertidumbre en ciertos casos, a la hora de considerar las características constructivas en base al año de construcción.

\subsection{RefERENCIAS}

Aksoezen, M., Daniel, M., Hassler, U., Kohler, N., 2015. Building age as an indicator for energy consumption. Energy Build. 87, 74-86. doi:10.1016/j.enbuild.2014.10.074

Ascione, F., De Masi, R.F., de Rossi, F., Fistola, R., Sasso, M., Vanoli, G.P., 2013. Analysis and diagnosis of the energy performance of buildings and districts: Methodology, validation and development of Urban Energy Maps. Cities 35, 270-283. doi:10.1016/j.cities.2013.04.012

Boardman, B., 2007. Examining the carbon agenda via the 40\% House scenario. Build. Res. Inf. 35, 363-378. doi:10.1080/09613210701238276

Bourdic, L., Salat, S., Nowacki, C., 2012. Assessing cities: a new system of cross-scale spatial indicators. Build. Res. Inf. 40, 592-605. doi:10.1080/09613218.2012.703488

Bouzarovski, S., Sarlamanov, R., Petrova, S., 2011. The Governance of Energy Poverty in Southeastern Europe.

Byrd, Ho, 2012. Transport energy and city density: A case study of how renewable energy can reverse the curve, en: 6th Australasian Housing Researchers' Conference. Adelaide.

Capeluto, I.G., 2003. The influence of the urban environment on the availability of daylighting in office buildings in Israel. Build. Environ. 38, 745-752. doi:10.1016/S0360-1323(02)00238-X

Caputo, P., Costa, G., Ferrari, S., 2013. A supporting method for defining energy strategies in the building sector at urban scale. Spec. Sect. Long Run Transitions to Sustain. Econ. Struct. Eur. Union Beyond 55, 261-270. doi:http://dx.doi.org/10.1016/j.enpol.2012.12.006

Cheng, V., Steemers, K., 2011. Modelling domestic energy consumption at district scale: A tool to support national and local energy policies. Environ. Model. Softw. 26, 1186-1198. doi:10.1016/j.envsoft.2011.04.005

Crespo, J., Soto, J., ARKE arquitectos, Bengoa, A., Nisch, B., Díaz, N., Vogt, A., Díaz, S., Royo, R., Berger, W., Vidal, J., Hernández, M., Barambio, M., Wassouf, M., 2011. Guía del estándar Passivhaus. Edificios de consumo energético casi nulo. Fundación de la Energía de la Comunidad de Madrid, Madrid.

CTE, 2013. Orden FOM/1635/2013, de 10 de septiembre, por la que se actualiza el Documento Básico DB-HE Ahorro de Energía del Código Técnico de la Edificación, aprobado por Real Decreto 314/2006, de 17 de marzo. España.

Dall'O', G., Galante, A., Torri, M., 2012. A methodology for the energy performance classification of residential building stock on an urban scale. Energy Build. 48, 211-219. doi:10.1016/j.enbuild.2012.01.034 
Dascalaki, E.G., Droutsa, K.G., Balaras, C.A., Kontoyiannidis, S., 2011. Building typologies as a tool for assessing the energy performance of residential buildings - A case study for the Hellenic building stock. Energy Build. 43, 3400-3409. doi:http://dx.doi.org/10.1016/j.enbuild.2011.09.002

DesignBuilder UK, 2015. DesignBuilder help [WWW Document]. URL http://www.designbuilder.co.uk/helpv3.4/ (accedido 12.12.15).

Enshen, L., 2005. Are the energy efficient rates (RVRs) approximate in different climatic locations for the same building with the same reform? Build. Environ. 40, 557-562. doi:10.1016/j.buildenv.2004.06.015

Farahbakhsh, H., Ugursal, V.I., Fung, A.S., 1998. A residential end-use energy consumption model for Canada. Int. J. Energy Res. 22, 1133-1143. doi:10.1002/(SICI)1099114X(19981025)22:13<1133::AID-ER434>3.0.CO;2-E

Firth, S.K., Lomas, K.J., Wright, a. J., 2010. Targeting household energy-efficiency measures using sensitivity analysis. Build. Res. Inf. 38, 25-41. doi:10.1080/09613210903236706

Florio, P., Teissier, O., 2015. Estimation of the Energy Performance Certificate of a housing stock characterised via qualitative variables through a typology-based approach model: A fuel poverty evaluation tool. Energy Build. 89, 39-48. doi:10.1016/j.enbuild.2014.12.024

Fonseca, J.A., Schlueter, A., 2015. Integrated model for characterization of spatiotemporal building energy consumption patterns in neighborhoods and city districts. Appl. Energy 142, 247-265. doi:10.1016/j.apenergy.2014.12.068

Futcher, J.A., Mills, G., 2013. The role of urban form as an energy management parameter. Energy Policy 53, 218-228. doi:10.1016/j.enpol.2012.10.080

Gaffron, P., Huismans, G., Skala, F., 2008. Ecocity book II: how to make it happen. Vienna.

Ghosh, S., Vale, R., 2009. Typologies and Basic Descriptors of New Zealand Residential Urban Forms. J. Urban Des. 14, 507-536. doi:10.1080/13574800903265371

González, A., Donnelly, A., Jones, M., Chrysoulakis, N., Lopes, M., 2013. A decision-support system for sustainable urban metabolism in Europe. Environ. Impact Assess. Rev. 38, 109-119. doi:10.1016/j.eiar.2012.06.007

Gouveia, J.P., Fortes, P., Seixas, J., 2012. Projections of energy services demand for residential buildings: Insights from a bottom-up methodology. Energy 47, 430-442. doi:10.1016/j.energy.2012.09.042

Granadeiro, V., Correia, J.R., Leal, V.M.S., Duarte, J.P., 2013. Envelope-related energy demand: A design indicator of energy performance for residential buildings in early design stages. Energy Build. 61, 215-223. doi:10.1016/j.enbuild.2013.02.018

Hens, H., Verbeeck, G., Verdonck, B., 2001. Impact of energy efficiency measures on the CO2 emissions in the residential sector, a large scale analysis. Energy Build. 33, 275-281.

Huang, Y.J., Berkeley, L., 2000. A Bottom-Up Engineering Estimate of the Aggregate Heating and Cooling Loads of the Entire US Building Stock Prototypical Residential Buildings, en: Proceedings of the 2000 ACEEE summer study on energy efficiency in buildings. Pacific Grove, pp. 135-148.

Instituto Valenciano de la Edificación, 2014. TABULA. Catálogo de tipología edificatoria residencial en España. Valencia. 
Johnston, D., Lowe, R., Bell, M., 2005. An exploration of the technical feasibility of achieving CO2 emission reductions in excess of $60 \%$ within the UK housing stock by the year 2050. Energy Policy 33, 1643-1659. doi:10.1016/j.enpol.2004.02.003

Jones, P., Patterson, J., Lannon, S., 2007. Modelling the built environment at an urban scale-Energy and health impacts in relation to housing. Landsc. Urban Plan. 83, 39-49. doi:10.1016/j.landurbplan.2007.05.015

Košir, M., Capeluto, I.G., Krainer, A., Kristl, Ž., 2014. Solar potential in existing urban layouts-Critical overview of the existing building stock in Slovenian context. Energy Policy 69, 443-456. doi:10.1016/j.enpol.2014.01.045

Luederitz, C., Lang, D.J., Von Wehrden, H., 2013. A systematic review of guiding principles for sustainable urban neighborhood development. Landsc. Urban Plan. 118, 40-52. doi:10.1016/j.landurbplan.2013.06.002

Makido, Y., Dhakal, S., Yamagata, Y., 2012. Relationship between urban form and CO2 emissions: Evidence from fifty Japanese cities. Urban Clim. 2, 55-67. doi:10.1016/j.uclim.2012.10.006

Martins, T.A.L., Adolphe, L., Bastos, L.E.G., 2014. From solar constraints to urban design opportunities: Optimization of built form typologies in a Brazilian tropical city. Energy Build. 76, 43-56. doi:10.1016/j.enbuild.2014.02.056

Mata, É., Kalagasidis, A.S., Johnsson, F., 2013. A modelling strategy for energy, carbon, and cost assessments of building stocks. Energy Build. 56, 100-108. doi:10.1016/j.enbuild.2012.09.037

Mauro, G.M., Hamdy, M., Vanoli, G.P., Bianco, N., Hensen, J.L.M., 2015. A new methodology for investigating the cost-optimality of energy retrofitting a building category. Energy Build. 107, 456-478. doi:10.1016/j.enbuild.2015.08.044

McKenna, R., Merkel, E., Fehrenbach, D., Mehne, S., Fichtner, W., 2013. Energy efficiency in the German residential sector: A bottom-up building-stock-model-based analysis in the context of energy-political targets. Build. Environ. 62, 77-88. doi:10.1016/j.buildenv.2013.01.002

Natarajan, S., Levermore, G.J., 2007. Predicting future UK housing stock and carbon emissions. Energy Policy 35, 5719-5727. doi:10.1016/j.enpol.2007.05.034

Oke, T.R., 1988. Street design and urban canopy layer climate. Energy Build. 11, 103-113. doi:10.1016/0378-7788(88)90026-6

Okeil, A., 2010. A holistic approach to energy efficient building forms. Energy Build. 42, 1437-1444. doi:10.1016/j.enbuild.2010.03.013

Parlamento Europeo, 2008. Directiva 2008/98/CE, de 19 de Noviembre, sobre los residuos y por la que se derogan determinadas Directivas.

Penna, P., Prada, A., Cappelletti, F., Gasparella, A., 2015. Multi-objectives optimization of Energy Saving Measures in existing buildings. 49th AICARR Int. Conf. - Hist. Exist. Build. Des. retrofit 95, 57-69. doi:10.1016/j.enbuild.2014.11.003

Ren, Z., Paevere, P., McNamara, C., 2012. A local-community-level, physically-based model of enduse energy consumption by Australian housing stock. Energy Policy 49, 586-596.

Rueda, S., 2007. Barcelona, ciudad mediterránea, compacta y compleja. Una visión de futuro más sostenible. Barcelona.

Salat, S., 2009. Energy loads, CO2 emissions and building stocks: morphologies, Typologies, Energy Systems and Behaviour. Build. Res. Inf. 37, 598-609. doi:10.1080/09613210903162126 
Sharifi, A., Murayama, A., 2013. A critical review of seven selected neighborhood sustainability assessment tools. Environ. Impact Assess. Rev. 38, 73-87. doi:10.1016/j.eiar.2012.06.006

Shorrock, L., Dunster, J., 1997. The physically-based model BREHOMES and its use in deriving scenarios for the energy use and carbon dioxide emissions of the UK housing stock. Energy Policy 25, 1027-1037. doi:10.1016/S0301-4215(97)00130-4

Snäkin, J.-P.A., 2000. An engineering model for heating energy and emission assessment The case of North Karelia, Finland. Appl. Energy 67, 353-381.

Wilson, B., 2013. Urban form and residential electricity consumption: Evidence from Illinois, USA. Landsc. Urban Plan. 115, 62-71. doi:10.1016/j.landurbplan.2013.03.011

Yezioro, A., Capeluto, I.G., Shaviv, E., 2006. Design guidelines for appropriate insolation of urban squares. Renew. Energy 31, 1011-1023. doi:10.1016/j.renene.2005.05.015

Zhao, J., Xiao, L., Tang, L., Shi, L., Su, X., Wang, H., Song, Y., Shao, G., 2014. Effects of spatial form on urban commute for major cities in China. Int. J. Sustain. Dev. World Ecol. 1-8. doi:10.1080/13504509.2014.922132 



\section{DESARROLLO DE LA METODOLOGÍA}





\subsection{INTRODUCCIÓN}

El presente capítulo propone una metodología de evaluación energética pasiva del parque edificatorio residencial existente basada en las variables respuesta y covariables identificadas en el Capítulo 3 y define los procedimientos necesarios a seguir en cada una de las etapas de las que se compone.

El capítulo está estructurado según se muestra en la Figura 4.1. En el apartado 4.2 se define el objetivo general de la metodología y se presentan los requisitos que esta debe reunir. El apartado 4.3 presenta un análisis del nivel de satisfacción de los requisitos establecidos por las metodologías ya existentes en la literatura, basadas en un enfoque bottom-up, y revisadas anteriormente en los Capítulos 2 y 3 , del que se extrae la necesidad de desarrollar una nueva metodología que reúna la totalidad de los requisitos expuestos. En el apartado 4.4 se presenta la estructura de la metodología y los apartados $4.5,4.6,4.7$ y 4.8 desarrollan cada una de las etapas que la componen.

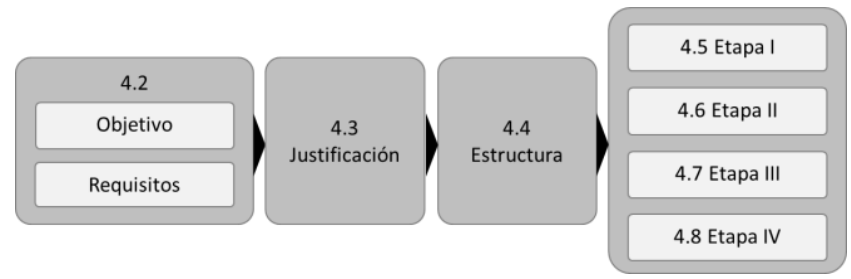

Figura 4.1 Estructura del Capítulo 4

\subsection{ObJetivo y ReQuisitos de la metodología}

El objetivo de la metodología es establecer un procedimiento transparente para la evaluación energética del comportamiento pasivo del parque edificatorio residencial existente, teniendo en cuenta los condicionantes de la morfología urbana.

Tomando como referencia las conclusiones extraídas en el Capítulo 2, se establecen los requisitos que debe de reunir la metodología, los cuales se exponen en la Figura 4.2. Como pre-requisito se establece que el enfoque en el que debe basarse la metodología es el bottom-up, es decir, siguiendo una perspectiva de abajo a arriba, de manera que la evaluación energética se efectúe sobre una muestra representativa de edificios y las conclusiones se extrapolen a escala urbana. 


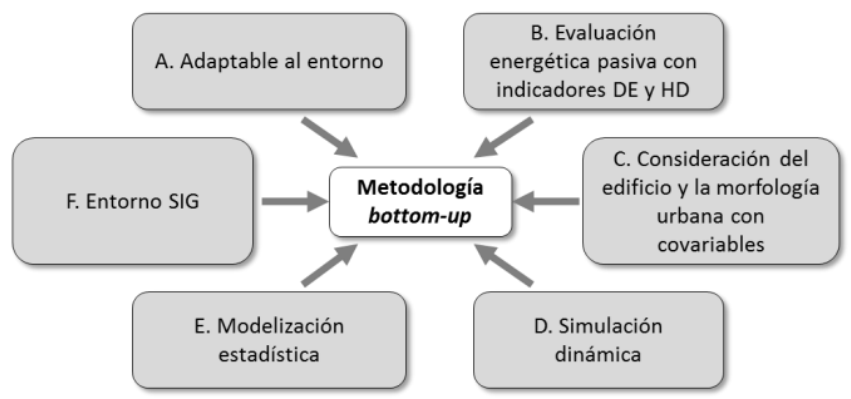

Figura 4.2 Requisitos de la metodología

A continuación, se justifica la necesidad de cada uno de los requisitos y se exponen los fundamentos teóricos tenidos en cuenta para definir cada una de las etapas.

\subsubsection{ReQuisito A: ADAPTABle Al ENTORNo}

Como se apunta en las conclusiones del Capítulo 2, cualquier herramienta o metodología debe ser capaz de adaptarse a las características del propio entorno. Retomando el análisis de las HESU, el Capítulo 3 propone una estructura común de comparación de los indicadores contenidos en ellas y la primera categoría, "sitio y suelo", hace referencia precisamente a este aspecto. Así, una metodología adecuadamente adaptada al entorno debe tener en cuenta criterios como las condiciones climáticas del lugar (aprovechar las condiciones óptimas de topografía, soleamiento o iluminación) o la compacidad, pues las condiciones del entorno son bien diferentes en una ciudad dispersa donde predominan las tipologías de vivienda unifamiliar aislada en una ciudad compacta, en la que predominan los edificios plurifamiliares que conforman manzanas cerradas.

Además, otros aspectos como el contexto socio-económico, histórico o político, pueden también determinar diferencias relevantes que deben ser considerados en el desarrollo de la metodología.

\subsubsection{ReQuisito B: eVAlUACIÓN energética PASIVA MEDIANTE LOS INDICADORES ENERGÉTICOS DE Y HD}

El parque edificatorio existente debe ser evaluado energéticamente teniendo en cuenta aspectos como la geometría, la orientación de las fachadas de los edificios, los materiales y aislamientos térmicos de los cerramientos y los usos de los espacios, aspectos que darán muestra de su comportamiento energético pasivo.

Se emplearán los cuatro indicadores (o variables respuesta) seleccionados en el Capítulo 3 para evaluar el comportamiento energético pasivo del parque edificatorio. Estos son: la demanda energética de refrigeración $\left(D E_{r}\right)$ y de calefacción $\left(D E_{c}\right)$, y las horas de disconfort de verano $\left(H D_{v}\right)$ y de invierno $\left(H D_{i}\right)$ en evolución libre. 


\subsubsection{REQUISITO C: CONSIDERACIÓN DEL EDIFICIO Y DE LA MORFOLOGÍA URBANA MEDIANTE COVARIABLES}

La metodología integrará las características físicas del entorno edificado, las cuales pueden definirse por las cinco covariables identificadas en el Capítulo 3, manzana urbana (MU), proporción de calle (ratio $\mathrm{H} / \mathrm{W}$ ) y orientación (O), a nivel urbano, y factor de forma (S/V) y año de construcción (A) a nivel de edificio. La definición de estas variables queda descrita en el referido capítulo.

\subsubsection{REQUISITO D: SIMULACIÓN DINÁMICA}

De la revisión sobre evaluación energética de edificios realizada en el apartado 2.5 del Capítulo 2 , se deriva el uso necesario de la simulación dinámica, la cual, en contraposición a los procedimientos estacionarios, ofrece un cálculo mucho más exhaustivo y permite extraer resultados detallados de forma horaria. En cuanto a la herramienta de cálculo empleada para desarrollar la metodología, podría utilizarse cualquiera de las herramientas revisadas que proporcionen los resultados de las variables respuesta.

En este caso, se selecciona el programa EnergyPlus, que funciona como motor de cálculo, y el programa DesignBuilder, que proporciona al anterior una interfaz gráfica, visual e intuitiva. EnergyPlus es capaz de ofrecer como resultado datos sobre confort térmico (número horas de disconfort en evolución libre) y demanda energética (kWh) y de reflejar la realidad del funcionamiento del edificio de una forma detallada, en lo que se refiere a ocupación, horarios de permanencia y cargas internas. El cálculo de transferencia de calor a través de las superficies lo realiza en 3D e incluye una base de datos climáticos que puede ser ampliada por las plantillas que incluye DesingBuilder. Además, por lo que respecta a la evaluación pasiva, EnergyPlus ofrece mejores capacidades que otras herramientas, pues incluye un análisis solar y de sombras muy detallado, tiene en cuenta la masa térmica para el cálculo de cargas y la presión de vapor de los materiales y ofrece amplias posibilidades para incluir diferentes tipos de acristalamiento y protecciones solares. Así, EnergyPlus junto con la interfaz de DesignBuilder consideran todos los aspectos necesarios a incluir en la metodología: clima, cargas energéticas por espacios según el uso de los mismos, consignas de confort ambiental, propiedades de cerramientos y ventanas, sistemas de iluminación y su control en función de la iluminación natural, y la interacción entre todos ellos.

\subsubsection{REQUISITO E: MOdELIZACIÓN ESTADÍSTICA}

Otro de los requisitos que debe satisfacer la metodología es emplear un método para agregar el comportamiento energético del parque edificatorio residencial a una escala urbana, como también se extrae de las conclusiones del Capítulo 2. Para ello, se empleará la modelización estadística para llevar a cabo el tratamiento estadístico de los resultados de la evaluación energética y desarrollar un modelo para agregar o extrapolar los resultados de dicho diagnóstico energético desde la escala de edificio a la escala urbana, siguiendo el enfoque bottom-up.

Para ello, se requiere una metodología estadística que permita identificar el nivel de significación de cada una de las covariables y extrapolar el comportamiento energético a un área urbana determinada objeto de estudio.

En este sentido, conocer la dinámica y el comportamiento de un determinado sistema real permite predecir valores considerando el efecto de ciertas variables. Ello se estudia en el marco de la inferencia estadística, utilizando sistemas de ecuaciones diferenciales que permiten predecir valores 
teniendo en cuenta la influencia de un conjunto determinado de covariables. Particularmente, este trabajo utiliza inferencia estadística Bayesiana, la cual proporciona un enfoque integrado para realizar inferencia, predicción y tomar decisiones.

Los modelos Bayesianos modernos utilizan métodos de simulación para trazar predicciones de distribuciones. El método Markov Chain Monte Carlo (MCMC) se utiliza ampliamente en inferencia Bayesiana, el cual permite tratar conjuntos de datos de naturaleza espacial y espacio-temporal (Blangiardo and Camaletti, 2015). MCMC se combinó con el enfoque Stochastic Partial Differential Equation (SPEDE), de cuya unión surge la Integrated Nested Laplace Approximation (INLA), un algoritmo determinístico propuesto por Rue y Martino (2007) que probó la obtención de resultados exactos y rápidos. INLA fue iniciado como un programa independiente, pero pronto fue combinado con R (R Development Core Team, 2011), un software computacional estadístico de uso libre, dando lugar a R-INLA package (INLA, 2016) (Rue and Martino, 2009a). Desde entonces, R-INLA se ha convertido en un programa popular entre estadistas e investigadores, con aplicaciones de diversa índole, como por ejemplo en los campos de la epidemiología, las ciencias ambientales y las sociales.

El presente trabajo emplea la metodología INLA, a través de R-INLA package, con el objetivo de desarrollar un modelo de predicción del comportamiento energético del parque residencial de edificios existente, considerando un conjunto de variables respuesta y covariables determinadas.

Las ventajas que aporta el uso de INLA con respecto a otros métodos, como pueden ser MCMC o los modelos lineales generalizados (Generalized Linear Models, GLM), son:

- Tiempos computacionales razonables, que permiten al usuario trabajar con modelos complejos de una forma rápida y eficaz.

- Permite integrar tantas covariables como se desee, pudiendo incorporar a posteriori nuevas covariables en el modelo.

- Permite analizar el nivel de significación de las covariables.

- Al trabajar con inferencia Bayesiana, no requiere trabajar con distribuciones exclusivamente normales.

Mediante la metodología INLA, los datos pueden ser idealizados como realizaciones de un proceso estocástico indexado, según

$$
Y(\cdot) \equiv\{y(\cdot) \in R\}
$$

donde $y(\cdot)$ es un subconjunto temporal de $R$.

Los datos pueden ser presentados por un conjunto de observaciones $y=\left\{y_{1}, \ldots, y_{n}\right\}$ (Blangiardo et al., 2013; Cameletti et al., 2013). Una estructura de correlación temporal es una entidad matemática compleja y su estimación práctica es todavía más compleja si las covariables están incluidas (Vlad et al., 2015).

En estadística, para estimar un modelo general, es útil modelar la media de la unidad $i$-ésimo utilizando un predictor linear aditivo, definido en una escala adecuada según la expresión:

$$
\eta_{i}=\beta_{0}+\sum_{m=1}^{M} \beta_{m} z_{m i}+\sum_{l=1}^{L} f_{l}\left(v_{l i}\right)
$$


donde $\beta_{0}$ es un escalar que representa el intercepto, $\beta=\left(\beta_{1}, \ldots, \beta_{M}\right)$ son los coeficientes que cuantifican el efecto de las covariables $z=\left(z_{1}, \ldots, z_{M}\right)$ sobre la variable respuesta, y $f=\left\{f_{1}(),. \ldots f_{L}().\right\}$ es un conjunto de funciones definidas en términos de un conjunto de covariables $v=v\left(v_{1}, \ldots, v_{L}\right)$. Desde esta definición, variando la forma de la función $f_{1}($.$) se pueden estimar$ diferentes tipos de modelos, desde regresión estándar $i$ jerárquica a modelos espaciales o espaciotemporales (Rue and Martino, 2009b).

Por tanto, se puede definir el modelo si añadimos las covariables oportunas. En el caso que nos atiene, la estructura general del modelo sería

$$
\eta_{i}=\beta_{0}+\sum_{i} \beta_{1} X_{i}
$$

donde $\beta_{1}$ representa el coeficiente que cuantifica el efecto de las covariables en las variables respuesta $X_{i}$, ya que no existen en este caso covariables representadas en forma de función.

\subsubsection{REQUISITO F: ENTORNO SIG}

El último de los requisitos de la metodología se relacionan con el uso de un Sistema de Información Geográfica para su planteamiento, desarrollo e implementación. De la revisión de metodologías se observa que algunos de los modelos hacen uso de SIG, lo que facilita el manejo de un volumen extenso de información y permite también su visualización en mapas.

Son múltiples las definiciones que pretenden explicar el concepto de SIG. Una definición muy precisa y que integra todos los aspectos del SIG tal y como ha evolucionado y como se conoce en la actualidad, es la siguiente: un SIG es un sistema que integra tecnología informática, personas e información geográfica y cuya principal función es capturar, analizar, almacenar, editar y representar datos georreferenciados (Olaya, 2012).

Los SIG permiten introducir información sobre mapas de forma que esta queda almacenada y disponible para ser leída y editada. Además, permiten el análisis de dichos datos, lo que incluye desde consultas sencillas hasta la elaboración de complejos modelos. Gracias a sus funciones, los SIG proporcionan resultados tales como mapas, informes o gráficos, generados a partir de la información almacenada en ellos.

En el caso de proyectos en el ámbito urbano es necesaria la manipulación y el tratamiento de un gran volumen de datos complejos, que definen las características propias de las zonas. Especialmente en estos casos, un SIG constituye una herramienta muy útil para tratar la información densa y extraer conclusiones al respecto. Además, una base de datos basada en un enfoque bottomup permite llevar a cabo acciones FIS (Forecasting Information Systems) (Moffatt, 2001), para estimar el comportamiento de los edificios en diferentes escalas espaciales y escenarios temporales. Mientras que los SIG son bidimensionales, los FIS ofrecen un análisis en cuatro dimensiones. Las dos primeras son, como en los SIG, el espacio, la tercera es el comportamiento dinámico de los edificios y la cuarta viene establecida por la evaluación de dicho comportamiento en diferentes momentos temporales. Los escenarios pueden ser condicionados por el desarrollo y crecimiento urbano, y representados alterando los datos del parque edificado. En estos términos, los FIS permiten a los urbanistas, proyectistas y otros agentes intervinientes en el proceso edificatorio, cuantificar y comparar el comportamiento energético de diferentes opciones en el desarrollo urbano. Por 
ejemplo, conocer el efecto de un futuro desarrollo urbano en una ciudad o cuantificar el impacto de la implementación de una determinada legislación en materia de eficiencia energética.

Existen diversas herramientas SIG en el mercado, algunas de ellas son de uso libre, como por ejemplo QGIS, GRASS, JUMP, SEXTANTE, gVSIG, y otros requieren de licencia de uso comercial, como ArcGIS, Idrisi TAIGA o Autodesk Map.

En el marco de esta tesis se emplea la herramienta gvSIG Desktop (Asociación gvSIG, 2014) para tratar la información de forma georreferenciada y generar mapas urbanos energéticos que representen los resultados de la evaluación energética del parque edificatorio, es decir, los resultados de las cuatro variables respuesta, $\mathrm{DE}_{\mathrm{r}}, \mathrm{DE}_{\mathrm{c}}, \mathrm{HD}_{\mathrm{v}}$ y $\mathrm{HD}_{\mathrm{i}}$.

Se selecciona la aplicación informática gvSIG Desktop, de uso libre, orientada a representar, editar, analizar y gestionar información desde el punto de vista de las relaciones espaciales. La primera versión de gVSIG surgió en octubre de 2004 y su origen se encuentra en la migración a software libre de la Generalitat Valenciana. Desde el año 2010 el proyecto es gestionado por la Asociación gvSIG. La versión utilizada en este trabajo es la v1.12. La herramienta está desarrollada bajo los valores de la colaboración y el conocimiento compartido, por lo que ha evolucionado rápidamente y en pocos años se ha convertido en una de las aplicaciones más utilizadas para la gestión de información geográfica.

\subsection{JUSTIFICACIÓN DE LA NECESIDAD DE UNA NUEVA METOdOLOGÍA}

Como se ha revisado anteriormente, existen ya diversos modelos que proponen metodologías de evaluación energética del parque edificatorio. Sin embargo, ninguno de ellos reúne los seis requisitos identificados como fundamentales. La Tabla 4.1 presenta el alcance de cada uno de los modelos analizados basados en un enfoque bottom-up, indicando el cumplimiento o no de los mismos. 
Tabla 4.1 Alcance de los modelos bottom-up analizados

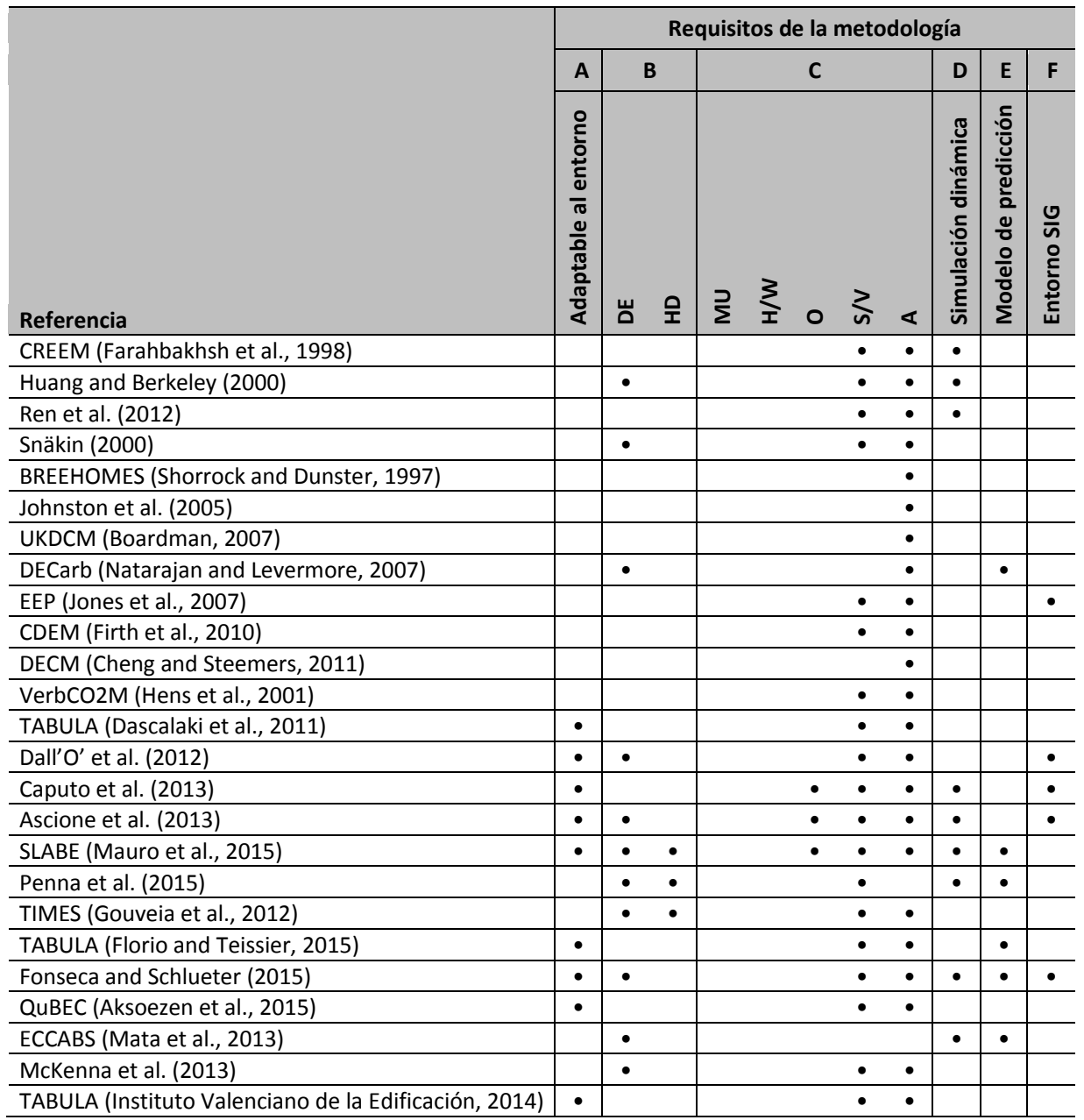

En cuanto al requisito $A$, más de la mitad de los trabajos no presentan una metodología o modelo aplicable en otros contextos. Mayoritariamente, las metodologías se desarrollan específicamente para el entorno edificado en el que se aplican, a través de un caso de aplicación que puede alcanzar la escala de barrio, ciudad o incluso país o región. Y ello representa precisamente un hándicap, al no poder ser replicada en otras localizaciones. Cabe recordar que, como se extrajo de la revisión de herramientas de evaluación de la sostenibilidad urbana realizada en el Capítulo 2, una herramienta debe ser adaptable al contexto en el que se implementa, el cual, puede ser muy variable incluso en el contexto de un mismo país. Por ello, es importante el potencial de desarrollar una metodología general, aplicable a diferentes contextos. Entre los modelos que cumplen el requisito $A$, algunos de ellos (Dascalaki et al., 2011; Florio and Teissier, 2015; Instituto Valenciano de la Edificación, 2014) están basados en el proyecto TABULA, por lo que proponen una caracterización armonizada de las 
tipologías edificatorias, en un amplio rango de países europeos. En el resto de los casos que reúnen el requisito $A$, se establece una metodología genérica que sí puede ser extrapolada en otros contextos y la desarrollan a través de un caso de aplicación.

El requisito $B$ es satisfecho parcialmente por, aproximadamente, la mitad de los modelos, que integran la demanda energética como indicador de evaluación, proporcionando una estimación del comportamiento pasivo de los edificios. No obstante, el indicador de confort térmico, únicamente es considerado en tres de ellos (Gouveia et al., 2012; Mauro et al., 2015; Penna et al., 2015), que tal y como se ha justificado anteriormente, resulta un indicador complementario al anterior para evaluar el comportamiento energético pasivo.

En cuanto al requisito $C$, se aprecia que las covariables relativas al entorno urbano son prácticamente obviadas en los modelos. Únicamente Ascione et al. (2013), Caputo et al. (2013) y Mauro et al., (2015) tienen en consideración la orientación como factor influyente en el comportamiento energético. Las covariables manzana urbana (MU) y proporción de calle (H/W) son obviadas por todos los modelos, constituyen una aportación la metodología propuesta en este trabajo. Por el contrario, las variables a nivel de edificio son ampliamente abordadas por la mayoría de los modelos. Tanto la tipología (a través de S/V) como la transmitancia térmica de la envolvente (a través del año de construcción, A), son empleados para clasificar el parque edificado.

La simulación dinámica, que comprende requisito $D$, es adoptada por nueve de los modelos. Estos confían en herramientas reconocidas internacionalmente como es EnergyPlus o TRNSYS. Sin embargo, el resto de los modelos emplean programas simplificados de evaluación desarrollados en el propio país donde se aplica el modelo, como respuesta al cumplimiento de la normativa relativa a ahorro de energía y certificación energética. Es el caso de TEE-KENAK en Grecia (Dascalaki et al., 2011), CENED+ en la región Lombardi de Italia (Dall'O' et al., 2012), ETSAP en Portugal (Gouveia et al., 2012) o CERMA en España (ATECYR and Universidad Politécnica de Valencia, 2011). La utilización de programas no dinámicos no es apropiada para analizar el funcionamiento pasivo del parque edificado, ya que no permite realizar un análisis horario, de temperaturas y del nivel de disconfort para los ocupantes. Así, la utilización de programas específicos hace compleja la aplicación de las diferentes metodologías en otras regiones, precisamente porque muchos de ellos utilizan herramientas propias desarrolladas en el país.

El requisito $E$, se refiere al método empleado para la predicción del comportamiento energético de la totalidad del parque edificado. Este aspecto, recogido en la Tabla 2.5 del Capítulo 2, puede estar basado en tres enfoques, extrapolación, bases de datos o método de predicción, como se vio en el referido capítulo. La mayoría de los modelos revisados se basan en los dos primeros y confían la agregación de resultados desde la escala de edificio a la escala urbana, por simple extrapolación de los resultados obtenidos de la evaluación de un conjunto de edificios representativos (generalmente definido únicamente por su tipología edificatoria). Los valores de los indicadores energéticos se utilizan como referencia y se asumen los mismos para todos los edificios contenidos dentro de una misma tipología de edificio. En la Tabla 4.1 únicamente se puntean los modelos basados en un modelo de predicción complejo, pues se considera que los otros dos enfoques no aportan novedad a las metodologías. Únicamente los trabajos realizados por Florio y Teissier (2015), Mata et al. (2013), Mauro et al. (2015), Natarajan y Levermore (2007) y Penna et al. (2015), se alejan de estos enfoques más simplificados y desarrollan específicamente modelos más complejos de predicción.

Por último, el requisito F es cumplido por Ascione et al. (2013), Caputo et al. (2013), Dall'O' et al. (2012), Fonseca y Schlueter (2015), Jones et al. (2007), quienes integran el entorno SIG en sus metodologías. Puede decirse que, a pesar del enriquecimiento que aporta la visualización de los resultados en mapas, los SIG tienen un bajo nivel de implementación en los modelos. 
Por tanto, ninguna de las herramientas bottom-up desarrolladas hasta la fecha integra los seis requisitos en la metodología que se propone, cuya originalidad y novedad radica en:

- Metodología genérica. La metodología proporciona las pautas y los procedimientos necesarios para implementar la metodología en otros contextos geográficos (país, región, ciudad o barrio).

- Enfoque urbano. Para realizar la evaluación energética se tiene en consideración la influencia del contexto urbano, no únicamente el edificio como elemento aislado. La mayoría de modelos analizados determinan unos valores de referencia para las variables energéticas para un conjunto de tipologías edificatorias representativas, mediante un método de cálculo de régimen estacionario o dinámico, y extrapolan dichos valores al conjunto de edificios que conforman un stock. La presente metodología tiene en cuenta, además de la tipología edificatoria, un conjunto de covariables urbanas determinadas por la configuración del entorno construido, que, al igual que el edificio, tienen una influencia significativa en el comportamiento energético del parque edificado.

- Evaluación energética pasiva. La metodología pretende evaluar el comportamiento energético pasivo del parque edificado, a través de los indicadores de demanda energética y confort térmico.

- Inferencia estadística. Para realizar el proceso de extrapolación del diagnóstico energético a escala urbana se desarrolla un modelo de predicción de las variables energéticas o indicadores $\left(D E_{r}, D E_{c}, H D_{v}\right.$ y $\left.H D_{i}\right)$ basado en la inferencia estadística, que integra tanto las covariables a nivel de edificio como a nivel urbano. Así, el valor de los indicadores energéticos puede predecirse para cada edificio que conforma el parque, de forma individualizada y pormenorizada.

- Entorno SIG. La metodología de desarrolla a través de un Sistema de Información Geográfica, que permite plasmar los resultados en mapas energéticos urbanos.

\subsection{Estructura de la metodología}

La metodología propuesta se basa en un enfoque bottom-up y combina dos técnicas propias de dicho enfoque para llevar a cabo la evaluación energética de edificios:

- Técnica de ingeniería: simulación energética de las condiciones físicas y térmicas de un conjunto de edificios de referencia representativos del parque existente, $y$

- Técnica estadística: inferencia estadística para el desarrollo de un modelo de predicción de la demanda energética y las horas de disconfort de los edificios que forman parte de un área urbana consolidada.

El marco metodológico consiste en cuatro etapas principales, descritas en la Figura 4.3, desde la parte inferior (Etapa I) a la superior (Etapa IV). Los cuadros de texto sombreados representan los resultados que se obtienen de cada etapa y que sirven como información de entrada para la siguiente. En la parte izquierda, se detallan las herramientas informáticas seleccionados para desarrollar cada una de las etapas. 


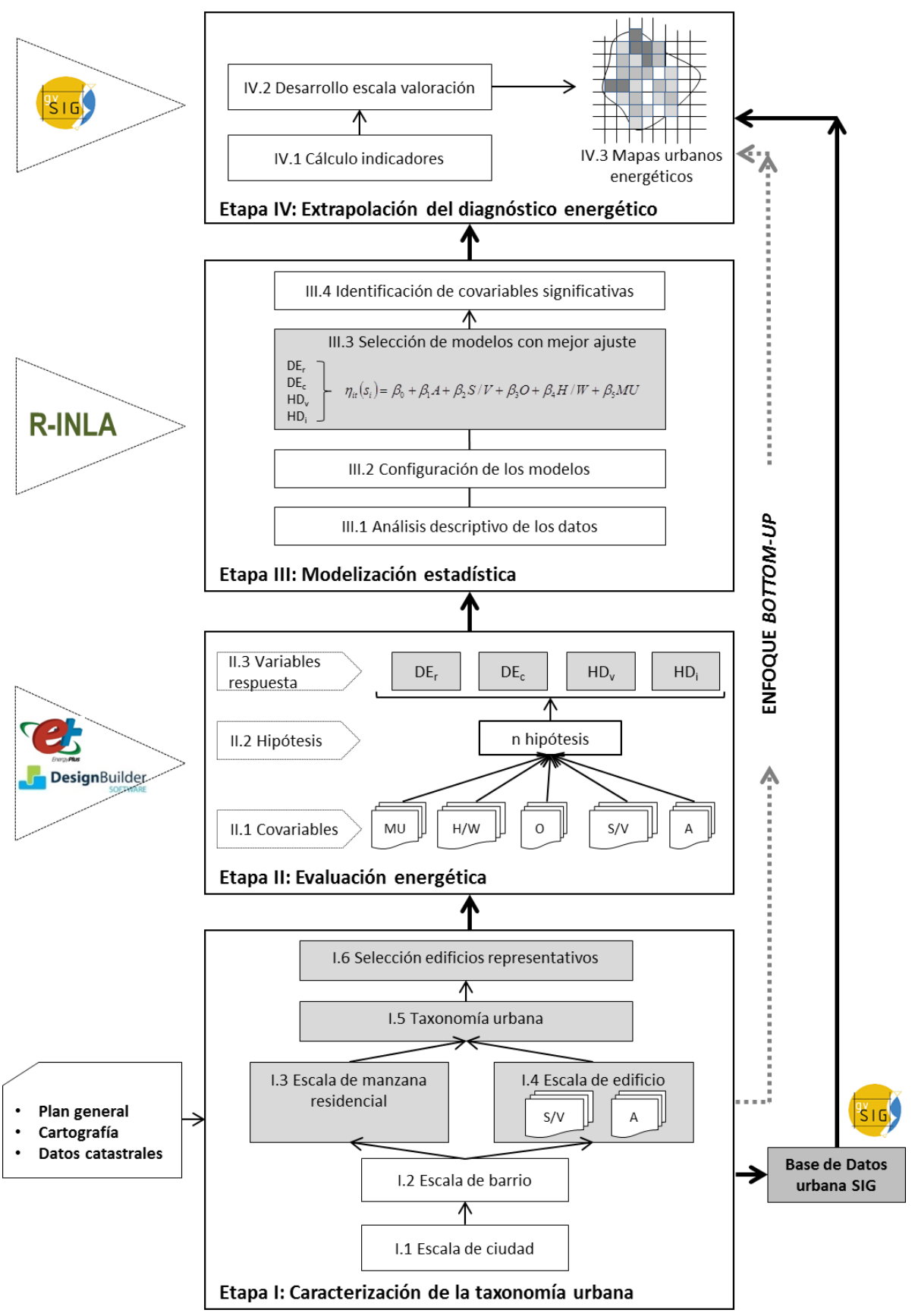

Figura 4.3 Etapas de la metodología propuesta 
- Etapa I: Caracterización de la taxonomía urbana. El parque de edificios residencial se desglosa según su taxonomía en cuatro escalas, desde la más amplia a la más concreta: ciudad, barrio, manzana urbana residencial y edificio. Para llevar a cabo la clasificación, se requiere recabar información sobre el Plan General de Ordenación Urbana (PGOU) de la ciudad, la cartografía y datos catastrales actualizados. El uso de la tecnología SIG resulta especialmente útil en esta etapa, ya que permite generar una base de datos de información urbana georreferenciada, también necesaria en el desarrollo de etapas posteriores. En esta etapa se define el conjunto de los valores para las covariables (MU, $\mathrm{H} / \mathrm{W}, \mathrm{O}, \mathrm{S} / \mathrm{V}$ y A) que adoptan específicamente para el área urbana objeto de estudio. Como resultado de la etapa se obtiene un conjunto de tipologías de manzana residencial y de tipologías edificatorias características del área urbana, que definen su taxonomía, y se selecciona un conjunto de edificios muestra representativos que serán objeto de evaluación energética en la Etapa II.

- Etapa II: Evaluación energética. En esta etapa, los edificios representativos del área urbana objeto de estudio son evaluados energéticamente, dentro de su contexto urbano. Mediante la combinación de las covariables se obtiene un conjunto de hipótesis, que serán objeto de simulación. Los resultados de simular las hipótesis de cálculo generarán los valores de las variables respuesta $\left(D E_{r}, D E_{c}, H D_{v}\right.$ y $\left.H D_{i}\right)$, los cuales proporcionarán un diagnóstico energético del comportamiento pasivo de dichas hipótesis.

- Etapa III: Modelización estadística. Los resultados obtenidos en la Etapa II son procesados y analizados estadísticamente, lo que permite cuantificar el efecto de cada covariable sobre las variables respuesta. Esta etapa tiene como resultado un conjunto de cuatro ecuaciones matemáticas que permiten predecir, mediante inferencia estadística Bayesiana, los valores de las variables respuesta para cada edificio individual que forme parte del área urbana bajo estudio.

- Etapa IV: Extrapolación del diagnóstico energético a escala urbana. Una vez obtenidas las ecuaciones para las variables respuesta, el comportamiento energético del conjunto de edificios incluidos en el área urbana objeto de estudio puede ser estimado mediante predicción, en función de los parámetros urbanos y del edificio (valores que adoptan en cada caso las covariables). Los resultados son agregados de abajo hacia arriba, siguiendo el enfoque bottom-up, y son así extrapolados desde la escala individual del edificio a la escala urbana. La tecnología SIG posibilita esta etapa y permite la representación gráfica de los resultados en mapas urbanos energéticos.

Así pues, la Etapa I constituye la recogida de información y la identificación previa de la realidad del área urbana objeto de estudio. Las Etapas II y III constituyen la fase experimental de la investigación, en la que las variables seleccionadas son analizadas de forma física y estadística. La Etapa IV deja atrás la fase experimental para retomar de nuevo la realidad urbana del entorno en el que se aplica la metodología y agregar los resultados obtenidos en las fases anteriores para extrapolarlos a una escala urbana. 


\subsection{ETAPA I: CARACTERIZACIÓN DE LA TAXONOMÍA URBANA}

El objetivo de esta etapa es caracterizar el parque residencial de edificios existente en tipologías de edificios y tipologías de manzana urbana. La Figura 4.4 muestra el diagrama de caracterización en las cuatro escalas fundamentales, de la más general a la más particular: escala de ciudad, escala de barrio, escala de manzana residencial y escala de edificio.

Dentro de las escalas de ciudad y de barrio, la Figura 4.4 indica los patrones de morfología urbana predominantes y ejemplos de los tipos de barrios que podrían encontrarse en cualquier ciudad. Dentro de la escala de manzana residencial, se indican los criterios de selección para caracterizar las tipologías de manzana, y dentro de la escala de edificio, los criterios para caracterizar las tipologías edificatorias. Una vez se alcanza la última escala, la de edificio, se seleccionan unos edificios muestra que son representativos del parque edificatorio, lo que ayudará a simplificar el proceso de evaluación energética en la Etapa II.

Además del procedimiento para la caracterización de la taxonomía urbana, como resultado de esta Etapa I, se obtiene el procedimiento para crear una base de datos SIG donde toda la información urbana quede georreferenciada en la cartografía de la ciudad. Tener la información georreferenciada permite en esta etapa, por último, asociar las tipologías edificatorias a las tipologías de manzana, de manera que el parque edificatorio puede ser cuantificado según su taxonomía y los patrones de manzanas tipo pueden ser identificados dentro del área de estudio.

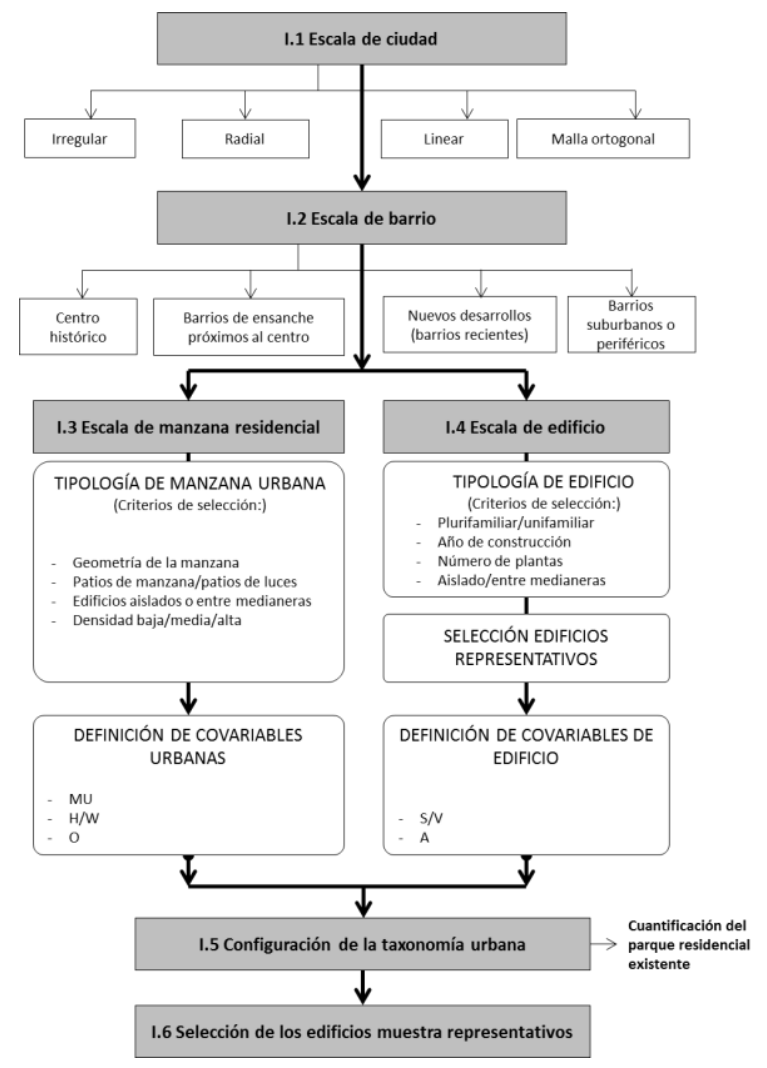

Figura 4.4 Procedimiento para la caracterización de la taxonomía urbana 


\subsubsection{I.1 ESCALA DE CIUDAD: IDENTIFICACIÓN DE PATRONES URBANOS}

En la escala de ciudad se identifica la configuración urbana de la misma. Resulta complejo describir todas las morfologías urbanas existentes, pero según Marshall (2005), existen cuatro trazados urbanos de presencia habitual en la ciudad.

- Irregular: consiste en una red desorganizada de arterias que no conforman ningún patrón específico. Es característico de los centros históricos donde los inicios del desarrollo urbano no venían marcados por ninguna ordenación urbana específica.

- Radial o radiocéntrico: organiza la ciudad mediante una estructura ramificada que parte de un centro neurálgico, recordando a la estructura conformada por la copa de un árbol.

- Lineal: consiste en una estructura predominantemente longitudinal donde se diversifican lateralmente ramificaciones poco extensas, recordando a la espina de un pez.

- Retícula ortogonal: organiza las calles en líneas paralelas y perpendiculares de manera que se encuentran en ángulos rectos, formando una estructura ortogonal.

La Figura 4.5 muestra cuatro ejemplos de ciudades españolas o barrios específicos que atienden a estos cuatro trazados urbanos.

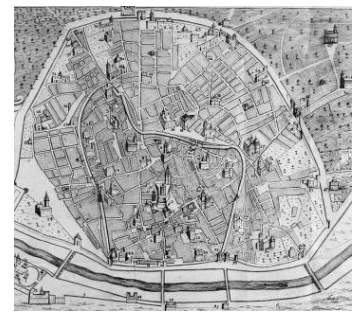

Irregular

(Centro histórico de Valencia)

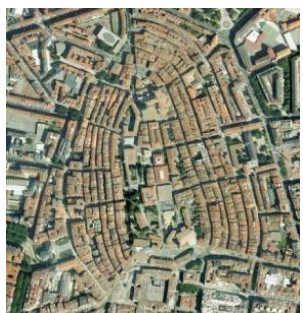

Radial

(Vitoria)

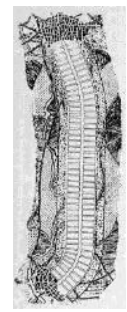

Lineal (Ciudad Lineal de Madrid)

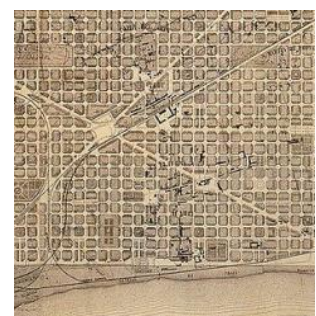

Ortogonal

(Ensanche de Barcelona)

Figura 4.5 Ejemplos de ciudades con trazados urbanos característicos de la ciudad española

Las particularidades geométricas de una ciudad pueden ser estudiadas mediante el análisis de la cartografía disponible y el PGOU. Ambos aportan la información necesaria para desmenuzar el trazado urbano e identificar los patrones urbanos que conforman la ciudad, atendiendo a su configuración urbana.

\subsubsection{I.2 ESCALA DE BARRIO: IDENTIFICACIÓN DE TIPOS DE BARRIOS}

Dentro de una ciudad, los barrios conforman sistemas urbanos de menor escala que funcionan como pequeñas ciudades. Desde el punto de vista del trazado urbano, los barrios se componen de un conjunto de manzanas de características geométricas similares que juntas le confieren cierta identidad. Por otro lado, desde el punto de vista socio-económico y socio-demográfico, los barrios suelen estar integrados por población con similar poder adquisitivo, factor que contribuye a definir su carácter, los hábitos de sus habitantes y las actividades que en él se desarrollan, lo que influye a su vez en los patrones de comportamiento que derivan en necesidades energéticas concretas. 
En general, se pueden distinguir cuatro tipos de barrios atendiendo a las razones históricas que condicionan la evolución del trazado urbano y su morfología. Éstas se describen a continuación:

- Centro histórico: formado por el casco histórico tradicional de la ciudad que marcaba los primeros asentamientos urbanos y que, habitualmente en ciertos momentos históricos, estuvo delimitado por murallas de la Edad Media que constituyeron una barrera a su expansión, originando un trazado urbano propio que perdura hoy todavía en muchos casos inamovible en el tiempo. Esta tipología de barrio está caracterizada por una estructura irregular en la que la organización de las manzanas da lugar a una configuración anárquica, sin patrones claramente definidos. Las calles tienden a ser estrechas y de anchos variables, y los edificios se erigen con alturas no siempre homogéneas; factores que dan lugar a obstrucciones solares frecuentes en las fachadas de los edificios que recaen a dichas calles. La tipología edificatoria típica en los centros históricos son las viviendas unifamiliares entre medianeras y los edificios plurifamiliares, también entre medianeras, con patios de luces pequeños, lo que da lugar a manzanas sin grandes patios internos.

- Barrios de ensanche: situados en las proximidades de los centros históricos y originados durante las primeras expansiones de la ciudad. Generalmente, su trazado urbano ya fue concebido por un planeamiento urbano que establecía ciertas ordenanzas urbanísticas, originando pues, estructuras urbanas mejor organizadas que habitualmente resultaban en retículas de geometría más regular que los anteriores. La tipología predominante en los ensanches son los edificios plurifamiliares de viviendas, en algunos casos, combinados con antiguas viviendas unifamiliares procedentes de los primeros amagos de expansión de la ciudad, todos ellos entre medianeras. Las calles son más anchas y los edificios son de mediana altura, lo que desemboca en densidades urbanas altas. En los barrios de ensanche se encuentran habitualmente manzanas urbanas cerradas de grandes dimensiones con patios internos de dimensiones considerables que favorecen la entrada de luz y la ventilación en las fachadas posteriores de los edificios que recaen en estos patios de manzana.

- Nuevos desarrollos urbanos: formados por nuevos barrios de más reciente construcción dirigidos a una población de poder adquisitivo medio y alto. En ellos abundan los edificios plurifamiliares en altura y en condominio cerrado (con zonas comunes como parques infantiles, piscinas o zonas deportivas propias) y viviendas unifamiliares aisladas, pareadas o adosadas en hilera. Generalmente las calles son anchas, lo que contribuye a disminuir las obstrucciones solares. Se caracterizan por tener una densidad media o baja.

- Barrios suburbanos o periféricos: distribuidos en zonas periféricas de la ciudad, suelen conformar pequeñas zonas suburbanas con población de bajo poder adquisitivo. Habitualmente se encuentran en ellos tipologías de vivienda unifamiliar entre medianeras conformando pequeñas manzanas urbanas, o edificios plurifamiliares de mediana altura, lo que da lugar a densidades medias o bajas.

\subsubsection{I.3 ESCALA DE MANZANA URBANA: IDENTIFICACIÓN DE PATRONES DE MANZANA}

Dentro del barrio, cada manzana puede estar constituida por un grupo de edificios dispuestos de una determinada forma que le confiere la geometría a la manzana. Su geometría depende de parámetros como:

- Forma de las calles (anchura y longitud) y altura de los edificios

- Existencia de patios interiores de luces y/o patios de manzana 
- Edificios aislados o entre medianeras

- Densidad alta, media o baja

En términos generales, la clasificación siguiendo estos parámetros resulta en manzanas lineales, irregulares, cuadradas o rectangulares, o edificios aislados que conforman por sí solos una única manzana. Los patios de manzana y los patios de luces juegan un papel muy importante en el soleamiento, la ventilación y la iluminación natural, factores que, como se ha apuntado anteriormente, condicionan enormemente el comportamiento energético de los edificios.

Para identificar las tipologías de manzana, se deberá analizar pormenorizadamente la trama urbana de la ciudad, a través de su PGOU y cartografía.

\subsubsection{I.4 ESCALA DE EDIFICIO: IDENTIFICACIÓN DE TIPOLOGÍAS EDIFICATORIAS}

Las tipologías de edificios también contribuyen a definir el paisaje urbano característico de la ciudad. De acuerdo con lo expuesto en el Capítulo 3, la tipología edificatoria se define mediante dos covariables: factor de forma (S/V) y año de construcción (A).

El factor de forma viene determinado por la morfología del edificio y se clasifica en función de tres aspectos:

- Ocupación: edificio plurifamiliar o unifamiliar

- Número de plantas: número de plantas sobre rasante, incluyendo la planta baja

- Adyacencia: edificio aislado o entre medianeras

Los tres criterios anteriores definen las dimensiones y morfología del edificio, referidas como la clase, y se pueden expresar de forma numérica mediante el factor de forma ( $S / V)$. Los edificios plurifamiliares implican mayor tamaño que las viviendas unifamiliares, lo que hará que ambas tipologías tengan distintas ratios $\mathrm{S} / \mathrm{V}$. Por otro lado, el número de plantas también condiciona el tamaño del edificio, modificando así su S/V. Y, por último, el nivel de adyacencia influirá en el intercambio de calor entre el interior del edificio y el ambiente exterior, pues un edificio aislado tiene mayor porcentaje de superficie de envolvente en contacto con el exterior que un edificio entre medianeras.

La segunda de las covariables, el año de construcción (A), concluye la definición de la tipología edificatoria. El año de construcción se identifica mediante la delimitación en los periodos temporales que comprenden hitos históricos y normativos relevantes, que marcan el paso del tiempo. Estos llevan implícito el tipo de solución constructiva empleada para ejecutar el edificio, por lo que se asociarán con un valor de transmitancia térmica para cada uno de los cerramientos del edificio.

Los periodos temporales pueden ser definidos por épocas en las que se empleaban técnicas de construcción similares, atendiendo a tres razones principales:

- Soluciones constructivas típicas. Vienen determinadas según la antigüedad del edificio, la cual condiciona las técnicas constructivas empleadas con el paso del tiempo.

- Hitos históricos. Situaciones políticas o históricas han marcado momentos relevantes en el tiempo, condicionando la manera de construir.

- Normativa de edificación en materia de eficiencia energética en edificación. La entrada en vigor o modificación de ciertas legislaciones imponen cambios que suponen puntos de inflexión en el uso de aislamiento térmico en la edificación. Con el paso del tiempo, la 
normativa endurece los requisitos y las exigencias de aislamiento térmico se ven incrementadas.

De esta manera, los periodos de construcción se caracterizan mediante la asociación de una $U$ a cada uno de los elementos que componen la envolvente térmica del edificio. Así, es posible crear un paquete de soluciones constructivas típicas asignando un valor de transmitancia térmica para cada una de ellas y para cada uno de los periodos temporales identificados. Con ello, puede elaborarse una tabla con las características contenidas en la Tabla 4.2, expuesta de forma genérica.

Tabla 4.2 Paquete de valores de transmitancias térmicas (U) para cada periodo temporal constructivo

\begin{tabular}{|l|l|l|l|l|}
\hline & \multicolumn{4}{|c|}{$\mathbf{U}\left(\mathbf{W} / \mathbf{m}^{2} \mathbf{K}\right)$} \\
\hline Elemento de la envolvente & Periodo 1 & Periodo 2 & $\ldots$ & Periodo $\mathbf{~}$ \\
\hline Fachada $\mathrm{U}_{\mathrm{F}}$ & & & & \\
\hline Cubierta $\mathrm{U}_{\mathrm{C}}$ & & & & \\
\hline Medianeras $\mathrm{U}_{\mathrm{M}}$ & & & & \\
\hline Suelo $\mathrm{U}_{\mathrm{S}}$ & & & & \\
\hline Cerramientos con terreno $\mathrm{U}_{\mathrm{T}}$ & & & & \\
\hline Huecos $\mathrm{U}_{\mathrm{H}}$ & & & & \\
\hline Puentes térmicos $\mathrm{U}_{\mathrm{PT}}$ & & & & \\
\hline
\end{tabular}

El cruce de ambas covariables, $\mathrm{S} / \mathrm{V}$ y A, dará lugar a una matriz de tipologías de edificios, tal y como se muestra en la Figura 4.6, la cual muestra el esquema conceptual para la caracterización y la obtención final de una matriz final de tipologías edificatorias.

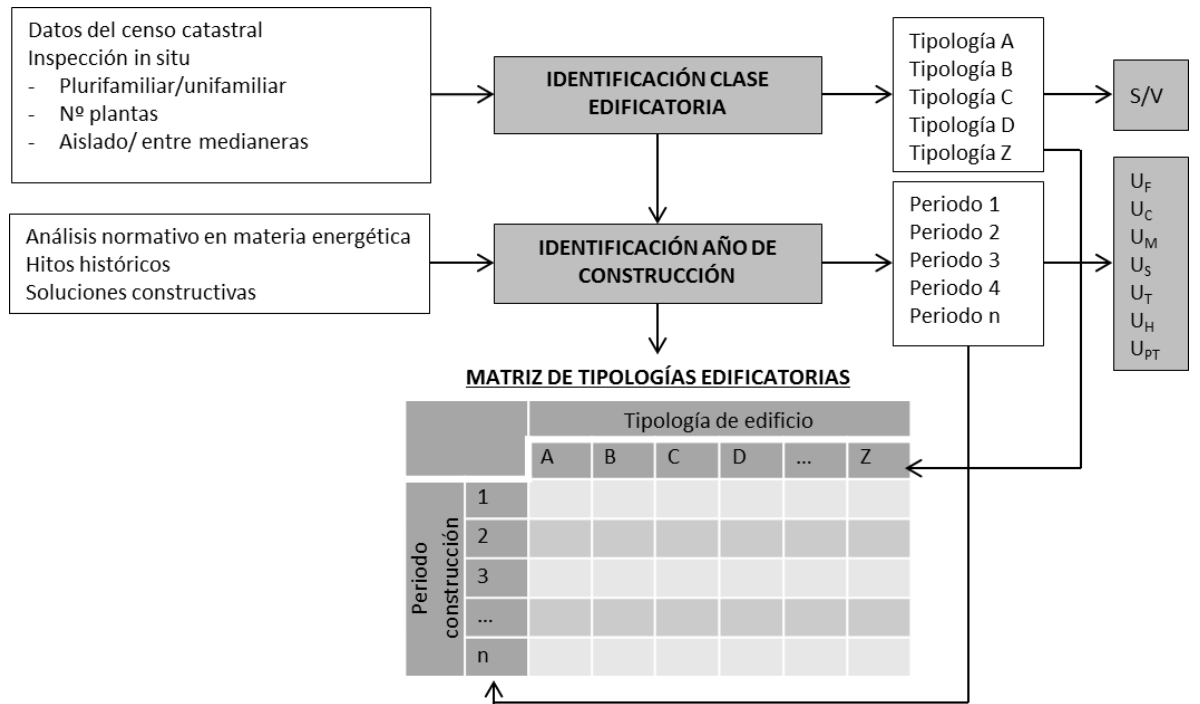

Figura 4.6 Metodología para la caracterización de la tipología edificatoria 


\subsubsection{I.5 CONFIGURACIÓN DE LA TAXONOMÍA URBANA REPRESENTATIVA}

Llegados a este punto, cabe indicar que las tipologías de edificios y las de manzana no funcionan de forma independiente, sino que están íntimamente relacionadas entre sí. Como se observa en la Figura 4.7, un determinado barrio contendrá unas tipologías de manzana concretas y, a su vez, estas contendrán unas tipologías edificatorias. Por ejemplo, una vivienda unifamiliar aislada nunca la encontraremos en una manzana urbana cerrada, donde todos los edificios presentes en ella serán entre medianeras, y así vendrá determinado en el PGOU de la ciudad. Sin embargo, sí podremos encontrar viviendas unifamiliares o plurifamiliares (ambas entre medianeras) de diferente número de plantas. Por ello, será necesario identificar las manzanas tipo presentes en el área urbana objeto de estudio y las tipologías edificatorias que tienen asociadas.

Una vez definida la taxonomía urbana en una determinada área urbana (barrio, ciudad, etc.), a través de la herramienta SIG, podrá realizarse dicha asociación, de manera que las manzanas tipo en el área de estudio podrán ser identificadas.

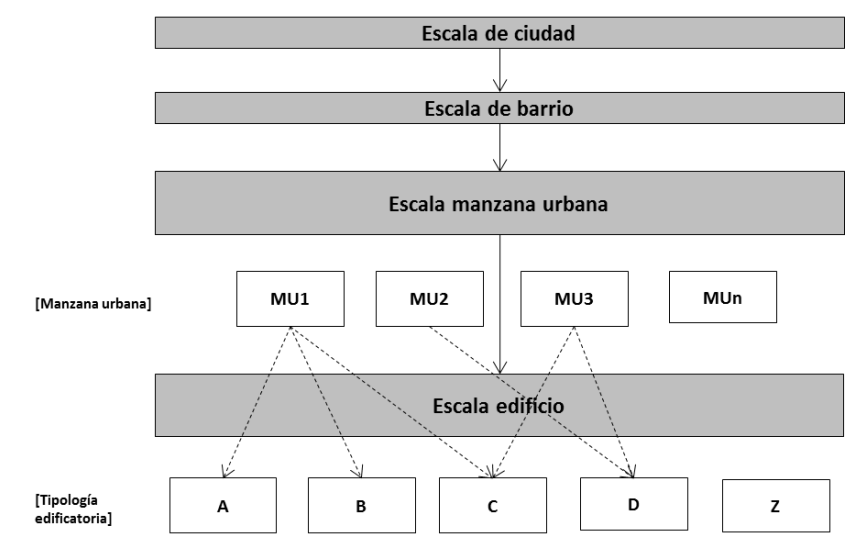

Figura 4.7 Procedimiento de asociación de tipologías edificatorias a tipologías de manzana urbana

\subsubsection{I.6 SELECCIÓN DE LOS EDIFICIOS REPRESENTATIVOS}

De cada una de las clases de edificios identificadas se selecciona un edificio que sea representativo. Para que los edificios representen correctamente a todos los de su clase, la selección se efectuará según los siguientes criterios:

- De las clases de edificios presentes en el área urbana objeto de estudio, se seleccionará un edificio real del periodo temporal predominante, es decir, el que presente mayor número de edificios construidos.

- El edificio seleccionado debe atender a su clase (mismo tipo de ocupación, número de plantas y adyacencia) y tener una superficie construida aproximada a la superficie media de todos los edificios de su tipología edificatoria. 
Estos edificios deben ser exhaustivamente analizados y descritos en detalle, para representar de forma fiable al espectro de edificios de su misma clase (tamaño, características físicas, zonificación, perfil de uso, etc.). Los edificios muestra representativos serán objeto de simulación energética en la Etapa II.

\subsubsection{CREACIÓN DE UNA BASE de dATOS EN ENTORNo SIG}

En esta Etapa I, el uso de una herramienta SIG permite taxonomizar un parque edificatorio residencial consolidado. La creación de una base de datos SIG representa una acción transversal en la metodología, que será no sólo necesaria en esta etapa, sino también en la Etapa IV, para realizar el diagnóstico energético del entorno urbano y generar los mapas energéticos urbanos.

Para poder evaluar energéticamente un entorno urbano consolidado integrado por multitud de edificios, resulta necesario conocer el número de edificios que compone cada una de las tipologías edificatorias, así como conocer su superficie construida. Con las tipologías definidas en la matriz de clases de edificios obtenida anteriormente, quedará representado todo el conjunto del parque edificatorio residencial existente del área urbana objeto de estudio. Identificando edificios representativos en cada una de las clases y evaluando éstos a nivel individual, los resultados podrán extrapolarse a escala urbana y predecir así el comportamiento energético de todo un barrio o incluso de toda una ciudad, siguiendo un enfoque bottom-up.

Los datos necesarios para poder clasificar a los edificios (antigüedad, clase edificatoria, número de plantas, superficie, etc.) son datos disponibles que pueden ser obtenidos de la Dirección General del Catastro (DGC, 2014) a través de su base de datos georreferenciada en base a la referencia catastral. La introducción de dichos datos en una herramienta SIG permite clasificar a los edificios de una determinada zona urbana en las tipologías edificatorias contenidas en la matriz, conocer el número que integra cada una de estas tipologías y, por último, visualizar dicha información en un mapa urbano. La información previa que es necesario recabar para constituir la base de datos en SIG queda resumida en la Figura 4.8. La Tabla 4.3 muestra un ejemplo de la información contenida en cada una de las columnas de la tabla de atributos a incorporar en la herramienta SIG, la cual contiene la información asociada a las parcelas catastrales y podrá ser interpretada por un SIG para generar mapas georreferenciados.

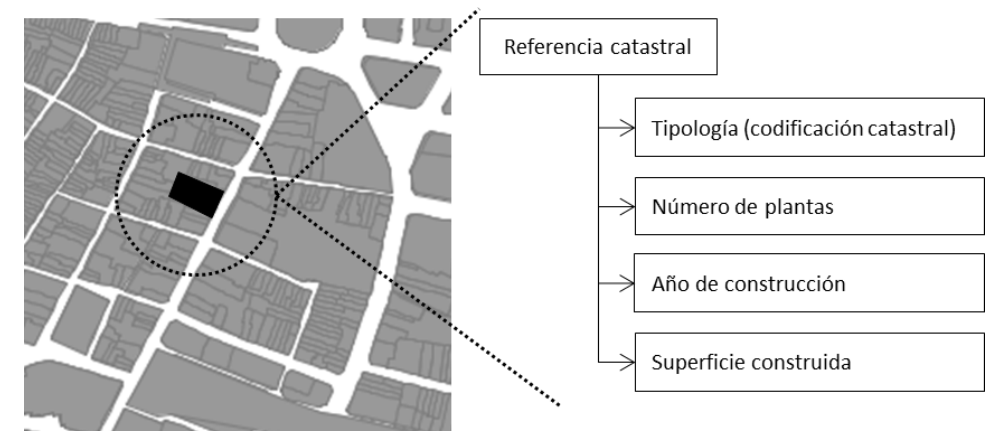

Figura 4.8 Información necesaria para cada parcela catastral 
Tabla 4.3 Ejemplo de información de entrada (tabla de atributos) para la creación de la base de datos SIG proporcionada por la DGC

\begin{tabular}{|c|c|c|c|c|}
\hline Referencia catastral & $\begin{array}{c}\text { Tipología (codificación } \\
\text { catastral) }\end{array}$ & $\begin{array}{c}\text { Número de } \\
\text { plantas }\end{array}$ & $\begin{array}{c}\text { Año de } \\
\text { construcción }\end{array}$ & $\begin{array}{c}\text { Superficie } \\
\text { construida }\end{array}$ \\
\hline 3807601YK5330N0008TA & 111 (Ver Tabla 4.4) & IV & 1976 & $19.592 \mathrm{~m}^{2}$ \\
\hline
\end{tabular}

La codificación empleada por la DGC para definir la tipología edificatoria hace referencia al uso principal al que está destinado el edificio y a su morfología (edificios plurifamiliares o unifamiliares, edificación abierta o en manzana cerrada, etc.). La codificación para los edificios de uso residencial, objeto de estudio en este trabajo, que emplea la DGC española queda reflejada en la Tabla 4.4. Determinados edificios pueden contener diferente codificación, en el caso de estar destinados a usos diversos (por ejemplo, un edificio plurifamiliar de viviendas con un local comercial en planta baja). Se deberá prestar especial atención en estos casos, para asignar el código correcto a la totalidad del edificio.

Tabla 4.4 Codificación de tipologías edificatorias según Dirección General del Catastro español (DGC, 2014)

\begin{tabular}{|l|l|l|}
\hline \multicolumn{2}{|l|}{ Codificación edificios uso residencial } \\
\hline \multirow{4}{*}{1.1 Viviendas colectivas de carácter urbano } & 1.1 .1 Edificación abierta \\
\cline { 2 - 3 } & 1.1 .2 En manzana cerrada \\
\cline { 3 - 3 } & 1.1 .3 & Garajes \\
\cline { 3 - 3 } & & Trasteros \\
\cline { 3 - 3 } & & Locales en estructura \\
\hline \multirow{2}{*}{ Viviendas unifamiliares de carácter urbano } & 1.2 .1 Edificación aislada o pareada \\
\cline { 3 - 3 } & 1.2 .2 En línea o manzana cerrada \\
\cline { 2 - 3 } & 1.2 .3 & Garajes \\
\cline { 3 - 3 } & & Porches en planta baja \\
\hline
\end{tabular}

La introducción de esta información catastral concreta de una determinada zona urbana en una herramienta SIG, permitirá obtener la taxonomía edificatoria y determinar el número de edificios que responden a cada una de las tipologías.

\subsection{ETAPA II: EVALUACIÓN ENERGÉTICA}

Esta segunda etapa de la metodología tiene por objeto establecer el procedimiento para llevar a cabo la evaluación energética pasiva de edificios, que permitirá determinar los valores de las cuatro variables respuesta en los edificios muestra representativos: demanda energética de refrigeración $\left(D E_{r}\right)$, demanda energética de calefacción $\left(D E_{c}\right)$, horas de disconfort en verano $\left(H D_{v}\right)$ y horas de disconfort en invierno $\left(H D_{i}\right)$.

Tal y como se ha indicado en el requisito D, la herramienta de cálculo adecuada es EnergyPlus (U.S. Department of Energy, 2013) con la interfaz gráfica de DesignBuilder (DesignBuilder UK, 2015), por presentar mejores capacidades para analizar el comportamiento energético pasivo del parque edificado.

Seleccionada el área urbana objeto de estudio e identificados los edificios representativos de cada tipología ( $A, B, C, \ldots, Z)$, estos serán evaluados energéticamente en su contexto urbano. La evaluación energética de los edificios representativos contribuye a simplificar el proceso de evaluación de un parque edificatorio, el cual, aun así, resulta complejo. Esta simplificación se asume para canalizar las posteriores etapas de la metodología, y extrapolar finalmente los resultados de una muestra representativa desde la escala individual de edificio a la escala de ciudad. 
Esta etapa se estructura en tres sub-etapas, tal y como se detalla en los siguientes apartados.

\subsubsection{II.1 DEFINICIÓN DE LAS COVARIABLES}

Para cada edificio representativo se definen los valores de las covariables, tanto a nivel de edificio como a nivel urbano, según las características físicas del entorno. Así, se obtendrá un abanico de posibles hipótesis por combinación de todas ellas, como se analizará en el siguiente apartado.

En el Capítulo 3 se han definido las tres covariables que establecen los parámetros necesarios para definir las tipologías de manzana y sus condicionantes del entorno urbano. Estas son:

- Patrón de manzana urbana (MU)

- $\quad$ Ratio altura-anchura de calle (H/W)

- Orientación solar de la fachada principal (O)

A nivel de edificio, también en el Capítulo 3, se han definido las dos covariables que caracterizan la tipología edificatoria:

- $\quad$ Factor de forma $(S / V)$

- $\quad$ Año de construcción (A)

Los valores de las cinco covariables deberán ser definidos para las tipologías de manzana y de edificio identificadas en el área urbana objeto de estudio.

\subsubsection{II.2 Planteamiento de las hipótesis de CÁlculo}

La Figura 4.9 presenta el diagrama de flujo para el planteamiento de hipótesis objeto de evaluación energética, a partir de la identificación de la taxonomía representativa.

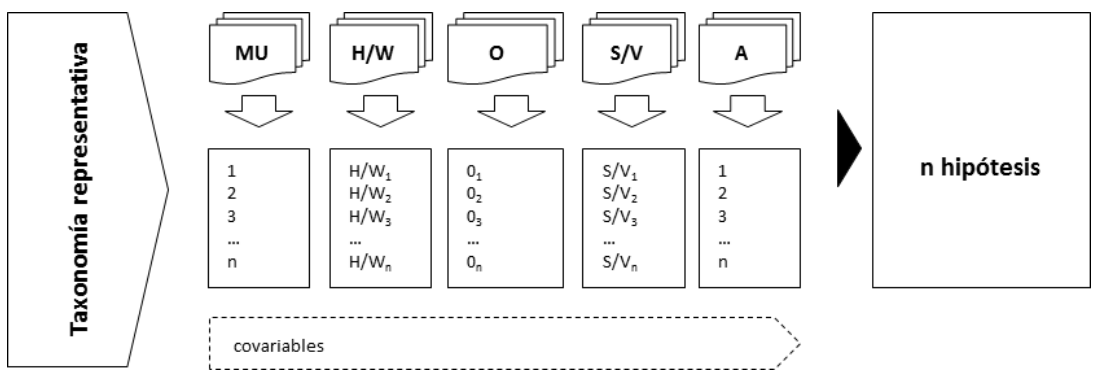

Figura 4.9 Procedimiento a seguir para el planteamiento de las hipótesis objeto de simulación energética

El número de hipótesis a conformar para cada edificio representativo vendrá dado por el número de posibles combinaciones entre todas las covariables, según la expresión:

$$
N_{\text {hipotesis }}=n_{M U} \times n_{H / W} \times n_{O} \times n_{S / V} \times n_{A}
$$




\subsubsection{II.3 DEFINICIÓN DE LOS PARÁMETROS DE CÁLCULO PARA LA OBTENCIÓN DE LAS VARIABLES RESPUESTA}

Conformadas las hipótesis de cálculo, se procede a la simulación energética dinámica. Para que los resultados de todas las hipótesis sean objetivamente comparables, los parámetros de entrada en la simulación de las hipótesis deben ser los mismos en todas ellas. Solamente así podrá determinarse la influencia que cada covariable tiene en la demanda energética y las horas de disconfort.

Así pues, deben definirse los parámetros en relación a las condiciones climáticas, densidad de ocupación, patrones de comportamiento de los ocupantes, tasas metabólicas y nivel de vestimenta, temperaturas de consigna, ganancias internas, condiciones de soleamiento y sombras, tasa de infiltración de aire y demanda de ACS, según se describe en el apartado 2.5.1 del Capítulo 2.

Tras simular las hipótesis, se obtienen los valores de las variables respuesta para cada una de las hipótesis planteadas, estas son:

- Demanda energética de refrigeración $\left(D E_{r}, k W h / m^{2} a n ̃ o\right)$

- Demanda energética de calefacción $\left(D E_{c}, k W h / m^{2} a n ̃ o\right)$

- Horas de disconfort en verano $\left(H D_{v}\right.$, horas/año)

- Horas de discomfort en invierno $\left(H D_{i}\right.$, horas/año)

\subsection{ETAPA III: MODELIZACIÓN ESTADÍSTICA}

Obtenidos los valores de las variables respuesta para cada una de las hipótesis planteadas, el objetivo de esta tercera etapa de la metodología es configurar un modelo de predicción que permita estimar las variables respuesta en un parque edificatorio consolidado, mediante inferencia estadística. Como se cita anteriormente en el requisito E de la metodología, se hará uso del método R-INLA para obtener las cuatro ecuaciones matemáticas que integren las covariables identificadas.

La Figura 4.10 establece el enfoque seguido para el desarrollo del modelo de predicción.

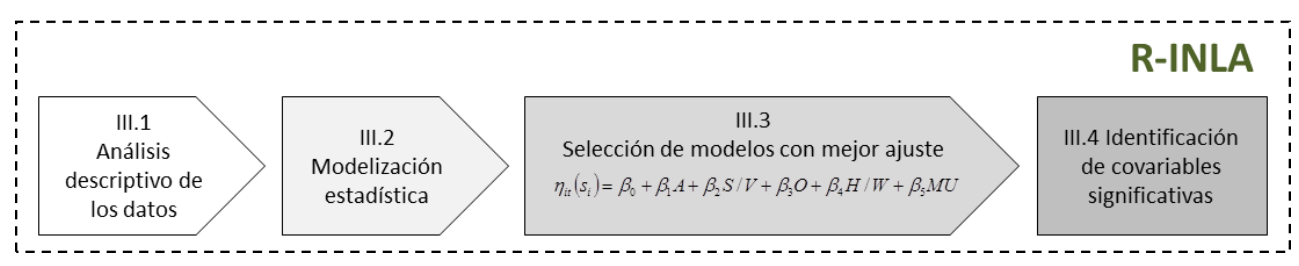

Figura 4.10 Enfoque metodológico para la modelización estadística

\subsubsection{III.1 ANÁLISIS DESCRIPTIVO DE LOS DATOS}

Los datos obtenidos de las simulaciones marcan el punto de partida de la modelización estadística. Estos deben ser tratados estadísticamente, de forma numérica y gráfica. Para ello, se estudian las medias, medianas, varianzas, percentiles e intervalos, por un lado, y los histogramas y diagramas de cajas y bigotes, por otro. 
Este análisis se puede realizar por medio de programas informáticos. En este caso, se selecciona el software $R$, por ser de uso libre y proporcionar un entorno completo para el análisis de datos y obtención de gráficos (R Development Core Team, 2011). Además, utilizado en combinación con la librería INLA (R-INLA package), permite llevar a cabo, posteriormente, la modelización estadística, tal y como se indica en el apartado 4.2 .5 de este capítulo.

\subsubsection{III.2 CONFIGURACIÓN DE LOS MODELOS}

A la expresión definida en el apartado 4.2.5

$$
\eta_{i t}\left(s_{i}\right)=\beta_{0}+\sum_{i} \beta_{1} X_{i}
$$

se le añaden las cinco covariables seleccionadas, $\mathrm{MU}, \mathrm{H} / \mathrm{W}, \mathrm{O}, \mathrm{S} / \mathrm{V}$ y $\mathrm{A}$, con sus correspondientes coeficientes $\beta_{1}$, que cuantifican el efecto de las covariables sobre las variables respuesta.

Con ello, se conforma la batería de modelos, de manera que se agotan todas las combinaciones posibles de covariables para analizar su efecto sobre las variables respuesta. Se desea comparar el efecto de la covariable manzana urbana (MU) en las diferentes variables respuesta, por lo que se conforma en primer lugar, dos baterías de modelos: la primera, considera únicamente cuatro covariables ( $\mathrm{H} / \mathrm{W}, \mathrm{O}, \mathrm{S} / \mathrm{V}$ y A) por separado (ver Tabla 4.5), mientras que la segunda considera esas cuatro covariables de forma conjunta (Tabla 4.6). Por otro lado, si se considera la covariable MU como una covariable más dentro del modelo, se obtienen otras dos baterías de modelos: una tercera considerando las cinco covariables de forma independiente ( $\mathrm{H} / \mathrm{W}, \mathrm{A}, \mathrm{O}, \mathrm{S} / \mathrm{V}$ y MU) (Tabla 4.7), y una cuarta considerando las cinco covariables pero de forma conjunta (Tabla 4.8).

De forma genérica, se presenta en la Tabla 4.5, Tabla 4.6, Tabla 4.7 y Tabla 4.8 las baterías de modelos que pueden obtenerse, donde cada una de las celdas representa un modelo de predicción distinto.

Tabla 4.5 Primera batería de modelos considerando las covariables $\mathrm{H} / \mathrm{W}, \mathrm{A}, \mathrm{O}$ y S/V por separado, comparando las MU

\begin{tabular}{|c|c|c|c|c|c|}
\hline & & $\mathrm{H} / \mathrm{W}$ & A & $\overline{0}$ & $s / V$ \\
\hline \multirow[t]{4}{*}{ MU1 } & $\mathrm{DE}_{\mathrm{r}}$ & & & & \\
\hline & $\mathrm{DE}_{\mathrm{c}}$ & & & & \\
\hline & $H D_{v}$ & & & & \\
\hline & $H D_{i}$ & & & & \\
\hline \multirow[t]{4}{*}{ MU2 } & $\mathrm{DE}_{\mathrm{r}}$ & & & & \\
\hline & $\mathrm{DE}_{\mathrm{C}}$ & & & & \\
\hline & $H D_{v}$ & & & & \\
\hline & $H D_{i}$ & & & & \\
\hline \multirow[t]{4}{*}{$\mathrm{MU}_{\mathrm{n}}$} & $D E_{r}$ & & & & \\
\hline & $\mathrm{DE}_{\mathrm{C}}$ & & & & \\
\hline & $H D_{v}$ & & & & \\
\hline & $H D_{i}$ & & & & \\
\hline
\end{tabular}


Tabla 4.6 Segunda batería de modelos considerando las covariables H/W, A, O y S/V de forma conjunta, comparando las MU

\begin{tabular}{|c|c|c|c|c|c|}
\hline & & $\mathrm{H} / \mathrm{W}$ & A & 0 & $S / V$ \\
\hline \multirow[t]{4}{*}{ MU1 } & $\mathrm{DE}_{\mathrm{r}}$ & & & & \\
\hline & $\mathrm{DE}_{\mathrm{C}}$ & & & & \\
\hline & $\mathrm{HD}_{\mathrm{v}}$ & & & & \\
\hline & $H D_{i}$ & & & & \\
\hline \multirow[t]{4}{*}{ MU2 } & $\mathrm{DE}_{\mathrm{r}}$ & & & & \\
\hline & $\mathrm{DE}_{\mathrm{C}}$ & & & & \\
\hline & $\mathrm{HD}_{\mathrm{v}}$ & & & & \\
\hline & $H D_{i}$ & & & & \\
\hline \multirow[t]{4}{*}{$\mathrm{MU}_{\mathrm{n}}$} & $\mathrm{DE}_{\mathrm{r}}$ & & & & \\
\hline & $\mathrm{DE}_{\mathrm{C}}$ & & & & \\
\hline & $H D_{v}$ & & & & \\
\hline & $H D_{i}$ & & & & \\
\hline
\end{tabular}

Tabla 4.7 Tercera batería de modelos considerando todas las covariables (H/W, A, O, S/V y MU) por separado

\begin{tabular}{|l|l|l|l|l|l|}
\hline & $H / W$ & $A$ & 0 & $S / V$ & $M U$ \\
\hline$D_{r}$ & & & & & \\
\hline$D_{C}$ & & & & & \\
\hline$H D_{v}$ & & & & & \\
\hline$H D_{i}$ & & & & & \\
\hline
\end{tabular}

Tabla 4.8 Cuarta batería de modelos considerando todas las covariables (H/W, A, O, S/V y MU) de forma conjunta

\begin{tabular}{|c|c|c|c|c|c|}
\hline & $\mathrm{H} / \mathrm{W}$ & A & 0 & $S / V$ & $\mathrm{MU}$ \\
\hline \multicolumn{6}{|l|}{$\mathrm{DE}_{\mathrm{r}}$} \\
\hline \multicolumn{6}{|l|}{$\mathrm{DE}_{\mathrm{C}}$} \\
\hline \multicolumn{6}{|l|}{$\mathrm{HD}_{\mathrm{v}}$} \\
\hline$H D_{i}$ & & & & & \\
\hline
\end{tabular}

\subsubsection{III.3 SELECCIÓN DE MODELOS CON MEJOR AJUSTE}

Una vez obtenidas las baterías de modelos, la comparación entre todos ellos puede llevarse a cabo mediante el parámetro Deviance Information Criterion (DIC) (Spiegelhalter et al., 2002), que establece un criterio de comparación de modelos Bayesianos, definido por la expresión

$$
\text { DIC }=" \text { bondad de ajuste } "+" \text { complejidad } "=D(\bar{\theta})+2 p_{D}
$$

donde $D(\bar{\theta})$ es la desviación del valor final de cada parámetro y $p_{D}$ denota el número efectivo de parámetros que miden la complejidad del modelo. El modelo es mejor cuando DIC toma valores más bajos.

Por otro lado, el Conditional Predictive Ordinate (CPO) (Pettit et al., 1990) también se tiene en cuenta para realizar la comparativa entre modelos, el cual expresa la probabilidad posterior de observar el valor (o el conjunto de valores) de $y_{i}$ cuando el modelo está ajustado a todos los datos excepto a $y_{i}$ 


$$
C P O_{i}=\pi\left(y_{i}^{o b s} \mid y_{-i}\right)
$$

En esta expresión, $y_{-i}$ denota las observaciones con el componente $i$-ésimo eliminado. Esto facilita la computación del cross-validated log-score (Gneiting and Raftery, 2007) para la selección del modelo $(-($ mean $(\log ($ cpo $))))$. Por lo tanto, el menor valor de DIC y de CPO sugiere el modelo con el menor error asociado. Un número mayor de parámetros significa mayor complejidad. Los mejores modelos son aquellos con el nivel más alto de complejidad y con una bondad alta de ajuste. Por tanto, el modelo que muestre el menor CPO y DIC será escogido como el más ajustado.

Obtenidos los modelos, el próximo paso es la comparación entre los valores observados y los valores predichos, que puede ser llevada a cabo mediante los coeficientes de correlación y el root mean square error (RMSE). Los modelos mejor ajustados serán aquellos que presenten un coeficiente de correlación alto y un bajo RMSE.

Así pues, para poder comparar los modelos, para cada modelo de las baterías planteadas se deberá calcular:

- $\quad \mathrm{CPO}$

- $\quad$ DIC

- coeficiente de correlación entre los valores observados y los predichos

- RMSE.

Estos parámetros serán comparados de acuerdo a lo expuesto anteriormente para identificar los modelos con mejor ajuste. Con todo lo anteriormente expuesto, se obtienen las ecuaciones de predicción de las variables respuesta:

$$
\begin{aligned}
& D E_{r}=\beta_{0}+\beta_{1} \cdot A+\beta_{2} \cdot S / V+\beta_{3} \cdot O+\beta_{3} \cdot H / W+\beta_{4} \cdot M U \\
& D E_{c}=\beta_{0}+\beta_{1} \cdot A+\beta_{2} \cdot S / V+\beta_{3} \cdot O+\beta_{3} \cdot H / W+\beta_{4} \cdot M U \\
& H D_{v}=\beta_{0}+\beta_{1} \cdot A+\beta_{2} \cdot S / V+\beta_{3} \cdot O+\beta_{3} \cdot H / W+\beta_{4} \cdot M U \\
& H D_{i}=\beta_{0}+\beta_{1} \cdot A+\beta_{2} \cdot S / V+\beta_{3} \cdot O+\beta_{3} \cdot H / W+\beta_{4} \cdot M U
\end{aligned}
$$

\subsubsection{III.4 IDENTIFICACIÓN DE COVARIABLES SIGNIFICATIVAS}

Con el objeto de identificar qué covariables tienen un efecto más significativo sobre las variables respuesta, se analizan los efectos fijos de todos los modelos (denotados por $\beta_{i}$ ), de los cuales se espera que tengan una influencia sistemática y predecible sobre los datos. La computación de los errores estándar de los efectos fijos implica la inversión de una matriz y otros cálculos complejos para obtener las diagonales de la inversa de la matriz. Cuando la matriz es grande, dicha estimación de los errores requiere operaciones computacionales muy complejas, por lo que muchos procedimientos no proporcionan una estimación del error para los efectos fijos. En el contexto de este trabajo, el enfoque Bayesiano basado en la aproximación de Laplace (INLA) proporciona un adecuado y rápido procedimiento para calcular los errores, para cada modelo planteado.

Los efectos fijos se expresan según $\beta_{i}$ (media y percentiles (del percentil 2,5\% hasta el $97,5 \%$ )) y se presentarán, para cada uno de los modelos, en las tablas anteriores (Tabla 4.5 - Tabla 4.8). 
Para la identificación de las variables significativas, cabe indicar que estas tienen la media y los percentiles sin cambio de signo. El signo positivo implica que las variables respuesta aumenten cuando lo hace la covariable, mientras que el signo negativo implica que las variables respuesta disminuyen cuando también lo hace la covariable.

\subsection{ETAPA IV: EXTRAPOLACIÓN DEL DIAGNÓSTICO ENERGÉtICO A ESCALA URBANA}

Obtenidas las cuatro ecuaciones de predicción de las variables respuesta, esta cuarta etapa de la metodología tiene como finalidad estimar el comportamiento energético del parque edificatorio que conforma el área de estudio. Para ello, los resultados obtenidos para cada edificio representativo deben ser extrapolados desde la escala individual de edificio a la escala urbana. La tecnología SIG resulta una herramienta fundamental en esta fase al permitir tratar un volumen extenso y complejo de información urbana. La determinación de los valores de los indicadores de evaluación energética en cada uno de los edificios del área de estudio, a nivel individual, permite su agregación para conocer el comportamiento energético del barrio completo, siguiendo el enfoque bottom-up. La representación de los resultados en esta Etapa IV se presenta en mapas urbanos energéticos, que constituyen una herramienta visual para mostrar las cuatro variables respuesta del modelo: $D E_{r}, D E_{c}$, $H D_{v}$ y $H D_{i}$.

La Figura 4.11 presenta el esquema conceptual de dicha agregación, desde la escala individual de edificio a la escala urbana.

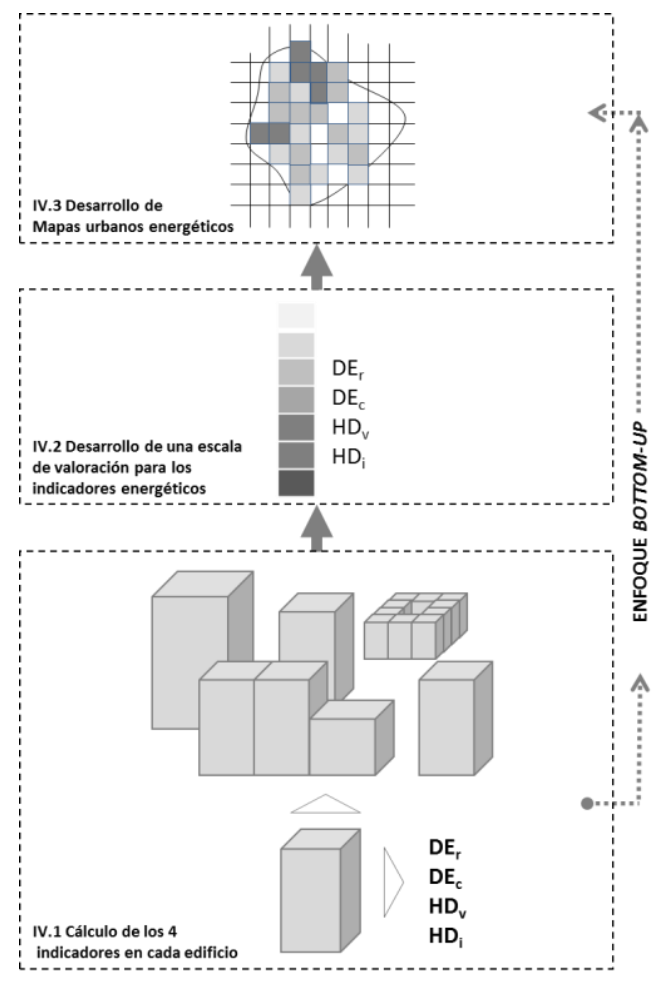

Figura 4.11 Procedimiento de agregación 


\subsubsection{IV.1 CÁLCULO DE LOS INDICADORES ENERGÉTICOS EN CADA EDIFICIO}

Tras la fase experimental de evaluación energética y tratamiento estadístico de sus resultados, se retoma la realidad urbana. Las cuatro ecuaciones de predicción deben ser aplicadas a cada uno de los edificios que forman parte del área urbana, teniendo en cuenta las covariables que afectan individualmente a cada edificio, lo que permite estimar su demanda energética de calefacción y de refrigeración y las horas anuales de disconfort para invierno y para verano. Con ello, el efecto de las covariables asociadas a cada edificio queda integrado para determinar el comportamiento energético.

Desde un enfoque bottom-up, al representar los resultados de la evaluación de cada edificio en la herramienta SIG, se obtiene el diagnóstico energético del parque edificado que conforma el área de estudio de manera global.

Cada una de las referencias catastrales de la tabla de atributos utilizada en la herramienta SIG, lleva asociados los cuatro valores de las correspondientes variables respuesta $\left(D E_{r}, D E_{c}, H D_{v}\right.$ y $\left.H D_{i}\right)$, según se muestra en la Tabla 4.9.

Tabla 4.9 Formato de la tabla de atributos de SIG

\begin{tabular}{|c|c|c|c|c|c|c|c|c|}
\hline \multicolumn{4}{|c|}{} & \multicolumn{7}{c|}{ Indicadores energéticos } \\
\hline $\begin{array}{c}\text { Referencia } \\
\text { catastral }\end{array}$ & Sup.construida & $\ldots$ & $\mathrm{DE}_{\mathrm{r}}$ & $\mathrm{DE}_{\mathrm{r}}$ total & $\mathrm{DE}_{\mathrm{c}}$ & $\mathrm{DE}_{\mathrm{c}}$ total & $\mathbf{H D}_{\mathrm{v}}$ & $\mathbf{H D}_{\mathbf{i}}$ \\
\hline$\ldots$ & $\mathrm{m}^{2}$ & $\ldots$ & $\mathrm{kWh} / \mathrm{m}^{2}$ año & $\mathrm{kWh} / \mathrm{año}$ & $\mathrm{kWh} / \mathrm{m}^{2} \mathrm{año}$ & $\mathrm{kWh} /$ año & horas/año & horas/año \\
\hline
\end{tabular}

Al contener la tabla de atributos la superficie construida de cada edificio, multiplicando dicha superficie por la demanda energética del edificio (en $\mathrm{kWh} / \mathrm{m}^{2}$ año), se puede estimar la demanda energética total del área urbana estudiada. Las horas de disconfort se obtienen de manera directa aplicando la ecuación (en horas/año).

\subsubsection{IV.2 DesarRollo de UNA ESCALA DE VALORACIÓN PARA LOS INDICADORES ENERGÉTICOS}

Para representar los resultados del diagnóstico energético se elabora una escala de valoración que clasifica los valores de los cuatro indicadores. La delimitación de los rangos en dicha escala se realiza de dos formas:

- Indicadores de demanda energética $\left(D E_{r}, D E_{c}\right)$. Se utiliza la clasificación energética de indicadores para edificios existentes de España, según el procedimiento establecido en el Real Decreto 235/2013, de 5 de abril, por el que se aprueba el procedimiento básico para la certificación de la eficiencia energética de los edificios (Ministerio de la Presidencia, 2013), como se indica en la Tabla 4.10. 
Tabla 4.10 Escala de valoración para los indicadores $D E_{r}, y E_{c}$

\begin{tabular}{lll}
\hline Indicador energética & $\mathrm{ED}_{\mathrm{c}}\left[\mathrm{kWh} / \mathrm{m}^{2}\right.$ año $]$ & $\mathrm{ED}_{\mathrm{h}}\left[\mathrm{kWh} / \mathrm{m}^{2}\right.$ año] \\
\hline $\mathrm{A}$ & $\mathrm{ED}_{\mathrm{c}}<4,7$ & $\mathrm{ED}_{\mathrm{h}}<4,7$ \\
$\mathrm{~B}$ & $4,7 \leq \mathrm{ED}_{\mathrm{c}}<7,6$ & $4,7 \leq \mathrm{ED}_{\mathrm{h}}<10,9$ \\
$\mathrm{C}$ & $7,6 \leq \mathrm{ED}_{\mathrm{c}}<11,7$ & $10,9 \leq \mathrm{ED}_{\mathrm{h}}<19,6$ \\
$\mathrm{D}$ & $11,7 \leq \mathrm{ED}_{\mathrm{c}}<18$ & $19,6 \leq \mathrm{ED}_{\mathrm{h}}<32,8$ \\
$\mathrm{E}$ & $18 \leq \mathrm{ED}_{\mathrm{c}}<22,3$ & $32,8 \leq \mathrm{ED}_{\mathrm{h}}<64,5$ \\
$\mathrm{~F}$ & $22,3 \leq \mathrm{ED}_{\mathrm{c}}<27,4$ & $64,5 \leq \mathrm{ED}_{\mathrm{h}}<70,3$ \\
$\mathrm{G}$ & $\mathrm{ED}_{\mathrm{c}} \geq 27,4$ & $\mathrm{ED}_{\mathrm{h}} \geq 70,3$ \\
\hline
\end{tabular}

- Indicadores de horas de disconfort $\left(H D_{v}, H D_{i}\right)$. Al no existir una clasificación oficial para estos indicadores energéticos, se propone una escala de valoración en el marco de este trabajo, que comprende rangos de amplitud $1.000 \mathrm{~h} / a n ̃ o$, como se observa en la Tabla 4.11.

Tabla 4.11 Escala de valoración para los indicadores $D_{r}$, y $D E_{c}$

\begin{tabular}{ll}
\hline Indicador HD & $\mathrm{HD}[\mathrm{h} / \mathrm{año}]$ \\
\hline $\mathrm{A}$ & $\mathrm{HD}<1.000$ \\
$\mathrm{~B}$ & $1.000 \leq \mathrm{HD}<2.000$ \\
$\mathrm{C}$ & $2.000 \leq \mathrm{HD}<3.000$ \\
$\mathrm{D}$ & $3.000 \leq \mathrm{HD}<4.000$ \\
$\mathrm{E}$ & $4.000 \leq \mathrm{HD}<5.000$ \\
$\mathrm{~F}$ & $5.000 \leq \mathrm{HD}$ \\
\hline
\end{tabular}

\subsubsection{IV.3 DESARROLLO de MAPAS URBANOS ENERGÉtICOS}

Llegados a este punto, es posible representar gráficamente los resultados en la cartografía urbana. Así, de una forma intuitiva y visual, se pueden identificar fácilmente los edificios que demandan una mayor cantidad de energía y los que generan a sus ocupantes unas condiciones más desfavorables de confort térmico.

Los resultados se agruparán en diferentes rangos de valores, según las escalas de valoración propuestas en la Tabla 4.10 y la Tabla 4.11, de manera que los cuatro indicadores, $D_{r}, D E_{c}, H_{v}$ y $H D_{i}$, quedarán cuantificados como resultado de implementar la metodología a un área urbana objeto de estudio.

\subsection{ConcLusión}

El presente capítulo ha expuesto la metodología propuesta para la evaluación energética pasiva de un determinado parque edificatorio consolidado de edificios residenciales existentes, desde un enfoque bottom-up. Las diferentes etapas que la constituyen exponen, de forma genérica, el procedimiento que debe ser seguido para implementar la metodología en cualquier área urbana, bien a escala de barrio o de ciudad, y en España o en cualquier otro contexto. 
Mediante la consideración de cinco covariables, a nivel urbano y de edificio, es posible determinar la demanda de energía y las horas de disconfort para cada uno de los edificios que compone un área urbana, teniendo en cuenta no sólo el edificio como elemento individual y aislado, sino también el entorno urbano en el que este se ubica. El estudio en detalle de unos determinados edificios representativos de la totalidad del parque edificado y la asunción del enfoque bottom-up, hacen que la metodología permita extrapolar las conclusiones desde una escala de edificio a una escala de barrio o ciudad, simplificando el proceso que supondría analizar individualmente todos los edificios que componen el área de estudio.

Como mayor novedad, cabe destacar el proceso utilizado para la extrapolación del diagnóstico energético a escala urbana, el cual se desarrolla a través de un modelo de predicción que permite integrar los condicionantes urbanos y del edificio en las cuatro ecuaciones que constituyen los indicadores energéticos de evaluación. Ello evita el reduccionismo de asumir valores de demanda energética y de disconfort térmico para todos los edificios de una misma tipología, como se asume en muchos de los trabajos anteriormente realizados. De esta manera, los cuatro indicadores pueden ser determinados para cada edificio que integra el área de estudio, individualmente, según los valores que adoptan sus covariables asociadas.

La integración de la tecnología SIG permite crear una base de datos georreferenciada que contiene información urbana en diferentes niveles, lo que facilita el proceso de caracterización y, además, permite representar los resultados finales en mapas urbanos energéticos. La visualización de los resultados en mapas proporciona una interfaz intuitiva que pone a disposición de los diferentes agentes intervinientes en los procesos urbanísticos, una herramienta útil para la toma de decisiones, de forma objetiva y transparente.

Como se observa, la metodología propuesta se define de forma genérica por lo que puede adaptarse al contexto específico de la región donde vaya a ser implementada. Asimismo, ésta podría ser actualizada añadiendo nuevas variables respuesta para evaluar el edificio energéticamente, o bien, nuevas covariables, con el objetivo de investigar otros aspectos y su relación con el comportamiento energético del parque edificado.

\subsection{REFERENCIAS}

Aksoezen, M., Daniel, M., Hassler, U., Kohler, N., 2015. Building age as an indicator for energy consumption. Energy Build. 87, 74-86. doi:10.1016/j.enbuild.2014.10.074

Ascione, F., De Masi, R.F., de Rossi, F., Fistola, R., Sasso, M., Vanoli, G.P., 2013. Analysis and diagnosis of the energy performance of buildings and districts: Methodology, validation and development of Urban Energy Maps. Cities 35, 270-283. doi:10.1016/j.cities.2013.04.012

Asociación gvSIG, 2014. gvSIG Desktop.

ATECYR, Universidad Politécnica de Valencia, 2011. CERMA Programa informático simplificado según el método abreviado para la calificación de eficiencia energética de edificios residenciales.

Blangiardo, M., Camaletti, M., 2015. Spatial and Spatio-temporal Bayesian Models with R-INLA. John Wiley \& Sons, Chichester, West Susex.

Blangiardo, M., Cameletti, M., Baio, G., Rue, H., 2013. Spatial and Spatio-temporal Epidemiology Spatial and spatio-temporal models with R-INLA. Spat. Spatiotemporal. Epidemiol. 4, 33-49. doi:10.1016/j.sste.2012.12.001 
Boardman, B., 2007. Examining the carbon agenda via the $40 \%$ House scenario. Build. Res. Inf. 35 , 363-378. doi:10.1080/09613210701238276

Cameletti, M., Lindgren, F., Simpson, D., Rue, H., 2013. Spatio-temporal modeling of particulate matter concentration through the SPDE approach 109-131. doi:10.1007/s10182-012-0196-3

Caputo, P., Costa, G., Ferrari, S., 2013. A supporting method for defining energy strategies in the building sector at urban scale. Spec. Sect. Long Run Transitions to Sustain. Econ. Struct. Eur. Union Beyond 55, 261-270. doi:http://dx.doi.org/10.1016/j.enpol.2012.12.006

Cheng, V., Steemers, K., 2011. Modelling domestic energy consumption at district scale: A tool to support national and local energy policies. Environ. Model. Softw. 26, 1186-1198. doi:10.1016/j.envsoft.2011.04.005

Dall'O', G., Galante, A., Torri, M., 2012. A methodology for the energy performance classification of residential building stock on an urban scale. Energy Build. 48, 211-219. doi:10.1016/j.enbuild.2012.01.034

Dascalaki, E.G., Droutsa, K.G., Balaras, C.A., Kontoyiannidis, S., 2011. Building typologies as a tool for assessing the energy performance of residential buildings - A case study for the Hellenic $\begin{array}{lllll}\text { building stock. Build. } & \text { 3400-3409. }\end{array}$ doi:http://dx.doi.org/10.1016/j.enbuild.2011.09.002

DesignBuilder UK, 2015. DesignBuilder software.

DGC, 2014. Dirección General del Catastro.

Farahbakhsh, H., Ugursal, V.I., Fung, A.S., 1998. A residential end-use energy consumption model for Canada. Int. J. Energy Res. 22, 1133-1143. doi:10.1002/(SICI)1099114X(19981025)22:13<1133::AID-ER434>3.0.CO;2-E

Firth, S.K., Lomas, K.J., Wright, a. J., 2010. Targeting household energy-efficiency measures using sensitivity analysis. Build. Res. Inf. 38, 25-41. doi:10.1080/09613210903236706

Florio, P., Teissier, O., 2015. Estimation of the Energy Performance Certificate of a housing stock characterised via qualitative variables through a typology-based approach model: A fuel poverty evaluation tool. Energy Build. 89, 39-48. doi:10.1016/j.enbuild.2014.12.024

Fonseca, J.A., Schlueter, A., 2015. Integrated model for characterization of spatiotemporal building energy consumption patterns in neighborhoods and city districts. Appl. Energy 142, 247-265. doi:10.1016/j.apenergy.2014.12.068

Gneiting, T., Raftery, A.E., 2007. Strictly Proper Scoring Rules, Prediction , and Estimation Strictly Proper Scoring Rules, Prediction, and Estimation 102, 359-378. doi:10.1198/016214506000001437

Gouveia, J.P., Fortes, P., Seixas, J., 2012. Projections of energy services demand for residential buildings: Insights from a bottom-up methodology. Energy 47, 430-442. doi:10.1016/j.energy.2012.09.042

Hens, H., Verbeeck, G., Verdonck, B., 2001. Impact of energy efficiency measures on the CO2 emissions in the residential sector, a large scale analysis. Energy Build. 33, 275-281.

Huang, Y.J., Berkeley, L., 2000. A Bottom-Up Engineering Estimate of the Aggregate Heating and Cooling Loads of the Entire US Building Stock Prototypical Residential Buildings, en: Proceedings of the 2000 ACEEE summer study on energy efficiency in buildings. Pacific Grove, pp. 135-148. 
INLA, 2016. R-INLA project [WWW Document]. URL http://www.r-inla.org/ (accedido 9.15.15).

Instituto Valenciano de la Edificación, 2014. TABULA. Catálogo de tipología edificatoria residencial en España. Valencia.

Johnston, D., Lowe, R., Bell, M., 2005. An exploration of the technical feasibility of achieving CO2 emission reductions in excess of $60 \%$ within the UK housing stock by the year 2050. Energy Policy 33, 1643-1659. doi:10.1016/j.enpol.2004.02.003

Jones, P., Patterson, J., Lannon, S., 2007. Modelling the built environment at an urban scale-Energy and health impacts in relation to housing. Landsc. Urban Plan. 83, 39-49. doi:10.1016/j.landurbplan.2007.05.015

Marshall, S., 2005. Streets \& patterns. Taylor \& Francis, New York.

Mata, É., Kalagasidis, A.S., Johnsson, F., 2013. A modelling strategy for energy, carbon, and cost assessments of building stocks. Energy Build. 56, 100-108. doi:10.1016/j.enbuild.2012.09.037

Mauro, G.M., Hamdy, M., Vanoli, G.P., Bianco, N., Hensen, J.L.M., 2015. A new methodology for investigating the cost-optimality of energy retrofitting a building category. Energy Build. 107, 456-478. doi:10.1016/j.enbuild.2015.08.044

McKenna, R., Merkel, E., Fehrenbach, D., Mehne, S., Fichtner, W., 2013. Energy efficiency in the German residential sector: A bottom-up building-stock-model-based analysis in the context of energy-political targets. Build. Environ. 62, 77-88. doi:10.1016/j.buildenv.2013.01.002

Ministerio de la Presidencia, 2013. Real Decreto 235/2013, de 5 de abril, por el que se aprueba el procedimiento básico para la certificación de la eficiencia energética de los edificios. España.

Moffatt, S., 2001. Methods for the evaluation of the environmental performance of building stock. Editorial review by Illari Aho, Findland.

Natarajan, S., Levermore, G.J., 2007. Predicting future UK housing stock and carbon emissions. Energy Policy 35, 5719-5727. doi:10.1016/j.enpol.2007.05.034

Olaya, V., 2012. Sistemas de Información Geográfica.

Penna, P., Prada, A., Cappelletti, F., Gasparella, A., 2015. Multi-objectives optimization of Energy Saving Measures in existing buildings. 49th AICARR Int. Conf. - Hist. Exist. Build. Des. retrofit 95, 57-69. doi:10.1016/j.enbuild.2014.11.003

Pettit, A.L.I., Journal, S., Statistical, R., Series, S., 1990. The conditional predictive ordinate for the normal distribution 52, 175-184.

R Development Core Team, 2011. R: A Language and Environment for Statistical Computing.

Ren, Z., Paevere, P., McNamara, C., 2012. A local-community-level, physically-based model of enduse energy consumption by Australian housing stock. Energy Policy 49, 586-596.

Rue, H., Martino, S., 2009a. Approximate Bayesian inference for latent Gaussian models by using integrated nested Laplace approximations. J. R. Stat. Soc. 319-392.

Rue, H., Martino, S., 2009b. Approximate Bayesian inference for latent Gaussian models by using integrated nested Laplace approximations 319-392.

Rue, H., Martino, S., 2007. Approximate Bayesian inference for hierarchical Gaussian Markov random field models. J. Stat. Plan. Inference 137, 3177-3192. doi:10.1016/j.jspi.2006.07.016 
Shorrock, L., Dunster, J., 1997. The physically-based model BREHOMES and its use in deriving scenarios for the energy use and carbon dioxide emissions of the UK housing stock. Energy Policy 25, 1027-1037. doi:10.1016/S0301-4215(97)00130-4

Snäkin, J.-P.A., 2000. An engineering model for heating energy and emission assessment The case of North Karelia, Finland. Appl. Energy 67, 353-381.

Spiegelhalter, D.J., Best, N.G., Carlin, B.P., 2002. Bayesian measures of model complexity and fit 583639.

U.S. Department of Energy, 2013. Energy Plus software.

Vlad, I.T., Juan, P., Mateu, J., 2015. Bayesian spatio-temporal prediction of cancer dynamics. Comput. Math. with Appl. 70, 857-868. doi:10.1016/j.camwa.2015.06.006 



\section{IMPLEMENTACIÓN DE LA METODOLOGÍA EN UN CASO DE APLICACIÓN}





\subsection{INTRODUCCIÓN}

Este capítulo tiene como objetivo implementar la metodología expuesta en el Capítulo 4 en un caso de estudio. Para ello, se selecciona la ciudad de Castellón de la Plana, una ciudad de tamaño medio con una población de 180.690 habitantes (INE, 2015). Castellón de la Plana se ubica en la costa este Mediterránea de España, según se indica en la Figura 5.1, a una latitud de $39^{\circ} 59^{\prime} 11^{\prime \prime} \mathrm{N}$ y una longitud de $0^{\circ} 2^{\prime} 12^{\prime \prime} \mathrm{E}$, lo que le concede un clima con inviernos templados y veranos cálidos, propio de la ciudad mediterránea.

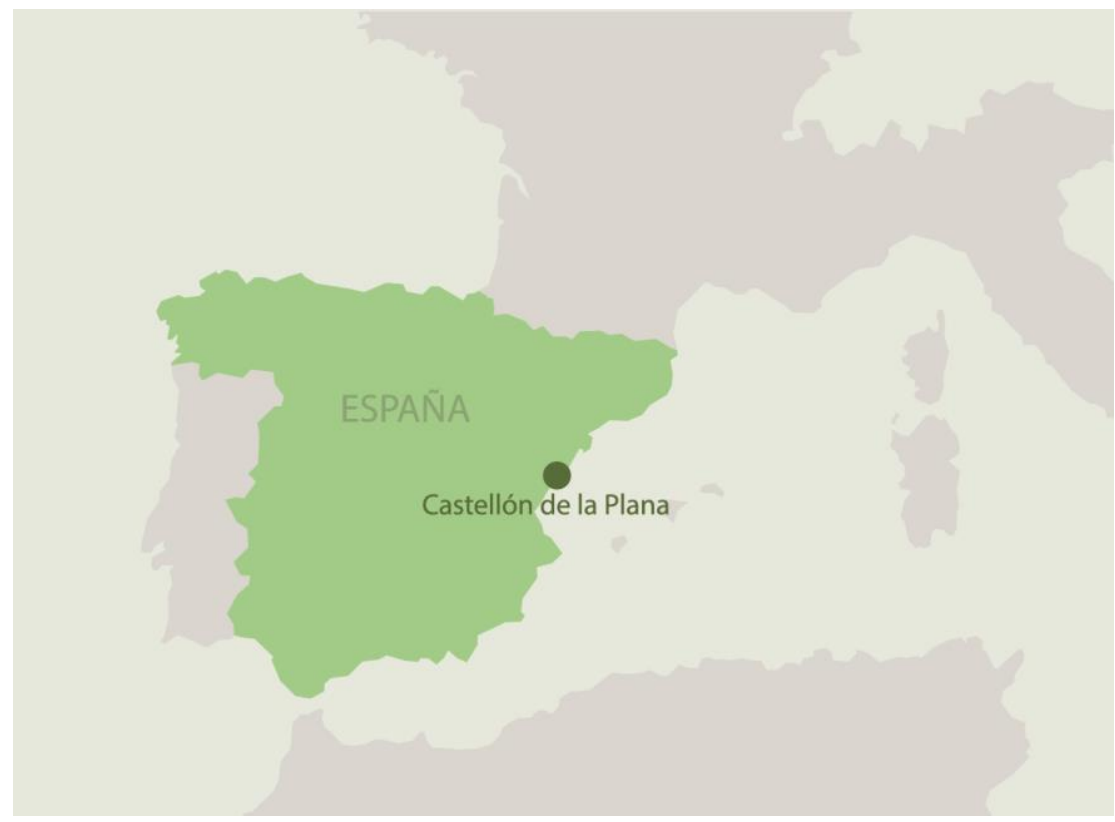

Figura 5.1 Ubicación de Castellón de la Plana

En primer lugar, se analiza el desarrollo urbanístico de la ciudad, haciendo especial hincapié en aquellos hechos históricos que han condicionado su crecimiento y que determinan el trazado urbano. En la Etapa I, se caracteriza la taxonomía urbana de la ciudad, en sus cuatro escalas (ciudad, barrio, manzana residencial y edificio). Con ello, se identifican los trazados urbanos y los barrios que la constituyen, lo que permite llegar a los niveles de manzana y edificio, para finalmente configurar la taxonomía urbana representativa. Una vez los edificios de la ciudad son caracterizados, se selecciona un barrio sobre el que se aplicarán el resto de etapas. A continuación, se identifica un conjunto de edificios representativos en el barrio, lo que permitirá abordar la Etapa II, en la que se lleva a cabo el proceso de evaluación energética. En esta, tras definir las covariables a nivel urbano y de edificio, se plantean las hipótesis de cálculo que serán objeto de simulación dinámica. En la Etapa III, se desarrolla la modelización estadística a partir de los resultados obtenidos de la evaluación energética para configurar los modelos de predicción, los cuales permiten determinar los indicadores energéticos. Por último, en la Etapa IV se extrapola el diagnóstico energético desde el 
nivel de edificio a escala urbana, de manera que el comportamiento energético pasivo del parque residencial de edificios existentes en el barrio queda cuantificado. La representación de los resultados en mapas urbanos energéticos constituye el resultado de la implementación de la metodología.

\subsection{Descripción del desarrollo urbanístico de Castellón de la Plana}

Este apartado describe la evolución urbanística de la ciudad desde su creación en el siglo XIII. Los hechos históricos acontecidos a lo largo del tiempo marcan de una forma determinante el crecimiento urbano, el cual adopta diferentes trazados que condicionarán el comportamiento energético de los edificios.

\subsubsection{LA VILLA MEDIEVAL AMURALLADA DE LOS SIGLOS XIII Y XIV}

Castellón de la Plana como ciudad fue concebida en el siglo XIII, como ordenación estructurada de grupos de alquerías musulmanas dispersas bajo una misma legislación del Rey En Jaume I y a la que le fueron otorgados los mismos privilegios de justicia que a la ciudad de Valencia.

El primer eje de población se construye paralelamente a la Acequia Mayor (con eje norte-sur) hacia el oeste, constituyéndose esta zona como centro neurálgico comercial durante siglos. El crecimiento posterior del núcleo se produce hacia el oeste, alejándose del mar para dejar precisamente estos terrenos útiles para el cultivo de las tierras más fértiles. Se trazan las calles de Enmedio (carrer $d^{\prime} E n m i g$ ) y Alloza (carrer $d^{\prime}$ Amunt), paralelas a la calle Mayor, y quedan cruzadas estas por la calle San Juan (hoy calle Colón). A la calle Alloza se le añaden calles secundarias para dar acceso a las viviendas, algunas de ellas sin salida, evocando la huella musulmana.

En el siglo XIV se levantan murallas, delimitando la villa con las actuales calle Gobernador al este (coincidente con la Acequia Mayor); calle San Luis y plaza Clavé al norte; la avenida del Rey al oeste, y la calle Ruiz Zorrilla, la Puerta del Sol, la calle Gasset, calle Escultor Viciano al sur. En la Figura 5.2 puede apreciarse la evolución de la villa desde el siglo XIII al siglo XIV, hasta adquirir la morfología amurallada configurada por los mencionados límites.
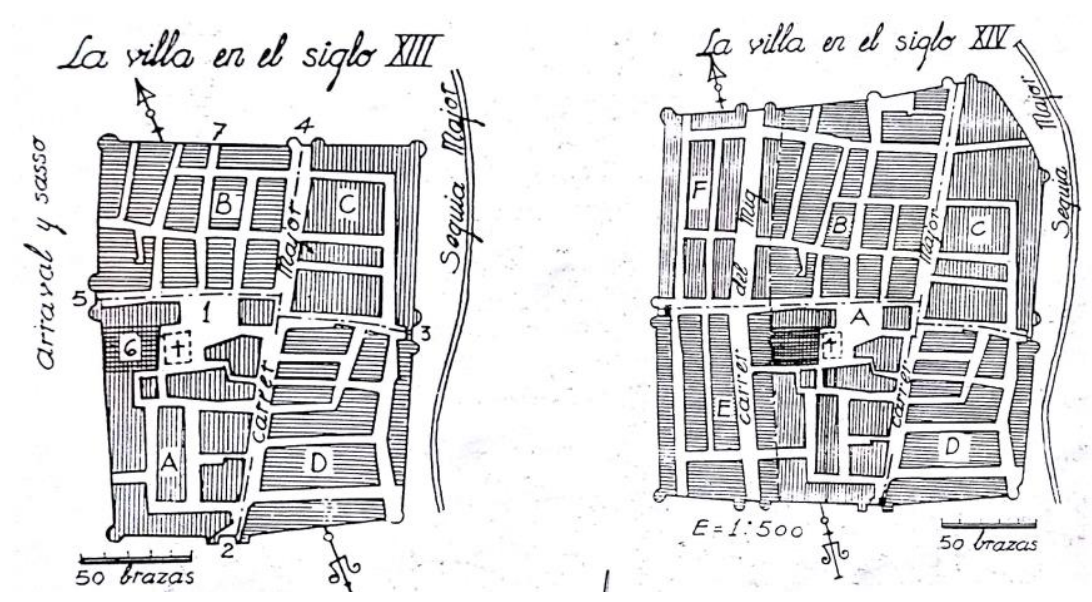

Figura 5.2 Castellón de la Plana en los siglos XIII y XIV según Vicente Traver Tomás (Sánchez Adell et al., 1993) 


\subsubsection{EL SURGIMIENTO DE LOS ARRABALES HASTA EL SIGLO XVIII}

En esta época, el crecimiento de la ciudad queda condicionado por la construcción de cinco conventos, el de San Francisco al sur en extramuros, el de la Purísima en intramuros, el de los frailes de San Doménec al sureste, el de los capuchinos al norte y el de San Agustín en intramuros. Posteriormente se agrega el convento de las monjas Capuchinas en la actual calle de Núñez de Arce en intramuros. Los conventos y edificios religiosos eran en la época elementos de atracción para la población, sobre todo más humilde, lo que acababa influyendo en la morfología y entramado urbano, generando nuevos focos de población en sus alrededores con la consecuente aparición de nuevas calles.

El siglo XVII implica importantes cambios en el interior de las murallas por la construcción de numerosos edificios públicos. Uno de los símbolos más distinguidos de la ciudad lo constituye el Fadrí, el campanario exento de planta octogonal levantado en 1604, junto a la catedral. En 1605 se inician las obras de la Llotja del Cànem (dedicada al comercio del cáñamo) en la Plaça de l'Herba y entre 1689 y 1716 se construye el nuevo Palau. Las plazas medievales existentes en la ciudad quedarán sustituidas por la Plaça Major, la que asumirá el rol de nuevo centro neurálgico junto al entorno de els Quatre Cantons y el carrer d'Enmig. La ciudad va rellenando los huecos internos de la estructura urbana y a su vez comienzan a aparecer casas en extramuros, que originan la formación de los arrabales. A finales del siglo XVII, los arrabales de Sant Nicolau y Sant Joan ya están constituidos, aglutinando al $10 \%$ de la población, y surgen otros dos nuevos, el de San Francisco al sur y el de San Félix al norte, siguiendo los caminos hacia el convento de San Francisco y a la ermita de San Roque, respectivamente (Figura 5.3).

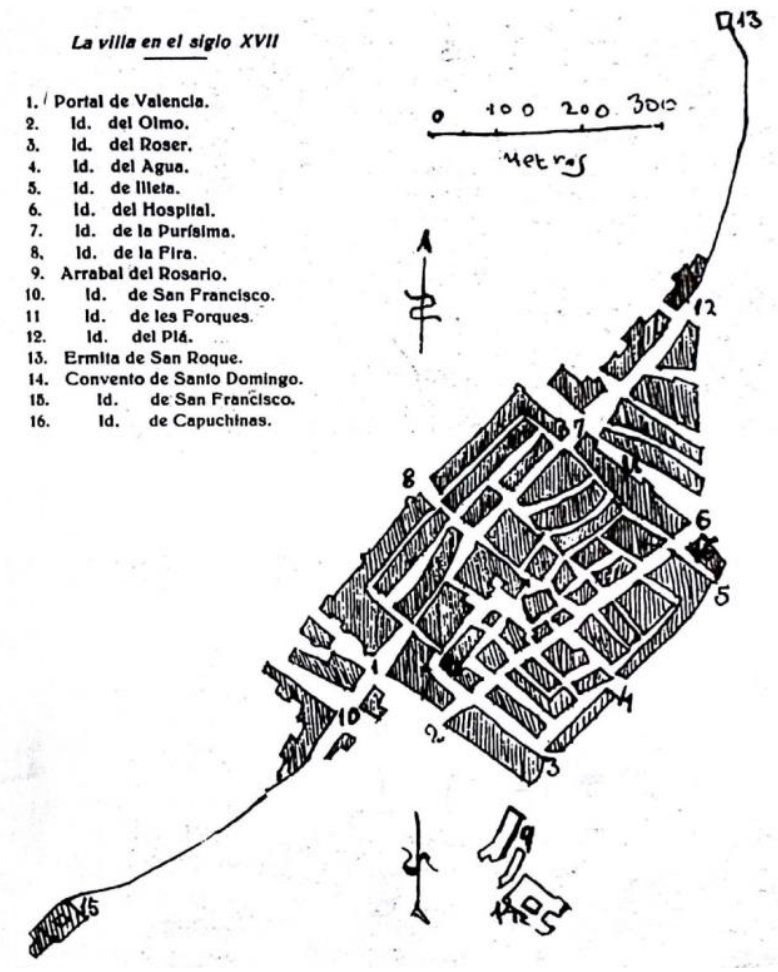

Figura 5.3 Castellón de la Plana en el siglo XVI según Gimeno Michavila. Arrabal de Roser y San Francisco al sur y el de les Forques al norte (Ortells Chabrera, 2004) 
Durante el siglo XVIII se produce un gran crecimiento en la ciudad, tanto económico como demográfico. Entre las actividades económicas destacan aquellas artesanales relacionadas con el cáñamo, condicionando incluso la fisionomía de la ciudad, siendo ejemplo la plaza de Huerto de los Sogueros y otras calles que también albergan dicha actividad. La población durante esta etapa, se ve incrementada de los 4.000 a casi los 15.000 habitantes.

La antigua muralla medieval y los fosos que la rodeaban se encontraban muy deteriorados con el paso de los años y fue a finales del siglo XVIII y principios del XIX cuando se lleva a cabo el derribo y saneamiento por orden del Gobernador Bermúdez de Castro, quien da actualmente nombre a la calle por donde discurría la acequia mayor. El nuevo terreno disponible que queda al derribar las murallas se cede por medio de adjudicaciones para la construcción de viviendas, con la condición de que los beneficiarios se encargaran del derribo, cubrición del foso y construcción de las viviendas en un plazo de dos años. El solar de cada una de las concesiones tenía unas dimensiones de cuatro metros de fachada, veinte de profundidad y una altura permitida de seis metros. En la actualidad, al recorrer las calles Gobernador, San Luís, plaza Clavé y la avenida del Rey, todavía se pueden encontrar multitud de edificaciones de estas características, como últimos vestigios de una etapa muy importante en el desarrollo de la ciudad Castelló de la Plana (Esteve-Comes, 2012).

Así, con el derribo de las murallas medievales en 1796, se anexionaron los arrabales en los que ya residía la mitad de la población (Ortells, 1999). Estas reformas urbanas contribuyeron a reordenar y sanear la ciudad.

\subsubsection{LA CIUDAD INDUSTRIAL EN EL SIGLO XIX}

En el primer tercio del siglo XIX, en 1837, con motivo de las guerras carlistas, la ciudad se vuelve a amurallar, englobando a los arrabales, proporcionándole así una morfología romboidal. Por el norte alcanzaba la ermita de San Roque y por el sur el convento de San Francisco. En el este, la Acequia Mayor continuaba siendo una barrera tras la cual no se produjo el crecimiento de la ciudad hasta más adelante. El nuevo romboide dejaba en su seno algunos huecos urbanos que más tarde albergarían nuevos barrios.

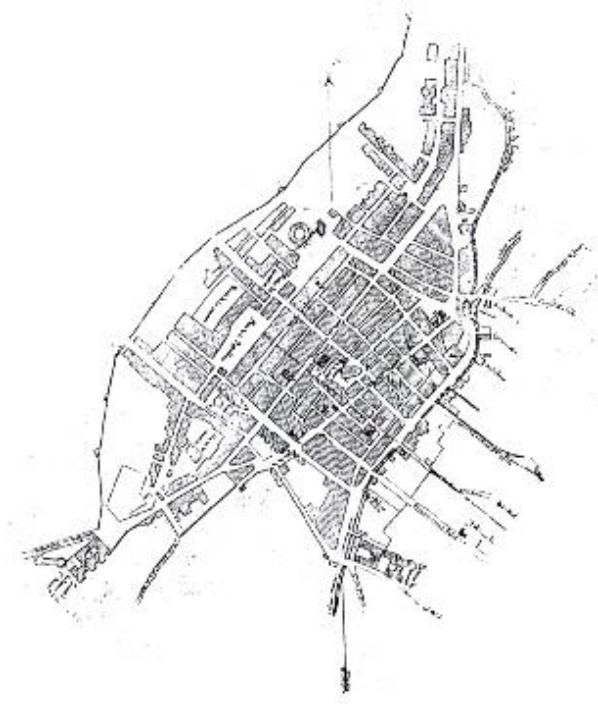

Figura 5.4 Murallas Carlistas en Castellón de la Plana en la segunda mitad del siglo XIX (Ortells Chabrera, 2004) 
La red de comunicaciones supone en estas fechas nuevos canales de evolución urbana. El camino Real de Valencia a Barcelona discurría de sur a norte por el oeste y constituía la arteria principal de la ciudad. Se mejora también el camino viejo de Alcora y Maestrazgo, se traslada el cementerio, se abre la carretera a Morella y Zaragoza y en 1862 el ferrocarril a Valencia ve la luz, situándose la estación a las afueras. La vía férrea constituirá durante muchos años el límite de crecimiento de la ciudad por el oeste. Se inaugura también la nueva carretera del Mar (hoy, avenida Hermanos Bou) que une el centro de la ciudad con el Grao, donde se ubica el puerto marítimo.

En el año 1885, el arquitecto Godofredo Ros de Ursinos redacta el primer plan de urbanización de la periferia de la ciudad. Cinco años después, en 1890, un nuevo plan articula el crecimiento en el sureste (calles Asensi, Herrero y Casalduch). También se inaugura en 1888 la línea de Castellón al Grao de La Panderola, un ferrocarril a vapor de vía estrecha que tenía por objeto cubrir las necesidades de comunicación y que acabó convirtiéndose en una de las infraestructuras más importantes de la provincia durante sus 75 años de funcionamiento. Los nuevos ejes constituyeron las guías de la futura expansión urbana moderna.

La evolución demográfica del municipio durante el siglo XIX experimenta un gran crecimiento, pasando de los casi 17.000 habitantes en 1847 a los 31.300 en 1897 (Ortells, 1999).

A finales del siglo XIX se derriban finalmente las murallas, hecho que origina nuevos cambios en la estructura urbana. También se van ejecutando diversas infraestructuras que dotan a la ciudad de asfaltado, red de teléfono, alumbrado eléctrico, hospital, instituto, entidades bancarias, cines y teatros.

\subsubsection{EL CRECIMIENTO A PRINCIPIOS DEL SIGLO XX}

Durante los inicios del siglo XX, la ciudad muestra un notable esplendor, luciendo un aspecto moderno. En esta época Castellón de la Plana contaba con diez barrios: Santa María, San Juan, San Nicolás, San Pedro, San Agustín, Santo Tomás, San Félix, San Roque, la Trinidad y el Grao. Se abren plazas como la Constitución (la actual Plaza Mayor), donde se celebra el mercado diario; la plaza del Rey Don Jaime que acoge el mercado semanal los lunes, la Plaza María Agustina y la Plaza Clavé, entre otras.

En 1911 Josep Gimeno Almela redacta el primer plan de ensanche, englobando a los dos anteriores, el cual fue aprobado mediante Real Decreto el 18 de septiembre de 1914. El plan subdividía a la zona sureste de la ciudad en dos zonas: la comprendida entre la carretera de Valencia y la avenida Casalduch, y la que consistía en una prolongación de la ciudad hasta el Parque del Oeste. A su vez, también dividía a la zona suroeste de la ciudad en dos zonas, el actual barrio Cremor y la zona comprendida entre la carretera de Valencia y la antigua vía del ferrocarril. La zona sureste se caracteriza por un entramado urbano con manzanas de dimensiones $60 \times 60 \mathrm{~m}$, mientras que la suroeste por manzanas mayores de $100 \times 200$ m (Olucha Montins, 1996).

En 1925, el arquitecto Vicente Traver Tomás redacta el primer Plan General de Ordenación y Urbanización de Castellón de la Plana, en el que propone una división de la ciudad en tres zonas: la zona interior o casco (delimitada por las antiguas murallas carlistas del siglo XIX), zona de ensanche (correspondiente a los anteriores planes de ensanche), y zona de expansión o ciudad jardín ${ }^{1}$

\footnotetext{
1 Movimiento urbanístico fundado en 1902 por Ebenezer Howard como respuesta a la necesidad de dotación de viviendas obreras. El modelo propone un centro urbano, rodeado por un cinturón vegetal, diseñado para el desarrollo de una vida saludable y actividad de trabajo, con un tamaño medio que posibilite la vida social y la plenitud de sus habitantes. El concepto establece un crecimiento moderado y la titularidad pública de los terrenos, con el fin de evitar la especulación (Howard, 1899).
} 
(correspondiente a las nuevas áreas de crecimiento). Sin embargo, el plan no fructificará debido a la llegada de la guerra civil.

\subsubsection{LA CIUDAD DE LA POSTGUERRA}

Tras la Guerra Civil, la ciudad experimenta sustanciosos y rápidos cambios demográficos que dan lugar a una gran expansión, no demasiado estructurada. En 1939 se aprobó un nuevo plan redactado también por el arquitecto Vicente Traver Tomás. Aunque el crecimiento de la ciudad tampoco siguió las directrices de este plan, muchas de las reformas interiores planteadas por Traver fueron ejecutadas años después de la guerra. La mayoría de estas iban encaminadas a la supresión de manzanas del tejido histórico, apareciendo en su lugar nuevas plazas, avenidas o calles rectilíneas.

Algunas de las reformas más importantes son la mejora de la plaza de Huerto de los Sogueros y la configuración de la Avenida del Rey (en 1956), aunque truncada en su extremo norte dejando desprovista a la ciudad de un gran eje de norte a sur. También la Plaza Mayor se ve remodelada en 1947. En la zona de ampliación se incluyen las vías inmediatamente contiguas al casco, siendo estas las Rondas, la calle Gobernador, calle Asensi, calle Trinidad, calle Herrero, calle San Roque y Sanahuja entre otras. La ciudad jardín se proponía como extensión de las anteriores para albergar los masets tradicionales dentro de la estructura urbana. La idea de ciudad jardín tampoco prospera, aunque recientemente han surgido barrios residenciales que evocan dicho concepto, como son el Pau Lledó y Pau Censal, integrados por viviendas unifamiliares que constituyen barrios de baja densidad.

A partir de los años sesenta y hasta la actualidad, la ciudad atraviesa una etapa clave que trascenderá en la configuración urbana. El aumento poblacional debido en gran parte a la inmigración (interior de España y Andalucía), hace alcanzar cifras que pasan de los 62.500 habitantes en 1960, a los 93.000 en 1971 hasta los 134.000 en 1989. Así, la población se duplica en tan sólo 30 años, lo que hace duplicar también el tejido urbano. Entre 1961 y 1980 se construyen 7.509 viviendas, de las cuales el $25 \%$ son edificios en altura de más de 5 plantas (en 1950 estos no alcanzaban el 1\%). En 1980, casi el 50\% de las viviendas contaba con menos de 25 años (Ortells, 1999).

Entre los años 50 y 60, algunos edificios de importancia y trazados viarios marcarán la aparición de nuevos barrios obreros, como es el caso del estadio de fútbol Castalia, la carretera nacional N-340 o la nueva Avenida del Mar, que junto con la existente vía férrea, iban configurando los nuevos límites urbanos. Al sur el Parque del Oeste (el barrio más geométrico de la ciudad con 20 manzanas de dimensiones similares), al norte els Mestrets, los barrios de Rafalafena y de Fadrell al este, los de la avenida Capuchinos y avenida de Lledó también al Norte. Cabe destacar que se introdujo, en barrios como el de Rafalafena, el nuevo concepto de open plan $^{2}$, donde predominan los condominios cerrados de orden abierto formados por grandes bloques de edificios aislados rodeados de zonas verdes, propios también de la ciudad jardín, concepto promovido por el Plan Traver del 1925.

\footnotetext{
Algunos ejemplos de ciudad jardín se pueden ver actualmente en Inglaterra, como Letchworth, Welwyn y en EE. UU., Radburn. En España, el concepto fue materializado, en algunos casos, a través de la Ley de casas baratas de 1921.

${ }^{2}$ Concepto surgido durante la década de 1950, que llegó a Europa a finales de 1970, concebido inicialmente para ser aplicado en la arquitectura y el urbanismo. En el ámbito del urbanismo, el concepto consiste en la creación de grandes espacios libres mediante una adecuada disposición de las edificaciones. Las edificaciones son de manzana abierta y no ocupan la totalidad de la superficie de parcela, de manera que estos espacios libres no están separados de la vía pública mediante ningún elemento físico, quedando como zonas verdes o destinadas a otros equipamientos, como deportivo, ocio o aparcamiento (Ward, 1999).
} 
En abril de 1945 tiene lugar un hecho importante en el trazado de la ciudad, pues comienzan las obras de la nueva avenida del Mar (las cuales se prologarán hasta el año 1963), que abrirán una vía principal desde la plaza Cardona Vives hasta el mar, desembocando así en el Grao.

El año 1958 se aprueban la Ordenanzas de Construcción y Saneamiento, que supusieron una ruptura con los planes anteriores y sirvieron como predecesoras de los actuales planes urbanísticos (Olucha Montins, 1996).

En 1963 se desarrolla y aprueba el Plan General de Ordenación Urbana (PGOU) de Castellón redactado por Romaní y Miquel, Prades Safont y Traver G. Espressati, según las bases de la Ley del Suelo de 1956. Esta enfoca con un carácter globalizador toda la problemática de la ciudad. No obstante, hasta la fecha, la rápida expansión de la ciudad no sigue un crecimiento ordenado según unas pautas planificadas, pues el Plan de 1963 no tuvo efectividad ante la carencia de los planes parciales que debían desarrollarlo. Así, ante la rápida y creciente demanda de construcción de vivienda, en la respuesta se pierde el concepto de crecimiento compacto. Además, en el PGOU no se preveía la incorporación de zonas verdes ajardinadas, cuando una de las actividades tradicionales principales de la ciudad era la huerta y el cultivo.

El crecimiento se expande hacia el oeste, superando la barrera de las vías férreas. Hacia el este, se desarrolla el Polígono Rafalafena, con un crecimiento más ortodoxo promovido por el Instituto Nacional de la Vivienda. La evolución de la ciudad, pues, sigue una tendencia marcadamente circular (o tentacular, alrededor de las vías de acceso a la ciudad) del entramado urbano, como se observa en la Figura 5.5. Esta estructura además, se ve complementada con la aparición de numerosos grupos periféricos, constituidos por viviendas dispersas generalmente de una sola planta y rodeadas por terreno agrícola, y generalmente caracterizados por la falta de equipamiento.

Otra consecuencia del crecimiento es el aumento desproporcionado de las alturas de los edificios en el casco urbano, que conlleva una densificación del mismo. Comienzan a erigirse edificios de alturas dispares, conviviendo los edificios habituales de 3 o 4 plantas, con los de alturas incluso superiores a 8 plantas, alcanzando las 12 y 14 plantas.

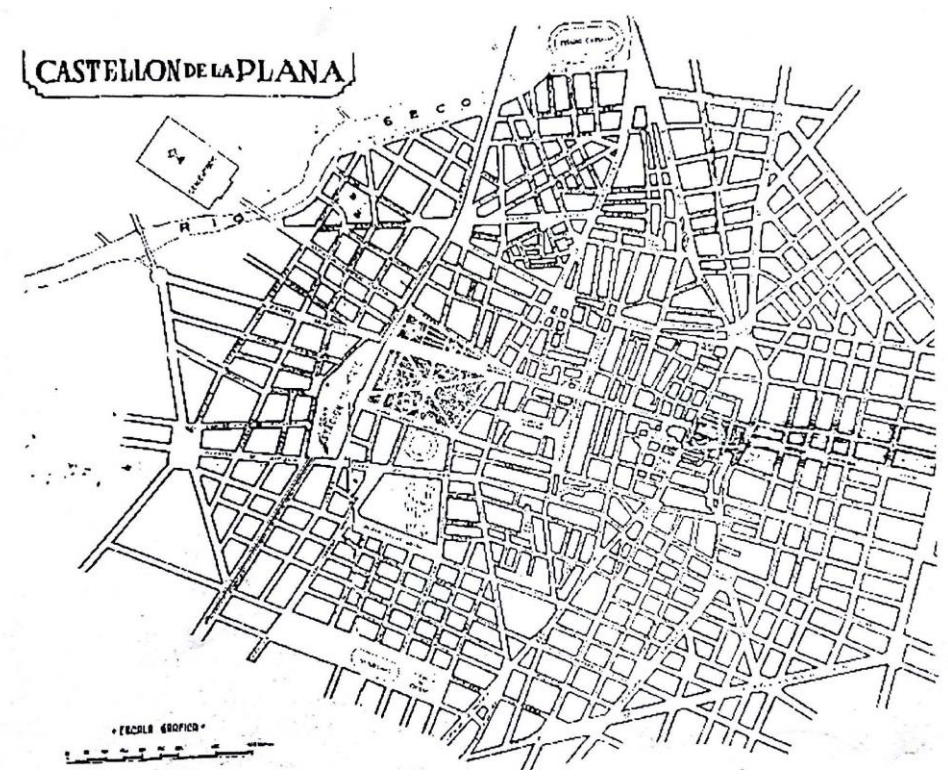

Figura 5.5 Forma circular de Castellón de la Plana en la década de los 50 (adaptado de Ortells Chabrera (2004)) 


\subsubsection{LA CIUDAD ACTUAL. FINALES DEL SIGLO XX E INICIOS DEL XXI}

El tejido urbano en los años 80 y 90 experimenta transformaciones importantes, dada la aparición de nuevos PGOU que ordenan el territorio de una forma más estructurada. Durante estos años, las reformas internas se completan con la remodelación de plazas, parques y jardines. En 1984 entra en vigor un nuevo PGOU que intentará reconducir el crecimiento desordenado sufrido años atrás. Posteriormente, el PGOU de 2000 introduce grandes actuaciones urbanísticas de uso residencial, dejando a la ciudad rodeada de nuevas zonas como son el PERI 19 y PAU Lledó en el norte, el PAU Gumbau en el este, el PERI 18 y PAU Censal en el sur, y la zona de la Universitat Jaume I al oeste.

En el año 2000 la nueva estación de ferrocarril abre sus puertas, rompiendo la barrera que suponía la antigua vía del tren y que impedía el crecimiento de la ciudad hacia el oeste. En el espacio ocupado pos las antiguas vías del tren se emplaza un bulevar que recorre su trazado de sur a norte. Queda así como nueva barrera en la zona del oeste, el cauce del río Seco.

El PGOU de 2000 fue derogado y actualmente se encuentra en redacción un nuevo Plan de Ordenación. Las sucesivas normas transitorias nos llevan hasta el día de hoy, en el que se encuentran en vigor las normas urbanísticas transitorias de urgencia para el municipio de Castellón de la Plana, aprobadas por acuerdo de 27 de febrero de 2015 por la Conselleria de Infraestructuras, Territorio y Medio Ambiente de la Generalitat Valenciana. Se proponen nueve zonas para el sector de la edificación residencial y se incluyen otras clases de suelo, zonas verdes, suelo dotacional, suelo industrial y suelo terciario.

En la Figura 5.6, puede observarse la evolución de la ciudad de Castellón de la Plana, desde sus inicios en el siglo XIII hasta los inicios del XIX.

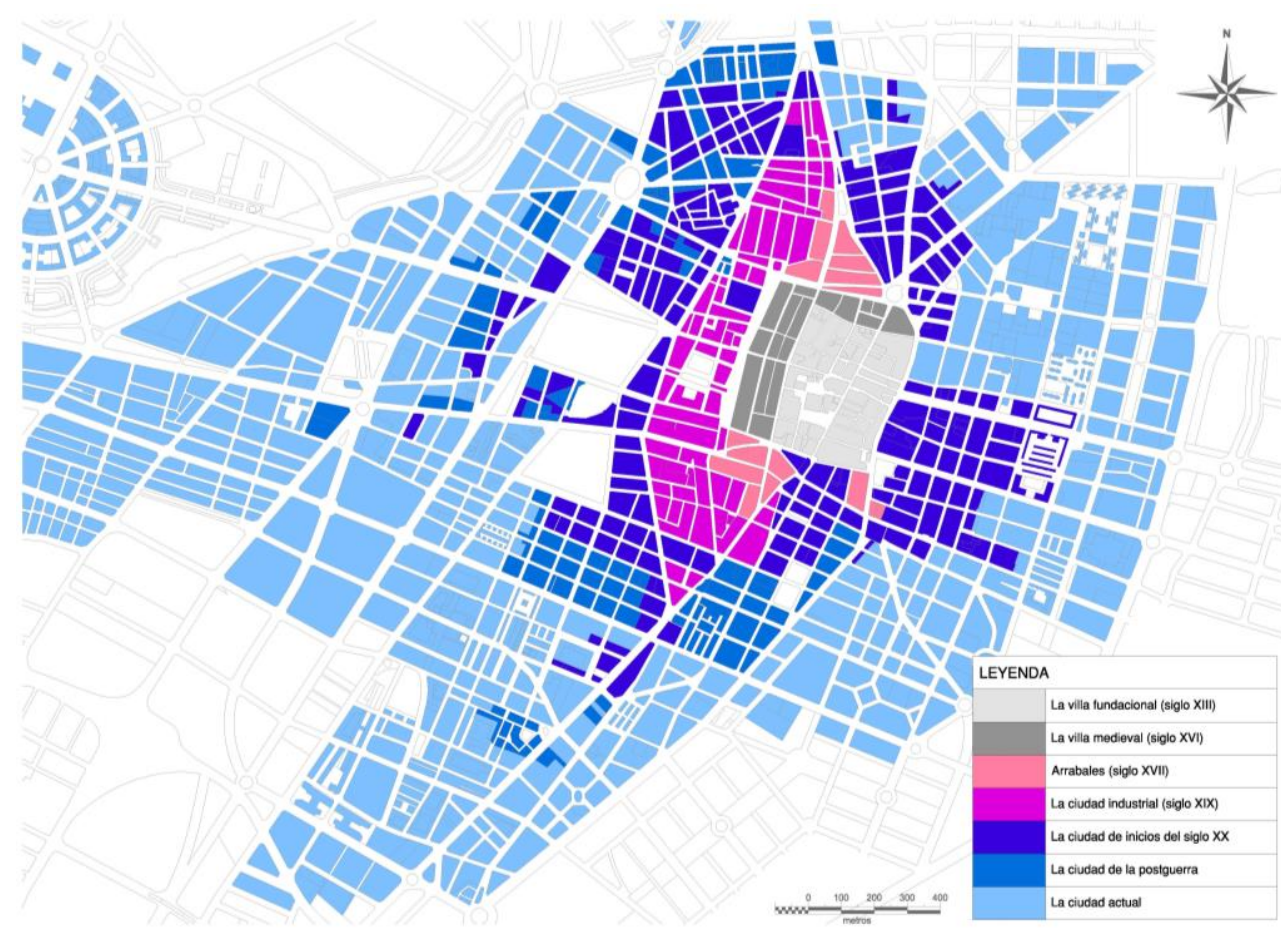

Figura 5.6 Desarrollo urbano de Castellón de la Plana (adaptado de Ortells Chabrera (2004)) 
La Tabla 5.1 sintetiza los PGOU que se han sucedido a lo largo del tiempo en la ciudad de Castellón de la Plana.

Tabla 5.1 Síntesis de Planes Urbanísticos de Castellón de la Plana

\begin{tabular}{|l|l|l|}
\hline Año & Plan & Características \\
\hline 1885 & Plan de Godofredo Ros de Ursinos & Periferia sureste de la ciudad (Armelar) \\
\hline 1890 & Plan del Sureste & Sureste \\
\hline 1914 & Plan de Ensanche (Josep Gimeno Almela) & Articulación del ensanche de la ciudad \\
\hline 1925 & Plan de Vicente Traver Tomás & $\begin{array}{l}\text { Tres zonas: casco, ensanche, ciudad jardín } \\
\text { No se ejecuta }\end{array}$ \\
\hline 1939 & Plan Vicente Traver Tomás & $\begin{array}{l}\text { No se ejecuta, sólo algunas reformas interiores } \\
\text { (apertura de calles y plazas) }\end{array}$ \\
\hline 1958 & Ordenanzas de Construcción y Saneamiento & $\begin{array}{l}\text { Ruptura con los planes anteriores, dan paso al } \\
\text { siguiente. }\end{array}$ \\
\hline 1963 & $\begin{array}{l}\text { Plan General de Ordenación Urbana de Castellón } \\
\text { (Romaní Miquel, Prades Safont, Vicente Traver Espressati) }\end{array}$ & $\begin{array}{l}\text { Adaptación a la Ley del Suelo 1956. } \\
\text { Carácter globalizador de la problemática global } \\
\text { de la ciudad. } \\
\text { Incumplimiento sistemático del mismo. }\end{array}$ \\
\hline 1984 & $\begin{array}{l}\text { Plan General de Ordenación Urbana de Castellón } \\
\text { (EUSA, S.L.) }\end{array}$ & $\begin{array}{l}\text { Pone freno a las consecuencias negativas del } \\
\text { anterior plan (diferencia de alturas, falta } \\
\text { servicios y zonas dotacionales) }\end{array}$ \\
\hline 2000 & Plan General de Ordenación Urbana de Castellón & $\begin{array}{l}\text { Nuevos zonas de expansión: } \\
\text { PERI 19, PAU Lledó, PAU Gumbau, PERI 18, } \\
\text { PAU Censal, y I zona de la Universitat Jaume I } \\
\text { Derogado. }\end{array}$ \\
\hline actualidad & PGOU en actual redacción & - \\
\hline
\end{tabular}

\subsection{EtAPA I: CARACTERIZACIÓN DE LA TAXONOMÍA URBANA}

En esta primera etapa se caracteriza la morfología de la ciudad, en sus cuatro escalas, ciudad, barrio, manzana y edificio. El uso de la herramienta gvSIG permite crear una base de datos georreferenciada, lo que representa una acción transversal a largo de esta etapa.

\subsubsection{I.1 ESCALA DE CIUDAD}

Tras analizar la cartografía de la ciudad y cómo está configurado el trazado de sus calles, se identifican tres patrones urbanos diferenciados, que se corresponden con el propio desarrollo urbanístico, según se observa en la Figura 5.7.

El centro histórico, los arrabales y las zonas próximas a estos hacia el oeste, se corresponden con un patrón urbano irregular, en el que predomina una marcada estructura anárquica que es consecuencia de la inexistencia de normas urbanísticas que marcaran el desarrollo urbano, hasta los inicios del siglo XX. En este trazado, las manzanas urbanas adoptan formas poligonales no demasiado definidas, predominan las calles estrechas con anchos variables, y las alturas de las edificaciones son marcadamente dispares. Los resquicios de viviendas unifamiliares entre medianeras, que constituyen la tipología tradicional de la ciudad, conviven con edificios plurifamiliares altos, lo que le otorga a estas zonas un paisaje anárquico y poco organizado urbanísticamente.

En las inmediaciones del centro histórico y a la derecha del arrabal norte, destaca una zona con un patrón urbano radial, conformado alrededor de una plaza circular ( $M$ 
calles que constituyen dicha zona. También puede advertirse este patrón radial en un barrio de nueva creación al oeste de la ciudad, conformado junto a la Universitat Jaume I. Su forma en semicírculo tiene como centro geométrico una rotonda que da acceso a la universidad y organiza las calles del barrio con un trazado radiocéntrico.

El crecimiento urbano a partir de los inicios del siglo XX da lugar a los barrios de ensanche con configuraciones mucho más estructuradas, que generalmente adoptan un patrón urbano ortogonal, aunque la orientación de dicho patrón varía según las zonas de la ciudad. Las manzanas urbanas son claramente de geometría cuadrada o rectangular, salvo excepciones. Estas zonas corresponden a barrios de ensanche originados a inicios del siglo XX y durante la postguerra, en los que predominan las manzanas cerradas, y a barrios de reciente creación, conformados por edificios aislados y conjuntos de viviendas unifamiliares, que responden a una tipología edificatoria más moderna.

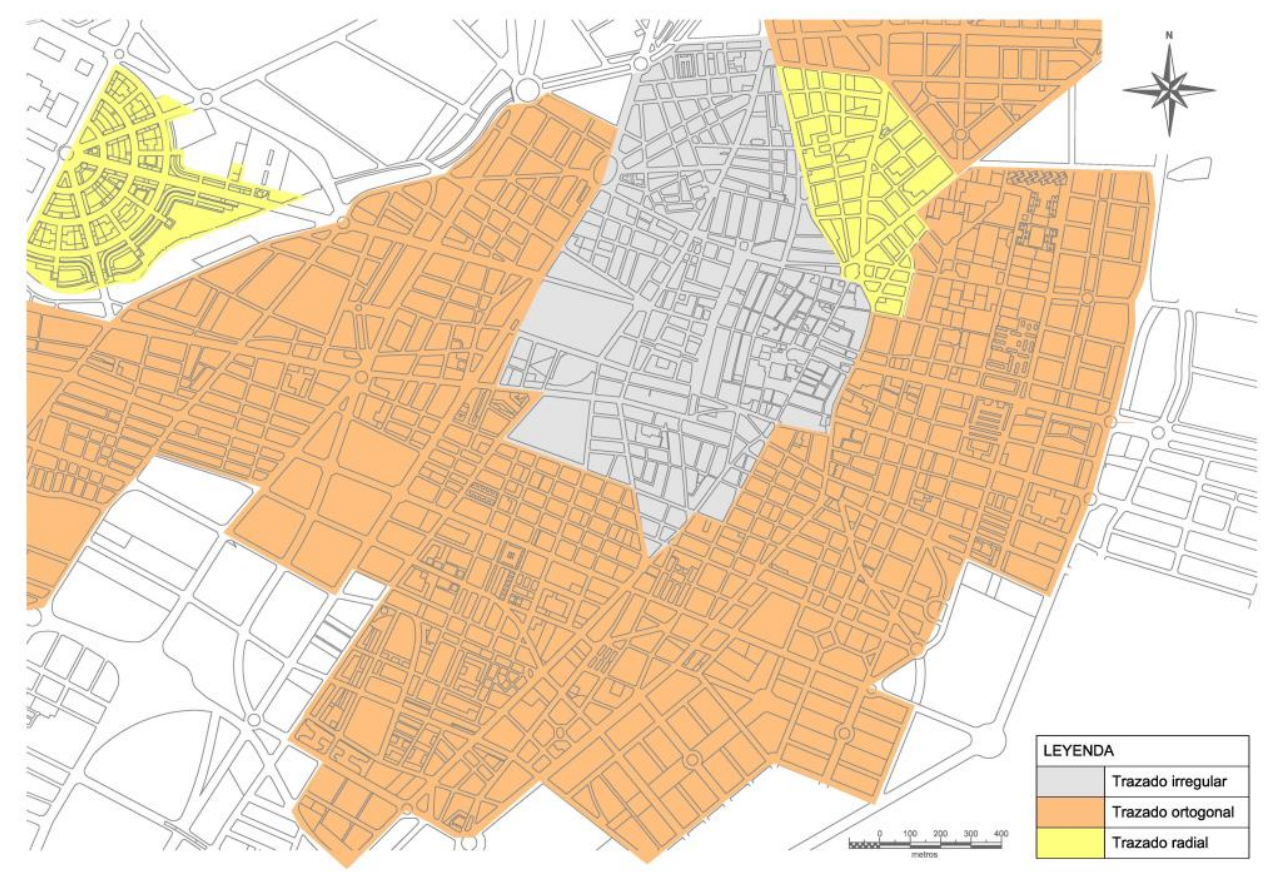

Figura 5.7 Identificación de patrones urbanos en la ciudad

\subsubsection{I.2 ESCALA DE BARRIO}

El desarrollo urbanístico de la ciudad, acorde a su evolución histórica, determina enormemente las ordenanzas urbanísticas que, desde su surgimiento en el año 1963, han tratado de planificar un crecimiento más ordenado. EI PGOU de Castellón de la Plana diferencia doce zonas residenciales, cuyas ordenanzas urbanísticas particulares condicionan la configuración urbana y delimitan los barrios (Excmo. Ayuntamiento de Castellón de la Plana, 2008). La Tabla 5.2 expone las doce zonas, junto con la definición que aporta el propio PGOU, e indica los barrios que en ellas se integran, así como el patrón urbano que define a cada uno de los barrios. 
Tabla 5.2 Delimitación de barrios en Castellón de la Plana según zonas residenciales del PGOU

\begin{tabular}{|c|c|c|c|}
\hline Zona PGOU & Definición PGOU & Barrio integrado* & Patrón urbano* \\
\hline $\mathrm{Z}-0$ & Corresponde a la zona de Casco Histórico & Casco Histórico & Irregular \\
\hline $\mathrm{Z}-1$ & $\begin{array}{l}\text { Corresponde a la zona de Casco Antiguo del siglo XIX y } \\
\text { su entorno }\end{array}$ & $\begin{array}{l}\text { San Roque } \\
\text { Herreo-Trinidad } \\
\text { Rey Don Jaime }\end{array}$ & $\begin{array}{l}\text { Irregular } \\
\text { Irregular } \\
\text { Irregular }\end{array}$ \\
\hline $\mathrm{Z}-2$ & $\begin{array}{l}\text { Corresponde a zonas de ensanche de casco antiguo } \\
\text { manzana cerrada de alta densidad }\end{array}$ & $\begin{array}{l}\text { Cronista Rocafort } \\
\text { Parque Ribalta } \\
\text { Estación } \\
\text { Carretera de Alcora } \\
\text { Parque del Oeste } \\
\text { Avenida de Valencia } \\
\text { Avenida Casalduch } \\
\text { Fadrell } \\
\text { Avenida del Mar } \\
\text { Capuchinos (o "Palmeretes") }\end{array}$ & $\begin{array}{l}\text { Irregular } \\
\text { Irregular } \\
\text { Ortogonal } \\
\text { Ortogonal } \\
\text { Ortogonal } \\
\text { Ortogonal } \\
\text { Ortogonal } \\
\text { Ortogonal } \\
\text { Ortogonal } \\
\text { Radial } \\
\end{array}$ \\
\hline Z-3 & $\begin{array}{l}\text { Corresponde a la regulación de la edificación en el } \\
\text { casco urbano del Grao, una escisión de la ciudad junto a } \\
\text { la costa }\end{array}$ & Grao & Ortogonal \\
\hline Z-4 & $\begin{array}{l}\text { Ordenanza para la ordenación de zonas conocidas } \\
\text { como grupos periféricos a las afueras del núcleo } \\
\text { urbano }\end{array}$ & $\begin{array}{l}\text { Virgen del Pilar } \\
\text { Venta Rosita } \\
\text { San José Obrero } \\
\text { Los Cubos } \\
\text { San Lorenzo } \\
\text { Rossers - San Roque } \\
\text { Tombatossals } \\
\text { Río Seco } \\
\text { Lourdes } \\
\text { Perpetuo Socorro } \\
\text { Roquetes } \\
\text { Etc. }\end{array}$ & Diverso \\
\hline Z-5 & $\begin{array}{l}\text { Corresponde a grupos de promoción pública y diseño } \\
\text { unitario }\end{array}$ & $\begin{array}{l}\text { Manzanas urbanas con } \\
\text { ordenanzas particulares } \\
\text { integradas en barrios }\end{array}$ & $\begin{array}{l}\text { Integrado en el } \\
\text { trazado del } \\
\text { barrio }\end{array}$ \\
\hline Z-6 & $\begin{array}{l}\text { Ordenanza de zonas de concentración de volumen } \\
\text { edificable y cesión de zonas verdes para uso público }\end{array}$ & $\begin{array}{l}\text { Manzanas urbanas con } \\
\text { ordenanzas particulares } \\
\text { integradas en barrios }\end{array}$ & $\begin{array}{l}\text { Integrado en el } \\
\text { trazado del } \\
\text { barrio }\end{array}$ \\
\hline Z-7 & $\begin{array}{l}\text { Corresponde a zonas de baja densidad, vivienda } \\
\text { unifamiliar aislada o agrupada, dispersa, fuera del } \\
\text { núcleo urbano }\end{array}$ & Vivienda dispersa & No definido \\
\hline Z-8 & $\begin{array}{l}\text { Ordenanza de zonas con planeamiento de desarrollo } \\
\text { aprobado con anterioridad al vigente Plan. } \\
\text { Corresponde a nuevos desarrollos urbanos regulados } \\
\text { mediante Planes Especiales de Reforma Interior (PERI), } \\
\text { Programas de Actuación Urbanística (PAU) y Planes } \\
\text { Parciales (PP) }\end{array}$ & $\begin{array}{l}\text { Polígono Rafalafena } \\
\text { PAU Lledó } \\
\text { PAU Gumbau } \\
\text { PAU Censal } \\
\text { Pi Gros } \\
\text { PERI } 18 \\
\text { PERI } 19 \\
\text { PP Universitat Jaume I (UJ) }\end{array}$ & $\begin{array}{l}\text { Ortogonal } \\
\text { Ortogonal } \\
\text { Ortogonal } \\
\text { Ortogonal } \\
\text { Ortogonal } \\
\text { Ortogonal } \\
\text { Ortogonal } \\
\text { Radial } \\
\end{array}$ \\
\hline Z-9 & $\begin{array}{l}\text { Corresponde a zonas de vivienda en bloque con } \\
\text { ordenanza de volumen }\end{array}$ & $\begin{array}{l}\text { Manzanas urbanas con } \\
\text { ordenanzas particulares } \\
\text { integradas en barrios }\end{array}$ & No definido \\
\hline $\begin{array}{l}\text { ENTORNO } \\
\text { BENEFICENCIA }\end{array}$ & $\begin{array}{l}\text { Ordenanza especial para la manzana delimitada por las } \\
\text { calles Guitarrista Tárrega, Santo Domingo, en proyecto } \\
\text { y Plaza Borrull }\end{array}$ & Integrado en el barrio Fadrell & Ortogonal \\
\hline $\begin{array}{l}\text { ENTORNO } \\
\text { BASILICA } \\
\text { LLEDO }\end{array}$ & $\begin{array}{l}\text { Ordenanza especial para regular el entorno de la } \\
\text { Basílica de Lledó }\end{array}$ & Basílica Lledó & No definido \\
\hline
\end{tabular}

* El texto en color gris indica las zonas fuera del ámbito del núcleo urbano de la ciudad 
La Z-0 corresponde con el Casco Histórico de la ciudad y sus límites están formados por aquellos que delimitaban la antigua villa medieval amurallada del siglo XIV. El tejido urbano que surgió sin planeamiento urbanístico conlleva un desorden complejo. La existencia de pequeñas parcelas, que emplazaban viviendas unifamiliares de 4 metros de fachada y una altura de 4 plantas (PB+III), originó calles estrechas que perduran en la actualidad. Con la evolución de la ciudad, esta zona se ha mantenido como centro neurálgico comercial y de servicios, aunque los antiguos edificios conviven con edificios más recientes de uso residencial, que después de la agrupación de diversas parcelas pequeñas han dado lugar a edificaciones de mayor longitud de fachada y altitud, superando en algunos casos las 10 plantas. La estructura de la zona da lugar a un tejido irregular con gran descompensación en la altura de los edificios.

La Z-1 corresponde a las primeras expansiones del Casco Histórico en el siglo XIX hacia el oeste de la ciudad, dando lugar a tres barrios. El barrio San Roque, que engloba al arrabal norte, constituye la primera evolución de la ciudad en extramuros durante los siglos XVI y XVII, alcanzando la extensión que tiene actualmente en el siglo XIX. El barrio Herrero-Trinidad se originó con la evolución de la ciudad hacia el sur hacia las afueras de las murallas, también durante la misma franja temporal que el arrabal del norte. El barrio Rey Don Jaime surgió como expansión urbana hacia el oeste, durante el siglo XVIII, al otro lado de la avenida de su mismo nombre. Los tres barrios albergan tanto la típica vivienda unifamiliar de agricultores de la época, como edificios mucho más recientes de tipología plurifamiliar, y tienen características urbanísticas muy similares que atienden a un patrón urbano irregular.

La Z-2 corresponde a los barrios de ensanche originados ya a principios del siglo XX, durante la postguerra y las últimas décadas. Se distinguen 10 barrios que atienden a una configuración mucho más ordenada que las Z-0 y Z-1, con un trazado generalmente ortogonal. Estos son los que se indican en la Tabla 5.2.

La Z-8 corresponde a nuevos desarrollos urbanos surgidos tras la postguerra y en años más recientes, que fueron originados a través de instrumentos de ordenación urbana específicos para dichas zonas, mediante Planes Especiales de Reforma Interior (PERI), Programas de Actuación Urbanística (PAU) y Planes Parciales (PP), que dan lugar a barrios independientes.

El resto de zonas definidas por el PGOU corresponden al núcleo urbano del Grao (Z-3), a grupos periféricos alejados del núcleo urbano (Z-4) y a viviendas unifamiliares dispersas (Z-7 y el entorno de la Basílica Lledó), alejadas también del núcleo urbano, que no responden a ningún patrón urbano. La Z-5, Z-6 y Z-9 son manzanas urbanas que se rigen por unas ordenanzas específicas, pero que quedan integradas en alguno de los barrios anteriormente definidos incluidos dentro del núcleo urbano, por tanto, con su mismo patrón urbano.

La Figura 5.8 muestra la ubicación de los barrios integrados en el núcleo urbano en la cartografía de la ciudad, y los superpone al desarrollo urbano. Se aprecia claramente que la evolución histórica de la ciudad condiciona la constitución de los barrios y la configuración urbana que estos tienen, permaneciendo inamovible con el paso del tiempo. 


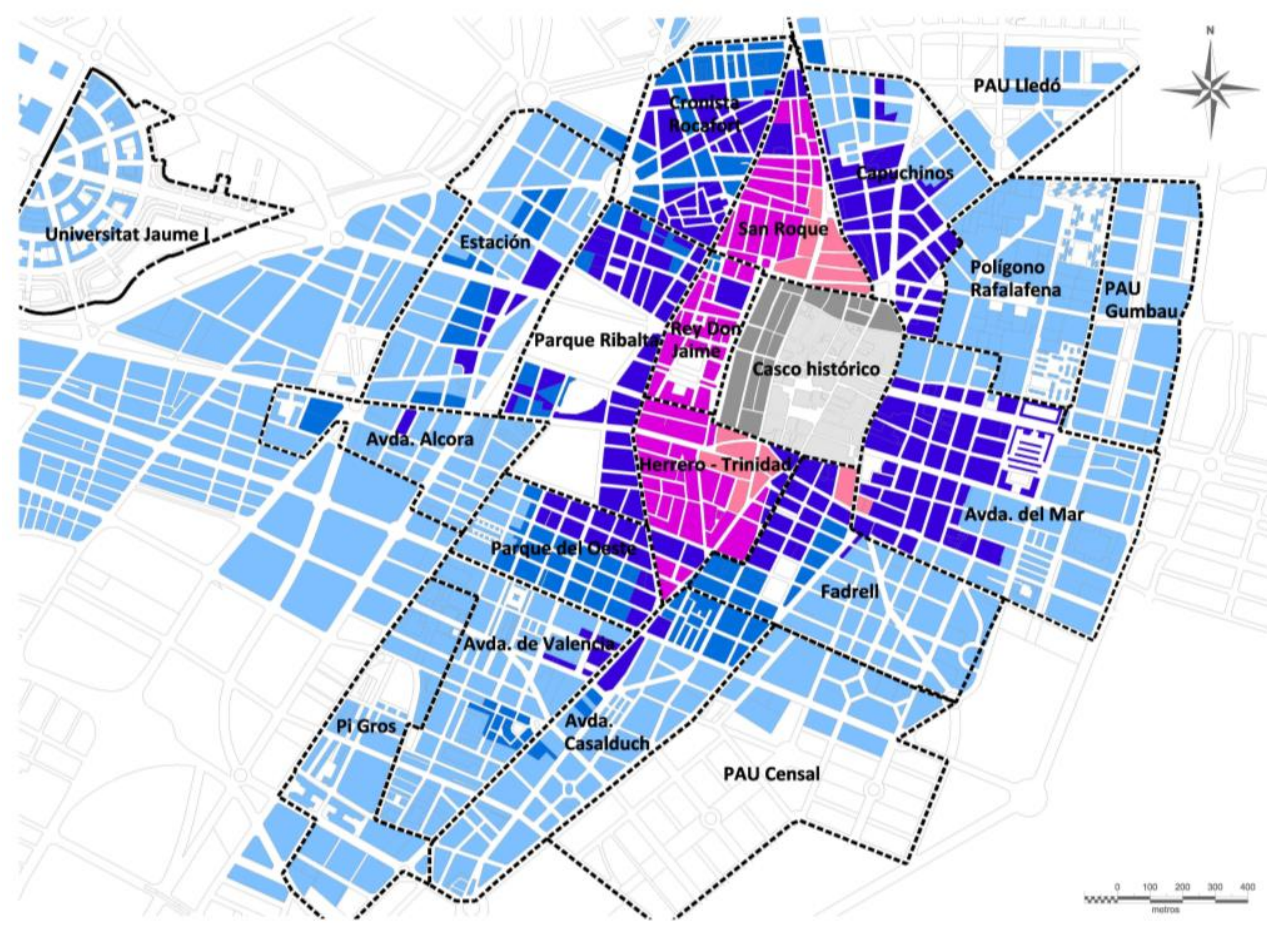

Figura 5.8 Identificación de barrios y superposición a la evolución urbana de la ciudad

\subsubsection{I.3 ESCALA DE MANZANA URBANA}

Tras analizar el planeamiento urbano de la ciudad e identificar los barrios que la constituyen, se procede al estudio de las tipologías de manzana existentes, según los criterios establecidos en la metodología para la caracterización de la taxonomía urbana (Figura 4.3 del Capítulo 4):

- Geometría de la manzana

- Existencia o no de patios de manzana o de luces

- Presencia de edificios aislados o entre medianeras

- Densidad urbana baja, media o alta.

El patrón urbano es un aspecto clave que influye directamente en la morfología de la manzana. Teniendo en cuenta estos criterios, se identifican 7 tipologías de manzana urbana, cuyas características se presentan en la Tabla 5.3. En esta se exponen, además, las ventajas e inconvenientes que presenta cada tipología atendiendo a criterios de eficiencia energética. 


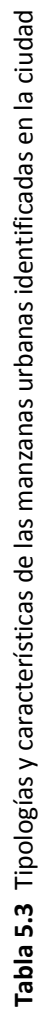

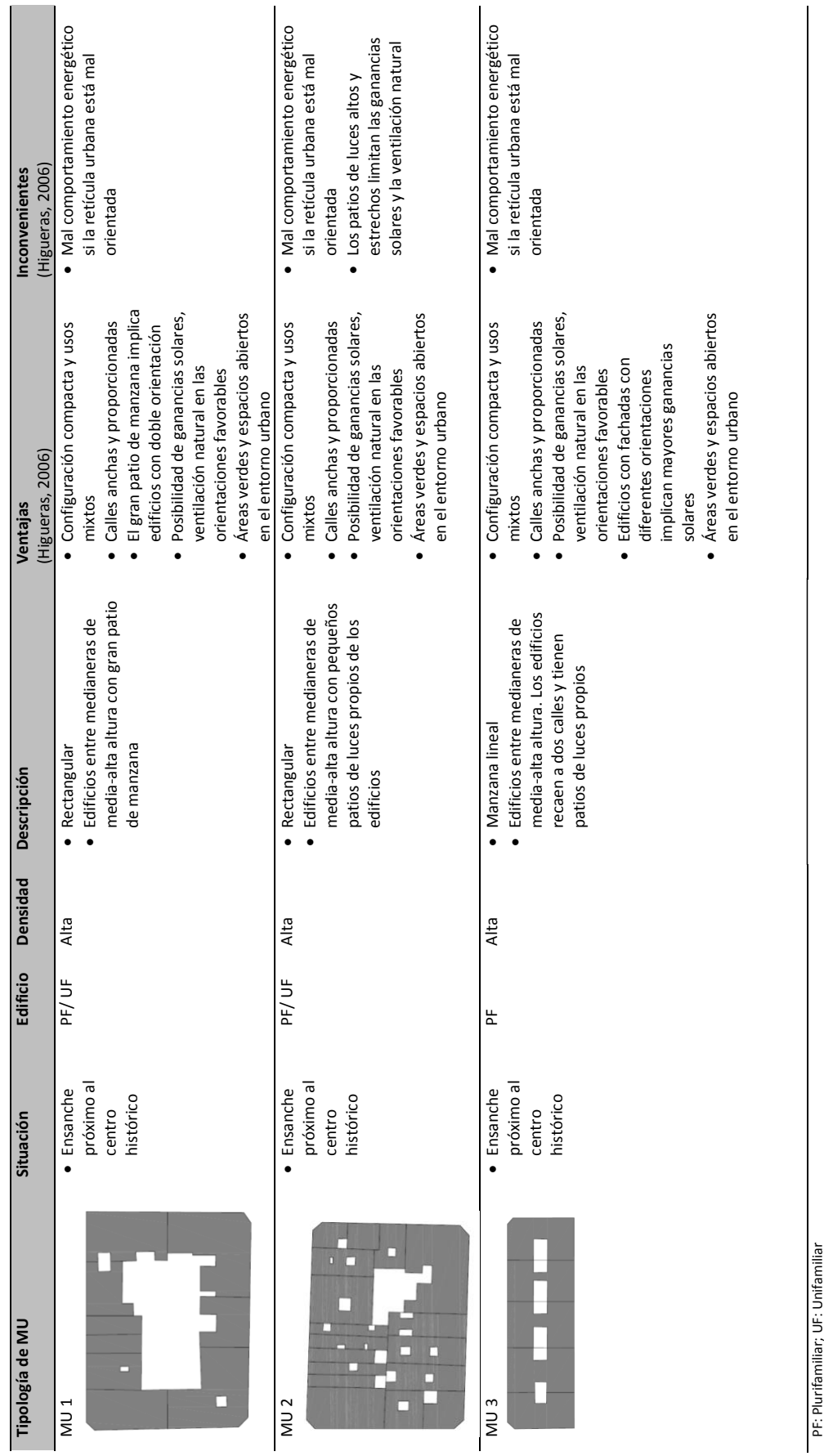




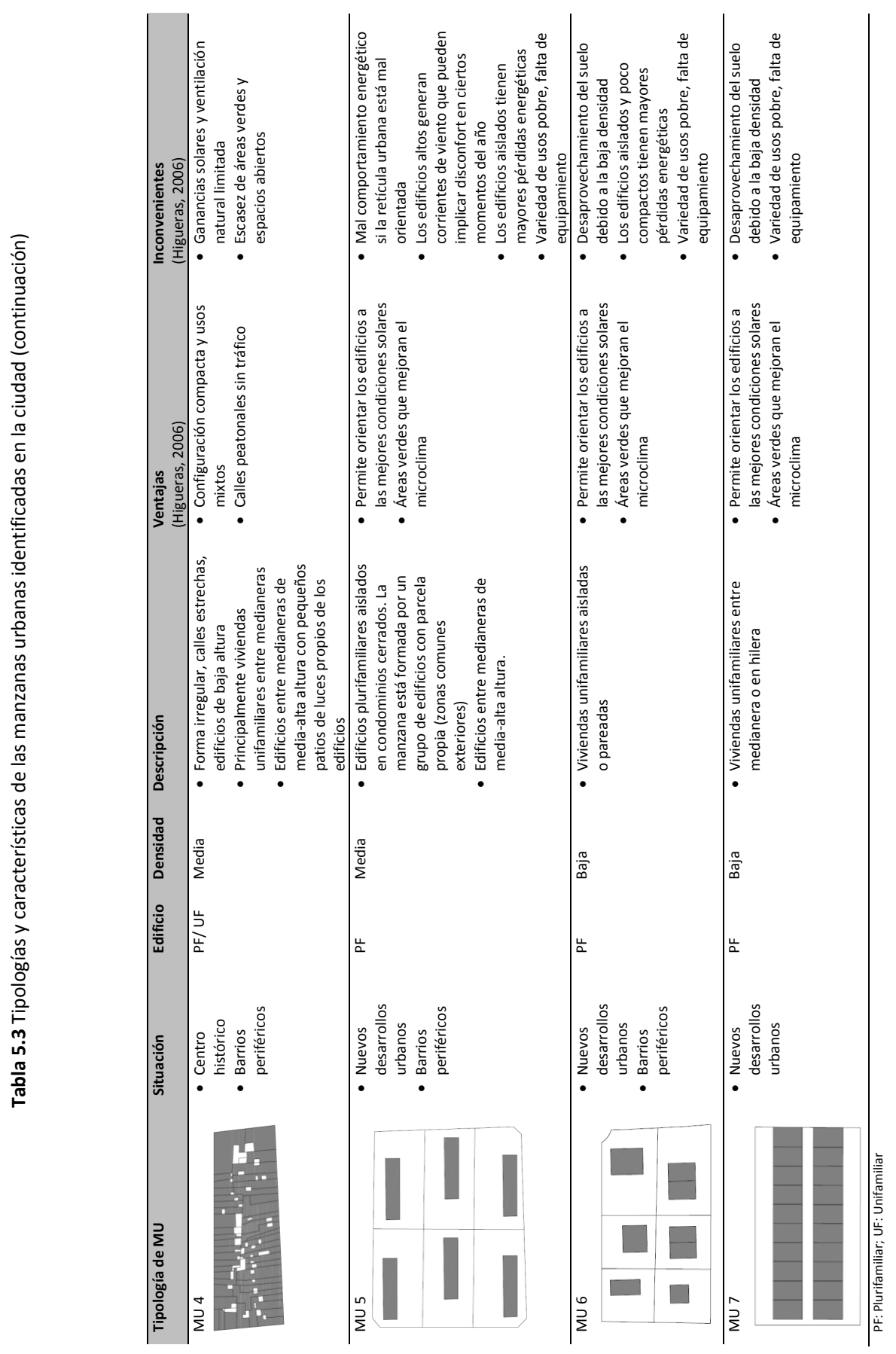




\subsubsection{I.4 ESCALA DE EDIFICIO}

Para caracterizar las tipologías edificatorias, se aplica el procedimiento definido en la Figura 4.4 del Capítulo 4. Son dos los parámetros tenidos en cuenta para realizar dicha caracterización: la clase edificatoria y el año de construcción. La obtención de ambos aspectos se expone en los dos apartados siguientes.

\subsubsection{Identificación de la clase de edificio}

Los criterios que se establecen para caracterizar a los edificios son:

- tipo de ocupación (plurifamiliar o unifamiliar)

- tipo de adyacencia (aislado o entre medianeras)

- número de plantas

El número de plantas tomado como límite para establecer la clasificación de los edificios es de 4 . El criterio tomado se basa en la existencia o no de ascensor en el edificio, pues la disposición del mismo en edificios antiguos era únicamente obligatoria en edificios con más de 4 plantas, lo que tiene como consecuencia que existan muchos edificios no mayores de 4 plantas en el paisaje urbano.

Así, estos tres criterios definen las dimensiones y la morfología del edificio, lo que llevará asociado un factor de forma (S/V), el cual define el grado de compacidad del mismo. Los edificios plurifamiliares implican mayor tamaño que las viviendas unifamiliares, lo que hará que tengan distintas ratios $\mathrm{S} / \mathrm{V}$. Por otro lado, se considera que un edificio de hasta 4 plantas es relativamente bajo, lo que implicará menor compacidad (mayor S/V), y a partir de 4 plantas es alto, lo que le concederá al edificio mayor compacidad (menor S/V). Por último, la adyacencia influirá en el intercambio de calor entre el interior del edificio y el ambiente exterior, pues un edificio aislado tiene mayor porcentaje de superficie de envolvente en contacto con el exterior que un edificio entre medianeras.

Al tipo de ocupación y adyacencia, aspectos de clasificación establecidos por la DGC (2014) (Tabla 4.4 del Capítulo 4), se le añade en número de plantas, lo que da lugar a un total de 6 clases de edificios, tal y como se recoge en la Tabla 5.4.

Tabla 5.4 Obtención de clases de edificio

\begin{tabular}{llll}
\hline Ocupación & Adyacencia & No plantas & Clase edificatoria \\
\hline $\mathrm{PF}$ & Aislada & $\leq 4$ & $\mathrm{PF}_{\mathrm{A}(\leq 4)}$ \\
& & $>4$ & $\mathrm{PF}_{\mathrm{A}(>4)}$ \\
& Entre medianeras & $\leq 4$ & $\mathrm{PF}_{\mathrm{M}(\leq 4)}$ \\
& & $>4$ & $\mathrm{PF} \mathrm{M}_{(>4)}$ \\
$\mathrm{UF}$ & Aislada & $\leq 4$ & $\mathrm{UF}_{\mathrm{A}(\leq 4)}$ \\
& Entre medianeras & $\leq 4$ & $\mathrm{UF}_{\mathrm{M}(\leq 4)}$ \\
\hline
\end{tabular}

La descripción de las características de cada clase de edificio, así como su ubicación habitual dentro de los tipos de barrio, se recoge en la Tabla 5.5. 
Tabla 5.5 Identificación de clases de edificios

\begin{tabular}{|c|c|c|c|c|c|}
\hline $\begin{array}{l}\text { Clase de } \\
\text { edificio }\end{array}$ & Situación & MU & $\begin{array}{l}\text { PF/ } \\
\text { UF }\end{array}$ & Adyacencia & $\begin{array}{l}\text { № } \\
\text { plantas }\end{array}$ \\
\hline $\mathrm{PF}_{\mathrm{A}(\leq 4)}$ & $\begin{array}{l}\text { - Nuevos desarrollos } \\
\text { urbanos } \\
\text { - Barrios periféricos }\end{array}$ & MU5 & $\mathrm{PF}$ & Aislado & $\leq 4$ \\
\hline $\mathrm{PF}_{\mathrm{A}(>4)}$ & $\begin{array}{l}\text { - Nuevos desarrollos } \\
\text { urbanos } \\
\text { - Barrios periféricos }\end{array}$ & MU5 & $\mathrm{PF}$ & Aislado & $>4$ \\
\hline $\mathrm{PF}_{\mathrm{M}(\leq 4)}$ & $\begin{array}{l}\text { - Centro histórico } \\
\text { - Ensanche próximo al } \\
\text { centro histórico } \\
\text { - Barrios periféricos }\end{array}$ & $\begin{array}{l}\text { MU1 } \\
\text { MU2 } \\
\text { MU4 }\end{array}$ & $\mathrm{PF}$ & $\begin{array}{l}\text { Entre } \\
\text { medianeras }\end{array}$ & $\leq 4$ \\
\hline $\mathrm{PF}_{\mathrm{M}(>4)}$ & $\begin{array}{l}\text { - Ensanche próximo al } \\
\text { centro histórico } \\
\text { - Centro histórico }\end{array}$ & $\begin{array}{l}\text { MU1 } \\
\text { MU2 } \\
\text { MU3 } \\
\text { MU4 }\end{array}$ & PF & $\begin{array}{l}\text { Entre } \\
\text { medianeras }\end{array}$ & $>4$ \\
\hline$U \mathrm{~F}_{\mathrm{A}(\leq 4)}$ & $\begin{array}{l}\text { - Nuevos desarrollos } \\
\text { urbanos } \\
\text { - Barrios periféricos }\end{array}$ & & UF & Aislado & $\leq 4$ \\
\hline $\mathrm{UF}_{\mathrm{M}(\leq 4)}$ & $\begin{array}{l}\text { - Nuevos desarrollos } \\
\text { urbanos } \\
\text { - Barrios periféricos } \\
\text { - Centro histórico }\end{array}$ & & UF & $\begin{array}{l}\text { Entre } \\
\text { medianeras }\end{array}$ & $\leq 4$ \\
\hline
\end{tabular}

\subsubsection{Delimitación de los periodos temporales}

El segundo de los aspectos para caracterizar las tipologías edificatorias es el año de construcción del edificio. Este proporcionará información muy útil sobre las características constructivas de la envolvente del edificio, condicionadas por la normativa en vigor en dicho periodo, en cuanto al uso de aislamiento térmico y tipo de materiales constructivos empleados. De hecho, no pueden entenderse las soluciones constructivas que conforman un edificio sin previamente fijar la mirada en el desarrollo y la evolución en el tiempo de la región objeto de estudio.

Así, la clasificación en periodos de construcción viene condicionada por factores de diversa índole que han tenido influencia en el desarrollo urbano de la región, atendiendo a razones tanto históricas 
(hitos históricos y políticos), como normativas (entrada en vigor de nueva legislación, planes generales urbanísticos, etc.), como económicas.

En cuanto a las razones históricas, se deberá prestar atención a aquellos hechos que hayan marcado la evolución constructiva de la zona urbana, como son las guerras, el movimiento migratorio ruralurbano o la aparición de nuevas técnicas constructivas y materiales.

En la Comunidad Valenciana, la evolución histórica desde comienzos del siglo XX ha condicionado fuertemente la forma de construir los edificios, de manera que se aprecia un notable cambio sobre todo durante la década de los 50 , cuando la construcción con hormigón armado comienza a tomar fuerza (Instituto Valenciano de la Edificación, 2011).

Hasta finales del siglo XIX, los edificios estaban constituidos por estructuras de muros de carga de fábrica de ladrillo cerámico (visto, en la mayoría de las ocasiones) y vigas de madera, que fueron sustituyéndose progresivamente por vigas y cerchas de acero laminado. La elevación de los edificios no sobrepasaba las seis plantas de altura. Las fachadas las constituían los propios muros de carga, ejecutados con fábricas gruesas de hasta 2 pies de espesor, de una sola hoja sin aislamiento térmico y rigidizadas por las medianeras y la propia tabiquería interior de las viviendas. Las cubiertas descansaban sobre las vigas de madera o metálicas, siendo, o bien inclinadas con falso techo de cañizo y yeso, o bien planas con cámara de aire ventilada y solado apoyado sobre tabiquillos conejeros ("a la catalana"). Las carpinterías exteriores eran fundamentalmente de madera e incorporaban vidrios monolíticos, los cuales proporcionaban baja resistencia térmica.

Desde principios del siglo XX hasta los años 1940, finalizada la Guerra Civil española, las estructuras con muros de carga seguían implantadas en todo el país. A pesar de la aparición de las primeras industrias cementeras en España, en la Comunidad Valenciana la primera cementera no se instala hasta el año 1922 (Temes Cordovez, 2009). Antes de la guerra de 1936, este territorio tenía que importar la mayoría del cemento que consumía, hasta que, tras la guerra, se instalan nuevas industrias cementeras para dar respuesta a la creciente demanda de cemento, frente a la alta demanda de vivienda. Es en la década de los 40 cuando más se evidencia el consumo de cemento, como consecuencia de la aprobación del nuevo régimen del Plan de Obras Públicas y el Plan Nacional de Ordenación y Reconstrucción (Box, 2012), los cuales hacen una fuerte apuesta por el uso del hormigón como material para construir tanto viviendas como obras públicas.

El fin de la Guerra Civil y la llegada del Franquismo suponen un momento importante para la arquitectura y la construcción en España, ya que el nuevo régimen aboga por la reconstrucción de las ciudades siguiendo la nueva ideología. En 1939 se crea el Instituto Nacional de la Vivienda, la Dirección General de Arquitectura y la Dirección General de Regiones Devastadas y Reparaciones. Con la creación de dichos organismos, se aprueba el Plan Nacional de Ordenación y Reconstrucción que, junto con la Asamblea de Madrid, sienta las bases de la arquitectura y el urbanismo inmediato a la posguerra.

La protección de las industrias cementeras consideradas de interés nacional, lleva al Instituto Nacional de la Vivienda a introducir en los años 1941-1943 Decretos y Órdenes para la limitación del uso del hierro en edificación, también debido a la escasez de material, y potenciar el uso del hormigón armado. Así pues, es a partir de esta época cuando el hormigón armado toma fuerza como material para proyectar y ejecutar estructuras de edificios.

Las primeras estructuras en hormigón armado son porticadas con luces de entre 3 y 4 metros, con vigas de canto para zunchar los forjados y servir como soporte para el apoyo de las fachadas, las cuales dejan de asumir una función estructural para convertirse en cerramientos no portantes. Se imponen también los forjados con viguetas de hormigón y entrevigado con bovedillas de yeso, cerámica u hormigón. Las fachadas pasan a ser muros de doble hoja, estando la hoja exterior constituida por fábrica de $1 / 2$ o 1 pie mientras que la interior, por fábrica de ladrillo hueco sencillo 
(generalmente de $4 \mathrm{~cm}$ de espesor). Durante esta época, la cámara de aire intermedia todavía no incorpora aislamiento térmico, el cual no llegará a instaurarse hasta dentro de cuatro décadas. También durante esta década comienza a generalizarse el uso de la cubierta plana, ejecutándose de una sola hoja debido a la aparición del hormigón aligerado, que permite crear una superficie para la formación de pendientes, así como para la capa de impermeabilización, sobre la que descansa el pavimento. Se introducen también en este período las carpinterías de hierro y aluminio, correderas y abatibles, que implican bajo aislamiento térmico y alta permeabilidad al aire.

Todas las restricciones en el uso de materiales llegan a menguar considerablemente la calidad de las estructuras construidas, originando un gran mercado negro paralelo, no existiendo controles de calidad ni tampoco personal cualificado en el país para trabajar con nivel aceptable la nueva técnica del hormigón armado. Así pues, el resultado de estas dos décadas, entre los años 40 y 60 , es un aumento progresivo de las estructuras de hormigón en los edificios, pero de muy baja calidad constructiva.

En 1957 llegan las Normas Técnicas del Sector de la Edificación (MV) (Ministerio de la Vivienda, 1957), desarrolladas por la Dirección General de Arquitectura, dependiente entonces del Ministerio de Gobernación. Diez años más tarde y como consecuencia del uso generalizado del hormigón, se crea la EH-68 (Gobierno de España, 1968), la primera Instrucción para el proyecto y ejecución de estructuras de hormigón armado. De esta forma, por primera vez, comienza a regularse normativamente la actividad de la construcción.

En la década de los 70, las estructuras porticadas de hormigón armado alcanzan mayores luces, entre los 4 y 5 metros, elevándose también en altura. Las fachadas ven reducido el espesor de su hoja principal exterior, incorporando a su vez un revoco de mortero en su cara interior para contrarrestar el riesgo por humedad. En el año 1972 ven la luz las Normas Tecnológicas de la Edificación (NTE) (Ministerio de Vivienda, 1972) con carácter recomendatorio y en 1977 las NBE Normas Básicas de la Edificación (Ministerio de Obras Públicas y Urbanismo, 1977), de obligado cumplimiento. Con las segundas, llega la Norma Básica sobre Condiciones Térmicas en los Edificios (NBE-CT-79, 1979), que supone la obligatoriedad de incorporar aislamiento térmico y limitar así las pérdidas térmicas a través de los cerramientos. Al final de esta década, consecuencia de la introducción de patentes en los productos de impermeabilización y aislamiento térmico, surge la cubierta invertida, que implica una mejora considerable en la durabilidad de las azoteas. Las carpinterías de madera y hierro comienzan a ser sustituidas por carpinterías de aluminio, manteniéndose los vidrios monolíticos de bajas prestaciones.

Así pues, los años 80 suponen un cambio en las condiciones constructivas de los edificios. La forma reglada de ejecutar los elementos constructivos según las nuevas normas de edificación, la incorporación del aislamiento térmico en la envolvente térmica y la reglamentación del hormigón armado, hacen aumentar la calidad en la edificación. Las estructuras ven incrementadas sus luces, entre 5 y 6 metros, y se instauran las vigas planas (lo que también comporta mayores deformaciones en las fábricas). Las fachadas y cubiertas incorporan ya aislamiento térmico y las carpinterías comienzan a incorporar vidrios dobles con cámara de aire intermedia. La tabiquería interior adopta un mayor espesor (de 4 a $7 \mathrm{~cm}$ o incluso $11 \mathrm{~cm}$ ) para alojar el paso de instalaciones.

Durante los años 90, las estructuras adquieren mayor esbeltez y comienza a hacerse uso de los tabiques ligeros de cartón-yeso para trasdosar la hoja principal de fachada y como tabiquería interior. Las carpinterías aportan mejores prestaciones, las metálicas incorporan la opción de rotura de puente térmico, vidrios dobles normales o bajo emisivos, y las carpinterías de PVC, cámaras de aire intermedias, para proporcionar mayor aislamiento e impermeabilidad al aire.

Cuando desde Europa los requerimientos se endurecen y surge la EPDB 2002 relativa a la eficiencia energética de los edificios (Comisión Europea, 2002), esta se transpone en España en el año 2006 a 
través del CTE (CTE, 2006), el Reglamento de Instalaciones Térmicas en los Edificios (Ministerio de la Presidencia, 2007) y el Procedimiento Básico para la certificación de la eficiencia energética de los edificios (Ministerio de la Presidencia, 2013), como ya se indica en el Capítulo 2. Con la entrada en vigor del CTE y su DB DB HE1, se limita expresamente la demanda de energía en los edificios, con el objetivo de reducir los consumos energéticos y limitar las emisiones de $\mathrm{CO}_{2}$, indicadores que deberán ser demostrados con la certificación energética del edificio.

Las prestaciones de la envolvente térmica mejoran en los edificios construidos a partir de la entrada en vigor del CTE, por la obligatoriedad de aumentar los espesores de aislamiento térmico según la zona climática en la que se ubica el edificio, limitar el riesgo de condensaciones y mejorar las características de los huecos.

Por otro lado, en septiembre de 2013 se aprueba una modificación del CTE con respecto al DB HE, que introduce cambios sustanciales y más restrictivos en las exigencias térmicas de la envolvente de los edificios. Sin embargo, debido al poco número de edificios de nueva planta construidos con los requisitos del CTE de 2013, este período no se diferencia expresamente en la clasificación propuesta en este trabajo.

Las consideraciones anteriores se recogen de forma gráfica en la Tabla 5.6. 
Tabla 5.6 Evolución temporal de los sistemas constructivos en edificios residenciales

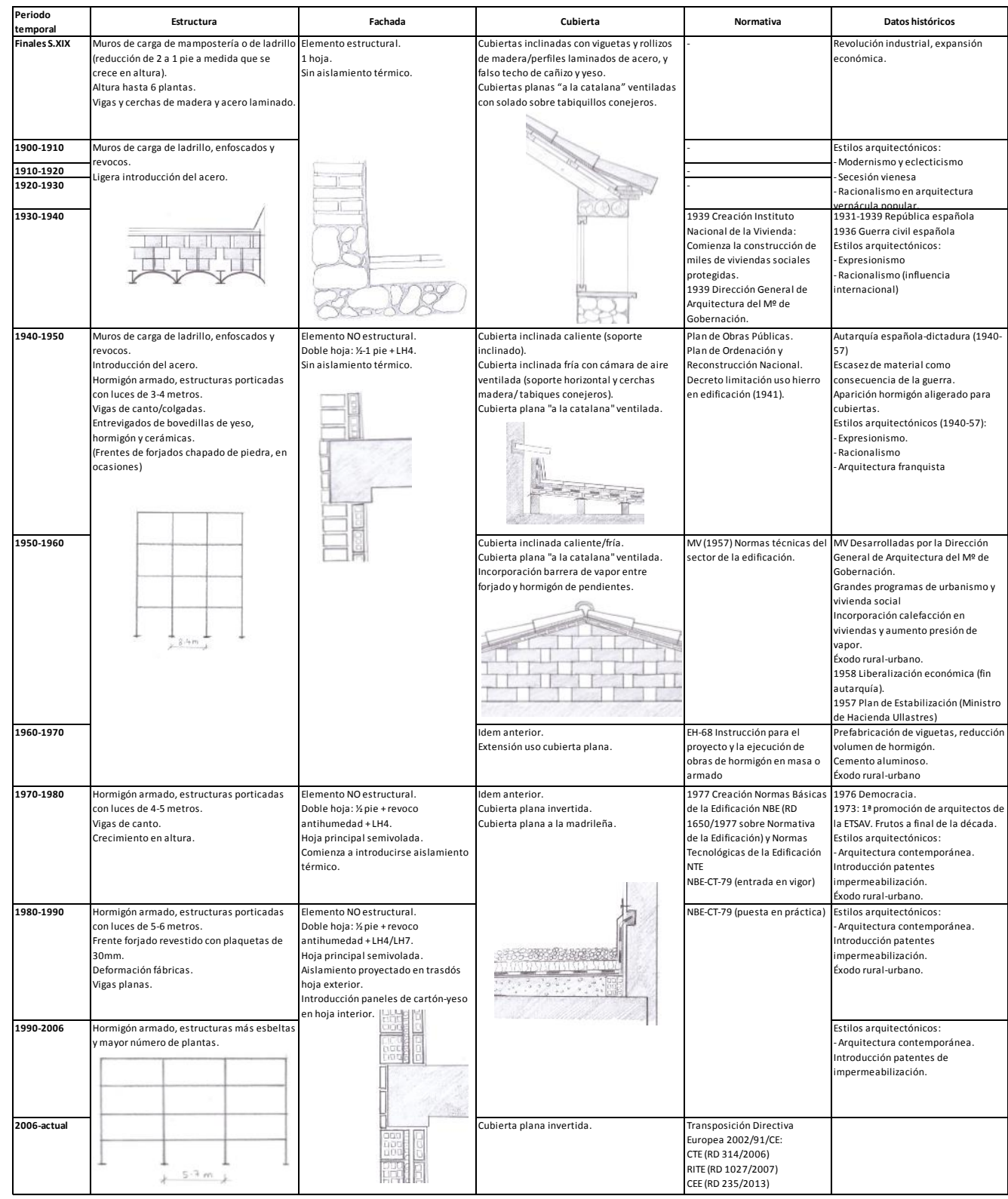


Tabla 5.6 Evolución temporal de los sistemas constructivos en edificios residenciales (continuación)

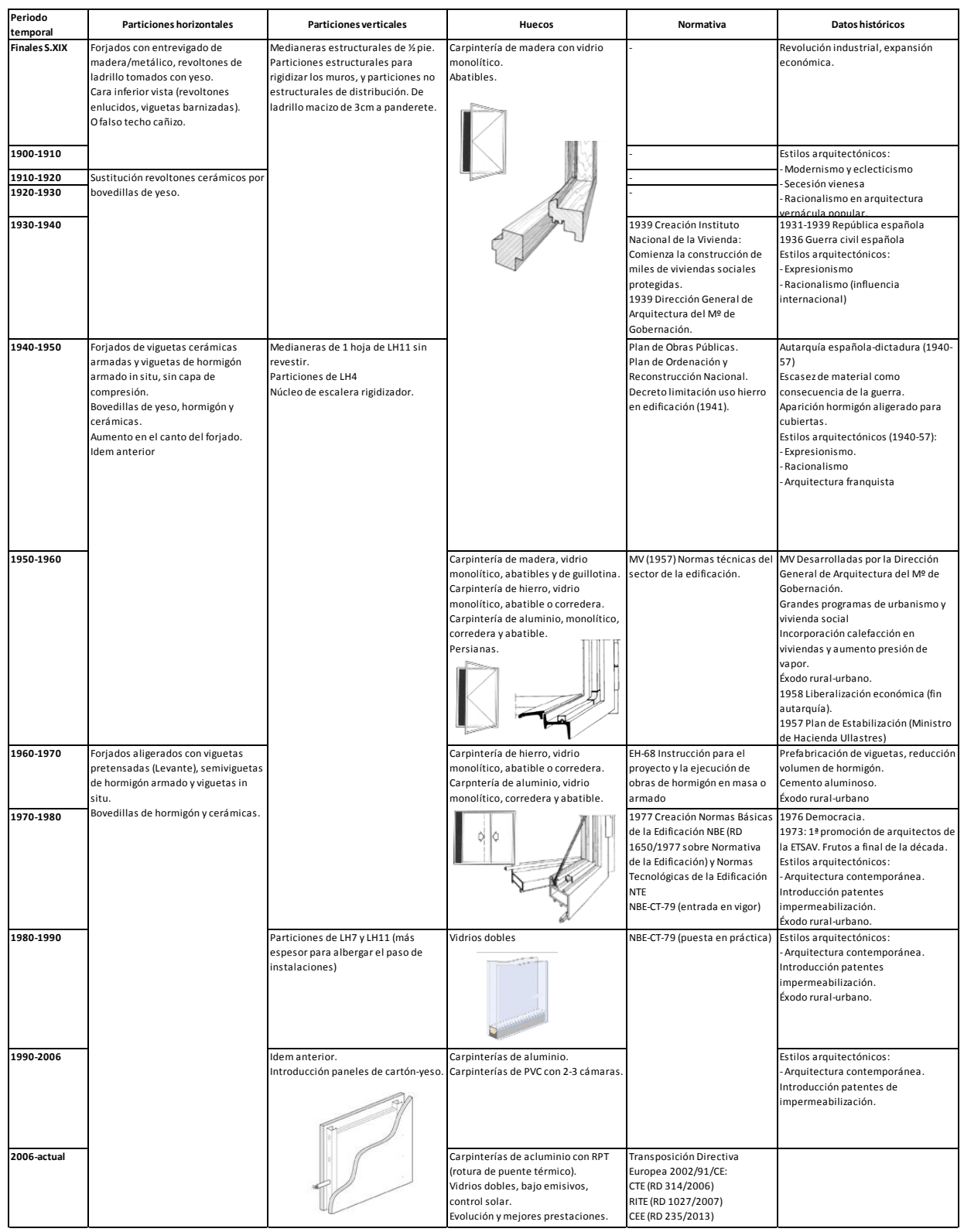


Atendiendo a estas consideraciones, se establece una clasificación en 5 períodos temporales, cada uno de los cuales recoge el conjunto de edificios construidos en las fechas que los definen. Dicha clasificación queda recogida en la Figura 5.9.

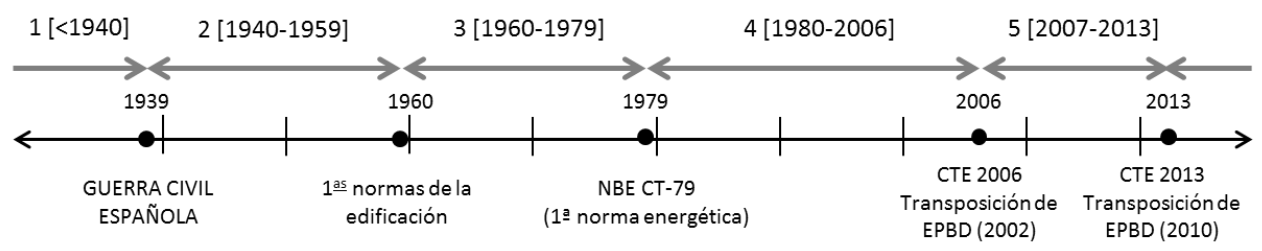

Figura 5.9 Períodos temporales de construcción propuestos

\subsubsection{Obtención de la matriz de tipologías edificatorias}

Cruzando los dos aspectos anteriormente definidos, las 6 clases de edificios y los 5 periodos temporales de construcción, se obtienen 30 tipologías edificatorias, como se muestra en la Figura 5.10 .

\begin{tabular}{|c|c|c|c|c|c|}
\hline Ocupación & Adyacencia & № plantas & Clase edificio & $\begin{array}{l}\text { Año de } \\
\text { construcción }\end{array}$ & $\begin{array}{l}\text { Tipología } \\
\text { edificatoria }\end{array}$ \\
\hline UF & $\begin{array}{l}\text { Aislada } \\
\text { Entre medianeras } \\
\text { Aislada } \\
\text { Entre medianeras }\end{array}$ & $\begin{array}{l}\leq 4 \\
>4 \\
\leq 4 \\
>4 \\
\leq 4 \\
\leq 4\end{array}$ & $\begin{array}{l}\mathrm{PF}_{\mathrm{A}(\leq 4)} \\
\mathrm{PF}_{\mathrm{A}(>4)} \\
\mathrm{PF}_{\mathrm{M}(\leq 4)} \\
\mathrm{PF}_{\mathrm{M}(>4)} \\
\mathrm{UF}_{\mathrm{A}(\leq 4)} \\
\mathrm{UF} \mathrm{F}_{\mathrm{M}(\leq 4)}\end{array}$ & $\begin{array}{l}1:<1940 \\
2: 1940-1959 \\
3: 1960-1979 \\
4: 1980-2006 \\
5: 2007-2013\end{array}$ & $\begin{array}{l}30 \text { tipologías: } \\
{\left[1 \mathrm{PF}_{\mathrm{A}(\leq 4)}, 2 \mathrm{PF}_{\mathrm{A}(\leq 4)},\right.} \\
3 \mathrm{PF}_{\mathrm{A}(\leq 4)}, 4 \mathrm{PF}_{\mathrm{A}(\leq 4)}, \\
5 \mathrm{PF}_{\mathrm{A}(\leq 4)}, \ldots, \\
\left.6 \mathrm{UF}_{\mathrm{M}(\leq 4)]}\right]\end{array}$ \\
\hline
\end{tabular}

Figura 5.10 Obtención de las 30 tipologías edificatorias en la ciudad

Para poder identificar las tipologías edificatorias en el caso de estudio, se procede a generar la base de datos en entorno SIG con la herramienta gvSIG (Asociación gvSIG, 2014), para la totalidad de la ciudad. Los datos de entrada necesarios son obtenidos de la Dirección General del Catastro (DGC, 2014) en formato alfanumérico. Estos son, la referencia catastral (que va asociada a cada parcela y por tanto proporciona el resto de información en formato georreferenciado), la tipología de edificio (según la codificación catastral), el número de plantas (en números romanos), el año de construcción y la superficie construida $\left(e \mathrm{~m}^{2}\right.$ ). Sin embargo, la información disponible en la DGC no se encuentra en el formato correcto para ser interpretado por la herramienta SIG, por lo que resulta necesario una depuración y un tratamiento de los datos previamente a poder ser utilizados. Así, descargada la tabla de atributos que contiene la información catastral, son necesarias las operaciones siguientes:

1. Eliminación de la base de datos los inmuebles que no sean de uso residencial y codificar correctamente aquellos edificios que contengan usos distintos.

2. Conversión de la columna de la tabla de atributos que hace referencia al número de plantas, de un formato en números romanos a numérico (por ejemplo: de IV a 4).

3. Generación de la matriz de clases de edificios (ver Figura 5.11) y asignación de un código (A1, B3, C2, D4, ..., Zn). Para ello, se realizan dos filtrados (uno por número de plantas y otro por periodo de construcción) hasta obtener todas las tipologías: 
a. Primer filtrado. Según la nomenclatura definida por el catastro se clasifica a los edificios en: plurifamiliar aislado, plurifamiliar entre medianeras, unifamiliar aislado y unifamiliar entre medianeras. El filtrado consiste en desglosar los edificios plurifamiliares en cuatro categorías según su número de plantas. Para ello, la columna de la tabla de atributos referente a "tipología" se cruzará con la de "número de plantas" $y$, con ello, se obtiene un número determinado de capas en SIG, una por cada tipología edificatoria.

b. Segundo filtrado. Cada una de las tipologías resultantes del primer filtrado se desglosa en tantas clases de edificios como periodos temporales de construcción se han establecido para el área urbana estudiada, en este caso, cinco. Así pues, se obtienen 30 clases de edificios:

$\left[n^{\mathrm{o}}\right.$ tipologías edificatoras $] \times\left[n^{\mathrm{o}}\right.$ periodostemporale $\}=\left[n^{\mathrm{o}}\right.$ clasesedificio $\}$

Se obtendrá una capa SIG por cada tipología de edificio.

La Figura 5.11 sintetiza el procedimiento conceptual llevado a cabo en la herramienta SIG para la obtención de las clases de edificios.

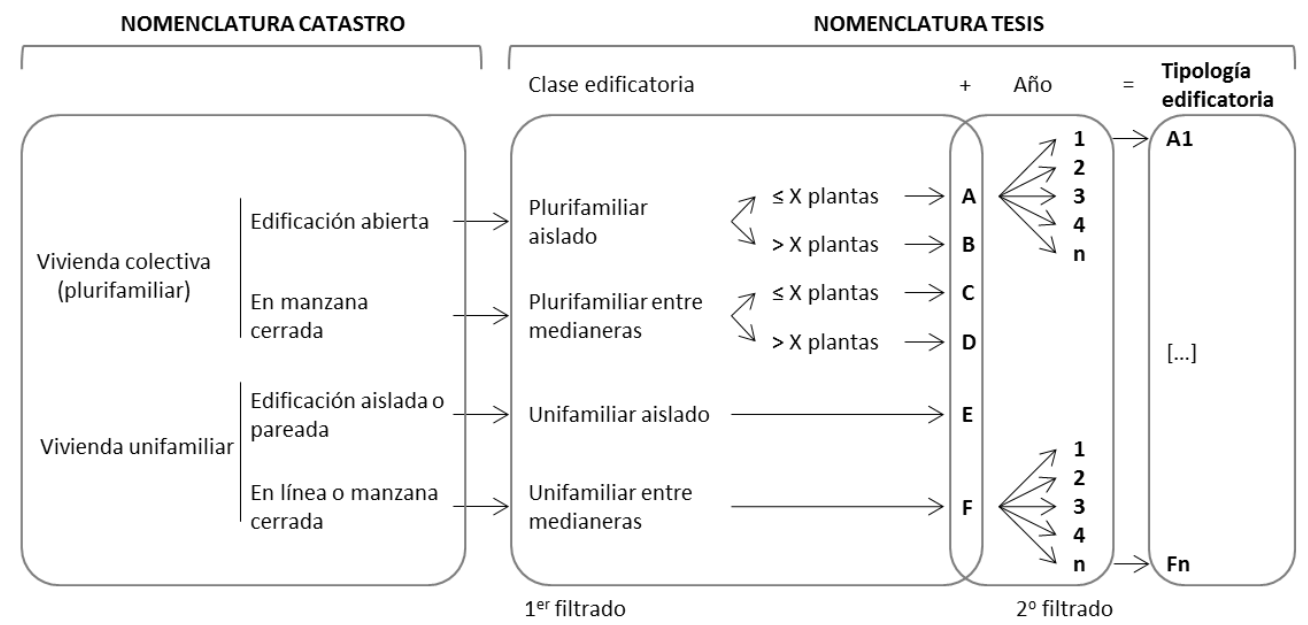

Figura 5.11 Procedimiento a seguir para la obtención de las clases de edificios en un SIG

El filtrado da como resultado la clasificación del conjunto de edificios que constituyen la ciudad, en base a su tipología edificatoria. La Figura 5.12 muestra la visualización de los edificios clasificados según su clase y la Figura 5.13 según su año de construcción. La Figura 5.14 muestra un ejemplo de la información de entrada contenida en la tabla de atributos, la cual se encuentra georreferenciada en base a la referencia catastral. 


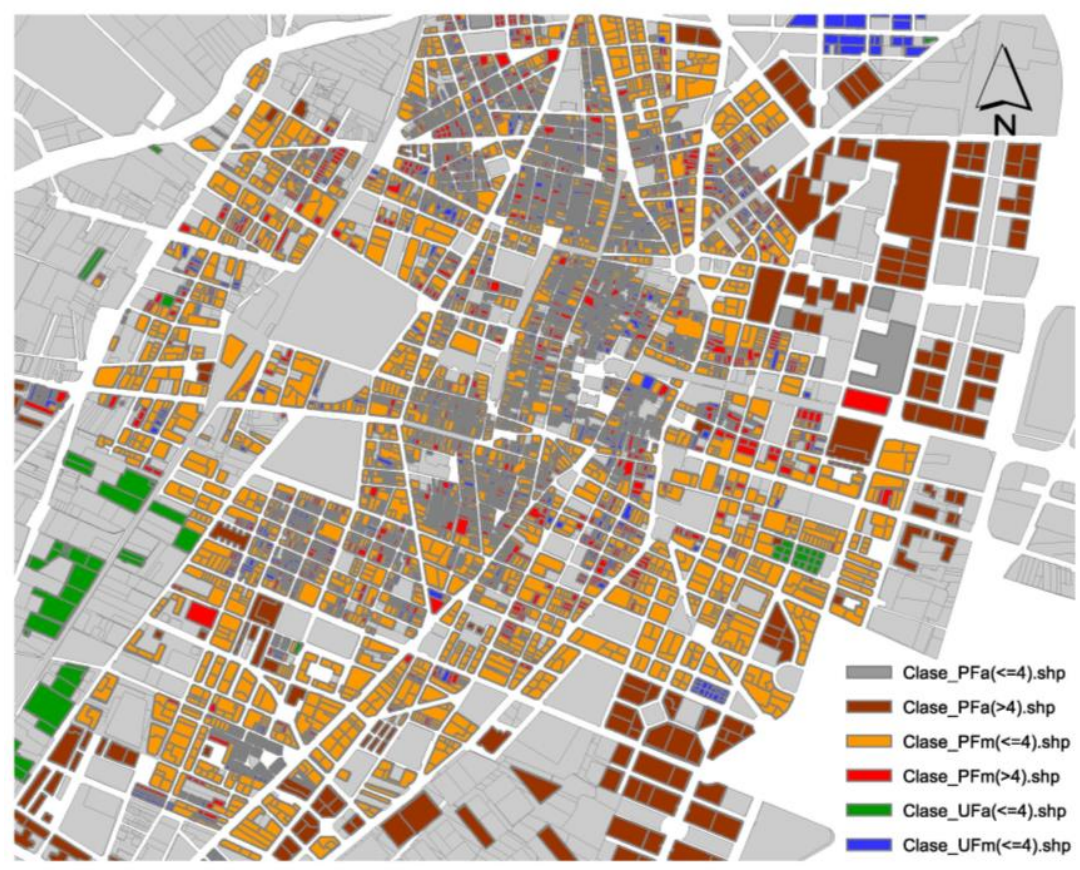

Figura 5.12 Visualización de las clases de edificios en el entorno SIG

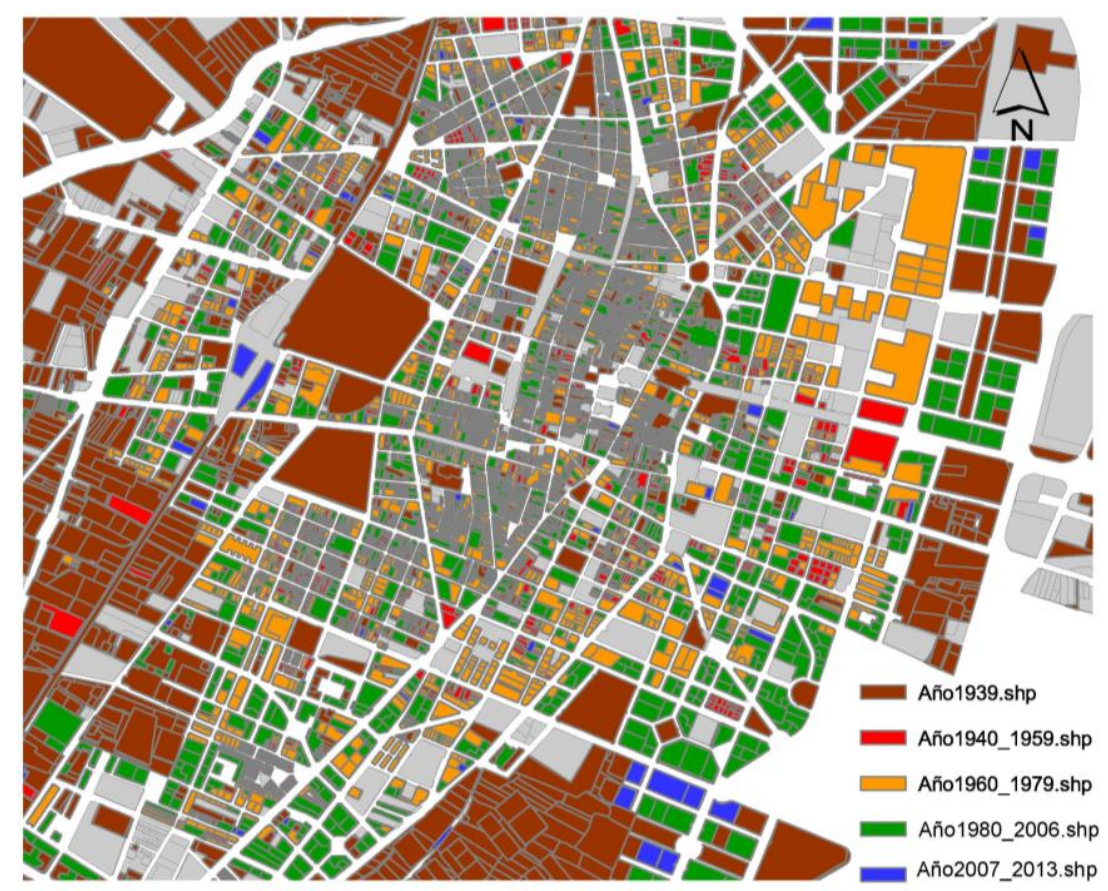

Figura 5.13 Visualización de los años de construcción de los edificios en el entorno SIG 


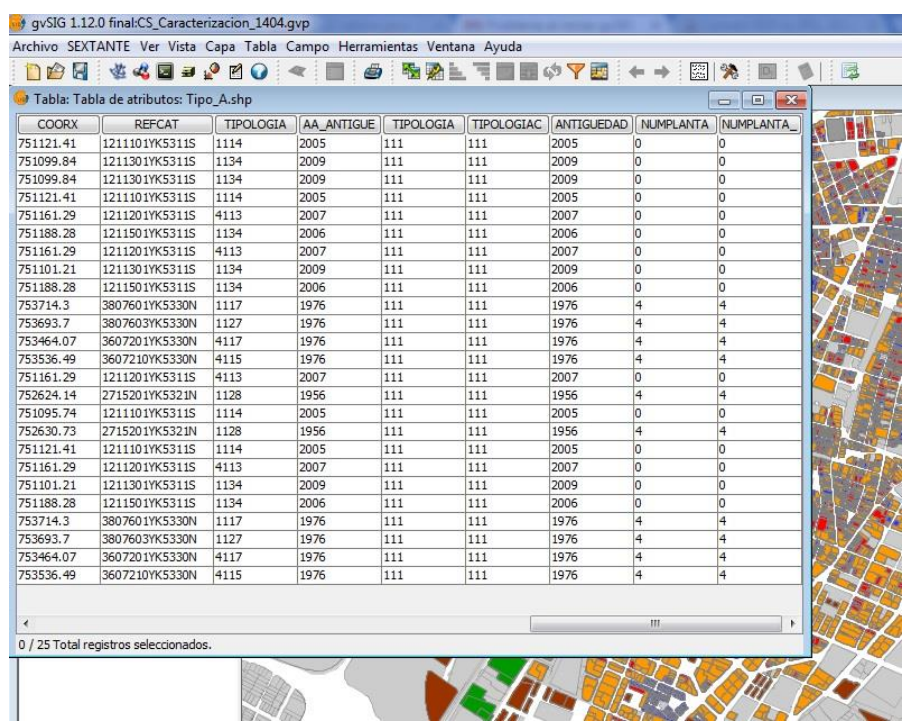

Figura 5.14 Ejemplo de la tabla de atributos en gvSIG

Generada la base de datos en entorno SIG, es posible caracterizar los edificios según la matriz de tipologías edificatorias e identificar el número de edificios contenidos en cada una de ellas. Tras eliminar de la base de datos todos aquellos edificios ubicados en barrios periféricos que no forman parte del núcleo urbano de Castellón, se contabilizan un total de 17.946 edificios. Los resultados de dicho filtrado se muestran en la matriz de la Tabla 5.7.

Tabla 5.7 Matriz de tipologías edificatorias en la ciudad

\begin{tabular}{|c|c|c|c|c|c|c|c|}
\hline \multirow[b]{2}{*}{ Periodo temporal } & \multicolumn{6}{|c|}{ Clase de edificio } & \multirow[b]{2}{*}{ Total } \\
\hline & $\mathrm{PF}_{\mathrm{A}(\leq 4)}$ & $\mathrm{PF}_{\mathrm{A}(>4)}$ & $\mathrm{PF}_{\mathrm{M}(\leq 4)}$ & $\mathrm{PF}_{\mathrm{M}(>4)}$ & $U F_{A(\leq 4)}$ & $U F_{M(\leq 4)}$ & \\
\hline $1[<1940]$ & - & - & 443 & 16 & 63 & 3.537 & 4.059 \\
\hline 2 [1940-1959] & 2 & 12 & 836 & 137 & 63 & 2.016 & 3.066 \\
\hline 3 [1960-1979] & 8 & 90 & 887 & 2.917 & 20 & 994 & 4.916 \\
\hline 4 [1980-2006] & 2 & 489 & 534 & 2.560 & 33 & 1.038 & 4.656 \\
\hline 5 [2007-2013] & - & 181 & 182 & 445 & 211 & 230 & 1.249 \\
\hline Total & 12 & 772 & 2.882 & 6.075 & 390 & 7.815 & 17.946 \\
\hline
\end{tabular}

Claramente, se aprecia una tendencia ascendente en la construcción de edificios a lo largo del siglo XX, especialmente durante el periodo de construcción 3 (1960-1979), precisamente con anterioridad a la entrada en vigor de la NBE-CT-79. Ello trae como consecuencia que un $67,10 \%$ de los edificios carezcan de aislamiento térmico en su envolvente. El $25,94 \%$ de los edificios, los construidos en el periodo 4 (1980-2006), incorporan un tímido aislamiento térmico acorde a la NBE-CT-79 y solo el 6,96\% restante se adaptan a los estándares del CTE (2006), lo que denota una baja calidad térmica de la envolvente del parque edificatorio residencial construido en Castellón de la Plana hasta la fecha. La evolución en el volumen edificado se muestra en la Figura 5.15. 


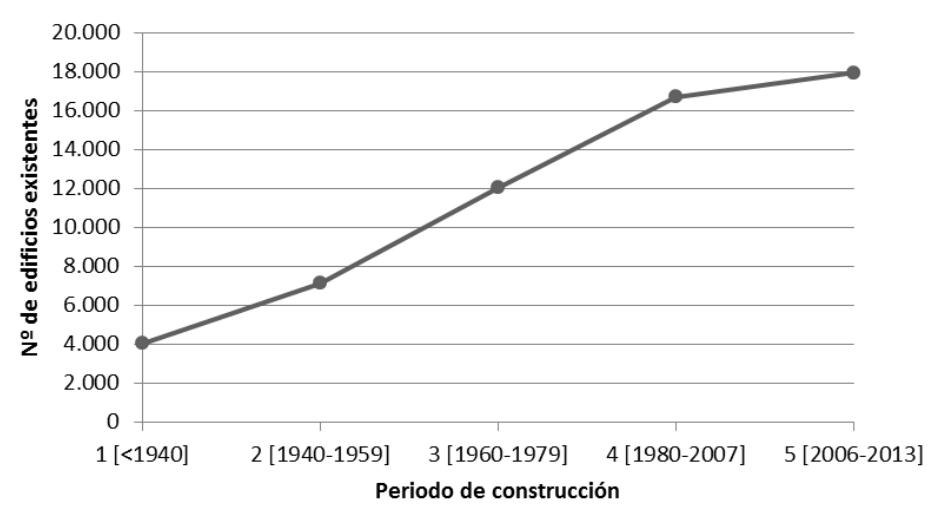

Figura 5.15 Evolución en la construcción de edificios en Castellón de la Plana

En cuanto a la clase edificatoria, de la matriz se extrae que las clases predominantes en la ciudad son la $\mathrm{PF}_{\mathrm{M}(\leq 4)}$ (edificios plurifamiliares entre medianeras de altura menor o igual a 4 plantas), la $\mathrm{PF}_{\mathrm{M}(\leq 4)}$ (edificios plurifamiliares entre medianeras de más de 4 plantas) y la $U F_{M(\leq 4)}$ (viviendas unifamiliares entre medianeras), ya que juntas suponen el $93,46 \%$ de los edificios.

Cruzando los dos aspectos (clase y año de construcción) se obtiene que las tipologías de edificios más abundantes en la ciudad son las siguientes:

- $2 \mathrm{PF}_{\mathrm{M}(\leq 4)}$

- $\quad 3 P F_{M(\leq 4)}$

- $\quad 3 P F_{M(>4)}$

- $\quad 1 U \mathrm{~F}_{\mathrm{M}(\leq 4)}$

Identificadas las tipologías predominantes, se selecciona en apartados siguientes, un barrio de la ciudad que contenga en un alto porcentaje dichas tipologías edificatorias, para que sea representativo.

\subsubsection{I.5 CONFIGURACIÓN DE LA TAXONOMÍA URBANA REPRESENTATIVA}

Identificadas las tipologías de manzana y las tipologías edificatorias, se puede establecer un esquema taxonómico que interrelacione las cuatro escalas de caracterización: ciudad, barrio, manzana urbana y edificio. La Figura 5.16 muestra las conexiones entre los elementos de estas cuatro escalas, estableciendo así las posibilidades de asociación entre manzanas urbanas y clases de edificios. La figura indica también algunos ejemplos de vivienda que se pueden encontrar en cada clase. 


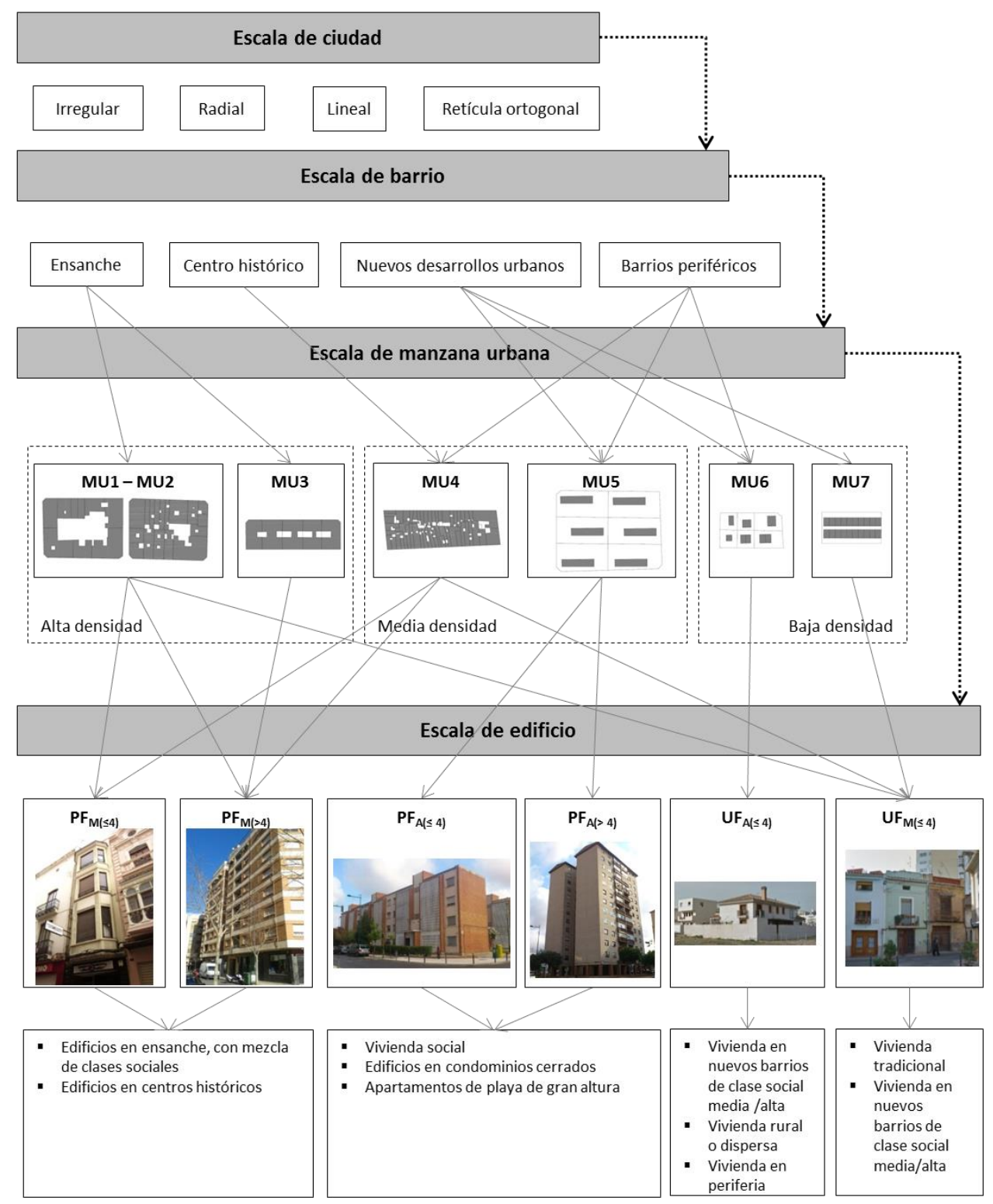

Figura 5.16 Taxonomía urbana de la ciudad de Castellón de la Plana 


\subsubsection{I.6 SELECCIÓN DE LOS EDIFICIOS REPRESENTATIVOS}

Para concretar el caso de estudio, se selecciona un barrio de la ciudad. Para ello, se ha identificado un barrio que recoge las tipologías edificatorias más representativas de la ciudad $\left(\mathrm{PF}_{\mathrm{M}(\leq 4)}, \mathrm{PF}_{\mathrm{M}(>4)}\right.$, $\left.\mathrm{UF}_{\mathrm{M}(\leq 4)}\right)$, el barrio "Parque del Oeste" (ver Figura 5.17).

El barrio se sitúa al sur del Hospital Provincial de Castellón y se extiende hacia el este. Queda delimitado por las calles Padre Jofre y Pelayo al norte, por la ronda Mijares y avenida de Valencia al este, por la calle Jacinto Benavente, Parque del Oeste y Escalante al sur, y por la Gran Vía de Tárrega Monteblanco al oeste.

El barrio se define como una amplia franja de ensanche de la ciudad de trazado claramente reticular que atiende a una malla ortogonal con manzanas rectangulares y achaflanadas en sus esquinas. Las edificaciones existentes son principalmente de uso residencial, aunque con usos mixtos, donde los edificios plurifamiliares de viviendas se combinan con actividades comerciales en sus plantas bajas y pequeños talleres de uso industrial. Existe una tipología muy clara de edificios, correspondiente a edificios adosados entre medianeras que conforman manzanas cerradas, entre los que se encuentran tanto viviendas unifamiliares de una a cuatro plantas como bloques de viviendas de distintos periodos de construcción que alcanzan mayoritariamente las ocho alturas.

Las calles son generalmente de anchura mediana, a excepción de las grandes avenidas que delimitan el barrio, que cuentan con anchos mayores. Las calles, a pesar de contar generalmente con dos carriles y aparcamiento, tienen aceras muy estrechas que no incorporan ningún tipo de arbolado.

En cuanto a equipamientos, el barrio cuenta con la proximidad del Hospital Provincial y de un colegio de educación primaria. Las zonas verdes son escasas, únicamente existe el Parque del Oeste situado en las proximidades y la zona verde vinculada al hospital.

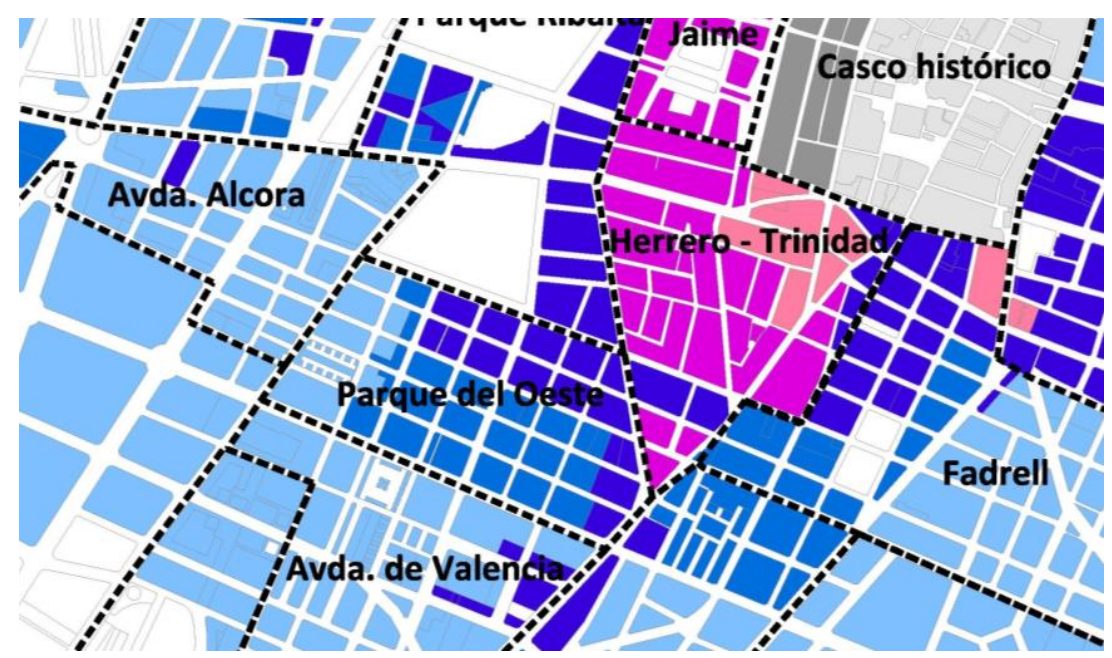

Figura 5.17 Ubicación del barrio Parque del Oeste en el contexto de la ciudad

Las tres tipologías de edificios identificadas en el barrio $\left(\mathrm{PF}_{\mathrm{M}(\leq 4)}, \mathrm{PF}_{\mathrm{M}(>4)}, \mathrm{UF} \mathrm{F}_{\mathrm{M}(\leq 4)}\right)$ corresponden a edificios entre medianeras, pues al estar este constituido por manzanas cerradas, solo es posible encontrar estas clases edificatorias. 
Los edificios seleccionados deben representar fielmente al conjunto de edificios contenidos en su clase. Así, con el objetivo de seleccionar tres edificios representativos, se ha llevado a cabo un análisis de la superficie construida por tipología edificatoria en todo el barrio, cuyos resultados se presentan en la Tabla 5.8. Se obtiene que la superficie construida media de las tres clases de edificios es de $338,74 \mathrm{~m}^{2}$ para $\mathrm{PF}_{\mathrm{M}(\leq 4)}$, de $1.760,83 \mathrm{~m}^{2}$ para $\mathrm{PF}_{\mathrm{M}(>4)}$ y de $153,99 \mathrm{~m}^{2}$ para $U \mathrm{~F}_{\mathrm{M}(\leq 4)}$. De esta manera, se han seleccionado tres edificios reales cuya superficie construida se asimila a las tres anteriores (ver Figura 5.18), respectivamente.

Cabe indicar que la superficie construida a la que se refiere la tabla, hace referencia a la superficie construida de los espacios del edificio destinados únicamente a uso residencial, por lo que no se computan las plantas destinadas a aparcamiento y/o trastero, ni los locales comerciales o de otros usos que existen en las plantas bajas y entresuelos.

Tabla 5.8 Análisis de la superficie construida por tipología edificatoria en el barrio para selección de los edificios muestra representativos

\begin{tabular}{|c|c|c|c|c|c|c|}
\hline \multirow{2}{*}{$\begin{array}{l}\text { Clase de } \\
\text { edificio }\end{array}$} & \multirow{2}{*}{$\begin{array}{c}\text { Tipología } \\
\text { edificatoria }\end{array}$} & \multirow[b]{2}{*}{ № edificios } & \multicolumn{2}{|c|}{$\begin{array}{l}\text { Sup. Construida por tipología } \\
\text { destinada a uso residencial }\end{array}$} & \multirow{2}{*}{$\begin{array}{c}\text { Sup. Media } \\
\text { por tipología } \\
\left(\mathrm{m}^{2}\right)\end{array}$} & \multirow{2}{*}{$\begin{array}{c}\text { Sup. Media } \\
\text { por clase } \\
\left(\mathrm{m}^{2}\right)\end{array}$} \\
\hline & & & $\left(\mathrm{m}^{2}\right)$ & $\%$ & & \\
\hline \multirow[t]{5}{*}{$P F_{M(\leq 4)}$} & $1 \mathrm{PF}_{\mathrm{M}(\leq 4)}$ & 21 & 4425 & $1,23 \%$ & 210,71 & \multirow{5}{*}{338,74} \\
\hline & $2 \mathrm{PF}_{\mathrm{M}(\leq 4)}$ & 38 & 8888 & $2,46 \%$ & 233,89 & \\
\hline & $3 P F_{M(\leq 4)}$ & 33 & 10771 & $2,98 \%$ & 326,39 & \\
\hline & $4 \mathrm{PF}_{\mathrm{M}(\leq 4)}$ & 18 & 10286 & $2,85 \%$ & 571,44 & \\
\hline & $5 P F_{M(\leq 4)}$ & 4 & 1405 & $0,39 \%$ & 351,25 & \\
\hline \multirow[t]{5}{*}{$P F_{M(>4)}$} & $1 \mathrm{PF}_{\mathrm{M}(>4)}$ & 0 & 0 & $0,00 \%$ & 0 & \multirow{5}{*}{$1.760,83$} \\
\hline & $2 \mathrm{PF}_{\mathrm{M}(>4)}$ & 2 & 714 & $0,20 \% *$ & $357^{*}$ & \\
\hline & $3 P F_{M(>4)}$ & 91 & 115539 & $32,01 \%$ & $1.269,66$ & \\
\hline & $4 \mathrm{PF}_{\mathrm{M}(>4)}$ & 73 & 153936 & $42,65 \%$ & $2.108,71$ & \\
\hline & $5 P F_{M(>4)}$ & 9 & 17137 & $4,75 \%$ & $1.904,11$ & \\
\hline \multirow[t]{5}{*}{$\mathrm{UF}_{\mathrm{M}(\leq 4)}$} & $1 \mathrm{UF}_{\mathrm{M}(\leq 4)}$ & 136 & 16238 & $4,50 \%$ & 119,40 & \multirow{5}{*}{153,99} \\
\hline & $2 U_{\mathrm{M}(\leq 4)}$ & 86 & 10986 & $3,04 \%$ & 127,74 & \\
\hline & $3 U F_{M(\leq 4)}$ & 32 & 5191 & $1,44 \%$ & 162,21 & \\
\hline & $4 U_{M(\leq 4)}$ & 24 & 4122 & $1,14 \%$ & 171,75 & \\
\hline & $5 U F_{M(\leq 4)}$ & 7 & 1322 & $0,37 \%$ & 188,86 & \\
\hline Total & & 574 & 360.960 & $100,00 \%$ & 360.960 & \\
\hline
\end{tabular}

* Valor no considerado para obtener la superficie media, por ser atípico dentro de su clase.

La Figura 5.18 muestra una imagen de cada uno de los edificios seleccionados como representativos. 


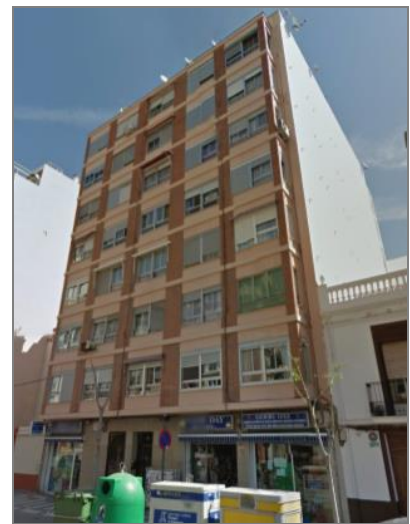

$P F_{M(>4)}\left(2.006,61 \mathrm{~m}^{2}\right)$

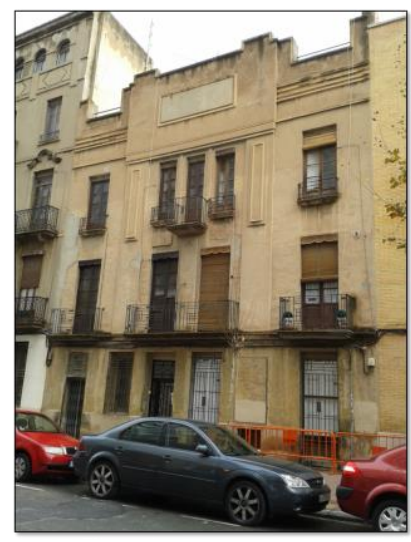

$\mathrm{PF}_{\mathrm{M}(\leq 4)}\left(337,98 \mathrm{~m}^{2}\right)$

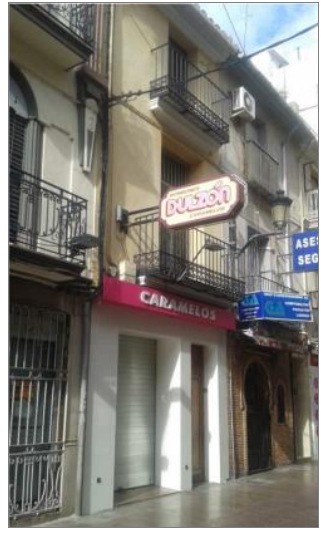

$U F_{M(\leq 4)}\left(165,24 m^{2}\right)$

Figura 5.18 Edificios muestra representativos y superficie construida

El edificio $\mathrm{PF}_{\mathrm{M}(>4)}$ se construyó en el año 1971 y consta de ocho plantas sobre rasante distribuidas de la siguiente forma:

- Planta baja: constituida por un local comercial y el zaguán de acceso a las plantas de vivienda. La planta baja no se tendrá en consideración en el análisis energético, al no corresponder con un uso residencial, por lo que se define como un espacio no habitable, a efectos térmicos.

- Plantas tipo: existen 7 plantas tipo de vivienda, constituidas cada una de ellas por 4 viviendas, A, B, C, D. Las cuatro viviendas tienen huecos en la fachada principal del edificio; dos de ellas ( $A$ y $D)$, además tienen huecos en la fachada posterior.

El edificio $\mathrm{PF}_{\mathrm{M}(\leq 4)}$ se construyó en el año 1940 y consta de 3 plantas sobre rasante distribuidas de la siguiente forma:

- Planta baja: está constituida por un local comercial, una vivienda y el zaguán de acceso al resto de plantas de vivienda. El local comercial no se tendrá en consideración en el análisis energético, al no corresponder con un uso residencial, por lo que se define como un espacio no habitable.

- Plantas tipo: existen 2 plantas tipo de vivienda, constituidas cada una de ellas por 2 viviendas, A y B. Las dos viviendas tienen huecos tanto en la fachada principal del edificio como en la fachada posterior.

El edificio $U F_{M(\leq 4)}$ se construyó en el año 1925 y consta de 4 plantas sobre rasante distribuidas de la siguiente forma:

- Planta baja: alberga dos locales comerciales, por lo que se define toda la planta como no habitable.

- Plantas primera y segunda: corresponden a una vivienda unifamiliar, con huecos tanto en la fachada principal como en la posterior. 
- Planta bajo cubierta: forma parte de la vivienda, pero corresponde a una zona destinada a uso de almacén, por lo que se considera como un espacio no habitable a efectos del análisis energético.

Por otro lado, las manzanas presentes en el barrio responden a las tipologías $\mathrm{MU}_{1}$ y $\mathrm{MU}_{2}$, identificadas en la Tabla 5.3. La Figura 5.19 muestra estas tipologías de manzana y las clases de edificios que estas contienen.

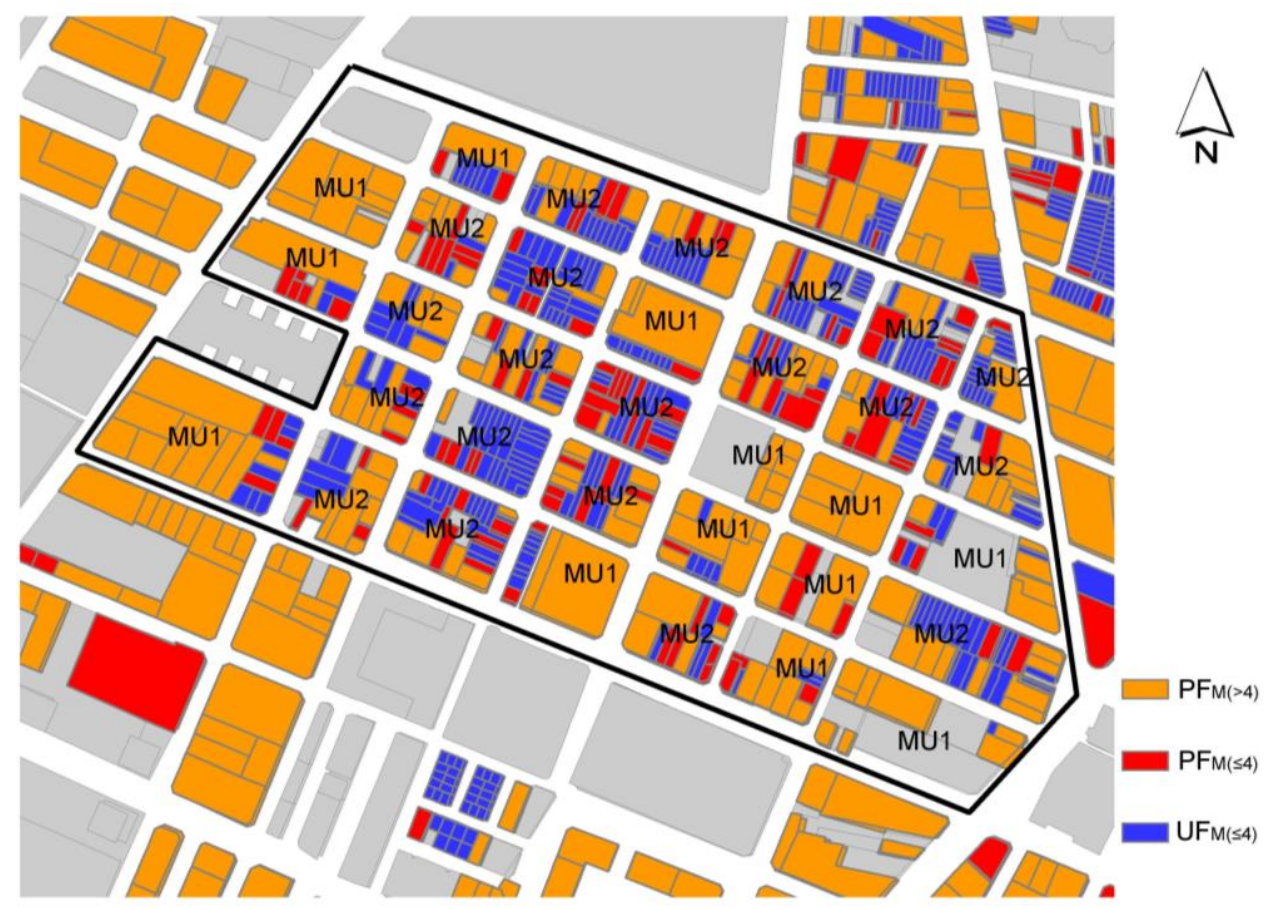

Figura 5.19 Visualización en entorno SIG de las clases de edificios y tipologías de manzanas contenidas en el barrio

Para identificar la manzana típica que caracteriza el barrio, se determina el porcentaje de superficie construida de cada clase de edificio contenidos en cada una de las manzanas. La Tabla 5.9 muestra el número de edificios, la superficie construida en $\mathrm{m}^{2} \mathrm{y} \%$ de superficie construida por cada tipología de edificio. 
Tabla 5.9 Número de edificios, superficie construida $\left(\mathrm{m}^{2}\right)$ y \% de superficie construida por clase de edificio y por tipología de manzana

\begin{tabular}{|c|c|c|c|c|c|c|c|c|c|c|}
\hline & \multirow[b]{3}{*}{ Año de construcción } & \multicolumn{9}{|c|}{ Clase de edificio } \\
\hline & & \multicolumn{3}{|c|}{$P F_{M(>4)}$} & \multicolumn{3}{|l|}{$\mathrm{PF}_{\mathrm{M}(\leq 4)}$} & \multicolumn{3}{|l|}{$U F_{M(\leq 4)}$} \\
\hline & & № & $\mathrm{m}^{2}$ & $\%$ & № & $\mathrm{m}^{2}$ & $\%$ & № & $\mathrm{m}^{2}$ & $\%$ \\
\hline \multirow[t]{6}{*}{ MU1 } & $1(<1940)$ & - & - & - & 2 & 376 & $5,37 \%$ & 14 & 1.442 & $30,42 \%$ \\
\hline & 2 (1940-1959) & - & - & - & 7 & 1.885 & $26,91 \%$ & 12 & 1.388 & $29,28 \%$ \\
\hline & $3(1960-1979)$ & 34 & 53.315 & $45,91 \%$ & 7 & 2.326 & $33,20 \%$ & 6 & 1.221 & $25,75 \%$ \\
\hline & $4(1980-2006)$ & 20 & 53.119 & $45,74 \%$ & 4 & 1.992 & $28,44 \%$ & 3 & 459 & $9,68 \%$ \\
\hline & $5(2007-2013)$ & 7 & 9.694 & $8,35 \%$ & 1 & 426 & $6,08 \%$ & 1 & 231 & $4,87 \%$ \\
\hline & & & 116.128 & $90,81 \%$ & & 7.005 & $5,48 \%$ & & 4.741 & $3,71 \%$ \\
\hline \multirow[t]{6}{*}{ MU2 } & $1(<1940)$ & - & - & - & 21 & 4.419 & $12,36 \%$ & 131 & 15.954 & $43,36 \%$ \\
\hline & 2 (1940-1959) & 1 & 146 & $0,07 \%$ & 30 & 6.724 & $18,81 \%$ & 58 & 7.661 & $20,82 \%$ \\
\hline & 3 (1960-1979) & 54 & 60.797 & $27,24 \%$ & 27 & 8.656 & $24,21 \%$ & 25 & 3.796 & $10,32 \%$ \\
\hline & $4(1980-2006)$ & 35 & 39.865 & $17,86 \%$ & 13 & 7.972 & $22,30 \%$ & 19 & 3.435 & $9,34 \%$ \\
\hline & $5(2007-2013)$ & 5 & 6.245 & $2,80 \%$ & 3 & 979 & $2,74 \%$ & 7 & 1.206 & $3,28 \%$ \\
\hline & & & 107.053 & $63,78 \%$ & & 28.750 & $17,12 \%$ & & 32.052 & $19,10 \%$ \\
\hline
\end{tabular}

Se observa que la $\mathrm{MU}_{1}$ está compuesta en su mayor parte $(90,81 \%)$ por edificios plurifamiliares entre medianeras altos $\left(\mathrm{PF}_{\mathrm{M}(>4)}\right)$, con algunos edificios plurifamiliares entre medianeras de menos de 4 plantas $\left(\mathrm{PF}_{\mathrm{M}(\leq 4)}\right)$ y algunas viviendas unifamiliares $\left(\mathrm{UF}_{\mathrm{M}(\leq 4)}\right)$. Se aprecia que las $\mathrm{MU}_{1}$ son manzanas de más reciente creación, motivo por el que predominan los edificios de grandes dimensiones.

En la $\mathrm{MU}_{2}$ abundan las viviendas unifamiliares tradicionales antiguas $\left(\mathrm{UF}_{\mathrm{M}(\leq 4)}\right)$ y también tienen presencia los edificios plurifamiliares de baja altura $\left(\mathrm{PF}_{\mathrm{M}(\leq 4)}\right)$, pues corresponden a las edificaciones principalmente antiguas ligadas al momento de la creación del barrio en los inicios del siglo XX, que dificultaron a posteriori la configuración de un gran patio de manzana. Sin embargo, los edificios plurifamiliares altos son también la clase predominante $(63,78 \%)$ en esta manzana.

De hecho, si se superpone la tipología de manzana urbana al desarrollo histórico del barrio, se aprecia que las $\mathrm{MU}_{2}$ están situadas precisamente al norte del barrio, por donde este comenzó a crearse, mientras que las $\mathrm{MU}_{1}$ están situadas más hacia el sur, pues corresponden a una tipología más reciente de manzana. Los resultados de la Tabla 5.9 se indican gráficamente en la Figura 5.20.

$\mathrm{MU}_{1}$

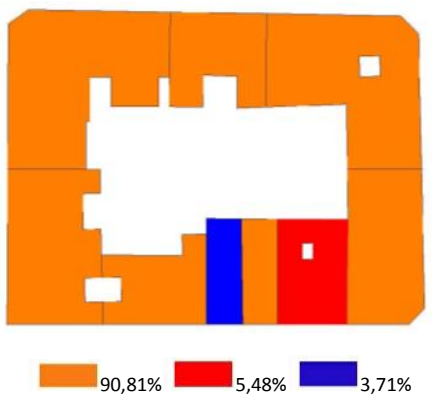

$\mathrm{MU}_{2}$

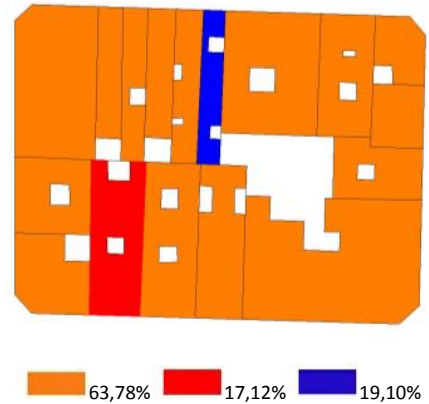

$\mathrm{PF}_{\mathrm{A}(\leq 4)}$

$\mathrm{PF}_{\mathrm{A}(>4)}$

$P F_{M(\leq 4)}$

$P F_{M(>4)}$

$U \mathrm{~F}_{\mathrm{A}(\leq 4)}$

$U F_{M(\leq 4)}$

Figura 5.20 Configuración de las manzanas $\mathrm{MU}_{1}$ y $\mathrm{MU}_{2}$ en el barrio. 


\subsection{EtAPa II: EVAlUACIÓN ENERgÉTICA}

La caracterización del barrio da paso a la Etapa II de la metodología, en la que el área urbana es analizada energéticamente. Los resultados de esta Etapa II son los valores de los cuatro indicadores (o variables respuesta) que cuantificarán el comportamiento energético de las hipótesis de simulación dinámica:

- Demanda energética de refrigeración $\left(D E_{r}\right), k W h / m^{2} a n ̃ o$

- Demanda energética de calefacción $\left(D E_{c}\right), k W h / m^{2} a n ̃ o$

- Horas de disconfort en verano $\left(H D_{v}\right), h / a n ̃ o$

- Horas de disconfort en invierno $\left(H D_{i}\right), h$ /año

Tal y como se ha indicado en la descripción de la metodología en el capítulo 4, el programa de simulación utilizado para llevar a cabo esta etapa es EnergyPlus (U.S. Department of Energy, 2013) con la interfaz gráfica de DesignBuilder (DesignBuilder UK, 2015). Cada uno de los tres apartados siguientes corresponden a las tres sub-etapas de las que se compone la evaluación energética.

\subsubsection{II.1 DEFINICIÓN DE LAS COVARIABLES}

\subsubsection{Definición de las covariables a nivel urbano}

El barrio responde a una estructura ortogonal de manzanas que le confieren cierta regularidad y estructuración en su morfología. Como se desprende de la Etapa I, se identifican dos tipologías de manzana urbana cerrada, diferenciadas por la presencia o no de un patio de manzana $\left(\mathrm{MU}_{1}\right.$ y $\left.\mathrm{MU}_{2}\right)$. Ambas manzanas tienen dimensiones muy similares, con ligeras variaciones que han sido simplificadas para llevar a cabo la simulación energética. $\mathrm{MU}_{1}$ tiene un gran patio de manzana, mientras que $\mathrm{MU}_{2}$ no presenta patio de manzana, sino pequeños patios de luces propios de los edificios que constituyen la manzana. Las características dimensionales de las dos tipologías se presentan en la Tabla 5.10. La máxima altura de edificación establecida por el PGOU es de 8 plantas, que corresponde a unos $24 \mathrm{~m}$, la cual se ha tomado en las simulaciones como valor más alto posible que puede darse en el barrio. Además, se identifican dos anchos de calle, de 10 y $20 \mathrm{~m}$, de manera que la combinación de ambos parámetros (altura y anchura) determinan dos ratios $\mathrm{H} / \mathrm{W}$ de calle: 2,4 y 1,2 , respectivamente. 
Tabla 5.10 Características de las manzanas urbanas residenciales

\begin{tabular}{|c|c|c|}
\hline Características & $\mathrm{MU}_{1}$ & $\mathrm{MU}_{2}$ \\
\hline \multicolumn{3}{|l|}{ Configuración } \\
\hline Descripción & Gran patio de manzana & Pequeños patios de luces propios \\
\hline$A(m)$ & 70 & 70 \\
\hline$B(m)$ & 50 & 50 \\
\hline$C(m)$ & $34-38$ & - \\
\hline $\mathrm{D}(\mathrm{m})$ & $14-18$ & - \\
\hline $\mathrm{H}_{\mathrm{U}}$ Altura $(\mathrm{m})$ & 24 & 24 \\
\hline $\mathrm{W}_{\mathrm{U}}$ Anchura (m) & $W_{U}=10$ & $W_{U}=10$ \\
\hline $\mathrm{H}_{\mathrm{U}} / \mathrm{W}_{\mathrm{U}}$ & 2.4 & 2.4 \\
\hline
\end{tabular}

Definidas las covariables MU y H/W presentes en el barrio, falta definir la covariable O (orientación) para finalizar la caracterización de la morfología urbana. Según la Figura 3.11 del Capítulo 3, la orientación de la fachada principal de los edificios viene determinada por el ángulo que forma la normal a la fachada con el norte geográfico y corresponde con: norte (300ㅇ $>\alpha \leq 60$ ) ), este $\left(60^{\circ}>\alpha \leq 135 \circ\right)$, sur $\left(135^{\circ}>\alpha \leq 225\right.$ ㅇ) y oeste $(225 \circ>\alpha \leq 300 \%)$. Con motivo de la configuración, la geometría rectangular de las manzanas no corresponde con la ortogonalidad del eje que determina la posición del norte geográfico, sino que estas están orientadas tal y como muestra la Figura 5.21, formando un ángulo de $24^{\circ}$ con respecto al Sur. Así pues, existen cuatro orientaciones correspondientes a norte $\left(154^{\circ} \mathrm{E}\right)$, sur $\left(24^{\circ} \mathrm{O}\right)$, este $\left(66^{\circ} \mathrm{E}\right)$ y oeste $\left(114^{\circ} \mathrm{O}\right)$.

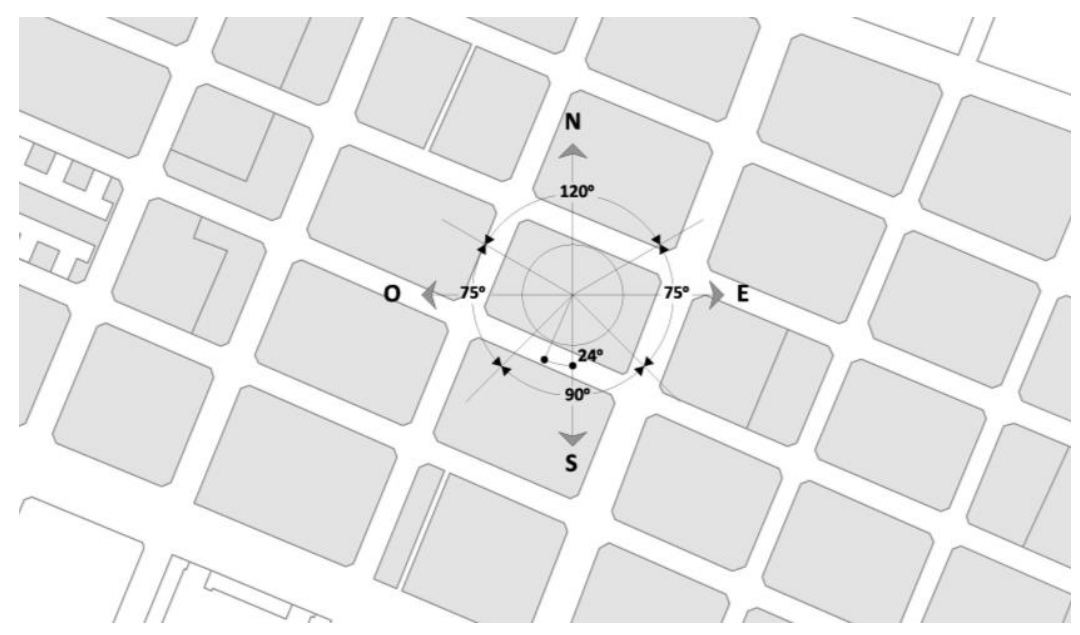

Figura 5.21 Orientación de las fachadas de los edificios en el barrio 


\section{Capítulo 5}

\subsubsection{Definición de las covariables a nivel de edificio}

Seleccionados los edificios representativos, estos se caracterizan según sus dimensiones para así determinar la primera de las covariables, el factor de forma (S/V). La Tabla 5.11 resume sus características dimensionales, identificando el volumen (V) y la superficie de envolvente (S), que serán necesarios para obtener el factor de forma o compacidad del edificio.

Tabla 5.11 Características dimensionales de los edificios muestra $\mathrm{PF}_{\mathrm{M}(>4),} \mathrm{PF}_{\mathrm{M}(\leq 4)}$ y $U \mathrm{~F}_{\mathrm{M}(\leq 4)}$

\begin{tabular}{lllll}
\hline Propiedades & $\mathrm{PF}_{\mathrm{M}_{(>4)}}$ & UF $_{\mathrm{M}_{(\leq 4)}}$ \\
\hline
\end{tabular}

La geometría de cada uno de los edificios es generada en el software DesignBuilder, tal y como queda definida gráficamente en las Figura 5.22, Figura 5.23 y Figura 5.24. 


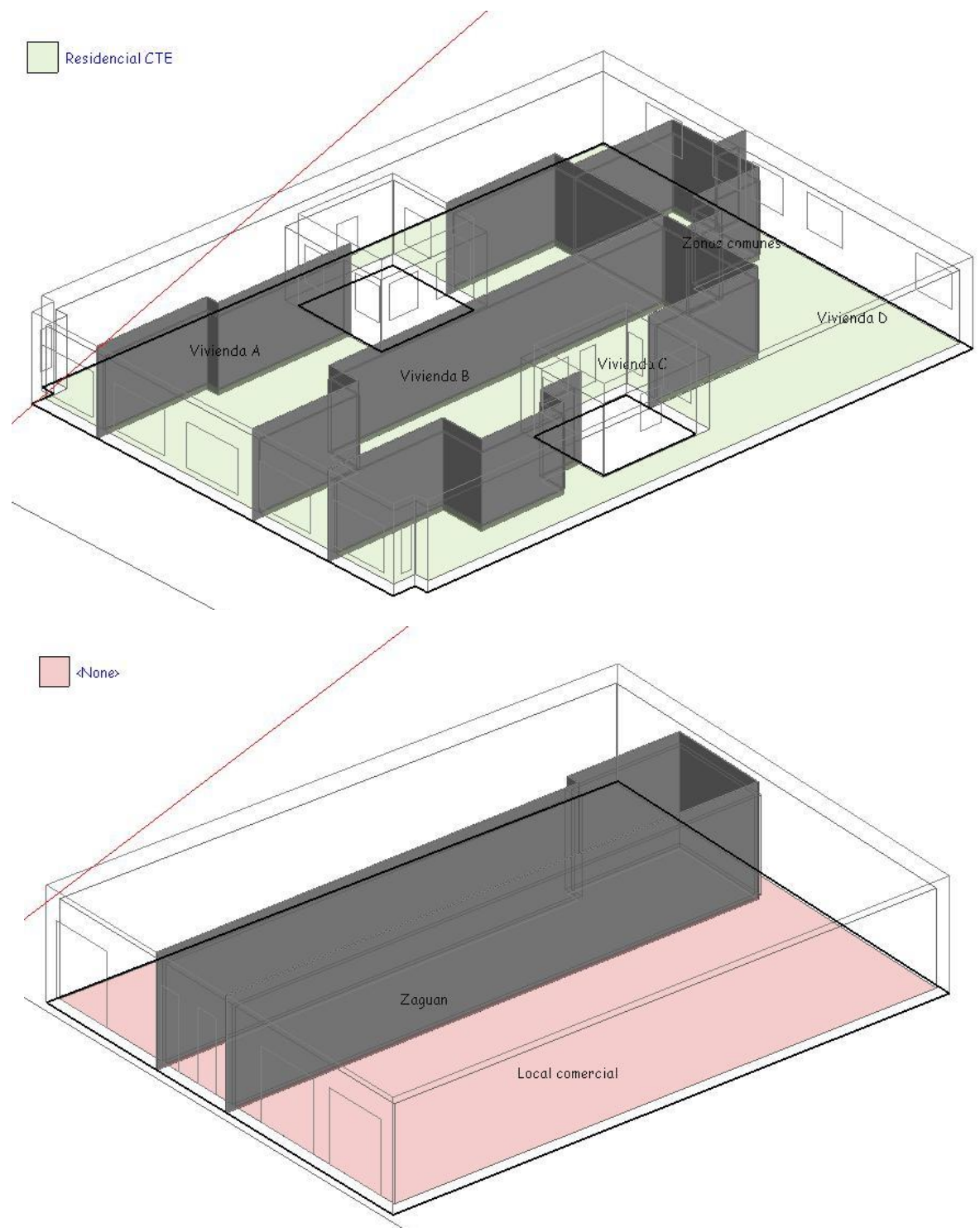

Figura 5.22 Planta baja (inferior) y planta tipo (superior) del edificio $\mathrm{PF}_{\mathrm{M}(>4)}$ 


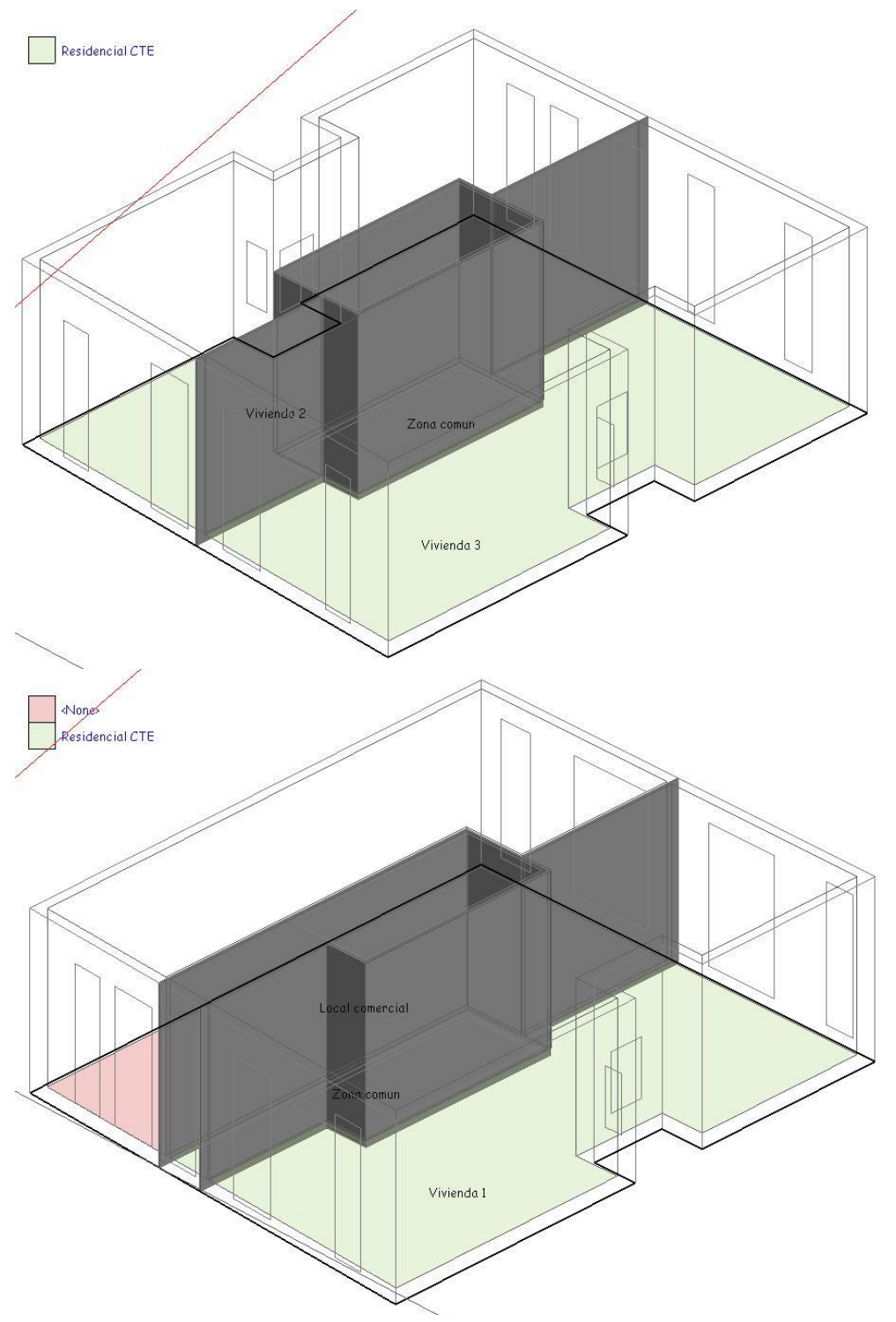

Figura 5.23 Planta baja (inferior) y planta tipo (superior) del edificio $\mathrm{PF}_{\mathrm{M}(\leq 4)}$ 
$\square$ None:
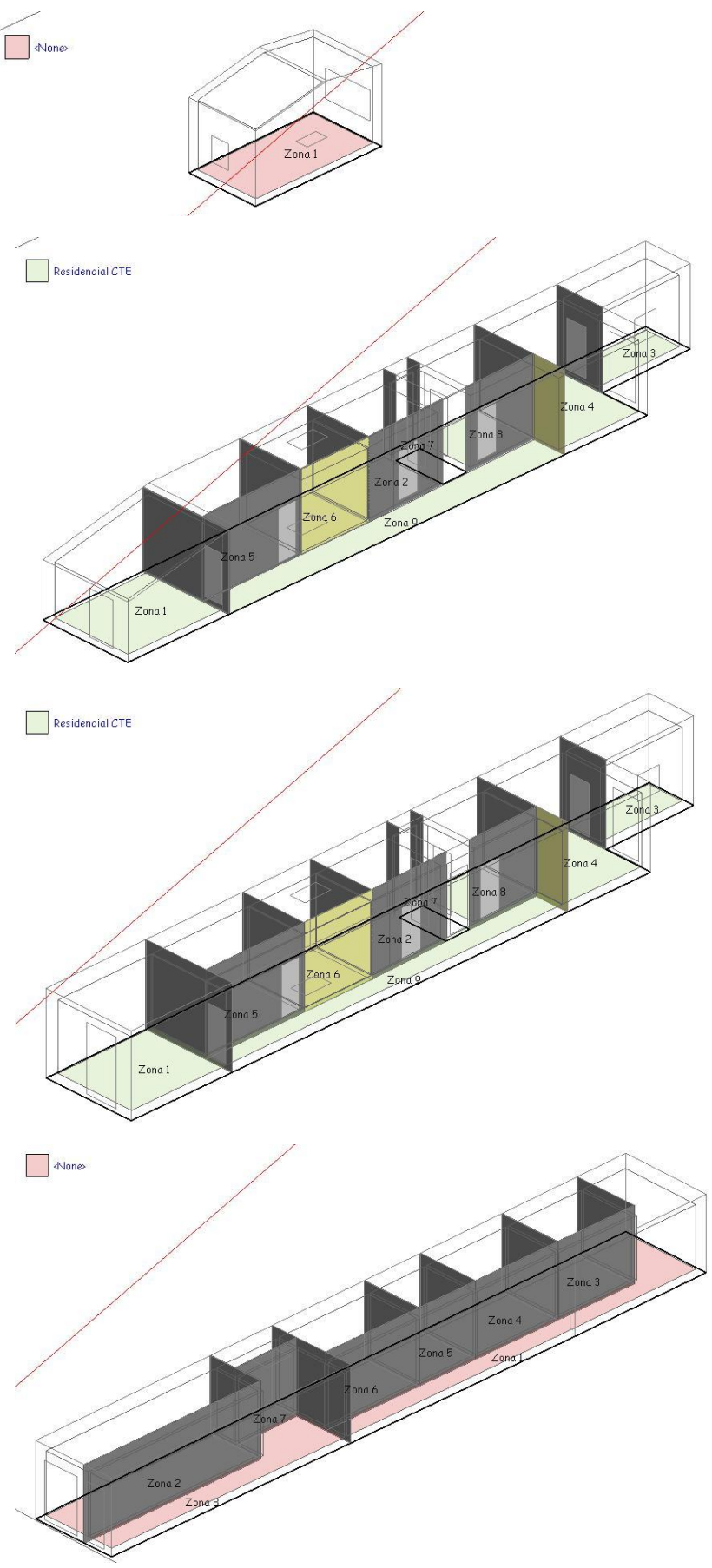

Figura 5.24 Planta baja, primera, segunda y bajo cubierta (de abajo a arriba) del edificio $\mathrm{UF}_{\mathrm{M}(\leq 4)}$ 
La segunda covariable a nivel de edificio es el año de construcción (A) y viene establecido en 5 periodos temporales, como se concluye en la Figura 5.9: 1 [anterior a 1940], 2 [1940-1659], 3 [19601979], 4 [1980-2006] y 5 [2007-2013]. Como establece la metodología, cada uno de estos periodos es caracterizado por el conjunto de soluciones constructivas típicas que definen los elementos del edificio. Así pues, cada una de las soluciones utilizadas habitualmente en cada periodo ha sido identificada (Tabla 5.6) y se ha calculado su transmitancia térmica (U), de manera que cada periodo queda identificado por un paquete de valores de $U$ para los elementos de fachada, cubierta, suelos, particiones horizontales, particiones verticales y huecos. Los cinco paquetes de valores de $\mathrm{U}$ para cada uno de los periodos quedan recogidos en la Tabla 5.12. Los puentes térmicos han sido calculados según el método simplificado definido en la norma EN ISO 14683 (CEN, 2011) y quedan recogidos en la Tabla 5.13 . 
Tabla 5.12 Transmitancias térmicas de las soluciones constructivas contempladas en los cinco periodos temporales

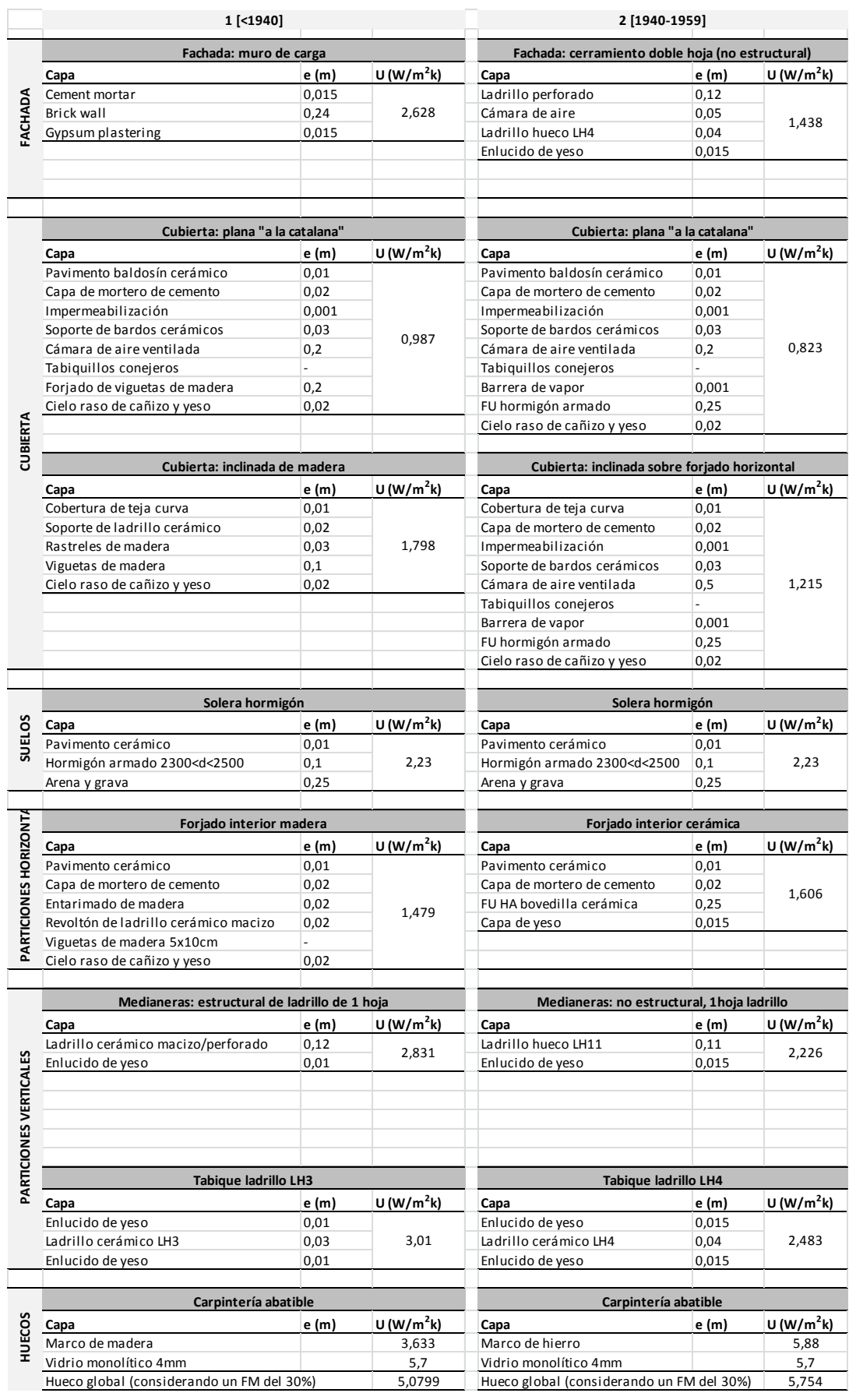


Tabla 5.12 Transmitancias térmicas de las soluciones constructivas contempladas en los cinco periodos temporales (continuación)

\begin{tabular}{|c|c|c|c|c|c|c|}
\hline \multirow{9}{*}{ 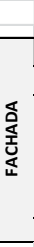 } & \multicolumn{3}{|c|}{3 [1960-1979] } & \multicolumn{3}{|c|}{$4[1980-2006]$} \\
\hline & \multicolumn{3}{|c|}{ Fachada: cerramiento doble hoja (no estructural) } & \multicolumn{3}{|c|}{ Fachada: cerramiento doble hoja (no estructural) aislada } \\
\hline & Capa & e $(\mathrm{m})$ & $U\left(W / m^{2} k\right)$ & Capa & e $(\mathrm{m})$ & $U\left(W / m^{2} k\right)$ \\
\hline & Ladrillo perforado & 0,12 & \multirow{5}{*}{1,438} & Brick wall & 0,11 & \multirow{6}{*}{0,75} \\
\hline & Enfoscado mortero cemento & 0,015 & & Cement mortar & 0,015 & \\
\hline & Cámara de aire & 0,05 & & Air gap & 0,03 & \\
\hline & Ladrillo hueco LH4 & 0,04 & & Thermal insulation $(\lambda: 0,04 \mathrm{~W} / \mathrm{mk})$ & 0,02 & \\
\hline & Enlucido de yeso & 0,015 & & Brick wall & 0,07 & \\
\hline & & & & Gypsum plastering & 0,015 & \\
\hline \multirow{22}{*}{ 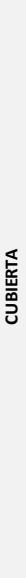 } & \multicolumn{3}{|c|}{ Cubierta: plana a la "madrileña" } & \multicolumn{3}{|c|}{ Cubierta: plana a la "madrileña" con aislamiento } \\
\hline & Capa & e $(\mathrm{m})$ & $U\left(W / m^{2} k\right)$ & Capa & e $(\mathrm{m})$ & $U\left(W / m^{2} k\right)$ \\
\hline & Pavimento baldosín cerámico & 0,01 & \multirow{7}{*}{1,413} & Pavimento baldosín cerámico & 0,01 & \multirow{7}{*}{0,557} \\
\hline & Capa de mortero de cemento & 0,02 & & Capa de mortero de cemento & 0,02 & \\
\hline & Impermeabilización & 0,001 & & Impermeabilización & 0,001 & \\
\hline & Hormigón celular (formación ptes.) & 0,05 & & Aislamiento térmico $(\lambda: 0,04 \mathrm{~W} / \mathrm{mk})$ & 0,04 & \\
\hline & Barrera de vapor & 0,001 & & Hormigón celular (formación ptes.) & 0,05 & \\
\hline & FU hormigón armado & 0,3 & & FU hormigón armado & 0,3 & \\
\hline & Capa de yeso & 0,015 & & Capa de yeso & 0,015 & \\
\hline & & & & & & \\
\hline & & & & & & \\
\hline & Cubierta: inclinada sobre $f$ & orjado ho & ontal & Cubierta: inclinada & teja e $4 \mathrm{cr}$ & \\
\hline & Capa & e $(\mathrm{m})$ & $U\left(W / m^{2} k\right)$ & Capa & e (m) & $U\left(W / m^{2} k\right)$ \\
\hline & Cobertura de teja curva & 0,01 & \multirow{9}{*}{1,215} & Cobertura de teja curva & 0,01 & \multirow{9}{*}{0,704} \\
\hline & Capa de mortero de cemento & 0,02 & & Capa de mortero de cemento & 0,02 & \\
\hline & Impermeabilización & 0,001 & & Aislamiento térmico $(\lambda: 0,04 \mathrm{~W} / \mathrm{mk})$ & 0,04 & \\
\hline & Soporte de bardos cerámicos & 0,03 & & FU inclinado hormigón armado & 0,03 & \\
\hline & Cámara de aire ventilada & 0,5 & & Capa de yeso & 0,015 & \\
\hline & Tabiquillos conejeros & - & & & & \\
\hline & Barrera de vapor & 0,001 & & & & \\
\hline & FU hormigón armado & 0,25 & & & & \\
\hline & Cielo raso de cañizo y yeso & 0,02 & & & & \\
\hline & Solera hormi & gón & & Solera horn & & \\
\hline$\check{c}$ & Capa & $e(m)$ & $U\left(W / m^{2} k\right)$ & Capa & e (m) & $U\left(W / m^{2} k\right)$ \\
\hline 己ّ & Pavimento cerámico & 0,01 & & Pavimento cerámico & 0,01 & \\
\hline & Hormigón armado $2300<\mathrm{d}<2500$ & 0,1 & 2,23 & Hormigón armado $2300<\mathrm{d}<2500$ & 0,1 & 2,23 \\
\hline & Arena y grava & 0,25 & & Arena y grava & 0,25 & \\
\hline E & Forjado interior $h$ & ormigón & & Forjado interior & migón & \\
\hline ర్ల్ & Capa & e (m) & $U\left(W / m^{2} k\right)$ & Capa & e (m) & $U\left(W / m^{2} k\right)$ \\
\hline 뜽 & Pavimento cerámico & 0,01 & & Pavimento cerámico & 0,01 & \\
\hline 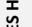 & Capa de mortero de cemento & 0,02 & רבת 1 & Capa de mortero de cemento & 0,02 & רבים \\
\hline 岁 & FU HA bovedilla hormigón & 0,25 & 1,877 & FU HA bovedilla hormigón & 0,25 & 1,877 \\
\hline 은 & Capa de yeso & 0,015 & & Capa de yeso & 0,015 & \\
\hline$\frac{\alpha}{\alpha}$ & & & & & & \\
\hline & Medianeras: no estructur & al, 1hoja & rillo & Medianeras: no estructu & 2 hojas & \\
\hline & Capa & e (m) & $U\left(W / m^{2} k\right)$ & Capa & e (m) & $U\left(W / m^{2} k\right)$ \\
\hline & Ladrillo hueco LH11 & 0,11 & & Enfoscado mortero cemento & 0,015 & \\
\hline 岂 & Enlucido de yeso & 0,015 & 2,226 & Ladrillo hueco LH11 & 0,11 & \\
\hline $\overrightarrow{\mathbb{S}}$ & & & & Cámara de aire & 0,02 & 1,358 \\
\hline 点 & & & & Ladrillo hueco LH4 & 0,04 & \\
\hline$\sum_{n}^{u}$ & & & & Enlucido de yeso & 0,015 & \\
\hline 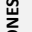 & & & & & & \\
\hline 음 & Tabique ladrillc & o LH4 & & Tabique ladri & H7 & \\
\hline & Capa & e $(\mathrm{m})$ & $U\left(W / m^{2} k\right)$ & Capa & e $(\mathrm{m})$ & $U\left(W / m^{2} k\right)$ \\
\hline & Enlucido de yeso & 0,015 & & Enlucido de yeso & 0,015 & \\
\hline & Ladrillo cerámico LH4 & 0,04 & 2,483 & Ladrillo cerámico LH7 & 0,07 & 2,003 \\
\hline & Enlucido de yeso & 0,015 & & Enlucido de yeso & 0,015 & \\
\hline & Carpintería corr & edera & & Carpintería co & dera & \\
\hline 乞 & Capa & e $(m)$ & $U\left(W / m^{2} k\right)$ & Capa & e (m) & $U\left(W / m^{2} k\right)$ \\
\hline 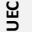 & Marco de aluminio & & 5,881 & Marco de aluminio & & 5,881 \\
\hline & Vidrio monolítico $4 \mathrm{~mm}$ & & 5,7 & Vidrios dobles $4+6+4 \mathrm{~mm}$ & & 3,146 \\
\hline & Hueco global (considerando un FM d & del $30 \%)$ & 5,7543 & Hueco global (considerando un FM d & $0 \%)$ & 3,9665 \\
\hline
\end{tabular}


Tabla 5.12 Transmitancias térmicas de las soluciones constructivas contempladas en los cinco periodos temporales (continuación)

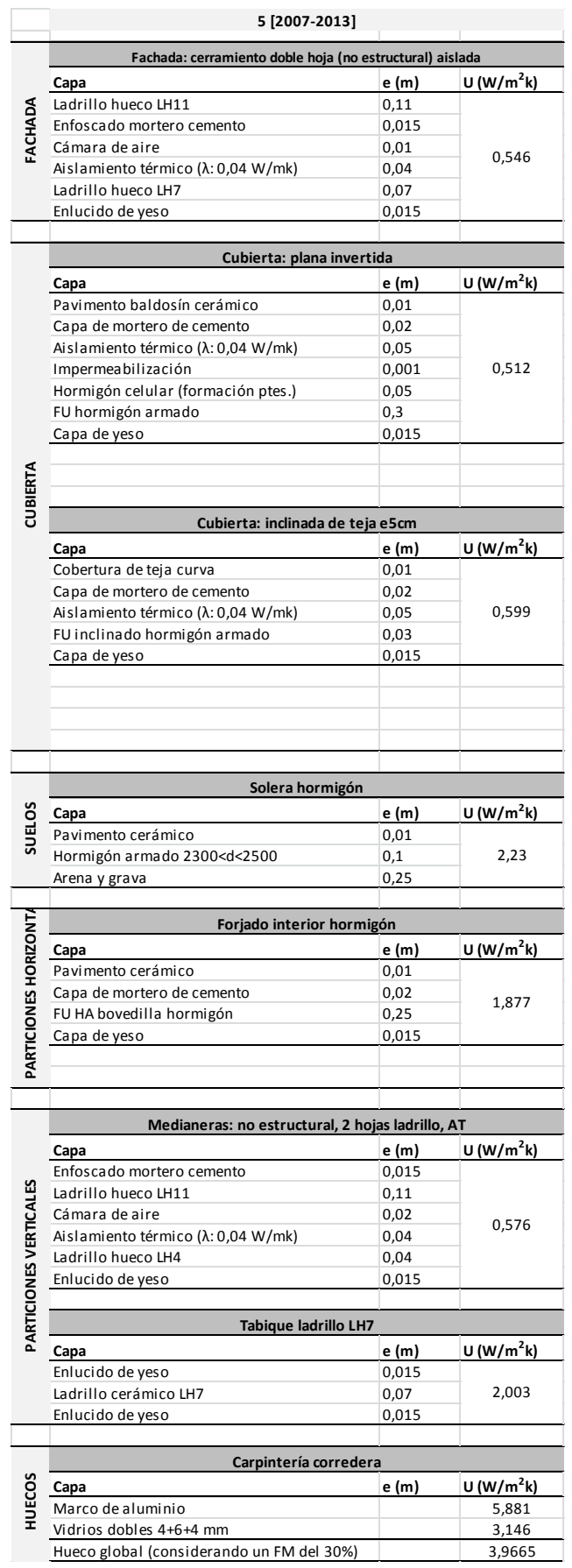


Tabla 5.13 Transmitancias térmicas de los puentes térmicos en los cinco periodos temporales

\begin{tabular}{|c|c|c|c|c|c|c|}
\hline & & & Per & tempor & & \\
\hline \multirow{9}{*}{ 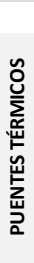 } & & 1 & 2 & 3 & 4 & 5 \\
\hline & Tipo de encuentro & \multicolumn{5}{|c|}{$\Psi(\mathrm{W} / \mathrm{mk})$} \\
\hline & Cubierta-Fachada & 0,8 & 0,82 & 0,77 & 0,87 & 0,89 \\
\hline & Fachada-Suelo terreno & 1,55 & 1,92 & 1,92 & 2,13 & 2,2 \\
\hline & Esquina de fachada & 0,08 & 0,08 & 0,08 & 0,08 & 0,08 \\
\hline & \multirow{2}{*}{ Fachada-Suelo (no terreno) } & 1,34 & 1,05 & 1,05 & 0,97 & 0,93 \\
\hline & & 0,59 & 0,13 & 0,13 & 0,92 & 0,95 \\
\hline & $\begin{array}{l}\text { Dintel en hueco } \\
\text { Alféizar en hueco }\end{array}$ & 0 & 0,8 & 0,8 & 0,2 & 0,23 \\
\hline & Jamba en hueco & 0,17 & 0,43 & 0,43 & 0,48 & 0,49 \\
\hline
\end{tabular}

\subsubsection{Resumen de covariables para evaluar el comportamiento energético del barrio}

La Tabla 5.14 resume los valores de las cinco covariables.

Tabla 5.14 Definición de covariables

\begin{tabular}{lllll}
\hline \multicolumn{2}{l}{ Covariables } \\
\cline { 1 - 3 } MU & H/W & O & S/V & A \\
\hline 1 & $2.4(\mathrm{H}=24 \mathrm{~m} ; \mathrm{W}=10 \mathrm{~m})$ & $0^{\circ}(\mathrm{N})$ & 0.3 & $1(<1940)$ \\
2 & $1.2(\mathrm{H}=24 \mathrm{~m} ; \mathrm{W}=20 \mathrm{~m})$ & $90^{\circ}(\mathrm{E})$ & 0.26 & $2(1940-1959)$ \\
& & $180^{\circ}(\mathrm{S})$ & 0.4 & $3(1960-1979)$ \\
& & $270^{\circ}(\mathrm{W})$ & & $4(1980-2006)$ \\
& & & & $5(2007-2013)$ \\
\hline
\end{tabular}

\subsubsection{II.2 PLANTEAMIENTO de LAS Hipótesis de CÁlCULO}

Acorde con la Figura 4.9 del Capítulo 4, se configura la Figura 5.25 teniendo en cuenta los valores que adoptan las cinco covariables. La combinación entre todas ellas da como resultado un total de 240 hipótesis, que representan todas las posibilidades de manzana, ratio H/W, orientación, factor de forma de los edificios y año de construcción. Esta simplificación permite evaluar toda la casuística del área urbana, para después desarrollar un modelo estadístico de predicción que permita estimar las variables respuesta en todos los edificios reales que existen en el barrio.

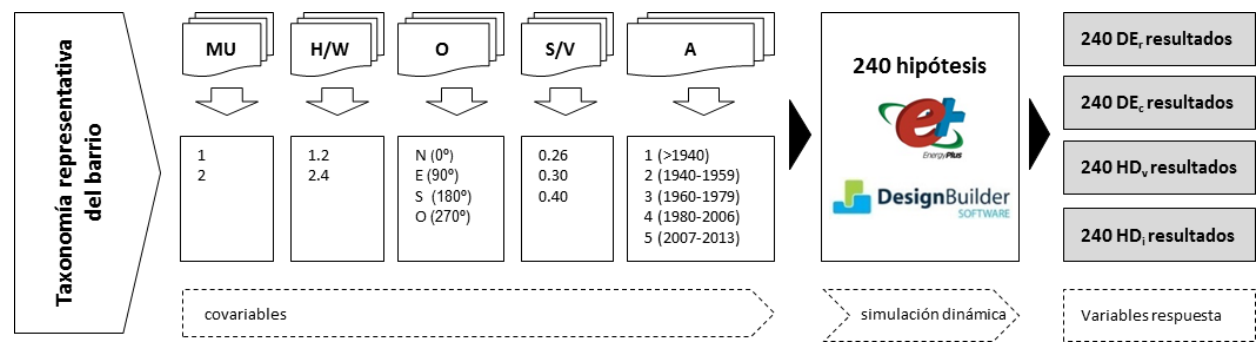

Figura 5.25 Configuración de las 240 hipótesis para determinar las cuatro variables respuesta 
Las covariables de las 240 hipótesis obtenidas se describen en la tabla All.1 del Anexo II Hipótesis de Cálculo ${ }^{3}$.

La configuración de las 240 hipótesis en el programa de simulación no es tarea sencilla, pues deben configurarse una a una teniendo en cuenta numerosos parámetros. Por un lado, se define la disposición urbana del edificio en el contexto de la manzana y el ancho de calle, con lo que quedan definidas las covariables $\mathrm{MU}, \mathrm{H} / \mathrm{W}$ y $\mathrm{O}$. Estas combinaciones deben simularse para cada una de las tres clases edificatorias, definidas por la covariable S/V. Y, finalmente, deben incorporarse los cinco periodos temporales (covariable A), lo que implica configurar el paquete de las soluciones constructivas del edificio de cada periodo, en todas las hipótesis.

La Figura 5.26 muestra un ejemplo de la configuración urbana que adoptan las hipótesis $81,82,83$ y 84, definidas por la tipología de manzana $\mathrm{MU}_{1}$, un ancho de calle de $10 \mathrm{~m}\left(\mathrm{H} / \mathrm{W}_{2,4}\right)$, las cuatro orientaciones ( $\mathrm{H} 81$ a N, $\mathrm{H} 82$ a S, $\mathrm{H} 83$ a $\mathrm{E}$ y $\mathrm{H} 84$ a 0 ), para la tipología edificatoria $1 \mathrm{P}_{\mathrm{FM}(\leq 4)}$ en el periodo temporal 1 [anterior a 1940]. Como se observa en dicha figura, se considera en el cálculo el contexto urbano de las manzanas colindantes, que previsiblemente tendrán influencia en el comportamiento energético de los edificios, al modificar las condiciones de soleamiento y sombras.

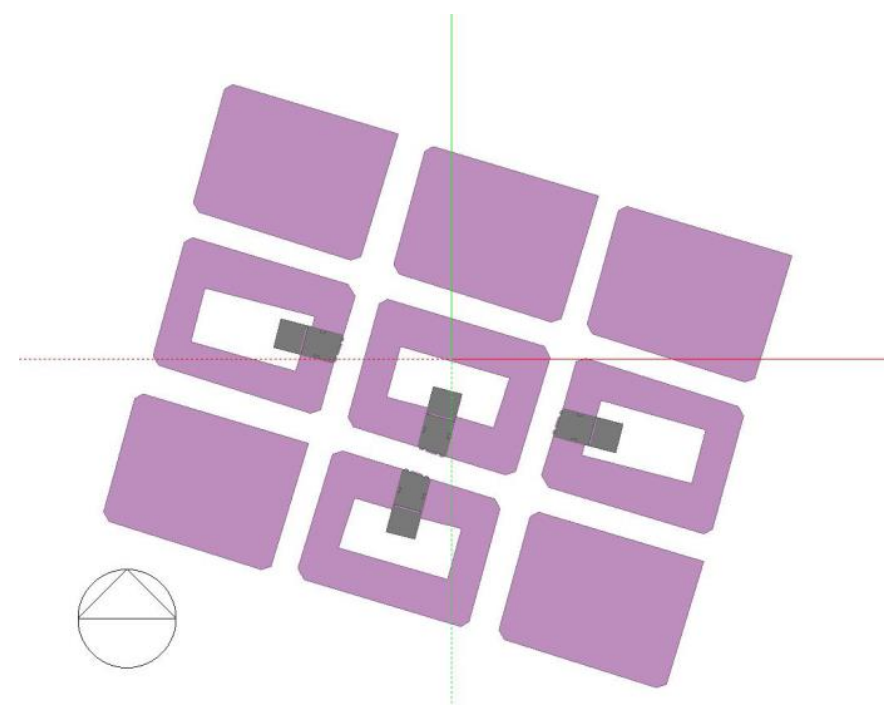

Figura 5.26 Ejemplo de configuración de la H81, H82, H83 y H84 en DesignBuilder

La Figura 5.27 muestra otros cuatro ejemplos, las $\mathrm{H} 229, \mathrm{H} 230, \mathrm{H} 231$ y H232, que correponden a la tipología de manzana $\mathrm{MU}_{2}$, ancho de calle de $20 \mathrm{~m}\left(\mathrm{H} / \mathrm{W}_{1,2}\right)$, las cuatro orientaciones $(\mathrm{H} 229$ a $\mathrm{N}$, $\mathrm{H} 230$ a S, H231 a E y H232 a O), para la tipología edificatoria $\mathrm{PF}_{\mathrm{M}(>4)}$ en el periodo temporal 5 [20072013].

\footnotetext{
${ }^{3}$ El Anexo II Hipótesis de Cálculo expone los valores que asumen las covariables en cada una de las 240 hipótesis de cálculo planteadas, para ser simuladas con la herramienta DesignBuilder.
} 


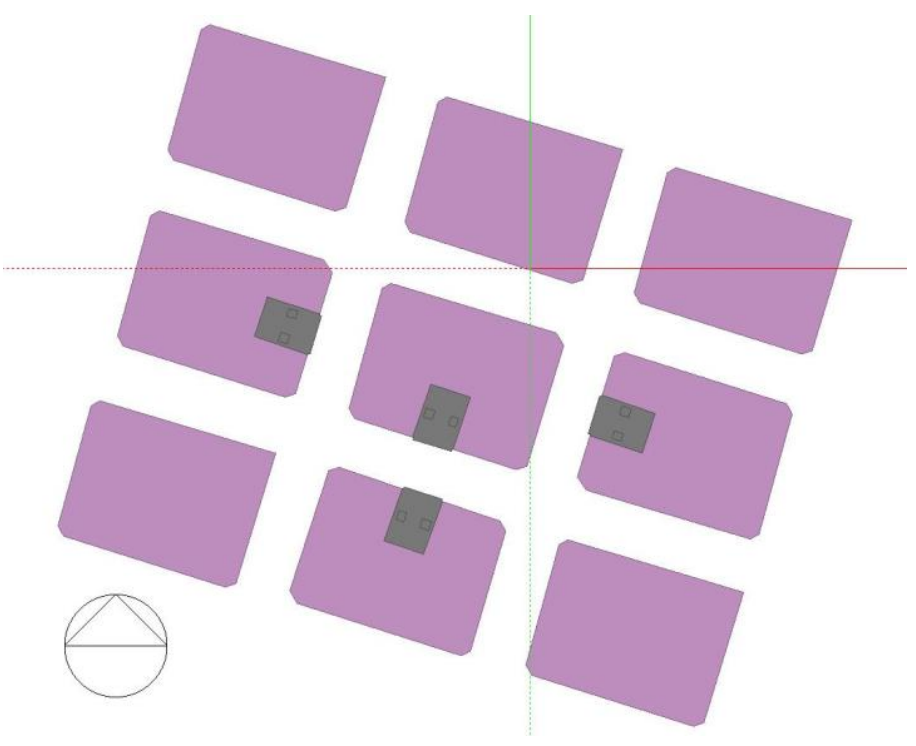

Figura 5.27 Ejemplo de configuración de la H229, H230, H231 y H232 en DesignBuilder

Este mismo procedimiento se sigue en el resto hipótesis, hasta configurar la totalidad de las 240 . Cabe indicar que el paquete de soluciones constuctivas que definen cada uno de los cinco periodos se configuran internamente en el programa por medio de cinco plantillas diferentes que incluyen las soluciones de fachada, medianera, cubierta, suelo, partición interior, huecos y puentes térmicos, descritas anteriormente en la Tabla 5.12 y la Tabla 5.13.

\subsubsection{II.3 Definición de los parámetros de cálculo para la obtención de las VARIABLES RESPUESTA}

Como solicitaciones exteriores se establece el clima definido para la localidad de Castellón de la Plana, que se corresponde con una zona climática B3, según el Código Técnico de la Edificación (CTE). Los valores de temperatura y radiación solar se introducen en el software DesignBuilder en forma de plantilla climática, proporcionada por la empresa distribuidora del software (Aurea Consulting, 2015), que ha elaborado unas plantillas ajustadas a las exigencias de todas las zonas climáticas del territorio español, según los parámetros oficiales establecidos por el CTE.

En cuanto a las solicitaciones interiores, tal y como se establece en el apartado 4.6.3 del Capítulo 4, los parámetros de cálculo deben ser los mismos en todas las hipótesis, previamente a lanzar las simulaciones. Dichos parámetros se presentan en la Tabla 5.15. El patrón de ocupación adoptado corresponde con los perfiles de uso establecidos por el CTE, en su actualización de 2013 (CTE, 2013), al igual que los valores de cargas operacionales para edificios de uso residencial.

Por otro lado, acorde a los resultados obtenidos, se considera que el periodo con necesidades de calefacción opera desde el 1 de octubre al 31 de mayo, y el periodo con necesidades de refrigeración opera desde el 1 de junio al 30 de septiembre. 
Tabla 5.15 Parámetros de cálculo considerados en DesignBuilder

\begin{tabular}{|c|c|c|}
\hline Parámetro & Unidad & Valor \\
\hline \multicolumn{3}{|l|}{ Ocupación } \\
\hline Densidad & persona $/ \mathrm{m}^{2}$ & 0,03 \\
\hline \multirow[t]{4}{*}{ Patrón horario } & & Día laboral: 7:00-15:00 [25\%]; \\
\hline & & $15: 00-23: 00[50 \%]$ \\
\hline & & $23: 00-7: 00[100 \%]$ \\
\hline & & Fines de semana: 0:00 -24:00 [100\%] \\
\hline Tasa metabólica & W/persona & 117,2 \\
\hline Vestimenta en invierno/verano & clo & $1 / 0,5$ \\
\hline \multicolumn{3}{|l|}{ Temperaturas de consigna } \\
\hline Calefacción & ${ }^{\circ} \mathrm{C}$ & 20 \\
\hline Refrigeración & ${ }^{\circ} \mathrm{C}$ & 25 \\
\hline Ventilación natural & ${ }^{\circ} \mathrm{C}$ & 24 \\
\hline \multicolumn{3}{|l|}{ Ganancias internas } \\
\hline Cargas internas & $\mathrm{W} / \mathrm{m}^{2}$ & 8,8 \\
\hline Iluminación & $w / m^{2}-100$ lux & 4,4 \\
\hline Ganancias misceláneas & $\mathrm{W} / \mathrm{m}^{2}$ & 4,4 \\
\hline \multicolumn{3}{|c|}{ Ganancias solares } \\
\hline \multicolumn{3}{|c|}{ Incluye todos los edificios en el cálculo del sombreado } \\
\hline \multicolumn{3}{|c|}{ Modela reflexiones (también sombreado sobre el terreno) } \\
\hline \multicolumn{3}{|l|}{ Demanda de ACS } \\
\hline Demanda ACS & $\mathrm{I} / \mathrm{m}^{2}$ día & 0,84 \\
\hline \multicolumn{3}{|l|}{ Infiltración } \\
\hline Tasa de renovaciones/hora & $h^{-1}$ & 0,82 \\
\hline Tasa de caudal de aire & I/s por persona & 10 \\
\hline
\end{tabular}

Las simulaciones dinámicas se realizan de forma horaria, de manera que los resultados pueden ser obtenidos para cada hora de todos los días de un año tipo. El número de etapas para realizar cada simulación es de 10 etapas por hora. 


\subsection{ETAPA III: Modelización estadística}

En esta etapa, los resultados obtenidos de la evaluación energética son tratados estadísticamente para obtener las cuatro ecuaciones de predicción de los cuatro indicadores energéticos que permitirán evaluar el comportamiento pasivo del parque edificatorio residencial del barrio, $D_{r}, D E_{c}$, $H D_{v}, H D_{i}$. Se diferencian cuatro sub-etapas, que se describen en los siguientes apartados.

\subsubsection{III.1 ANÁLISIS DESCRIPTIVO DE LOS DATOS}

Los datos obtenidos de las simulaciones determinan el punto de partida de este apartado. En primer lugar, los datos son analizados estadísticamente de forma numérica y gráfica, como se muestra en la Tabla 5.16 y la Figura 5.28. Como se observa, los datos presentan fuerte variabilidad. En el caso de $\mathrm{DE}_{\mathrm{r}}$, los valores reales son negativos porque se requiere extraer energía del interior del edificio, mientras que en el caso de $D E_{c}$, los valores son positivos porque se requiere un aporte energético. Para realizar la modelización estadística, los valores originales negativos de la variable $D E_{r}$ han sido multiplicados por $(-1)$. El resto de variables, $D_{c}, H_{v}$ y $H D_{i}$ adoptan valores positivos, y no han requerido de una transformación.

Tabla 5.16 Descripción de las variables respuesta $D E_{r}, D E_{c}, H D_{v}$ y $H D_{i}$

\begin{tabular}{lllllll}
\hline Variable & Mínimo & $\mathbf{1}^{\text {er }}$ cuartil & Mediana & Media & $\mathbf{3}^{\text {er }}$ cuartil & Máximo \\
\hline $\mathrm{DE}_{\mathrm{r}}$ & 0,0234 & 0,653 & 1,333 & 1,660 & 2,457 & 5,580 \\
$\mathrm{DE}_{\mathrm{c}}$ & 22,19 & 64,46 & 96,54 & 96,50 & 122,70 & 211,90 \\
$\mathrm{HD}_{\mathrm{v}}$ & 117,60 & 438,70 & 637,40 & 722,60 & 1029,00 & 1597,00 \\
$\mathrm{HD}_{\mathrm{i}}$ & 3830,00 & 4735,00 & 4911,00 & 4859,00 & 5049,00 & 5303,00 \\
\hline
\end{tabular}

La Figura 5.28 ilustra el histograma y el diagrama de cajas y bigotes para las cuatro variables respuesta (o indicadores). En dicha figura se observa la forma de cada distribución, respondiendo la variable $D E_{r}$ a una distribución de tipo Gamma, por tener altas frecuencias en los valores más pequeños y disminuir con valores más altos, y las demás variables $\left(D E_{c}, H D_{v}\right.$ y $\left.H D_{i}\right)$, a una distribución Gaussiana.

La Figura 5.29, muestra los mismos datos desglosados en las dos tipologías de manzana urbana $\left(\mathrm{MU}_{1}\right.$ y $\mathrm{MU}_{2}$ ). Se puede observar que las distribuciones siguen siendo las mismas que anteriormente. Ello denota la coherencia en el hecho de modelar los datos todos en conjunto $\left(\mathrm{MU}_{1}+\mathrm{MU}_{2}\right)$ y por separado en $\mathrm{MU}_{1}$ y $\mathrm{MU}_{2}$. 


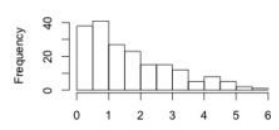

DEr

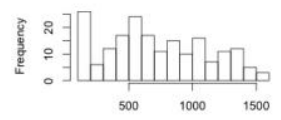

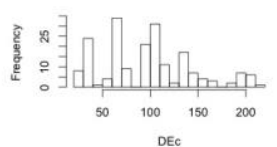

DEc

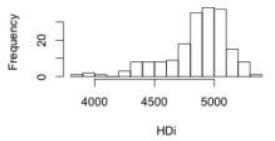

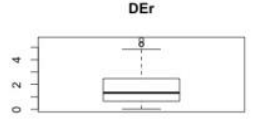
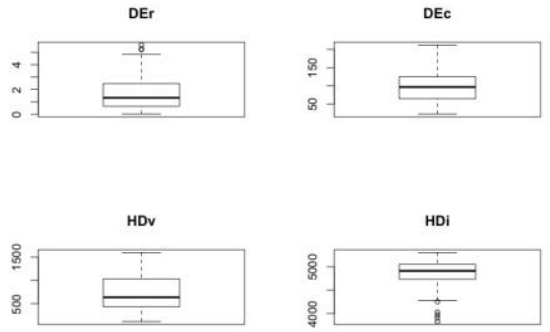

Figura 5.28 Histograma (izquierda) y diagrama de cajas y bigotes (derecha) de las variables respuesta

MU1

MU2

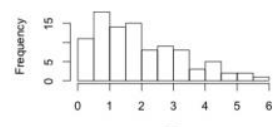

DEr

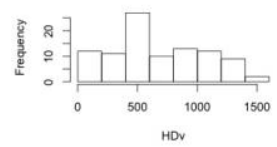

EDr
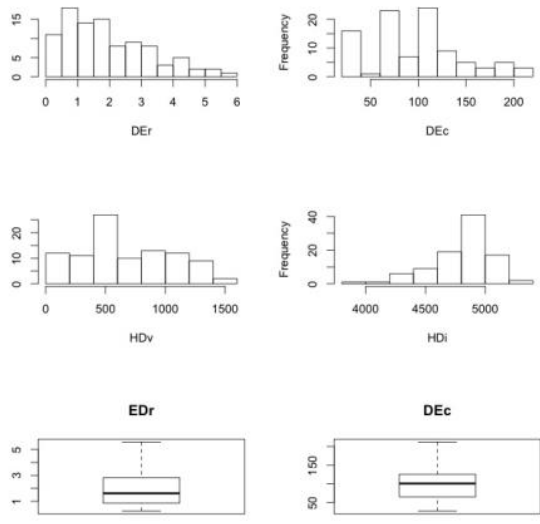

DEc
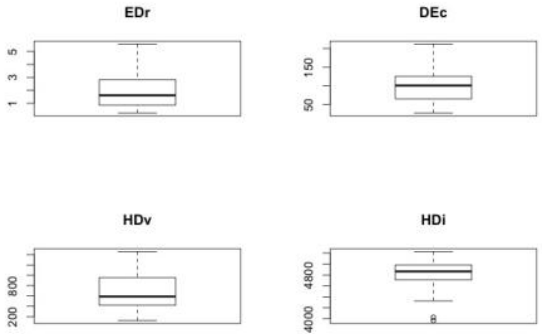

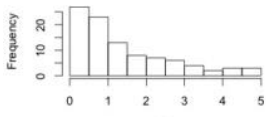

DEr
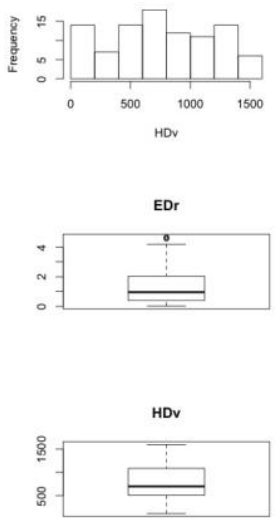
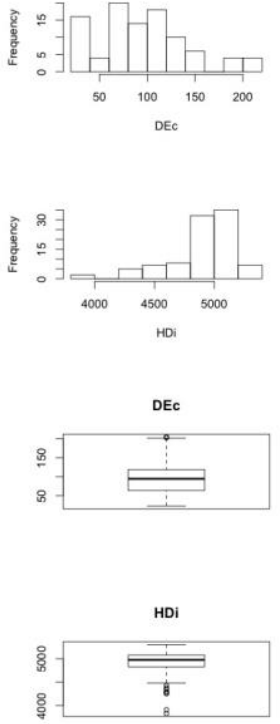

Figura 5.29 Histograma (arriba) y diagrama de cajas y bigotes (abajo) de las variables respuesta para $\mathrm{MU}_{1}$ (izquierda) y $\mathrm{MU}_{2}$ (derecha)

\subsubsection{III.2 CONFIGURACIÓN DE LOS MODELOS}

El tratamiento de los datos, como se apunta en el Capítulo 4, ha sido ejecutado mediante el software libre R statistical pakage (versión 3.1) (R Development Core Team, 2011) y el R-INLA package (INLA, 2016). Combinando las variables y covariables, se obtiene la batería de modelos que se organiza como sigue. Por un lado, se considera la manzana urbana (covariable MU) fuera del 
modelo, con el objetivo de poder comparar los resultados obtenidos para cada una de las dos manzanas identificadas. Ello da lugar a una primera batería de 32 modelos donde se combinan las 4 variables respuesta con las covariables $\mathrm{H} / \mathrm{W}, \mathrm{A}, \mathrm{O}$ y S/V , de forma separada. A continuación, se conforma una segunda batería de 8 modelos, teniendo en cuenta las cuatro covariables anteriores de forma conjunta. Por otro lado, MU se integra como una covariable más, por lo se obtiene una tercera batería formada por 20 modelos. Por último, las cinco covariables (H/W, A, O, S/V y MU) se analizan de forma conjunta, obteniendo una cuarta batería compuesta por 4 modelos. Se originan pues un total de 64 modelos. El primer conjunto de cuatro tablas (Tabla 5.17, Tabla 5.18, Tabla 5.19 y Tabla 5.20) muestran los valores de DIC para las cuatro baterías de modelos. El segundo conjunto de tablas (Tabla 5.21, Tabla 5.22, Tabla 5.23 y Tabla 5.24) muestran los valores de CPO.

Tabla 5.17 DIC para la primera batería de 32 modelos considerando las covariables H/W, A, O y S/V por separado, comparando $\mathrm{MU}_{1}$ y $\mathrm{MU}_{2}$

\begin{tabular}{llllll}
\hline & & H/W & A & O & S/V \\
\hline $\mathrm{DE}_{\mathrm{r}}$ & $\mathrm{MU1}$ & 289,88 & 253,31 & 296,38 & 240,38 \\
$\mathrm{DE}$ & & 1035,85 & 1059,57 & 1045,48 & 1020,27 \\
$\mathrm{HD}_{\mathrm{v}}$ & & 524,74 & 396,55 & 526,40 & 512,92 \\
$\mathrm{HD}_{\mathrm{i}}$ & & 445,38 & 404,37 & 447,70 & 431,22 \\
$\mathrm{DE}$ & $\mathrm{MU} 2$ & 247,17 & 203,51 & 251,64 & 224,21 \\
$\mathrm{DE}_{\mathrm{c}}$ & & 1029,79 & 1047,36 & 1040,28 & 1014,11 \\
$\mathrm{HD}_{\mathrm{v}}$ & & 547,11 & 442,83 & 548,57 & 532,85 \\
$\mathrm{HD}_{\mathrm{i}}$ & $-411,06$ & $-446,00$ & $-408,79$ & $-419,93$ \\
\hline
\end{tabular}

Tabla 5.18 DIC para la segunda batería de 8 modelos considerando las covariables H/W, A, O y S/V de forma conjunta, comparando $\mathrm{MU}_{1}$ y $\mathrm{MU}_{2}$

\begin{tabular}{lll}
\hline & & H/W; A; O; S/V \\
\hline$D E_{r}$ & MU1 & 126,08 \\
$D E_{c}$ & & 996,10 \\
$H D_{v}$ & 381,15 \\
$H D_{i}$ & & 384,18 \\
$D E_{r}$ & MU2 & 151,56 \\
$D E_{c}$ & & 983,74 \\
$H D_{v}$ & 425,85 \\
$H D_{i}$ & 430,52 \\
\hline
\end{tabular}

Tabla 5.19 DIC para la tercera bacteria de 24 modelos considerando todas las covariables (H/W, A, O, S/V y MU) por separado

\begin{tabular}{llllll}
\hline & H/W & A & O & S/V & MU \\
\hline $\mathrm{DE}_{\mathrm{r}}$ & 550,98 & 483,59 & 560,92 & 490,49 & 558,99 \\
$\mathrm{DE}_{\mathrm{c}}$ & 2050,29 & 1971,48 & 2049,33 & 2026,12 & 2057,42 \\
$\mathrm{HD}_{\mathrm{v}}$ & 1070,93 & 849,77 & 1073,99 & 1045,44 & 1071,33 \\
$\mathrm{HD}_{\mathrm{i}}$ & 920,70 & 848,46 & 927,74 & 899,20 & 922,71 \\
\hline
\end{tabular}


Tabla 5.20 DIC para la cuarta bacteria de 4 modelos considerando todas las covariables (H/W, A, O, S/V y MU) de forma conjunta

\begin{tabular}{ll}
\hline & H/W; $\mathbf{A} ; \mathbf{O} ; \mathbf{S} / \mathbf{V} ; \mathbf{M U}$ \\
\hline $\mathrm{DE}_{\mathrm{r}}$ & 319,82 \\
$\mathrm{DE}_{\mathrm{c}}$ & 1942,99 \\
$H D_{\mathrm{v}}$ & 804,58 \\
$H D_{\mathrm{i}}$ & 815,43 \\
\hline
\end{tabular}

Tabla 5.21 CPO para la primera batería de 32 modelos considerando las covariables H/W, A, O y S/V por separado, comparando $\mathrm{MU}_{1}$ y $\mathrm{MU}_{2}$

\begin{tabular}{llllll}
\hline & & H/W & A & O & S/V \\
\hline $\mathrm{DE}_{\mathrm{r}}$ & $\mathrm{MU1}$ & 1,541498 & 1,319262 & 1,508144 & 1,250554 \\
$\mathrm{DE}_{\mathrm{c}}$ & & 5,394913 & 5,520670 & 5,445634 & 5,313597 \\
$\mathrm{HD}_{\mathrm{v}}$ & 2,731860 & 2,063948 & 2,740482 & 2,670111 \\
$\mathrm{HD}_{\mathrm{i}}$ & & 2,321519 & 2,109037 & 2,333540 & 2,247051 \\
$\mathrm{DE}_{\mathrm{r}}$ & $\mathrm{MU2}$ & 1,309396 & 1,060710 & 1,286546 & 1,165767 \\
$\mathrm{DE}_{\mathrm{c}}$ & & 5,364257 & 5,457064 & 5,419085 & 5,282162 \\
$\mathrm{HD}_{\mathrm{v}}$ & 2,848420 & 2,304734 & 2,856211 & 2,773782 \\
$\mathrm{HD}_{\mathrm{i}}$ & 2,470266 & 2,289598 & 2,480160 & 2,422938 \\
\hline
\end{tabular}

Tabla 5.22 CPO para la segunda batería de 8 modelos modelos considerando las covariables H/W, A, O y S/V de forma conjunta, comparando $\mathrm{MU}_{1}$ y $\mathrm{MU}_{2}$

\begin{tabular}{lll}
\hline & & H/W; $\mathbf{A} ; \mathbf{O} ; \mathbf{S} / \mathbf{V}$ \\
\hline $\mathrm{DE}_{\mathrm{r}}$ & $\mathrm{MU1}$ & 0,658676 \\
$\mathrm{DE}_{\mathrm{c}}$ & & 5,187748 \\
$\mathrm{HD}_{\mathrm{v}}$ & 1,985435 \\
$\mathrm{HD}_{\mathrm{i}}$ & & 2,002094 \\
$\mathrm{DE}$ & $\mathrm{MU} 2$ & 0,788749 \\
$\mathrm{DE}$ & & 5,124821 \\
$\mathrm{H} \mathrm{v}_{\mathrm{v}}$ & 2,218651 \\
$\mathrm{HD}_{\mathrm{i}}$ & 2,244737 \\
\hline
\end{tabular}

Tabla 5.23 CPO para la tercera batería de 24 modelos considerando todas las covariables (H/W, A, O, S/V y MU) por separado

\begin{tabular}{llllll}
\hline & H/W & A & O & S/V & MU \\
\hline $\mathrm{DE}_{\mathrm{r}}$ & 1,434107 & 1,259472 & 1,459823 & 1,276742 & 1,455178 \\
$\mathrm{DE}_{\mathrm{c}}$ & 5,339549 & 5,135604 & 5,337008 & 5,276180 & 5,358084 \\
$\mathrm{HD}_{\mathrm{v}}$ & 2,788211 & 2,212131 & 2,796270 & 2,721721 & 2,789244 \\
$\mathrm{HD}_{\mathrm{i}}$ & 2,398959 & 2,211349 & 2,417017 & 2,342444 & 2,404779 \\
\hline
\end{tabular}

Tabla 5.24 CPO para la cuarta batería de 4 modelos considerando todas las covariables (H/W, A, O, S/V y MU) de forma conjunta

\begin{tabular}{ll} 
& H/W; $\mathbf{A} ; \mathbf{O} ; \mathbf{S} / \mathbf{V} ; \mathbf{M U}$ \\
\hline $\mathrm{DE}_{\mathrm{r}}$ & 0,833192 \\
$\mathrm{DE}_{\mathrm{c}}$ & 5,059606 \\
$H D_{\mathrm{v}}$ & 2,095318 \\
$H D_{\mathrm{i}}$ & 2,124434 \\
\hline
\end{tabular}




\subsubsection{III.3 SELECCIÓN DE MODELOS CON MEJOR AJUSTE}

De los resultados obtenidos, se puede deducir que en todos los casos la inclusión de un número mayor de covariables mejora los modelos, ya que los DIC y CPO obtenidos son menores en aquellos modelos que incluyen las cinco covariables. Por tanto, el hecho de incluir la manzana urbana MU como una covariable más, mejora el modelo, pues conlleva un menor error asociado, tal y como se explicó en el apartado 4.7.3 del Capítulo 4. Por ejemplo, cuando analizamos los valores de DIC para los primeros cuatro modelos de $\mathrm{DE}_{\mathrm{r}}$ que relacionan $\mathrm{MU}_{1}$ con cada una de las covariables de forma separada (primera fila de la Tabla 5.17), observamos que el mejor modelo es $D_{\mathrm{r}(M U 1 \leftrightarrow S / N)}$. Sin

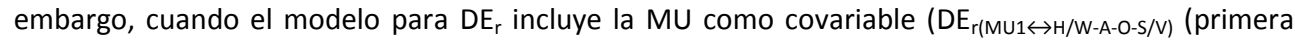
fila en Tabla 5.18), el DIC es incluso menor, lo que indica que es un mejor modelo. Lo mismo ocurre con el CPO de estos mismos ejemplos de modelos, es menor en el modelo que incluye todas las covariables. Este hecho se repite en el resto de modelos.

Por otro lado, si comparamos aquellos modelos que integran MU como covariable, observamos el mismo comportamiento. El modelo para $\mathrm{DE}_{\mathrm{r}(\mathrm{H} / \mathrm{W}-\mathrm{A}-\mathrm{O}-\mathrm{S} / \mathrm{V}-\mathrm{MU})}$ en la cuarta batería (primera fila de la Tabla 5.20) es mejor que los modelos que integran las covariables por separado (primera fila de la Tabla 5.19), es decir $D E_{r(H / W)}, D E_{r(A)}, D E_{r(O)}, D E_{r(S / N)}, D E_{r(M U)}$.

Por último, se determina el coeficiente de correlación entre los valores observados y los valores predichos y el error asociado RMSE para todos los modelos. Los resultados se muestran en la Tabla 5.25, Tabla 5.26, Tabla 5.27 y Tabla 5.28.

Tabla 5.25 Correlación y RMSE para la primera batería de 32 modelos

\begin{tabular}{llllll}
\hline & & H/W & A & O & S/V \\
\hline $\mathrm{DE}_{\mathrm{r}}$ & $\mathrm{MU1}$ & $0,3272 / 1,2473$ & $0,5828 / 1.0727$ & $0,2069 / 1,2893$ & $0,6624 / 0,9872$ \\
$\mathrm{DE}_{\mathrm{c}}$ & & $0,04242 / 52,3090$ & $-0,7130 / 59,2891$ & $0,03917 / 54,8400$ & $0,1555 / 48,3402$ \\
$\mathrm{HD}_{\mathrm{v}}$ & & $0,1321 / 3,6207$ & $0,8611 / 1,8569$ & $0,02381 / 3,6517$ & $0,3611 / 3,4065$ \\
$\mathrm{HD}_{\mathrm{i}}$ & & $0,2088 / 2,3945$ & $0,6129 / 1,9341$ & $0,1388 / 2,4237$ & $0,4184 / 2,2249$ \\
$\mathrm{DE}_{\mathrm{r}}$ & $\mathrm{MU2}$ & $0,2956 / 1,1434$ & $0,5539 / 1,0097$ & $0,1532 / 1,1867$ & $0,6006 / 0,9662$ \\
$\mathrm{DE}_{\mathrm{c}}$ & & $0,0436 / 50,6284$ & $-0,7411 / 55,6610$ & $-0,0159 / 53,3735$ & $0,1809 / 46,8202$ \\
$\mathrm{HD}_{\mathrm{v}}$ & & $0,1335 / 4,0682$ & $0,8177 / 2,3630$ & $0,0546 / 4,0989$ & $0,3905 / 3,7796$ \\
$\mathrm{HD}_{\mathrm{i}}$ & & $0,1807 / 2,7722$ & $0,5719 / 2,3111$ & $0,0981 / 2,8032$ & $0,3433 / 2,6493$ \\
\hline
\end{tabular}

Tabla 5.26 Correlación y RMSE para la segunda batería de 8 modelos

\begin{tabular}{lll}
\hline & & H/W; A; O; S/V \\
\hline $\mathrm{DE}_{\mathrm{r}}$ & $\mathrm{MU1}$ & $0,9077 / 0,5673$ \\
$\mathrm{DE}_{\mathrm{c}}$ & & $0,5210 / 41,5530$ \\
$\mathrm{HD}_{\mathrm{v}}$ & & $0,8906 / 1,6608$ \\
$\mathrm{HD}_{\mathrm{i}}$ & & $0,7242 / 1,6874$ \\
$\mathrm{DE}_{\mathrm{r}}$ & $\mathrm{MU2}$ & $0,8303 / 0,6799$ \\
$\mathrm{DE}_{\mathrm{c}}$ & & $0,5689 / 38,9334$ \\
$\mathrm{HD}_{\mathrm{v}}$ & & $0,8597 / 2,0965$ \\
$\mathrm{HD}_{\mathrm{i}}$ & & $0,6465 / 2,1484$ \\
\hline
\end{tabular}


Tabla 5.27 Correlación y RMSE para la tercera batería de 20 modelos

\begin{tabular}{llllll}
\hline & $\mathbf{H} / \mathbf{W}$ & $\mathbf{A}$ & $\mathbf{O}$ & $\mathbf{S} / \mathbf{V}$ & $\mathbf{M U}$ \\
\hline $\mathrm{DE}$ & $0,3038 / 1,2305$ & $0,5562 / 1,0776$ & $0,1795 / 1,2712$ & $0,6168 / 1,0187$ & $0,2239 / 1,2587$ \\
$\mathrm{DE}_{\mathrm{c}}$ & $0,0429 / 49,8644$ & $0,7257 / 40,6334$ & $0,0119 / 49,6547$ & $0,1678 / 46,9283$ & $-0,0557 / 50,799$ \\
$\mathrm{HD}_{\mathrm{v}}$ & $0,1316 / 3,8814$ & $0,8303 / 2,1820$ & $0,0397 / 3,9124$ & $0,3731 / 3,6327$ & $0,1236 / 3,8854$ \\
$\mathrm{HD}_{\mathrm{i}}$ & $0,1907 / 2,6246$ & $0,8303 / 2,1745$ & $0,0119 / 2,6732$ & $0,3723 / 2,4819$ & $0,16197 / 2,6384$ \\
\hline
\end{tabular}

Tabla 5.28 Correlación y RMSE para la cuarta batería de 4 modelos

\begin{tabular}{ll}
\hline & H/W; $\mathbf{A} ; \mathbf{O} ; \mathbf{S} / \mathbf{V} ; \mathbf{M U}$ \\
\hline $\mathrm{DE}_{\mathrm{r}}$ & $0,8815 / 0,6336$ \\
$\mathrm{DE}_{\mathrm{c}}$ & $0,6266 / 37,0674$ \\
$H D_{\mathrm{v}}$ & $0,8744 / 1,8996$ \\
$H D_{\mathrm{i}}$ & $0,6824 / 1,9539$ \\
\hline
\end{tabular}

Al observar la primera batería de 32 modelos en la Tabla 5.25, se puede deducir que los modelos que mejor predicen los valores de las variables respuesta son aquellos que incluyen las covariables $A$ y $S / V$, debido a que poseen unos coeficientes de correlación mayores. Sin embargo, también se puede observar que la segunda batería de modelos tienen claramente las correlaciones más altas, pues incluyen las cuatro covariables conjuntamente, para cada tipo de MU. Por ello, éstos presentan un menor RMSE asociado entre los valores predichos y los observados.

De la Tabla 5.27 y la Tabla 5.28, donde MU se considera como una covariable más, se puede extraer una conclusión similar. Los modelos que incluyen las cinco covariables conjuntamente presentan mejor ajuste que los modelos que las consideran por separado.

Finalmente, comparando los dos conjuntos de modelos mejor ajustados (segundo y cuarto), se puede concluir que el mejor es el cuarto, es decir, el que incluye todas las covariables conjuntamente, ya que presenta los coeficientes de correlación más altos y los menores RMSE asociados.

La Figura 5.30 muestra gráficamente la correlación entre los valores observados y los predichos para los cuatro modelos seleccionados, los cuales incluyen todas las covariables. Los resultados mostrados revelan que el modelo que mejor se ajusta es $H D_{r(H / W-A-O-S / V-M U)}$, con un coeficiente de correlación de 0,87 , seguido por $\mathrm{DE}_{\mathrm{r}(\mathrm{H} / \mathrm{W}-\mathrm{A}-\mathrm{O}-\mathrm{S} / \mathrm{N}-\mathrm{MU})}$ con $0,86, \mathrm{HD}_{\mathrm{i}(\mathrm{H} / \mathrm{W}-\mathrm{A}-\mathrm{O}-\mathrm{S} / \mathrm{N}-\mathrm{MU})}$ con 0,68 y finalmente $D E_{C(H / W-A-O-S / V-M U)}$ con 0,63. 

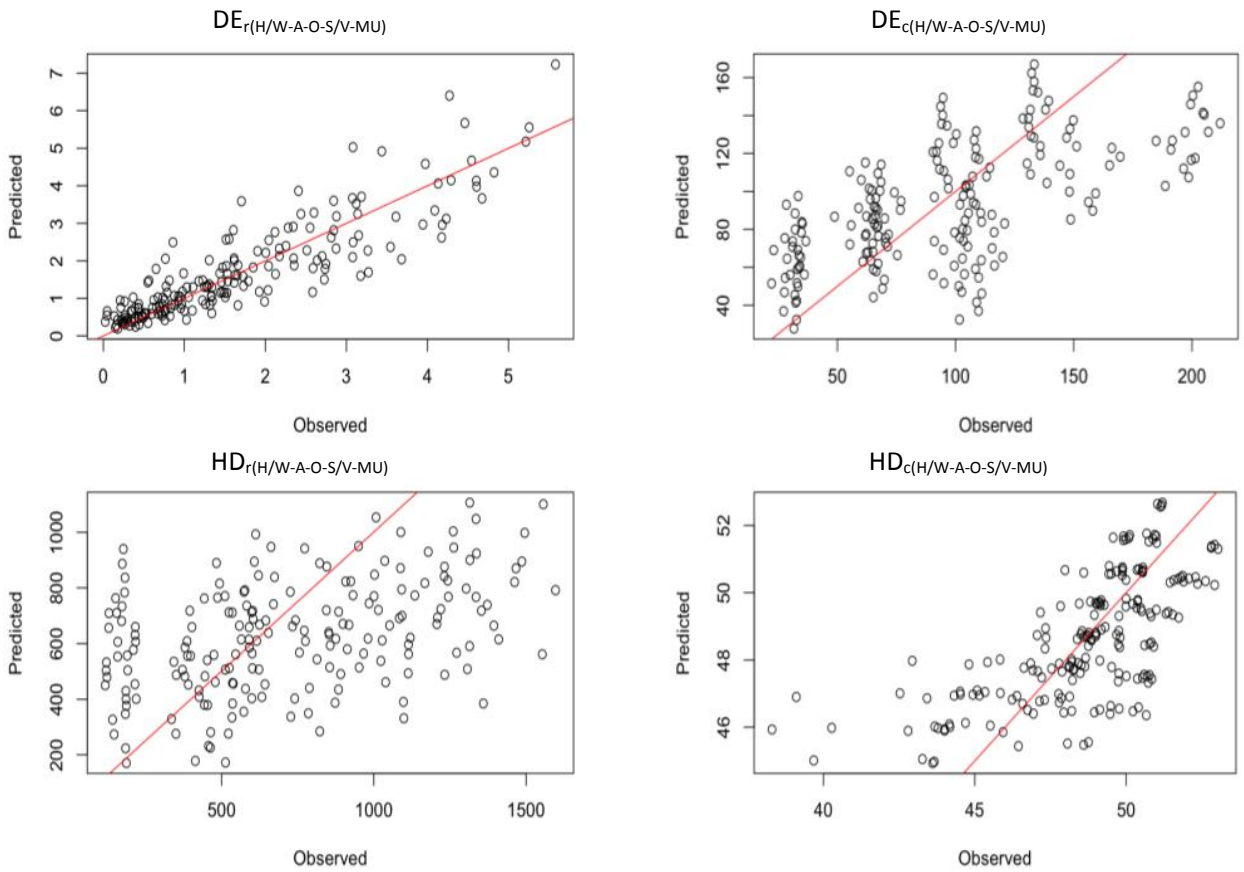

Figura 5.30 Coeficiente de correlación ente los valores observados y los predichos de los modelos seleccionados

De acuerdo a las conclusiones obtenidas en la comparación de modelos, los últimos cuatro modelos (cuarto conjunto) han sido seleccionados como los modelos con mejor ajuste por presentar los coeficientes de correlación más altos con los menores RMSE asociados. Siguiendo la expresión:

$$
\eta_{i t}\left(s_{i}\right)=\beta_{0}+\sum_{i} \beta_{1} X_{i}
$$

los cuatro modelos han sido configurados incluyendo los coeficientes que determinan el efecto de cada covariable, los cuales se muestran en la Tabla 5.32 del apartado 5.5.4. Los mismos se presentan a través de los cuatro algoritmos siguientes:

$$
\begin{gathered}
D E_{r}=2,6480+(0,3336 \cdot A)+(-6,5815 \cdot S / V)+(0,0013 \cdot O)+(-0,4637 \cdot H / W)+(-0,4372 \cdot M U) \\
D E_{c}=46,8932+(-17,6330 \cdot A)+(118,4408 \cdot S / V)+(-0,0505 \cdot O)+(19,8277 \cdot H / W)+(14,5047 \cdot M U) \\
H D_{v}=6,9152+(-2,1639 \cdot A)+(13,6464 \cdot S / V)+(-0,0015 \cdot O)+(0,8659 \cdot H / W)+(0,9760 \cdot M U) \\
H D_{i}=44,5077+(-0,9679 \cdot A)+(12,5778 \cdot S / V)+(-0,004 \cdot O)+(0,8951 \cdot H / W)+(0,9202 \cdot M U)
\end{gathered}
$$

Obtenidas las cuatro ecuaciones de predicción, variando los valores de las covariables según los condicionantes urbanos y edificatorios, es posible predecir la demanda energética para calefacción y refrigeración y las horas de disconfort anuales para verano e invierno, para cada edificio que integra el barrio objeto de estudio. En el caso de la ecuación para la variable $D_{r}$, al tratarse de una distribución de familiar Gamma como se desprende de Figura 5.28, debe aplicarse la función 
exponencial del resultado obtenido de la ecuación (Blangiardo y Camaletti, 2015). La agregación de dichos resultados dará lugar al diagnóstico del comportamiento energético pasivo del barrio en su conjunto.

\subsubsection{III.4 IDENTIFICACIÓN DE COVARIABLES SIGNIFICATIVAS}

En este apartado se analiza la influencia de cada covariable sobre las variables respuesta, a través de los efectos fijos de todos los modelos (denotados por $\beta_{i}$ ). Éstos están presentados de la Tabla 5.29, la Tabla 5.30, la Tabla 5.31 y la Tabla 5.32.

Tabla 5.29 Efectos fijos: $\beta_{i}$ (media [percentil 2,5; percentil 97,5]). Primer conjunto de 32 modelos

\begin{tabular}{llllll}
\hline & & H/W & A & O & S/V \\
\hline $\mathrm{DE}_{\mathrm{r}}$ & $\mathrm{MU} 1$ & $-0,3745[-0,5955 ;-0,1538]$ & $0,3238[0,2428 ; 0,4041]$ & $0,0014[0,0000 ; 0,0028]$ & $-8,2477[-10,0081 ;-6,4818]$ \\
$\mathrm{DE}_{\mathrm{c}}$ & & $36,8255[26,7441 ; 47,0489]$ & $7,5230[1,5431 ; 14,0321]$ & $0,2333[0,1391 ; 0,3322]$ & $139,2179[95,5385 ; 182,7811]$ \\
$\mathrm{HD}_{\mathrm{v}}$ & & $0,8402[-0,3677 ; 2,0482]$ & $-2,2046[-2,4676 ;-1,9416]$ & $-0,0007[-0,0080 ; 0,0066]$ & $21,3303[10,2201 ; 32,4048]$ \\
$\mathrm{HD}_{\mathrm{i}}$ & & $0,9917[0,1900 ; 1,7977]$ & $-1,0224[1,2959 ;-0,7478]$ & $0,0038[-0,0011 ; 0,0086]$ & $18,8925[11,5351 ; 26,3047]$ \\
$\mathrm{DE}_{\mathrm{r}}$ & $\mathrm{MU} 2$ & $-0,4397[-0,7328 ;-0,1469]$ & $0,4700[0,3601 ; 0,5777]$ & $0,0020[0,0000 ; 0,0040]$ & $-7,8284[-10,3440 ;-5,3079]$ \\
$\mathrm{DE}_{\mathrm{c}}$ & & $34,2280[24,3390 ; 44,2917]$ & $5,2809[-0,5471 ; 11,4892]$ & $0,1986[0,1060 ; 0,2956]$ & $134,4105[90,9687 ; 177,7394]$ \\
$\mathrm{HD} D_{\mathrm{v}}$ & $0,9653[-0,3888 ; 2,3199]$ & $-2,3467[-2,6810 ;-2,0123]$ & $-0,0020[-0,0102 ; 0,0062]$ & $25,6614[13,4154 ; 37,8582]$ \\
$\mathrm{HD} D_{\mathrm{i}}$ & $0,0085[-0,0008 ; 0,0178]$ & $-0,0113[-0,0146 ;-0,0081]$ & $0,0000[-0,0001 ; 0,0000]$ & $0,1620[0,0726 ; 0,2512]$ \\
\hline
\end{tabular}

Tabla 5.30 Efectos fijos: $\beta_{i}$ (media [percentil 2,5; percentil 97,5]). Segundo conjunto de 8 modelos

\begin{tabular}{|c|c|c|}
\hline & & H/W; A; O; S/V \\
\hline $\mathrm{DE}_{\mathrm{r}}$ & MU1 & $-0,4137[-0,5125 ;-0,3149] ; 0,2725[0,2297 ; 0,3152] ; 0,0009[0,0003 ; 0,0015] ;-7,2562[-8,2794 ;-6,2303]$ \\
\hline $\mathrm{DE}_{\mathrm{c}}$ & & $31,6630[20,1911 ; 43,5282] ;-13,3457[-18,5742 ;-7,9547] ; 0,0984[0,0177 ; 0,1805] ; 100,4968[48,2215 ; 152,0663]$ \\
\hline$H D_{v}$ & & $0,8170[0,2512 ; 1,3828] ;-2,1055[-2,3496 ;-1,8613] ;-0,0008[-0,0042 ; 0,0025] ; 11,6464[5,8796 ; 17,4134]$ \\
\hline$H D_{i}$ & & $0,9203[0,3459 ; 1,4967] ;-0,9111[-1,1589 ;-0,6623] ; 0,0036[0,0017 ; 0,0036] ; 13,7288[7,8825 ; 19,6182]$ \\
\hline $\mathrm{DE}_{\mathrm{r}}$ & MU2 & $-0,5189[-0,7086 ;-0,3293] ; 0,4091[0,3210 ; 0,4969] ; 0,0020[0,0007 ; 0,0032] ;-5,7667[-7,6639 ;-3,8597]$ \\
\hline $\mathrm{DE}_{\mathrm{c}}$ & & $30,0743[19,1843 ; 41,4377] ;-14,2590[-19,1722 ;-9,1602] ; 0,0673[-0,0081 ; 0,1445] ; 108,4249[56,8547 ; 159,093]$ \\
\hline$H D_{v}$ & & $0,9335[0,2202 ; 1,6469] ;-2,2142[-2,5219 ;-1,9065] ;-0,0022[-0,0064 ; 0,0021] ; 15,8751[8,6411 ; 23,1090]$ \\
\hline$H D_{i}$ & & $0,9645[0,2336 ; 1,6991] ;-0,9780[-1,2932 ;-0,6609] ;-0,0024[-0,0068 ; 0,0019] ; 13,2601[5,8608 ; 20,7335]$ \\
\hline
\end{tabular}

Tabla 5.31 Efectos fijos: $\beta_{i}$ (media [percentil 2,5; percentil 97,5]). Tercer conjunto de 20 modelos

\begin{tabular}{llllll}
\hline & H/W & A & O & S/V & MU \\
\hline $\mathrm{DE}_{\mathrm{r}}$ & $-0,401[-0,589 ;-0,213]$ & $0,377[0,306 ; 0,448]$ & $0,002[0,0004 ;-0,003]$ & $-8,071[-9,681 ;-6,458]$ & $-0,352[-0,581 ;-0,123]$ \\
$\mathrm{DE}_{\mathrm{c}}$ & $28,331[19,99 ; 36,818]$ & $-8,486[-12,444 ;-4,231]$ & $0,1255[0,0608 ; 0,192]$ & $142,972[102,013 ; 183,88]$ & $29,941[19,739 ; 40,31]$ \\
$\mathrm{HD}_{\mathrm{v}}$ & $0,8813[-0,0345 ; 1,797]$ & $-2,2811[-2,4992 ;-2,063]$ & $-0,0015[-0,0070 ; 0,004]$ & $23,964[15,4843 ; 32,4275]$ & $0,9949[-0,1055 ; 2,095]$ \\
$\mathrm{HD}_{\mathrm{i}}$ & $0,9344[0,3143 ; 1,555]$ & $-1,0732[-1,2904 ;-0,856]$ & $0,0006[-0,0032 ; 0,0043]$ & $17,7913[11,9501 ; 23,6473]$ & $0,9690[0,2207 ; 1,7185]$ \\
\hline
\end{tabular}

Tabla 5.32 Efectos fijos: $\beta_{i}$ (media [percentil 2,5; percentil 97,5]). Cuarto conjunto de 4 modelos

\begin{tabular}{ll}
\hline \multicolumn{1}{c}{$\mathbf{H} / \mathbf{W} ; \mathbf{A} ; \mathbf{O} ; \mathbf{S} / \mathbf{V} ; \mathbf{M U}$} \\
\hline $\mathrm{DE}_{\mathrm{r}}$ & $-0,4637[-0,5733 ;-0,3542] ; 0,3336[0,2846 ; 0,3824] ; 0,0013[0,0007 ; 0,0020] ;-6,5815[-7,6931 ;-5,4668] ;-0,4372[-0,5687 ;-0,3059]$ \\
$\mathrm{DE}_{\mathrm{c}}$ & $19,8277[11,8708 ; 27,9586] ;-17,6330[-21,0943 ;-14,1163] ; 0,0505[-0,0009 ; 0,1025] ; 118,4408[73,1675 ; 163,3233] ; 14,5047[4,9883 ; 24,228]$ \\
$\mathrm{HD}_{\mathrm{v}}$ & $0,8659[0,4116 ; 1,3199] ;-2,1639[-2,3599 ;-1,9679] ;-0,0015[-0,0042 ; 0,0012] ; 13,6464[9,0016 ; 18,2881] ; 0,9760[0,4309 ; 1,5207]$ \\
$\mathrm{HD}_{\mathrm{i}}$ & $0,8951[0,4291 ; 1,3616] ;-0,9679[-1,1690 ;-0,7665] ; 0,0004[-0,0023 ; 0,0032] ; 12,5778[7,8164 ; 17,3513] ; 0,9202[0,3610 ; 1,4800]$ \\
\hline
\end{tabular}

Aquellas variables que son significativas tienen la media, el percentil $2,5 \%$ y el $97,5 \%$ sin cambio de signo. El signo positivo implica que la variable respuesta aumenta cuando aumenta la covariable. EI signo negativo implica que la variable respuesta disminuye cuando también lo hace la covariable.

$\mathrm{Si}$ analizamos detenidamente los efectos fijos, observamos que todas las covariables son representativas en algún momento. La más significativa es el factor de forma (S/V), seguida del año 
de construcción (A) y la proporción de calle (H/W), ambas significativas de forma similar. La cuarta variable más significativa es la manzana urbana (MU) y finalmente la orientación (O).

En relación al factor de forma, valores más altos de $S / \mathrm{V}$ implican edificios menos compactos y conducen a transferencias de calor más altas entre el ambiente interior del edificio y el exterior, en el caso de $D E_{c}$. Podemos observar que a medida que $S / V$ aumenta, las variables respuesta $H D_{v}$ y $H D_{i}$ también aumentan, lo que significa que los edificios con mayores coeficientes de forma (menos compactos) comportan un peor confort térmico en su interior.

Con respecto a A, se observa que las horas de disconfort anuales para verano e invierno disminuyen a medida que el año de construcción es más reciente. Ello está en concordancia con el hecho de que las soluciones constructivas de la envolvente térmica mejoran con el paso del tiempo. Los edificios más recientes incluyen materiales de aislamiento térmico en su envolvente, confiriendo mejores prestaciones a las fachadas, las cubiertas, los suelos y los huecos, lo que conduce a una menor demanda energética de calefacción que los edificios más antiguos. Con respecto a la demanda de calefacción $\left(D E_{c}\right)$, esta también disminuye a con soluciones constructivas más recientes. Sin embargo, la demanda de refrigeración $\left(D E_{r}\right)$ aumenta frente a este hecho, que será analizado con mayor profundidad en el Capítulo 6.

En relación a la ratio $\mathrm{H} / \mathrm{W}$ de calle, se puede observar que a medida que $\mathrm{H} / \mathrm{W}$ aumenta, las variables respuesta $D E_{c}, H D_{v}$ y $H D_{i}$ también aumentan. Para $D E_{c}$, ello supone que valores altos de $H / W$ conducen a una mayor demanda energética de calefacción, explicada por la escasa posibilidad de acceso solar (altos ratios de $\mathrm{H} / \mathrm{W}$ ) que impide las ganancias térmicas naturales por soleamiento. En el caso de $D E_{r}$, altos ratios de $H / W$ conducen a menor demanda energética de refrigeración (valores próximos a 0), también debido al escaso acceso solar (especialmente durante la temporada de verano) que, en este caso, tiene un efecto favorable.

La manzana urbana (MU) también está íntimamente relacionada con el acceso solar en los edificios. $\mathrm{MU}_{1}$ ofrece la posibilidad de grandes ganancias solares en las fachadas interiores de los edificios, ya que recaen a un gran patio de manzana; mientras que $\mathrm{MU}_{2}$, al disponer de pequeños patios de luces propios de los edificios, no ofrece dicha posibilidad. Por ello, los edificios emplazados en la $\mathrm{MU}_{2}$ demandan menor cantidad de energía durante el verano $\left(D E_{r}\right)$.

La covariable orientación (O), se muestra únicamente significativa en el caso de $D_{r}$, pero con valores muy próximos a 0 , lo que indica un bajo nivel de significancia. A pesar de que la orientación no parece, a priori demasiado significativa, se observa que los modelos en los que se incluye tienen un menor RMSE asociado, por lo que se concluye que, incluir el efecto de la orientación, mejora el modelo. Sin embargo, la orientación es un aspecto más complejo, pues ambas tipologías de MU ofrecen diferentes condicionantes, por lo que requiere de un estudio más pormenorizado que ayude a determinar su efecto sobre las variables respuesta de forma más detallada. El Capítulo 6 aborda con mayor profundidad este aspecto.

Estas y otras consideraciones se discuten de forma más exhaustiva en el Capítulo 6.

\subsection{ETAPA IV: EXTRAPOLACIÓN DEL DIAGNÓSTICO ENERGÉTICO A ESCALA URBANA}

En esta cuarta y última etapa, se determina el diagnóstico energético de los edificios que constituyen el barrio objeto de estudio para extrapolar conclusiones a una escala urbana. Cada una de las cuatro ecuaciones de predicción de los indicadores de evaluación energética, $D E_{r}, D E_{c}, H_{v} y$ $H D_{i}$, son aplicadas a los edificios contenidos en el área urbana, individualmente. 
La tecnología SIG permite tratar el gran volumen de información generado y realizar los cálculos de los cuatro indicadores. Para ello, las covariables de cada edificio individual han sido determinadas e integradas en la base de datos SIG, a través de una tabla de atributos georreferenciada en base a la referencia catastral. Como resultado de aplicar las ecuaciones de predicción, se obtienen los valores de las cuatro variables respuesta para cada edificio individual que compone el barrio. Posteriormente, los resultados de esta evaluación individual son agregados para determinar la demanda energética y las horas de disconfort de la totalidad del barrio.

Siguiendo el procedimiento establecido en la Figura 4.11 del Capítulo 4, que define tres fases diferenciadas, se desarrolla a continuación la Etapa IV, siguiendo un enfoque bottom-up.

\subsubsection{IV.1 CÁLCULO DE LOS INDICADORES ENERGÉtICOS EN CADA EDIFICIO}

A modo de ejemplo, la Tabla 5.33 muestra el procedimiento seguido para el cálculo de cada uno de los indicadores, como resultado de aplicar las cuatro ecuaciones de predicción obtenidas de la modelización estadística.

Tabla 5.33 Cálculo de los cuatro indicadores energéticos para cada edificio

\begin{tabular}{|c|c|c|c|c|c|c|c|c|c|c|c|c|c|c|c|}
\hline 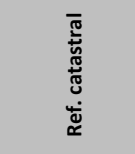 & 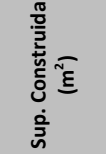 & 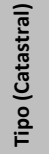 & i⿱ & 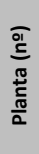 & 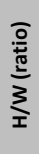 & $\varangle$ & $\frac{\sigma}{0}$ & $\frac{\sigma}{\xi}$ & $\grave{\Sigma}$ & 童 & 岃凯 & 岂 & 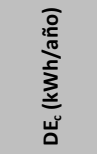 & 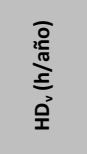 & 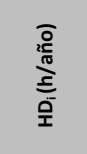 \\
\hline 2200612YK5320S & 256 & 112 & 2007 & 3 & 2,4 & 5 & 270 & 0,3 & 2 & 2,02 & 518,24 & 84,49 & $21.629,77$ & 381,47 & $4.753,81$ \\
\hline 2499801YK5229N & 208 & 112 & 1970 & 3 & 2,4 & 3 & 270 & 0,3 & 1 & 1,61 & 334,56 & 105,25 & $21.892,54$ & 716,65 & $4.855,37$ \\
\hline 2300126YK5320S & 223 & 112 & 1950 & 2 & 2,4 & 2 & 180 & 0,3 & 2 & 0,66 & 147,62 & 132,84 & $29.624,50$ & $1.044,14$ & $5.040,58$ \\
\hline 2302506YK5320S & 250 & 112 & 1960 & 3 & 1,2 & 3 & 0 & 0,3 & 2 & 1,28 & 318,93 & 82,32 & $20.582,27$ & 750,85 & $4.829,18$ \\
\hline 2302509YK5320S & 129 & 112 & 1983 & 3 & 1,2 & 4 & 0 & 0,3 & 2 & 1,78 & 229,73 & 64,69 & 8345,79 & 534,46 & 4732,39 \\
\hline 2501113YK5320S & 417 & 112 & 1991 & 4 & 1,6 & 4 & 0 & 0,3 & 2 & 1,48 & 616,91 & 72,62 & 30285,52 & 569,09 & 4768,20 \\
\hline ... & $\cdots$ & $\cdots$ & $\ldots$ & $\ldots$ & $\cdots$ & $\ldots$ & $\ldots$ & $\ldots$ & $\ldots$ & $\ldots$ & $\ldots$ & $\ldots$ & $\ldots$ & $\ldots$ & $\ldots$ \\
\hline Total barrio & $313.301,00$ & & & & & & & & & & $\begin{array}{l}\text { 523.530,78 } \\
\text { MWh/año }\end{array}$ & & $\begin{array}{l}\text { 29.354,89 } \\
\text { MWh/año }\end{array}$ & & \\
\hline
\end{tabular}

La demanda energética a nivel global del barrio se estima en 523,53 MWh/año para la demanda de refrigeración y en 29.354,89 MWh/año para la demanda de calefacción. Como se observa, la demanda de calefacción representa un mayor reto a la hora de prever una intervención de rehabilitación energética en el barrio, pues es donde se encuentra el mayor potencial de ahorro energético del parque residencial. 


\subsubsection{IV.2 DesarRollo de UNA ESCALA DE VALORACIÓN PARA LOS INDICAdoRES ENERGÉTICOS}

Con el objetivo de presentar los resultados en un mapa SIG, se plantea previamente una escala de valoración para los indicadores. Concretamente, se establecen tres escalas de valoración, siendo estas:

- demanda energética de refrigeración, $\mathrm{DE}_{\mathrm{r}}$

- demanda energética de calefacción, $\mathrm{DE}_{\mathrm{c}}$

- horas anuales de disconfort, HD

La clasificación propuesta en este trabajo se basa en la clasificación energética de indicadores para los edificios existentes utilizada en España. La escala se establece desde el indicador A al G. Debido a que los valores para $D E_{r}$ están concentrados en el indicador $A$ y los valores de $D E_{c}$ en el $G$, en el marco de este trabajo se propone una clasificación extendida. En esta, se desglosan los indicadores $A$ y $G$ en cuatro indicadores adicionales, respectivamente ( $A 1, A 2, A 3, A 4, G 1, G 2, G 3$ y G4), con el objetivo de clasificar más pormenorizadamente la demanda energética de los edificios del barrio. Esta clasificación se muestra en la Tabla 5.34. En el caso de las horas de disconfort anuales no existe ninguna clasificación oficial para este indicador, por lo que se ha propuesto una clasificación en el marco de este trabajo, de la clase $\mathrm{A}$ a la $\mathrm{F}$, en rangos de 1.000 horas/año, como se muestra en la Tabla 5.35.

Tabla 5.34 Escala de valoración para el indicador energético DE basado en la clasificación propuesta por la legislación española para edificios existentes ( $\mathrm{kWh} / \mathrm{m}^{2}$ año)

\begin{tabular}{|c|c|c|}
\hline Indicador energético & $D E_{r}\left[k W h / m^{2} a n ̃ o\right]$ & $\mathrm{DE}_{\mathrm{c}}\left[\mathrm{kWh} / \mathrm{m}^{2} \mathrm{año}\right]$ \\
\hline $\mathrm{A} 1^{*}$ & $\mathrm{DE}_{\mathrm{r}}<0,7$ & $\mathrm{DE}_{\mathrm{c}}<4,7$ \\
\hline $\mathrm{A} 2 *$ & $0,7 \leq \mathrm{DE}_{\mathrm{r}}<1,5$ & \\
\hline $\mathrm{A} 3 *$ & $1,5 \leq \mathrm{DE}_{\mathrm{r}}<3$ & \\
\hline $\mathrm{A} 4 *$ & $3 \leq D E_{r}<4,7$ & \\
\hline B & $4,7 \leq D E_{r}<7,6$ & $4,7 \leq \mathrm{DE}_{\mathrm{c}}<10,9$ \\
\hline C & $7,6 \leq \mathrm{DE}_{\mathrm{r}}<11,7$ & $10,9 \leq \mathrm{DE}_{\mathrm{c}}<19,6$ \\
\hline D & $11,7 \leq \mathrm{DE}_{\mathrm{r}}<18$ & $19,6 \leq \mathrm{DE}_{\mathrm{c}}<32,8$ \\
\hline$E$ & $18 \leq \mathrm{DE}_{\mathrm{r}}<22,3$ & $32,8 \leq \mathrm{DE}_{\mathrm{c}}<64,5$ \\
\hline $\mathrm{F}$ & $22,3 \leq \mathrm{DE}_{\mathrm{r}}<27,4$ & $64,5 \leq \mathrm{DE}_{\mathrm{c}}<70,3$ \\
\hline $\mathrm{G} 1 *$ & $27,4 \leq \mathrm{DE}_{\mathrm{r}}$ & $70,3 \leq \mathrm{DE}_{\mathrm{c}}<102,3$ \\
\hline $\mathrm{G} 2 *$ & & $102,3 \leq \mathrm{DE}_{\mathrm{c}}<134,3$ \\
\hline $\mathrm{G} 3 *$ & & $134,3 \leq \mathrm{DE}_{\mathrm{c}}<166,9$ \\
\hline G4* & & $166,9 \leq \mathrm{DE}_{\mathrm{c}}$ \\
\hline
\end{tabular}

Tabla 5.35 Escala de valoración para el indicador energético HD (horas/año)

\begin{tabular}{|c|c|}
\hline Indicador HD & HD [h/año] \\
\hline A & $\mathrm{HD}<1.000$ \\
\hline B & $1.000 \leq \mathrm{HD}<2.000$ \\
\hline c & $2.000 \leq \mathrm{HD}<3.000$ \\
\hline D & $3.000 \leq \mathrm{HD}<4.000$ \\
\hline E & $4.000 \leq \mathrm{HD}<5.000$ \\
\hline $\mathrm{F}$ & $5.000 \leq \mathrm{HD}$ \\
\hline
\end{tabular}




\subsubsection{IV.3 DESARROLLO DE MAPAS URBANOS ENERGÉTICOS}

La representación gráfica de los cuatro indicadores de $\mathrm{DE}_{\mathrm{r}}, \mathrm{DE}_{\mathrm{c}}, \mathrm{HD}_{\mathrm{v}}$ y $H \mathrm{HD}_{\mathrm{i}}$ calculados para cada edificio que integra el barrio, se muestra en la Figura 5.31, Figura 5.32, Figura 5.33 y Figura 5.34, respectivamente.

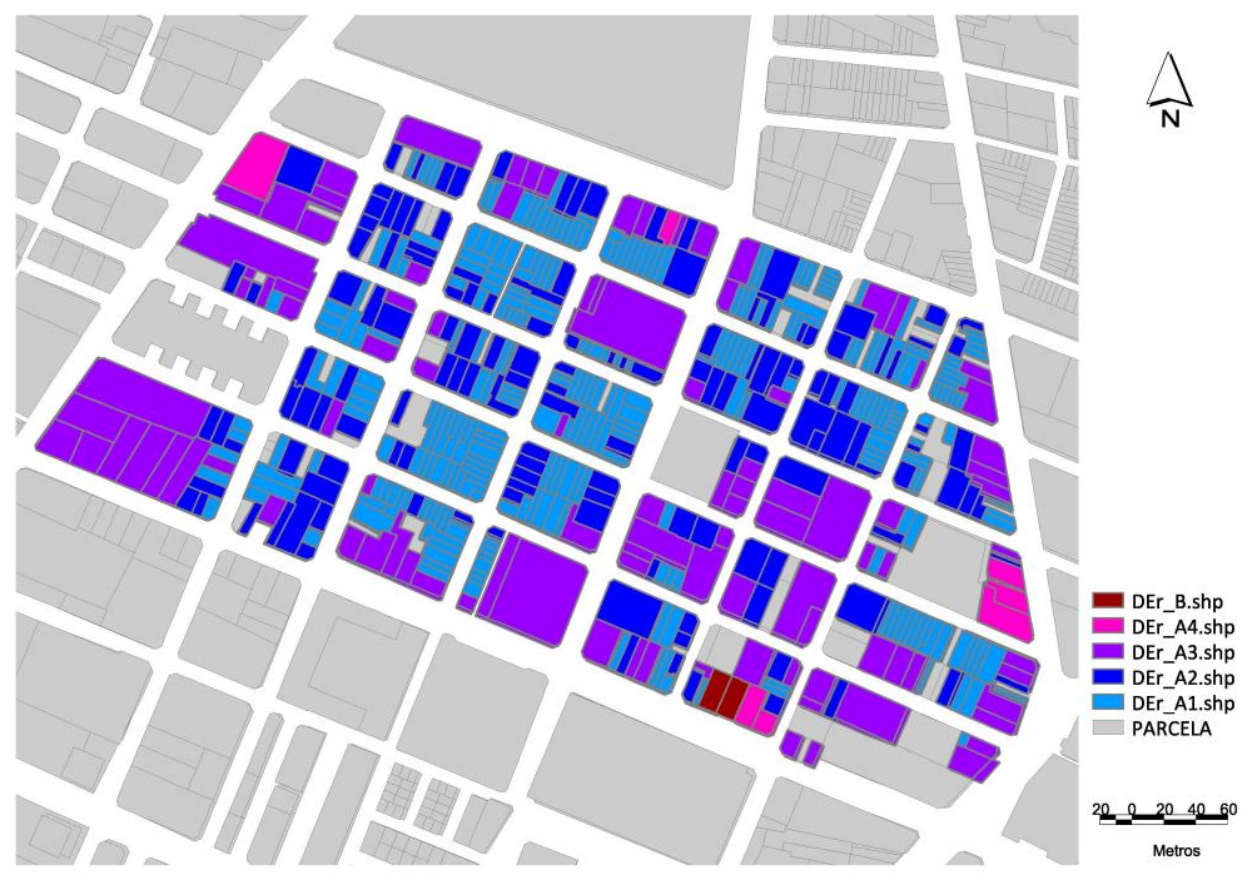

Figura 5.31 Mapa energético urbano para el indicador $D E_{r}$

Representar los indicadores en mapas urbanos energéticos permite identificar interesantes relaciones entre los diferentes aspectos evaluados.

En relación a la demanda de refrigeración, todos los edificios del barrio muestran un muy buen comportamiento, estando englobados mayoritariamente dentro del indicador A (menor de 4,7 $\mathrm{kWh} / \mathrm{m}^{2}$ año) y quedando solamente dos de ellos englobados en el indicador B (entre 4,7 y 7,6 $\mathrm{kWh} / \mathrm{m}^{2}$ año), adoptando así valores muy bajos. Aun así, se aprecian ligeras diferencias en aquellos edificios incluidos dentro de la tipología de manzana $\mathrm{MU}_{2}$, que muestran demandas energéticas menores, debido a que están más condicionados por la presencia de obstáculos que generan situaciones de sombra. También se aprecia que, como ya se concluyó del análisis de la significancia de las covariables, los edificios de construcción más reciente muestran un peor comportamiento frente a la refrigeración, y así se refleja en el mapa energético.

Cabe indicar que, a priori, la demanda energética de refrigeración no genera grandes problemas, por lo que a la hora de tomar decisiones sobre una intervención de rehabilitación energética en el barrio, se deberán tener en cuenta, además, los demás indicadores. 


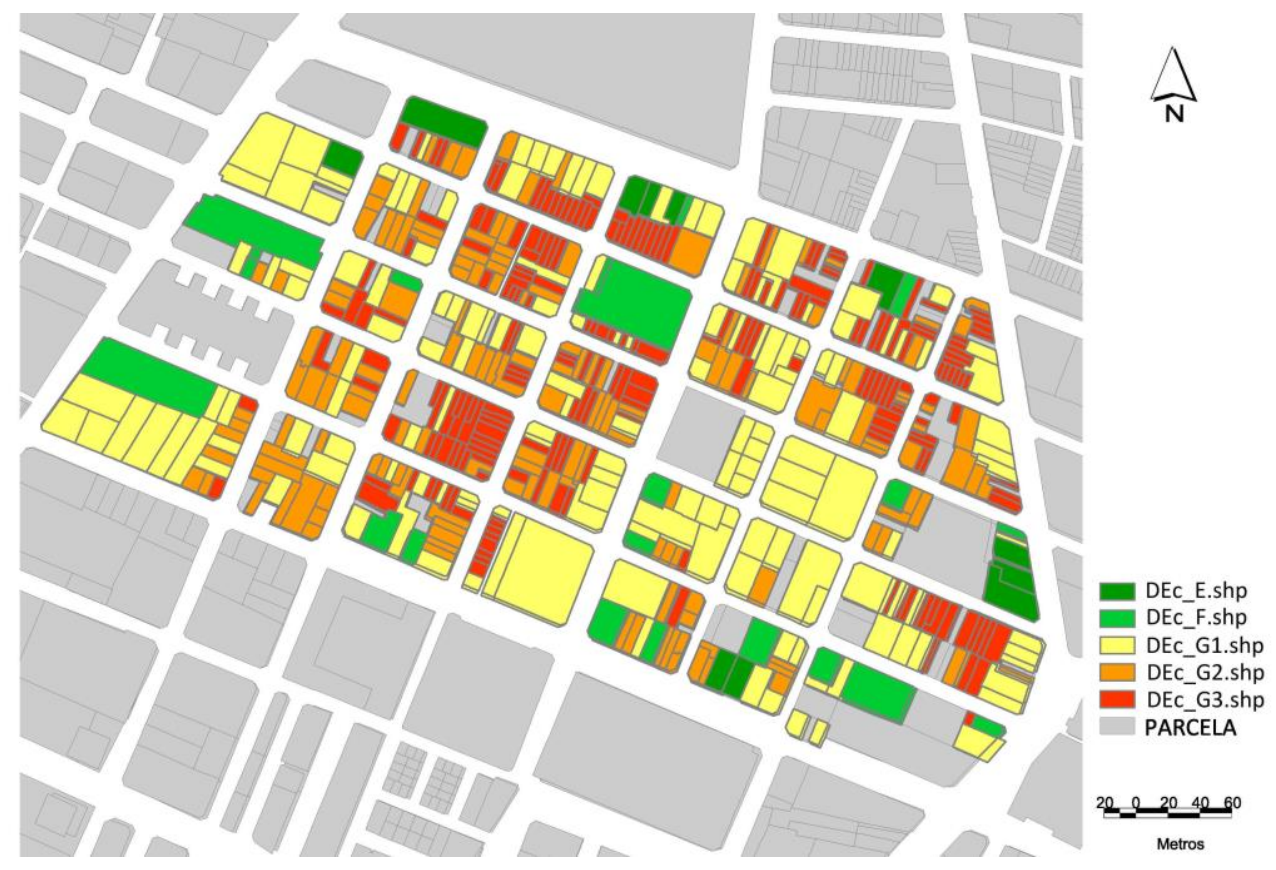

Figura 5.32 Mapa energético urbano para el indicador $D_{c}$

En cuanto a la demanda de calefacción, sí se aprecian notables diferencias en el comportamiento de los edificios. $L a E_{c}$ oscila entre los indicadores $E, F$ y $G$, alcanzando diferencias de hasta 134 $\mathrm{kWh} / \mathrm{m}^{2}$ año. Según se observa en el mapa de la Figura 5.32, los edificios que mayor demanda de calefacción presentan son los que se encuentran en las manzanas $\mathrm{MU}_{2}$ (más antiguas). Así, la tipología $\mathrm{MU}_{2}$ garantiza en los edificios una menor $\mathrm{DE}_{\mathrm{c}}$. También se observa que los edificios orientados hacia las calles principales que delimitan el barrio, presentan menor $\mathrm{DE}_{c}$, explicado por la mayor anchura de estas, que implica menores ratios $\mathrm{H} / \mathrm{W}$. Así, las tonalidades rojizas del mapa permiten identificar con facilidad las manzanas urbanas con peor comportamiento energético frente a la calefacción, en el periodo invernal. El indicador de demanda energética de calefacción será decisivo a la hora de tomar decisiones sobre rehabilitación energética de los edificios del barrio y priorizar el orden de las intervenciones. 


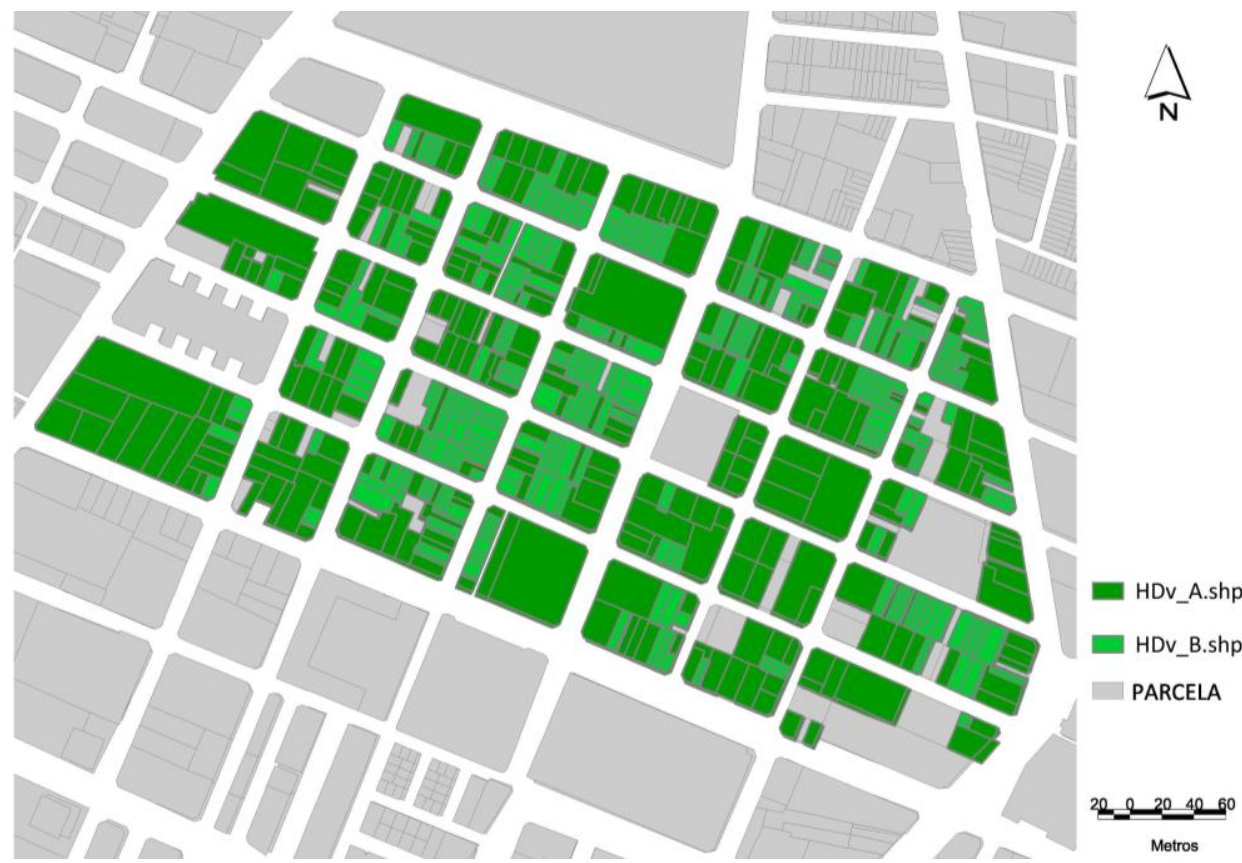

Figura 5.33 Mapa energético urbano para el indicador $H D_{v}$

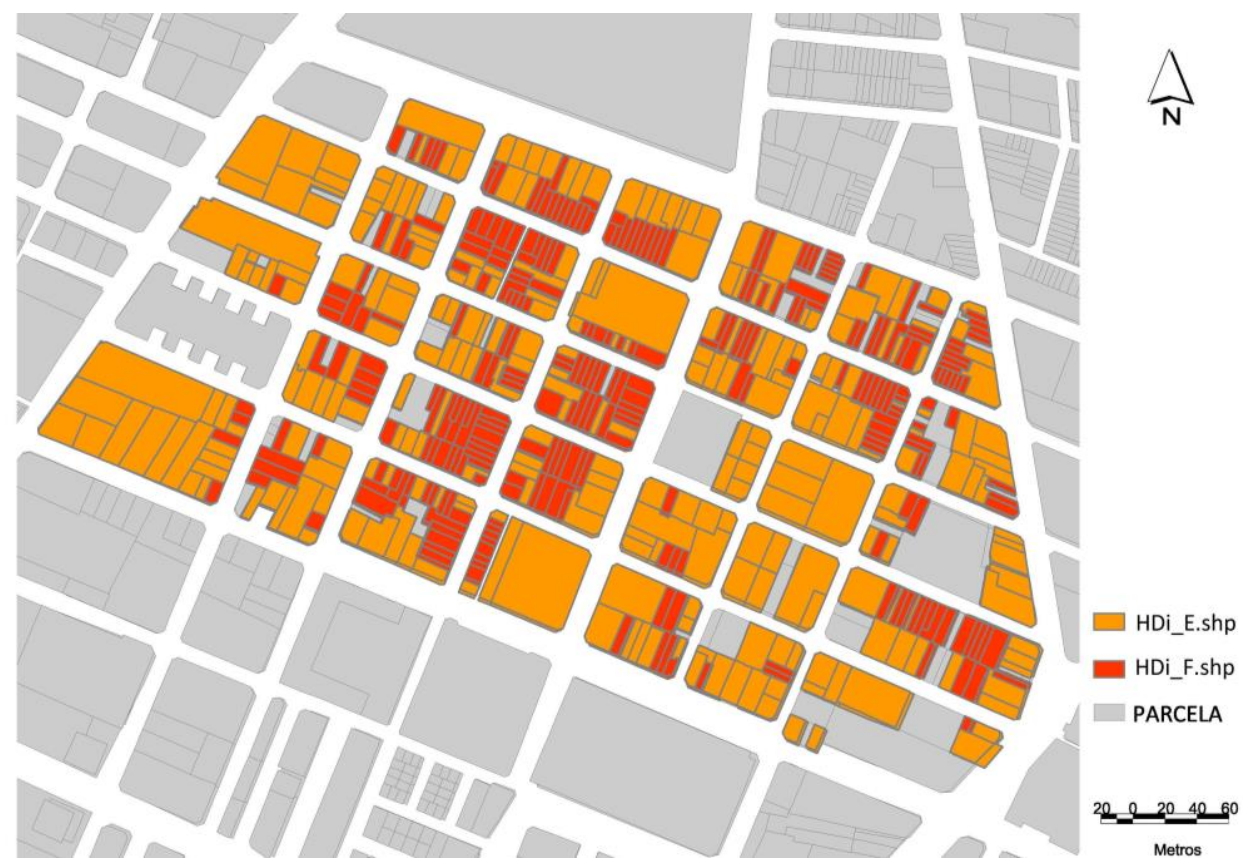

Figura 5.34 Mapa energético urbano para el indicador $H D_{i}$ 
En cuanto al indicador de disconfort térmico en verano e invierno, los resultados se asemejan a los de la demanda de refrigeración y calefacción, respectivamente, por lo que pueden extraerse conclusiones similares.

\subsection{CONCLUSIÓN}

La implementación de la metodología en un caso real de estudio, como son la ciudad y el barrio seleccionados, pone de manifiesto que el modelo propuesto en el marco de esta tesis permite caracterizar el comportamiento energético pasivo de diferentes áreas urbanas, en el ámbito de la edificación residencial.

Cuando se propone una metodología de evaluación energética del parque edificatorio, el mayor reto es identificar una serie de covariables, tanto a escala urbana como de edificio, que afecten de forma significativa a los indicadores de evaluación y cuantificar con exactitud dicho efecto. Las covariables seleccionadas a través de la revisión de las HESU y las metodologías de evaluación ya existentes en la literatura, se muestran todas ellas adecuadas para integrar el modelo de predicción, pues todas son significativas y contribuyen a mejorar los modelos estadísticos diseñados, reduciendo el error asociado entre los valores reales y los predichos.

Como se desprende de su implementación en el presente capítulo, la metodología ha podido ser adaptada completamente a los condicionantes específicos de la región y del barrio, en lo que a solicitaciones exteriores e interiores, taxonomía urbana y condiciones de soleamiento y sombras se refiere, como se establece en la definición de parámetros de cálculo en el Capítulo 2. Siguiendo el procedimiento establecido en cada una de las etapas descritas en el Capítulo 4, han podido ser definidas las cinco covariables específicamente para el barrio objeto de estudio, seleccionados los edificios representativos y evaluados estos energéticamente, teniendo en cuenta el abanico de hipótesis que pueden darse en este entorno urbano, lo que permite alcanzar un nivel detallado para la caracterización energética de cada edificio, a nivel individual. Así, los cuatro indicadores energéticos son determinados para todos los edificios, atendiendo a los condicionantes específicos del contexto urbano por los que se ven influenciados: manzana urbana en la que se ubican (MU), proporción de calle $(H / W)$, orientación $(O)$, factor de forma $(S / V)$ y año de construcción $(A)$. La extrapolación del diagnóstico energético del barrio en su totalidad se lleva a cabo agregando los resultados de cada edificio a una escala urbana, siguiendo un enfoque bottom-up.

Por otro lado, la representación de los resultados de los indicadores en mapas urbanos energéticos contribuye a la visualización gráfica, permitiendo identificar con facilidad aquellas manzanas o zonas urbanas que tienen asociado un peor comportamiento energético. Para ello, ha sido crucial el uso de un etorno SIG (gvSIG Desktop), que ha permitido tatar el gran volumen de información requerido de una forma georreferenciada, en base a la referencia catastral de cada edificio contenido en el área de estudio.

Con todo ello, se ensalzan cada uno de los seis requisitos que una metodología debe integrar, expuestos en el Capítulo 4, para poder llevar a cabo con objetividad y transparencia la evaluación energética pasiva de un parque edificatorio residencial existente.

Cabe indicar que, en este caso, el cálculo de los indicadores energéticos se ha realizado sobre un único barrio de la ciudad. No obstante, si la metodología se implementara sobre los demás barrios que la constituyen, podrían compararse e identificarse aquellos con una mayor necesidad de intervención a la hora de rehabilitarlos energéticamente, y priorizar así el orden de las actuaciones. 
Como potencial aplicación de la metodología cabe destacar que esta permite a los diferentes agentes intervinientes en procesos de regeneración urbana, como arquitectos, arquitectos técnicos, ingenieros, urbanistas y autoridades locales, caracterizar el comportamiento energético de un municipio y representarlo a través de mapas urbanos energéticos, lo que constituye un instrumento muy útil para asistir durante los procesos de toma de decisión. Así pues, la identificación de los barrios más vulnerables desde el punto de vista de la eficiencia energética supone el punto de partida para iniciar procesos de rehabilitación, regeneración y renovación urbana, y priorizar las actuaciones en base a unos indicadores que evalúen dicho comportamiento de una manera cuantitativa y objetiva.

\subsection{REFERENCIAS}

Asociación gvSIG, 2014. gvSIG Desktop.

Aurea Consulting, 2015. ecoeficiente [WWW Document]. URL http://ecoeficiente.es/ (accedido 12.21.15).

Blangiardo, M., Camaletti, M., 2015. Spatial and Spatio-temporal Bayesian Models with R-INLA. John Wiley \& Sons, Chichester, West Susex.

Box, Z., 2012. EL urbanismo de la nación. Arquitectura, urbanismo y capitalidad en el primer franquismo (1). Rev. Estud. Políticos (nueva época) 151-181.

CEN, 2011. EN ISO 14683, Thermal bridges in building construction - Linear thermal transmittance Simplified methods and default values.

Comisión Europea, 2002. Directiva 2002/91/CE del parlamento Europeo y del Consejo de 16 de diciembre de 2002 relativa a la eficiencia energética de los edificios. Comunidad Europea.

CTE, 2013. Orden FOM/1635/2013, de 10 de septiembre, por la que se actualiza el Documento Básico DB-HE Ahorro de Energía del Código Técnico de la Edificación, aprobado por Real Decreto 314/2006, de 17 de marzo. España.

CTE, 2006. Real Decreto 314/2006, de 17 de marzo, por el que se aprueba el Código Técnico de la Edificación. España.

DesignBuilder UK, 2015. DesignBuilder software.

Esteve-Comes, A., 2012. Paseando por las calles de Castellón. Castelló de la Plana.

Excmo. Ayuntamiento de Castellón de la Plana, 2008. Plan General de Ordenación Urbana. Texto refundido 2008. Documento de trabajo. Castellón de la Plana.

Gobierno de España, 1968. EH-68 Decreto 2987/1968 por el que se aprueba la instrucción para el proyecto y ejecución de obras de hormigón en massa y armado. España.

Higueras, E., 2006. Urbanismo bioclimático ISBN: 978-84-252-2071-5. Gustavo Gili, Barcelona.

Howard, E., 1899. Town and Country Planning Association.

INE, 2015. Spanish Statistical Office [WWW Document]. URL http://www.ine.es/

INLA, 2016. R-INLA project [WWW Document]. URL http://www.r-inla.org/ (accedido 9.15.15).

Instituto Valenciano de la Edificación, 2011. Catálogo de Soluciones Constructivas de Rehabilitación, 1a Edición. ed. Valencia. 
Ministerio de la Presidencia, 2013. Real Decreto 235/2013, de 5 de abril, por el que se aprueba el procedimiento básico para la certificación de la eficiencia energética de los edificios. España.

Ministerio de la Presidencia, 2007. Real Decreto 1027/2007, de 20 de julio, por el que se aprueba el Reglamento de Instalaciones Térmicas en los Edificios RITE. España.

Ministerio de la Vivienda, 1957. Normativa técnica de la edificación del Ministerio de Vivienda. España.

Ministerio de Obras Públicas y Urbanismo, 1977. Orden de 28 de julio de 1977 por la que se desarrolla el Real Decreto 1650/1977, de 10 de junio, sobre Normativa de la Edificación. España.

Ministerio de Vivienda, 1972. Decreto 3565/1972, de 23 de diciembre, por el que se establecen las Normas Tecnológicas de la Edificación NTE. España.

NBE-CT-79, 1979. Real Decreto. Norma Básica de la Edificación sobre condiciones térmicas en los edificios. España.

Olucha Montins, F., 1996. Guia d'arquitectura Castelló. Castelló de la Plana.

Ortells Chabrera, V., 2004. Atles de Castelló de la Plana. Castelló de la Plana.

Ortells, V., 1999. La ciudad de Castellón de la Plana. Castelló de la Plana.

R Development Core Team, 2011. R: A Language and Environment for Statistical Computing.

Sánchez Adell, J., Olucha Montins, F., Sánchez Almela, E., 1993. Elenco de fechas para la historia urbana de Castellón de la Plana. Castelló de la Plana.

Temes Cordovez, R.R., 2009. La introducción del hormigón armado y su uso como sistema estructural de la vivienda en España . El caso concreto de la ciudad de Valencia, en: Actas del Sexto Congreso Nacional de Historia de la Construcción. Valencia 21 - 24 de octubre de 2009. Instituto Juan de Herrera - ISBN: 978-84-9728-317-5, Madrid, pp. 1419-1429.

U.S. Department of Energy, 2013. Energy Plus software.

Ward, P., 1999. A history of domestic space. Privacy and the Canadian home. UBC Press, Vancouver. 


\section{ANÁLISIS DE LA INFLUENCIA DE LAS COVARIABLES EN EL COMPORTAMIENTO ENERGÉTICO PASIVO}





\subsection{INTRODUCCIÓN}

Como se ha justificado con la investigación desarrollada, el urbanismo es un aspecto clave que no puede ser obviado cuando hablamos de la eficiencia energética del parque edificado. Cuando se está redactando el planeamiento urbanístico de una ciudad, debería existir la obligatoriedad de justificar aspectos como son el diseño de las calles o la altura máxima de las edificaciones, no sólo con criterios funcionales y estéticos, sino también con criterios de eficiencia energética (Ministerio de Vivienda del Gobierno de España, 2010).

En este sentido, las ordenanzas municipales son una potente herramienta para ordenar la ciudad acorde a las necesidades de su población, de manera que se justifique desde el interés general y la utilidad pública (Higueras, 2006). Por ello, la aplicación de criterios bioclimáticos a los espacios públicos para conseguir un buen comportamiento pasivo de los edificios que los circundan resulta un gran reto para reducir el consumo energético de nuestras ciudades. Sin embargo, sorprenden las escasas referencias al tema en las ordenanzas municipales, limitándose en la mayoría de los casos a principios generales que no descienden a detalles concretos.

Se pueden nombrar algunos casos, como por ejemplo la Guía de Buenas Prácticas de Edificación Sostenible de Vilanova i la Geltrú, que establece criterios concretos en relación a la orientación, los cerramientos opacos y huecos, cubiertas, particiones interiores y gestión de residuos. También es interesante la Ordenanza Fiscal sobre el Impuesto de Construcciones, Instalaciones y Obras del Ayuntamiento de Tarragona, que incentiva fiscalmente la implantación de medidas en relación a la orientación, la ventilación interior, la iluminación natural, la inercia térmica y el uso de energías renovables. Destaca también la Ordenanza Municipal de Urbanización y Edificación Bioclimática de Tres Cantos en Madrid (Casanova et al., 2003), desarrollada por iniciativa de la administración local para adoptar una regulación normativa integradora con el fin de reducir el consumo de recursos en la creación de nuevos desarrollos urbanos, desde la perspectiva de la sostenibilidad. Esta resulta especialmente interesante, por estructurar las estrategias de acondicionamiento tanto activo como pasivo siguiendo el esquema de articulado de una ordenanza convencional. Su nivel de concreción alcanza no solo la edificación y el urbanismo, sino también criterios en relación al agua, residuos y de construcción de edificaciones, y propone estrategias para actuar también en tejidos ya consolidados.

A pesar de los ejemplos existentes en el territorio nacional, es evidente todavía el bajo grado de acogida que tiene la incorporación de criterios de eficiencia energética en las ordenanzas municipales y planeamientos urbanos por parte de las administraciones locales.

A la hora de integrar estos criterios en la legislación, las estrategias no deben ceñirse únicamente a nuevos ámbitos de planeamiento urbano, sino que deben atender también a las necesidades de las áreas urbanas consolidadas. Así, se pueden plantear dos situaciones diferentes:

- Planteamiento de una ordenanza para un tejido urbano ya existente

- Planteamiento de una ordenanza para un tejido urbano de nueva creación (nuevos desarrollos urbanos)

En el primer caso, tejido existente, la ciudad ya cuenta con una determinada configuración urbana, por tanto, el primer paso será evaluar críticamente si la configuración está contribuyendo a la creación de una ciudad energéticamente eficiente o no, y si caben criterios para el acondicionamiento pasivo de las edificaciones. La metodología propuesta en este trabajo permite evaluar energéticamente el parque edificatorio existente y realizar así un diagnóstico energético que 
permita identificar barrios con mayor necesidad de intervención y renovación. Por ello, tiene una aplicación directa en este caso, como herramienta de diagnóstico. En este sentido, cuando los resultados del diagnóstico son desfavorables, las posibilidades de modificar un tejido urbano ya consolidado son escasas. Las actuaciones posibles probablemente estarán limitadas, especialmente si hablamos de acondicionamiento pasivo. Hay que tener en cuenta que las ciudades son sistemas rígidos en los que resulta muy complejo, o en algunos casos, simplemente imposible, modificar su configuración. Por tanto, nos encontramos ante un escenario que constituye un complejo reto.

En el segundo caso, la cuestión es menos compleja de resolver, pues podrán dictarse las directrices adecuadas para redactar un nuevo planeamiento urbano atendiendo a criterios de ahorro y eficiencia energética, previamente a ejecutar la urbanización del espacio público y definir las dimensiones, geometría y orientación de las parcelas urbanas.

El presente capítulo presenta un análisis en profundidad de la influencia de las covariables en el comportamiento energético pasivo del parque edificatorio residencial, a partir de los resultados de la evaluación energética obtenidos de implementar la metodología en el barrio Parque del Oeste de la ciudad de Castellón de la Plana, correspondiente a la Etapa II del Capítulo 5. A partir de las conclusiones extraídas de este análisis de resultados, se proporciona un conjunto de recomendaciones a tener en cuenta en el diseño de las covariables para, mejorar el comportamiento energético pasivo del parque edificatorio residencial. Siguiendo estas recomendaciones, se plantea una nueva configuración urbana para el barrio, lo que permite validar la reducción de la demanda energética global que supondría esta nueva configuración con respecto al entramado urbano existente actualmente. Finalmente, se establece un conjunto de estrategias, a escala urbana y de edificio, tanto para nuevas planificaciones urbanas como para tejidos urbanos ya consolidados.

La estructura que sigue el capítulo se muestra en la Figura 6.1.

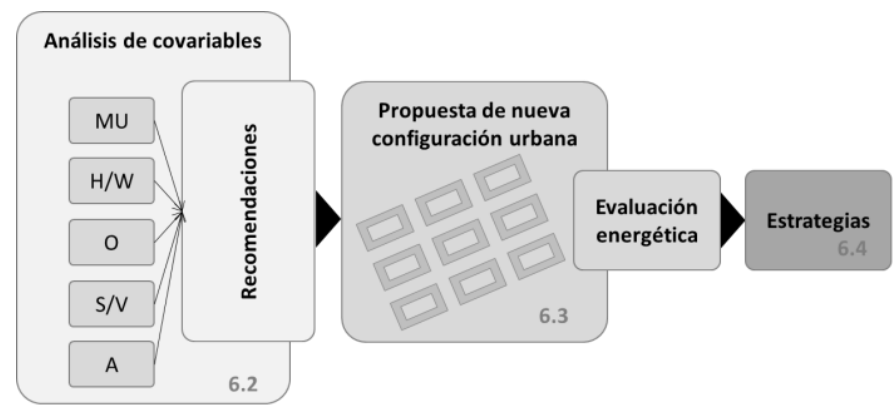

Figura 6.1 Estructura del Capítulo 6

\subsection{ANÁLISIS DE LA INFLUENCIA DE LAS COVARIABLES SOBRE LOS INDICADORES ENERGÉTICOS}

En el Capítulo 5 se ha desarrollado un modelo para determinar el comportamiento energético pasivo del parque residencial que conforma el barrio tomado como caso de estudio. Las cuatro ecuaciones que componen el modelo tienen en cuenta, además de los aspectos relacionados con el edificio, que vienen determinados por las covariables factor de forma del edificio $(S / V)$ y año de construcción $(A)$, 
los aspectos de la configuración urbana, que vienen determinados por las covariables orientación (O), tipo de manzana urbana (MU) y proporción de calle (H/W). El conjunto de las cinco covariables determinan la situación en la que se encuentra un edificio, no como elemento aislado, sino como parte integrante de una determinada área urbana. Las ecuaciones desarrolladas permiten obtener los valores de los indicadores energéticos demanda energética $\left(D E_{r}\right.$ y $\left.D E_{c}\right)$ y horas de disconfort $\left(H D_{v}\right.$ y $\left.\mathrm{HD}_{\mathrm{i}}\right)$, ambos en situación de invierno y de verano.

Como profundización del apartado 5.5.4 del Capítulo 5, en este apartado se analizan aisladamente cada una de las cinco covariables con el fin de poder extraer recomendaciones que puedan aplicarse a entornos urbanos residenciales para mejorar su comportamiento energético pasivo.

Por lo tanto, en el presente apartado se analiza la influencia que cada una de las covariables tiene sobre los cuatro indicadores energéticos $\left(D_{r}, D E_{c}, H D_{v}, H D_{i}\right)$ y se describen las pautas a tener en cuenta en el diseño de las mismas. Los efectos fijos, $\beta_{i}$, corresponden a los coeficientes que determinan el efecto de cada covariable en las cuatro ecuaciones obtenidas, para el caso de aplicación utilizado. Se recuerdan dichas ecuaciones.

$$
\begin{gathered}
D E_{r}=2,6480+(0,3336 \cdot A)+(-6,5815 \cdot S / V)+(0,0013 \cdot O)+(-0,4637 \cdot H / W)+(-0,4372 \cdot M U) \\
D E_{c}=46,8932+(-17,6330 \cdot A)+(118,4408 \cdot S / V)+(-0,0505 \cdot O)+(19,8277 \cdot H / W)+(14,5047 \cdot M U) \\
H D_{v}=6,9152+(-2,1639 \cdot A)+(13,6464 \cdot S / V)+(-0,0015 \cdot O)+(0,8659 \cdot H / W)+(0,9760 \cdot M U) \\
H D_{i}=44,5077+(-0,9679 \cdot A)+(12,5778 \cdot S / V)+(-0,004 \cdot O)+(0,8951 \cdot H / W)+(0,9202 \cdot M U)
\end{gathered}
$$

Como se concluyó en el Capítulo 5, todas las covariables son significativas y se ordenan, según su nivel de significancia, de mayor a menor, de la siguiente forma: $\mathrm{S} / \mathrm{V}, \mathrm{A}, \mathrm{H} / \mathrm{W}, \mathrm{MU}$ y $\mathrm{O}$. No obstante, el nivel de significancia de la covariable $\mathrm{H} / \mathrm{W}$ está muy próximo al de $\mathrm{A}$, por lo que son significativas prácticamente por igual. Así, se observa que las dos covariables relacionadas con el edificio (S/V y A) y la proporción de calle $(\mathrm{H} / \mathrm{W})$, relacionada con el urbanismo, son muy significativas $\mathrm{y}$, por tanto, las que tienen mayor influencia en el comportamiento energético del parque edificatorio residencial. Seguidamente, se sitúa MU y, finalmente, la $\mathrm{O}$, que se muestra como la menos significativa de las cinco.

En los siguientes apartados se analiza individualmente el efecto de cada una de estas covariables sobre las variables respuesta (o indicadores energéticos), siguiendo el orden establecido por nivel de significancia. Los gráficos presentados en la Figura 6.2, Figura 6.3, Figura 6.5, Figura 6.9 y Figura 6.11 representan los resultados globales de la simulación energética llevada a cabo en la Etapa II del caso de aplicación.

\subsubsection{FACTOR DE FORMA (S/V)}

El factor de forma resulta la covariable más significativa. Los coeficientes para los cuatro indicadores, $\mathrm{DE}_{\mathrm{r}}, \mathrm{DE}_{\mathrm{c}}, \mathrm{HD}_{\mathrm{v}}$ y $\mathrm{HD}_{\mathrm{i}}$, adoptan los valores más altos, siendo $-6,58,118,44,13,65$ y 12,58 , respectivamente.

La Figura 6.2 muestra los resultados obtenidos de la simulación energética en la Etapa II del caso de aplicación para de las cuatro variables respuesta en función de la covariable $S / \mathrm{V}$, para las dos tipologías de manzana, $\mathrm{MU}_{1}$ y $\mathrm{MU}_{2}$. 
MU1

$D_{\mathrm{r}}$

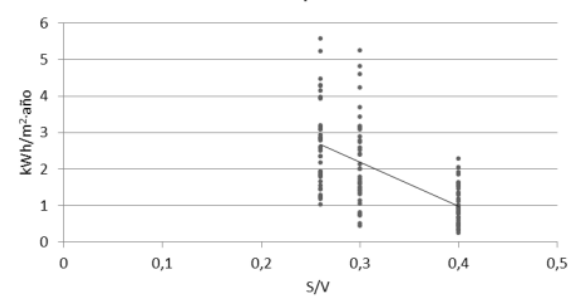

$\mathrm{DE}_{\mathrm{c}}$

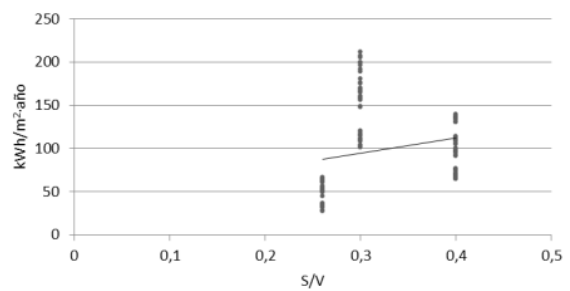

$H D_{v}$

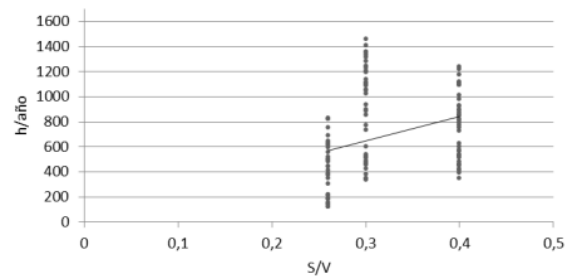

$H_{i}$

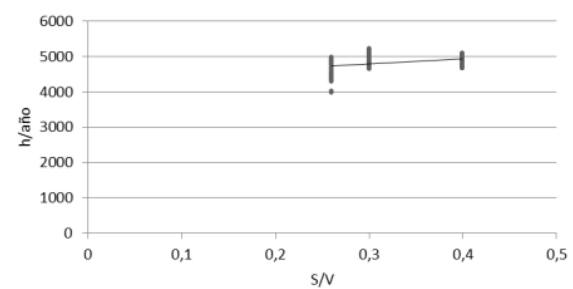

MU2

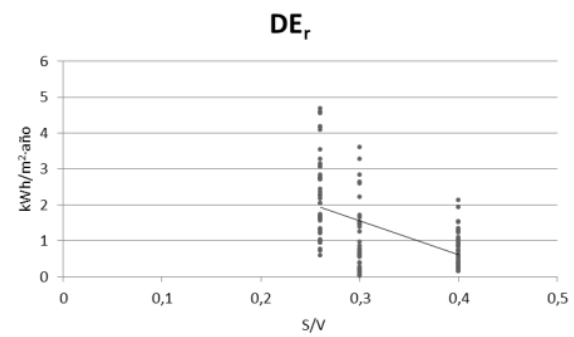

$\mathrm{DE}_{\mathrm{c}}$

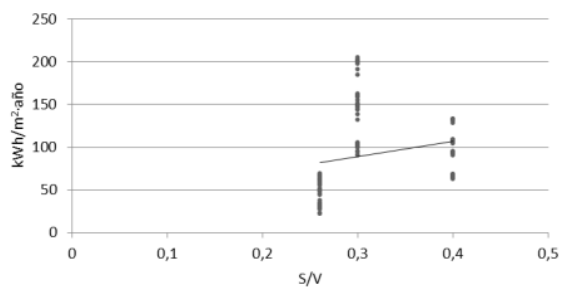

$H D_{v}$

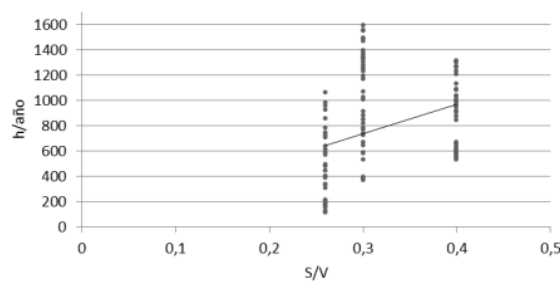

$H_{\text {i }}$

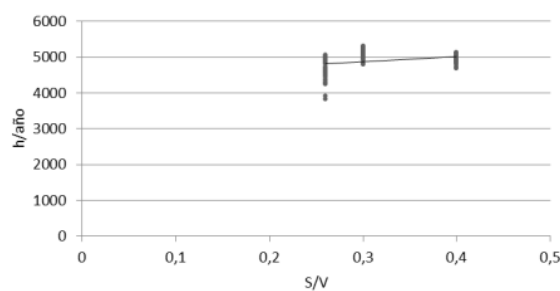

Figura 6.2 Resultados de las variables respuesta $\left(D E_{r}, D E_{c}, H D_{v}, H D_{i}\right)$ en los tres factores de forma $(S / V)$, para la $\mathrm{MU}_{1}$ y $\mathrm{MU}_{2}$

Se observa que la demanda de refrigeración desciende, acercándose al valor 0 , a medida que el factor de forma del edificio (S/V) aumenta, es decir, cuando el edificio es menos compacto. Sin embargo, con la demanda de calefacción ocurre precisamente al contrario. Esta disminuye cuando el edificio es más compacto (menor S/V). Por tanto, se puede afirmar que los edificios compactos presentan un mejor comportamiento energético en cuanto a calefacción, de manera que requieren 
menor cantidad de energía durante el invierno, pero no frente a la refrigeración, pues requieren mayor cantidad de energía en verano para alcanzar las condiciones óptimas de confort.

\section{Conclusión relativa a $\mathrm{S} / \mathrm{V}$ :}

Los edificios más compactos (menor factor de forma, S/V) implican menores demandas de calefacción y menos horas de disconfort, tanto en invierno como en verano. Sin embargo, presentan un peor comportamiento frente a la refrigeración.

\subsubsection{AÑO DE CONSTRUCCIÓN (A)}

La segunda covariable más significativa es el año de construcción. La demanda energética media de las simulaciones energéticas ha sido representada en los cinco periodos temporales establecidos (Figura 6.3).
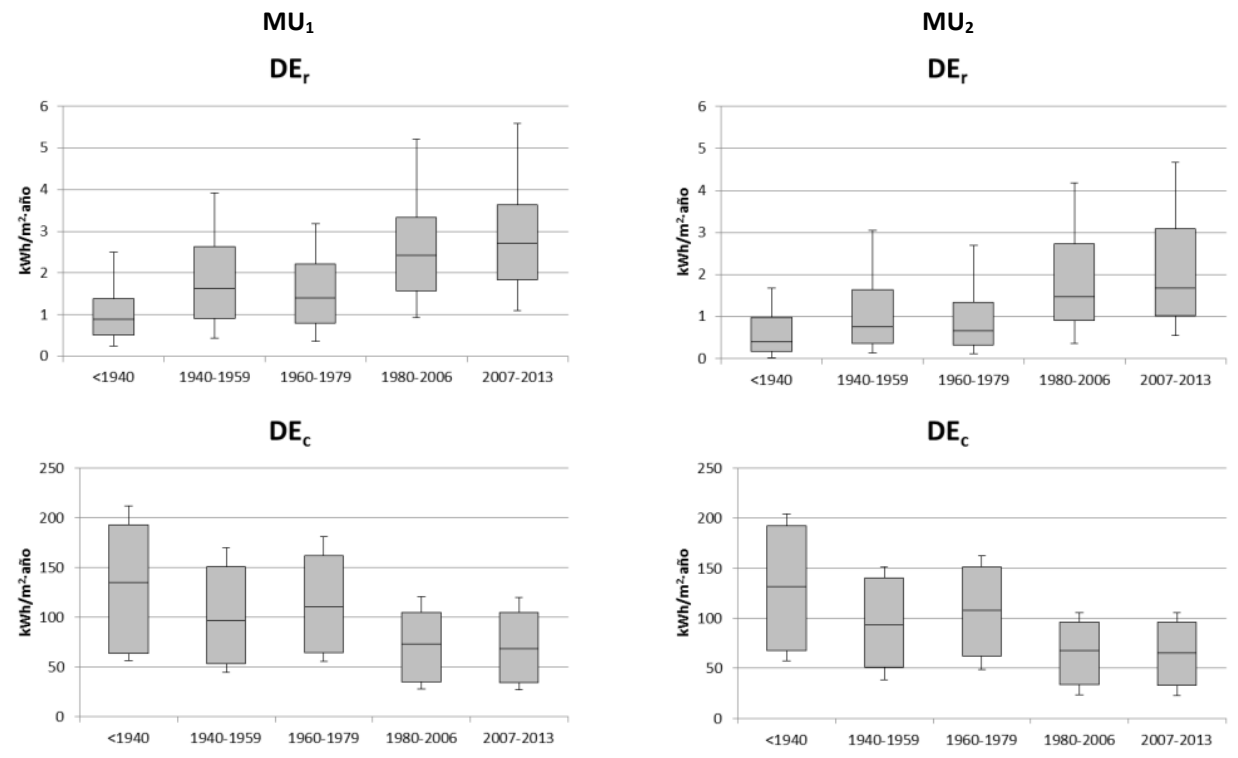

$\mathrm{DE}_{\mathrm{c}}$

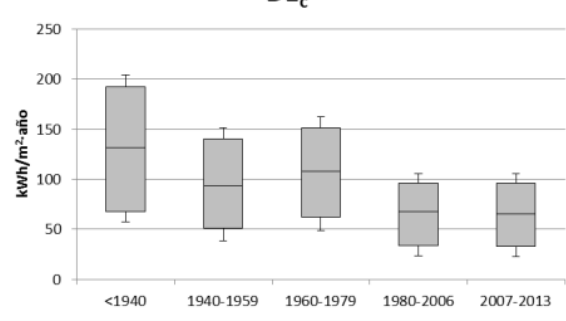

$H_{\mathrm{v}}$
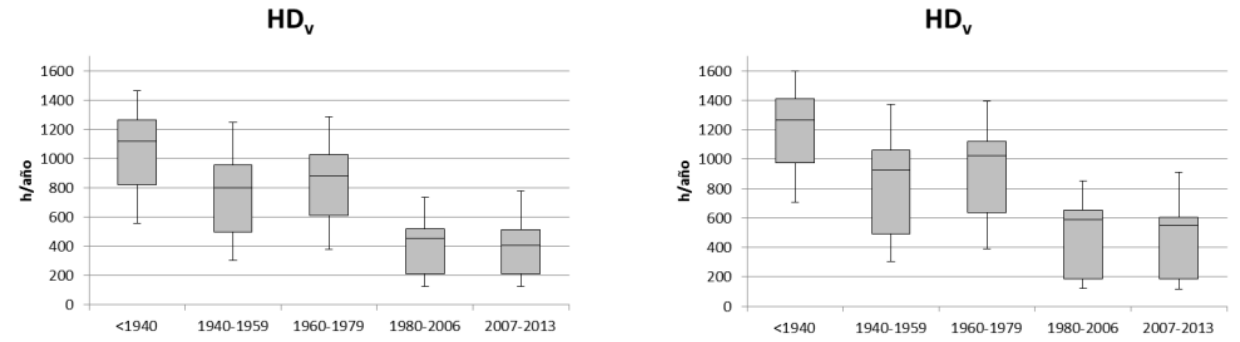

Figura 6.3 Resultados de las variables respuesta $\left(D E_{r}, D E_{c}, H D_{v}, H D_{i}\right)$ en los cinco periodos temporales, para la $\mathrm{MU}_{1}$ y $\mathrm{MU}_{2}$ 
$H D_{i}$

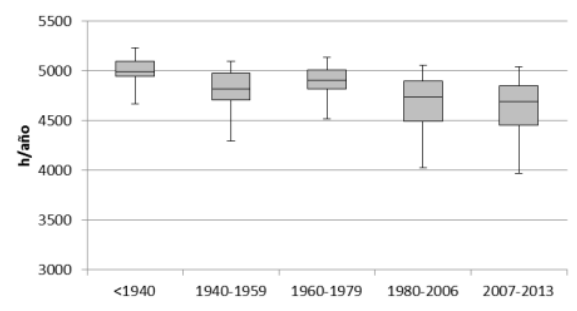

$H_{\mathrm{i}}$

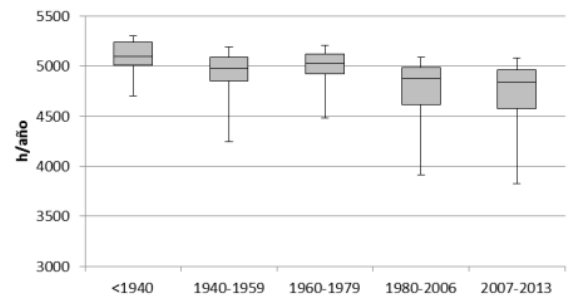

Figura 6.3 Resultados de las variables respuesta $\left(D E_{r}, D E_{c}, H D_{v}, H D_{i}\right)$ en los cinco periodos temporales, para la $\mathrm{MU}_{1}$ y $\mathrm{MU}_{2}$ (continuación)

Puesto que las transmitancias térmicas de los elementos constructivos del edificio son las que influyen en su demanda y horas de disconfort, se estudia a través de la Figura 6.4 la evolución de los valores que adoptan sus $\mathrm{U}$ a lo largo de los cinco periodos temporales.

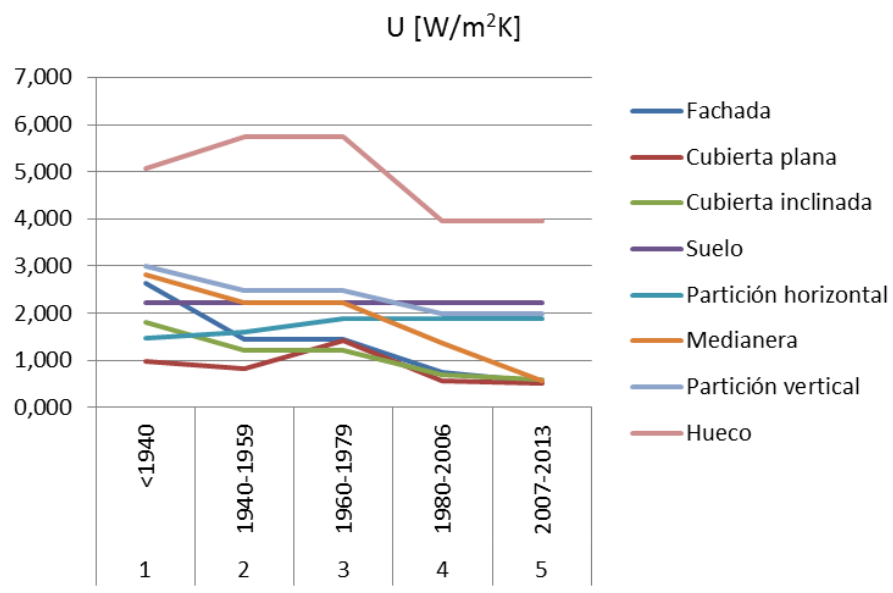

Figura 6.4 Evolución temporal de la transmitancia térmica $\left(\mathrm{kWh} / \mathrm{m}^{2}\right.$ año) de los elementos de envolvente térmica

Respecto a la demanda de calefacción, se puede observar que la tendencia descendente es la misma a lo largo del tiempo. A continuación, se realiza un análisis de los factores que influyen en dicha tendencia, a lo largo de los cinco periodos:

- La mayor demanda energética de calefacción, próxima a los $200 \mathrm{kWh} / \mathrm{m}^{2}$ año, recae en los edificios construidos anteriormente a 1940, debido a las deficientes condiciones de las soluciones constructivas empleadas para ejecutar su envolvente. En este primer periodo, la fachada de los edificios estaba constituida generalmente por muros de carga de una sola hoja que formaban parte de la estructura del edificio que, aunque eran de gran espesor, carecían de aislamiento térmico, lo que hacía alcanzar los valores muy altos de transmitancia térmica. Sin embargo, veremos más adelante que el grueso de los muros constituye una característica favorable para la demanda de refrigeración. La transmitancia 
térmica de la cubierta inclinada también alcanza su valor más alto en este periodo. No ocurre lo mismo con la cubierta plana, donde la existencia de una cámara de aire ventilada hace mejorar su comportamiento energético. Los huecos, formados generalmente por marcos de madera y vidrios monolíticos tienen una transmitancia elevada, sin embargo, mejor que en sucesivos periodos temporales, cuando los marcos de madera son sustituidos por marcos metálicos, grandes conductores del calor.

- En el segundo periodo temporal, de 1940 a 1959, la demanda de calefacción experimenta un notable descenso, situándose en torno a los $150 \mathrm{kWh} / \mathrm{m}^{2}$ año. La introducción de las estructuras de hormigón armado hace abandonar a las fachadas su función estructural, convirtiéndose estas en muros de doble hoja con cámara de aire intermedia, que mejora considerablemente la transmitancia térmica de este elemento constructivo (de 2,628 a $1,438 \mathrm{~W} / \mathrm{m}^{2} \mathrm{~K}$ ). La cubierta plana "a la catalana" ya utilizada en el periodo anterior, no experimenta cambios sustanciales en la transmitancia térmica, únicamente se reduce ligeramente por la inclusión de barrera de vapor. La cubierta inclinada, tradicionalmente de madera con viguetas y rastreles, pasa a convertirse en una cobertura inclinada sobre un soporte de tabiquillos conejeros, el cual descansa sobre un forjado horizontal de hormigón, generando una cámara de aire ventilada que funciona como amortiguador térmico entre el ambiente interior del edificio y el exterior, lo que reduce la transmitancia térmica de la solución de cubierta. El uso de marcos metálicos en los huecos se generaliza, sufriendo un empeoramiento de la transmitancia térmica de 5,078 a 5,754 W/m ${ }^{2} \mathrm{~K}$.

- En el tercer periodo, de 1960 a 1979, se observa un aumento de la demanda energética de calefacción, de en torno a $10 \mathrm{kWh} / \mathrm{m}^{2}$ año. Los movimientos migratorios de la población desde el entorno rural a las ciudades conllevaron procesos de construcción precipitados para dar respuesta a la alta demanda de viviendas, en los que se emplearon técnicas constructivas más deficientes. La cubierta "a la catalana" es sustituida por la cubierta "a la madrileña", la cual no incorpora cámara de aire entre sus capas, lo que hace aumentar considerablemente la transmitancia térmica. Hasta este periodo, no existe en España ninguna legislación relativa a ahorro de energía, por tanto, ninguna exigencia que obligue al uso de aislamiento térmico en la envolvente de los edificios.

- El cuarto periodo, de 1980 a 2006, viene delimitado por la entrada en vigor de la primera Norma Básica sobre Condiciones Térmicas en los Edificios (NBE-CT-79, 1979) y del Código Técnico de la Edificación (CTE, 2006). La primera de ellas, consecuencia de la crisis del petróleo de 1970 obligó a replantear los requerimientos térmicos en los edificios debido al elevado consumo energético que estos suponen y constituye la primera legislación en España que obliga a disponer un material de aislamiento térmico mínimo en la envolvente de los edificios, principalmente en fachadas y cubiertas. Los edificios construidos a partir del año 1980, por tanto, ya incorporan algún tipo de aislamiento y así se refleja en la considerable reducción de las transmitancias térmicas de los elementos de fachada y cubierta. La fachada incorpora un aislamiento de unos $2 \mathrm{~cm}$ de en su cámara de aire y las cubiertas, tanto la plana como la inclinada, de unos $4 \mathrm{~cm}$. Las medianeras empiezan a constituirse con cerramiento de doble hoja con cámara de aire intermedia que, aunque en la mayoría de veces se encuentra sin aislamiento, contribuye a reducir la transmitancia térmica. Los huecos generalmente están formados por marcos de aluminio con elevada conductividad y vidrios dobles con cámara de aire intermedia entre ambas láminas de vidrio que hace mejorar el comportamiento del conjunto global del hueco (de 5,754 en el periodo anterior a $3,966 \mathrm{~W} / \mathrm{m}^{2} \mathrm{~K}$ ). Todo ello tiene un efecto muy considerable en la demanda energética de calefacción de los edificios, que experimenta una reducción en torno a los $60 \mathrm{kWh} / \mathrm{m}^{2}$ año. 
- El quinto y último periodo temporal, incluye a los edificios construidos a partir del año 2007, año en que entró en vigor el CTE (2006), hasta 2013, cuando entra en vigor la actualización del CTE (2013). Durante el periodo de vigencia del CTE (2006), su DB HE tiene como principal objetivo limitar la demanda energética de los edificios, estableciendo unos valores máximos y límite de transmitancia térmica para los diferentes elementos de la envolvente térmica. El endurecimiento de los criterios de la NBE-CTE-79 anterior supone un importante avance. No obstante, este endurecimiento no es demasiado relevante y así se refleja en la sutil reducción de la demanda energética de calefacción de los edificios construidos en este periodo. El ligero aumento del espesor de los aislamientos térmicos (de 2 a $4 \mathrm{~cm}$ en fachadas, y de 4 a $5 \mathrm{~cm}$ en cubiertas) y de la obligatoriedad de incluirlo en medianeras (en muchas de las zonas climáticas) no es suficiente para conseguir una reducción significativa de la demanda.

Con respecto a la demanda energética de refrigeración, la tendencia es precisamente inversa a la anterior: en periodos de construcción más actuales, la demanda de refrigeración aumenta, alejándose del valor 0 . Ello se debe a la inercia térmica que aporta la tipología de cerramiento de fachada presente en los edificios más antiguos, constituida por muros de carga de fábrica de ladrillo de una sola hoja, con un elevado espesor y una alta densidad. Estas dos características hacen que se aproveche excepcionalmente bien la inercia térmica del cerramiento, manteniendo la temperatura operativa interior del edificio alrededor de la temperatura de consigna de verano. Las dos propiedades que definen la inercia térmica de un elemento, el desfase de la onda térmica y la amortiguación total, expresan el retardo de las altas temperaturas exteriores en transferirse hacia el interior del edificio. El cálculo de ambas propiedades del cerramiento de fachada indican una elevada amortiguación térmica, especialmente durante el verano, que consigue evitar situaciones de disconfort y hace prácticamente nula la demanda de refrigeración. Además, la influencia que los obstáculos presentes en el entorno (edificios colindantes) tienen sobre la demanda energética de refrigeración es muy relevante, lo que contribuye también a reducir la demanda de refrigeración. En el Anexo III Análisis detallado de la demanda de refrigeración ${ }^{1}$ se profundiza en la influencia de la inercia térmica y de los obstáculos solares, lo que ha permitido llegar a esta conclusión.

\section{Conclusión relativa a A:}

Existe una tendencia general a disminuir la demanda de calefacción y las horas de disconfort en invierno en los edificios de construcción más reciente. Tan solo se observa un ligero cambio de tendencia en los edificios construidos en el periodo 3 (1960-1979), debido a la mengua en la calidad constructiva de los cerramientos de dicha época.

Existe una tendencia general en aumentar la demanda de refrigeración en los edificios más actuales, que responde a la pérdida de inercia térmica de los cerramientos de la envolvente. Sin embargo, las horas de disconfort en verano son menores en los edificios de más reciente construcción.

\subsubsection{Ratio altura-ANChura de CAlle (H/W)}

La Figura 6.5 presenta los resultados de los cuatro indicadores en función de la ratio $\mathrm{H} / \mathrm{W}$, que define la proporción de la calle y es responsable de la accesibilidad solar en las fachadas de los edificios. Los resultados se muestran por separado para las dos tipologías de manzana, $M_{1}$ y $M_{2}$, lo que permite comparar y analizar también la influencia de estas en los indicadores energéticos.

\footnotetext{
${ }^{1}$ En el Anexo III Análisis detallado de la demanda de refrigeración se profundiza en el estudio de las causas que influyen en la demanda energética de refrigeración, a partir de las simulaciones dinámicas con la herramienta DesignBuilder. A partir de este análisis, se concluye que la inercia térmica y el soleamiento influyen notablemente en dicha demanda.
} 
MU1

$\mathrm{DE}_{\mathrm{r}}$

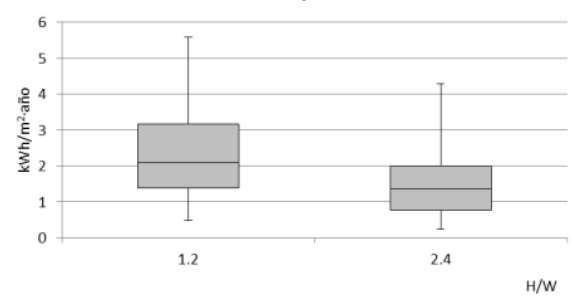

$\mathrm{DE}_{\mathrm{c}}$

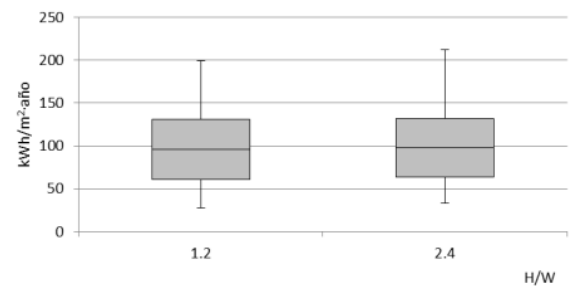

$H D_{v}$

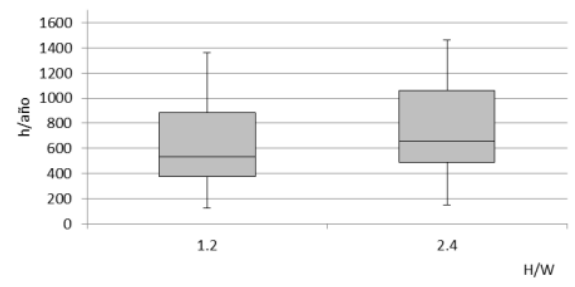

$H_{\mathrm{i}}$

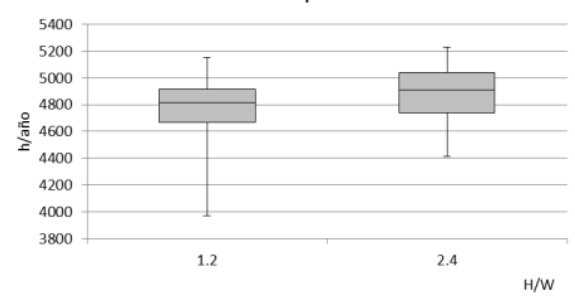

MU2

$\mathrm{DE}_{\mathrm{r}}$

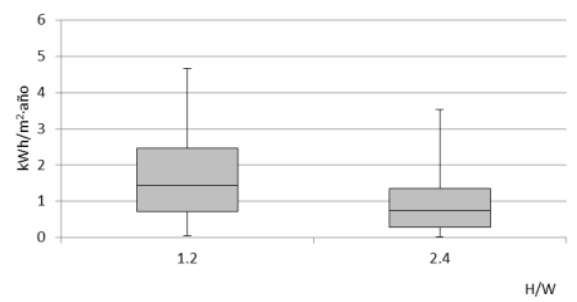

$\mathrm{DE}_{\mathrm{c}}$

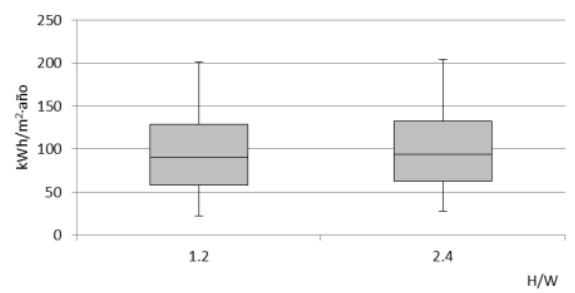

$H D_{v}$

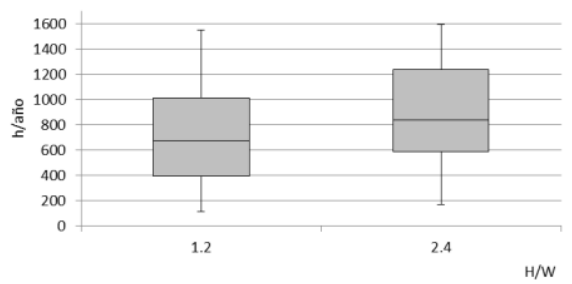

$H D_{i}$

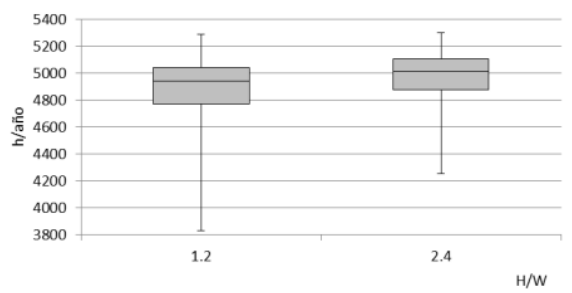

Figura 6.5 Resultados de las variables respuesta $\left(D_{r}, D E_{c}, H D_{v}, H D_{i}\right)$ en las dos ratios $H / W$, para la $M_{1}$ y $M_{2}$

En cuanto a la demanda de refrigeración, se observa que esta es menor en edificios ubicados en calles con una ratio de 2,4 . La causa es que ratios altas de $\mathrm{H} / \mathrm{W}$ implican calles estrechas con edificios altos, las cuales limitan la accesibilidad solar. Este fenómeno puede ser perjudicial en invierno, cuando interesa que la mayor parte posible de la radiación solar llegue a las fachadas de los edificios y penetre por sus huecos para calentar el interior del edificio de manera natural, y así se aprecia con la $\mathrm{DE}_{c}$, que es mayor en la ratio $\mathrm{H} / \mathrm{W}_{2,4}$. Sin embargo, ratios altas de $\mathrm{H} / \mathrm{W}$ son positivas en condiciones de verano, cuando las ganancias solares son poco deseadas y precisamente interesa 
el fenómeno contrario al anterior, es decir, evitar que la radiación solar penetre a través de los huecos, incrementando la demanda de refrigeración. La proximidad entre edificios genera sombras importantes que propician esta situación.

Para estudiar con mayor detalle el efecto de la ratio $\mathrm{H} / \mathrm{W}$, se toma como ejemplo la hipótesis H82 $\left(\mathrm{MU}_{1}\right.$, ancho de calle $10 \mathrm{~m}$, orientación $\mathrm{S}$, tipología edificatoria $\mathrm{PF}(\leq 4)$, periodo de construcción 1$)$, correspondiendo a una ratio $\mathrm{H} / \mathrm{W}_{2,4}$, y se compara con la $\mathrm{H} 102$, siendo esta la homóloga de la $\mathrm{H} 82$ pero considerando un ancho de calle de $20 \mathrm{~m}\left(\mathrm{H} / \mathrm{W}_{1,2}\right)$. La Figura 6.6 muestra los datos de radiación solar en cada uno de los meses del año y los resultados de ganancias solares por ventanas exteriores debidos al acceso de la radiación solar a través de los huecos del edificio, en la H82 y la H102.
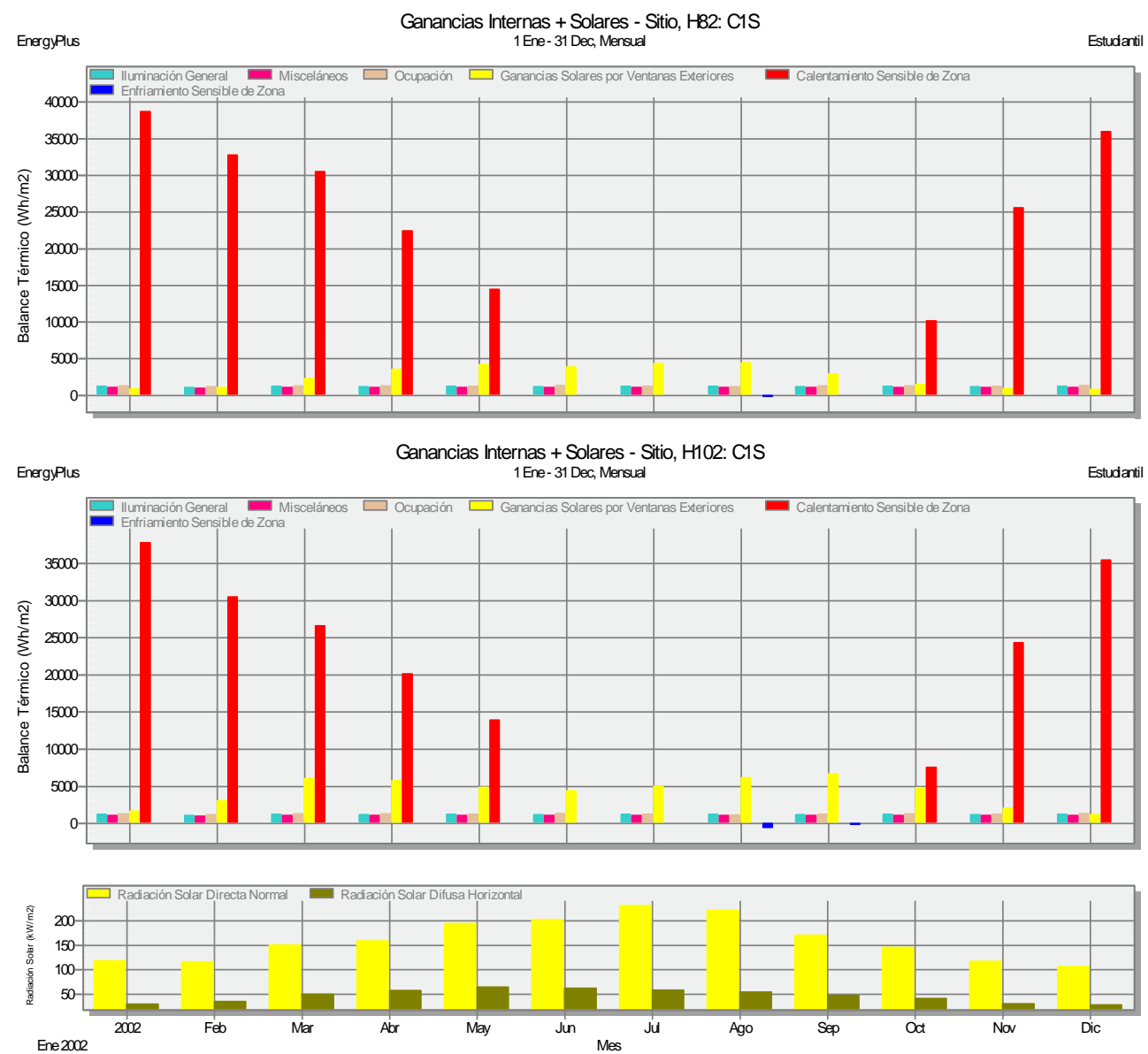

Figura 6.6 Datos sobre radiación solar propia del sitio y resultados de ganancias internas y solares en las H82 y $\mathrm{H} 102$

Se aprecia que, para la misma intensidad de radiación solar, en la $\mathrm{H} 102\left(\mathrm{H} / \mathrm{W}_{1,2}\right)$ las ganancias solares son mayores tanto en invierno como en verano. Incluso, se observa un incremento en los meses de primavera y otoño y un descenso en los meses de verano, lo que resulta beneficioso. En verano, mayores ganancias hacen aumentar la demanda de refrigeración, pero en invierno, dado 
que interesa un aprovechamiento de la radiación mayor, el efecto es beneficioso para reducir la demanda de calefacción.

En el caso de $\mathrm{H} / \mathrm{W}$, las demandas energéticas tienen su efecto en las horas de disconfort, pues se observa que cuando la demanda de refrigeración o calefacción aumenta, también lo hace el número de horas de disconfort. Entre ambos indicadores $\left(H D_{v}\right.$ y $\left.H D_{i}\right)$, siempre es mayor el número de horas de disconfort durante en invierno $\left(H D_{\mathrm{i}}\right)$, pues además de abarcar un periodo temporal más amplio, la demanda de calefacción es considerablemente mucho mayor.

Por tanto, se puede concluir que ratios bajas de $\mathrm{H} / \mathrm{W}$ hacen mejorar el comportamiento energético del parque edificatorio. Analizada la situación existente en el barrio, surge la inquietud de determinar cuál es la ratio $\mathrm{H} / \mathrm{W}$ óptima que garantice unas adecuadas condiciones de soleamiento, especialmente en el periodo invernal, cuando la captación de radiación solar debe ser aprovechada para reducir la demanda de calefacción.

Así pues, la distancia entre los edificios necesaria para garantizar el soleamiento en un día concreto del año, puede establecerse mediante el método gráfico (por medio de cartas solares) y analítico, en función del ancho de calle, el acimut solar y el acimut del plano de la edificación. Esta relación se expresa en la Figura 6.7:

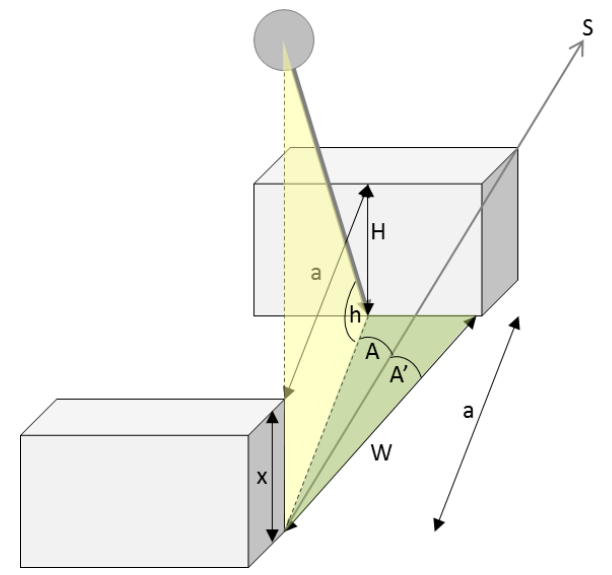

Figura 6.7 Parámetros para el cálculo de H/W (Granados, 2006)

donde,

H altura de la edificación que recibe sol medida desde su coronación

W anchura de la calle

A acimut del sol

$A^{\prime} \quad$ acimut de la normal al eje de la edificación

h elevación solar

a segmento determinado entre las dos edificaciones por el plano vertical de acimut $\mathrm{A}$

Geométricamente, puede establecerse la siguiente relación: 


$$
\begin{gathered}
W=a \cdot \cos \left(A+A^{\prime}\right) \\
H=a \cdot \operatorname{tg} h=\frac{W}{\cos \left(A+A^{\prime}\right)} \cdot \operatorname{tg} h=d \cdot \sec \left(A+A^{\prime}\right) \cdot \operatorname{tg} h
\end{gathered}
$$

de donde se obtiene la siguiente relación $\mathrm{H} / \mathrm{W}$ para garantizar el soleamiento en un momento del año concreto:

$$
\frac{H}{W}=\sec \left(A+A^{\prime}\right) \cdot \operatorname{tg} h
$$

Se considera que, a efectos de eficiencia energética, un elemento tiene accesibilidad solar si recibe al menos dos horas de radiación solar directa durante el solsticio de invierno, que se produce el 21 de diciembre (Higueras, 2006). Este momento es el más desfavorable del año, por lo que, cumpliendo este requisito en el solsticio invernal, se asegura que el resto del año se reciban más horas de sol.

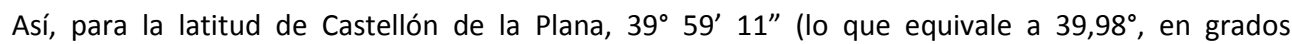
decimales), en el solsticio de invierno la elevación solar es de $26,61^{\circ}$ a las $12: 00$ hora solar, según se observa en la carta solar de la Figura 6.8.
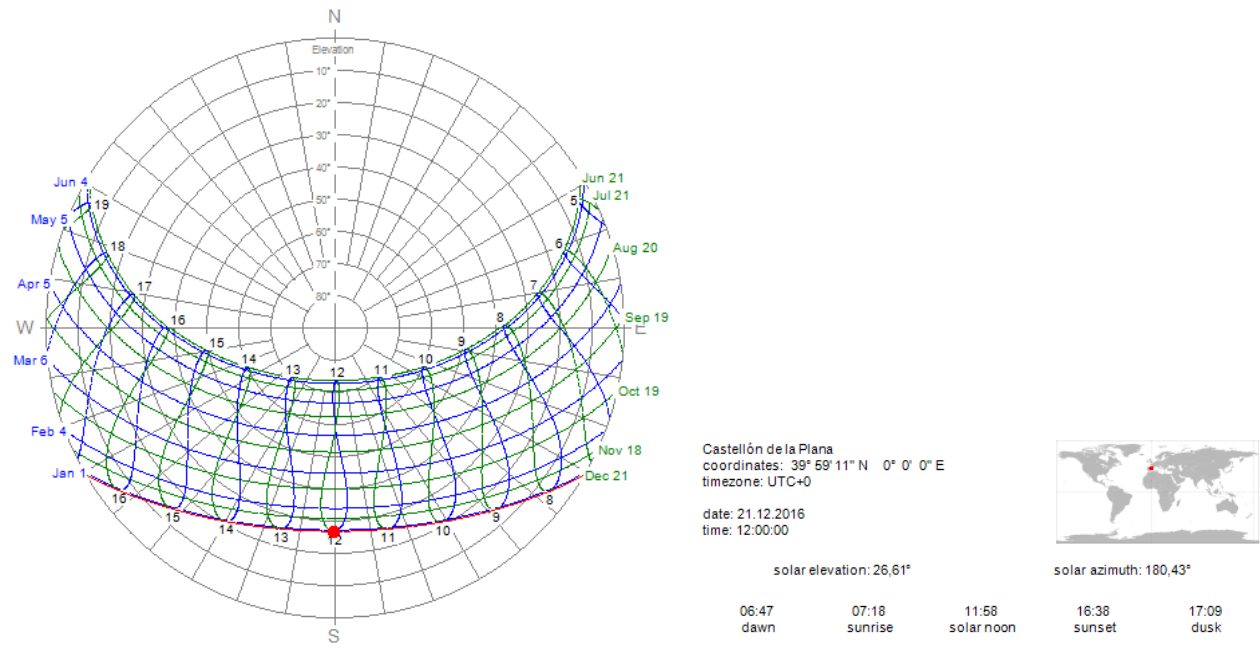

Figura 6.8 Carta solar estereográfica para la latitud 39,98o (Matusiak, 2016)

Para un edificio orientado perfectamente a $\mathrm{S}$ (acimut de la edificación $0^{\circ}$ ), la relación $\mathrm{H} / \mathrm{W}$ a las 12:00 hora solar (acimut solar $0^{\circ}$ ) equivale a 0,50 , lo que implica que el ancho de la calle (W) debe ser el doble de la altura de la edificación (H). Ello está en la línea con lo propuesto por la herramienta CGYM (Ministerio de Medio Ambiente y Medio Rural y Marino, 2010), en su indicador CGYM.7 Proporción de calle, por lo que pueden adoptarse los criterios establecidos en dicho indicador ( $\mathrm{H} / \mathrm{W}<0,5$ : excelente; $0,5<\mathrm{H} / \mathrm{W}<1$ : buena; $1<\mathrm{H} / \mathrm{W}<2$ : suficiente; $2<\mathrm{H} / \mathrm{W}<3,5$ : insuficiente; $H / W>3,5$ : muy insuficiente).

De aplicar la expresión anterior, se observa que, cuando la orientación de las edificaciones no es exactamente a $\mathrm{S}$, sino que la normal de su fachada forma un pequeño acimut, la $\mathrm{W}$ puede reducirse. Este hecho conlleva la ventaja de poder diseñar un ancho de calle (W) más reducido, sin minorar las 
condiciones de soleamiento. De esta manera, se lograrían tejidos urbanos más compactos, admitiendo una mayor edificabilidad.

\section{Conclusión relativa a $\mathrm{H} / \mathrm{W}$ :}

Ratios H/W altas (calles estrechas en relación a la altura de los edificios enfrentados) hacen aumentar la demanda de calefacción, mientras que contribuyen a disminuir la demanda de refrigeración.

La ratio $\mathrm{H} / \mathrm{W}$ óptima adopta un valor máximo de 0,50. Este valor podría aumentarse ligeramente si la retícula se posiciona con un pequeño ángulo hacia el SE o SO, favoreciendo la configuración de tejidos urbanos más compactos.

\subsubsection{Manzana urbana (MU)}

La Figura 6.9 analiza de forma conjunta los resultados de la covariable MU.

MU

$\mathrm{DE}_{\mathrm{r}}$

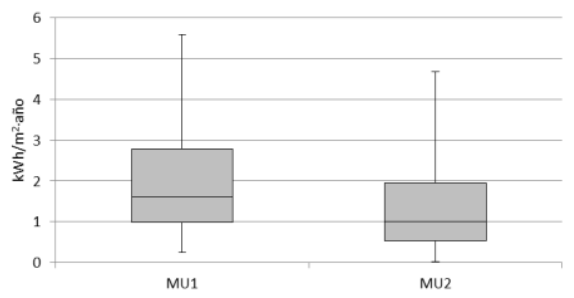

$H D_{v}$

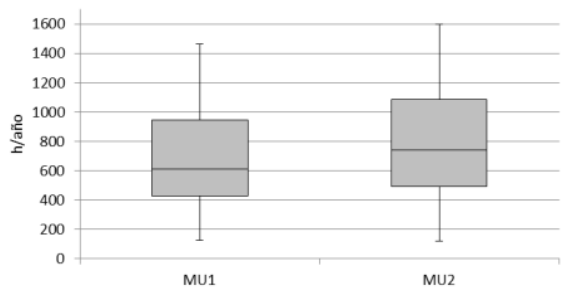

$\mathrm{DE}_{\mathrm{c}}$

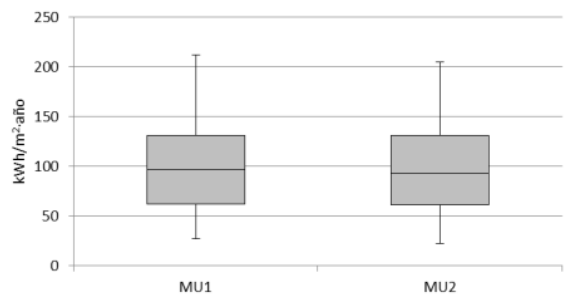

$H D_{i}$

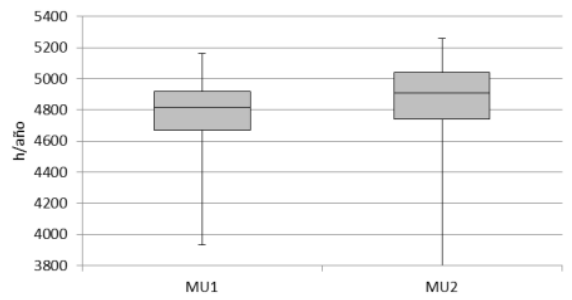

Figura 6.9 Resultados de las variables respuesta $\left(D E_{r}, D_{c}, H D_{v}, H D_{i}\right)$ en $M_{1}$ y $M_{2}$

Si observamos los resultados globales de los indicadores energéticos, se observa que:

- La demanda de refrigeración $\left(D E_{r}\right)$ es menor en $\mathrm{MU}_{2}$

- La demanda de calefacción $\left(D_{c}\right)$ es prácticamente la misma en $\mathrm{MU}_{2}$ y $\mathrm{MU}_{1}$

- Las horas de disconfort en verano $\left(\mathrm{HD}_{\mathrm{v}}\right)$ son mayores en $\mathrm{MU}_{2}$

- Las horas de disconfort en invierno $\left(\mathrm{HD}_{\mathrm{i}}\right)$ son mayores en $\mathrm{MU}_{2}$

En cuanto al indicador relativo a las horas de disconfort, se aprecia un ligero aumento en la tipología de manzana $\mathrm{MU}_{2}$, tanto para el periodo estival como para el invernal. Esto indica que las manzanas 
cerradas sin grandes patios interiores reducen, por un lado, la posibilidad de ganancias solares durante el invierno, las cuales se traducen en ganancias térmicas naturales que dejan de llegar al interior del edificio y que harían disminuir la demanda de calefacción. Y, por otro lado, reducen también la posibilidad de ventilación natural en los edificios, ocasionando un aumento en la demanda de refrigeración. El hecho de existir un patio de manzana amplio en $\mathrm{MU}_{1}$, genera una doble fachada en los edificios: la que recae al viario público exterior y la que recae al interior del patio de manzana. La amplitud del patio a menudo genera una distancia entre las fachadas internas de los edificios incluso mayor que el ancho de calle que separa sus fachadas exteriores, lo que aumenta la accesibilidad solar y posibilita la ventilación natural cruzada entre fachadas opuestas, propiciando así un mejor comportamiento energético.

Para el diseño de los edificios son recomendables geometrías de edificaciones alargadas en el eje $\mathrm{E}-\mathrm{O}$, con la mayor superficie de fachada a $\mathrm{S}$, preferiblemente, y a $\mathrm{N}$; lo que puede extenderse a la geometría de la manzana urbana (Olgyay, 1963). Según el mencionado autor, la relación recomendada entre la profundidad de la edificación y la longitud para obtener una máxima superficie orientada a $S$ es como mínimo de 1,5, con la fachada menor (o con menor número de huecos) orientada a $\mathrm{O}$, para zonas climáticas de la región templada, como es el caso. Ello puede extenderse a la forma de la manzana urbana, por lo que optará por la proporción que se observa en la Figura 6.10.

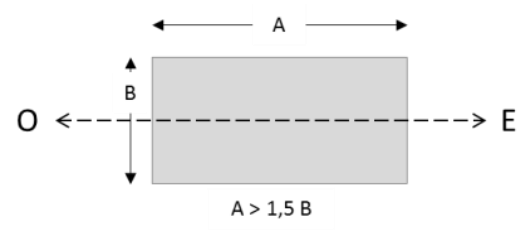

Figura 6.10 Proporción de la manzana

\section{Conclusión relativa a MU:}

La tipología de manzana $\mathrm{MU}_{1}$, con grandes patios de manzana interiores, resulta más favorable en el comportamiento energético de los edificios, pues contribuye a reducir la demanda energética de calefacción (significativamente más elevada que la de refrigeración). Las horas de disconfort son menores también en dicha tipología de manzana.

La proporción adecuada de manzana cumple la relación A > 1,5B, según la Figura 6.10.

\subsubsection{ORIENTACIÓN (O)}

Esta covariable se muestra como la menos significativa de las cinco que integran el modelo. Sin embargo, como se concluyó en el Capítulo 5, la consideración de la misma en las ecuaciones de predicción contribuye a mejorar el modelo. El análisis más pormenorizado sobre la orientación llevado a cabo en el presente apartado tiene por objeto justificar la baja significancia de la orientación en el modelo, la cual a priori, parecería susceptible de influir notablemente en el comportamiento energético del parque edificado.

La Figura 6.11 compara los resultados de las cuatro orientaciones solares de la fachada principal de los edificios, diferenciando entre la $\mathrm{MU}_{1}$ y la $\mathrm{MU}_{2}$. 
MU1

$\mathrm{DE}_{\mathrm{r}}$

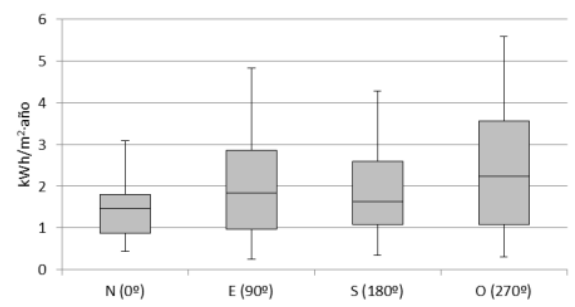

$\mathrm{DE}_{\mathrm{c}}$
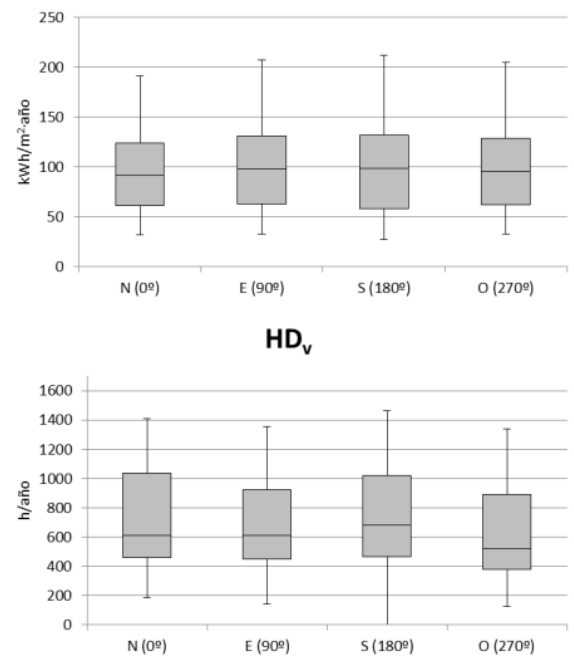

$H D_{i}$

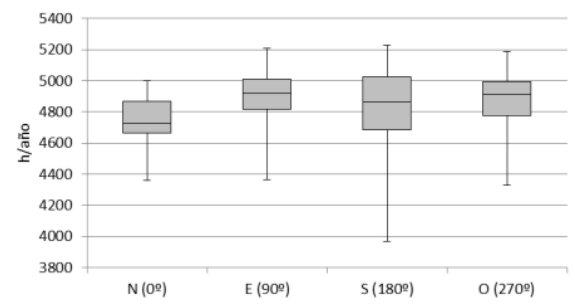

MU2

$\mathrm{DE}_{\mathrm{r}}$

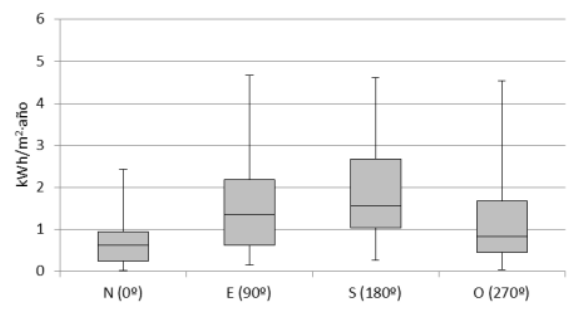

$\mathrm{DE}_{\mathrm{c}}$

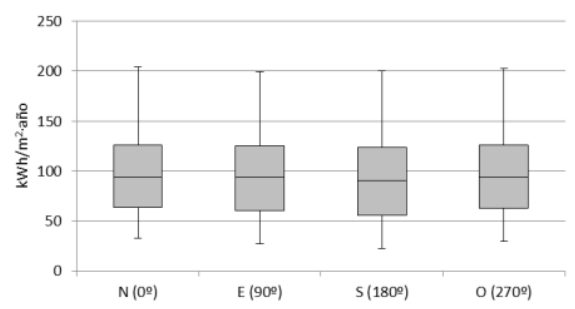

$H D_{v}$

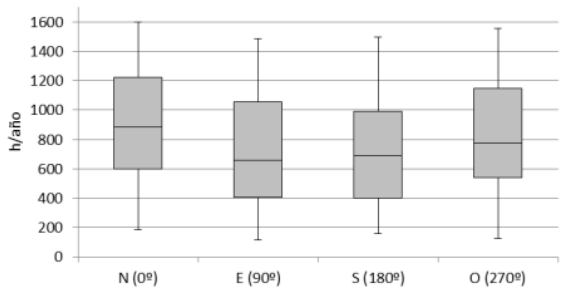

$H D_{i}$

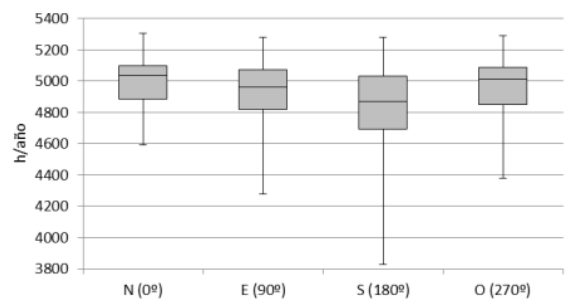

Figura 6.11 Resultados de las variables respuesta $\left(D E_{r}, D E_{c}, H D_{v}, H D_{i}\right)$ en las cuatro orientaciones, para la $M U_{1}$ y $\mathrm{MU}_{2}$

En cuanto a los resultados de demandas energéticas, es complejo extraer conclusiones globales aplicables a los dos tipos de manzana urbana. La $\mathrm{MU}_{1}$ proporciona al edificio dos orientaciones opuestas. Cuando la fachada principal está orientada a $\mathrm{S}$, la fachada que recae al patio de manzana está orientada a $\mathrm{N}$, y cuando la fachada principal está orientada a $\mathrm{E}$, la fachada al patio lo está a $\mathrm{O}$. Lo mismo ocurre con las otras dos orientaciones, $\mathrm{N}$ y $\mathrm{O}$. Por lo que en el caso de $\mathrm{MU}_{1}$, como se observa en los gráficos de $D E_{r}$ y $D E_{c}$, existe muy poca variación entre los datos, especialmente entre 
las parejas de orientaciones $\mathrm{S}-\mathrm{N}$ y $\mathrm{E}-\mathrm{O}$. Se observa que en $\mathrm{MU}_{1}$, hay incluso menor $\mathrm{DE}_{\mathrm{c}}$ en $\mathrm{N}$, porque la amplitud del patio puede ser incluso mayor que la de la calle, ofreciendo a la respectiva fachada $S$ mayor posibilidad de soleamiento.

En el caso de $\mathrm{MU}_{2}$, el edificio únicamente consta de una fachada que recae a la calle y que tiene una determinada orientación. Así pues, la variabilidad de $\mathrm{DE}_{\mathrm{r}}$ entre las cuatro orientaciones es notable, siendo de menor a mayor: fachada $\mathrm{N}, \mathrm{E}$ y $\mathrm{O}$ prácticamente por igual, y $\mathrm{S}$. En la $\mathrm{DE}_{\mathrm{c}}$ los valores están muy equiparados, lo que hace pensar que, durante los meses de invierno, en los que la elevación solar es pequeña, la ratio $\mathrm{H} / \mathrm{W}$ de calle determina en mayor medida las posibilidades de accesibilidad solar, por ello esta es más significativa.

En relación a las horas de disconfort, se observa una tendencia similar entre la $D E_{r}$ y la $H D_{v}$ y la $D E_{c}$ y la $\mathrm{HD}_{\mathrm{i}}$, tanto en $\mathrm{MU}_{1}$ como en $\mathrm{MU}_{2}$. Sin embargo, en $\mathrm{MU}_{1}$ el disconfort térmico es inferior. Por ello, resulta más favorable la tipología de manzana $\mathrm{MU}_{1}$, pues ofrece en general un mejor comportamiento pasivo.

Del análisis de estos resultados se extrae que la configuración urbana influye enormemente en los resultados de las variables respuesta, pues modifica la influencia natural que la orientación suele tener en edificios aislados. Por ejemplo, una fachada orientada a $S$, susceptible de recibir el mayor porcentaje de soleamiento de un día de invierno, puede estar obstaculizada por la presencia de un edificio alto y próximo y no recibir apenas sol.

Para ilustrar la gran influencia de la configuración urbana en el comportamiento energético pasivo del parque edificado, y en particular, su efecto sobre la orientación, se han realizado un conjunto de nuevas simulaciones que dan prueba de esta conclusión. Se toma el edificio de tipología $\mathrm{PF}_{\mathrm{M}(>4)}$, el cual tiene cuatro viviendas por planta y se analiza la misma vivienda (tipo B de planta 6, ver Figura 6.12), con sólo una fachada, en las cuatro orientaciones. Las simulaciones se realizan suponiendo el edificio aislado, libre de obstáculos en las inmediaciones que puedan ocasionar sombras. Esto permite identificar la demanda energética asociada a única vivienda orientada en las cuatro orientaciones, para su comparación, tal y como se muestra en la Tabla 6.1.

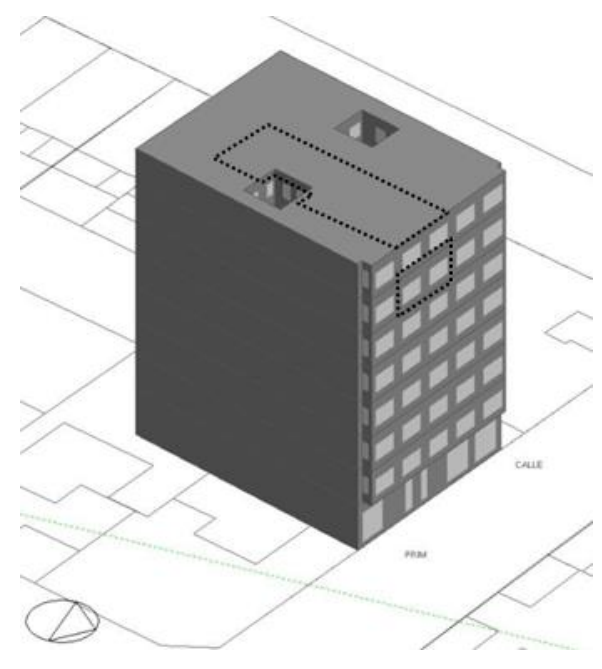

Figura 6.12 Vivienda tipo $B$ de la planta 6 en el edificio $P F_{M(>4)}$ 
Tabla 6.1 Comparativa de DE y HD de una misma vivienda orientada a N, E, S y O

\begin{tabular}{lllll} 
& $\mathrm{DE}_{\mathrm{r}}\left[\mathrm{kWh} / \mathrm{m}^{2}\right.$ año] & $\mathrm{DE}_{\mathrm{c}}\left[\mathrm{kWh} / \mathrm{m}^{2}\right.$ año] & $\mathrm{HD}_{\mathrm{v}}[\mathrm{h} / \mathrm{año}]$ & $\mathrm{HD}_{\mathrm{i}}[\mathrm{h} / \mathrm{año}]$ \\
\hline Vivienda a N & 6,60 & 20,54 & 85,83 & $4.080,00$ \\
Vivienda a E & 14,26 & 11,98 & 80,33 & $2.447,51$ \\
Vivienda a S & 10,36 & 7,77 & 82,00 & $3.038,66$ \\
Vivienda a O & 13,72 & 18,70 & 82,16 & $3.613,16$ \\
\hline
\end{tabular}

Los resultados expuestos en la Tabla 6.1 indican que, cuando no hay obstáculos alrededor, la demanda energética de refrigeración evoluciona, de menor a mayor, de la siguiente forma: N, S, E y O. Y la demanda de calefacción: S, E, O y N. Los resultados atienden a la lógica de los fundamentos radiación solar y demuestran pues, que la configuración urbana puede influir enormemente en dicha demanda.

Además, cabe observar que la demanda de refrigeración se aprecia mucho mayor cuando el edificio se encuentra aislado, en torno a $14 \mathrm{kWh} / \mathrm{m}^{2}$ año en las orientaciones este y oeste, valor muy alejado de los 1-2 kWh/ $\mathrm{m}^{2}$ año obtenidos en dichas orientaciones cuando el edificio se encuentra ubicado entre medianeras, como es el caso en el contexto urbano del barrio bajo estudio.

Analizada la influencia de la orientación del edificio, esta debe ser contextualizada en la ordenación urbana, pues la estructura del viario público determina la orientación de las fachadas de los edificios. Las calles con eje $\mathrm{N}-\mathrm{S}$, generan fachadas orientadas al $\mathrm{E}$ y al $\mathrm{O}$. Estas fachadas reciben horas de sol de mañana o de tarde, respectivamente. Esta opción permite que todas las fachadas tengan horas de sol, pero nunca en las horas centrales del día, cuando se puede lograr un mayor aprovechamiento. Así, la orientación E-O únicamente se considera aconsejable en latitudes mayores a $40^{\circ}$ (climas más fríos), siempre que los veranos no sean excesivamente calurosos, ya que en las fachadas $O$ durante la tarde, el recalentamiento excesivo puede originar situaciones de gran disconfort térmico (Higueras, 2006).

En las calles con eje $\mathrm{E}-\mathrm{O}$, se generan fachadas orientadas al $\mathrm{N}$ y al $\mathrm{S}$. La fachada $\mathrm{S}$ es la óptima para el invierno, como se apunta anteriormente, y también es bastante favorable para el verano, ya que no genera una alta demanda de refrigeración y, además, resulta más sencilla de proteger frente al soleamiento que las fachadas $\mathrm{E}$ y $\mathrm{O}$. Sin embargo, la fachada $\mathrm{N}$ únicamente resultaría óptima para verano. En este caso, resolver la fachada $\mathrm{N}$ representa un reto, que pasaría por abrir dicha fachada al patio de manzana, volviendo así a generar una fachada a $\mathrm{S}$, como ya se ha apuntado anteriormente. Otro aspecto a considerar en este caso es procurar diseñar adecuadamente el interior de las viviendas para que no haya ninguna sin abertura a las dos fachadas opuestas, $\mathrm{N}$ y $\mathrm{S}$.

Por otro lado, según Higueras (2006) y Olgyay (1963), se recomienda orientar ligeramente la fachada hacia el E, considerada como la ideal para la zona templada, por recibir gran parte de la radiación de la mañana y menor porcentaje durante la tarde, cuando en verano el exceso de radiación resulta muy perjudicial. Concretamente, se aconseja un ángulo de unos $18^{\circ} \mathrm{E}$. Sin embargo, este es un aspecto que debe verificarse previamente a asumir sus beneficios sin más, y tomar la importante decisión de cómo ordenar y planificar el viario urbano, como se verá más adelante.

\section{Conclusión relativa a 0:}

En edificios sin obstáculos alrededor, la demanda energética de refrigeración evoluciona, según la orientación de su fachada principal, de menor a mayor, de la siguiente forma: N, S, E y O.

La configuración urbana del entorno modifica la influencia natural que la orientación suele tener, lo que demuestra la importancia del contexto urbano en el comportamiento energético del parque edificado. 


\subsection{Propuesta de nueva configuración uRbana y su eValuación energética}

El análisis realizado anteriormente sobre cada una de las covariables ha permitido establecer un conjunto de recomendaciones para el diseño del planeamiento urbano. Así, teniendo en cuenta todo lo anterior, se concluye que la manzana idónea para latitudes próximas a $39,98^{\circ}$ en el hemisferio Norte, debe reunir los siguientes condicionantes:

- El factor de forma del edificio (S/V) debe adoptar valores bajos (edificios más compactos).

- Las soluciones constructivas empleadas para el diseño de la envolvente deben tener valores bajos de transmitancia térmica (U).

- La ratio óptima de proporción de calle cumple una relación máxima de 0,50. Orientar la retícula de manzanas urbanas a SE permite reducir el ancho de calle (W) y, por tanto, propicia estructuras urbanas más compactas. Así, para edificaciones orientadas a $18^{\circ} \mathrm{E}$, la relación máxima $\mathrm{H} / \mathrm{W}$ podría aumentarse a 0,53.

- La tipología de manzana $\mathrm{MU}_{1}$ es más apropiada, con patio de manzana grande en su interior, ya que permite abrir dos fachadas en los edificios orientadas a N-S. De esta manera, ningún edificio quedaría orientado completamente a $\mathrm{N}$.

- La forma de las manzanas debe ser rectangular (manteniendo la proporción $A>1,5 B$, según la Figura 6.10) y su eje longitudinal debe desarrollarse en la directriz solar E-O, de manera que la mayor superficie de fachada quede orientada a $\mathrm{S}$.

- Se recomienda orientar el eje de las calles en dirección E-O, de manera que el viario forme una retícula rectangular que favorezca orientar las fachadas de la mayoría de los edificios a $\mathrm{N}$ y a S.

- La orientación principal de los edificios a SE (con un ángulo de acimut $18^{\circ}$ ) es, a priori, mejor, aunque debe verificarse experimentalmente.

- Los edificios deben diseñarse de manera que cada una de las viviendas tenga dos fachadas en orientaciones opuestas, o bien S-N, o bien E-O.

Siguiendo estos criterios, se busca conformar la manzana urbana óptima, analizando el efecto de sus dimensiones y proporciones. Cada una de estas recomendaciones debe ser aplicada siguiendo un orden lógico en el diseño de los elementos del planeamiento urbano, desde la escala urbana a la de edificio. El procedimiento seguido para configurar la manzana urbana se muestra en la Figura 6.13. 


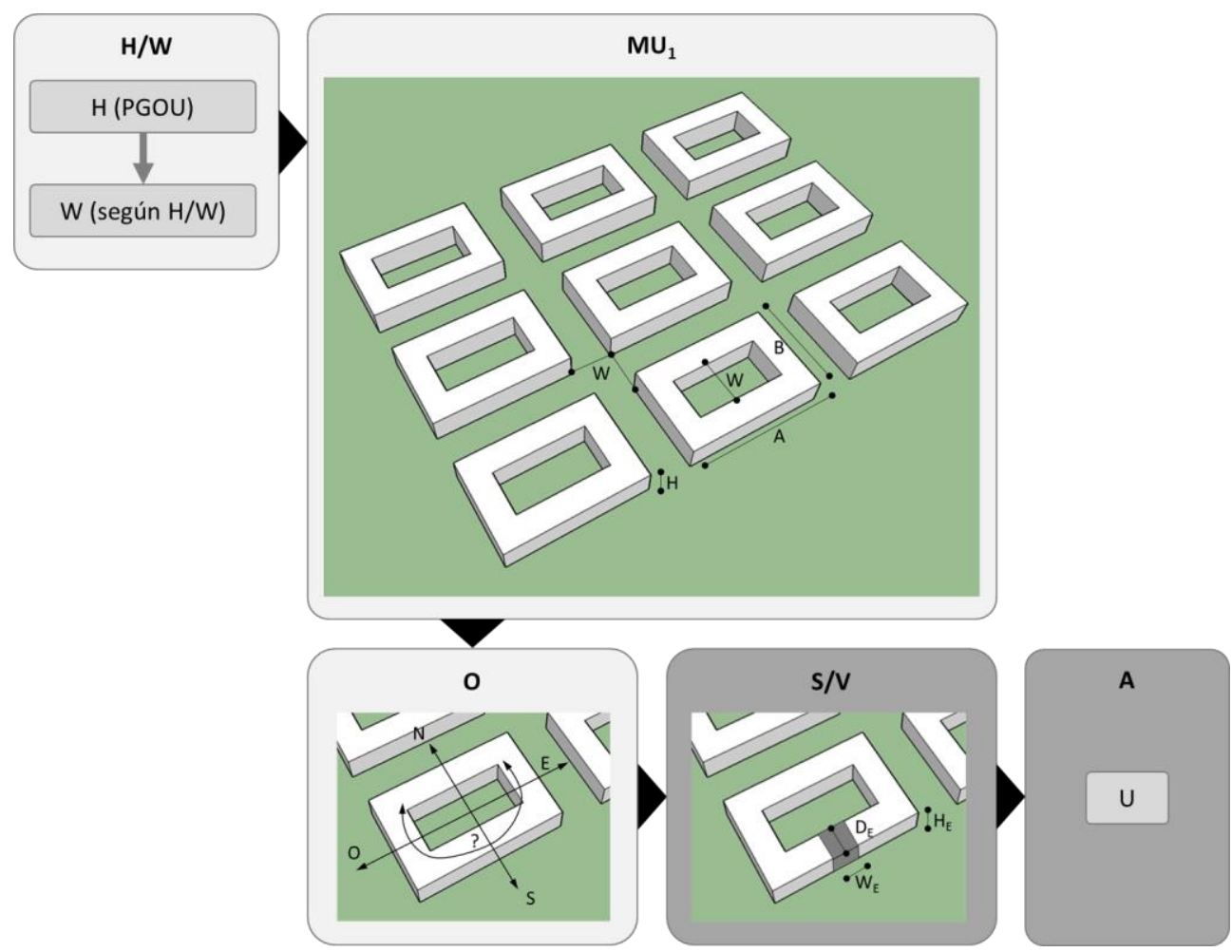

Figura 6.13 Procedimiento para definir la configuración urbana

Identificada la $\mathrm{MU}_{1}$ como la tipología de manzana idónea, cabe tener en cuenta que el parámetro determinante que condiciona sus dimensiones es la altura de las edificaciones, dada por el número máximo de plantas permitido según el PGOU de la ciudad. Para conformar una manzana con patio interior que asegure el soleamiento en la fachada $\mathrm{S}$ de los edificios que recaen a él, la relación $\mathrm{H} / \mathrm{W}$ también debe respetarse cuando se determina el ancho de manzana óptimo. La Tabla 6.2 presenta el resultado de analizar dos configuraciones de manzana, partiendo de los condicionantes del PGOU de Castellón de la Plana. En ella se presentan las ventajas e inconvenientes detectados en cada una de ellas. 
Tabla 6.2 Estudio de dos diseños de manzana urbana

\begin{tabular}{|c|c|c|c|}
\hline Criterios de diseño & Dimensiones & Ventajas & Inconvenientes \\
\hline \multicolumn{4}{|l|}{ Opción 1} \\
\hline $\begin{array}{l}\text { - Se asumen los parámetros } \\
\text { regulados según el PGOU del } \\
\text { barrio: } \\
-8 \text { plantas }(24 \mathrm{~m}) \\
-20 \mathrm{~m} \text { de profundidad } \\
\text { edificación } \\
\text { - } \mathrm{H} / \mathrm{W}=0,53 ; \mathrm{W}=45,30 \mathrm{~m}\end{array}$ & $\begin{array}{l}A=128,00 \mathrm{~m} \\
B=85,30 \mathrm{~m} \\
W=45,30 \mathrm{~m} \\
H=24,00 \mathrm{~m}\end{array}$ & $\begin{array}{l}\text { - No obstaculización de } \\
\text { soleamiento por } \\
\text { edificaciones } \\
\text { enfrentadas. }\end{array}$ & $\begin{array}{l}\text { - Ancho de calle excesivo (de } 45,30 \mathrm{~m} \text {, } \\
\text { cuando las calles más anchas de la } \\
\text { ciudad tienen alrededor de } 30 \mathrm{~m} \text { ) } \\
\text { - Dimensión de manzana excesiva para } \\
\text { una ciudad de tamaño medio, como } \\
\text { Castellón. } \\
\text { - Genera dispersión de la ciudad. } \\
\text { - Baja compacidad, bajo } \\
\text { aprovechamiento del suelo. } \\
\text { - Implica mayores desplazamientos de } \\
\text { movilidad (tiempo y distancia). } \\
\text { - Menguan las relaciones sociales y la } \\
\text { vitalidad económica del barrio. }\end{array}$ \\
\hline \multicolumn{4}{|l|}{ Opción 2} \\
\hline $\begin{array}{l}\text { - Se reduce la altura de } \\
\text { edificación a } 6 \text { plantas }(18 \mathrm{~m}) \\
\text { - Se asume que las plantas } \\
\text { bajas de los edificios son de } \\
\text { uso terciario (mixticidad de } \\
\text { usos) } \\
\text { - La profundidad de edificación } \\
\text { se fija en } 16 \mathrm{~m} \\
\text { - } \mathrm{H} / \mathrm{W}=0,53 ; \mathrm{W}=28,30 \mathrm{~m}\end{array}$ & $\begin{array}{l}A=90,45 \mathrm{~m} \\
B=60,30 \mathrm{~m} \\
W=28,30 \mathrm{~m} \\
H=18,00 \mathrm{~m}\end{array}$ & $\begin{array}{l}\text { - No obstaculización de } \\
\text { soleamiento por } \\
\text { edificaciones } \\
\text { enfrentadas. } \\
\text { - Dimensiones próximas a } \\
\text { la manzana tipo } \\
\text { existente en el barrio, } \\
\text { para lograr un } \\
\text { aprovechamiento del } \\
\text { suelo similar. } \\
\text { - Mayor compacidad y } \\
\text { aprovechamiento del } \\
\text { suelo. } \\
\text { - Menores } \\
\text { desplazamientos. }\end{array}$ & $\begin{array}{l}\text { - Ancho de calle }(28,30 \mathrm{~m}) \text { todavía } \\
\text { notable, aproximado al de las calles más } \\
\text { anchas de la ciudad. }\end{array}$ \\
\hline
\end{tabular}

La opción 1 queda condicionada por la altura de 8 plantas $(\mathrm{H}=24 \mathrm{~m})$ que establece el PGOU en el barrio, que para lograr que todas las fachadas a la calle no queden obstaculizadas solarmente por las edificaciones enfrentadas, obliga a prever un ancho de calle (W) de 45,30 m. De la misma manera, para garantizar esta misma condición en las fachadas que recaen al patio interior de la manzana, la dimensión mínima del patio de manzana debería ser también de $W=45,30 \mathrm{~m}$, lo que hace agrandar en exceso las dimensiones totales de la manzana ( $A=128 \mathrm{~m}$ y $B=85,30 \mathrm{~m}$, similares a las del ensanche del Plan Cerdà (1859) de la ciudad de Barcelona). Por otro lado, el ancho de calle óptimo $(45,30 \mathrm{~m})$ genera demasiada separación entre las manzanas, que comportaría ciertos inconvenientes, como por ejemplo, una mayor dispersión urbana ligada a una menor compacidad y a un bajo aprovechamiento del suelo, mayores desplazamientos de movilidad al generarse distancias mayores, o una mengua en las relaciones sociales entre los vecinos al dispersarse la densidad de población (habitantes/Ha). En este sentido, cabe recordar que se debe buscar el equilibrio con otros aspectos de la sostenibilidad urbana, pues, como se observa en la Tabla 3.2 del Capítulo 3, la morfología urbana está íntimamente relacionada con los aspectos de "sitio y suelo" y "movilidad y transporte".

La opción 2 busca reducir las dimensiones de la manzana, lo que implica necesariamente modificar el número de plantas máximo permitido por el PGOU a $6(\mathrm{H=18} \mathrm{m})$. Además, esta altura, referida a la altura donde es necesario garantizar el soleamiento, podría verse reducida si se asume que las plantas bajas de los edificios están destinadas a usos terciarios. Por tanto, en este caso, habría que 
garantizar el soleamiento en las 5 últimas plantas $(\mathrm{H}=15 \mathrm{~m})$ de los edificios. Con ello, el ancho de calle podría reducirse hasta $28,30 \mathrm{~m}(\mathrm{~W})$, al igual que la dimensión menor interior del patio de manzana. Este diseño genera manzanas de dimensiones menores, más en concordancia con el planeamiento del barrio y la envergadura de la ciudad, lo que no supondría modificar en exceso las condiciones de edificabilidad y compacidad. Además, el ancho de calle de $28,30 \mathrm{~m}$, aunque está por encima del ancho de calle medio de la ciudad, es asumible dentro de su PGOU.

De esta manera, a priori, la manzana propuesta en la opción 2 podría satisfacer las necesidades energéticas. Sin embargo, se verifica la condición de asegurar las dos horas de soleamiento durante el solsticio de invierno en las fachadas con radiación solar directa ( $E, S$ y $O)$, teniendo en cuenta la obstrucción solar que provocan las edificaciones enfrentadas (ver Figura 6.14).

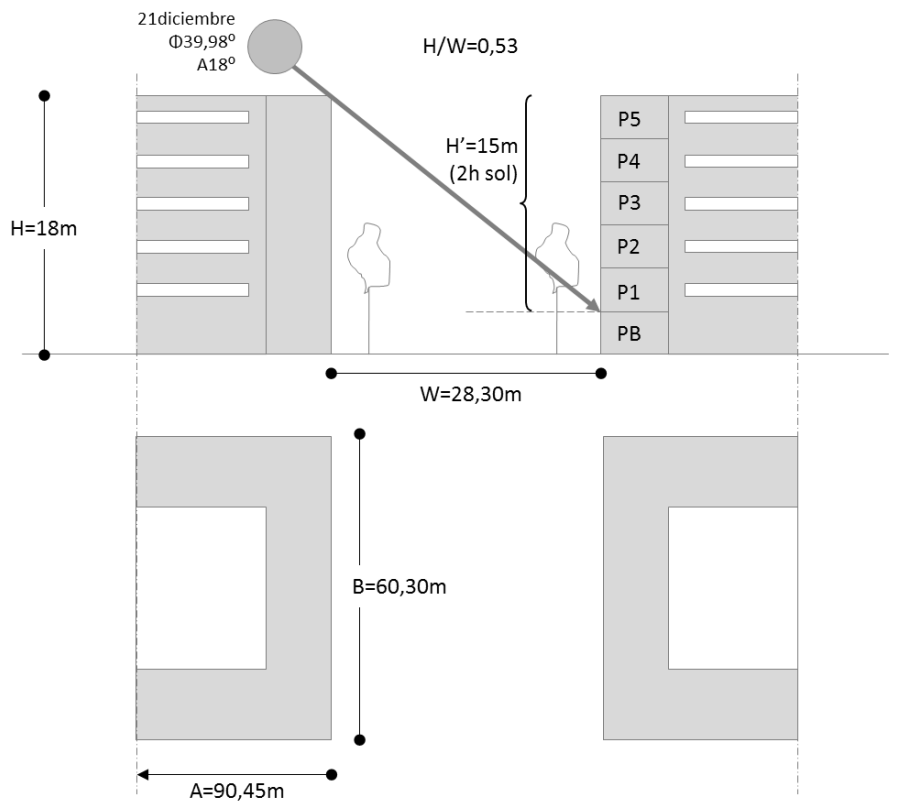

Figura 6.14 Configuración geométrica de la nueva manzana

Para ello, por un lado, se emplea la carta solar estereográfica para representar la máscara de sombra y determinar el intervalo de tiempo en el que la fachada recibe sol el solsticio de invierno. $Y$, por otro, mediante el cálculo analítico se determina la H/W en cada caso y con ello la W necesaria para garantizar el soleamiento en las tres fachadas. Cuando la $\mathrm{W}^{\prime}$ calculada es menor que la $\mathrm{W}$ establecida ( $28,30 \mathrm{~m}$ ), existe accesibilidad solar en la fachada analizada. Cabe indicar que los valores están calculados para el caso más desfavorable, que es el nivel de forjado suelo de planta primera, para garantizar el soleamiento en todas las plantas de uso residencial de los edificios. La Tabla 6.3 muestra los resultados del cálculo. 
Tabla 6.3 Análisis del soleamiento en las fachadas S, E y O de la manzana en el solsticio de invierno

\begin{tabular}{|c|c|c|c|c|c|c|c|c|}
\hline Máscara de sombra & Hora & $\mathrm{h}$ & A & $A^{\prime}$ & $H / W$ & $H^{\prime}(m)$ & $W^{\prime}(m)$ & Observaciones \\
\hline \multicolumn{9}{|l|}{ Fachada E } \\
\hline & E 8:30h & $10,26^{\circ}$ & $-47,32^{9}$ & $108^{\circ}$ & 0,37 & 15 & 40,58 & Sin accesibilidad \\
\hline & E 9:00h & $14,26^{\circ}$ & $-41,61^{\circ}$ & $108^{\circ}$ & 0,63 & 15 & 23,63 & \multirow{3}{*}{$2 \mathrm{~h}$ de sol } \\
\hline & E 10:00h & $20,89^{\circ}$ & $-28,98^{\circ}$ & $108^{\circ}$ & 2 & 15 & 7,48 & \\
\hline & E 10:30h & $25,17^{0}$ & $-14,77^{0}$ & $108^{\circ}$ & 8,34 & 15 & 1,80 & \\
\hline \multicolumn{9}{|l|}{ Fachada S } \\
\hline & S8:00h & $5,92^{\circ}$ & $-52,66^{\circ}$ & $18^{\circ}$ & 0,13 & 15 & 119,00 & Sin accesibilidad \\
\hline & S9:00h & $14,26^{\circ}$ & $-41,61^{\circ}$ & $18^{0}$ & 0,28 & 15 & 54,10 & Sin accesibilidad \\
\hline & S 10:00h & $20,89^{\circ}$ & $-28,98^{\circ}$ & $18^{0}$ & 0,39 & 15 & 38,60 & Sin accesibilidad \\
\hline & S 11:00h & $25,17^{0}$ & $-14,77^{0}$ & $18^{\circ}$ & 0,47 & 15 & 31,87 & Sin accesibilidad \\
\hline & S 12:00h & $26,61^{\circ}$ & $0^{0}$ & $18^{\circ}$ & 0,53 & 15 & 28,30 & \multirow{3}{*}{$2 \mathrm{~h}$ de sol } \\
\hline & S 13:00h & $25^{\circ}$ & $15,61^{\circ}$ & $18^{\circ}$ & 0,56 & 15 & 26,80 & \\
\hline & S 14:00h & $20,57^{0}$ & $29,73^{\circ}$ & $18^{\circ}$ & 0,56 & 15 & 26,90 & \\
\hline & S15:00h & $13,83^{\circ}$ & $42,28^{\circ}$ & $18^{\circ}$ & 0,49 & 15 & 30,20 & Sin accesibilidad \\
\hline & S 16:00h & $5,41^{\circ}$ & $53,34^{\circ}$ & $18^{\circ}$ & 0,29 & 15 & 50,68 & Sin accesibilidad \\
\hline \multicolumn{9}{|l|}{ Fachada $\mathrm{O}$} \\
\hline \multirow{7}{*}{$(-)<\quad s \quad \begin{array}{l}10: 30 \mathrm{~h} \\
\mathrm{~s}\end{array}$} & O 10:30h & $23,36^{\circ}$ & $22,05^{\circ}$ & $72^{\circ}$ & 6,12 & 15 & 2,45 & \multirow{4}{*}{$2,5 \mathrm{~h}$ de sol } \\
\hline & O 11:00h & $25,17^{0}$ & $14,77^{\circ}$ & $72^{\circ}$ & 8,34 & 15 & 1,80 & \\
\hline & O 12:00h & $26,61^{\circ}$ & $0^{\circ}$ & $72^{\circ}$ & 1,62 & 15 & 9,25 & \\
\hline & O 13:00h & $25^{\circ}$ & $-15,61^{\circ}$ & $72^{\circ}$ & 0,84 & 15 & 17,80 & \\
\hline & O 14:00h & $20,57^{0}$ & $-29,73^{\circ}$ & $72^{\circ}$ & 0,51 & 15 & 29,60 & Sin accesibilidad \\
\hline & O 15:00h & $13,83^{\circ}$ & $-42,28^{\circ}$ & $72^{\circ}$ & 0,28 & 15 & 52,91 & Sin accesibilidad \\
\hline & O 16:00h & $5,41^{\circ}$ & $-53,34^{\circ}$ & $72^{\circ}$ & 0,10 & 15 & 150,00 & Sin accesibilidad \\
\hline
\end{tabular}

Como se observa en la Tabla 6.3, las tres fachadas $(E, S, O)$ reciben al menos dos horas de sol, pues en las tres existe posibilidad de recibir radiación solar directa. Por tanto, la opción 2 sugerida podría mejorar a priori el comportamiento energético del barrio. Así, para asegurar soleamiento en una altura de $\mathrm{H}^{\prime}=15 \mathrm{~m}$, el ancho de la calle (W) debe de ser de 28,30 m, tanto en las calles con eje en dirección E-O como N-S.

Llegados a este punto, se realizan nuevas simulaciones para comprobar si efectivamente se producen mejoras en el comportamiento energético de los edificios que componen esta configuración urbana. Además, se pretende determinar cuál es la orientación óptima de las fachadas, teniendo en cuenta tanto la demanda de calefacción como la de refrigeración, por lo que los cálculos incluyen diversas orientaciones solares: $120^{\circ} \mathrm{E}, 45^{\circ} \mathrm{O}, 18^{\circ} \mathrm{O}, 0^{\circ} \mathrm{S}, 18^{\circ} \mathrm{E}, 45^{\circ} \mathrm{E}$ y $120^{\circ} \mathrm{E}$.

Dado que la profundidad de edificación planteada es de $16 \mathrm{~m}$, para lanzar las simulaciones se toma el edificio de referencia de la tipología edificatoria $\mathrm{PF}_{(<4)}$, por tener este $14,70 \mathrm{~m}$ de profundidad y encajar así en la geometría de la manzana. Se realizan algunas modificaciones sobre el mismo, pues la altura de planta existente es de $4,50 \mathrm{~m}$, al tratarse de una edificación antigua. Esta altura es poco habitual en edificaciones actuales, en las que predominan los $3 \mathrm{~m}$. Así, se configura un edificio de $\mathrm{PB}+\mathrm{V}$ (con una planta sótano, no habitable), con la misma distribución de la planta tipo y la planta baja destinada completamente a uso terciario (por lo que no se computa en los cálculos térmicos), que representaría a la nueva tipología edificatoria a considerar en el planeamiento urbano. La planta tipo está constituida por dos viviendas y cada una de ellas tiene dos fachadas, una a la calle y otra al 
patio de manzana, de manera que tienen orientaciones opuestas. El edificio resultante tiene las características que se detallan en la Tabla 6.4.

Tabla 6.4 Características dimensionales del edificio tomado como referencia

\begin{tabular}{l} 
Edificio de referencia \\
\hline
\end{tabular}

El factor de forma (S/V) del edificio ficticio es de 0,28 , muy próximo al $S / \mathrm{V}$ del edificio representativo de clase $\operatorname{PF}_{(\geq 4)}(0,26)$, por lo que el edificio tomado como referencia en este caso es compacto y susceptible de tener una baja demanda energética de calefacción. El porcentaje de huecos o superficie acristalada es de $31,20 \%$, en torno al de los edificios seleccionados para desarrollar el modelo. Para realizar las simulaciones, no se han tenido en cuenta las protecciones solares del propio edificio.

Puesto que las recomendaciones obtenidas son para nuevas planificaciones urbanas, se toma como referencia el periodo temporal 5, que aglutina el paquete de soluciones constructivas más recientes. Podrían tomarse los nuevos requisitos establecidos en el CTE (2013), sin embargo este no establece unos requisitos mínimos de aislamiento térmico, sino que limita la demanda energética de calefacción y refrigeración, lo que otorga cierta libertad a la hora de cumplir las exigencias, pero también hace que los espesores de aislamiento térmico no puedan estandarizarse para la diversa casuística.

Se plantean siete opciones:

- La opción 1, contempla una orientación de la manzana en el eje SO-NE formando la normal de la fachada un ángulo de $120^{\circ} \mathrm{O}$.

- La opción 2, contempla una orientación de la manzana en el eje NO-SE formando la normal de la fachada un ángulo de $45^{\circ} \mathrm{O}$. 
- La opción 3, contempla la orientación de la manzana en el eje NO-SE formando la normal de la fachada un ángulo de $18^{\circ} \mathrm{O}$.

- La opción 4, contempla la orientación de la manzana en el eje O-E, perfectamente orientadas al $\mathrm{S}$.

- La opción 5, contempla la orientación de la manzana en el eje SO-NE formando un ángulo de $18^{\circ} \mathrm{E}$.

- La opción 6, contempla la orientación de la manzana en el eje SO-NE formando un ángulo de $45^{\circ} \mathrm{E}$.

- La opción 7, contempla la orientación de la manzana en el eje SE-NO formando un ángulo de $120^{\circ} \mathrm{E}$.

Cada una de estas 7 opciones genera cuatro orientaciones diferentes de fachada, lo que da como resultado un total de 28 hipótesis, como se define en la Tabla 6.5 . 
Tabla 6.5 Determinación de indicadores para las diferentes orientaciones de la manzana

\begin{tabular}{|c|c|c|c|c|c|c|}
\hline & Definición gráfica & O. fach.ppal. & $D E_{r}\left[k W h / m^{2} a n ̃ o\right]$ & $D E_{c}\left[k W h / m^{2} a n ̃ o\right]$ & 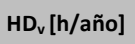 & $H D_{i}[h / a n ̃ o]$ \\
\hline \multirow{4}{*}{1} & & NO $\left(120^{\circ} \mathrm{O}\right)$ & 9,75 & 42,49 & 100,95 & $4.207,42$ \\
\hline & & $\operatorname{NE}\left(150^{\circ} \mathrm{E}\right)$ & 5,42 & 38,29 & 188,16 & $3.966,49$ \\
\hline & & $\mathrm{E}\left(60^{\circ} \mathrm{E}\right)$ & 10,19 & 40,14 & 99,16 & $4.100,03$ \\
\hline & & $\mathrm{S}\left(30^{\circ} \mathrm{O}\right)$ & 5,49 & 39,27 & 196,25 & $4.027,31$ \\
\hline \multirow{4}{*}{2} & & NO $\left(135^{\circ} \mathrm{O}\right)$ & 6,80 & 38,79 & 168,08 & $4.062,89$ \\
\hline & & $\operatorname{NE}\left(135^{\circ} \mathrm{E}\right)$ & 7,70 & 41,18 & 138,05 & $4.159,91$ \\
\hline & & $\mathrm{E}\left(45^{\circ} \mathrm{E}\right)$ & 7,23 & 39,53 & 162,14 & $4.090,85$ \\
\hline & & $\mathrm{O}\left(45^{\circ} \mathrm{O}\right)$ & 7,94 & 40,66 & 136,35 & $4.101,56$ \\
\hline \multirow{4}{*}{3} & & $N\left(162^{\circ} \mathrm{E}\right)$ & 4,12 & 37,14 & 225,11 & $4.031,54$ \\
\hline & & $E\left(72^{\circ} \mathrm{E}\right)$ & 11,97 & 43,13 & 85,16 & $4.108,54$ \\
\hline & & $\mathrm{S}\left(18^{\circ} \mathrm{O}\right)$ & 4,62 & 35,85 & 223,61 & $3.965,72$ \\
\hline & & $\mathrm{O}\left(108^{\circ} \mathrm{O}\right)$ & 10,88 & 44,01 & 91,19 & $4.142,44$ \\
\hline \multirow{4}{*}{4} & & $\mathrm{~N}\left(180^{\circ} \mathrm{N}\right)$ & 3,86 & 36,73 & 234,89 & $4.027,00$ \\
\hline & & $\mathrm{E}\left(90^{\circ} \mathrm{E}\right)$ & 12,69 & 42,901 & 84,49 & $4.047,23$ \\
\hline & & $\mathrm{S}\left(0^{\circ} \mathrm{S}\right)$ & 4,03 & 35,05 & 237,14 & $3.939,15$ \\
\hline & & $\mathrm{O}\left(90^{\circ} \mathrm{O}\right)$ & 11,79 & 44,43 & 84,33 & $4.161,17$ \\
\hline \multirow{4}{*}{5} & & $N\left(162^{\circ} \mathrm{O}\right)$ & 4,70 & 38,24 & 211,23 & $4.121,29$ \\
\hline & & $E\left(108^{\circ} E\right)$ & 10,78 & 41,92 & 98,29 & $4.018,83$ \\
\hline & & $\mathrm{S}\left(18^{\circ} \mathrm{E}\right)$ & 4,68 & 36,36 & 212,16 & $4.034,84$ \\
\hline & & $\mathrm{O}\left(72^{\circ} \mathrm{O}\right)$ & 10,39 & 44,27 & 92,50 & $4.187,52$ \\
\hline \multirow{4}{*}{6} & & $\operatorname{NO}\left(135^{\circ} \mathrm{O}\right)$ & 7,97 & 40,98 & 137,44 & $4.190,41$ \\
\hline & & $\operatorname{NE}\left(135^{\circ} \mathrm{E}\right)$ & 6,93 & 39,12 & 163,82 & $3.970,51$ \\
\hline & & $\mathrm{E}\left(45^{\circ} \mathrm{E}\right)$ & 8,26 & 38,92 & 131,60 & $4.123,16$ \\
\hline & & $\mathrm{O}\left(45^{\circ} \mathrm{O}\right)$ & 7,18 & 41,32 & 162,07 & $4.087,68$ \\
\hline \multirow{4}{*}{7} & & $\mathrm{NO}\left(150^{\circ} \mathrm{O}\right)$ & 6,14 & 39,63 & 176,25 & $4.087,54$ \\
\hline & & $\mathrm{NE}\left(120^{\circ} \mathrm{E}\right)$ & 8,88 & 39,56 & 124,02 & $4.068,93$ \\
\hline & & $S\left(30^{\circ} \mathrm{E}\right)$ & 5,48 & 39,60 & 187,05 & $4.126,71$ \\
\hline & & $\mathrm{O}\left(60^{\circ} \mathrm{O}\right)$ & 8,85 & 41,21 & 123,35 & $4.147,35$ \\
\hline
\end{tabular}


La comparación entre los resultados de estas 28 simulaciones permite identificar la orientación óptima. Con dichos resultados se elabora un gráfico donde quedan representadas las demandas de calefacción y de refrigeración en cada una de las orientaciones de la fachada principal del edificio (ver Figura 6.15). Se observa que los mínimos valores de $D_{c}$ se dan en las orientaciones $S$ y $N$ y los máximos en las $\mathrm{E}$ y $\mathrm{O}$. Con la demanda de refrigeración ocurre precisamente al contrario, los valores máximos de $\mathrm{DE}_{\mathrm{r}}$ se dan en las orientaciones $\mathrm{E}$ y $\mathrm{O}$ y los mínimos en las $\mathrm{N}$ y $\mathrm{S}$. Por ello, orientar el eje longitudinal de las manzanas en dirección E-O (ver Figura 6.10) generaría la mayor parte de la superficie de las fachadas en la orientación favorable $\mathrm{N}$ y $\mathrm{S}$, donde se producen las mínimas $\mathrm{DE}_{\mathrm{c}}$ y $D E_{r}$, pero las otras dos fachadas quedarían orientadas en la peor orientación, $E$ y $O$, donde precisamente se producen los valores máximos de $D E_{c}$ y $D E_{r}$. Por este motivo, es conveniente buscar la orientación óptima, en la que los valores estén más compensados. En el gráfico de la Figura 6.15, se observa que este óptimo se da en un rango de orientaciones comprendido entre $18^{\circ} \mathrm{E}$ y $45^{\circ} \mathrm{E}$, lo que genera fachadas opuestas en el rango $135^{\circ} \mathrm{O}$ y $162^{\circ} \mathrm{O}$. En dichos rangos, se registran valores bajos de $\mathrm{DE}_{\mathrm{c}}$, al mismo tiempo que los valores de $\mathrm{DE}_{\mathrm{r}}$ son aceptables. Puede, por ello, considerarse esta franja (opción 5) como la orientación óptima en la que diseñar las manzanas urbanas, delimitadas por la retícula del viario público, corroborándose la hipótesis planteada por Olgyay (1963).

Su rango simétrico, el comprendido entre $18^{\circ} \mathrm{O}$ y $45^{\circ} \mathrm{O}$, podría resultar también favorable. Sin embargo, la radiación solar de la mañana es más soportable que la de la tarde, como consecuencia del recalentamiento de la atmósfera.

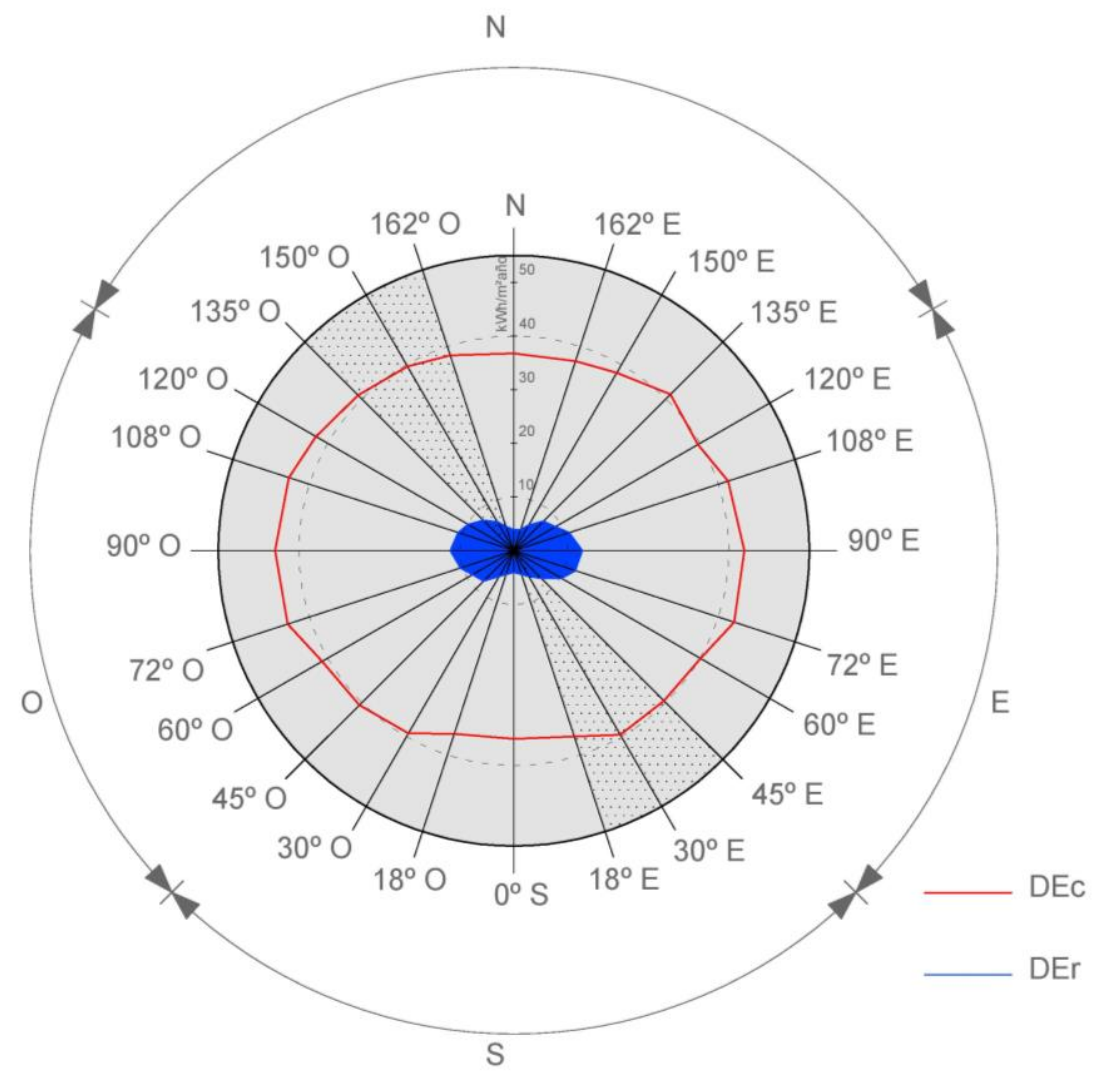

Figura 6.15 Gráfico de relación entre la demanda energética y la orientación. Orientación óptima 
La Figura 6.16 muestra el soleamiento en el solsticio de invierno en las cuatro orientaciones que genera la manzana urbana propuesta.

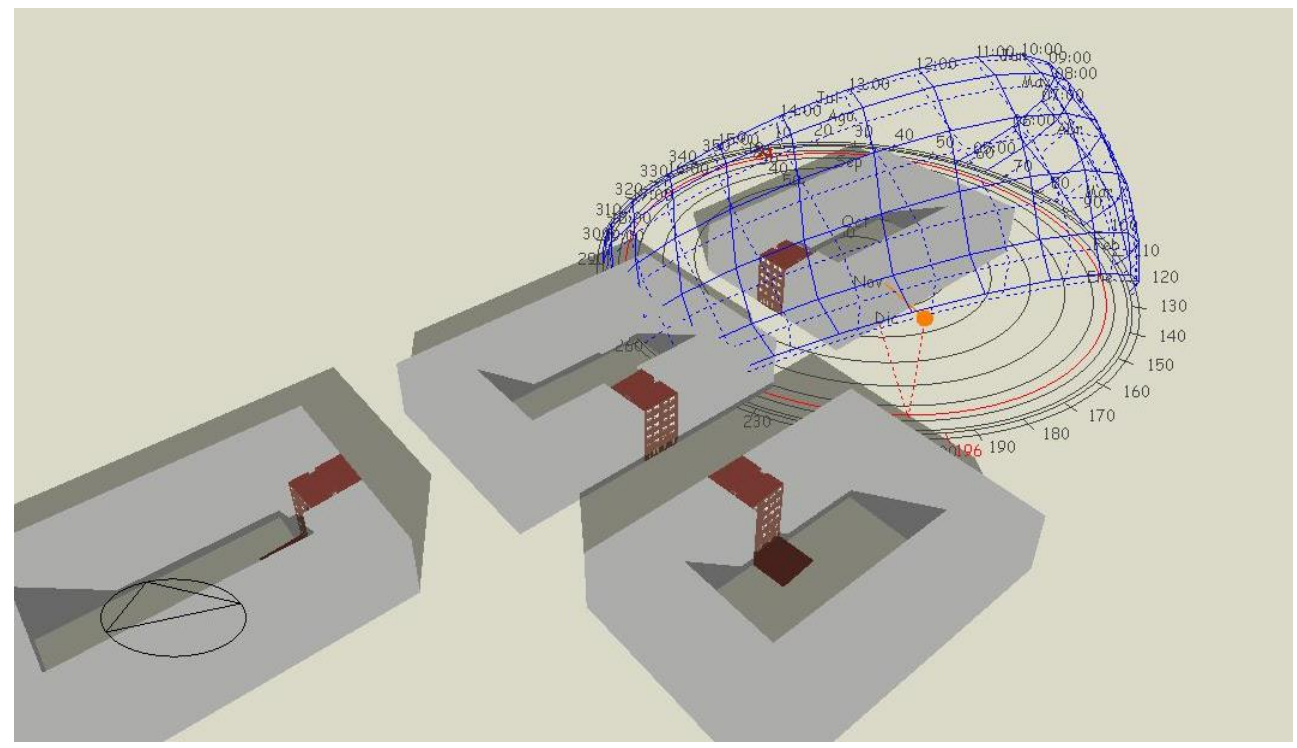

Figura 6.16 Soleamiento en la orientación de manzana óptima (solsticio invierno)

\section{Evaluación energética de un área urbana con la configuración propuesta}

Para determinar el ahorro energético que supondría la ordenación urbana de nuevos desarrollos con la morfología urbana propuesta, se toma la superficie del barrio $(17,6 \mathrm{Ha})$ y se desarrolla en dicha superficie la planificación urbana propuesta. Para obtener manzanas enteras se necesita una superficie algo mayor $(18,4 \mathrm{Ha})$, que posteriormente se corregirá con los valores de demanda energética. La Figura 6.17, muestra cómo quedaría la configuración urbana de un nuevo barrio tras aplicar las directrices aquí expuestas.

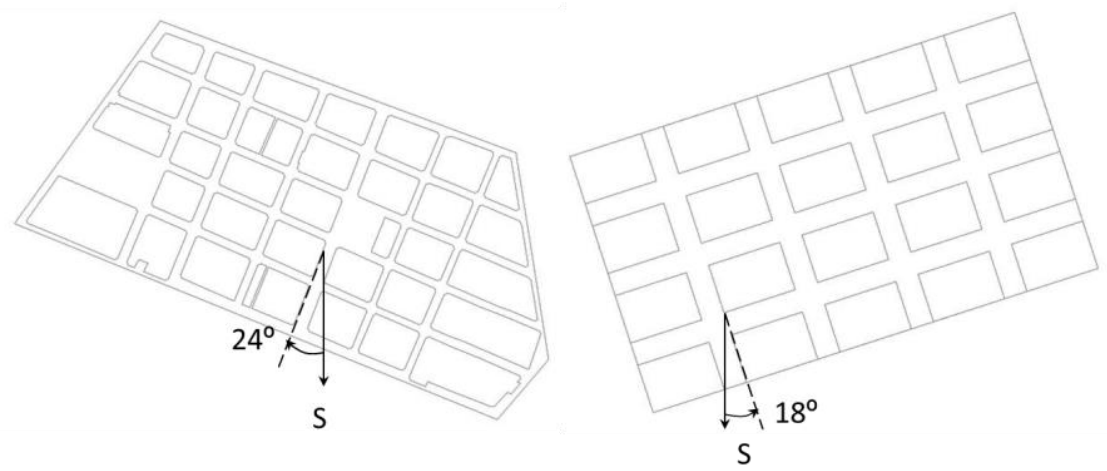

Figura 6.17 Configuración urbana existente (izquierda) y propuesta (derecha) 
Cada una de las manzanas urbanas que componen el área, quedaría configuradas de la forma que se muestra en la Figura 6.18. Así, siete de los edificios quedaría orientados a N (su fachada principal), siete a $\mathrm{S}$, tres a $\mathrm{E}$ y tres a $\mathrm{O}$.

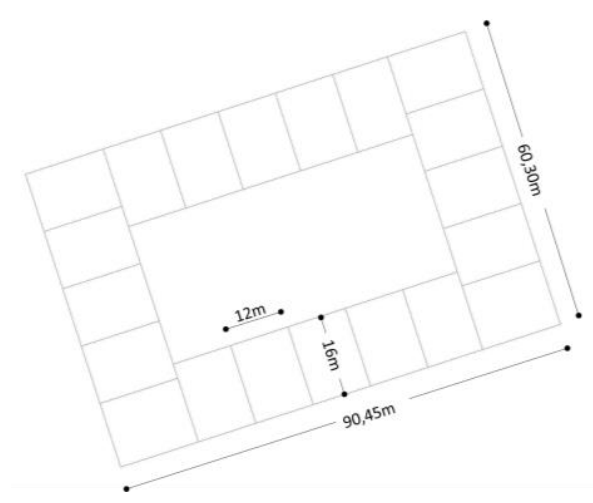

Figura 6.18 Configuración de las edificaciones en la manzana urbana propuesta

Con el total de las 20 manzanas, que se comportan energéticamente de la misma forma, se pueden determinar los cuatro indicadores energéticos. El cálculo se realiza para el total de las 20 manzanas $(18,4 \mathrm{Ha})$ y después se realiza la conversión para una superficie de $17,6 \mathrm{Ha}$, igual a la del barrio del caso de estudio (Tabla 6.6), para poder realizar la comparativa.

Tabla 6.6 Cálculo de los indicadores energéticos en la planificación urbana propuesta

\begin{tabular}{|c|c|c|c|c|c|c|c|c|c|c|}
\hline 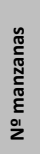 & 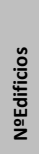 & $\circ$ & 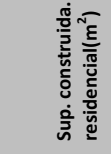 & 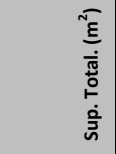 & 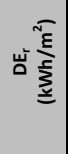 & 㟔部 & 崖 & 岁点 & 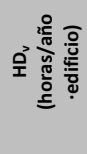 & 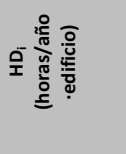 \\
\hline 20 & 7 & $\mathrm{~N}$ & 720,97 & $100.935,8$ & 3,17 & $319.966,49$ & 42,88 & 4.328.127,10 & 211,23 & $4.121,29$ \\
\hline 20 & 7 & S & 720,97 & $100.935,8$ & 3,02 & $304.826,12$ & 41,64 & $4.202 .966,71$ & 212,16 & $4.034,84$ \\
\hline 20 & 3 & $\mathrm{E}$ & 720,97 & $43.258,2$ & 5,87 & $253.925,63$ & 42,17 & $1.824 .198,29$ & 98,29 & $4.018,83$ \\
\hline 20 & 3 & 0 & 720,97 & $43.258,2$ & 5,64 & $243.976,25$ & 44,33 & $1.917 .636,00$ & 92,50 & $4.187,52$ \\
\hline \multicolumn{4}{|r|}{ En $18,4 \mathrm{Ha}$} & $288.388,0$ & & $1.122 .694,50$ & & $12.272 .928,12$ & & \\
\hline \multicolumn{4}{|r|}{ En $17,6 \mathrm{Ha}$} & $275.849,4$ & & $1.073 .881,68$ & & $11.739 .322,55$ & & \\
\hline
\end{tabular}

Con ello se obtiene un total de 1.073,88 MWh/año de demanda de refrigeración y 11.739,32 MWh/año de demanda de calefacción. En la Tabla 6.7 se muestra la comparativa con la situación actual, de manera que se estima una reducción de la demanda energética de calefacción del 60,01\%. La demanda de refrigeración, sin embargo, sufre un significativo aumento del 205,13\%. En la situación existente, al ser las calles estrechas, en verano apenas accede el sol a las fachadas de los edificios, por lo que la demanda de refrigeración es muy baja o, en algunos casos, prácticamente inexistente. Sin embargo, ello conlleva una importante penalización en la demanda energética de calefacción. Por este motivo, la consiguiente disminución de la demanda de calefacción en la nueva situación propuesta, compensa con creces el aumento en la demanda de refrigeración, pues entre ambas, se lograría aun así, una reducción de la demanda energética global del 57,12\%, valor muy 
significativo. Ello demuestra, una vez más, la importancia que tiene la morfología urbana en el comportamiento energético del parque edificado.

Tabla 6.7 Comparativa entre configuración existente y propuesta para una superficie de referencia de 17,6 Ha

\begin{tabular}{llll}
\hline & Barrio existente & Nueva planificación & Variación (\%) \\
\hline Sup. Construida $\left(\mathbf{m}^{2}\right)$ & $313.301,00$ & $275.849,4$ & $-11,95 \%$ \\
$\mathrm{DE}_{\mathrm{r}}(\mathrm{MWh} / \mathrm{año})$ & 523,53 & $1.073,88$ & $205,13 \%$ \\
$\mathrm{DE}_{\mathrm{c}}$ (MWh/año) & $29.354,89$ & $11.739,32$ & $-60,01 \%$ \\
$\mathrm{DE}_{\mathrm{G}}{ }^{*}(\mathrm{MWh} / \mathrm{año})$ & $29.878,42$ & $12.813,20$ & $-57,12 \%$ \\
\hline \multicolumn{2}{c}{${ }^{*} \mathrm{DE}_{\mathrm{G}}$ : Demanda energética global }
\end{tabular}

Además de las estrategias ya descritas anteriormente en relación a las cinco covariables, se pueden emplear otras estrategias que contribuyan a corregir picos de demanda energética y situaciones de disconfort térmico, como por ejemplo, emplear una correcta distribución de los espacios dentro de las viviendas para captar o evitar la radiación solar (según el uso de mismos), la utilización de protecciones solares y la realización de actuaciones sobre las soluciones constructivas de la envolvente térmica del edificio. Entre ellas, destaca el importante papel que tiene el uso de protecciones solares correctamente diseñadas, las cuales contribuyen a reducir considerablemente la demanda de refrigeración en el periodo estival, cuando estas están operativas. Pero, sin embargo, consiguen no afectar negativamente a la demanda de calefacción durante el periodo invernal. La consideración de estas en los edificios del barrio puede corregir, por tanto, el aumento en la demanda de refrigeración en el periodo estival.

Estas consideraciones, tienen un papel muy importante en el diseño bioclimático o pasivo de los edificios, por lo que no pueden obviarse tanto en las nuevas planificaciones urbanas como en los tejidos urbanos ya consolidados. Sin embargo, estas no constituyen directrices geométricas ni dimensionales que afecten al diseño urbano ni a la geometría del edificio. Así, deben ser estudiadas a nivel de edificio y requieren de un estudio en profundidad, que queda fuera del alcance del presente trabajo.

\subsection{Relación De estrategias pasivas para mejorar el comportamiento ENERGÉTICO DEL PARQUE EDIFICATORIO RESIDENCIAL}

Teniendo en cuenta todo lo anteriormente expuesto, la Tabla 6.8 resume el conjunto de estrategias pasivas, tanto a escala urbana como de edificio, que pueden ser consideradas para mejorar el comportamiento energético pasivo del parque edificatorio residencial.

Todas ellas sirven como directrices para el desarrollo de nuevas planificaciones urbanas. En el supuesto de tejidos urbanos consolidados, las posibilidades de actuar sobre el mismo son escasas, por lo que las medidas a considerar pueden ser, prácticamente, implementadas únicamente a nivel de edificio. 
Tabla 6.8 Estrategias pasivas para mejorar el comportamiento energético del parque edificatorio residencial

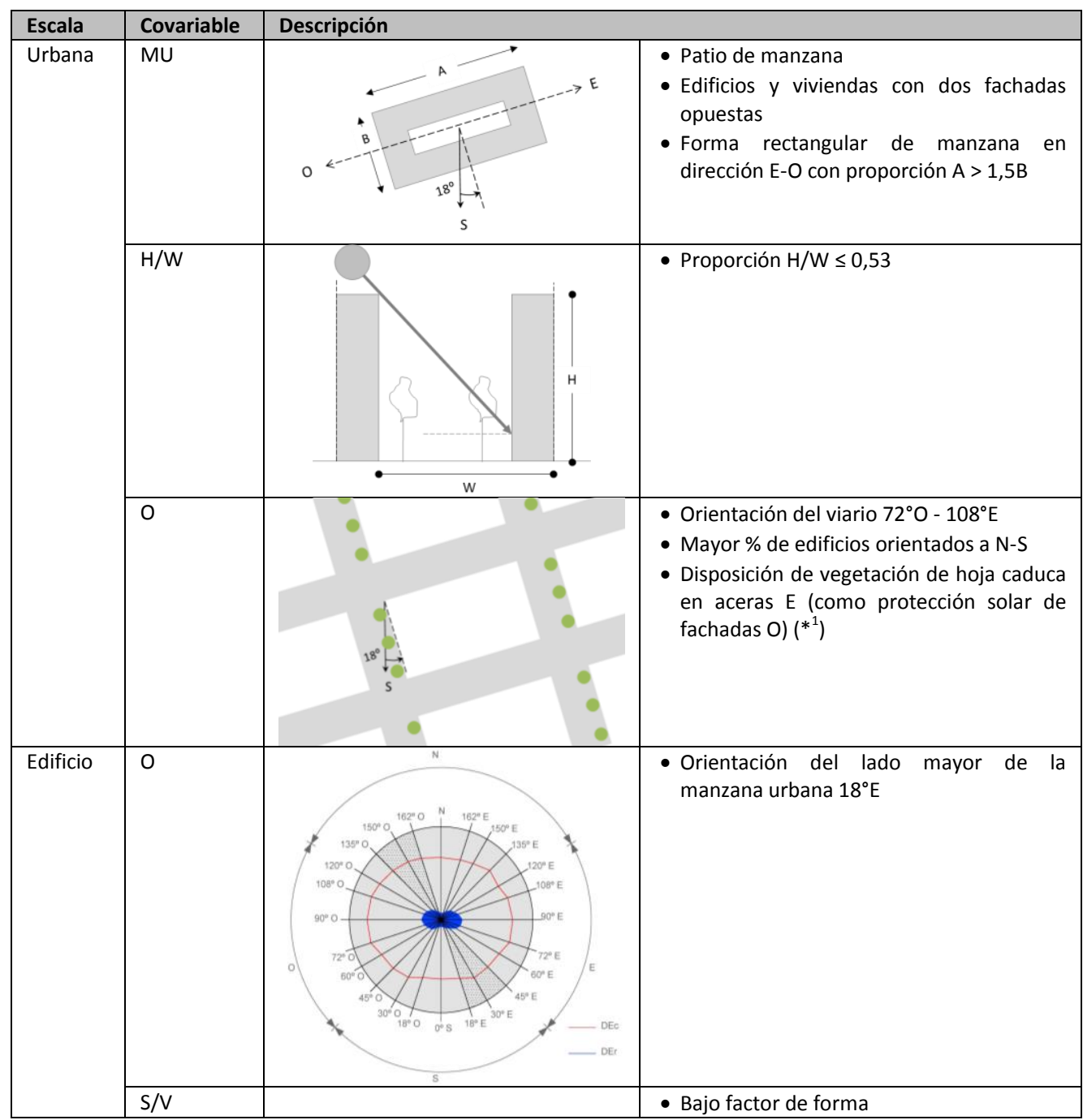

Obviamente, a nivel de edificio existen muchas otras estrategias que podrían implementarse, como se ha comentado anteriormente. Por ejemplo, en relación a los huecos, la colocación de una doble ventana puede mejorar notablemente el comportamiento energético de los edificios, al reducir infiltraciones y proporcionar mayor aislamiento térmico. O, en relación a los elementos opacos, estudiar las posibilidades que ofrece cada cerramiento para incorporar aislamiento térmico. Por otro lado, pueden adoptarse otras estrategias activas de acondicionamiento como la sustitución de equipos térmicos antiguos de baja eficiencia o la integración de energías renovables. Probablemente, en tramas urbanas consolidadas, se deba ejercer una fuerte apuesta por las medidas activas, ya que la implementación de medidas pasivas está fuertemente limitada, al no poder modificarse los condicionantes geométricos del urbanismo. No obstante, las estrategias 
activas no tendrían ningún efecto positivo sobre la demanda energética, sino que contribuirían a paliar el consumo final de energía en el parque edificatorio, no pudiendo evitarlo en su totalidad, como sí se puede conseguir por medio de un buen diseño pasivo. Sin embargo, no es objeto del presente trabajo investigar medidas de eficiencia energética en los edificios, pues este resulta un amplio campo de estudio que merece, por sí solo, un análisis en profundidad.

\subsection{CONCLUSIÓN}

El presente capítulo realiza un análisis y discusión de los resultados del diagnóstico energético del barrio objeto de estudio en el Capítulo 5, el cual permite determinar ciertas recomendaciones que podrían tenerse en cuenta a la hora de llevar a cabo actuaciones de renovación urbana, en relación a las cinco covariables. A su vez, propone una nueva configuración urbana que podría ser considerada a la hora de elaborar las ordenanzas urbanísticas de un nuevo planeamiento urbano en la ciudad. La comparativa entre ambas situaciones, la actual y la propuesta, contribuye a validar la hipótesis sobre la importancia de la morfología urbana en el comportamiento energético del parque edificatorio.

Como demuestran los resultados comparativos sobre demanda energética entre el tejido actual del barrio y el nuevo tejido propuesto, cuando se apuesta por un adecuado diseño urbano, el potencial de ahorro es muy alto, y pueden alcanzarse reducciones del $57,12 \%$. Este dato puede considerarse muy positivo, más aún teniendo en cuenta que puede lograrse únicamente mediante el diseño pasivo, sin necesidad de recurrir a los sistemas activos de acondicionamiento. La reducción de la demanda energética necesaria para cumplir con los nuevos estándares establecidos por el nuevo CTE (2013), fijados entorno a los $15 \mathrm{kWh} / \mathrm{m}^{2}$.año tanto para calefacción como para refrigeración en una zona climática B3, puede conseguirse mediante la actuación sobre la envolvente térmica de los edificios y la adecuada resolución de los puentes térmicos.

Como se menciona anteriormente, la intervención sobre tejidos urbanos ya existentes, sin embargo, resulta muy compleja, pues la configuración de estos no puede ser modificada. Por ello, en estos casos resulta crucial disponer de los instrumentos que permitan realizar un diagnóstico energético para estudiar, a posteriori, posibles mejoras y evaluar cuantitativamente su potencial de ahorro. Tras conocer el diagnóstico energético del área urbana en la que se desee intervenir, las acciones a llevar a cabo deberán basarse principalmente en actuaciones sobre los propios edificios, y basarse tanto en medidas pasivas como activas. Ello supone un amplio campo de estudio, de interesante consideración para futuros desarrollos.

Por último, mencionar que las administraciones locales cobran especial importancia en este sentido y adoptan un papel estratégico para integrar criterios de eficiencia energética en las ordenanzas municipales y, además, regular y priorizar las actuaciones de rehabilitación, ahora ya amparadas y fomentadas por la legislación a través de la Ley $3 R$ sobre rehabilitación, regeneración y renovación urbanas (Gobierno de España, 2013). Por ello, el grado de compromiso que la administración asuma será clave para lograr construir y reconstruir nuestras ciudades siguiendo unas directrices adecuadas en el camino hacia la sostenibilidad urbana y la eficiencia energética.

\subsection{Referencias}

Casanova, M., Díaz-Palacios, S., Elizalde, J., Garachana, R., Gil, J., Higueras, E., 2003. Ordenanza Municipal de Urbanización y Edificación Bioclimática. España. 
Cerdà, I., 1859. Teoría de la construcción de las ciudades. Aplicada al proyecto de reforma y ensanche de Barcelona. Barcelona.

CTE, 2013. Orden FOM/1635/2013, de 10 de septiembre, por la que se actualiza el Documento Básico DB-HE Ahorro de Energía del Código Técnico de la Edificación, aprobado por Real Decreto 314/2006, de 17 de marzo. España.

CTE, 2006. Real Decreto 314/2006, de 17 de marzo, por el que se aprueba el Código Técnico de la Edificación. España.

Gobierno de España, 2013. Ley 8/2013, de 26 de junio, de rehabilitación, regeneración y renovación urbanas. España.

Granados, H., 2006. Principios y estrategias del diseño bioclimático en la arquitectura y el urbanismo. Eficiencia energética. Madrid.

Higueras, E., 2006. Urbanismo bioclimático ISBN: 978-84-252-2071-5. Gustavo Gili, Barcelona.

Matusiak, M., 2016. SolarBeam software.

Ministerio de Medio Ambiente y Medio Rural y Marino, 2010. Sistema de indicadores y condicionantes para ciudades grandes y medianas.

Ministerio de Vivienda del Gobierno de España, 2010. Libro Blanco de la Sostenibilidad en el Planeamiento Urbanístico Español. Madrid.

NBE-CT-79, 1979. Real Decreto. Norma Básica de la Edificación sobre condiciones térmicas en los edificios. España.

Olgyay, V., 1963. Design With Climate: Bioclimatic Approach to Architectural Regionalism. Princeton University Press, Princeton. 


\section{CONCLUSIONES Y FUTUROS DESARROLLOS}





\subsection{CONCLUSIONES}

La propuesta metodológica expuesta en esta tesis constituye una herramienta de diagnóstico energético del parque edificatorio residencial existente en tejidos urbanos consolidados. Tras desarrollar el trabajo, se extrae un conjunto de conclusiones que se presentan a continuación, de forma general y según cada uno de los objetivos planteados al inicio de la investigación.

\section{Conclusiones generales}

- El auge en el sector de la edificación residencial tuvo lugar en los años previos a la introducción de normativa relativa a la eficiencia energética en los edificios. Este hecho deja como legado un extenso parque de edificios residenciales obsoleto con respecto a los estándares actuales sobre ahorro y consumo de energía, que requiere ser intervenido y rehabilitado energéticamente.

- El marco normativo actual, además de fijar su mirada en la ciudad consolidada, otorga a las administraciones locales un papel estratégico para llevar a cabo las actuaciones de rehabilitación edificatoria y de renovación urbana. El grado de compromiso que la administración asuma será clave para lograr el éxito de estos procesos, pero también existe la necesidad de dotar a la administración de herramientas que faciliten la identificación de las áreas urbanas energéticamente más vulnerables y la implementación de actuaciones.

- A pesar de que existen metodologías ya desarrolladas para evaluar energéticamente el parque edificatorio, ninguna de ellas satisface por completo el conjunto de requisitos identificados como necesarios a integrar por una metodología de evaluación energética.

- La metodología propuesta ofrece versatilidad, pues permite la incorporación de nuevas covariables, que podrían ser integradas en las ecuaciones de predicción con el fin de investigar otros aspectos de la morfología urbana o del edificio, y la relación de estos con el comportamiento energético del parque edificado.

- El enfoque urbano de la metodología trata el aspecto energético desde una perspectiva global e integradora, de manera que los indicadores energéticos desarrollados podrían ser incorporados a una herramienta de evaluación de la sostenibilidad urbana (HESU) para evaluar el aspecto energético como parte integrante de la sostenibilidad urbana.

\section{Conclusiones relativas al Objetivo 1}

Conocer el estado del arte sobre cada una de las temáticas que se abordan en la tesis

- La normativa relacionada con la eficiencia energética de los edificios está en constante evolución y concede progresivamente más importancia a los aspectos pasivos que afectan al comportamiento energético del parque edificatorio.

- Una HESU debe ser adaptable a las características del entorno en el cual se implementa y reflejar y evaluar con objetividad las particularidades que lo definen, tanto en lo que se refiere a los aspectos físicos como al contexto socio-económico.

- Es recomendable que los indicadores propuestos por una HESU sean cuantitativos, de manera que evalúen, a través de una escala de puntuación, el nivel de cumplimiento de las exigencias 
establecidas por cada indicador. Integrar un método de ponderación que relacione el peso de cada indicador con el resto, también contribuye a aumentar la objetividad de la herramienta.

- En una metodología de evaluación energética, el enfoque bottom-up es el adecuado cuando el objetivo de la misma es evaluar el comportamiento energético de un parque edificatorio con precisión. En la metodología propuesta se adopta este enfoque, el cual permite evaluar una muestra representativa de edificios y extrapolar las conclusiones a una escala urbana.

- El procedimiento de cálculo adecuado para llevar a cabo la evaluación energética de edificios, con un nivel alto de precisión, es la simulación dinámica.

\section{Conclusiones relativas al Objetivo 2}

Identificar un conjunto de variables que permitan evaluar el comportamiento energético pasivo del parque edificatorio residencial existente

- Los aspectos ambientales son los que más atención reciben por las HESU y, dentro de estos, aquellos relacionados con la energía adquieren un papel relevante, posicionándose en el tercer lugar de los aspectos más tratados.

- Las metodologías de evaluación energética desarrolladas hasta la fecha consideran ampliamente los aspectos pasivos relacionados con el edificio. Sin embargo, los aspectos relacionados con la morfología urbana quedan relegados a un segundo plano, siendo sistemáticamente obviados.

- La relevancia que la categoría "morfología urbana" adquiere en las HESU, no obstante, es muy significativa, posicionándola en el primer lugar de los aspectos más tratados por los indicadores. Como demuestra la revisión, esta guarda una íntima relación con otras categorías, entre las que destacan "energía" y "edificación y vivienda". La estrecha relación entre estos tres aspectos denota la importancia de la morfología urbana para alcanzar la sostenibilidad urbana y demuestra también que esta no debe ser obviada al evaluar energéticamente un parque edificatorio. Como consecuencia de ello, la morfología urbana es uno de los aspectos integrantes en la metodología propuesta, a través de las covariables $\mathrm{MU}, \mathrm{H} / \mathrm{W}$ y $\mathrm{O}$.

- Existe un amplio consenso entre las metodologías analizadas en que los aspectos del edificio que están relacionados con su comportamiento pasivo son la compacidad, definida a través del factor de forma (S/V), y la transmitancia térmica de la envolvente, definida a través del año de construcción (A). Ambos aspectos son integrados en la metodología propuesta como covariables relacionadas con el edificio. Como se deriva del Anexo III Análisis detallado de la demanda de refrigeración, la inercia térmica tiene una importancia relevante en el comportamiento energético de los edificios, influyendo en el desfase térmico y la amortiguación de onda térmica del cerramiento. Así, en el caso de soluciones constructivas antiguas, la elevada inercia térmica de los cerramientos contribuye a mantener la temperatura operativa interior del edificio alrededor de la temperatura de consigna de verano. Ello impide que las temperaturas altas exteriores se transfieran hacia el interior del edificio, evitando situaciones de disconfort y haciendo prácticamente nula la demanda de refrigeración. Por ello, además de la covariable $A$, que considera las propiedades térmicas estáticas, podría tenerse en cuenta en futuros desarrollos de la metodología la integración de la inercia térmica, como propiedad dinámica de la envolvente térmica.

- Se seleccionan como indicadores energéticos de evaluación pasiva (o variables respuesta) la demanda energética de refrigeración $\left(D E_{r}\right)$ y de calefacción $\left(D E_{c}\right)$ y las horas de disconfort en verano $\left(H D_{v}\right)$ e invierno $\left(H D_{i}\right)$. 


\section{Conclusiones relativas al Objetivo 3}

Proponer un procedimiento para caracterizar el parque residencial de edificios de un entorno urbano consolidado e identificar la taxonomía urbana representativa

- El procedimiento definido para la caracterización del parque edificatorio residencial existente permite la identificación de manzanas urbanas por un lado, y de tipologías edificatorias por otro, lo que conduce a obtener la taxonomía urbana representativa del área objeto de estudio. Ello tiene como finalidad la simplificación del proceso de evaluación energética, pues únicamente será necesario modelar una muestra representativa de edificios, cuyos resultados pueden ser extrapolados a la escala urbana.

- El desarrollo de esta caracterización en un entorno SIG facilita el proceso y permite crear una base de datos georreferenciada que servirá también para representar los resultados del diagnóstico energético en mapas urbanos energéticos.

\section{Conclusiones relativas al Objetivo 4}

Desarrollar un modelo de predicción, basado en los métodos empírico y estadístico, que permita estimar, a escala urbana, el comportamiento energético de los edificios, a través de los indicadores y covariables previamente identificados

- Dentro del enfoque bottom-up, la técnica experimental (o de ingeniería) permite definir detalladamente los parámetros de cálculo durante la simulación energética y considerar todas las covariables seleccionadas. En particular, la simulación dinámica permite desglosar de una forma pormenorizada la demanda energética del edificio (en calefacción y refrigeración) y conocer las horas de disconfort en cada momento a lo largo de todo un año tipo. Además, permite estimar otros parámetros relevantes como son la distribución de temperaturas, el balance térmico y las pérdidas energéticas a través de cada tipo de cerramiento, lo que posibilita indagar en las causas que provocan ciertos comportamientos. La evaluación energética se realiza sobre una muestra de edificios representativos seleccionados según los criterios establecidos en la metodología, lo que permite simplificar el proceso de evaluación energética. Se simula un conjunto de hipótesis que reflejan la realidad urbana, planteadas por combinación de todas las covariables, de manera que se obtiene un extenso conjunto de resultados que serán tratados estadísticamente.

- En combinación con la técnica experimental, la técnica estadística permite modelizar los datos extraídos del análisis energético y obtener un conjunto de ecuaciones de predicción de los indicadores energéticos, $D E_{r}, D E_{c}, H D_{v}$ y $H D_{i}$, teniendo en cuenta el efecto de cada una de las covariables integradas en las ecuaciones.

- El método de predicción utilizado en la metodología para realizar la evaluación a escala urbana constituye su mayor novedad, puesto que este no se basa en la mera extrapolación de los resultados de evaluar un conjunto de edificios representativos a todos los edificios de su misma tipología, como proponen la mayoría de metodologías existentes. En la metodología aquí propuesta, además de considerar las covariables a nivel de edificio, se tienen en cuenta covariables relativas al entorno urbano que también condicionan el comportamiento energético del parque edificatorio residencial ( $\mathrm{MU}, \mathrm{H} / \mathrm{W}$ y O). Considerando estos aspectos, los cuatro indicadores energéticos son determinados de forma individual para cada edificio incluido en el área de estudio, según el valor que adoptan las covariables que estos llevan asociadas. 
- El modelo permite ampliar el número de covariables, de manera que podrían incorporarse otros aspectos que sean susceptibles de influir en el comportamiento energético pasivo del parque edificatorio residencial.

\section{Conclusiones relativas al Objetivo 5}

Proponer un procedimiento que permita representar los resultados de implementar la metodología en mapas urbanos energéticos

- El nivel de implementación de la tecnología SIG es todavía bajo entre las metodologías existentes en la literatura. Sin embargo, el desarrollo de la metodología propuesta en un entorno SIG, tal y como queda demostrado en el caso de aplicación, facilita el tratamiento de un gran volumen de información y permite generar mapas urbanos energéticos para identificar con claridad las áreas urbanas con mayor vulnerabilidad energética. Ello pone a disposición del usuario una interfaz visual para representar los resultados de implementar la metodología.

\section{Conclusiones relativas al Objetivo 6}

Implementar la metodología propuesta en un caso de aplicación

Como resultado de implementar la metodología en el barrio propuesto de Castellón de la Plana, se extraen las siguientes conclusiones:

- La inclusión de todas las covariables identificadas contribuye a mejorar el modelo de predicción. Se identifica que todas las variables son significativas, lo que refleja la pertinencia de incluir todas ellas en las cuatro ecuaciones de predicción obtenidas tras la modelización estadística. No obstante, se identifica que no todas las covariables son significativas al mismo nivel, por lo que unas tienen más influencia que otras sobre el comportamiento energético pasivo del parque edificatorio residencial. Así, las covariables se muestran significativas en el siguiente orden: $\mathrm{S} / \mathrm{V}, \mathrm{A}$ y $\mathrm{H} / \mathrm{W}$ por igual, $\mathrm{MU}, \mathrm{O}$.

- En relación al factor de forma del edificio, esta se presenta como la covariable más significativa del modelo. Valores bajos de $\mathrm{S} / \mathrm{V}$ (edificios más compactos) llevan asociada una menor demanda energética de calefacción, aunque incrementan ligeramente la demanda de refrigeración. A pesar de ello, es recomendable el diseño de edificios con un bajo factor de forma.

- En relación al año de construcción (A), los edificios de construcción más reciente presentan una menor demanda de calefacción, obviamente propiciada por las mejores prestaciones de su envolvente térmica, pero en contraposición presentan una peor demanda de refrigeración. La gran inercia térmica de las fachadas de los edificios antiguos favorece la amortiguación del paso de calor, reduciendo así la demanda energética en el periodo estival, particularmente, en edificios construidos con anterioridad a 1940, cuyas fachadas estaban constituidas mayoritariamente por muros de carga.

- En relación a la proporción de calle, ratios altas H/W implican menor demanda de refrigeración, pero también mayor demanda de calefacción. Puesto que la demanda de calefacción en el barrio es la más relevante, conviene diseñar entornos urbanos con una relación $\mathrm{H} / \mathrm{W}$ máxima de 0,53 , para evitar que los edificios enfrentados generen sombras y perjudiquen la demanda de calefacción, incrementándola. La corrección de la demanda de refrigeración en el periodo estival es menos crítica, pues el exceso de radiación solar puede controlarse a través de la disposición de protecciones solares que contribuyen a reducir dicha demanda. 
- En relación a la tipología de manzana urbana, la $\mathrm{MU}_{1}$, la cual integra un gran patio de manzana, resulta la más favorable, pues comporta un mejor confort térmico para los ocupantes de los edificios tanto en verano como en invierno.

- En relación a la orientación (0), las simulaciones realizadas adicionalmente demuestran que la morfología urbana puede modificar enormemente el efecto natural de las orientaciones, pudiendo llegar a ser muy perjudicial en la demanda energética y el confort térmico. Por ello, conviene respetar una relación $\mathrm{H} / \mathrm{W}$ baja y diseñar manzanas urbanas con patios de manzana $\left(\mathrm{MU}_{1}\right)$ que garanticen soleamiento en dos de las fachadas de los edificios con orientaciones opuestas, lo que hace mejorar considerablemente su comportamiento energético. Por otro lado, conviene diseñar el eje de las calles en dirección E-O y orientar el lado de mayor dimensión de la geometría rectangular de la manzana a S. La orientación óptima de la normal de las fachadas resulta en un ángulo de $18^{\circ} \mathrm{E}$, con respecto a $\mathrm{S}$.

- El desarrollo de mapas urbanos energéticos permite visualizar con claridad aquellos conjuntos edificatorios del barrio que más energía requieren para alcanzar las condiciones óptimas de confort térmico. Precisamente, ellos coinciden con las manzanas urbanas más antiguas.

- Reducir la demanda energética de calefacción en el barrio supone el mayor reto, pues esta supera con creces a la demanda energética de refrigeración. Es la demanda energética de calefacción, pues, donde se encuentra el mayor potencial de ahorro, por lo que las estrategias de acondicionamiento a adoptar deberán ir encaminadas a reducir, prioritariamente, la misma.

- En análisis en profundidad de los resultados de la evaluación energética permite establecer un conjunto de estrategias de acondicionamiento pasivo, tanto para el entorno urbano como para el edificio, en el tejido existente en el barrio y en nuevas planificaciones urbanas. La propuesta de una nueva morfología urbana en base a estas estrategias evidencia el gran potencial que supone apostar por un adecuado diseño urbano, pudiéndose alcanzar ahorros energéticos de, aproximadamente, un $60 \%$.

- Realizar el diagnóstico energético en todos los barrios de la ciudad permitiría comparar su comportamiento energético e identificar aquellos barrios más vulnerables, a los que se les asocia una necesidad preferente de rehabilitación energética.

- La implementación de la metodología en un municipio puede servir de apoyo a la administración local y otros agentes durante la elaboración de políticas energéticas y la toma de decisiones, y constituir un instrumento para la propuesta de estrategias tanto para la intervención en tejidos existentes ya consolidados, como para el diseño de futuros planeamientos urbanos.

\subsection{FUtUROS DESARROLLOS}

Tras el desarrollo del trabajo se han obtenido ciertos resultados en los que resultaría interesante profundizar, abriendo así paso a futuras líneas de investigación relacionadas con la tesis, las cuales se presentan a continuación.

\section{En relación al desarrollo de la metodología:}

- Implementar la metodología en otros patrones urbanos (irregular, radial, lineal, etc.) para determinar diferentes conjuntos de ecuaciones de predicción que complementen al conjunto aquí obtenido. Ello permitiría caracterizar energéticamente toda una ciudad y comparar el comportamiento energético de diferentes áreas urbanas. 
- Integrar nuevas covariables en la metodología para investigar su efecto sobre el comportamiento energético pasivo del parque edificatorio residencial. Como por ejemplo podrían ser, el efecto de la inercia térmica de los cerramientos de la envolvente del edificio u otros aspectos bioclimáticos relacionados con el urbanismo (viento, vegetación, etc.) y que son considerados en las HESU.

- Integrar el uso de la tecnología BIM (Building Information Modelling) en el desarrollo de la metodología e interrelacionarla con la tecnología SIG. Ello permitiría, además de georreferenciar la información urbana en mapas mediante SIG, alcanzar un nivel mucho más profundo de detalle a nivel de edificio mediante BIM. Las herramientas BIM permiten la gestión de datos del edificio durante su ciclo de vida, de manera que una gran cantidad de información constructiva del edificio queda almacenada. Esta podría ser tratada para explorar otros aspectos significativos en el comportamiento energético del parque edificatorio residencial.

\section{En relación a la aplicación de la metodología:}

- Obtener datos de consumo energético real, a través de facturas energéticas o de la monitorización del edificio, y compararlos con datos experimentales simulados de demanda energética. Ello permitiría investigar los factores que influyen en la desviación entre demanda y consumo, como podrían ser el patrón de comportamiento de los ocupantes, su poder adquisitivo o su nivel de concienciación medioambiental, los cuales resultan de difícil estimación durante el proceso de simulación, pero, sin embargo, tienen una gran influencia en el consumo energético final del edificio, provocando grandes desviaciones.

- Como se desprende del análisis de las HESU, los aspectos socio-económico son temas poco abordados en el análisis de la sostenibilidad urbana. Sin embargo, su elevada influencia en el consumo energético del parque edificado, hace que sean aspectos interesantes a estudiar e incorporar en futuras posibles mejoras de la metodología. Así, podrían explorarse nuevas covariables socio-económicas asociadas a los consumos. Ello podría realizarse por medio de encuestas que, además de recoger información socio-económica sobre los usuarios, podrían recabar información sobre posibles intervenciones o reformas que hayan experimentado los edificios, para ajustar las características constructivas de su envolvente térmica.

- Determinado el diagnóstico energético de un área urbana, resulta interesante estudiar mejoras de eficiencia energética, pasivas y activas, y cuantificar sus beneficios en el comportamiento energético del parque edificatorio residencial. La base de datos SIG y la evaluación energética de los edificios representativos, como resultados de la implementación de la metodología, servirían como base en este estudio. Ello haría posible el diseño de diversos escenarios, como son, por ejemplo, la cuantificación del ahorro obtenido tras implementar una determinada estrategia, o estudiar los efectos de la puesta en práctica de una nueva normativa u ordenanza municipal.

- La caracterización del parque edificatorio residencial de la ciudad y la base de datos SIG obtenida pueden emplearse en otros estudios con diferente finalidad, como, por ejemplo, el análisis de aspectos sociales y económicos. Así, la incorporación de nueva información a la base de datos permitiría el cruce de información para establecer relaciones de dependencia entre estos y el aspecto energético.

- Analizar el impacto de la implementación de soluciones constructivas de rehabilitación edificatoria integrando, además del aspecto energético, el aspecto ambiental a través de la metodología de Análisis de Ciclo de Vida. 


\section{PUBLICACIONES RELACIONADAS}

Propuesta metodológica para la caracterización del comportamiento energético pasivo del parque edificatorio residencial existente considerando su contexto urbano. 

Las publicaciones derivadas de la presente tesis, según cada una de las temáticas, son las que se exponen en la Tabla 8.1.

Tabla 8.1 Publicaciones relacionadas con la tesis

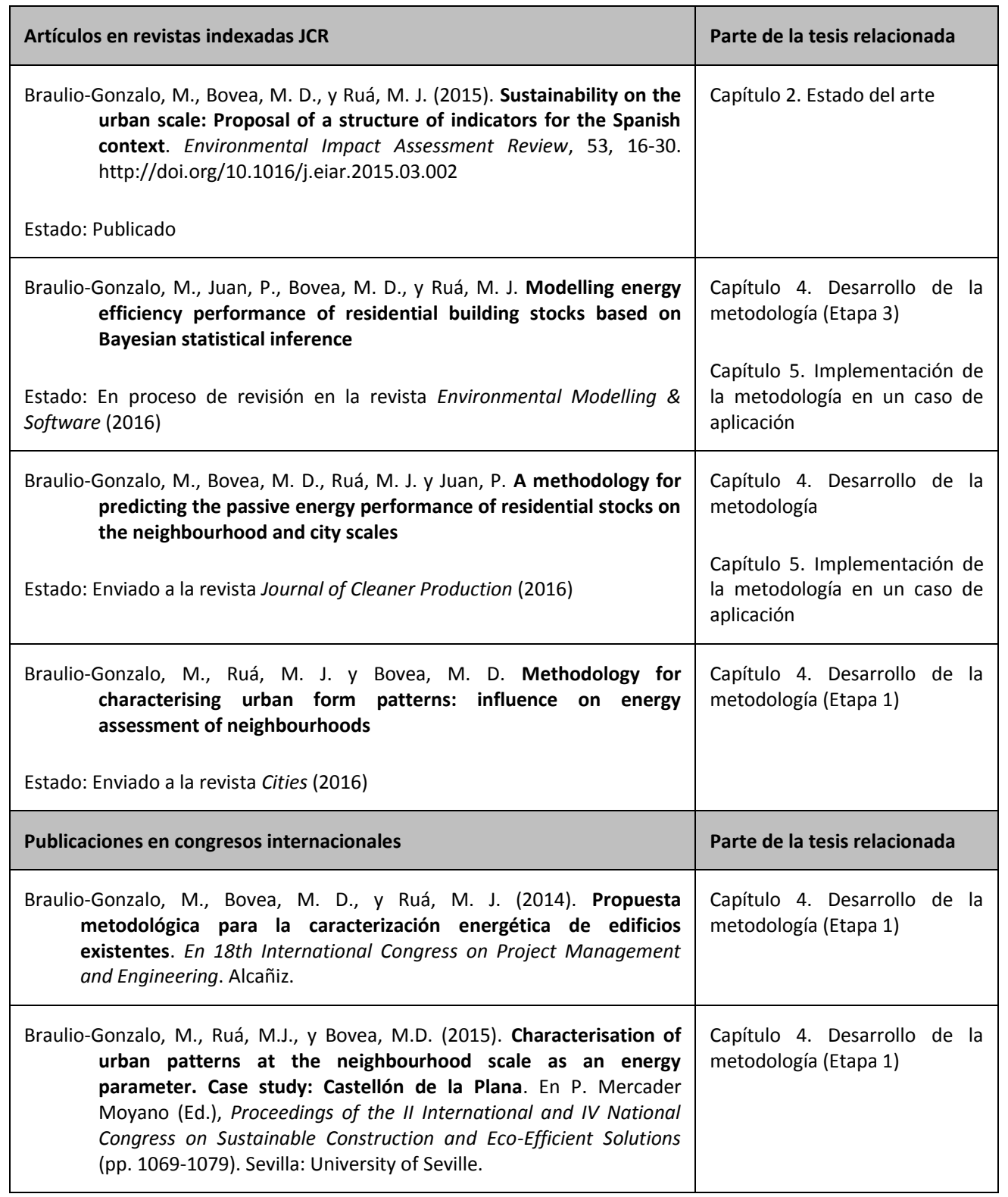





\section{ANEXO I. LISTADO DE INDICADORES DE SOSTENIBILIDAD URBANA}



Tabla Al.1 Lista de indicadores en la herramienta LEED ND

\begin{tabular}{|c|c|}
\hline Code & Categories / Indicators \\
\hline & SMART LOCATION AND LINKAGE \\
\hline LEED.1 & Smart Location \\
\hline LEED. 2 & Imperilled Species and Ecological Communities \\
\hline LEED.3 & Wetland and Water Body Conservation \\
\hline LEED.4 & Agricultural Land Conservation \\
\hline LEED.5 & Floodplain Avoidance \\
\hline LEED. 6 & Preferred Locations \\
\hline LEED.7 & Brownfield Redevelopment \\
\hline LEED.8 & Locations with Reduced Automobile Dependence \\
\hline LEED.9 & Bicycle Network and Storage \\
\hline LEED.10 & Housing and Jobs Proximity \\
\hline LEED.11 & Steep Slope Protection \\
\hline LEED.12 & Site Design for Habitat or Wetland and Water Body Conservation \\
\hline LEED.13 & Restoration of Habitat or Wetlands and Water Bodies \\
\hline \multirow[t]{2}{*}{ LEED.14 } & Long-Term Conservation Management of Habitat or Wetlands and Water Bodies \\
\hline & NEIGHBORHOOD PATTERN AND DESIGN \\
\hline LEED.15 & Walkable Streets \\
\hline LEED.16 & Compact Development \\
\hline LEED.17 & Connected and Open Community \\
\hline LEED.18 & Walkable Streets \\
\hline LEED.19 & Compact Development \\
\hline LEED. 20 & Mixed-Use Neighbourhood Centres \\
\hline LEED. 21 & Mixed-Income Diverse Communities \\
\hline LEED. 22 & Reduced Parking Footprint \\
\hline LEED.23 & Street Network \\
\hline LEED.24 & Transit Facilities \\
\hline LEED. 25 & Transportation Demand Management \\
\hline LEED. 26 & Access to Civic and Public Spaces \\
\hline LEED. 27 & Access to Recreation Facilities \\
\hline LEED. 28 & Visitability and Universal Design \\
\hline LEED.29 & Community Outreach and Involvement \\
\hline LEED.30 & Local Food Production \\
\hline LEED.31 & Tree-Lined and Shaded Streets \\
\hline \multirow[t]{2}{*}{ LEED.32 } & Neighbourhood Schools \\
\hline & GREEN INFRASTRUCTURE AND BUILDINGS \\
\hline LEED.33 & Certified Green Building \\
\hline LEED.34 & Minimum Building Energy Efficiency \\
\hline LEED.35 & Minimum Building Water Efficiency \\
\hline LEED.36 & Construction Activity Pollution Prevention \\
\hline LEED.37 & Certified Green Buildings \\
\hline LEED.38 & Building Energy Efficiency \\
\hline LEED.39 & Building Water Efficiency \\
\hline LEED.40 & Water-Efficient Landscaping \\
\hline LEED.41 & Existing Building Reuse \\
\hline LEED.42 & Historic Resource Preservation and Adaptive Use \\
\hline LEED.43 & Minimized Site Disturbance in Design and Construction \\
\hline LEED.44 & Stormwater Management \\
\hline LEED.45 & Heat Island Reduction \\
\hline LEED.46 & Solar Orientation \\
\hline LEED.47 & On-Site Renewable Energy Sources \\
\hline LEED.48 & District Heating and Cooling \\
\hline LEED.49 & Infrastructure Energy Efficiency \\
\hline
\end{tabular}


Tabla Al.1 Lista de indicadores en la herramienta LEED ND (continuación)

\begin{tabular}{ll}
\hline Code & Categories / Indicators \\
\hline LEED.50 & Wastewater Management \\
LEED.51 & Recycled Content in Infrastructure \\
LEED.52 & Solid Waste Management Infrastructure \\
LEED.53 & Light Pollution Reduction \\
\hline & INNOVATION AND DESIGN PROCESS \\
\hline LEED.54 & Innovation and Exemplary Performance \\
LEED.55 & LEED ${ }^{\circledR}$ Accredited Professional \\
\hline & REGIONAL PRIORITY CREDIT \\
\hline LEED.56 & Regional Priority \\
\hline
\end{tabular}


Tabla Al.2 Lista de indicadores en la herramienta BREEAM Communities

\begin{tabular}{|c|c|}
\hline Code & Categories / Indicators \\
\hline & CLIMATE \& ENERGY \\
\hline BRE.1 & Flood and risk assessment (Location) \\
\hline BRE.2 & Surface water runoff \\
\hline BRE.3 & Rainwater SUDS \\
\hline BRE.4 & Heat Island \\
\hline BRE.5 & Energy Efficiency \\
\hline BRE.6 & Onsite Renewables \\
\hline BRE.7 & Future Renewable(s) \\
\hline BRE.8 & Services \\
\hline BRE.9 & Water consumption \\
\hline BRE.10 & Design-Weather Resilience \\
\hline \multirow[t]{2}{*}{ BRE.11 } & Sub/smart-metering \\
\hline & RESOURCES \\
\hline BRE.12 & Low impact \\
\hline BRE.13 & Locally sourced materials \\
\hline BRE.14 & Road Construction \\
\hline BRE.15 & Resource Efficiency \\
\hline BRE.16 & Groundwater \\
\hline \multirow[t]{2}{*}{ BRE.17 } & Land Remediation \\
\hline & PLACE SHAPING \\
\hline BRE.18 & Sequential Approach \\
\hline BRE.19 & Land Reuse \\
\hline BRE.20 & Building Reuse \\
\hline BRE.21 & Landscaping \\
\hline BRE.22 & Design and access \\
\hline BRE.23 & Green areas \\
\hline BRE.24 & Local Demographics \\
\hline BRE.25 & Affordable Housing \\
\hline BRE.26 & Secured by Design \\
\hline BRE.27 & Active Frontages \\
\hline BRE.28 & Defensive Spaces \\
\hline BRE.29 & Local Vernacular \\
\hline BRE.30 & Security Lighting \\
\hline BRE.31 & Form of Development-Connectivity \\
\hline \multirow[t]{2}{*}{ BRE.32 } & Form of Development-Pedestrian Movement \\
\hline & TRANSPORT \\
\hline BRE.33 & Location/Capacity \\
\hline BRE.34 & Availability-Frequency \\
\hline BRE.35 & Facilities \\
\hline BRE.36 & Local Amenities \\
\hline BRE.37 & Network-cycling \\
\hline BRE.38 & Facilities-cycling \\
\hline BRE.39 & Car clubs \\
\hline BRE.40 & Flexible parking-Traffic \\
\hline BRE.41 & Local parking-Traffic \\
\hline BRE.42 & Home Zones-Traffic \\
\hline BRE.43 & Transport Assessment-Traffics \\
\hline BRE.44 & Electric vehicle charching points-Low carbon transport \\
\hline BRE.45 & Transport Impacts-Road design \\
\hline BRE.46 & Commercial LGV Plan-Vehicular Access \\
\hline
\end{tabular}


Tabla Al.2 Lista de indicadores en la herramienta BREEAM Communities (continuación)

\begin{tabular}{ll}
\hline Code & Categories / Indicators \\
\hline & COMMUNITY \\
\hline BRE.47 & Inclusive Design \\
BRE.48 & Consultation \\
BRE.49 & Development user guide \\
BRE.50 & Management and operation \\
\hline & ECOLOGY \\
\hline BRE.51 & Ecological Survey \\
BRE.52 & Biodiversity Action Plan \\
BRE.53 & Native Flora \\
BRE.54 & Wildlife corridors \\
\hline & BUSINESS \\
\hline BRE.55 & Business Priority Sectors \\
BRE.56 & Labour and Skills \\
BRE.57 & Employment \\
BRE.58 & New business \\
BRE.59 & Investment \\
\hline & BUILDINGS \\
\hline BRE.60 & Domestic-Code for sustainable homes \\
BRE.61 & Domestic-Code for sustainable homes \\
BRE.62 & Building refurbishment \\
\hline & INNOVATION \\
\hline BRE.63 & Innovation \\
\hline &
\end{tabular}


Tabla AI.3. Lista de indicadores en la herramienta CASBEE UD

\begin{tabular}{|c|c|}
\hline Code & Categories/Indicators \\
\hline & QUD1 Natural Environment (microclimates and ecosystems) \\
\hline & 1.1.1 Consideration and conservation of microclimates in pedestrian space in summer \\
\hline CASBEE.1 & 1.1.1.1 Mitigation of heat island effect with the passage of air \\
\hline CASBEE.2 & 1.1.1.2 Mitigation of heat island effect with shading \\
\hline CASBEE.3 & 1.1.1.3 Mitigation of heat island effect with green space and open water etc. \\
\hline \multirow[t]{2}{*}{ CASBEE.4 } & 1.1.1.4 Consideration for the positioning of heat exhaust \\
\hline & 1.1.2 Consideration and conservation of terrain \\
\hline CASBEE. 5 & 1.1.2.1 Building layout and shape design that consider existing topographic character \\
\hline CASBEE. 6 & 1.1.2.2 Conservation of topsoil \\
\hline \multirow[t]{2}{*}{ CASBEE. 7} & 1.1.2.3 Consideration of soil contamination \\
\hline & 1.1.3 Consideration and conservation of water environment \\
\hline CASBEE. 8 & 1.1.3.1 Conservation of water bodies \\
\hline CASBEE.9 & 1.1.3.2 Conservation of aquifers \\
\hline \multirow[t]{2}{*}{ CASBEE.10 } & 1.1.3.3 Consideration of water quality \\
\hline & 1.1.4 Conservation and creation of habitat \\
\hline CASBEE.11 & 1.1.4.1 Grasping the potential of the natural environment \\
\hline CASBEE.12 & 1.1.4.2 Conservation or regeneration of natural resources \\
\hline CASBEE.13 & 1.1.4.3 Creating ecosystem networks \\
\hline \multirow[t]{2}{*}{ CASBEE.14 } & 1.1.4.4 Providing a suitable habitat for flora and fauna \\
\hline & 1.1.5 Other consideration for the environment inside the designated area \\
\hline CASBEE.15 & 1.1.5.1 Ensuring good air quality, acoustic and vibration environments \\
\hline CASBEE.16 & 1.1.5.2 Improving the wind environment \\
\hline \multirow[t]{3}{*}{ CASBEE.17 } & 1.1.5.3 Securing sunlight \\
\hline & QUD2 Service functions for the designated area \\
\hline & 1.2.1 Performance of supply and treatment systems(mains water, sewerage and energy) \\
\hline CASBEE.18 & 1.2.1.1 Reliability of supply and treatment systems \\
\hline \multirow[t]{2}{*}{ CASBEE.19 } & $\begin{array}{l}\text { 1.2.1.2 Flexibility to meet changing demand and technical innovation in supply and treatment } \\
\text { systems }\end{array}$ \\
\hline & 1.2.2 Performance of information systems \\
\hline CASBEE.20 & 1.2.2.1 Reliability of information systems \\
\hline CASBEE.21 & 1.2.2.2 Flexibility to meet changing demand and technical innovation in information systems \\
\hline \multirow[t]{2}{*}{ CASBEE.22 } & 1.2.2.3 Usability (information systems) \\
\hline & 1.2.3 Performance of transportation systems \\
\hline CASBEE.23 & 1.2.3.1 Sufficient capacity of transportation systems \\
\hline \multirow[t]{2}{*}{ CASBEE.24 } & 1.2.3.2 Securing safety in pedestrian areas etc. \\
\hline & 1.2.4 Disaster and crime prevention performance \\
\hline CASBEE. 25 & 1.2.4.1 Understanding the risk from natural hazards \\
\hline CASBEE.26 & 1.2.4.2 Securing open space as wide area shelter \\
\hline CASBEE.27 & 1.2.4.3 Providing proper evacuation routes \\
\hline \multirow[t]{2}{*}{ CASBEE. 28} & 1.2.4.4 Crime prevention performance (surveillance and territoriality) \\
\hline & 1.2.5 Convenience of daily life \\
\hline CASBEE.29 & 1.2.5.1 Distance to daily-use stores and facilities \\
\hline CASBEE.30 & 1.2.5.2 Distance to medical and welfare facilities \\
\hline CASBEE.31 & 1.2.5.3 Distance to educational and cultural facilities \\
\hline CASBEE.32 & 1.2.6 Consideration for universal design \\
\hline
\end{tabular}


Tabla Al.3 Lista de indicadores en la herramienta CASBEE UD (continuación)

\begin{tabular}{|c|c|}
\hline Code & Categories/Indicators \\
\hline & QUD3 Contribution to the local community (history, culture, scenery and revitalization) \\
\hline & 1.3.1 Use of local resources \\
\hline CASBEE.33 & 1.3.1.1 Use of local industries, personnel and skills \\
\hline CASBEE.34 & 1.3.1.2 Conservation and use of historical, cultural and natural assets \\
\hline \multirow[t]{2}{*}{ CASBEE. 35} & 1.3.2 Contribution to the formation of social infrastructure \\
\hline & 1.3.3 Consideration for nurturing a good community \\
\hline CASBEE.36 & 1.3.3.1 Formation of local centres and fostering of vitality and communication \\
\hline \multirow[t]{2}{*}{ CASBEE. 37} & 1.3.3.2 Creation of various opportunities for public involvement \\
\hline & 1.3.4. Consideration for urban context and scenery \\
\hline CASBEE.38 & 1.3.4.1 Formation of urban context and scenery \\
\hline \multirow[t]{3}{*}{ CASBEE.39 } & 1.3.4.2 Harmony with surroundings \\
\hline & LRUD1 Environmental impact on microclimates, façade and landscape \\
\hline & 2.1.1 Reduction of thermal impact on the environment outside the designated area in summer \\
\hline CASBEE.40 & 2.1.1.1 Planning of building group layout and forms to avoid blocking wind \\
\hline CASBEE.41 & 2.1.1.2 Consideration for paving materials \\
\hline CASBEE.42 & 2.1.1.3 Consideration for building cladding materials \\
\hline \multirow[t]{2}{*}{ CASBEE.43 } & 2.1.1.4 Consideration for reduction of waste heat \\
\hline & 2.1.2 Mitigation of impact on geological features outside the designated area \\
\hline CASBEE.44 & 2.1.2.1 Prevention of soil contamination \\
\hline \multirow[t]{2}{*}{ CASBEE.45 } & 2.1.2.2 Reduction of ground subsidence \\
\hline & 2.1.3 Prevention of air pollution affecting outside the designated area \\
\hline CASBEE.46 & 2.1.3.1 Source control measures \\
\hline CASBEE.47 & 2.1.3.2 Measures concerning means of transport \\
\hline \multirow[t]{2}{*}{ CASBEE.48 } & 2.1.3.3 Atmospheric purification measures \\
\hline & 2.1.4 Prevention of noise, vibration and odor affecting outside the designated area \\
\hline CASBEE.49 & 2.1.4.1 Reduction of the impact of noise \\
\hline CASBEE.50 & 2.1.4.2 Reduction of the impact of vibration \\
\hline \multirow[t]{2}{*}{ CASBEE.51 } & 2.1.4.3 Reduction of the impact of odor \\
\hline & 2.1.5 Mitigation of wind hazard and sunlight obstruction affecting outside the designated area \\
\hline CASBEE.52 & 2.1.5.1 Mitigation of wind hazard \\
\hline \multirow[t]{2}{*}{ CASBEE.53 } & 2.1.5.2 Mitigation of sunlight obstruction \\
\hline & 2.1.6 Mitigation of light pollution affecting outside the designated area \\
\hline CASBEE.54 & 2.1.6.1 Mitigation of light pollution from lighting and advertising displays etc. \\
\hline \multirow[t]{3}{*}{ CASBEE. 55} & 2.1.6.2 Mitigation of sunlight reflection from building facade and landscape materials \\
\hline & LRUD2 Social infrastructure \\
\hline & 2.2.1 Reduction of mains water supply (load) \\
\hline CASBEE.56 & 2.2.1.1 Encouragement for the use of stored rainwater \\
\hline \multirow[t]{2}{*}{ CASBEE.57 } & 2.2.1.2 Water recirculation and use through a miscellaneous water system \\
\hline & 2.2.2 Reduction of rainwater discharge load \\
\hline CASBEE.58 & 2.2.2.1 Mitigation of surface water runoff using permeable paving and percolation trenches \\
\hline CASBEE.59 & $\begin{array}{l}\text { 2.2.2.2 Mitigation of rainwater outflow using retaining pond and flood control basins } \\
\text { 2.2.3 Reduction of the treatment load from sewage and graywater }\end{array}$ \\
\hline CASBEE.60 & 2.2.3.1 Load reduction using high-level treatment of sewage and graywater \\
\hline \multirow[t]{2}{*}{ CASBEE.61 } & 2.2.3.2 Load levelling using water discharge balancing tanks etc. \\
\hline & 2.2.4 Reduction of waste treatment load \\
\hline CASBEE.62 & 2.2.4.1 Reduction of collection load using centralized-storage facilities \\
\hline CASBEE.63 & 2.2.4.2 Installation of facilities to reduce the volume and weight of waste and employ composting \\
\hline \multirow[t]{2}{*}{ CASBEE.64 } & 2.2.4.3 Classification, treatment and disposal of waste \\
\hline & 2.2.5 Consideration for traffic load \\
\hline CASBEE.65 & 2.2.5.1 Reduction of the total traffic volume through modal shift \\
\hline \multirow[t]{2}{*}{ CASBEE.66 } & 2.2.5.2 Efficient traffic assignment on local road network \\
\hline & 2.2.6 Effective energy use for the entire designated area \\
\hline
\end{tabular}


Tabla AI.3 Lista de indicadores en la herramienta CASBEE UD (continuación)

\begin{tabular}{ll}
\hline Code Categories/Indicators \\
\hline CASBEE.67 & 2.2.6.1 Area network of unused and renewable energy \\
CASBEE.68 & 2.2.6.2 Load levelling of electrical power and heat through area network \\
CASBEE.69 & 2.2.6.3 Area network of high-efficient energy system \\
\hline & LRUD3 Management of the local environment \\
\hline & 2.3.1 Consideration of global warming \\
CASBEE.70 & 2.3.1.1 Construction and materials, etc. (global warming) \\
CASBEE.71 & 2.3.1.2 Energy (global warming) \\
CASBEE.72 & 2.3.1.3 Transportation (global warming) \\
& 2.3.2 Environmentally responsible construction management \\
CASBEE.73 & 2.3.2.1 Acquisition of ISO14001 certification \\
CASBEE.74 & 2.3.2.2 Reduction of by-products of construction \\
CASBEE.75 & 2.3.2.3 Energy saving activity during construction \\
CASBEE.76 & 2.3.2.4 Reduction of construction-related impact affecting outside the designated area \\
CASBEE.77 & 2.3.2.5 Selection of materials with consideration for the global environment \\
CASBEE.78 & 2.3.2.6 Selection of materials with consideration for impact on health \\
& 2.3.3 Regional transportation planning \\
CASBEE.79 & 2.3.3.1 Coordinating with the administrative master plans for transportation system \\
CASBEE.80 & 2.3.3.2 Measures for transportation demand management \\
& 2.3.4 Monitoring and management system \\
CASBEE.81 & 2.3.4.1 Monitoring and management system to reduce energy usage inside the designated \\
& area \\
CASBEE.82 & 2.3.4.2 Monitoring and management system to conserve the surrounding environment of \\
& the designated area
\end{tabular}


Tabla Al.4 Lista de indicadores en la herramienta ECOCITY

\begin{tabular}{|c|c|}
\hline Code & Element/Theme/Objective/Measure \\
\hline & 1. REGIONAL AND URBAN CONTEXT \\
\hline & 1.1 NATURAL ENVIRONMENT \\
\hline & 1.1.1 Strive for the protection of the surrounding landscape and its natural elements \\
\hline ECO.1 & $\begin{array}{l}\text { Consider the boundaries of the city as a zone for exchange between the city and surroundings (water } \\
\text { cycle, vegetation, wildlife, recreation) and create conditions for the penetration of the surrounding } \\
\text { landscape into the city. }\end{array}$ \\
\hline ECO.2 & Establish sound measures to avoid unplanned future extensions of settlements. \\
\hline ECO.3 & $\begin{array}{l}\text { Strive for a recreation of landscape/natural habitats in areas with a declining population or industry } \\
\text { ("shrinking cities"). }\end{array}$ \\
\hline ECO.4 & Preserve bio-diversity and habitats in the surrounding landscape. \\
\hline ECO.5 & Minimise the impact of harmful substances on vegetation, wildlife and water systems. \\
\hline ECO.6 & $\begin{array}{l}\text { Preserve or re-establish green corridors on the regional and municipal scale as open-space connections. } \\
\text { 1.1.2 Strive for the protection of the surrounding landscape and its natural elements }\end{array}$ \\
\hline ECO.7 & $\begin{array}{l}\text { Offer recreational areas in the surrounding landscape with attractive connections from the urban area } \\
\text { to help people relate to the natural environment and to offer opportunities for weekend recreation } \\
\text { close to residential areas. }\end{array}$ \\
\hline ECO.8 & $\begin{array}{l}\text { Develop and foster sustainable regional agriculture (e.g. organise direct marketing of regional food), } \\
\text { forestry and tourism, also maintaining the cultural landscape. }\end{array}$ \\
\hline ECO.9 & $\begin{array}{l}\text { Use surplus biomass from regional agriculture and forestry for energy generation. } \\
\text { 1.1.3 Plan in accordance with the climatic, topographical and geological setting }\end{array}$ \\
\hline
\end{tabular}

ECO.10 Use (and preserve) landscape and topographic elements that are important for the urban climate (e.g. groves and forests as cold air sources, lakes as climatic balancing elements, valleys and mountain sides as air exchange corridors) and avoid barriers in air exchange corridors.

ECO.11 Keep industry and unavoidable sources of air pollution out of areas and corridors which are important for the urban climate and consider the main wind directions when expanding settlement areas.

ECO.12 Consider the local climatic conditions for the design of public spaces (wind protection, roofs as rain protection, exposure to the sun, shadowing elements) and for building design (shape, materials, energy concept, etc.).

ECO.13 Take the local topography into account for the transport systems (e.g. for walking and cycling pathways), for energy-efficiency (e.g. by avoiding settlements on shadowy northern inclinations) and for water systems (e.g. rainwater management on the surface).

ECO.14 Plan with the geological conditions (soil, groundwater, etc.) e.g. for urban greenery, rainwater management and constructing buildings.

\subsection{BUILT ENVIRONMENT}

1.2.1 Strive for a polycentric, compact and transit-oriented urban structure

ECO.15 Strive for a polycentric structure of the city with good accessibility of basic facilities and of the city centre as the main provider of higher-order infrastructures and working places.

ECO.16 Organise the city as a network of mixed-use urban quarters with individual characteristics and identities.

ECO.17 Concentrate urban development at sites with a high potential for public transport, locating new settlements (and new buildings in existing settlements) along (potential) axes of public transport (Transit Oriented Development), and avoid developments that disturb open-space patterns between these axes (green fingers).

ECO.18 Integrate new and existing developments into public transport and communication networks on the local, metropolitan, regional, national and global scale.

ECO.19 Strive for land management on the regional and local scale.

ECO.20 Structure prices and subsidies to achieve changes in development patterns and the transportation system (e.g. building subsidies, road pricing, PT fares etc. differentiated according to location and time). 
Tabla Al.4 Lista de indicadores en la herramienta ECOCITY (continuación)

\begin{tabular}{|c|c|}
\hline Code & Element/Theme/Objective/Measure \\
\hline & 1.2.2 Consider concentration and decentralisation for supply and disposal systems \\
\hline ECO.21 & $\begin{array}{l}\text { Consider the decentralised concentration of energy supply systems such as district heating networks } \\
\text { (rather than either huge community heating systems on the scale of entire cities or quarters or very } \\
\text { small individual systems). }\end{array}$ \\
\hline ECO.22 & $\begin{array}{l}\text { Maximise the share of renewable energy sources on the regional and local level (e.g. wind power } \\
\text { stations or biomass cogeneration power plants from regional sources). }\end{array}$ \\
\hline ECO.23 & $\begin{array}{l}\text { Strive for the decentralisation of wastewater treatment on the site (wastewater wetland facilities) or in } \\
\text { buildings (grey water purification plants). }\end{array}$ \\
\hline ECO.24 & $\begin{array}{l}\text { Consider biogas generation from wastewater (black water) for the operation of co-generation or heat } \\
\text { plants on site. }\end{array}$ \\
\hline \multirow[t]{2}{*}{ ECO.25 } & Offer possibilities for composting and re-using organic waste on site. \\
\hline & 1.2.3 Promote use, re-use and revitalisation of the cultural heritage \\
\hline ECO.26 & $\begin{array}{l}\text { Respect the cultural heritage of the region regarding the historical urban grain (e.g. phases of growth } \\
\text { and development, hierarchy and design of street network, texture of building lots, land-use patterns). }\end{array}$ \\
\hline \multirow[t]{3}{*}{ ECO.27 } & $\begin{array}{l}\text { Refer to the regional and local building typologies (also regarding protection from sun, wind, rain, } \\
\text { snow, etc.), regional culture for living, aesthetics based on local craft skills, etc. and strive to maintain } \\
\text { and re-use existing elements such as buildings, open-space elements and infrastructure (also as a } \\
\text { contribution to a genius loci based on the continuity of the urban cultural heritage). }\end{array}$ \\
\hline & 2. URBAN STRUCTURE \\
\hline & 2.1 DEMAND FOR LAND \\
\hline
\end{tabular}

\subsubsection{Promote the reuse of soil and existing buildings to reduce the land demand and buildings}

ECO.28 Strive for a compact city using all possibilities for internal development e.g. in gaps between blocks or buildings (but avoiding overcrowding and ensuring adequate green spaces).

ECO.29 Prioritise the reuse of existing sites (brown field developments) in suitable locations.

ECO.30 Minimise the share of vacant dwellings, buildings and plots through municipal management (e.g. register of available plots/properties within the city, activities for inner city developments).

\subsubsection{Develop structures of qualified high density}

ECO.31 Aim at qualified high density to reduce land consumption and to promote a high social density as well as to promote viability and cost effectiveness of public transport, community heating systems and provision of basic facilities.

ECO.32 Consider issues which limit density such as passive and active use of solar energy, good day-lighting conditions, sufficient open spaces, surfaces for water management, air exchange corridors.

ECO.33 Concentrate the highest development densities around public transport stops.

ECO.34 Use compact and multi-storey building typologies for residential housing and commercial uses.

ECO.35 Consider increasing density by minimising land-demand for motorised traffic and parking.

\subsection{LAND USE}

2.2.1 Organise a balance of residential, employment and educational uses as well as supply (of goods and services), and social and recreational facilities

ECO.36 Provide a balanced ratio of residential housing and working places.

ECO.37 Provide a balanced ratio of residential housing and commercial units (especially retail for daily needs) as well as cultural, educational and social facilities (e.g. kindergarten, primary, secondary schools, general practitioners, pubs restaurants).

ECO.38 On new sites, include facilities attracting inhabitants of the entire community as focal points (community building).

ECO.39 Maintain and strengthen existing mix of uses while adding new uses into existing mono-functional areas.

ECO.40 Ensure that these facilities are distributed well to enable short travel distances (on foot, by bike or by public transport) within the neighbourhood or the city. 
Tabla Al.4 Lista de indicadores en la herramienta ECOCITY (continuación)

\begin{tabular}{ll}
\hline Code & Element/Theme/Objective/Measure \\
ECO.41 & $\begin{array}{l}\text { 2.2.2 Enable fine-meshed, mixed-use structures at building, block or neighbourhood level } \\
\text { Strive for variability and flexibility of urban and building structures to facilitate changes of use over }\end{array}$ \\
ECO.42. & $\begin{array}{l}\text { Optimise the locations for mixed-use at building level (e.g. with commercial uses on the lower floors, } \\
\text { residential uses higher up) or at block level (with commercial buildings on the northern edge of blocks } \\
\text { or with west or east orientation). }\end{array}$ \\
ECO.43 & Create differentiated areas with different meshes of mixed structures and different ratios of uses.
\end{tabular}

\subsection{PUBLIC SPACE}

\subsubsection{Provide attractive and liveable public space for everyday life, including considerations of} legibility and connectivity

ECO.44 Plan for sufficient public space (squares, convivial streetscapes, green areas) close to living and working environments.

ECO.45 Strive for multi-functionality (avoid mono-functionality) and a strong identity of public spaces.

ECO.46 Create varying urban fabrics of open spaces, building typologies and landscape elements for vivid neighbourhoods with a distinctive genius loci.

ECO.47 Plan a hierarchical system of public spaces (squares, parks, streetscapes) that is interconnected through pedestrian networks and provides changing attractions along spatial sequences; avoid architectural barriers.

ECO.48 Create opportunities for communication and encounter by designing open spaces to enable sufficient quantity and quality of possible social contacts in (high density) neighbourhood areas (e.g. in neighbourhood centres).

ECO.49 Orientate buildings towards public spaces (windows, entrances, attractive ground floor facades, which front appropriate uses).

ECO.50 Provide open-space elements and architecture of high aesthetic quality (water design, surfaces in streets and squares, facades, street furniture, etc.), enabling a variety of sensory experiences, also for children.

ECO.51 Minimise the share of road space provided solely for motor vehicles and the disturbance of public spaces by motorised traffic (bearing in mind especially safety and noise issues).

\subsection{LANDSCAPE / GREEN SPACES}

\subsubsection{Integrate natural elements and cycles into the urban tissue}

ECO.52 Create and conserve habitats for urban wildlife (animals and plants) and habitat networks (use linear elements to connect open spaces, avoid barriers, create stepping-stone habitats, consider ecological bridges), including green corridors into the surrounding landscape.

ECO.53 Maximise soft landscaping areas for planting (at ground level as well as on facades and roofs).

ECO.54 Create, maintain or recultivate/restore green and water elements within the city (trees, hedges, grassland, planting areas and containers, watercourses, fountains, etc.), especially those of bioclimatic importance.

ECO.55 Maintain the natural embankments and shore areas of surface waters (ponds, lakes, streams or rivers), where necessary restore them.

ECO.56 Minimise sealed surfaces (footprints of buildings, treatment of pavements, parking spaces, etc.).

ECO.57 Strive for a balanced hierarchy of public, semi-public and private green spaces, providing opportunities for gardening for the inhabitants, considering also city farms in appropriate locations.

ECO.58 Offer accessible areas to provide children with personal experience of and conscious perception of the natural environment. 
Tabla Al.4 Lista de indicadores en la herramienta ECOCITY (continuación)

\begin{tabular}{|c|c|}
\hline Code & Element/Theme/Objective/Measure \\
\hline & 2.5 URBAN COMFORT \\
\hline & 2.5.1 Strive for a high daily, seasonal and annual outdoor comfort \\
\hline ECO.59 & $\begin{array}{l}\text { Consider the exposure of public spaces to bioclimatic conditions (light, wind, sun, rain, snow, etc.) to } \\
\text { permit the use of public spaces throughout the day and the seasons. }\end{array}$ \\
\hline ECO.60 & $\begin{array}{l}\text { Develop the geometry of quarters and neighbourhoods according to the requirements of urban } \\
\text { ventilation (choose climatically favourable layouts and materials for green spaces, blocks and } \\
\text { buildings). }\end{array}$ \\
\hline ECO.61 & $\begin{array}{l}\text { Plan for and use water surfaces (e.g. as part of a rainwater management systems) to improve urban } \\
\text { comfort and to contribute to natural ventilation on the block or building level. }\end{array}$ \\
\hline ECO.62 & $\begin{array}{l}\text { Increase the absorption capacity of urban land for rainwater (and the filtering capacity for emissions) } \\
\text { by planting and maintaining trees and other vegetation, constructing green roofs and facades and by } \\
\text { leaving ground unsealed where appropriate. }\end{array}$ \\
\hline \multirow[t]{2}{*}{ ECO.63 } & $\begin{array}{l}\text { Reduce the impact of infrastructure for mobile telecommunications, electricity supply, electric railway } \\
\text { systems and other technical devices on people's health and well-being (avoiding their exposure to } \\
\text { electromagnetic radiation by keeping sufficient distances and using screening materials and } \\
\text { structures). }\end{array}$ \\
\hline & 2.5.2 Minimise noise and air pollution \\
\hline ECO.64 & $\begin{array}{l}\text { Avoid noise emissions at source by taking active measures to reduce emissions from traffic, commercial } \\
\text { uses, leisure and sports activities. }\end{array}$ \\
\hline ECO.65 & $\begin{array}{l}\text { Improve the air quality by reducing gaseous and particulate emissions from traffic, commercial and } \\
\text { industrial units, power stations and household heating systems at source. }\end{array}$ \\
\hline ECO.66 & $\begin{array}{l}\text { Control imissions through passive measures (sufficient distances, protective walls/embankments, } \\
\text { shelterbelt plantings, layout of blocks, buildings and floors). }\end{array}$ \\
\hline \multirow[t]{2}{*}{ ECO.67 } & Minimise the impact of construction works on urban comfort. \\
\hline & 2.6 BUILDINGS \\
\hline
\end{tabular}

\subsubsection{Maximise indoor comfort and resource conservation throughout the lifecycle of buildings}

ECO.68 Maintain and re-use existing buildings for existing uses or convert them for new uses and promote their refurbishment (especially regarding energy demand and supply).

ECO.69 Strive for low-energy or passive-house standard in terms of construction and heating, ventilation and air-conditioning (HVAC) equipment (building services).

ECO.70 Use building materials which are 'healthy' in production, construction, use and demolition.

ECO.71 Maximise the durability, detachability and the recyclability of materials and structures.

ECO.72 Allow for reverse-engineering, e.g. to enable later installation of HVAC equipment (building services).

ECO.73 Reduce maintenance requirements of buildings.

\subsubsection{Plan flexible, communicative and accessible buildings}

ECO.74 Use flexible building designs to facilitate change of use over time (e.g. from residential to commercial) as well as transformation and adaptation of internal spaces by the user.

ECO.75 Strive for the close connections of buildings to public spaces and for active frontages (facades, allocation of uses and entrances), avoiding architectural barriers to accessibility (lay-out of buildings causing detours, steps, etc.).

ECO.76 Strive for communicative buildings with innovative ideas for living.

ECO.77 Seek new housing concepts for senior citizens including mixed generation housing concepts ('young and old' projects). 
Tabla AI.4 Lista de indicadores en la herramienta ECOCITY (continuación)

\begin{tabular}{ll}
\hline Code & Element/Theme/Objective/Measure \\
\hline ECO.78 & $\begin{array}{l}\text { Consider that buildings are suitable for mixed-use structures (e.g. for commercial uses on the lower } \\
\text { floors, residential uses higher up). }\end{array}$ \\
\hline 3. TRANSPORT \\
\hline 3.1 SLOW MODES/PUBLIC TRANSPORT
\end{tabular}

3.1.1 Minimise distances (in time and space) between activities to reduce travel demand

ECO.79 Design pedestrian-oriented urban structures with short distances (see density, mixed use) also situating buildings so that they allow the planning of pedestrian networks without long detours (also avoiding main traffic arteries, which are difficult to cross, within a neighbourhood).

ECO.80 Integrate all important destinations (shops, schools, major employment locations) within mixed use neighbourhoods and/or close to public transport stops and ensure good connections to external destinations.

ECO.81 Create high quality open spaces and structures (squares, parks, streetscapes, etc.) close to residential areas to reduce demand for leisure travel.

\subsubsection{Give priority to pedestrian and cycle paths as the main network for internal neighbourhood} traffic

ECO.82 Interconnect pedestrian and cycle paths to a dense network, which is as far as possible independent from major routes for motorised travel but not so isolated as to create security problems.

ECO.83 Integrate public spaces and streetscapes of high spatial quality and changing public activities into the network for non-motorised modes (for attractive walking/cycling and for social control).

ECO.84 Plan for an attractive cycling network that allows speedy circulation also beyond the neighbourhood scale.

ECO.85 Eliminate danger and disturbances from motorised traffic.

ECO.86 Provide barrier-free accessibility to transport networks and buildings for everyone - including the handicapped and those with prams, pushchairs or carts to transport goods.

ECO.87 Provide attractive supporting infrastructure for pedestrians - with e.g. continuous weather protection (arcades, passages, roofed pavements) along the main routes as well as benches/seats - and for cyclists (parking and storage facilities for bikes, weather protection, etc.).

3.1.3 Give priority to public transport for the connections beyond the neighbourhood level

ECO.88 Integrate well-aligned public transport lines and corridors (close to people and allowing rapid connections) into the urban structure and design the structure of a new neighbourhood around the (optimised) routes of public transport.

ECO.89 Develop an integrated system of public transport (demand-responsive transport services, bus, light rail, heavy rail) to provide connections both within the municipalities and in regional networks and provide bike \& ride / kiss \& ride facilities at stops and interchanges.

ECO.90 Optimise distances between public transport stops to maximise rider catchments and provide central stops in the centre of new neighbourhoods.

ECO.91 Allocate stops to uses and vice versa in such a way that the majority of important public facilities are situated near the stops. 
Tabla Al.4 Lista de indicadores en la herramienta ECOCITY (continuación)

\begin{tabular}{|c|c|}
\hline Code & Element/Theme/Objective/Measure \\
\hline & $\begin{array}{l}\text { 3.1.4 Provide mobility management measures to support modal shift to environmentally } \\
\text { compatible modes }\end{array}$ \\
\hline ECO.92 & $\begin{array}{l}\text { Establish mobility centres providing comprehensive and easily accessible information on local public } \\
\text { transport and railway including schedules and inter-modal travel options (mobility help-desk, internet } \\
\text { platform) and offering comprehensive services for diverse transport demands (e.g. sale of public } \\
\text { transport tickets; reservation for demand responsive transport; bicycle station for parking, repair, } \\
\text { hire, etc.; car-sharing and hire systems, ride-share agency). }\end{array}$ \\
\hline ECO.93 & $\begin{array}{l}\text { Provide real-time information on timetables for passengers at stations, in vehicles and on the internet } \\
\text { (arrivals, departures, connections and schedule changes) from a control station. }\end{array}$ \\
\hline ECO.94 & $\begin{array}{l}\text { Target new households with tailored advice on mobility alternatives, possibly including introductory } \\
\text { offers on public transport season tickets, car clubs, etc. }\end{array}$ \\
\hline ECO.95 & $\begin{array}{l}\text { Offer "mobility packages", e.g. including car sharing offers, public transport information, reduced cost } \\
\text { season ticket, low cost home delivery services, discounts on taxi services, etc. }\end{array}$ \\
\hline ECO.96 & $\begin{array}{l}\text { Organise awareness-raising-campaigns and provide advice for larger institutions (e.g. businesses, } \\
\text { schools, etc.) on sustainable organisation of mobility of both employees and customers, as well as the } \\
\text { use of their own vehicle fleet. }\end{array}$ \\
\hline
\end{tabular}

\subsection{INDIVIDUAL MOTORISED TRAVEL}

\subsubsection{Reduce volume and speed of individual motorised traffic}

ECO.97 Reduce the speed of motorised traffic by using traffic calming measures and appropriate regulations.

ECO.98 Strive for a differentiated shape and hierarchy of the road network (lane width, speeds, etc.) with lower levels of the hierarchy not dominated by motorised traffic (e.g. home zones, bicycle streets) and with minimum through traffic.

ECO.99 Plan car-free or car-reduced areas of sufficient size to allow all the advantages of living and moving without a car to be experienced.

ECO.100 Minimise land consumption for motorised traffic (length and width of streets, areas for parking).

ECO.101 Promote efficient use of cars (e.g. through car-sharing or an agency for ride-sharing).

ECO.102 Restrict access to particular areas for non-public motorised traffic (e.g. to city or neighbourhood centres).

\subsubsection{Support the reduction of motorised traffic through parking management}

ECO.103 Reduce the provision of parking spaces (i.e. the required ratio of parking space per dwelling or work space), especially in central areas with good public transport access; develop car-reduced and car-free areas.

ECO.104 Manage demand for parking through parking charges in central areas to reduce car traffic there.

ECO.105 Minimise parking spaces in public areas to reduce the impact of private cars on the quality of public spaces and reduce overall land consumption for remaining parking places (multi-storey parking, mechanical systems).

ECO.106 Concentrate parking spaces in collective car parks and district parking garages within an acceptable distance to dwellings and not directly at the front door or even inside residential buildings (locating district parking lots at least the same average distances away as public transit stops).

\subsection{TRANSPORT OF GOODS}

3.3.1 develop a neighbourhood logistics and delivery concept to minimise the need for individual load carrying by car 
Tabla Al.4 Lista de indicadores en la herramienta ECOCITY (continuación)

\begin{tabular}{|c|c|}
\hline Code & Element/Theme/Objective/Measure \\
\hline ECO.107 & $\begin{array}{l}\text { Organise a neighbourhood logistics system (neighbourhood logistics / distribution centre, shopping } \\
\text { boxes, etc.) including co-ordinated goods delivery to private households (also for products ordered via } \\
\text { e-commerce); using alternatively fuelled vehicles (e.g. electricity from renewable sources or } \\
\text { hydrogen). }\end{array}$ \\
\hline ECO.108 & $\begin{array}{l}\text { Integrate locations for waste collection and storage facilities (containers, etc.) in the urban and } \\
\text { building structure to ensure efficient access for collection vehicles. }\end{array}$ \\
\hline ECO.109 & $\begin{array}{l}\text { Locate facilities generating demand for goods transportation at sites allowing short distances for city } \\
\text { logistics. }\end{array}$ \\
\hline ECO.110 & $\begin{array}{l}\text { Use information system technologies to optimise routes of delivery, waste collection and } \\
\text { (construction) material transport. } \\
\text { 3.3.2 Plan efficient construction logistics }\end{array}$ \\
\hline ECO.111 & Promote the use of local materials to minimise construction traffic. \\
\hline ECO.112 & Plan the re-use of excavation materials on-site as far as possible. \\
\hline \multirow[t]{3}{*}{ ECO.113 } & Organise necessary construction traffic (removal, delivery, distribution) in an effective way. \\
\hline & 4. ENERGY AND MATERIAL FLOWS \\
\hline & 4.1 ENERGY \\
\hline
\end{tabular}

\subsubsection{Optimise energy efficiency of the urban structure}

ECO.114 Design compact settlements and compact buildings weighing up low surface to volume ratios against the need for solarisation (next measure) and day-lighting.

ECO.115 Solarise the urban structure: layout of buildings for passive heating/cooling and for natural daylighting (orientate buildings to the sun, avoid shading by optimising the heights of buildings in relation to distances between them, design roofs to use solar applications efficiently).

ECO.116 Strive for high-density developments enabling the economic application of district heating systems or co-generation plants.

\subsubsection{Minimise energy demand of buildings}

ECO.117 Reduce energy losses by striving for a high insulation standard in new and existing buildings (low energy houses, passive-houses) and for a compact design of buildings (low surface-to-volume ratio).

ECO.118 Reduce the heating demand in temperate and cold climates by maximising passive solar energy gains (i.e. high ratio of windows and glass facades on south facades).

ECO.119 Reduce energy demand for cooling in hot climates by reducing uncontrollable solar irradiation into buildings (including devices for protection against overheating, e.g. shades, blinds, etc.) and by reducing the electricity consumption (to avoid additional internal heat generation i.e. through computers, electric devices).

ECO.120 Reduce electricity demand through efficient lighting systems, natural day-light systems (reflectors, light-shelves, light pipes).

ECO.121 Reduce hot water consumption through use of water saving installations.

ECO.122 Use efficient ventilation systems (controlled ventilation, heat recovery, natural ventilation systems including indoor planting zones, do not use conventional air-conditioning).

ECO.123 Use efficient cooling systems (cooling of concrete components, ground ducts, absorption heat pumps, indoor planting zones, water elements, atriums and courtyards).

\subsubsection{Maximise the efficiency of energy use and supply}

ECO.124 124. Use efficient heating, ventilating and cooling equipment as well as electrical devices controlled by IT based facility management.

ECO.125 Use energy-saving lighting appliances in buildings and for public space.

ECO.126 Use co-generation plants (CHP) for district heating networks of appropriate size for short pipe lengths preferentially, when demand for heat ensures a useful application of the waste heat. 
Tabla Al.4 Lista de indicadores en la herramienta ECOCITY (continuación)

\begin{tabular}{|c|c|}
\hline Code & Element/Theme/Objective/Measure \\
\hline & 4.1.4 Give preference to renewable sources for energy supply \\
\hline ECO.127 & Use solar energy, biomass and/or heat recovery for room heating/cooling and water heating. \\
\hline ECO.128 & Use photovoltaics, wind engines and/or biomass co-generation plants. \\
\hline \multirow[t]{3}{*}{ ECO.129 } & Provide surfaces for active solar systems on roofs and facades. \\
\hline & 4.2 WATER \\
\hline & 4.2.1 Minimise primary water consumption \\
\hline ECO.130 & Use water saving devices for baths, toilets, kitchens etc. and where appropriate use compost toilets. \\
\hline ECO.131 & Collect rainwater for use in toilets, washing machines, gardening, car wash, etc. \\
\hline ECO.132 & $\begin{array}{l}\text { Recycle grey water (all domestic waste water but faeces) for use in toilets, washing machines, } \\
\text { gardening, car wash, etc. }\end{array}$ \\
\hline ECO.133 & $\begin{array}{l}\text { Use an efficient watering system for green areas (and preferably use plants with low water demand). } \\
\text { 4.2.2 Minimise impairment of the natural water cycle }\end{array}$ \\
\hline ECO.134 & $\begin{array}{l}\text { Maximise permeability of urban soil and paved surfaces (e.g. parking and play areas, informal foot \& } \\
\text { cycle paths, etc.). }\end{array}$ \\
\hline ECO.135 & Strive for unsealing of existing sealed surfaces where appropriate. \\
\hline ECO.136 & $\begin{array}{l}\text { Practise storm water management using rain water retention and infiltration measures to maintain } \\
\text { the natural water balance and relieve the waste water treatment plants (green roofs, infiltration } \\
\text { swales and hollows, trench drain infiltration, retention ponds) taking into account natural flow rates. }\end{array}$ \\
\hline ECO.137 & $\begin{array}{l}\text { Avoid infiltration of natural water cycles by polluted effluent (discharge) (such as from extensive } \\
\text { metallic surfaces e.g. zinc and copper roofs and from intensively used traffic areas) and/or use filter } \\
\text { technologies. }\end{array}$ \\
\hline ECO.138 & Maintain or revitalise natural water bodies (ponds, lakes streams and rivers with soft embankments). \\
\hline ECO.139 & $\begin{array}{l}\text { Use rainwater fed landscaping elements to provide a sensory experience to increase the quality of } \\
\text { public space, to improve urban comfort and to make people aware of water cycle. }\end{array}$ \\
\hline \multirow[t]{3}{*}{ ECO.140 } & $\begin{array}{l}\text { Where appropriate purify black and grey water in wastewater wetland areas on site (e.g. reed-bed } \\
\text { sewage treatment). }\end{array}$ \\
\hline & 4.3 WASTE \\
\hline & 4.3.1 Minimise the volume of waste generated and of waste going to disposal \\
\hline ECO.141 & $\begin{array}{l}\text { Promote sharing of goods and devices ("sharing instead of ownership") by supporting the exchange of } \\
\text { goods and providing hire / loan services in neighbourhoods. }\end{array}$ \\
\hline ECO.142 & $\begin{array}{l}\text { Promote re-use and recycling of waste by separately collecting valuable products and providing } \\
\text { interim storage and collection services. }\end{array}$ \\
\hline ECO.143 & Promote composting systems for treating the biological fractions of waste on site. \\
\hline ECO.144 & $\begin{array}{l}\text { Avoid the disposal of untreated waste and creation / disposal of waste with negative impacts on } \\
\text { health, well-being and the environment. }\end{array}$ \\
\hline ECO.145 & $\begin{array}{l}\text { Minimise the amount of excavated material to be disposed of (during construction phases) by } \\
\text { reducing the amount of soil to be excavated and by using the excavated soil on site, e.g. as building } \\
\text { material (concrete aggregates, refilling), as landscaping material, for noise embankments, as cover } \\
\text { material, for backfilling, etc. }\end{array}$ \\
\hline ECO.146 & Maximise separate collection and recycling of construction / demolition rubble (preferably on site). \\
\hline
\end{tabular}


Tabla AI.4 Lista de indicadores en la herramienta ECOCITY (continuación)

\begin{tabular}{|c|c|}
\hline Code & Element/Theme/Objective/Measure \\
\hline & 4.4 BUILDING MATERIALS \\
\hline & 4.4.1 Minimise primary building material consumption and maximise recyclability of materials \\
\hline ECO.147 & Maximise the re-use of buildings and building components. \\
\hline ECO.148 & Design compact settlements instead of detached houses. \\
\hline ECO.149 & $\begin{array}{l}\text { Reduce the demand for building materials by reducing hard transport surfaces (particularly } \\
\text { tarmacked roads for motorised traffic), by reducing basement areas and by designing lightweight } \\
\text { constructions (e.g. timber). }\end{array}$ \\
\hline ECO.150 & Use recycled materials. \\
\hline ECO.151 & $\begin{array}{l}\text { Consider the construction, use and deconstruction phases of buildings when selecting materials } \\
\text { (design for recycling): maximise detachability (e.g. screws instead of glue), reusability and } \\
\text { recyclability of materials (possibility for re-use of structures is preferential to practicable material } \\
\text { recovery); consider reverse-engineering for hvac equipment (building services, supply networks). }\end{array}$ \\
\hline \multirow[t]{2}{*}{ ECO.152 } & $\begin{array}{l}\text { Introduce a building inventory (Material Accounting System): information on quantity and quality (i.e. } \\
\text { composition) of all building materials to document the recycling as well as pollutant potential of the } \\
\text { building. }\end{array}$ \\
\hline & 4.4.2 Maximise the use of environmentally friendly and non-hazardous building materials \\
\hline ECO.153 & Use local and regional materials. \\
\hline ECO.154 & Use materials of high durability. \\
\hline ECO.155 & Maximise the use of recycled materials for buildings (e.g. recycle concrete or building rubble on site) \\
\hline ECO.156 & Maximise the share of renewable materials (e.g. timber structures, paper pellets for insulation). \\
\hline ECO.157 & Avoid harmful substances (e.g. pvc, solvents, phthalates). \\
\hline \multirow[t]{3}{*}{ ECO.158 } & Use building materials with a low demand for primary and non-renewable energy. \\
\hline & 5. SOCIO-ECONOMY \\
\hline & 5.1 SOCIAL ISSUES \\
\hline
\end{tabular}

\subsubsection{Promote social diversity and integration for a balanced social structure}

ECO.159 Aim at a mixed population in terms of income, age, cultural background and lifestyle concepts.

ECO.160 Provide a balanced variety of dwelling types for different population groups (e.g. singles, families, senior citizens) and ownership models (owner-occupied flats and rented apartments, including subsidised / social housing).

ECO.161 Consider social diversity and integration early on in the planning stage since the planning processes for different types of projects (types of accommodation, target user groups) vary considerably.

ECO.162 Ensure participation of citizens, stakeholders and users in decision-making throughout all phases of the project.

ECO.163 Increase the identification of people with the new development by starting participation processes early on in the planning process and by establishing building cooperatives (fostering contacts among future neighbours before moving to new dwellings).

\subsubsection{Provide social and other infrastructure with good accessibility}

ECO.164 Provide social services (child care, care for the elderly and other persons in need of support) and health care services (general practitioner, pharmacy etc.) within walking distances (from public transport stops) for most people.

ECO.165 Provide retail facilities for daily needs easily accessibly on foot and by bike.

\subsection{ECONOMY}

\subsubsection{Offer incentives for businesses and enterprises to move to the area}

ECO.166 Use regional and local economic strengths for attracting businesses and enterprises.

ECO.167 Take existing and emerging regional clusters of businesses into account when selecting businesses to be addressed

ECO.168 Investigate the possibility of offering start-up credits (are there local credit institutions and are they willing to provide loans?) for appropriate small and medium sized enterprises (SMEs) wanting to establish themselves in the area.

ECO.169 Prepare targeted information on access to markets for appropriate goods and services (e.g. can businesses find suppliers and customers in the area and are there markets that can easily be opened up from the location in question?). 
Tabla Al.4 Lista de indicadores en la herramienta ECOCITY (continuación)

Code Element/Theme/Objective/Measure

ECO.170 Favour SMEs, which are appropriate for fine meshed, mixed-use structures.

ECO.171 Pay attention to the "communication potential" by providing good access to the transport network and information and communication media.

\subsubsection{Use the available labour resources}

ECO.172 Analyse the strengths and local specifics of the labour force including the availability of workers with different qualifications.

ECO.173 Where possible, promote the employment of people living near to their work places.

ECO.174 Where possible, promote the relocation of employees (potential commuters) to dwellings near their working places.

ECO.175 Look for particular educational institutions (e.g. universities) that enhance the attractiveness of the location.

\subsection{COSTS}

\subsubsection{Strive for a long-lived economic infrastructure}

ECO.176 Consider the availability of land in the planning area at fair prices (comparison of land prices in this area and in others, restrictions regarding the usage / purchase of land in this area in comparison to others).

ECO.177 Consider potential problems with respect to property rights (does the acquisition of land constitute a problem?).

ECO.178 Consider life-cycle cost models for infrastructure integrating all costs (many ecological measures with higher investment cost lead to lower operating costs and resulting lower life-cycle cost).

ECO.179 Develop a compact urban form with sufficient density as a precondition for attractive and economically viable public transport systems and retail services as well as lower costs for the technical infrastructure (length of energy and water supply networks per head of population, etc.).

ECO.180 Seek alternative models to finance ecological infrastructure (i.e. sale of shares for photovoltaic solar power plants, green electricity collectives).

ECO.181 Consider contracting models for operating the technical infrastructure (e.g. companies operating cogeneration plants (chp) or wood chip energy supply facilities).

\subsubsection{Offer low cost housing, workplaces and space for non-profit uses}

ECO.182 Minimise life-cycle costs for buildings (construction, operation, recovery, disposal).

ECO.183 Integrate high-density areas with compact building typologies to decrease construction costs and proportional plot costs.

ECO.184 Offer low-price dwellings through special procedures for low price plots (e.g. Städtebauliche Entwicklungsmaßnahme24), long-term plot-lease, etc.) as well as through low construction costs and thus low sales costs in order to give more social groups the possibility to own property.

ECO.185 Minimise construction costs for buildings through selection of appropriate materials and heating, ventilation and air-conditioning systems, prefabricated modules, appropriate tendering procedures.

ECO.186 Provide conditions for lower household expenditure (i.e. in car-free areas with high-quality provision for other modes; through energy efficient buildings, etc.).

ECO.187 Provide favourable conditions for establishing building cooperatives (advice, long-term lease options for plots, etc.) - such groups generally achieve lower building costs than developers.

ECO.188 Minimise maintenance and operating costs by selecting appropriate materials and HVAC systems and building services.

ECO.189 Offer semi-refurbished existing buildings or new buildings, which are not ready-to-use (i.e. needing some work input from the future users) as an offer to non-profit or low-profit uses. 
Tabla Al.5 Lista de indicadores en la herramienta Le modele INDI-RU 2005

\begin{tabular}{|c|c|}
\hline Code & Objective/Sub-objective/Indicator \\
\hline & 1. PRESERVE AND ENHANCE HERITAGE AND CONSERVE RESOURCES \\
\hline & 1.1 Reduce energy consumption and improve energy management \\
\hline INDI.1 & $\begin{array}{l}\text { 1.1.1 Percentage of households with heating - ventilation - insulation better than the average of } \\
\text { existing stock (lower consumption than the national average) }\end{array}$ \\
\hline INDI.2 & $\begin{array}{l}\text { 1.1.2 Percentage of park buildings with new heating - ventilation - insulation better than that required } \\
\text { by regulation (RT 2000-Réglementation thermique) }\end{array}$ \\
\hline INDI.3 & 1.1.3 Measures to save energy consumption in the residential and tertiary sector \\
\hline INDI.4 & 1.1.4 Amount of energy costs in the social housing sector \\
\hline INDI.5 & 1.1.5. Energy consumption of public buildings \\
\hline INDI.6 & 1.1.6 Energy consumption of public lighting. \\
\hline INDI.7 & 1.1.7 Percentage of homes and public buildings (including lighting) that use renewable energy \\
\hline INDI.8 & $\begin{array}{l}\text { 1.1.8 Measures to reduce greenhouse gases emissions caused by heating residential buildings and } \\
\text { public tertiary }\end{array}$ \\
\hline
\end{tabular}

\subsection{Improve water resources management and quality}

INDI.9 1.2.1 Water consumption in the residential sector

INDI.10 1.2.2 Percentage of public facilities using water-saving techniques

INDI.11 1.2.3 Percentage of residential and commercial buildings reusing rainwater

INDI.12 1.2.4 Percentage of stormwater managed in the urban plot from waterproofed areas.

INDI.13 1.2.5 Quality of the sewage network

\subsection{Avoid urban sprawl and improve space management}

INDI.14 1.3.1 Urban density

INDI.15 1.3.2 Area of public open space per capita available (depending on the location of the neighbourhood)

INDI.16 1.3.3 Percentage of brownfield and contaminated land

INDI.17 1.3.4 Number of criteria in the implementation and regulation of the Local Town Planning Plan (compared with $21 \%$ obj. Of HQE2R)

1.4 Optimise the use of materials (raw materials) and their management

INDI.18 1.4.1 Percentage of constructed / rehabilitated / demolished buildings that use recycled / environmental labelling / environmental certifications or standards / ACV standards of materials and equipment.

INDI.19 1.4.2 Percentage of public facilities constructed / renovated / demolished, including an environmental quality approach

1.5 Preserve and enhance what has been built and natural heritage

INDI.20 1.5.1 Measures to preserve and enhance architectural heritage

INDI.21 1.5.2 Percentage of green space subjected to measures to preserve or enhance natural heritage and biodiversity

\section{IMPROVE THE QUALITY OF THE LOCAL ENVIRONMENT}

2.1 Preserve and enhance the landscape and visual quality

INDI.22 2.1.1 Requirements and measures taken to maintain or improve the quality of entries, the neighbourhood and continuity of spaces.

INDI.23 2.1.2 Measures and requirements to be considered in urban furniture and the visual quality of public lighting.

\subsection{Improve the quality of housing and buildings}

INDI.24 2.2.1 Building shabby facades (in the urban environment of the district to be treated)

INDI.25 2.2.2 Percentage of projects or constructed or renovated buildings that take into account the context and immediate environment (orientation, ventilation, insolation, shade, proximity to public transport, etc.)

INDI.26 2.2.3 Number of vacant homes.

INDI.27 2.2.4 Number of adapted housing in new developments or housing that can be adapted for the elderly and disabled 
Tabla Al.5 Lista de indicadores en la herramienta Le modele INDI-RU 2005 (continuación)

\begin{tabular}{|c|c|}
\hline Code & Objective/Sub-objective/Indicator \\
\hline & 2.3 Improve cleanliness, hygiene and health \\
\hline INDI.28 & 2.3.1 Importance of public and private spaces that are poorly maintained \\
\hline INDI.29 & 2.3.2 Percentage of unhealthy dwellings that do not meet standards of comfort \\
\hline INDI.30 & 2.3.3 Proportion of overcrowded housing ( 2 children or more per room) \\
\hline \multirow[t]{2}{*}{ INDI.31 } & 2.3.4 Medical supply: public or private sector or hospitals \\
\hline & 2.4 Improve safety and risk management (housing and neighbourhood) \\
\hline INDI.32 & 2.4.1 Number of crimes, and theft crimes per 1,000 citizens \\
\hline INDI.33 & 2.4.2 Number of victims of trafficking involving pedestrians and two-wheelers per 1,000 inhabitants \\
\hline INDI.34 & $\begin{array}{l}\text { 2.4.3 Proportion of the population exposed to hazardous products or materials requiring special } \\
\text { monitoring }\end{array}$ \\
\hline \multirow[t]{2}{*}{ INDI.35 } & 2.4.4 Proportion of the population exposed to natural unprotected hazards \\
\hline & 2.5 Improve air quality (indoors and surroundings) \\
\hline INDI.36 & 2.5.1 Proportion of new buildings that meet specifications for indoor air quality. \\
\hline INDI.37 & $\begin{array}{l}\text { 2.5.2 Proportion of the population exposed to } \mathrm{NO}_{2} \text { pollution exceeding } 50 \mathrm{ug} / \mathrm{m}^{3} \text { average annual } \\
\text { hourly }\end{array}$ \\
\hline \multirow[t]{2}{*}{ INDI.38 } & 2.5.3 Number of days per year in which the population is exposed to ozone pollution \\
\hline & 2.6 Reduce noise \\
\hline INDI.39 & 2.6.1 Percentage of the population exposed to noise \\
\hline INDI.40 & 2.6.2 Proportion of the population exposed to noise of $65 \mathrm{~dB}(\mathrm{~A})$ Leq and between 18:00 to 10:00 p.m. \\
\hline \multirow[t]{2}{*}{ INDI.41 } & $\begin{array}{l}\text { 2.6.3 Proportion of construction / demolition / rehabilitation considering the noise problem for } \\
\text { residents }\end{array}$ \\
\hline & 2.7 Minimise waste and improve management \\
\hline INDI.42 & 2.7.1 Proportion of household waste collected by sorting and separate collection \\
\hline \multirow[t]{3}{*}{ INDI.43 } & 2.7.2 Proportion of construction / demolition / rehabilitation that considers waste management \\
\hline & 3. ENHANCE DIVERSITY \\
\hline & 3.1 Ensure the diversity of the population \\
\hline INDI.44 & 3.1.1 Diversity of the workforce by professional category \\
\hline INDI.45 & 3.1.2 Employment rate (employed persons / population of working age) \\
\hline \multirow[t]{2}{*}{ INDI.46 } & 3.1.3 Population distribution by age \\
\hline & 3.2 Ensure diversity of functions (economic and social) \\
\hline INDI.47 & 3.2.1 Number of jobs per 1,000 inhabitants \\
\hline INDI.48 & 3.2.2 Number of points of sale per 1,000 persons \\
\hline \multirow[t]{2}{*}{ INDI.49 } & 3.2.3 Number of facilities and public services within $300 \mathrm{~m}$ of homes \\
\hline & 3.3 Ensure diversity of housing supply \\
\hline INDI.50 & 3.3.1 Diversity of housing according to their status: owner-occupied, private rental, social, public, etc. \\
\hline INDI.51 & 3.3.2 Diversity of housing by size \\
\hline \multirow[t]{3}{*}{ INDI.52 } & 3.3.3 Diversity of housing by type: single, grouped individually, small group, large scale, etc. \\
\hline & 4. ENHANCE INTEGRATION \\
\hline & 4.1 Increase levels of education and skills. \\
\hline INDI.53 & 4.1.1 Proportion of children leaving primary school late. \\
\hline INDI.54 & 4.1.2 Truancy rate \\
\hline \multirow[t]{2}{*}{ INDI.55 } & 4.1.3 Number of cases of violence and crime in schools in the area. \\
\hline & 4.2 Promote public access to employment, services and facilities of the city \\
\hline INDI.56 & $\begin{array}{l}\text { 4.2.1 Population living within } 300 \mathrm{~m} \text { of a facility or public service, or public transport stop, to travel } \\
\text { directly to equipment or a public service. }\end{array}$ \\
\hline INDI.57 & 4.2.2 Unemployment rate \\
\hline INDI.58 & 4.2.3 Presence of urban voids between the district and the city-district or facilities or attractions. \\
\hline
\end{tabular}


Tabla AI.5 Lista de indicadores en la herramienta Le modele INDI-RU 2005 (continuación)

\begin{tabular}{|c|c|}
\hline Code & Objective/Sub-objective/Indicator \\
\hline & $\begin{array}{l}4.3 \text { Improve the attractiveness of the area by creating living spaces and meeting places for all city } \\
\text { residents }\end{array}$ \\
\hline INDI.59 & 4.3.1 Presence of facilities or services of common interest \\
\hline INDI.60 & 4.3.2 Number of days a year marked by a market-type event, show, exhibit, etc. \\
\hline \multirow[t]{2}{*}{ INDI.61 } & 4.3.3 Proportion of main dwellings in the total housing stock \\
\hline & $\begin{array}{l}\text { 4.4 Avoid motorised travel and improve transportation infrastructure of low environmental impact } \\
\text { (transport, two wheels, on foot) }\end{array}$ \\
\hline INDI.62 & $\begin{array}{l}\text { 4.4.1 Length of streets in the district (public transport, pedestrian walkways, bike path) in linear feet } \\
\text { per inhabitant }\end{array}$ \\
\hline INDI.63 & 4.4.2 Proportion of journeys made by public transport \\
\hline INDI.64 & $\begin{array}{l}\text { 4.4.3 Proportion of journeys made on foot or bicycle, depending on the location of the district } \\
\text { regarding the city }\end{array}$ \\
\hline INDI.65 & 4.4.4 Length of streets without footpaths or footpaths in disrepair \\
\hline INDI.66 & 4.4.5 Municipal or private systems that favour motorised traffic and public transport. \\
\hline \multirow[t]{3}{*}{ INDI.67 } & 4.4.6 Quality of parking system \\
\hline & 5. STRENGTHEN SOCIAL RELATIONSHIPS \\
\hline & 5.1 Strengthen social cohesion and participation \\
\hline INDI.68 & $\begin{array}{l}\text { 5.1.1 Percentage of the population participating in sustainable development initiatives in the area } \\
\text { (especially in Agenda 21). }\end{array}$ \\
\hline \multirow[t]{2}{*}{ INDI.69 } & $\begin{array}{l}\text { 5.1.2 Number of built and rehabilitated landscaped public spaces as part of a consultation with } \\
\text { residents' buildings. }\end{array}$ \\
\hline & 5.2 Improve solidarity networks and social capital \\
\hline INDI.70 & 5.2.1 Percentage of the population participating in community activities and solidarity actions \\
\hline INDI.71 & 5.2.2 Presence of activities in the social and solidarity economy field \\
\hline INDI.72 & $\begin{array}{l}\text { 5.2.3 Presence of integration of economic activities into the area (construction waste, wood, } \\
\text { maintenance, etc.) }\end{array}$ \\
\hline INDI.73 & 5.2.4 Presence of North / South solidarity \\
\hline
\end{tabular}


Tabla Al.6 Lista de indicadores en la herramienta BIRDGE

\begin{tabular}{|c|c|}
\hline Code & Sustainability dimension/Category/Indicator \\
\hline \multicolumn{2}{|c|}{ ENVIRONMENTAL } \\
\hline & 1. ENERGY \\
\hline BRDG.1 & Energy consumption by cooling/heating \\
\hline BRDG.2 & Anthropogenic heat \\
\hline BRDG.3 & Bowen ratio \\
\hline \multirow[t]{2}{*}{ BRDG.4 } & Percentage of energy from renewable sources \\
\hline & 2. THERMAL COMFORT \\
\hline BRDG.5 & Thermal comfort index (cooling power) \\
\hline BRDG.6 & Air temperature \\
\hline \multirow[t]{2}{*}{ BRDG.7 } & Number of days above air temperature threshold \\
\hline & 3. WATER \\
\hline BRDG.8 & Water consumption \\
\hline BRDG.9 & Evapotranspiration \\
\hline BRDG.10 & Infiltration \\
\hline BRDG.11 & Surface run-off \\
\hline \multirow[t]{2}{*}{ BRDG.12 } & Potential flood risk \\
\hline & 4. GREENHOUSE GASES \\
\hline \multirow[t]{2}{*}{ BRDG.13 } & Emissions $(\mathrm{CO} 2, \mathrm{CH} 4)$ \\
\hline & 5. AIR QUALITY \\
\hline BRDG.14 & Concentrations (NOx, PM10, PM2.5, O3, CO, SO2) \\
\hline BRDG.15 & Exceedances (NOx, PM10, O3, SO2) \\
\hline BRDG.16 & Potential population exposure (NOx, PM10, O3, SO2) \\
\hline \multicolumn{2}{|r|}{ (1) } \\
\hline & 6. LAND USE \\
\hline BRDG.17 & New urbanized areas \\
\hline BRDG.18 & Brownfields re-used \\
\hline \multirow[t]{2}{*}{ BRDG.19 } & Density of development \\
\hline & 7. MOBILITY/ACCESSIBILITY \\
\hline BRDG.20 & Quality of pedestrian \\
\hline BRDG.21 & Length of cycle-ways provided \\
\hline BRDG.22 & Length of new roads provided \\
\hline BRDG.23 & Percentage of use of public transport \\
\hline \multirow[t]{2}{*}{ BRDG.24 } & Number of inhabitants with access to public transport \\
\hline & 8. SOCIAL INCLUSION \\
\hline BRDG.25 & Number of inhabitants with access to services \\
\hline \multirow[t]{2}{*}{ BRDG.26 } & Number of inhabitants with access to social housing \\
\hline & 9. HUMAN WELL-BEING \\
\hline BRDG.27 & Number of inhabitants affected by flash flooding \\
\hline BRDG.28 & Number of inhabitants affected by heat waves \\
\hline \multicolumn{2}{|c|}{ ECONOMIC } \\
\hline & 10. COST OF PROPOSED DEVELOPMENT \\
\hline & 11. EFFECTS ON LOCAL ECONOMY (EMPLOYMENT) \\
\hline & 12. EFFECTS ON LOCAL ECONOMY (REVENUE) \\
\hline
\end{tabular}


Tabla Al.7 Lista de indicadores en la herramienta KITCASP

\begin{tabular}{ll}
\hline Code & Policy Theme/Indicator \\
\hline \multicolumn{1}{c}{ 1. ECONOMIC COMPETITIVENESS AND RESILIENCE } \\
\hline KIT.1 & GDP per capita/GVA per capita \\
KIT.2 & Employment rate of population aged 20-64 \\
KIT.3 & Total R \& D expenditure as \% of GDP \\
KIT.4 & Balance of external trade \\
KIT.5 & Economic structure \\
\hline & 2. INTEGRTED SPATIAL DEVELOPMENT \\
\hline KIT.6 & Population density - Population change \\
KIT.7 & House completions \\
KIT.8 & Modal split \\
KIT.9 & Land use change \\
KIT.10 & Access to services (hospitals and schools) \\
\hline & 3. SOCIAL COHESION AND QUALITY OF LIFE \\
\hline KIT.11 & Population aged 30 -34 with tertiary education \\
KIT.12 & Population at risk of poverty \\
KIT.13 & Green space accessibility \\
KIT.14 & Well-being index \\
KIT.15 & Dependency ratio \\
\hline & 4. ENVIRONMENTAL RESOURCE MANAGEMENT \\
\hline KIT.16 & Renewable energy production (wind, hydro, biomass, etc.) \\
KIT.17 & Greenhouse gas emissions \\
KIT.18 & Population at risk of flooding (living in flood-prone areas) \\
KIT.19 & Number and status of protected European habitats and species \\
KIT.20 & Water quality status \\
\hline &
\end{tabular}


Tabla AI.8 Lista de indicadores en la herramienta LB

\begin{tabular}{|c|c|}
\hline Código & Categoría/Subcategoría/Indicador \\
\hline & 1. CRITERIOS DE ACTUACIÓN SOBRE EL ENTORNO DE LA CIUDAD \\
\hline & 1.0. Preservar, mantener y proteger el capital natural \\
\hline LB.1 & 1.01. Preservar los ecosistemas existentes (naturales y artificiales) \\
\hline LB. 2 & 1.02. Respetar e integrarse en el territorio \\
\hline LB.3 & 1.03. Conectar las diversas zonas protegidas \\
\hline LB.4 & 1.04. Respetar el paisaje \\
\hline LB.5 & 1.05. Conservar el suelo (reducir el consumo y preservar su productividad) \\
\hline \multirow{3}{*}{ LB. 6} & 1.06. Favorecer la producción local \\
\hline & 2. CRITERIOS DE ACTUACIÓN EN EL ÁMBITO URBANO \\
\hline & 2.0. Definir una estructura y un modelo urbano más sostenible \\
\hline LB.7 & 2.01. Complejizar los usos del suelo \\
\hline LB.8 & 2.02. Fomentar la compacidad urbana (densidad, edificabilidad, etc.) \\
\hline \multirow[t]{2}{*}{ LB.9 } & 2.03. Fomentar el policentrismo \\
\hline & 2.1. Fomentar un uso más sostenible del patrimonio edificado \\
\hline LB.10 & 2.11. Fomentar un uso intensivo y eficiente del patrimonio construído \\
\hline LB.11 & 2.12. Fomentar la rehabilitación (frente a la obra nueva) \\
\hline LB.12 & 2.13. Adoptar criterios bioclimáticos para la urbanización y la edificación \\
\hline LB.13 & 2.14. Fomentar la diversidad de tipos residenciales \\
\hline \multirow[t]{2}{*}{ LB.14 } & 2.15. Complejizar los usos de los edificios \\
\hline & 2.2. Fomentar la diversidad, calidad y versatilidad de los espacios públicos urbanos \\
\hline LB.15 & 2.21. Eliminar barreras arquitectónicas \\
\hline LB.16 & 2.22. Diseñar espacios multifuncionales y legibles \\
\hline LB.17 & 2.23. Aplicar criterios bioclimáticos a los espacios abiertos \\
\hline LB.18 & 2.24. Incorporar mobiliario urbano polivalente \\
\hline \multirow[t]{2}{*}{ LB.19 } & 2.25. Reducir tipologías que favorezcan la privatización de los espacios abiertos \\
\hline & 2.3. Favorecer el acceso a la naturaleza (zonas verdes) \\
\hline LB. 20 & 2.31. Definir una superficie mínima de las zonas verdes (por persona, vivienda, etc.) \\
\hline LB. 21 & 2.32. Definir criterios de forma y tamaños mínimos para las zonas verdes \\
\hline LB. 22 & 2.33. Fomentar la biodiversidad \\
\hline LB. 23 & 2.34. Introducir redes verdes a escala de barrio y de ciudad \\
\hline LB. 24 & 2.35. Favorecer el acceso de los ciudadanos a las zonas verdes \\
\hline LB. 25 & 2.36. Incorporar elementos vegetales en los espacios públicos \\
\hline \multirow[t]{2}{*}{ LB.26 } & 2.37. Conectar ecológicamente las distintas zonas verdes \\
\hline & 2.4. Mejorar la accesibilidad a los equipamientos \\
\hline LB. 27 & 2.41. Definir una oferta adecuada de equipamientos y servicios públicos \\
\hline \multirow[t]{3}{*}{ LB. 28} & 2.42. Fomentar la proximidad a los equipamientos y dotaciones \\
\hline & 3. CRITERIOS DE ACTUACIÓN EN TEMAS DE TRANSPORTE \\
\hline & 3.0. Reducir distancias \\
\hline LB. 29 & 3.01. Asociar residencia y empleo \\
\hline LB. 30 & 3.02. Establecer plataformas logísticas de distribución en cada barrio \\
\hline LB.31 & 3.03. Reservar espacios para comercialización de productos locales \\
\hline \multirow[t]{2}{*}{ LB.32 } & 3.04. Reducir las infraestructuras necesarias para el funcionamiento de la ciudad \\
\hline & 3.1. Potenciar los medios de transporte no motorizados \\
\hline LB.33 & 3.11. Integrar las redes peatonales y ciclistas con las zonas verdes \\
\hline LB.34 & 3.12. Aumentar el espacio disponible para el peatón \\
\hline LB.35 & 3.13. Construir redes peatonales y ciclistas de barrio \\
\hline LB.36 & 3.14. Disponer aparcamientos para bicicletas \\
\hline LB.37 & 3.15. Integrar la bicicleta con el transporte público \\
\hline
\end{tabular}


Tabla Al.8 Lista de indicadores en la herramienta LB (continuación)

\begin{tabular}{|c|c|}
\hline Código & Categoría/Subcategoría/Indicador \\
\hline & 3.2. Reducir el tráfico motorizado privado, potenciando el transporte público \\
\hline LB.38 & 3.21. Establecer una oferta adecuada de transporte público a escala urbana \\
\hline LB.39 & 3.22. Construir redes integradas de transporte público \\
\hline LB.40 & 3.23. Reducir velocidad del tráfico motorizado privado \\
\hline LB.41 & 3.24. Reducir la superficie destinada al vehículo privado \\
\hline LB.42 & 3.25. Restringir el uso del vehículo privado \\
\hline \multirow[t]{3}{*}{ LB. 43} & 3.26. Limitar las plazas de aparcamiento para vehículos privados \\
\hline & 4. CRITERIOS DE ACTUACIÓN EN CUANTO A RECURSOS \\
\hline & 4.0. Optimizar y reducir el consumo de energía \\
\hline LB.44 & 4.01. Fomentar el ahorro y promover la eficiencia energética \\
\hline LB.45 & 4.02. Adaptar la morfología urbana a las condiciones bioclimáticas \\
\hline LB.46 & 4.03. Aprovechar el sol y el viento en las viviendas y en los espacios exteriores \\
\hline LB.47 & 4.04. Estructuras urbanas compatibles con sistemas centralizados de calefacción \\
\hline LB. 48 & 4.05. Fomentar el uso de energías renovables \\
\hline \multirow[t]{2}{*}{ LB.49 } & 4.06. Fomentar la producción local de energía \\
\hline & 4.1. Optimizar y reducir el consumo de agua \\
\hline LB. 50 & 4.11. Reducir las pérdidas de en las redes de distribución \\
\hline LB.51 & 4.12. Fomentar tipos edificatorios con menores demandas de agua \\
\hline LB.52 & 4.13. Fomentar los sistemas eficientes de riego \\
\hline LB. 53 & 4.14. Incentivar la recogida de aguas pluviales en los edificios \\
\hline LB.54 & 4.15. Utilizar sistemas de retención y filtración de aguas pluviales \\
\hline LB. 55 & 4.16. Tratar y recuperar los cauces naturales de agua \\
\hline \multirow[t]{2}{*}{ LB.56 } & 4.17. Fomentar el empleo de pavimentos permeables \\
\hline & 4.2. Minimizar el impacto de los materiales de construcción \\
\hline LB.57 & 4.21. Reducir los movimientos de tierras \\
\hline LB. 58 & 4.22. Fomentar el empleo de materiales locales \\
\hline LB.59 & 4.23. Emplear técnicas constructivas que faciliten la reutilización \\
\hline LB. 60 & 4.24. Fomentar el empleo de materiales fácilmente reciclables \\
\hline \multirow[t]{3}{*}{ LB.61 } & 4.25. Fomentar el uso compartido de redes de servicios \\
\hline & 5. CRITERIOS DE ACTUACIÓN EN CUANTO A RESIDUOS \\
\hline & 5.0. Reducir los residuos \\
\hline LB.62 & 5.01. Fomentar la recogida selectiva y las redes separativas de saneamiento \\
\hline LB. 63 & 5.02. Proximidad del usuario a los sistemas de recogida \\
\hline LB.64 & 5.03. Promover reservas para compostaje y tratamiento de residuos vegetales \\
\hline LB. 65 & 5.04. Utilizar sistemas de aprovechamiento de aguas grises \\
\hline \multirow[t]{2}{*}{ LB.66 } & 5.05. Fomentar el reciclaje y la reutilización \\
\hline & 5.1. Gestionar los residuos para reducir su impacto \\
\hline LB. 67 & 5.11. Obligar al tratamiento de residuos peligrosos \\
\hline LB.68 & 5.12. Gestión de residuos generados por la construcción y demolición \\
\hline LB.69 & 5.13. Construir sistemas de depuración no agresivos con el entorno \\
\hline \multirow[t]{3}{*}{ LB.70 } & 5.14. Reducir las emisiones y los vertidos contaminantes \\
\hline & 6. CRITERIOS DE ACTUACIÓN EN TEMAS DE COHESIÓN SOCIAL \\
\hline & 6.0. Favorecer la cohesión del tejido social e impedir la exclusión \\
\hline LB.71 & 6.01. Fomentar el asociacionismo \\
\hline LB.72 & 6.02. Reservar espacios para entidades sin ánimo de lucro \\
\hline LB.73 & 6.03. Fomentar la complejidad social \\
\hline LB.74 & 6.04. Fomentar la identificación de la población con su entorno (patrimonio cultural) \\
\hline LB.75 & 6.05. Favorecer el acceso a la vivienda \\
\hline
\end{tabular}


Tabla Al.8 Lista de indicadores en la herramienta LB (continuación)

\begin{tabular}{|c|c|}
\hline Código & Categoría/Subcategoría/Indicador \\
\hline & 6.1. Complejizar el tejido social \\
\hline LB.76 & 6.11. Fomentar la mezcla de usos en cada barrio \\
\hline LB.77 & 6.12. Mejorar la oferta y el acceso de servicios y equipamientos en cada barrio \\
\hline LB.78 & 6.13. Incentivar el intercambio económico con el mundo rural \\
\hline LB.79 & 6.14. Promover un porcentaje mínimo de actividades de proximidad \\
\hline \multirow[t]{3}{*}{ LB.80 } & 6.15. Incentivar las actividades que favorezcan la diversidad de usos \\
\hline & 7. CRITERIOS DE ACTUACIÓN EN TEMAS DE GOBERNANZA \\
\hline & 7.0. Fomentar la transparencia administrativa \\
\hline LB.81 & 7.01. Ofrecer acceso a la información (incluyendo datos e informes técnicos) \\
\hline LB.82 & 7.02. Ofrecer cauces para el flujo de información en ambos sentidos \\
\hline \multirow[t]{2}{*}{ LB.83 } & 7.03. Establecer procedimientos de cooperación entre administraciones \\
\hline & 7.1. Favorecer la formación de los ciudadanos \\
\hline LB.84 & 7.11. Elaborar materiales divulgativos específicos \\
\hline LB.85 & 7.12. Desarrollar cursos y talleres y debates de urbanismo \\
\hline LB.86 & 7.13. Fomentar la educación y la sensibilización ambiental \\
\hline \multirow[t]{2}{*}{ LB.87 } & 7.14. Apoyar la elaboración de Agendas 21 \\
\hline & 7.2. Integrar la participación en el planeamiento \\
\hline LB.88 & 7.21. En el proceso de diagnóstico \\
\hline LB.89 & 7.22. En la toma de decisiones estratégicas \\
\hline LB.90 & 7.23. En la redacción del plan \\
\hline LB.91 & 7.24. En la aprobación del plan \\
\hline LB.92 & 7.25. En el proceso de seguimiento y supervisión del plan \\
\hline LB.93 & 7.26. Integrar las agendas 21 en el planeamiento \\
\hline
\end{tabular}


Tabla AI.9 Lista de indicadores en la herramienta SMIS

\begin{tabular}{|c|c|}
\hline Código & Categoría/Subcategoría/Indicador \\
\hline \multirow[t]{3}{*}{ Code } & Are/Category/Indicator \\
\hline & 1. OCUPACIÓN DEL SUELO \\
\hline & 01. Ocupación de los usos del suelo \\
\hline SMIS.1 & 01.1 Superficie artificial por habitante \\
\hline SMIS.2 & 01.2 Superficie artificial en relación a la superficie municipal \\
\hline \multirow[t]{2}{*}{ SMIS.3 } & 01.3 Superficie urbanizada del término municipal \\
\hline & 02. Densidad de población \\
\hline SMIS.4 & 02.1 Densidad de viviendas \\
\hline \multirow[t]{2}{*}{ SMIS.5 } & 02.2 Densidad de población de derecho y flotante \\
\hline & 03. Compacidad urbana \\
\hline \multirow[t]{2}{*}{ SMIS. 6} & 03.1 Dispersión de los núcleos de población \\
\hline & 04. Zonas verdes por habitante \\
\hline \multirow[t]{3}{*}{ SMIS.7 } & 04.1 Zonas verdes públicas y ejecutadas por el planeamiento \\
\hline & 2. COMPLEJIDAD URBANA \\
\hline & 05. Complejidad urbana \\
\hline SMIS.8 & 05.1 Número de actividades por habitante \\
\hline \multirow[t]{3}{*}{ SMIS.9 } & 06. Equilibrio entre actividad y residencia \\
\hline & 3. MOVILIDAD SOSTENIBLE \\
\hline & 07. Distribución modal del transporte urbano \\
\hline SMIS.10 & 07.1 Transporte modal intermunicipal \\
\hline \multirow[t]{2}{*}{ SMIS.11 } & 07.2 Tiempo y distancia media recorrida según motivo de desplazamiento \\
\hline & 08. Espacio viario para peatones \\
\hline \multirow[t]{2}{*}{ SMIS.12 } & 08.1 Proporción del número de calles con prioridad para peatones \\
\hline & 09. Espacio viario para bicicletas \\
\hline \multirow[t]{2}{*}{ SMIS.13 } & 09.1 Proximidad de la población a un carril bici \\
\hline & 10. Espacio viario para transporte público \\
\hline SMIS.14 & 10.1 Proximidad de la población a una parada de transporte público \\
\hline \multirow[t]{3}{*}{ SMIS.15 } & 10.2 Número de servicios interurbanos por núcleo urbano \\
\hline & 4. METABOLISMO URBANO \\
\hline & 11. Consumo de agua urbano \\
\hline \multirow[t]{2}{*}{ SMIS.16 } & 11.1 Pérdidas de agua en la red de distribución \\
\hline & 12. Depuración de las aguas residuales urbanas \\
\hline \multirow[t]{2}{*}{ SMIS.17 } & 12.1 Porcentaje de población conectada a sistemas de saneamiento \\
\hline & 13. Reutilización de las aguas residuales depuradas \\
\hline \multirow[t]{2}{*}{ SMIS.18 } & 13.1 Volumen de agua reutilizada por habitante \\
\hline & 14. Consumo final de energía \\
\hline \multirow[t]{2}{*}{ SMIS.19 } & 14.1 Consumo eléctrico municipal \\
\hline & 15. Producción local de energías renovables \\
\hline SMIS.20 & 15.1 Autosuficiencia energética local a partir de energías renovables \\
\hline SMIS.21 & 16. Generación de residuos sólidos urbanos \\
\hline SMIS.22 & 17. Recogida selectiva neta de residuos \\
\hline \multirow[t]{2}{*}{ SMIS. 23} & 18. Emisiones de $\mathrm{CO} 2$ equivalente \\
\hline & 19. Calidad del aire \\
\hline SMIS.24 & 19.1 Población expuesta a niveles de inmisión inferiores a 40 mg/m3 \\
\hline SMIS.25 & 20. Confort acústico \\
\hline
\end{tabular}


Tabla Al.9 Lista de indicadores en la herramienta SMIS (continuación)

\begin{tabular}{|c|c|}
\hline Código & Categoría/Subcategoría/Indicador \\
\hline & 5. COHESIÓN SOCIAL \\
\hline & 21. Envejecimiento de la población \\
\hline \multirow[t]{2}{*}{ SMIS.26 } & 21.1 Índice de segregación de las personas mayores \\
\hline & 22. Población de nacionalidad extranjera \\
\hline SMIS.27 & 22.1 Índice de segregación de la población extranjera \\
\hline \multirow[t]{2}{*}{ SMIS.28 } & 22.2 Población extranjera según procedencia \\
\hline & 23. Titulados superiores \\
\hline \multirow[t]{2}{*}{ SMIS.29 } & 23.1 Índice de segregación de la población con titulación superior \\
\hline & 24. Población activa \\
\hline SMIS.30 & 24.1 Tasa de paro \\
\hline \multirow[t]{2}{*}{ SMIS.31 } & 24.2 Tasa de dependencia \\
\hline & 25. Autocontención laboral \\
\hline SMIS.32 & 25.1 Autosuficiencia laboral \\
\hline \multirow[t]{2}{*}{ SMIS.33 } & 25.2 Índice de empleo local \\
\hline & 26. Proximidad a servicios urbanos básicos \\
\hline SMIS.34 & 26.1 Tiempo de acceso de la población a los servicios urbanos básicos \\
\hline SMIS.35 & 26.2 Acceso a nuevas tecnologías \\
\hline \multirow[t]{2}{*}{ SMIS.36 } & 27. Satisfacción de los ciudadanos con la comunidad local \\
\hline & 28. Tasa de asociacionismo \\
\hline \multirow[t]{3}{*}{ SMIS.37 } & 28.1 Población asociada \\
\hline & 6. AUMENTO DE LA BIODIVERSIDAD \\
\hline & 29. Superficie de paisaje recuperado \\
\hline SMIS.38 & 29.1 Inversión municipal proyectos de restauración y conservación ambiental \\
\hline SMIS.39 & 30. Superficie agrícola y ganadería ecológica \\
\hline
\end{tabular}


Tabla Al.10 Lista de indicadores en la herramienta CGYM

\begin{tabular}{|c|c|}
\hline Código & Área/Sub-área/Indicador \\
\hline & 1. OCUPACIÓN DEL SUELO \\
\hline & 1.1 Intesidad de uso \\
\hline CGYM.1 & 1.1.1 Densidad de viviendas \\
\hline \multirow[t]{3}{*}{ CGYM.2 } & 1.1.2 Compacidad absoluta \\
\hline & 2. ESPACIO PÚBLICO Y HABITABILIDAD \\
\hline & 2.1 Espacio público \\
\hline \multirow[t]{2}{*}{ CGYM.3 } & 2.1.1 Compacidad corregida \\
\hline & 2.1 Habitabilidad del espacio público \\
\hline CGYM.4 & 2.2.1 Calidad del aire \\
\hline CGYM.5 & 2.2.2 Confort acústico \\
\hline CGYM.6 & 2.2.3 Confort térmico \\
\hline CGYM.7 & 2.2.4 Accesibilidad del viario \\
\hline CGYM.8 & 2.2.5 Proporción de calle \\
\hline CGYM.9 & 2.2.6 Percepción espacial del verde urbano \\
\hline \multirow[t]{3}{*}{ CGYM.10 } & 2.2.7 Proximidad de la población a los servicios básicos \\
\hline & 3. MOVILIDAD Y SERVICIOS \\
\hline & 3.1 Configuración de la red \\
\hline CGYM.11 & 3.1.1 Modo de desplazamiento de la población \\
\hline \multirow[t]{2}{*}{ CGYM.12 } & 3.1.2 Proximidad de la población a redes de transporte público alternativas al automóvil \\
\hline & 3.2 Funcionalidad \\
\hline CGYM.13 & 3.2.1 Reparto del viario público: viario peatonal - viario vehicular \\
\hline \multirow[t]{2}{*}{ CGYM.14 } & 3.2.2 Proximidad de la población al aparcamiento para bicicletas \\
\hline & 3.3 Infraestructuras \\
\hline CGYM.15 & 3.3.1 Aparcamiento para el vehículo privado fuera de la calzada \\
\hline CGYM.16 & 3.3.2 Déficit infraestructural teórico de aparcamiento para el vehículo privado \\
\hline CGYM.17 & 3.3.3 Operaciones de carga y descarga de mercancías fuera de la calzada \\
\hline \multirow[t]{3}{*}{ CGYM.18 } & 3.3.4 Infraestructuras de servicios \\
\hline & 4. COMPLEJIDAD URBANA \\
\hline & 4.1 Diversidad \\
\hline CGYM.19 & 4.1.1 Índice de diversidad urbana \\
\hline CGYM.20 & 4.1.2 Equilibrio entre la actividad y la residencia \\
\hline CGYM.21 & 4.1.3 Proximidad a actividades comerciales de uso cotidiano \\
\hline \multirow[t]{2}{*}{ CGYM.22 } & 4.1.4 Actividades densas en conocimiento \\
\hline & 4.2 Funcionalidad \\
\hline \multirow[t]{3}{*}{ CGYM.23 } & 4.2.1 Continuidad espacial y funcional de la calle corredor \\
\hline & 5. ESPACIO VERDES Y BIODIVERSIDAD \\
\hline & 5.1 Estructura \\
\hline CGYM.24 & 5.1.1 Índice biótico del suelo \\
\hline CGYM.25 & 5.1.2 Espacio verde por habitante \\
\hline CGYM.26 & 5.1.3 Cubiertas verdes \\
\hline CGYM.27 & 5.1.4 Proximidad de la población a espacios verdes \\
\hline CGYM.28 & 5.1.5 Biodiversidad del arbolado \\
\hline \multirow[t]{2}{*}{ CGYM.29 } & 5.1.6 Conectividad de los corredores verdes urbanos \\
\hline & 5.2 Potencial \\
\hline CGYM.30 & 5.2.1 Índice de funcionalidad de los parques urbanos \\
\hline
\end{tabular}


Tabla Al.10 Lista de indicadores en la herramienta CGYM (continuación)

\begin{tabular}{|c|c|}
\hline & 6. METABOLISMO URBANO \\
\hline & 6.1 Energía \\
\hline CGYM.31 & $\begin{array}{l}\text { 6.1.1 Consumo energético por sectores (COe) (para tejidos urbanos } \\
\text { consolidados).Demanda energética por sectores (para nuevos desarrollos urbanísticos) }\end{array}$ \\
\hline CGYM.32 & 6.1.2 Producción local de energías renovables \\
\hline \multirow[t]{2}{*}{ CGYM.33 } & 6.1.3 Autosuficiencia energética a partir de energías renovables \\
\hline & 6.2 Agua \\
\hline CGYM.34 & $\begin{array}{l}\text { 6.2.1 Consumo hídrico por sectores (COh) (para tejidos urbanos consolidados) } \\
\text { Demanda hídrica por sectores (para nuevos desarrollos urbanísticos) }\end{array}$ \\
\hline CGYM.35 & 6.2.2 Regeneración de aguas marginales \\
\hline \multirow[t]{2}{*}{ CGYM.36 } & 6.2.3 Autosuficiencia hídrica \\
\hline & 6.3 Alimentos \\
\hline \multirow[t]{2}{*}{ CGYM.37 } & 6.3.1 Autoproducción de alimentos \\
\hline & 6.4 Residuos y materiales \\
\hline CGYM.38 & 6.4.1 Valorización de los residuos de la construcción y la demolición \\
\hline CGYM.39 & 6.4.2 Recogida selectiva neta \\
\hline CGYM.40 & 6.4.3 Dotación de contenedores de recogida selectiva \\
\hline CGYM.41 & 6.4.4 Proximidad de la población a puntos de recogida selectiva \\
\hline CGYM.42 & 6.4.5 Proximidad de la población a centros de recogida \\
\hline \multirow[t]{2}{*}{ CGYM.43 } & 6.4.6 Cierre del ciclo de la materia orgánica \\
\hline & 6.5 Atmósfera \\
\hline CGYM.44 & 6.5.1 Emisión de gases de efecto invernadero en la atmósfera \\
\hline \multirow[t]{3}{*}{ CGYM.45 } & 6.5.2 Contaminación lumínica \\
\hline & 7. COHESIÓN SOCIAL \\
\hline & 7.1 Mezcla de población \\
\hline CGYM.46 & 7.1.1 Índice de envejecimiento \\
\hline CGYM.47 & 7.1.2 Población extranjera \\
\hline \multirow[t]{2}{*}{ CGYM.48 } & 7.1.3 Titulados de tercer grado \\
\hline & 7.2 Acceso a la vivienda \\
\hline \multirow[t]{2}{*}{ CGYM.49 } & 7.2.1 Viviendas con protección oficial \\
\hline & 7.3 Equipamientos públicos \\
\hline CGYM.50 & 7.3.1 Dotación de equipamientos públicos \\
\hline \multirow[t]{2}{*}{ CGYM.51 } & 7.3.2 Proximidad de la población a equipamientos públicos \\
\hline & 8. FUNCIÓN GUÍA DE LA SOSTENIBILIDAD \\
\hline CGYM.52 & 8.1 Eficiencia del sistema urbano \\
\hline
\end{tabular}


Tabla Al.11. Lista de indicadores en la herramienta SEV

\begin{tabular}{|c|c|}
\hline Código & Categoría/Indicador \\
\hline & 1. MORFOLOGÍA URBANA \\
\hline SEV.1 & 1.1. Densidad edificatoria \\
\hline SEV. 2 & 1.2. Compacidad absoluta \\
\hline \multirow[t]{2}{*}{ SEV.3 } & 1.3. Compacidad corregida \\
\hline & 2. ESPACIO PÚBLICO Y MOVILIDAD \\
\hline SEV.4 & 2.1 Viario público para el tráfico del automóvil de paso y del transporte público de superficie \\
\hline SEV.5 & 2.2 Viario público para el peatón y otros usos del espacio público \\
\hline SEV.6 & 2.3 Continuidad de la calle corredor \\
\hline SEV.7 & 2.4 Prohibición de condominios cerrados \\
\hline SEV.8 & 2.5 Dotación de árboles según la proyección vertical de sombra en suelo \\
\hline SEV.9 & 2.6 Potencial de habitabilidad térmica en espacios urbanos \\
\hline SEV.10 & 2.7 Disposición de báculos sin contaminación lumínica \\
\hline SEV.11 & 2.8 Diseño e introducción de las TIC en el espacio público \\
\hline SEV.12 & 2.9 Accesibilidad a las paradas de la red de transporte público de superficie. Red segregada. \\
\hline SEV.13 & 2.10 Accesibilidad a la red de bicicletas. Red de carriles segregada \\
\hline SEV.14 & 2.11 Accesibilidad a plataformas logísticas subterráneas \\
\hline SEV.15 & 2.12 Reserva de espacios de estacionamiento: vehículos privado \\
\hline SEV.16 & 2.13 Galerías de servicios \\
\hline SEV.17 & 2.14 Reserva de espacios de estacionamiento: bicicletas \\
\hline \multirow[t]{2}{*}{ SEV.18 } & 2.15 Accesibilidad de los ciudadanos con movilidad reducida \\
\hline & 3. COMPLEJIDAD \\
\hline SEV.19 & 3.1 La complejidad urbana $(\mathrm{H})$ \\
\hline SEV.20 & 3.2 El reparto entre actividad y residencia \\
\hline SEV.21 & 3.3 Superficie mínima de los locales \\
\hline SEV.22 & 3.4 La proporción de actividades de proximidad \\
\hline SEV.23 & 3.5 Diversidad de actividades. Índice de especialización \\
\hline \multirow[t]{2}{*}{ SEV.24 } & 3.6 La proporción de actividades densas en conocimiento. Actividades @ \\
\hline & 4. METABOLISMO URBANO \\
\hline SEV.25 & 4.1 Autogeneración energética de las viviendas \\
\hline SEV.26 & 4.2 Autosuficiencia hídrica de la demanda urbana \\
\hline SEV.27 & 4.3 Minimización de los sistemas de recogida en el espacio público. Residuos sólidos urbanos \\
\hline SEV.28 & 4.4 Minimización y recuperación de los residuos generados en la construcción y demolición \\
\hline SEV.29 & 4.5 Uso de materiales reutilizados, reciclados y renovables \\
\hline SEV.30 & 4.6 Reserva de espacios para los procesos de autocompostaje y huertos urbanos \\
\hline SEV.31 & 4.7 Reserva de espacios para la instalación de puntos limpios \\
\hline \multirow[t]{2}{*}{ SEV.32 } & 4.8 Nivel sonoro \\
\hline & 5. BIODIVERSIDAD \\
\hline SEV.33 & 5.1 Acceso de los ciudadanos a espacios verdes \\
\hline SEV.34 & 5.2 Compensación a la impermeabilización y sellado: Índice de permeabilidad \\
\hline SEV.35 & 5.3 Dotación de árboles en el espacio público \\
\hline SEV.36 & 5.4 Corredores verdes \\
\hline SEV.37 & 5.5 Una segunda capa de biodiversidad en altura: cubiertas verdes \\
\hline SEV.38 & 5.6 Una segunda capa de biodiversidad en altura: enverdecimiento de fachadas \\
\hline SEV.39 & 5.7 Reserva de espacio libre en interiores de manzana \\
\hline SEV.40 & 5.8 Compacidad corregida ponderada \\
\hline \multirow[t]{2}{*}{ SEV.41 } & 5.9 Requerimientos de espacios de estancia \\
\hline & 6. COHESIÓN SOCIAL \\
\hline SEV.42 & 6.1 Acceso a los equipamientos y servicios básicos \\
\hline \multirow[t]{2}{*}{ SEV.43 } & 6.2 Mezcla de rentas en la edificación residencial: viviendas de protección pública \\
\hline & 7. SOSTENIBILIDAD \\
\hline SEV.44 & 7.1 Eficiencia del Sistema Urbano \\
\hline
\end{tabular}


Tabla AI.12. Lista de indicadores en la herramienta BCN

\begin{tabular}{ll}
\hline Código & Categoría/Indicador \\
\hline & 1. TERRITORIO \\
\hline BCN.1 & 1.1 Ocupación urbana del suelo \\
BCN.2 & 1.2 Protección de espacios de interés natural \\
\hline & 2. RESIDUOS \\
\hline BCN.3 & 2.1 Intensidad de producción de residuos de la economía local \\
BCN.4 & 2.2 Recuperación de residuos municipales \\
BCN.5 & 2.3 Utilización de los puntos limpios municipales \\
BCN.6 & 2.4 Recuperación de residuos industriales \\
\hline & 3. ENERGIA \\
\hline BCN.7 & 3.1 Intensidad energética local \\
BCN.8 & 3.2 Consumo final de energía \\
BCN.9 & 3.3 Estructura urbana: desplazamiento y movilidad de la población \\
BCN.10 & 3.4 Producción de energías renovables \\
BCN.11 & 3.5 Emisión de gases con efecto invernadero \\
\hline & 4. AGUA \\
\hline BCN.12 & 4.1 Intensidad de consumo de agua de la economía local \\
BCN.13 & 4.2 Abastecimiento de agua municipal \\
\hline
\end{tabular}


Tabla Al.13. Lista de indicadores en la herramienta BIL

\begin{tabular}{|c|c|}
\hline Código & Categoría/Indicador \\
\hline & 1. AGUA \\
\hline BIL.1 & 1. Consumo de agua \\
\hline \multirow[t]{2}{*}{ BIL.2 } & 2. Vertidos al agua \\
\hline & 2. ENERGÍA \\
\hline BIL.3 & 3. Consumo de energía \\
\hline \multirow[t]{2}{*}{ BIL.4 } & 4. Producción y consumo de energías renovables \\
\hline & 3. TRANSPORTE \\
\hline BIL.5 & 5. Movilidad local y transporte de pasajeros \\
\hline BIL.6 & 6. Intensidad de tráfico en la red de accesos a Bilbao \\
\hline BIL.7 & 7. Distribución de la longitud de las vías dedicadas a infraestructuras de transporte \\
\hline BIL.8 & 8. Parque móvil \\
\hline BIL.9 & 9. Índice de motorización \\
\hline \multirow[t]{2}{*}{ BIL.10 } & 10. Seguridad vial \\
\hline & 4. AIRE \\
\hline \multirow[t]{2}{*}{ BIL.11 } & 11. Calidad del aire urbano \\
\hline & 5. RUIDO \\
\hline \multirow[t]{2}{*}{ BIL.12 } & 12. Ruido urbano \\
\hline & 6. MEDIO NATURAL, BIODIVERSIDAD Y ZONAS VERDES \\
\hline BIL.13 & 13. Zonas verdes y espacios libres por habitante \\
\hline BIL.14 & 14. Reintroducción de especies arbóreas autóctonas \\
\hline \multirow[t]{2}{*}{ BIL.15 } & 15. Gasto municipal en medio ambiente \\
\hline & 7. SUELO \\
\hline \multirow[t]{2}{*}{ BIL.16 } & 16. Uso sostenible del suelo \\
\hline & 8. RESIDUOS \\
\hline \multirow[t]{2}{*}{ BIL.17 } & 17. Generación y gestión de residuos \\
\hline & 9. ESPACIO URBANO \\
\hline BIL.18 & 18. Disponibilidad de zonas públicas abiertas y de servicios en el municipio \\
\hline BIL.19 & 19. Número de viviendas protegidas terminadas anualmente \\
\hline \multirow[t]{2}{*}{ BIL.20 } & 20. Restauración de superficies urbanas \\
\hline & 10. ACTIVIDADES ECONÓMICAS \\
\hline BIL.21 & 21. Dinamismo de la economía local \\
\hline BIL.22 & 22. Integración del medio ambiente en las actividades del municipio \\
\hline BIL.23 & 23. Tasa de paro registrado \\
\hline \multirow[t]{2}{*}{ BIL.24 } & 24. Vitalidad turística \\
\hline & 11. SOCIEDAD \\
\hline BIL.25 & 25. Pobreza y exclusión social \\
\hline BIL.26 & 26. Satisfacción de la ciudadanía con la comunidad local \\
\hline BIL.27 & 27. Índice de Infancia/ Juventud/Envejecimiento y Dependencia de la población \\
\hline BIL.28 & 28. Gasto municipal en políticas sociales \\
\hline BIL.29 & 29. Implantación municipal en actividades de solidaridad internacional \\
\hline BIL.30 & 30. Integración de la población inmigrante \\
\hline BIL.31 & 31. Conocimiento del euskera \\
\hline \multirow[t]{2}{*}{ BIL.32 } & 32. Gasto municipal y organización de actividades culturales \\
\hline & 12. INFORMACIÓN, SENSIBILIZACIÓN Y PARTICIPACIÓN CIUDADANA \\
\hline BIL.33 & 33. Participación ciudadana \\
\hline BIL.34 & 34. Educación ambiental \\
\hline
\end{tabular}




\section{ANEXO II. HIPÓTESIS DE CÁLCULO}



Tabla All.1 Lista de indicadores en la herramienta LEED ND

\begin{tabular}{|c|c|c|c|c|c|}
\hline Hipótesis & Manzana urbana & Ratio H/W & Orientación & Factor de forma & Año construcción \\
\hline $\mathrm{H} 1$ & $\mathrm{MU}_{2}$ & $\mathrm{H} / \mathrm{W}_{2,4}$ & $\mathrm{~N}\left(0^{\circ} \stackrel{\circ}{)}\right.$ & $S / V_{0,40}$ & $1(<1940)$ \\
\hline $\mathrm{H} 2$ & $\mathrm{MU}_{2}$ & $\mathrm{H} / \mathrm{W}_{2,4}$ & $\mathrm{~S}\left(180^{\circ}\right)$ & $\mathrm{S} / \mathrm{V}_{0,40}$ & $1(<1940)$ \\
\hline $\mathrm{H3}$ & $\mathrm{MU}_{2}$ & $\mathrm{H} / \mathrm{W}_{2,4}$ & $E(90 \%)$ & $\mathrm{S} / \mathrm{V}_{0,40}$ & $1(<1940)$ \\
\hline $\mathrm{H} 4$ & $\mathrm{MU}_{2}$ & $\mathrm{H} / \mathrm{W}_{2,4}$ & $\mathrm{O}\left(270^{\circ}\right)$ & $\mathrm{S} / \mathrm{V}_{0,40}$ & $1(<1940)$ \\
\hline $\mathrm{H} 5$ & $\mathrm{MU}_{2}$ & $\mathrm{H} / \mathrm{W}_{2,4}$ & $\mathrm{~N}\left(\mathrm{O}^{\circ}\right)$ & $\mathrm{S} / \mathrm{V}_{0,40}$ & 2 (1940-1959) \\
\hline $\mathrm{H} 6$ & $\mathrm{MU}_{2}$ & $\mathrm{H} / \mathrm{W}_{2,4}$ & $\mathrm{~S}\left(180^{\circ}\right)$ & $\mathrm{S} / \mathrm{V}_{0,40}$ & 2 (1940-1959) \\
\hline $\mathrm{H} 7$ & $\mathrm{MU}_{2}$ & $\mathrm{H} / \mathrm{W}_{2,4}$ & $E(90 \div)$ & $S / V_{0,40}$ & 2 (1940-1959) \\
\hline $\mathrm{H} 8$ & $\mathrm{MU}_{2}$ & $\mathrm{H} / \mathrm{W}_{2,4}$ & $\mathrm{O}\left(270^{\circ}\right)$ & $\mathrm{S} / \mathrm{V}_{0,40}$ & 2 (1940-1959) \\
\hline $\mathrm{H9}$ & $\mathrm{MU}_{2}$ & $\mathrm{H} / \mathrm{W}_{2,4}$ & $\mathrm{~N}\left(\mathrm{O}^{\circ}\right.$ ) & $\mathrm{S} / \mathrm{V}_{0,40}$ & 3 (1960-1979) \\
\hline $\mathrm{H} 10$ & $\mathrm{MU}_{2}$ & $\mathrm{H} / \mathrm{W}_{2,4}$ & $\mathrm{~S}\left(180^{\circ}\right)$ & $\mathrm{S} / \mathrm{V}_{0,40}$ & 3 (1960-1979) \\
\hline $\mathrm{H} 11$ & $\mathrm{MU}_{2}$ & $\mathrm{H} / \mathrm{W}_{2,4}$ & $E(90 \div)$ & $\mathrm{S} / \mathrm{V}_{0,40}$ & 3 (1960-1979) \\
\hline $\mathrm{H} 12$ & $\mathrm{MU}_{2}$ & $\mathrm{H} / \mathrm{W}_{2,4}$ & $\mathrm{O}\left(270^{\circ}\right)$ & $\mathrm{S} / \mathrm{V}_{0,40}$ & 3 (1960-1979) \\
\hline $\mathrm{H} 13$ & $\mathrm{MU}_{2}$ & $\mathrm{H} / \mathrm{W}_{2,4}$ & $\mathrm{~N}\left(\mathrm{O}^{\circ}\right)$ & $\mathrm{S} / \mathrm{V}_{0,40}$ & 4 (1980-2006) \\
\hline $\mathrm{H} 14$ & $\mathrm{MU}_{2}$ & $\mathrm{H} / \mathrm{W}_{2,4}$ & $\mathrm{~S}\left(180^{\circ}\right)$ & $\mathrm{S} / \mathrm{V}_{0,40}$ & 4 (1980-2006) \\
\hline $\mathrm{H} 15$ & $\mathrm{MU}_{2}$ & $\mathrm{H} / \mathrm{W}_{2,4}$ & $E(90)$ & $\mathrm{S} / \mathrm{V}_{0,40}$ & 4 (1980-2006) \\
\hline $\mathrm{H} 16$ & $\mathrm{MU}_{2}$ & $\mathrm{H} / \mathrm{W}_{2,4}$ & $\mathrm{O}(270$ ) & $\mathrm{S} / \mathrm{V}_{0,40}$ & 4 (1980-2006) \\
\hline $\mathrm{H} 17$ & $\mathrm{MU}_{2}$ & $\mathrm{H} / \mathrm{W}_{2,4}$ & $\mathrm{~N}\left(\mathrm{O}^{\circ}\right.$ ) & $\mathrm{S} / \mathrm{V}_{0,40}$ & $5(2007-2013)$ \\
\hline $\mathrm{H} 18$ & $\mathrm{MU}_{2}$ & $\mathrm{H} / \mathrm{W}_{2,4}$ & $S\left(180^{\circ}\right)$ & $\mathrm{S} / \mathrm{V}_{0,40}$ & $5(2007-2013)$ \\
\hline $\mathrm{H} 19$ & $\mathrm{MU}_{2}$ & $\mathrm{H} / \mathrm{W}_{2,4}$ & $E(90)$ & $\mathrm{S} / \mathrm{V}_{0,40}$ & $5(2007-2013)$ \\
\hline $\mathrm{H} 2 \mathrm{O}$ & $\mathrm{MU}_{2}$ & $\mathrm{H} / \mathrm{W}_{2,4}$ & $\mathrm{O}(270 \div)$ & $\mathrm{S} / \mathrm{V}_{0,40}$ & $5(2007-2013)$ \\
\hline $\mathrm{H} 21$ & $\mathrm{MU}_{2}$ & $\mathrm{H} / \mathrm{W}_{1,2}$ & $\mathrm{~N}(0 \circ)$ & $\mathrm{S} / \mathrm{V}_{0,40}$ & $1(<1940)$ \\
\hline $\mathrm{H} 22$ & $\mathrm{MU}_{2}$ & $\mathrm{H} / \mathrm{W}_{1,2}$ & $S\left(180^{\circ}\right)$ & $\mathrm{S} / \mathrm{V}_{0,40}$ & $1(<1940)$ \\
\hline $\mathrm{H} 23$ & $\mathrm{MU}_{2}$ & $\mathrm{H} / \mathrm{W}_{1,2}$ & $E(90 \%)$ & $\mathrm{S} / \mathrm{V}_{0,40}$ & $1(<1940)$ \\
\hline $\mathrm{H} 24$ & $\mathrm{MU}_{2}$ & $\mathrm{H} / \mathrm{W}_{1,2}$ & $\mathrm{O}\left(270^{\circ}\right)$ & $\mathrm{S} / \mathrm{V}_{0,40}$ & $1(<1940)$ \\
\hline $\mathrm{H} 25$ & $\mathrm{MU}_{2}$ & $\mathrm{H} / \mathrm{W}_{1,2}$ & $\mathrm{~N}\left(\mathrm{O}^{\circ} \mathrm{o}\right)$ & $\mathrm{S} / \mathrm{V}_{0,40}$ & 2 (1940-1959) \\
\hline $\mathrm{H} 26$ & $\mathrm{MU}_{2}$ & $\mathrm{H} / \mathrm{W}_{1,2}$ & $\mathrm{~S}\left(180^{\circ}\right)$ & $\mathrm{S} / \mathrm{V}_{0,40}$ & 2 (1940-1959) \\
\hline $\mathrm{H} 27$ & $\mathrm{MU}_{2}$ & $\mathrm{H} / \mathrm{W}_{1,2}$ & $E(90 \%)$ & $\mathrm{S} / \mathrm{V}_{0,40}$ & 2 (1940-1959) \\
\hline $\mathrm{H} 28$ & $\mathrm{MU}_{2}$ & $\mathrm{H} / \mathrm{W}_{1,2}$ & $\mathrm{O}\left(270^{\circ}\right)$ & $\mathrm{S} / \mathrm{V}_{0,40}$ & 2 (1940-1959) \\
\hline $\mathrm{H} 29$ & $\mathrm{MU}_{2}$ & $\mathrm{H} / \mathrm{W}_{1,2}$ & $\mathrm{~N}\left(\mathrm{O}^{\circ} \mathrm{o}\right)$ & $\mathrm{S} / \mathrm{V}_{0,40}$ & $3(1960-1979)$ \\
\hline $\mathrm{H} 30$ & $\mathrm{MU}_{2}$ & $\mathrm{H} / \mathrm{W}_{1,2}$ & $\mathrm{~S}\left(180^{\circ}\right)$ & $\mathrm{S} / \mathrm{V}_{0,40}$ & 3 (1960-1979) \\
\hline H31 & $\mathrm{MU}_{2}$ & $\mathrm{H} / \mathrm{W}_{1,2}$ & $E(90 \%)$ & $\mathrm{S} / \mathrm{V}_{0,40}$ & $3(1960-1979)$ \\
\hline H32 & $\mathrm{MU}_{2}$ & $\mathrm{H} / \mathrm{W}_{1,2}$ & $\mathrm{O}\left(270^{\circ}\right)$ & $\mathrm{S} / \mathrm{V}_{0,40}$ & 3 (1960-1979) \\
\hline H33 & $\mathrm{MU}_{2}$ & $\mathrm{H} / \mathrm{W}_{1,2}$ & $\mathrm{~N}\left(\mathrm{O}^{\circ} \mathrm{O}\right)$ & $\mathrm{S} / \mathrm{V}_{0,40}$ & 4 (1980-2006) \\
\hline H34 & $\mathrm{MU}_{2}$ & $\mathrm{H} / \mathrm{W}_{1,2}$ & $\mathrm{~S}\left(180^{\circ}\right)$ & $\mathrm{S} / \mathrm{V}_{0,40}$ & 4 (1980-2006) \\
\hline H35 & $\mathrm{MU}_{2}$ & $\mathrm{H} / \mathrm{W}_{1,2}$ & $\mathrm{E}(90$ ㅇ) & $\mathrm{S} / \mathrm{V}_{0,40}$ & $4(1980-2006)$ \\
\hline H36 & $\mathrm{MU}_{2}$ & $\mathrm{H} / \mathrm{W}_{1,2}$ & $\mathrm{O}\left(270^{\circ}\right)$ & $\mathrm{S} / \mathrm{V}_{0,40}$ & $4(1980-2006)$ \\
\hline H37 & $\mathrm{MU}_{2}$ & $\mathrm{H} / \mathrm{W}_{1,2}$ & $\mathrm{~N}\left(\mathrm{O}^{\circ}\right)$ & $\mathrm{S} / \mathrm{V}_{0,40}$ & 5 (2007-2013) \\
\hline H38 & $\mathrm{MU}_{2}$ & $\mathrm{H} / \mathrm{W}_{1,2}$ & $\mathrm{~S}\left(180^{\circ}\right)$ & $\mathrm{S} / \mathrm{V}_{0,40}$ & $5(2007-2013)$ \\
\hline H39 & $\mathrm{MU}_{2}$ & $\mathrm{H} / \mathrm{W}_{1,2}$ & $\mathrm{E}(90 \%)$ & $\mathrm{S} / \mathrm{V}_{0,40}$ & 5 (2007-2013) \\
\hline $\mathrm{H} 40$ & $\mathrm{MU}_{2}$ & $\mathrm{H} / \mathrm{W}_{1,2}$ & $\mathrm{O}\left(270^{\circ}\right)$ & $\mathrm{S} / \mathrm{V}_{0,40}$ & $5(2007-2013)$ \\
\hline $\mathrm{H} 41$ & $\mathrm{MU}_{3}$ & $\mathrm{H} / \mathrm{W}_{2,4}$ & $\mathrm{~N}\left(\mathrm{O}^{\circ}\right)$ & $S / V_{0,40}$ & $1(<1940)$ \\
\hline $\mathrm{H} 42$ & $\mathrm{MU}_{3}$ & $\mathrm{H} / \mathrm{W}_{2,4}$ & $\mathrm{~S}\left(180^{\circ}\right)$ & $\mathrm{S} / \mathrm{V}_{0,40}$ & $1(<1940)$ \\
\hline $\mathrm{H} 43$ & $\mathrm{MU}_{3}$ & $\mathrm{H} / \mathrm{W}_{2,4}$ & $E(90)$ & $S / V_{0,40}$ & $1(<1940)$ \\
\hline $\mathrm{H} 44$ & $\mathrm{MU}_{3}$ & $\mathrm{H} / \mathrm{W}_{2,4}$ & $\mathrm{O}(270 \%)$ & $\mathrm{S} / \mathrm{V}_{0,40}$ & $1(<1940)$ \\
\hline $\mathrm{H} 45$ & $\mathrm{MU}_{3}$ & $\mathrm{H} / \mathrm{W}_{2,4}$ & $\mathrm{~N}\left(\mathrm{O}^{\circ} \mathrm{O}\right)$ & $\mathrm{S} / \mathrm{V}_{0,40}$ & 2 (1940-1959) \\
\hline $\mathrm{H} 46$ & $\mathrm{MU}_{3}$ & $\mathrm{H} / \mathrm{W}_{2,4}$ & $\mathrm{~S}\left(180^{\circ}\right)$ & $\mathrm{S} / \mathrm{V}_{0,40}$ & $2(1940-1959)$ \\
\hline $\mathrm{H} 47$ & $\mathrm{MU}_{3}$ & $\mathrm{H} / \mathrm{W}_{2,4}$ & $E(90 \%)$ & $\mathrm{S} / \mathrm{V}_{0,40}$ & $2(1940-1959)$ \\
\hline $\mathrm{H} 48$ & MU3 & H/W2,4 & $\mathrm{O}(270 \div)$ & S/V0,40 & $2(1940-1959)$ \\
\hline
\end{tabular}


Tabla All.1 Lista de indicadores en la herramienta LEED ND (continuación)

\begin{tabular}{|c|c|c|c|c|c|}
\hline Hipótesis & Manzana urbana & Ratio H/W & Orientación & Factor de forma & Año construcción \\
\hline $\mathrm{H} 49$ & $\mathrm{MU}_{3}$ & $\mathrm{H} / \mathrm{W}_{2,4}$ & $\mathrm{~N}\left(0^{\circ}\right)$ & $\mathrm{S} / \mathrm{V}_{0,40}$ & 3 (1960-1979) \\
\hline $\mathrm{H} 50$ & $\mathrm{MU}_{3}$ & $\mathrm{H} / \mathrm{W}_{2,4}$ & S (180) & $\mathrm{S} / \mathrm{V}_{0,40}$ & $3(1960-1979)$ \\
\hline $\mathrm{H} 51$ & $\mathrm{MU}_{3}$ & $\mathrm{H} / \mathrm{W}_{2,4}$ & $E(90 \%)$ & $\mathrm{S} / \mathrm{V}_{0,40}$ & 3 (1960-1979) \\
\hline $\mathrm{H} 52$ & $\mathrm{MU}_{3}$ & $\mathrm{H} / \mathrm{W}_{2,4}$ & $\mathrm{O}(270 \div)$ & $\mathrm{S} / \mathrm{V}_{0,40}$ & $3(1960-1979)$ \\
\hline $\mathrm{H} 53$ & $\mathrm{MU}_{3}$ & $\mathrm{H} / \mathrm{W}_{2,4}$ & $\mathrm{~N}\left(\mathrm{O}^{\circ} \mathrm{\circ}\right)$ & $\mathrm{S} / \mathrm{V}_{0,40}$ & 4 (1980-2006) \\
\hline $\mathrm{H} 54$ & $\mathrm{MU}_{3}$ & $\mathrm{H} / \mathrm{W}_{2,4}$ & S (180) & $\mathrm{S} / \mathrm{V}_{0,40}$ & $4(1980-2006)$ \\
\hline $\mathrm{H} 55$ & $\mathrm{MU}_{3}$ & $\mathrm{H} / \mathrm{W}_{2,4}$ & $E(90)$ & $\mathrm{S} / \mathrm{V}_{0,40}$ & $4(1980-2006)$ \\
\hline $\mathrm{H} 56$ & $\mathrm{MU}_{3}$ & $\mathrm{H} / \mathrm{W}_{2,4}$ & $\mathrm{O}(270 \div)$ & $\mathrm{S} / \mathrm{V}_{0,40}$ & $4(1980-2006)$ \\
\hline $\mathrm{H} 57$ & $\mathrm{MU}_{3}$ & $\mathrm{H} / \mathrm{W}_{2,4}$ & $\mathrm{~N}\left(0^{\circ}\right)$ & $\mathrm{S} / \mathrm{V}_{0,40}$ & $5(2007-2013)$ \\
\hline $\mathrm{H} 58$ & $\mathrm{MU}_{3}$ & $\mathrm{H} / \mathrm{W}_{2,4}$ & S (180ㅇ) & $\mathrm{S} / \mathrm{V}_{0,40}$ & $5(2007-2013)$ \\
\hline $\mathrm{H} 59$ & $\mathrm{MU}_{3}$ & $\mathrm{H} / \mathrm{W}_{2,4}$ & $E(90 \div)$ & $\mathrm{S} / \mathrm{V}_{0,40}$ & $5(2007-2013)$ \\
\hline $\mathrm{H} 60$ & $\mathrm{MU}_{3}$ & $\mathrm{H} / \mathrm{W}_{2,4}$ & $\mathrm{O}(270 \div)$ & $\mathrm{S} / \mathrm{V}_{0,40}$ & $5(2007-2013)$ \\
\hline $\mathrm{H} 61$ & $\mathrm{MU}_{3}$ & $\mathrm{H} / \mathrm{W}_{1,2}$ & $\mathrm{~N}\left(0^{\circ}\right)$ & $\mathrm{S} / \mathrm{V}_{0,40}$ & $1(<1940)$ \\
\hline $\mathrm{H} 62$ & $\mathrm{MU}_{3}$ & $\mathrm{H} / \mathrm{W}_{1,2}$ & $\mathrm{~S}\left(180^{\circ}\right)$ & $\mathrm{S} / \mathrm{V}_{0,40}$ & $1(<1940)$ \\
\hline $\mathrm{H} 63$ & $\mathrm{MU}_{3}$ & $\mathrm{H} / \mathrm{W}_{1,2}$ & $E(90)$ & $\mathrm{S} / \mathrm{V}_{0,40}$ & $1(<1940)$ \\
\hline $\mathrm{H} 64$ & $\mathrm{MU}_{3}$ & $\mathrm{H} / \mathrm{W}_{1,2}$ & $\mathrm{O}\left(270^{\circ}\right)$ & $\mathrm{S} / \mathrm{V}_{0,40}$ & $1(<1940)$ \\
\hline $\mathrm{H} 65$ & $\mathrm{MU}_{3}$ & $\mathrm{H} / \mathrm{W}_{1,2}$ & $N(0 \circ)$ & $\mathrm{S} / \mathrm{V}_{0,40}$ & 2 (1940-1959) \\
\hline $\mathrm{H} 66$ & $\mathrm{MU}_{3}$ & $\mathrm{H} / \mathrm{W}_{1,2}$ & $S\left(180^{\circ}\right)$ & $\mathrm{S} / \mathrm{V}_{0,40}$ & 2 (1940-1959) \\
\hline $\mathrm{H} 67$ & $\mathrm{MU}_{3}$ & $\mathrm{H} / \mathrm{W}_{1,2}$ & $E(90)$ & $\mathrm{S} / \mathrm{V}_{0,40}$ & 2 (1940-1959) \\
\hline $\mathrm{H} 68$ & $\mathrm{MU}_{3}$ & $\mathrm{H} / \mathrm{W}_{1,2}$ & $\mathrm{O}(270 \div)$ & $\mathrm{S} / \mathrm{V}_{0,40}$ & 2 (1940-1959) \\
\hline $\mathrm{H} 69$ & $\mathrm{MU}_{3}$ & $\mathrm{H} / \mathrm{W}_{1,2}$ & $\mathrm{~N}\left(0^{\circ}\right)$ & $\mathrm{S} / \mathrm{V}_{0,40}$ & 3 (1960-1979) \\
\hline $\mathrm{H} 70$ & $\mathrm{MU}_{3}$ & $\mathrm{H} / \mathrm{W}_{1,2}$ & S (180) & $\mathrm{S} / \mathrm{V}_{0,40}$ & 3 (1960-1979) \\
\hline H71 & $\mathrm{MU}_{3}$ & $\mathrm{H} / \mathrm{W}_{1,2}$ & $E(90)$ & $\mathrm{S} / \mathrm{V}_{0,40}$ & 3 (1960-1979) \\
\hline $\mathrm{H} 72$ & $\mathrm{MU}_{3}$ & $\mathrm{H} / \mathrm{W}_{1,2}$ & $\mathrm{O}(270 \div)$ & $\mathrm{S} / \mathrm{V}_{0,40}$ & 3 (1960-1979) \\
\hline $\mathrm{H} 73$ & $\mathrm{MU}_{3}$ & $\mathrm{H} / \mathrm{W}_{1,2}$ & $\begin{array}{l}\mathrm{N}(0 \circ) \\
\end{array}$ & $\mathrm{S} / \mathrm{V}_{0,40}$ & 4 (1980-2006) \\
\hline $\mathrm{H} 74$ & $\mathrm{MU}_{3}$ & $\mathrm{H} / \mathrm{W}_{1,2}$ & S (1809) & $\mathrm{S} / \mathrm{V}_{0,40}$ & 4 (1980-2006) \\
\hline $\mathrm{H} 75$ & $\mathrm{MU}_{3}$ & $\mathrm{H} / \mathrm{W}_{1,2}$ & $E(90 \%)$ & $\mathrm{S} / \mathrm{V}_{0,40}$ & 4 (1980-2006) \\
\hline $\mathrm{H} 76$ & $\mathrm{MU}_{3}$ & $\mathrm{H} / \mathrm{W}_{1,2}$ & $\mathrm{O}(270 \div)$ & $\mathrm{S} / \mathrm{V}_{0,40}$ & $4(1980-2006)$ \\
\hline $\mathrm{H} 77$ & $\mathrm{MU}_{3}$ & $\mathrm{H} / \mathrm{W}_{1,2}$ & $\mathrm{~N}(0 \circ)$ & $\mathrm{S} / \mathrm{V}_{0,40}$ & $5(2007-2013)$ \\
\hline $\mathrm{H} 78$ & $\mathrm{MU}_{3}$ & $\mathrm{H} / \mathrm{W}_{1,2}$ & S (180) & $\mathrm{S} / \mathrm{V}_{0,40}$ & $5(2007-2013)$ \\
\hline $\mathrm{H} 79$ & $\mathrm{MU}_{3}$ & $\mathrm{H} / \mathrm{W}_{1,2}$ & $\mathrm{E}\left(90^{\circ}\right.$ ) & $\mathrm{S} / \mathrm{V}_{0,40}$ & $5(2007-2013)$ \\
\hline $\mathrm{H} 80$ & $\mathrm{MU}_{3}$ & $\mathrm{H} / \mathrm{W}_{1,2}$ & $\mathrm{O}(270 \div)$ & $\mathrm{S} / \mathrm{V}_{0,40}$ & $5(2007-2013)$ \\
\hline H81 & $\mathrm{MU}_{2}$ & $\mathrm{H} / \mathrm{W}_{2,4}$ & $\mathrm{~N}\left(\mathrm{O}^{\circ}\right)$ & $\mathrm{S} / \mathrm{V}_{0,30}$ & $1(<1940)$ \\
\hline H82 & $\mathrm{MU}_{2}$ & $\mathrm{H} / \mathrm{W}_{2,4}$ & S (180) & $\mathrm{S} / \mathrm{V}_{0,30}$ & $1(<1940)$ \\
\hline H83 & $\mathrm{MU}_{2}$ & $\mathrm{H} / \mathrm{W}_{2,4}$ & $\mathrm{E}(90 \circ)$ & $S / V_{0,30}$ & $1(<1940)$ \\
\hline H84 & $\mathrm{MU}_{2}$ & $\mathrm{H} / \mathrm{W}_{2,4}$ & $\mathrm{O}(2709)$ & $\mathrm{S} / \mathrm{V}_{0,30}$ & $1(<1940)$ \\
\hline H85 & $\mathrm{MU}_{2}$ & $\mathrm{H} / \mathrm{W}_{2,4}$ & $\mathrm{~N}\left(\mathrm{O}^{\circ}\right)$ & $\mathrm{S} / \mathrm{V}_{0,30}$ & 2 (1940-1959) \\
\hline H86 & $\mathrm{MU}_{2}$ & $\mathrm{H} / \mathrm{W}_{2,4}$ & S (180) & $\mathrm{S} / \mathrm{V}_{0,30}$ & 2 (1940-1959) \\
\hline H87 & $\mathrm{MU}_{2}$ & $\mathrm{H} / \mathrm{W}_{2,4}$ & $\mathrm{E}(90$ (9) & $\mathrm{S} / \mathrm{V}_{0,30}$ & 2 (1940-1959) \\
\hline H88 & $\mathrm{MU}_{2}$ & $\mathrm{H} / \mathrm{W}_{2,4}$ & $\mathrm{O}(270 \div)$ & $\mathrm{S} / \mathrm{V}_{0,30}$ & 2 (1940-1959) \\
\hline H89 & $\mathrm{MU}_{2}$ & $\mathrm{H} / \mathrm{W}_{2,4}$ & $\mathrm{~N}\left(\mathrm{O}^{\circ}\right)$ & $\mathrm{S} / \mathrm{V}_{0,30}$ & 3 (1960-1979) \\
\hline $\mathrm{H} 90$ & $\mathrm{MU}_{2}$ & $\mathrm{H} / \mathrm{W}_{2,4}$ & S (180) & $\mathrm{S} / \mathrm{V}_{0,30}$ & 3 (1960-1979) \\
\hline H91 & $\mathrm{MU}_{2}$ & $\mathrm{H} / \mathrm{W}_{2,4}$ & $\mathrm{E}(90$ ) $)$ & $\mathrm{S} / \mathrm{V}_{0,30}$ & 3 (1960-1979) \\
\hline H92 & $\mathrm{MU}_{2}$ & $\mathrm{H} / \mathrm{W}_{2,4}$ & $\mathrm{O}(270 \div)$ & $\mathrm{S} / \mathrm{V}_{0,30}$ & 3 (1960-1979) \\
\hline H93 & $\mathrm{MU}_{2}$ & $\mathrm{H} / \mathrm{W}_{2,4}$ & $\mathrm{~N}(\mathrm{O} \cong)$ & $S / V_{0,30}$ & 4 (1980-2006) \\
\hline H94 & $\mathrm{MU}_{2}$ & $\mathrm{H} / \mathrm{W}_{2,4}$ & S (180) & $\mathrm{S} / \mathrm{V}_{0,30}$ & 4 (1980-2006) \\
\hline H95 & $\mathrm{MU}_{2}$ & $\mathrm{H} / \mathrm{W}_{2,4}$ & $\mathrm{E}(90$ ) $)$ & $\mathrm{S} / \mathrm{V}_{0,30}$ & 4 (1980-2006) \\
\hline H96 & $\mathrm{MU}_{2}$ & $\mathrm{H} / \mathrm{W}_{2,4}$ & $\mathrm{O}(270 \div)$ & $S / V_{0,30}$ & 4 (1980-2006) \\
\hline H97 & $\mathrm{MU}_{2}$ & $\mathrm{H} / \mathrm{W}_{2,4}$ & $\mathrm{~N}\left(\mathrm{O}^{\circ}\right)$ & $\mathrm{S} / \mathrm{V}_{0,30}$ & 5 (2007-2013) \\
\hline H98 & $\mathrm{MU}_{2}$ & $\mathrm{H} / \mathrm{W}_{2,4}$ & S (180) & $\mathrm{S} / \mathrm{V}_{0,30}$ & 5 (2007-2013) \\
\hline H99 & $\mathrm{MU}_{2}$ & $\mathrm{H} / \mathrm{W}_{2,4}$ & $\mathrm{E}(90 \%)$ & $\mathrm{S} / \mathrm{V}_{0,30}$ & 5 (2007-2013) \\
\hline $\mathrm{H} 100$ & $\mathrm{MU}_{2}$ & $\mathrm{H} / \mathrm{W}_{2,4}$ & $\mathrm{O}\left(270^{\circ}\right)$ & $\mathrm{S} / \mathrm{V}_{0,30}$ & 5 (2007-2013) \\
\hline
\end{tabular}


Tabla All.1 Lista de indicadores en la herramienta LEED ND (continuación)

\begin{tabular}{|c|c|c|c|c|c|}
\hline Hipótesis & Manzana urbana & Ratio $\mathrm{H} / \mathrm{W}$ & Orientación & Factor de forma & Año construcción \\
\hline $\mathrm{H} 101$ & $\mathrm{MU}_{2}$ & $\mathrm{H} / \mathrm{W}_{1,2}$ & $\mathrm{~N}\left(0^{\circ}=\right)$ & $\mathrm{S} / \mathrm{V}_{0,30}$ & $1(<1940)$ \\
\hline $\mathrm{H} 102$ & $\mathrm{MU}_{2}$ & $\mathrm{H} / \mathrm{W}_{1,2}$ & S (180) & $\mathrm{S} / \mathrm{V}_{0,30}$ & $1(<1940)$ \\
\hline $\mathrm{H} 103$ & $\mathrm{MU}_{2}$ & $\mathrm{H} / \mathrm{W}_{1,2}$ & $\mathrm{E}(90 \div)$ & $S / V_{0,30}$ & $1(<1940)$ \\
\hline $\mathrm{H} 104$ & $\mathrm{MU}_{2}$ & $\mathrm{H} / \mathrm{W}_{1,2}$ & $\mathrm{O}(2709)$ & $S / V_{0,30}$ & $1(<1940)$ \\
\hline $\mathrm{H} 105$ & $\mathrm{MU}_{2}$ & $\mathrm{H} / \mathrm{W}_{1,2}$ & $\mathrm{~N}\left(0^{\circ}\right)$ & $S / V_{0,30}$ & 2 (1940-1959) \\
\hline $\mathrm{H} 106$ & $\mathrm{MU}_{2}$ & $\mathrm{H} / \mathrm{W}_{1,2}$ & S (180) & $S / V_{0,30}$ & 2 (1940-1959) \\
\hline H107 & $\mathrm{MU}_{2}$ & $\mathrm{H} / \mathrm{W}_{1,2}$ & $\mathrm{E}(90 \circ)$ & $S / V_{0,30}$ & 2 (1940-1959) \\
\hline H108 & $\mathrm{MU}_{2}$ & $\mathrm{H} / \mathrm{W}_{1,2}$ & $\mathrm{O}(2709)$ & $S / V_{0,30}$ & 2 (1940-1959) \\
\hline $\mathrm{H} 109$ & $\mathrm{MU}_{2}$ & $\mathrm{H} / \mathrm{W}_{1,2}$ & $\mathrm{~N}\left(\mathrm{O}^{\circ}\right)$ & $\mathrm{S} / \mathrm{V}_{0,30}$ & 3 (1960-1979) \\
\hline $\mathrm{H} 110$ & $\mathrm{MU}_{2}$ & $\mathrm{H} / \mathrm{W}_{1,2}$ & S (180) & $\mathrm{S} / \mathrm{V}_{0,30}$ & 3 (1960-1979) \\
\hline H111 & $\mathrm{MU}_{2}$ & $\mathrm{H} / \mathrm{W}_{1,2}$ & $\mathrm{E}(90 \stackrel{9}{)}$ & $\mathrm{S} / \mathrm{V}_{0,30}$ & 3 (1960-1979) \\
\hline $\mathrm{H} 112$ & $\mathrm{MU}_{2}$ & $\mathrm{H} / \mathrm{W}_{1,2}$ & $\mathrm{O}(270 \%)$ & $\mathrm{S} / \mathrm{V}_{0,30}$ & 3 (1960-1979) \\
\hline $\mathrm{H} 113$ & $\mathrm{MU}_{2}$ & $\mathrm{H} / \mathrm{W}_{1,2}$ & $\mathrm{~N}\left(\mathrm{O}^{\circ}\right)$ & $\mathrm{S} / \mathrm{V}_{0,30}$ & 4 (1980-2006) \\
\hline $\mathrm{H} 114$ & $\mathrm{MU}_{2}$ & $\mathrm{H} / \mathrm{W}_{1,2}$ & S (180ㅇ) & $\mathrm{S} / \mathrm{V}_{0,30}$ & $4(1980-2006)$ \\
\hline $\mathrm{H} 115$ & $\mathrm{MU}_{2}$ & $\mathrm{H} / \mathrm{W}_{1,2}$ & $E(90 \%)$ & $\mathrm{S} / \mathrm{V}_{0,30}$ & 4 (1980-2006) \\
\hline $\mathrm{H} 116$ & $\mathrm{MU}_{2}$ & $\mathrm{H} / \mathrm{W}_{1,2}$ & $\mathrm{O}(270 \%)$ & $\mathrm{S} / \mathrm{V}_{0,30}$ & $4(1980-2006)$ \\
\hline H117 & $\mathrm{MU}_{2}$ & $\mathrm{H} / \mathrm{W}_{1,2}$ & $\mathrm{~N}\left(\mathrm{O}^{\circ}\right)$ & $\mathrm{S} / \mathrm{V}_{0,30}$ & 5 (2007-2013) \\
\hline $\mathrm{H} 118$ & $\mathrm{MU}_{2}$ & $\mathrm{H} / \mathrm{W}_{1,2}$ & S (180) & $\mathrm{S} / \mathrm{V}_{0,30}$ & 5 (2007-2013) \\
\hline H119 & $\mathrm{MU}_{2}$ & $\mathrm{H} / \mathrm{W}_{1,2}$ & $E(90 \%)$ & $\mathrm{S} / \mathrm{V}_{0,30}$ & 5 (2007-2013) \\
\hline $\mathrm{H} 120$ & $\mathrm{MU}_{2}$ & $\mathrm{H} / \mathrm{W}_{1,2}$ & $\mathrm{O}(270 \div)$ & $\mathrm{S} / \mathrm{V}_{0,30}$ & 5 (2007-2013) \\
\hline H121 & $\mathrm{MU}_{3}$ & $\mathrm{H} / \mathrm{W}_{2,4}$ & $\mathrm{~N}\left(\mathrm{O}^{\circ}\right)$ & $\mathrm{S} / \mathrm{V}_{0,30}$ & $1(<1940)$ \\
\hline H122 & $\mathrm{MU}_{3}$ & $\mathrm{H} / \mathrm{W}_{2,4}$ & S (180) & $\mathrm{S} / \mathrm{V}_{0,30}$ & $1(<1940)$ \\
\hline $\mathrm{H} 123$ & $\mathrm{MU}_{3}$ & $\mathrm{H} / \mathrm{W}_{2,4}$ & $E(90)$ & $\mathrm{S} / \mathrm{V}_{0,30}$ & $1(<1940)$ \\
\hline H124 & $\mathrm{MU}_{3}$ & $\mathrm{H} / \mathrm{W}_{2,4}$ & $\mathrm{O}(270 \div)$ & $\mathrm{S} / \mathrm{V}_{0,30}$ & $1(<1940)$ \\
\hline $\mathrm{H} 125$ & $\mathrm{MU}_{3}$ & $\mathrm{H} / \mathrm{W}_{2,4}$ & $\mathrm{~N}\left(\mathrm{0}^{\circ}\right)$ & $\mathrm{S} / \mathrm{V}_{0,30}$ & 2 (1940-1959) \\
\hline H126 & $\mathrm{MU}_{3}$ & $\mathrm{H} / \mathrm{W}_{2,4}$ & S (180) & $\mathrm{S} / \mathrm{V}_{0,30}$ & 2 (1940-1959) \\
\hline $\mathrm{H} 127$ & $\mathrm{MU}_{3}$ & $\mathrm{H} / \mathrm{W}_{2,4}$ & $E(90)$ & $\mathrm{S} / \mathrm{V}_{0,30}$ & 2 (1940-1959) \\
\hline $\mathrm{H} 128$ & $\mathrm{MU}_{3}$ & $\mathrm{H} / \mathrm{W}_{2,4}$ & $\mathrm{O}\left(270^{\circ}\right)$ & $\mathrm{S} / \mathrm{V}_{0,30}$ & 2 (1940-1959) \\
\hline H129 & $\mathrm{MU}_{3}$ & $\mathrm{H} / \mathrm{W}_{2,4}$ & $\mathrm{~N}\left(0^{\circ}\right)$ & $\mathrm{S} / \mathrm{V}_{0,30}$ & 3 (1960-1979) \\
\hline $\mathrm{H} 130$ & $\mathrm{MU}_{3}$ & $\mathrm{H} / \mathrm{W}_{2,4}$ & S (180ㅇ) & $\mathrm{S} / \mathrm{V}_{0,30}$ & 3 (1960-1979) \\
\hline H131 & $\mathrm{MU}_{3}$ & $\mathrm{H} / \mathrm{W}_{2,4}$ & $E(90)$ & $\mathrm{S} / \mathrm{V}_{0,30}$ & 3 (1960-1979) \\
\hline $\mathrm{H} 132$ & $\mathrm{MU}_{3}$ & $\mathrm{H} / \mathrm{W}_{2,4}$ & $O\left(270^{\circ}\right)$ & $\mathrm{S} / \mathrm{N}_{0,30}$ & 3 (1960-1979) \\
\hline $\mathrm{H} 133$ & $\mathrm{MU}_{3}$ & $\mathrm{H} / \mathrm{W}_{2,4}$ & $\mathrm{~N}\left(\mathrm{O}^{\circ}\right)$ & $\mathrm{S} / \mathrm{N}_{0,30}$ & 4 (1980-2006) \\
\hline $\mathrm{H} 134$ & $\mathrm{MU}_{3}$ & $\mathrm{H} / \mathrm{W}_{2,4}$ & S (180ㅇ) & $\mathrm{S} / \mathrm{V}_{0,30}$ & 4 (1980-2006) \\
\hline H135 & $\mathrm{MU}_{3}$ & $\mathrm{H} / \mathrm{W}_{2,4}$ & $\mathrm{E}(90 \stackrel{9}{)}$ & $\mathrm{S} / \mathrm{V}_{0,30}$ & 4 (1980-2006) \\
\hline $\mathrm{H} 136$ & $\mathrm{MU}_{3}$ & $\mathrm{H} / \mathrm{W}_{2,4}$ & $\mathrm{O}(270 \circ)$ & $S / V_{0,30}$ & $4(1980-2006)$ \\
\hline $\mathrm{H} 137$ & $\mathrm{MU}_{3}$ & $\mathrm{H} / \mathrm{W}_{2,4}$ & $\mathrm{~N}\left(\mathrm{O}^{\circ}\right)$ & $\mathrm{S} / \mathrm{V}_{0,30}$ & 5 (2007-2013) \\
\hline $\mathrm{H} 138$ & $\mathrm{MU}_{3}$ & $\mathrm{H} / \mathrm{W}_{2,4}$ & S (180) & $S / V_{0,30}$ & $5(2007-2013)$ \\
\hline H139 & $\mathrm{MU}_{3}$ & $\mathrm{H} / \mathrm{W}_{2,4}$ & $E(90 \cong)$ & $S / V_{0,30}$ & $5(2007-2013)$ \\
\hline $\mathrm{H} 140$ & $\mathrm{MU}_{3}$ & $\mathrm{H} / \mathrm{W}_{2,4}$ & $\mathrm{O}(2709)$ & $S / V_{0,30}$ & $5(2007-2013)$ \\
\hline $\mathrm{H} 141$ & $\mathrm{MU}_{3}$ & $\mathrm{H} / \mathrm{W}_{1,2}$ & $\mathrm{~N}(0 \mathrm{0})$ & $S / V_{0,30}$ & $1(<1940)$ \\
\hline $\mathrm{H} 142$ & $\mathrm{MU}_{3}$ & $\mathrm{H} / \mathrm{W}_{1,2}$ & S (180) & $S / V_{0,30}$ & $1(<1940)$ \\
\hline $\mathrm{H} 143$ & $\mathrm{MU}_{3}$ & $\mathrm{H} / \mathrm{W}_{1,2}$ & $\mathrm{E}(90 \circ)$ & $S / V_{0,30}$ & $1(<1940)$ \\
\hline $\mathrm{H} 144$ & $\mathrm{MU}_{3}$ & $\mathrm{H} / \mathrm{W}_{1,2}$ & $\mathrm{O}(2709)$ & $S / V_{0,30}$ & $1(<1940)$ \\
\hline $\mathrm{H} 145$ & $\mathrm{MU}_{3}$ & $\mathrm{H} / \mathrm{W}_{1,2}$ & $\mathrm{~N}(0 \mathrm{O})$ & $S / V_{0,30}$ & 2 (1940-1959) \\
\hline $\mathrm{H} 146$ & $\mathrm{MU}_{3}$ & $\mathrm{H} / \mathrm{W}_{1,2}$ & S (180) & $S / V_{0,30}$ & 2 (1940-1959) \\
\hline $\mathrm{H} 147$ & $\mathrm{MU}_{3}$ & $\mathrm{H} / \mathrm{W}_{1,2}$ & $\mathrm{E}(90 \circ)$ & $S / V_{0,30}$ & 2 (1940-1959) \\
\hline H148 & $\mathrm{MU}_{3}$ & $\mathrm{H} / \mathrm{W}_{1,2}$ & $\mathrm{O}(270 \circ)$ & $S / N_{0,30}$ & 2 (1940-1959) \\
\hline $\mathrm{H} 149$ & $\mathrm{MU}_{3}$ & $\mathrm{H} / \mathrm{W}_{1,2}$ & $\mathrm{~N}(0 \mathrm{0})$ & $S / V_{0,30}$ & 3 (1960-1979) \\
\hline $\mathrm{H} 150$ & $\mathrm{MU}_{3}$ & $\mathrm{H} / \mathrm{W}_{1,2}$ & S (180) & $S / V_{0,30}$ & 3 (1960-1979) \\
\hline $\mathrm{H} 151$ & $\mathrm{MU}_{3}$ & $\mathrm{H} / \mathrm{W}_{1,2}$ & $E(90 \circ)$ & $S / V_{0,30}$ & 3 (1960-1979) \\
\hline $\mathrm{H} 152$ & $\mathrm{MU}_{3}$ & $\mathrm{H} / \mathrm{W}_{1,2}$ & $\mathrm{O}(270 \cong)$ & $S / V_{0,30}$ & 3 (1960-1979) \\
\hline
\end{tabular}


Tabla All.1 Lista de indicadores en la herramienta LEED ND (continuación)

\begin{tabular}{|c|c|c|c|c|c|}
\hline Hipótesis & Manzana urbana & Ratio $\mathrm{H} / \mathrm{W}$ & Orientación & Factor de forma & Año construcción \\
\hline H153 & $\mathrm{MU}_{3}$ & $\mathrm{H} / \mathrm{W}_{1,2}$ & $\mathrm{~N}\left(\mathrm{O}^{\circ}\right)$ & $\mathrm{S} / \mathrm{V}_{0,30}$ & $4(1980-2006)$ \\
\hline H154 & $\mathrm{MU}_{3}$ & $\mathrm{H} / \mathrm{W}_{1,2}$ & S (180) & $\mathrm{S} / \mathrm{V}_{0,30}$ & 4 (1980-2006) \\
\hline $\mathrm{H} 155$ & $\mathrm{MU}_{3}$ & $\mathrm{H} / \mathrm{W}_{1,2}$ & $E(90)$ & $\mathrm{S} / \mathrm{V}_{0,30}$ & 4 (1980-2006) \\
\hline H156 & $\mathrm{MU}_{3}$ & $\mathrm{H} / \mathrm{W}_{1,2}$ & $\mathrm{O}(270 \div)$ & $\mathrm{S} / \mathrm{V}_{0,30}$ & 4 (1980-2006) \\
\hline $\mathrm{H} 157$ & $\mathrm{MU}_{3}$ & $\mathrm{H} / \mathrm{W}_{1,2}$ & $\mathrm{~N}\left(0^{\circ}\right)$ & $\mathrm{S} / \mathrm{V}_{0,30}$ & 5 (2007-2013) \\
\hline $\mathrm{H} 158$ & $\mathrm{MU}_{3}$ & $\mathrm{H} / \mathrm{W}_{1,2}$ & S (180) & $\mathrm{S} / \mathrm{V}_{0,30}$ & $5(2007-2013)$ \\
\hline $\mathrm{H} 159$ & $\mathrm{MU}_{3}$ & $\mathrm{H} / \mathrm{W}_{1,2}$ & $E(90)$ & $\mathrm{S} / \mathrm{V}_{0,30}$ & $5(2007-2013)$ \\
\hline $\mathrm{H} 160$ & $\mathrm{MU}_{3}$ & $\mathrm{H} / \mathrm{W}_{1,2}$ & $\mathrm{O}\left(270^{\circ}\right)$ & $\mathrm{S} / \mathrm{V}_{0,30}$ & 5 (2007-2013) \\
\hline H161 & $\mathrm{MU}_{2}$ & $\mathrm{H} / \mathrm{W}_{2,4}$ & $\mathrm{~N}\left(0^{\circ}\right)$ & $\mathrm{S} / \mathrm{V}_{0,26}$ & $1(<1940)$ \\
\hline $\mathrm{H} 162$ & $\mathrm{MU}_{2}$ & $\mathrm{H} / \mathrm{W}_{2,4}$ & S (180ㅇ) & $\mathrm{S} / \mathrm{V}_{0,26}$ & $1(<1940)$ \\
\hline $\mathrm{H} 163$ & $\mathrm{MU}_{2}$ & $\mathrm{H} / \mathrm{W}_{2,4}$ & $E(90)$ & $S / V_{0,26}$ & $1(<1940)$ \\
\hline $\mathrm{H} 164$ & $\mathrm{MU}_{2}$ & $\mathrm{H} / \mathrm{W}_{2,4}$ & $\mathrm{O}\left(270^{\circ}\right)$ & $\mathrm{S} / \mathrm{V}_{0,26}$ & $1(<1940)$ \\
\hline H165 & $\mathrm{MU}_{2}$ & $\mathrm{H} / \mathrm{W}_{2,4}$ & $\mathrm{~N}\left(0^{\circ}\right)$ & $\mathrm{S} / \mathrm{V}_{0,26}$ & 2 (1940-1959) \\
\hline H166 & $\mathrm{MU}_{2}$ & $\mathrm{H} / \mathrm{W}_{2,4}$ & S (180ㅇ) & $\mathrm{S} / \mathrm{V}_{0,26}$ & 2 (1940-1959) \\
\hline $\mathrm{H} 167$ & $\mathrm{MU}_{2}$ & $\mathrm{H} / \mathrm{W}_{2,4}$ & $\mathrm{E}(90$ (9) & $\mathrm{S} / \mathrm{V}_{0,26}$ & 2 (1940-1959) \\
\hline $\mathrm{H} 168$ & $\mathrm{MU}_{2}$ & $\mathrm{H} / \mathrm{W}_{2,4}$ & $\mathrm{O}\left(270^{\circ}\right)$ & $\mathrm{S} / \mathrm{V}_{0,26}$ & 2 (1940-1959) \\
\hline H169 & $\mathrm{MU}_{2}$ & $\mathrm{H} / \mathrm{W}_{2,4}$ & $N(0$ ) & $S / V_{0,26}$ & 3 (1960-1979) \\
\hline $\mathrm{H} 170$ & $\mathrm{MU}_{2}$ & $\mathrm{H} / \mathrm{W}_{2,4}$ & S (180ㅇ) & $S / V_{0,26}$ & 3 (1960-1979) \\
\hline $\mathrm{H} 171$ & $\mathrm{MU}_{2}$ & $\mathrm{H} / \mathrm{W}_{2,4}$ & $E(90)$ & $\mathrm{S} / \mathrm{V}_{0,26}$ & 3 (1960-1979) \\
\hline $\mathrm{H} 172$ & $\mathrm{MU}_{2}$ & $\mathrm{H} / \mathrm{W}_{2,4}$ & $\mathrm{O}(270 \div)$ & $S / V_{0,26}$ & 3 (1960-1979) \\
\hline $\mathrm{H} 173$ & $\mathrm{MU}_{2}$ & $\mathrm{H} / \mathrm{W}_{2,4}$ & $N(0$ ) $)$ & $\mathrm{S} / \mathrm{V}_{0,26}$ & 4 (1980-2006) \\
\hline $\mathrm{H} 174$ & $\mathrm{MU}_{2}$ & $\mathrm{H} / \mathrm{W}_{2,4}$ & S (180) & $\mathrm{S} / \mathrm{V}_{0,26}$ & 4 (1980-2006) \\
\hline $\mathrm{H} 175$ & $\mathrm{MU}_{2}$ & $\mathrm{H} / \mathrm{W}_{2,4}$ & $\mathrm{E}(90 \div)$ & $\mathrm{S} / \mathrm{V}_{0,26}$ & 4 (1980-2006) \\
\hline H176 & $\mathrm{MU}_{2}$ & $\mathrm{H} / \mathrm{W}_{2,4}$ & $\mathrm{O}\left(270^{\circ}\right)$ & $\mathrm{S} / \mathrm{V}_{0,26}$ & $4(1980-2006)$ \\
\hline H177 & $\mathrm{MU}_{2}$ & $H / W_{2,4}$ & $\mathrm{~N}\left(0^{\circ}\right)$ & $S / V_{0,26}$ & 5 (2007-2013) \\
\hline $\mathrm{H} 178$ & $\mathrm{MU}_{2}$ & $\mathrm{H} / \mathrm{W}_{2,4}$ & S (180) & $\mathrm{S} / \mathrm{V}_{0,26}$ & 5 (2007-2013) \\
\hline $\mathrm{H} 179$ & $\mathrm{MU}_{2}$ & $H / W_{2,4}$ & $E(90 \div)$ & $S / V_{0,26}$ & \begin{tabular}{|l|}
$5(2007-2013)$ \\
\end{tabular} \\
\hline $\mathrm{H} 180$ & $\mathrm{MU}_{2}$ & $\mathrm{H} / \mathrm{W}_{2,4}$ & $\mathrm{O}\left(270^{\circ}\right)$ & $\mathrm{S} / \mathrm{V}_{0,26}$ & 5 (2007-2013) \\
\hline $\mathrm{H} 181$ & $\mathrm{MU}_{2}$ & $\mathrm{H} / \mathrm{W}_{1,2}$ & $\mathrm{~N}\left(0^{\circ}\right)$ & $S / V_{0,26}$ & \begin{tabular}{|l|}
$1(<1940)$ \\
\end{tabular} \\
\hline H182 & $\mathrm{MU}_{2}$ & $\mathrm{H} / \mathrm{W}_{1,2}$ & S (180ㅇ) & $\mathrm{S} / \mathrm{V}_{0,26}$ & $1(<1940)$ \\
\hline H183 & $\mathrm{MU}_{2}$ & $\mathrm{H} / \mathrm{W}_{1,2}$ & $\mathrm{E}(90 \%)$ & $\mathrm{S} / \mathrm{V}_{0,26}$ & $1(<1940)$ \\
\hline $\mathrm{H} 184$ & $\mathrm{MU}_{2}$ & $\mathrm{H} / \mathrm{W}_{1,2}$ & $\mathrm{O}(270 \div)$ & $\mathrm{S} / \mathrm{V}_{0,26}$ & $1(<1940)$ \\
\hline $\mathrm{H} 185$ & $\mathrm{MU}_{2}$ & $\mathrm{H} / \mathrm{W}_{1,2}$ & $\mathrm{~N}\left(\mathrm{O}^{\circ}\right)$ & $\mathrm{S} / \mathrm{V}_{0,26}$ & 2 (1940-1959) \\
\hline $\mathrm{H} 186$ & $\mathrm{MU}_{2}$ & $\mathrm{H} / \mathrm{W}_{1,2}$ & S (180) & $\mathrm{S} / \mathrm{V}_{0,26}$ & 2 (1940-1959) \\
\hline $\mathrm{H} 187$ & $\mathrm{MU}_{2}$ & $\mathrm{H} / \mathrm{W}_{1,2}$ & $E(90 \circ)$ & $S / V_{0,26}$ & 2 (1940-1959) \\
\hline $\mathrm{H} 188$ & $\mathrm{MU}_{2}$ & $\mathrm{H} / \mathrm{W}_{1,2}$ & $\mathrm{O}\left(270^{\circ}\right)$ & $S / V_{0,26}$ & 2 (1940-1959) \\
\hline $\mathrm{H} 189$ & $\mathrm{MU}_{2}$ & $\mathrm{H} / \mathrm{W}_{1,2}$ & $\mathrm{~N}(0 \mathrm{O})$ & $S / V_{0,26}$ & 3 (1960-1979) \\
\hline $\mathrm{H} 190$ & $\mathrm{MU}_{2}$ & $\mathrm{H} / \mathrm{W}_{1,2}$ & S (180) & $S / V_{0,26}$ & 3 (1960-1979) \\
\hline $\mathrm{H} 191$ & $\mathrm{MU}_{2}$ & $\mathrm{H} / \mathrm{W}_{1,2}$ & $E(90 \circ)$ & $S / N_{0,26}$ & 3 (1960-1979) \\
\hline $\mathrm{H} 192$ & $\mathrm{MU}_{2}$ & $\mathrm{H} / \mathrm{W}_{1,2}$ & $\mathrm{O}(2709)$ & $S / V_{0,26}$ & 3 (1960-1979) \\
\hline $\mathrm{H} 193$ & $\mathrm{MU}_{2}$ & $\mathrm{H} / \mathrm{W}_{1,2}$ & $\mathrm{~N}(0 \mathrm{0})$ & $S / V_{0,26}$ & 4 (1980-2006) \\
\hline $\mathrm{H} 194$ & $\mathrm{MU}_{2}$ & $\mathrm{H} / \mathrm{W}_{1,2}$ & S (180) & $S / N_{0,26}$ & 4 (1980-2006) \\
\hline $\mathrm{H} 195$ & $\mathrm{MU}_{2}$ & $\mathrm{H} / \mathrm{W}_{1,2}$ & $\mathrm{E}(90 \div)$ & $S / N_{0,26}$ & 4 (1980-2006) \\
\hline H196 & $\mathrm{MU}_{2}$ & $\mathrm{H} / \mathrm{W}_{1,2}$ & $\mathrm{O}(2709)$ & $S / V_{0,26}$ & 4 (1980-2006) \\
\hline H197 & $\mathrm{MU}_{2}$ & $\mathrm{H} / \mathrm{W}_{1,2}$ & $\mathrm{~N}(0 \circ)$ & $S / V_{0,26}$ & 5 (2007-2013) \\
\hline H198 & $\mathrm{MU}_{2}$ & $\mathrm{H} / \mathrm{W}_{1,2}$ & S (180) & $S / V_{0,26}$ & 5 (2007-2013) \\
\hline H199 & $\mathrm{MU}_{2}$ & $\mathrm{H} / \mathrm{W}_{1,2}$ & $\mathrm{E}(90 \div)$ & $\mathrm{S} / \mathrm{V}_{0,26}$ & 5 (2007-2013) \\
\hline $\mathrm{H} 200$ & $\mathrm{MU}_{2}$ & $\mathrm{H} / \mathrm{W}_{1,2}$ & $\mathrm{O}\left(270^{\circ}\right)$ & $S / V_{0,26}$ & 5 (2007-2013) \\
\hline $\mathrm{H} 201$ & $\mathrm{MU}_{3}$ & $\mathrm{H} / \mathrm{W}_{2,4}$ & $\mathrm{~N}\left(0^{\circ}\right)$ & $S / V_{0,26}$ & $1(<1940)$ \\
\hline $\mathrm{H} 202$ & $\mathrm{MU}_{3}$ & $\mathrm{H} / \mathrm{W}_{2,4}$ & S (180) & $S / V_{0,26}$ & $1(<1940)$ \\
\hline $\mathrm{H} 203$ & $\mathrm{MU}_{3}$ & $\mathrm{H} / \mathrm{W}_{2,4}$ & $E(90 \circ)$ & $S / V_{0,26}$ & $1(<1940)$ \\
\hline $\mathrm{H} 204$ & $\mathrm{MU}_{3}$ & $\mathrm{H} / \mathrm{W}_{2,4}$ & $\mathrm{O}\left(270^{\circ}\right)$ & $S / V_{0,26}$ & $1(<1940)$ \\
\hline
\end{tabular}


Tabla All.1 Lista de indicadores en la herramienta LEED ND (continuación)

\begin{tabular}{|c|c|c|c|c|c|}
\hline Hipótesis & Manzana urbana & Ratio H/W & Orientación & Factor de forma & Año construcción \\
\hline $\mathrm{H} 205$ & $\mathrm{MU}_{3}$ & $\mathrm{H} / \mathrm{W}_{2,4}$ & $\mathrm{~N}\left(\mathrm{O}^{\circ} \mathrm{)}\right)$ & $\mathrm{S} / \mathrm{V}_{0,26}$ & 2 (1940-1959) \\
\hline $\mathrm{H} 206$ & $\mathrm{MU}_{3}$ & $\mathrm{H} / \mathrm{W}_{2,4}$ & S (180ㅇ) & $S / V_{0,26}$ & 2 (1940-1959) \\
\hline $\mathrm{H} 207$ & $\mathrm{MU}_{3}$ & $\mathrm{H} / \mathrm{W}_{2,4}$ & $E(90$ ) $)$ & $S / V_{0,26}$ & 2 (1940-1959) \\
\hline $\mathrm{H} 208$ & $\mathrm{MU}_{3}$ & $\mathrm{H} / \mathrm{W}_{2,4}$ & $\mathrm{O}(270 \div)$ & $\mathrm{S} / \mathrm{V}_{0,26}$ & 2 (1940-1959) \\
\hline $\mathrm{H} 209$ & $\mathrm{MU}_{3}$ & $\mathrm{H} / \mathrm{W}_{2,4}$ & $\mathrm{~N}\left(\mathrm{O}^{\circ}\right)$ & $\mathrm{S} / \mathrm{V}_{0,26}$ & 3 (1960-1979) \\
\hline $\mathrm{H} 210$ & $\mathrm{MU}_{3}$ & $\mathrm{H} / \mathrm{W}_{2,4}$ & $\mathrm{~S}\left(180^{\circ}\right)$ & $\mathrm{S} / \mathrm{V}_{0,26}$ & 3 (1960-1979) \\
\hline $\mathrm{H} 211$ & $\mathrm{MU}_{3}$ & $\mathrm{H} / \mathrm{W}_{2,4}$ & $E(90)$ & $\mathrm{S} / \mathrm{V}_{0,26}$ & 3 (1960-1979) \\
\hline $\mathrm{H} 212$ & $\mathrm{MU}_{3}$ & $\mathrm{H} / \mathrm{W}_{2,4}$ & $\mathrm{O}(270 \div)$ & $\mathrm{S} / \mathrm{V}_{0,26}$ & 3 (1960-1979) \\
\hline $\mathrm{H} 213$ & $\mathrm{MU}_{3}$ & $\mathrm{H} / \mathrm{W}_{2,4}$ & $\mathrm{~N}(0 \circ)$ & $\mathrm{S} / \mathrm{V}_{0,26}$ & 4 (1980-2006) \\
\hline $\mathrm{H} 214$ & $\mathrm{MU}_{3}$ & $\mathrm{H} / \mathrm{W}_{2,4}$ & S (180ㅇ) & $\mathrm{S} / \mathrm{V}_{0,26}$ & 4 (1980-2006) \\
\hline $\mathrm{H} 215$ & $\mathrm{MU}_{3}$ & $\mathrm{H} / \mathrm{W}_{2,4}$ & $E(90 \%)$ & $\mathrm{S} / \mathrm{V}_{0,26}$ & 4 (1980-2006) \\
\hline $\mathrm{H} 216$ & $\mathrm{MU}_{3}$ & $\mathrm{H} / \mathrm{W}_{2,4}$ & $\mathrm{O}(270 \div)$ & $\mathrm{S} / \mathrm{V}_{0,26}$ & $4(1980-2006)$ \\
\hline $\mathrm{H} 217$ & $\mathrm{MU}_{3}$ & $\mathrm{H} / \mathrm{W}_{2,4}$ & $\mathrm{~N}\left(\mathrm{O}^{\circ}\right.$ ) & $\mathrm{S} / \mathrm{V}_{0,26}$ & 5 (2007-2013) \\
\hline $\mathrm{H} 218$ & $\mathrm{MU}_{3}$ & $\mathrm{H} / \mathrm{W}_{2,4}$ & $\mathrm{~S}\left(180^{\circ}\right)$ & $\mathrm{S} / \mathrm{V}_{0,26}$ & $5(2007-2013)$ \\
\hline $\mathrm{H} 219$ & $\mathrm{MU}_{3}$ & $\mathrm{H} / \mathrm{W}_{2,4}$ & $E(90 \circ)$ & $\mathrm{S} / \mathrm{V}_{0,26}$ & 5 (2007-2013) \\
\hline $\mathrm{H} 220$ & $\mathrm{MU}_{3}$ & $\mathrm{H} / \mathrm{W}_{2,4}$ & $\mathrm{O}(270 \div)$ & $\mathrm{S} / \mathrm{V}_{0,26}$ & 5 (2007-2013) \\
\hline $\mathrm{H} 221$ & $\mathrm{MU}_{3}$ & $\mathrm{H} / \mathrm{W}_{1,2}$ & $N(0$ ) $)$ & $\mathrm{S} / \mathrm{V}_{0,26}$ & $1(<1940)$ \\
\hline $\mathrm{H} 222$ & $\mathrm{MU}_{3}$ & $\mathrm{H} / \mathrm{W}_{1,2}$ & $S\left(180^{\circ}\right)$ & $\mathrm{S} / \mathrm{V}_{0,26}$ & $1(<1940)$ \\
\hline $\mathrm{H} 223$ & $\mathrm{MU}_{3}$ & $\mathrm{H} / \mathrm{W}_{1,2}$ & $E(90)$ & $\mathrm{S} / \mathrm{V}_{0,26}$ & $1(<1940)$ \\
\hline $\mathrm{H} 224$ & $\mathrm{MU}_{3}$ & $\mathrm{H} / \mathrm{W}_{1,2}$ & $\mathrm{O}(270 \div)$ & $S / \mathrm{V}_{0,26}$ & $1(<1940)$ \\
\hline $\mathrm{H} 225$ & $\mathrm{MU}_{3}$ & $\mathrm{H} / \mathrm{W}_{1,2}$ & $\mathrm{~N}\left(\mathrm{O}^{\circ}\right)$ & $\mathrm{S} / \mathrm{V}_{0,26}$ & 2 (1940-1959) \\
\hline $\mathrm{H} 226$ & $\mathrm{MU}_{3}$ & $\mathrm{H} / \mathrm{W}_{1,2}$ & S (180ㅇ) & $\mathrm{S} / \mathrm{V}_{0,26}$ & 2 (1940-1959) \\
\hline $\mathrm{H} 227$ & $\mathrm{MU}_{3}$ & $\mathrm{H} / \mathrm{W}_{1,2}$ & $E(90)$ & $\mathrm{S} / \mathrm{V}_{0,26}$ & 2 (1940-1959) \\
\hline $\mathrm{H} 228$ & $\mathrm{MU}_{3}$ & $\mathrm{H} / \mathrm{W}_{1,2}$ & $\mathrm{O}(270 \div)$ & $\mathrm{S} / \mathrm{V}_{0,26}$ & 2 (1940-1959) \\
\hline $\mathrm{H} 229$ & $\mathrm{MU}_{3}$ & $\mathrm{H} / \mathrm{W}_{1,2}$ & $\mathrm{~N}\left(\mathrm{O}^{\circ}\right)$ & $\mathrm{S} / \mathrm{V}_{0,26}$ & 3 (1960-1979) \\
\hline $\mathrm{H} 230$ & $\mathrm{MU}_{3}$ & $\mathrm{H} / \mathrm{W}_{1,2}$ & S (180ㅇ) & $\mathrm{S} / \mathrm{V}_{0,26}$ & 3 (1960-1979) \\
\hline $\mathrm{H} 231$ & $\mathrm{MU}_{3}$ & $\mathrm{H} / \mathrm{W}_{1,2}$ & $E(90)$ & $\mathrm{S} / \mathrm{V}_{0,26}$ & 3 (1960-1979) \\
\hline $\mathrm{H} 232$ & $\mathrm{MU}_{3}$ & $\mathrm{H} / \mathrm{W}_{1,2}$ & $\mathrm{O}(270 \div)$ & $\mathrm{S} / \mathrm{V}_{0,26}$ & 3 (1960-1979) \\
\hline $\mathrm{H} 233$ & $\mathrm{MU}_{3}$ & $\mathrm{H} / \mathrm{W}_{1,2}$ & $\mathrm{~N}\left(\mathrm{O}^{\circ} \mathrm{o}\right)$ & $\mathrm{S} / \mathrm{V}_{0,26}$ & 4 (1980-2006) \\
\hline $\mathrm{H} 234$ & $\mathrm{MU}_{3}$ & $\mathrm{H} / \mathrm{W}_{1,2}$ & S (180은 & $\mathrm{S} / \mathrm{V}_{0,26}$ & 4 (1980-2006) \\
\hline $\mathrm{H} 235$ & $\mathrm{MU}_{3}$ & $\mathrm{H} / \mathrm{W}_{1,2}$ & $\mathrm{E}(90$ (9)) & $\mathrm{S} / \mathrm{V}_{0,26}$ & 4 (1980-2006) \\
\hline $\mathrm{H} 236$ & $\mathrm{MU}_{3}$ & $\mathrm{H} / \mathrm{W}_{1,2}$ & $\mathrm{O}(270 \div)$ & $\mathrm{S} / \mathrm{V}_{0,26}$ & 4 (1980-2006) \\
\hline $\mathrm{H} 237$ & $\mathrm{MU}_{3}$ & $\mathrm{H} / \mathrm{W}_{1,2}$ & $\mathrm{~N}\left(\mathrm{O}^{\circ}\right)$ & $\mathrm{S} / \mathrm{V}_{0,26}$ & $5(2007-2013)$ \\
\hline $\mathrm{H} 238$ & $\mathrm{MU}_{3}$ & $\mathrm{H} / \mathrm{W}_{1,2}$ & S (180ㅇ) & $\mathrm{S} / \mathrm{V}_{0,26}$ & $5(2007-2013)$ \\
\hline $\mathrm{H} 239$ & $\mathrm{MU}_{3}$ & $\mathrm{H} / \mathrm{W}_{1,2}$ & $E(90)$ & $\mathrm{S} / \mathrm{V}_{0,26}$ & $5(2007-2013)$ \\
\hline $\mathrm{H} 240$ & $\mathrm{MU}_{3}$ & $\mathrm{H} / \mathrm{W}_{1,2}$ & $\mathrm{O}(270 \div)$ & $S / V_{0,26}$ & $5(2007-2013)$ \\
\hline
\end{tabular}





\section{ANEXO III. ANÁLISIS DETALLADO DE LA DEMANDA DE REFRIGERACIÓN}





\section{III.1 INTRODUCCIÓN}

Los valores resultantes de las simulaciones energéticas realizadas en la Etapa II del caso de aplicación, adoptan valores próximos a 0 en relación a la demanda energética de refrigeración ( $\left.D E_{r}\right)$. Como se observa en la Figura 6.3 del Capítulo 6, la demanda de refrigeración es menor en los edificios más antiguos. Este Anexo tiene por objeto indagar en los motivos que provocan este hecho y justificar la afirmación proporcionada en el apartado 6.2.2 de dicho capítulo, que responsabiliza a la inercia térmica del cerramiento de fachada de la envolvente térmica y a la presencia de obstáculos solares en el entorno urbano, de los bajos valores de la variable respuesta $D E_{r}$.

\section{III.2 INFLUENCIA DE LA INERCIA TÉRMICA}

Para identificar las causas que provocan este comportamiento, se recurre al análisis de las temperaturas a las que se encuentra el aire interior, exterior y los cerramientos:

- Temperatura del aire $\left(\theta_{\mathrm{a}}\right)$ : es la temperatura media del aire interior de la estancia.

- Temperatura radiante $\left(\theta_{r}\right)$ : es la temperatura media radiante de los cerramientos de la zona.

- Temperatura operativa $\left(\theta_{0}\right)$ : se calcula como la media aritmética entre la temperatura interior del aire y la temperatura radiante de los cerramientos. Esta constituye un índice de bienestar de las personas que ocupan el interior de un edificio, puesto que su confort térmico no sólo depende de la temperatura interior del aire de las estancias, sino también de la temperatura a la que se encuentran los cerramientos (fachada, suelo, cubierta, etc.):

$$
\theta_{o p}=\frac{\theta_{a}+\theta_{r}}{2}
$$

- Temperatura exterior de bulbo seco $\left(\theta_{\mathrm{bs}}\right)$ : temperatura exterior según los datos climáticos del lugar.

Para realizar dicho análisis, se toma como ejemplo la hipótesis $\mathrm{H} 82\left(\mathrm{MU}_{1}\right.$, ancho de calle $10 \mathrm{~m}$, orientación $\mathrm{S}$, tipología edificatoria $\mathrm{PF}_{\mathrm{M}(\leq 4)}$, periodo de construcción 1). En las tres tipologías de edificios la tendencia en el comportamiento es muy similar, por lo que las conclusiones son aplicables en los tres casos. Al observar la evolución de las horas de disconfort a lo largo de todo un año (ver Figura All.1), se aprecia que el periodo más confortable es el estival (de junio a septiembre), concretamente el mes de agosto, donde se registran únicamente 221 horas de disconfort para el total de los 31 días del mes. La $\theta_{\text {bs }}$ es de $24,48^{\circ} \mathrm{C}$ y la $\theta_{0}$ es de $23,16^{\circ} \mathrm{C}$. Dado que la temperatura operativa de $23,16^{\circ} \mathrm{C}$ es inferior a la temperatura de consigna de $25^{\circ} \mathrm{C}$ establecida para verano (a partir de la cual los sistemas activos de acondicionamiento serían necesarios), no existe apenas demanda energética de refrigeración. Las 221 horas de disconfort corresponden a las horas durante los 31 días del mes, en las que la temperatura operativa supera los $25^{\circ} \mathrm{C}$ de consigna, momentos en los que sí existe una pequeña demanda de refrigeración. 

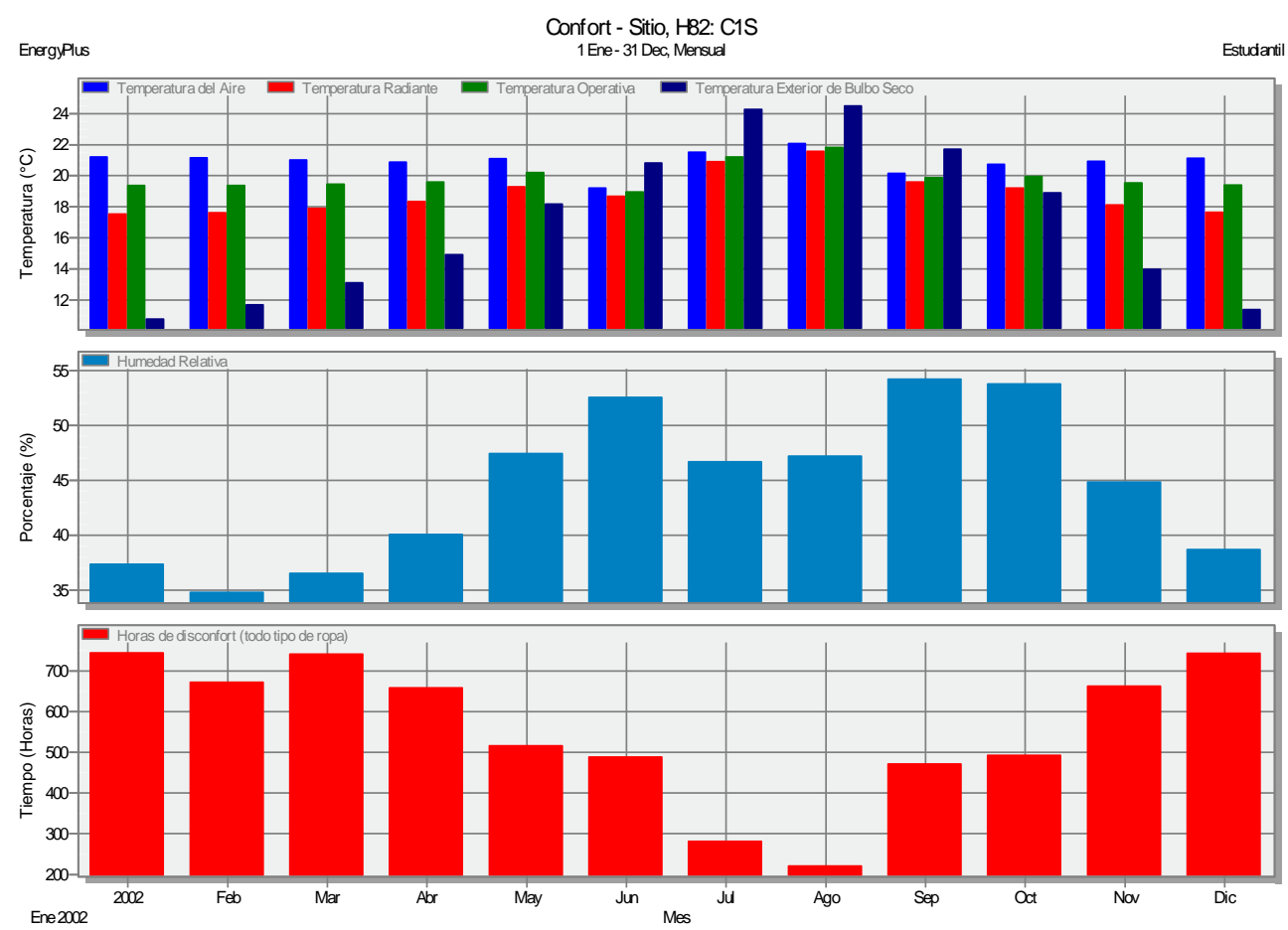

Figura Alll.1 Resultados de confort térmico para la H82

Este fenómeno puede ser explicado por la inercia térmica de los cerramientos de la envolvente. Si analizamos los resultados del balance térmico en la $\mathrm{H} 82$ (ver Figura Alll.2), observamos que la mayor parte de la energía se pierde a través de fachadas (denominado como muros en dicha figura), seguida de los acristalamientos, las cubiertas y los suelos. La infiltración supone pérdidas térmicas durante los meses del periodo infracalentado (de octubre a mayo), que se traducirán en aportes necesarios en forma de calor para suplirlas. En los meses de verano (de junio a septiembre) se traducen en ganancias también indeseadas, que contribuirán a aumentar la demanda energética de refrigeración. 

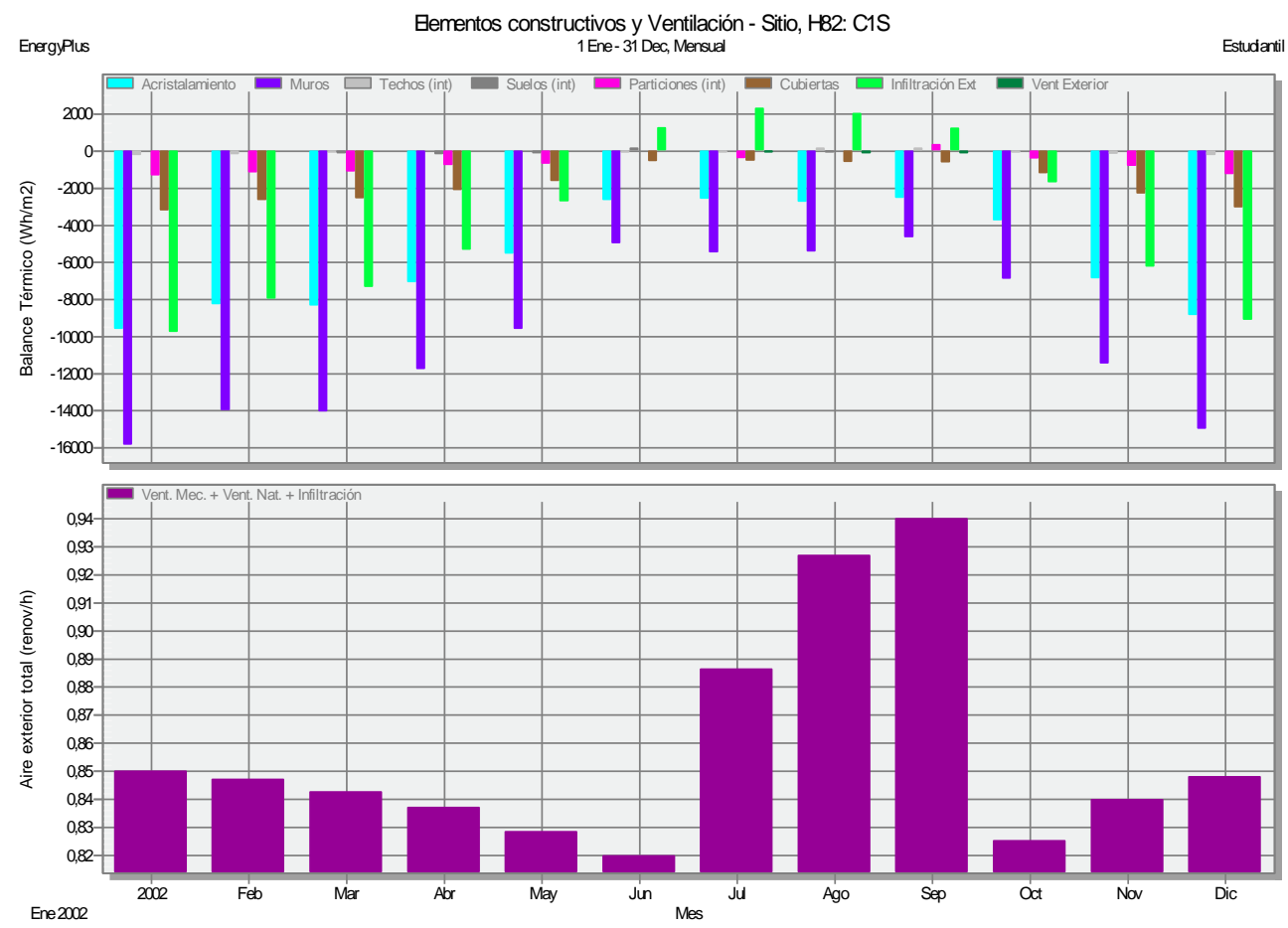

Figura Alll.2 Resultados del balance térmico en la H82

Analizado esto, se concluye que el cerramiento de la envolvente que más impacto tiene en las pérdidas energéticas es la fachada, por lo que el efecto de la inercia térmica de esta no pasará, probablemente, desapercibida y merece ser estudiada, pues puede explicar la baja demanda de refrigeración en el periodo estival.

Los parámetros que caracterizan el comportamiento de un cerramiento frente a variaciones de temperatura en el exterior son el desfase térmico (en horas) y la amortiguación de la onda térmica (\%).

El desfase de la onda térmica $\left(d_{f}\right)$ se aprecia claramente en los procesos de calentamiento solar de las fachadas y de las cubiertas. Una vez que la capa externa del cerramiento se ha calentado por la acción conjunta de la radiación solar y de la temperatura exterior, comienza un lento proceso de paso del calor por conducción desde esta capa hacia el interior del muro. El tiempo que tarda la onda de calor en atravesar el cerramiento se denomina desfase de onda térmica (Neila González, 2004).

Cuando las condiciones exteriores cambian (cesa la radiación solar y baja la temperatura exterior), parte del calor acumulado en el cerramiento se transmite hacia el exterior, produciéndose un rebote de la onda de calor. A este fenómeno se le conoce como amortiguación de la onda térmica $\left(\mathrm{f}_{\mathrm{a}}\right)$ (Neila González, 2004).

El cálculo de ambos fenómenos se describe a continuación:

- Desfase térmico $\left(d_{f}, h\right)$ : depende de la conductividad térmica $(\lambda)$, de la densidad $(\rho)$, del espesor $(e)$, del calor específico $\left(c_{e}\right)$ y del periodo del fenómeno $(t)$, que para aplicaciones 
climáticas es de 24 horas ( 1 día). El desfase es función de la difusividad térmica (a), la cual mide la velocidad de calentamiento y se expresa en $\left(\mathrm{m}^{2} / \mathrm{s} \times 10^{-6}\right)$. El desfase y la difusividad se calculan mediante las expresiones:

$$
d_{f}=\frac{23,0790 \cdot e}{\sqrt{a}} \quad a=\frac{\lambda}{\rho \cdot c_{e}}
$$

- Amortiguación de la onda térmica $\left(f_{a}, \%\right)$ : depende de la efusividad térmica $(b)$, que es la capacidad efectiva que ofrecen los materiales para acumular calor (en $\mathrm{s}^{1 / 2} \mathrm{~W} / \mathrm{m}^{2}{ }^{\circ} \mathrm{C}$ ), y para un periodo de 24 horas se calcula mediante las expresiones:

$$
f_{a}=1-e^{\left(\frac{-0,006 b \cdot e}{\lambda}\right)} \quad b=\sqrt{\rho \cdot c_{e} \cdot \lambda}
$$

La solución de fachada en el periodo constructivo 1 (anterior a 1940) está constituida por una gruesa fábrica de ladrillo cerámico de 1 pie de espesor. La Tabla Alll.1 muestra el cálculo de la inercia térmica para esta solución constructiva.

\begin{tabular}{|c|c|c|c|c|c|c|c|c|c|c|}
\hline Capa & $\begin{array}{l}e \\
(m)\end{array}$ & $\begin{array}{c}\lambda \\
(W / \mathrm{mK})\end{array}$ & $\begin{array}{c}P \\
\left(\mathrm{~kg} / \mathrm{m}^{3}\right)\end{array}$ & $\begin{array}{c}\mathrm{C}_{\mathrm{e}} \\
(\mathrm{K} / \mathrm{kgK})\end{array}$ & $\begin{array}{c}\text { A } \\
\left(\mathrm{m}^{2} / \mathrm{s} \cdot 10^{-6}\right)\end{array}$ & $\begin{array}{c}\text { b } \\
\left(\mathrm{s}^{1 / 2} \mathrm{~W} / \mathrm{m}^{2} \mathrm{O} \mathrm{C}\right)\end{array}$ & $\begin{array}{l}d_{f} \\
\text { (h) }\end{array}$ & $\begin{array}{c}\mathbf{f}_{\mathrm{a}} \text { de cada } \\
\text { capa } \\
\text { (tanto por uno) }\end{array}$ & $\begin{array}{c}\text { Amort. sobre } \\
\text { la energía que } \\
\text { traspasa }\end{array}$ & $\begin{array}{l}\text { Energía } \\
\text { que } \\
\text { traspasa }\end{array}$ \\
\hline $\begin{array}{l}\text { Mortero } \\
\text { cemento }\end{array}$ & 0,015 & 0,550 & 1125,000 & 1000,000 & 0,488 & 786,600 & 0,495 & 0,121 & - & $\begin{array}{l}1-, 121= \\
0,879\end{array}$ \\
\hline $\begin{array}{l}\text { Ladrillo } \\
\text { cerámico } \\
\text { perforado }\end{array}$ & 0,240 & 0,550 & 1125,000 & 1000,000 & 0,488 & 786,600 & 7,928 & 0,872 & $\begin{array}{l}0,872 \times 0,879= \\
0,766\end{array}$ & $\begin{array}{l}0,879- \\
0,766= \\
0,113\end{array}$ \\
\hline Yeso & 0,015 & 0,570 & 1150,000 & 1000,000 & 0,495 & 809,600 & 0,492 & 0,119 & $\begin{array}{l}0,233 \times 0,119= \\
0,028\end{array}$ & $\begin{array}{l}0,113- \\
0,028= \\
0,085\end{array}$ \\
\hline & & & & & & & 8,915 & & & $\begin{array}{l}1-0,085= \\
0,915\end{array}$ \\
\hline
\end{tabular}

Tabla AllI.1 Cálculo de la inercia térmica de la fachada considerada en el periodo temporal 1 (anterior a 1940)

El desfase de la onda térmica es de 8,915 horas y la amortiguación total es del 91,5\%. Estos valores se traducen en que la temperatura máxima de calor en un día de agosto, que se da en horas de mediodía, no llegará hasta casi 9 horas más tarde al interior del edificio, cuando ya es posible evacuar el calor por ventilación natural. Mediante este razonamiento, puede decirse que el cerramiento posee una muy buena inercia térmica que permite mantener una temperatura constante en el interior del edificio y reducir así la demanda de refrigeración hasta valores casi nulos.

Con un análisis más detallado de la hipótesis, hora a hora, se puede observar qué ocurre durante el día en el que se registra la máxima temperatura en el mes de agosto. Las horas después del mediodía en las que se da la máxima temperatura exterior de bulbo seco $\left(5: 00 \mathrm{pm}, 36,10^{\circ} \mathrm{C}\right)$, marcan el inicio de la acumulación térmica en el cerramiento. Con el desfase de casi 9 horas, el calor no llegaría a atravesarlo hasta entrada la noche (00:00-2:00 pm, 3h de disconfort), cuando ya es posible evacuarlo de forma natural mediante ventilación nocturna. 

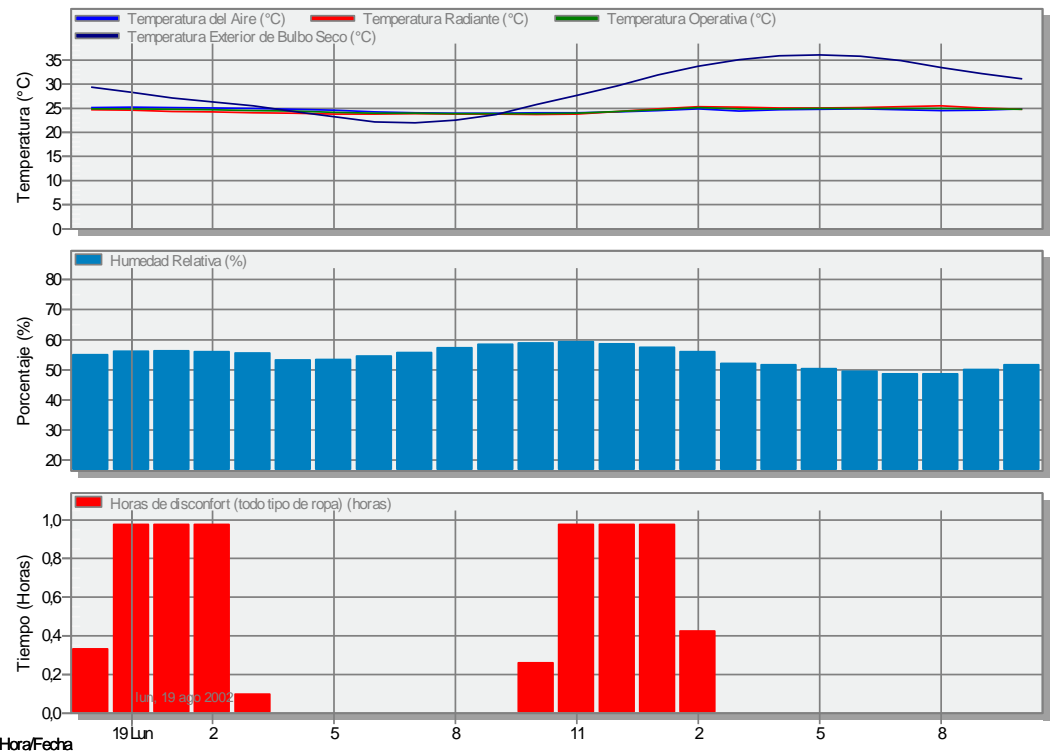

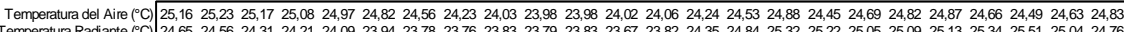

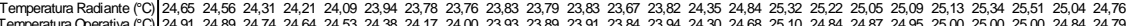

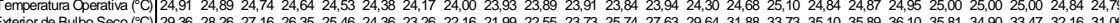

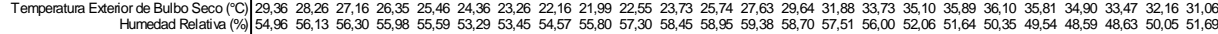

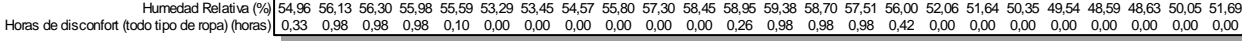

Figura Alll.3 Resultados horarios de confort en el día de máxima $\theta_{\mathrm{bs}}$ para la $\mathrm{H} 82$

Se puede concluir que el elevado espesor de la fábrica y la alta densidad de la misma, hacen que se aproveche excepcionalmente bien la inercia térmica del cerramiento, manteniendo la temperatura operativa interior alrededor de la temperatura de consigna de verano. Ello impide que las temperaturas altas exteriores se transfieran hacia el interior del edificio, evitando así situaciones de disconfort y haciendo prácticamente nula la demanda de refrigeración.

Como se apunta anteriormente y como se observa en la Figura All..3, la demanda de refrigeración aumenta en edificios de construcción más reciente. Aunque no supone una demanda energética de refrigeración elevada (valor máximo registrado de $5,58 \mathrm{kWh} / \mathrm{m}^{2}$ año), esta es bastante superior a la de los edificios más antiguos. Las soluciones constructivas actuales, de construcción ligera, tienen menor inercia térmica que limita el fenómeno anterior, lo que hace aumentar la demanda de refrigeración del edificio. Además, el tipo de construcción más hermética (ventanas de mejores prestaciones, juntas entre elementos constructivos mejor resueltas, etc.) hace reducir las infiltraciones, lo que también contribuye a reducir las renovaciones/hora y, por tanto, aumentar la $\mathrm{DE}_{\mathrm{r}}$.

\section{III.3 INFLUENCIA DE LOS OBSTÁCULOS SOLARES DEL ENTORNO}

Por otro lado, las condiciones de soleamiento y sombra del propio entorno del edificio, tienen también obviamente influencia sobre la demanda energética del edificio. Con la finalidad de analizar el efecto de las sombras del entorno en dicha demanda, se realiza una nueva simulación del edificio 
de la H82 suponiéndolo aislado. La Figura Alll.4 y la Figura All. 5 muestran la evolución de la $D_{r}$ y $\mathrm{DE}_{\mathrm{c}}$.

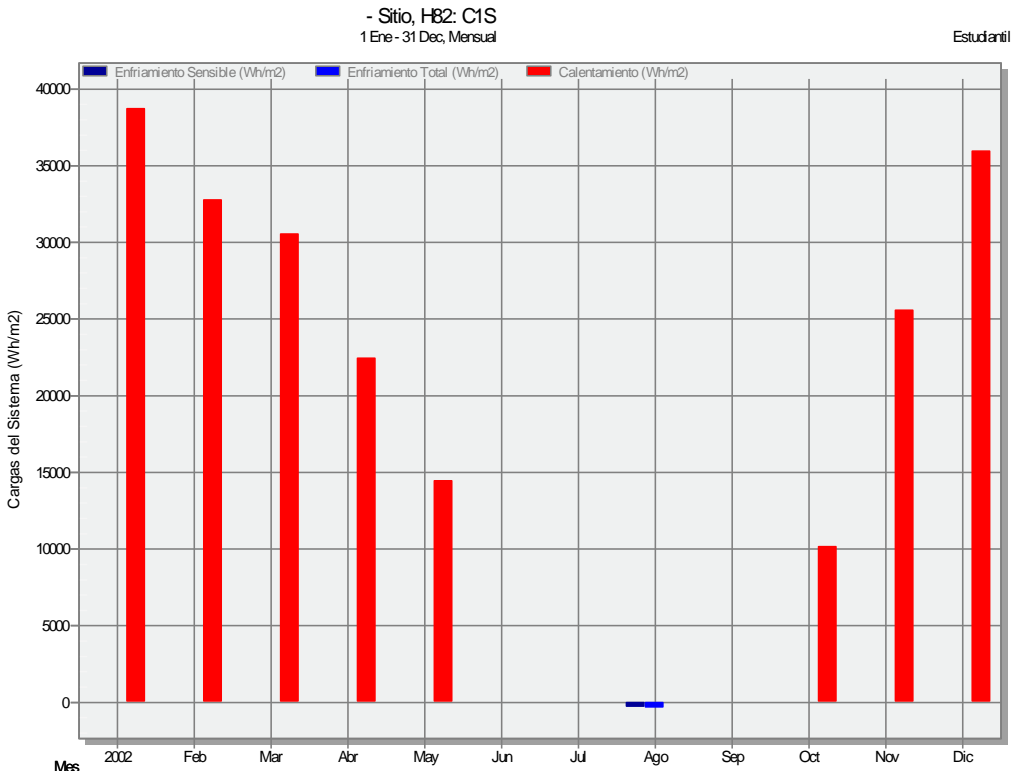

Figura All..4 Resultados de demandas energéticas mensuales para la H82

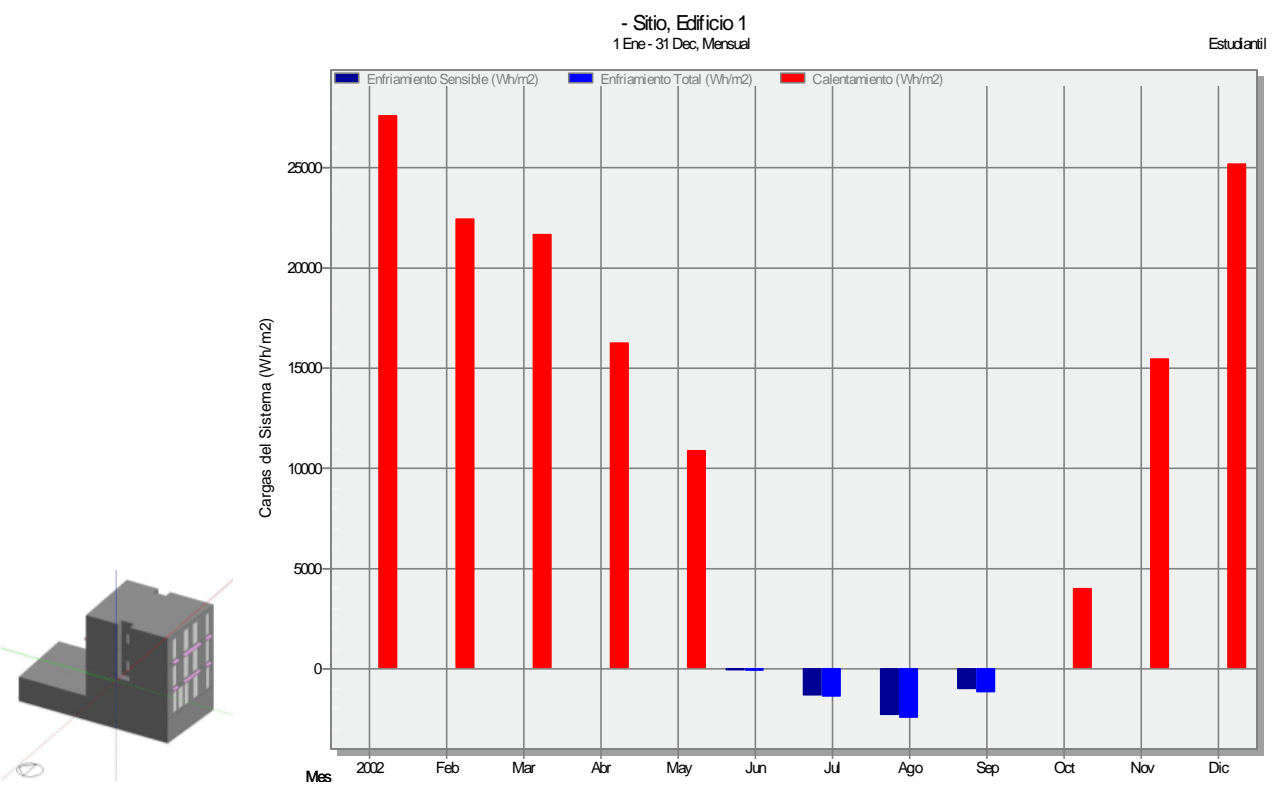

Figura Alll.5 Resultados de demandas energéticas mensuales para la H82, suponiendo el edificio aislado 
Tabla Alll.2 Comparativa de demandas energéticas entre $\mathrm{H} 82$ y edificio aislado

\begin{tabular}{lll}
\hline & $\mathrm{DE}_{\mathrm{r}}\left[\mathrm{kWh} / \mathrm{m}^{2}\right.$ año $]$ & $\mathrm{DE}_{\mathrm{c}}\left[\mathrm{kWh} / \mathrm{m}^{2}\right.$ año $]$ \\
\hline $\mathrm{H} 82$ & 0,47875 & 210,63353 \\
H82, edificio aislado & 5,27452 & 143,42367 \\
\hline
\end{tabular}

La Tabla AllI.2 compara la $D_{E_{r}}$ y $D E_{c}$ de ambas hipótesis, de la que se pueden observar dos aspectos. El primero, que la demanda de refrigeración aumenta cuando el edificio se encuentra aislado, pues este carece de elementos que obstaculicen la radiación solar, lo que resulta perjudicial durante los meses de verano. Y, el segundo, que la demanda de calefacción disminuye cuando el edificio está aislado, ya que todas las fachadas del edificio tienen accesibilidad solar, reduciendo así su demanda energética durante el invierno.

\section{III.4 REFERENCIAS}

Neila González, J. (2004). Arquitectura bioclimática en un entorno sostenible. ISBN: 84-89150-64-8. Munilla-Lería. 